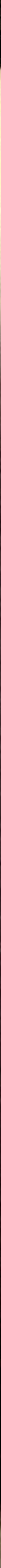





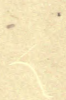

. 


\title{
FIELD AND GARDEN
}

\section{VEGETABLES OF AMERICA:}

\author{
CONTAINING
}

FULL DESCRIPTIONS OF NEARLY ELEVEN HUNDRED SPECIES AND VARIETIES; WITH DIRECTIONS FOR PROPAGATION, CULTURE, AND USE; ILLUSTRATED.

\section{B Y}

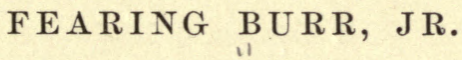

B O S T O :

J. E: TILTON AND COMPANY.

1865 . 
Entered, according to Act of Congress, in the year 1863 by FEARING BURR, JR.,

In the Clerk's Office of the District Court of the District of Massachusetts.

Entered, according to Act of Congress, in the year 1865, by FEARING BURR, JR.,

In the Clerk's Office of the District Court of the District of Massachusetts.

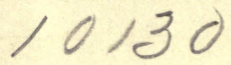

ELECTROTYPED AT THE

- Boston Stereotype Foundry, No. 4 Spring Lane.

Presswork by John Wilson \& Son, Boston. 


\section{HON. ALBERT FEARING,}

President of the Hingham Agricultural and Horticultural Society,

WHOSE EARNEST LABORS AND LIBERAL CONTRIBUTIONS IN THE CAUSE OF HCMANITY HAVE ENDEARED hIS NAME TO THE AGED POOR AND TO ORPHAN CHILDREN, AND WHOSE ACTIVE SERVICES HAVE EXERTED SO BENEFICIAL AN INFLUENCE ON Agricultural PURSits in HIS NATIVE TOWN,

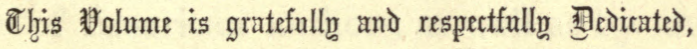
BY THE AUTHOR. 


\section{P R E F A C E.}

Tнобан embracing all the directions necessary for the successful management of a Vegetable Garden, the present volume is offered to the public as a manual, or guide, to assist in the selection of varieties rather than as a treatise on cultivation. Through the standard works of American authors, as well as by means of the numerous agricultural and horticultural periodicals of our time, all information of importance relative to the various methods of propagation and culture, now in general practice, can be readily obtained.

But, with regard to the characteristics which distinguish the numerous varieties; their difference in size, form, color, quality, and season 
of perfection; their hardiness, productiveness, and comparative value for cultivation, - these details, a knowledge of which is important as well to the experienced cultivator as to the beginner, have heretofore been obtained only through sources scattered and fragmentary.

To supply this deficiency in horticultural literature, I have endeavored, in the following pages, to give full descriptions of the vegetables common to the gardens of this country. It is not, however, presumed that the list is complete, as many varieties, perhaps of much excellence, are comparatively local: never having been described, they are, of course, little known. Neither is the expectation indulged that all the descriptions will be found perfect; though much allowance must be made in this respect for the influence of soil, locality, and climate, as well as for the difference in taste of different individuals.

Much time, labor, and expense have been 
devoted to secure accuracy of names and synonymes, - the seeds of nearly all of the prominent varieties having been imported both from England and France, and planted, in connection with American vegetables of the same name, with reference to this object alone.

The delay and patience required in the preparation of a work like the present may be in some degree appreciated from the fact, that in order to obtain some comparatively unimportant particular with regard to the foliage, flower, fruit, or seed, of some obscure and almost unknown plant, it has been found necessary to import the seed or root; to plant, to till, to watch, and wait an entire season.

Though some vegetables have been included which have proved of little value either for the table or for agricultural purposes, still it is believed such descriptions will be found by no means unimportant; as a timely knowledge of that which is inferior, or absolutely worthless, 
is often as advantageous as a knowledge of that which is of positive superiority.

That the volume may be acceptable to the agriculturist, seedsman, and to all who may possess, cultivate, or find pleasure in, a garden, is the sincere wish of the author.

Hingham, February, 1865. 


\section{ACKNOWLEDGMENTS.}

Is the preparation of this work, I have received the cheerful coöperation of many esteemed personal friends, to whom I would here express my grateful acknowledgments.

For many valuable suggestions with regard to the culture and general management of the Potato, as well as for much important information respecting nearly all of our American varieties of this vegetable, I am indebted to J. F. C. Hyde, Esq., of Newton, Mass., whose long experience in the production of seedlings, as well as in the cultivation of established kinds, will give peculiar value to this portion of the volume.

The illustrations, so excellent and truthful, are from the pencil of Mr. Isaac Sprague, of Cambridge, Mass., whose fine delineations of animal as well as vegetable life have won for him the reputation of being " the first of living artists."

I am peculiarly indebted to Rev. E. Porter Dyer, of Hingham, for much valuable advice and assistance, and cannot too fully express my obligations for the unvarying kindness and courteous manner in which repeated, and perhaps often unseasonable, requests for aid have been received and granted.

My acknowledgments are also due to Hon. JosEPH Breck, author of "Book of Flowers," and late President of the Massachusetts Horticultural Society; to Charles M. Hover, Esq., editor of "The Magazine of Horticul- 
ture," and President of the Massachusetts Horticultural Society; to Phineas B. Hover, Esq., nurseryman and seedsman, of Cambridge, Mass.; and to DAviel T. CurTIs, Esq., seedsman and florist, and for many years Chairman of the Committee on Vegetables of the Massachusetts Horticultural Society.

For information or other very acceptable assistance, I am also indebted to Rev. Calvin Lincoln, of Hingham, Mass. ; Rev. John L. Russell, of Salem, Mass.; John A. ButLER, Esq., of Chelsea, Mass.; Edward S. Ravd, Jun., Esq., of Boston; Mr. Austin Bronson, of Enfield, N. H.; George W. Pratt, Esq., of Boston; Mr. E. Henry Greenwood, of Needham, Mass.; Mr. Calvin A. Lincolv, of Hingham, Mass.; Dr. Thomas M. Brewer, of Boston, Mass.; Johs M. Ives, Esq., of Salem, Mass.; Mr. James Scotr, of Hatfield, Mass. ; Mr. Alonzo Crafts, of Whateley, Mass.; Mr. Jonn C. Hovey, of Cambridge, Mass.; Mr. IsaAC P. RAND, of Dorchester, Mass.; Mr. George Everetr, of Concord, Mass.; and Mr. Caleb Bates, of Kingston, Mass.

From a work entitled "Descriptions des Plantes Potagères, par Vilmorin, Andrieux, et Cie., Paris;" from Charles McIntosh's excellent "Book of the Garden;" the "Gardener's Assistant," by Roвert Thompson ; "Rogers's Vegetable Cultivator;" and "Lawson's Agriculturist's Manual," - I have made liberal extracts ; and lest, in the course of the volume, any omission of authority may occur where it should have been accredited, my indebtedness to the valuable publications above mentioned is here candidly confessed. 


\section{ABBREVIATIONS AND AUTHORITIES.}

Am. Agr. - The Amcrican Agriculturist. By Orange Judd, A. M. New

York. Monthly. 1812 to the present time.

Big. - Plants of Boston aud Vicinity. By JaCo Bigelow, M. D. Boston, 1840.

Bon Jard. - Le Bon Jardinier pour l'Année 1859. Par A. PoiteaU et M. VILMORIN.

Corb. - The American Gardener. By Willias Corbett. Concord, Boston, and New York, 1842.

Cot. Gard. - The Cottage Gardener. By George W. Johnsox and RoberT HoGG. Weekly. London.

Count. Gent. - The Country Gentleman. By LUTHER TUCKer and Sox. Weekly. Albany, N. Y.

De Cand. - De Candolle's Systema Naturale. By Prof. De CAndolle. 2 vols. 8vo. Paris, 1818, 1821.

Down.-The Fruit and Fruit-trees of America. By A.J. Downivg. Revised and corrected by Charles Dowving, 1858.

Gard. Chron. - The Gardener's Clironicle. Weekly. By Prof. Lindley. 1814 to the present time.

Gray. - Manual of the Botany of the Northern United States. By Prof. AsA

GraY. New York, 1857.

Hort. - The Horticulturist, and Journal of Art and Rural Taste. Monthly.

By P. BArry and J. JAY SMith. Philadelphia.

Hov. Mag. - The Magazine of Horticulture, Botany, and Rural Affairs. By

C. M. Hover. Boston. Monthly. 1834 to the present time.

Law.- The Agriculturist's Manual. By Peter LAwsoy and Sos. Edinburgh, 1836.

Lind. - A Guide to the Orchard and Kitchen Garden. By George Livdley. London, 1831.

Loud. - Encyclopadia of Gardening. By J. C. Louvos. London, 1850. 
Loud. - Encyclopædia of Agriculture. By J. C. Loudov. London, 1844.

Low. - The Elements of Practical Agriculture. By David Low. London, 1843.

McInt. - The Book of the Garden. By Charles McIntosh. 2 vols. Edinburgh and London, 1855.

Mill. - The Gardener's and Botanist's Dictionary. By Prillp Mrller. Revised by Prof. MarTYN. London, 1819.

Neill. - Neill's Journal of a Horticultural Tour, \&c. 8vo. Edinburgh, 1823.

New Am. Cyclopadia. - New American Cyclopædia. D. Appleton \& Co.,

New York. 16 vols. royal 8vo. 1857 to 1863.

Rog. - The Vegetable Cultivator. By Jorn Rogers. London, 1851.

Thomp. - The Gardener's Assistant. By RoBert THompson.

Trans. - The Transactions of the London Horticultural Society. Commenced 1815 , and continued at intervals to the present time.

Vil. - Description des Plantes Potagères. Par Viluorix, Axdrieux, et Cie. Paris, 1856. 


\section{CONTENTS.}

\section{CHAPTER I.}

ESCULENT ROOTS.

The Beet. Carrot. Chervil, Turnip-rooted. Chinese Potato, or Japanese Yam. Chufa, or Earth Almond. German Rampion. Jerusalem Artichoke. Oxalis, Tuberous. Oxalis, Deppe's. Parsnip. Potato. Radish. Rampion. Swede or Ruta-baga Turnip. Salsify, or Oyster Plant. Scolymus. Scorzonera. Skirret. Sweet Potato. Tuberousrooted Chickling Vetch. Tuberous-rooted Tropœolum. Turnip, . . . 1

\section{CHAPTER II.}

ALLIACEOUS PLANTS.

The Cive, Garlic. Leek. Onion. Rocambole. Shallot. Welsh Onion, 114

CHAPTER III.

ASPARAGINOUS PLANTS.

The Artichoke. Asparagus. Cardoon. Hop. Oosung. Phytolacea, . . 139

\section{CHAPTER IV.}

\section{CUCURBITACEOUS PLANTS.}

The Cucumber. Egyptian Cucumber. Globe Cucumber. Gourd, or Calabash. The Melon. Muskmelon. Persian Melons. Watermelon. 
Papanjay, or Sponge Cucumber. Prickly-fruited Gherkin. Pumpkin.

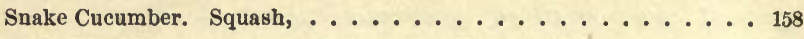

\section{CHAPTER V.}

BRASSICACEOUS PLANTS.

Borceole, or Kale. Broceoli. Brussels Sprouts. Cabbage. Cauliflower.

Colewort. Couve Tronehuda, or Portugal Cabbage. Kolı Rabi.

Pak-Chöi. Pe-Tsai, or Chinese Cabbage. Savoy. Sea-kale, . . . . 222

\section{CHAPTER VI.}

SPINACEOUS PLANTS.

Amaranthus. Black Nightshade. Leaf-beet, or Swiss Chard. Malabar Nightshade. Nettle. New Zealand Spinach. Orach. Patience Dock. Quinoa. Sea-beet. Shepherd's Purse. Sorrel. Spinach. Wild or Perennial Spinach, ............................ 279

\section{CHAPTER VII.}

\section{SALAD PLANTS.}

Alexanders. Brook-lime. Buekshorn Plantain. Burnet. Caterpillar. Celery. Celeriac, or Turnip-rooted Celery. Chervil. Chiccory, or Succory. Corchorus. Corn Salad. Cress, or Peppergrass. Cuckoo Flower. Dandelion. Endive. Horse radish. Lettuce. Madras Radish. Mailow, Curled-leaf. Mustard. Nasturtium. Garden Picridium. Purslain. Rape. Roquette, or Rocket. Samphire. Scurvygrass. Snails. Sweet-scented Chervil, or Sweet Cicely. Tarragon. Valeriana. Water-eress. Winter-cress, or Yellow Rocket. Woodsorrel. Worms,.................... 305

\section{CHAPTER VIII.}

OLERACEOUS PLANTS.

Angelica. Anise. Balm. Basil. Borage. Caraway. Clary. Coriander. Costmary. Cumin. Dill. Fennel. Lavender. Lovage. Marigold. 
Marjoram. Nigella. Parsley. Peppermint. Rosemary. Sage. Savory. Spearmint. Tansy. Thyme, ... . . . . . . . 391

\section{CHAPTER IX.}

\section{LEGUMINOUS PLANTS.}

American Garden-bean. Asparagus-bean. Lima Bean. Scarlet-runner. Sieva. Chick-pea. Chickling Vetch. English Bean. Japan Pea.

Lentil. Lupine. Pea. Pea-nut. Vetch, or Tare. Winged Pea, . . . 434

\section{CHAPTER X.}

\section{MEDICINAL PLANTS.}

Bene-plant. Chamomile. Coltsfoot. Elecampane. Hoarhound. Hyssop. Licorice. Mandrake, or May Apple. Pennyroyal. Poppy. Palmateleaved or Turkey Rhubarb. Rue. Saffron. Southernwood. Worm-

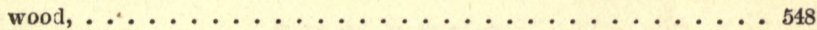

\section{CHAPTER XI.}

MUSHROOMS, OR ESCULENT FUNGI.

Agaricus. Boletus. Clavaria. Morchella, or Morel. Tuber, or Truffle, 567

\section{CHAPTER XII.}

MISCELLANEOUS VEGETABLES.

Alkekengi, or Ground Cherry. Corn. Egg-plant. Martynia. Oil Radish. Okra, or Gumbo. Pepper. Rhubarb, or Pie-plant. Sunflower.

Tobacco. Tomato, .................. 580 



\section{FIELD AND GARDEN VEGETABLES.}

\section{CHAPTER I.}

ESCULENT ROOTS.

The Beet. Carrot. Cherville, Turnip-rooted. Chinese Potato, or Japanese Yam. Chufa, or Earth Almond. German Rampion. Jerusalem Artichoke. Oxalis, Tuberous. Oxalis, Deppes. Parsnip. Potato. Radish. Rampion. Swede, or Ruta-baga Turnip. Salsify, or Oyster Plant. Scolymus. Scorzonera. Skirret. Sweet Potato. Tuberous-rooted Chickling Vetch. Tuberous-rooted Tropœolum. Turnip.

TH E B E E T.

Beta vulgaris.

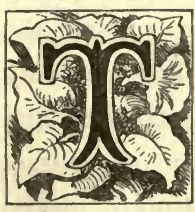

HE Common Beet, sometimes termed the Red Beet, is a half-hardy biennial plant; and is cultivated for its large, succulent, sweet, and tender roots. These attain their full size during the first year, but will not survive the winter in the open ground. The seed is produced the second year; after the ripening of which, the plant perishes.

When fully developed, the beet-plant rises about four feet in height, with an angular, channelled stem; long, slender branches; and large, oblong, smooth, thick, and fleshy leaves. The flowers are small, green, and are either sessile, or produced on very short peduncles. The calyxes, before maturity, are soft and fleshy; when ripe, hard and woodlike in texture. These calyxes, which are formed in small, united, rounded groups, or clusters, are of a brownish color, 
and about one fourth of an inch in diameter; the size, however, as well as depth of color, varying, to some extent, in the different varieties. Each of these clusters of dried calyxes contains from two to four of the true seeds, which are quite small, smooth, kidney-shaped, and of a deep reddish-brown color.

These dried clusters, or groups, are usually recognized as the seeds; about fifteen hundred of which will weigh one ounce. They retain their vitality from seven to ten years.

Soil and Fertilizers. - The soil best adapted to the beet is a deep, light, well-enriched, sandy loam. When grown on thin, gravelly soil, the roots are generally tough and fibrous; and when cultivated in cold, wet, clayey localities, they are often coarse, watery, and insipid, worthless for the table, and comparatively of little value for agricultural purposes.

A well-digested compost, formed of barn-yard manure, loam, and salt, makes the best fertilizer. Where this is not to be obtained, guano, superphosphate of lime, or bone-dust, may be employed advantageously as a substitute. Woodashes, raked or harrowed in just previous to sowing the seed, make an excellent surface-dressing, as they not only prevent the depredations of insects, but give strength and vigor to the young plants. The application of coarse, undigested, strawy manure, tends to the production of forked and misshapen roots, and should be avoided.

Propagation and Culture. - Beets are always raised from seed. For early use, sowings are sometimes made in November; but the general practice is to sow the seed in April, as soon as the frost is out of the ground, or as soon as the soil can be worked. For use in autumn, the seed should be sown about the middle or 20th of May; and, for the winter supply, from the first to the middle of June. Lay out the ground in beds five or six feet in width, and of a length proportionate to the supply required; spade or fork 
the soil deeply and thoroughly over; rake the surface smooth and even; and draw the drills across the bed, fourteen inches apart, and about an inch and a half in depth. Sow the seeds thickly enough to secure a plant for every two or three inches, and cover to the depth of the drills. Should the weather be warm and wet, the young plants will appear in seven or eight days. When they are two inches in height, they should be thinned to five or six inches apart; extracting the weaker, and filling vacant spaces by transplanting. The after-culture consists simply in keeping the plants free from weeds, and the earth in the spaces between the rows loose and open by frequent hoeings.

Taking the Crop. - Roots, from the first sowings, will be ready for use early in July ; from which time, until October, the table may be supplied directly from the garden. They should be drawn as fast as they attain a size fit for use ; which will allow more time and space for the development of those remaining.

For winter use, the roots must be taken up before the occurrence of heavy frosts, as severe cold not only greatly impairs their quality, but causes them to decay at the crown.

In harvesting, avoid cutting or bruising the skin; and in removing the leaves, be careful not to cut or wound the crown. After being spread a few hours in the sun to dry, they should be packed in earth or sand, slightly moist, and stored ont of reach of frost for the winter.

If harvested before receiving injury from cold, and properly packed, they will retain, in a good degree, their freshness and sweetness until the new crop is suitable for use.

Seed.-To raise seed, select smooth and well-developed roots, having the form, size, and color by which the pure variety is distinguished; and, in April, transplant them eighteen inches or two feet apart, sinking the crowns to a level with the surface of the ground. As the stalks increase 
in height, tie them to stakes for support. The plants will blossom in June and July, and the seeds will ripen in August.

In harvesting, cut off the plants near the ground, and spread them in a light and airy situation till they are sufficiently dried for threshing, or stripping off the seeds; after which the seeds should be exposed, to evaporate any remaining moisture.

An ounce of seed will sow from one hundred to one hundred and fifty feet of drill, according to the size of the variety; and about four pounds will be required for an acre.

Use.-Roots of medium size are generally to be preferred for table use. When their growth has been rapid and unchecked, they will be found succulent, free from fibre, and of good quality. The deepest or brightest colors are most esteemed.

The young plants make an excellent substitute for spinach ; and the leaves of some of the kinds, boiled when nearly full grown, and served as greens, are tender and well-flavored.

Some of the larger varieties are remarkably productive, and are extensively cultivated for agricultural purposes. From a single acre of land in good condition, thirty or forty tons are frequently harvested; and exceptional crops are recorded of fifty, and even sixty tons. In France, the White Sugar-beet is largely employed for the manufacture of sugar - the amount produced during one year being estimated to exceed that annually made from the sugar-cane in the State of Louisiana.

For sheep, dairy-stock, and the fattening of cattle, experience has proved the beet to be at once healthful, nutritious, and economical.

Varieties. - The varieties are quite numerous, and vary to a considerable extent in size, form, color, and quality. They are obtained by crossing, or by the intermixture of one kind with another. This often occurs naturally when two 
or more varieties are allowed to run to seed in close proximity, but is sometimes performed artificially by transferring the pollen from the flower of a particular variety to the stigma of the flower of another.

The kinds now in cultivation are as follow; viz. :-

Root produced entirely within the earth, Bark-skinbroadest near the crown, and thence tapering nod. Vil. regularly to a point; - average specimens measuring four inches in their greatest diameter, and about one foot in depth. Skin dark brown, thick, hard, and wrinkled, or striated, sometimes reticulated or netted, much resembling the bark of some descriptions of trees; whence the name. Flesh very deep, purplish-red, circled, and rayed, with paler red, fine-grained, sugary, and tender. Leaves numerous, spreading, bright green, slightly stained with red; the leaf-stems and nerves bright purplishred.

An early and comparatively new French variety, of fine flavor, excellent for summer use, and, if sown as late as the second week in June, equally valuable for the table during winter. Not recommended for field culture.

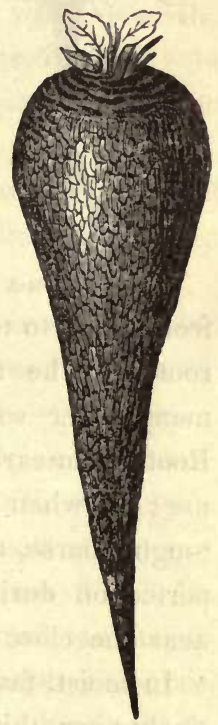

Bark-skinned Beet.

Sow in rows fourteen inches apart, and thin to six inches apart in the rows.

Root similar in form to the Castelnaudary, Barrott's but somewhat larger, smooth and regular, and son. Thomp. not apt to fork. Flesh dark crimson, fine-grained and tender. Leaf-stalks yellow. 
Bassano. Bulb flattened; six or seven inches in diameter

EARLY FLAT
BASSAN. by three or four inches in depth; not very regular TURNIP-ROOTED

BASANO.
EXTRA BARLY. ROVGE PLATE DE terminating in a small, slender tap-root. Skin of o in a small, slender tap-root. Skin of

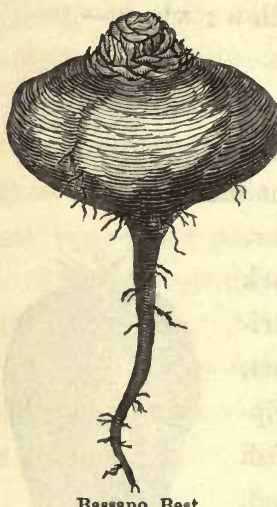
fine texture ; brown above ground; below the surface, clear rose-red. Flesh white, circled or zoned with bright pink; not close-grained, but very sugary and well-flavored. Leaves numerous, erect, of a lively green color, forming many separate groups or tufts, covering the entire top, or crown of the root. Leafstems short, greenish-white, washed or stained with rose.

An Italian variety, generally considered the earliest of garden-beets, being from seven to ten days earlier than the Early Blood Turniprooted. The flesh, although much coarser than that of many other sorts, is tender, sweet, and of good quality. Roots from early sowings are, however, not suited for winter use; as, when overgrown, they almost invariably become too tough, coarse, and fibrous for table use. To have them in perfection during winter, the seed should not be sown till near the close of June.

In moist, favorable seasons, it succeeds well in comparatively poor, thin soil.

Cultivate and preserve as directed for the Early Turniprooted.

Cattell's Root small, regularly tapering. Flesh deep Blood. blood-red. Leaves small, bright red, spreading, or inclined to grow horizontally. Quality good, - similar to that of the Red Castelnaudary; which variety it much resembles in its general character. 
On account of its small size, it requires little space, and may be grown in rows twelve inches apart.

A sub-variety of the Mangel Wurzel, produ- Cow-Horn cing its roots almost entirely above ground; only Wurzel. a small portion growing within the earth. Root Skrpexr-Lirk long and slender, two feet and a half in length, $\underset{\text { COW-HORN. }}{\text { CITY }}$. and nearly three inches in diameter, at its broadest part; often grooved or furrowed lengthwise, and almost invariably bent and distorted, - the effect either of the wind, or of the weight of its foliage. Flesh greenish white, circled with red at the centre. Leares of medium size, green, erect; the leaf-stems and nerves pale red or rose color.

It derives its different names from its various contorted forms ; sometimes resembling a horn, and often assuming a shape not unlike that of a serpent.

'The variety is much esteemed and extensively cultivated in some parts of Europe, although less productive than the White Sugar or Long Red Mangel Wurzel.

Aside from its smaller size, this variety much Early Manresembles the Comimon Red Mangel Wurzel. Eel Wurz ScarciRoot contracted towards the erown, which rises HATIVE. Vil. two or three inches above the surface of the soil, and tapering within the earth to a regular cone. Skin purplish rose, deeper colored than that of the last named. Flesh white, circled or zoned with pale red. Leaves spreading, green; the leaf-stems rose-colored.

It is remarkable for the regular and symmetrical form of its roots, which grow rapidly, and, if pulled while young, are tender, sweet, and well flavored. Planted the last of June, it makes a table-beet of more than average quality for winter use.

When sown early, it attains a comparatively large size, 
and should have a space of twenty inches between the rows; but when sown late, fifteen inches between the rows, and six inches between the plants in the rows, will afford ample space for their development.

Early Blood The roots of this familiar variety are pro-

Rooted. duced almost entirely within the earth, and EARLY TURNIP
BEET. to four and a half in depth, and about four inches

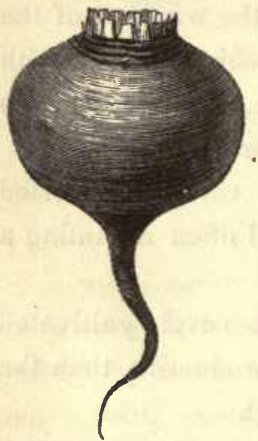
in diameter. Form turbinate, flattened, smooth, and symmetrical. Neck small, tap-root very slender, and regularly tapering. Skin deep purplish red. Flesh deep blood-red, sometimes circled and rayed with paler red, remarkably sweet and tender. Leaves erect, not very numerous, and of a deep-red color, sometimes inclining to green; but the stems and nerves always of a deep brilEarly Blood Turnip-Rooted. liant red.

The Early Blood Turnip Beet succeeds well from Canada to the Gulf of Mexico; and in almost every section of the United States is more esteemed, and inore generally cultivated for early use, than any other variety. Among market-gardeuers, it is the most popular of the summer beets. It makes a rapid growth, comes early to the table, and, when sown late, keeps well, and is nearly as valuable for use in winter as in summer and autumn.

In common with most of the table sorts, the turnip-rooted beets are much sweeter and more tender if pulled before they are fully grown; and consequently, to have a continued supply in their greatest perfection, sowings should be made from the beginning of April to the last of June, at intervals of two or three weeks. 
The roots, especially those intended for seed, should be harvested before severe frosts, as they are liable to decay when frozen at the crown, or even chilled.

Sow in drills fourteen inches apart; and when two inches in height, thin out the plants to six inches apart in the drills. An acre of land in good cultivation will yield from seven to eight hundred bushels.

An improved variety of the Long Red Mangel German Red Wurzel, almost regularly cylindrical, and ter- Wurzel. Wisetre $n$ 'minating at the lower extremity in an obtuse ALLMAGR. cone. It grows much out of ground, the neck or crown is comparatively small, it is rarely forked or deformed by small side roots, and is generally much neater aud more regular than the Long Red. Size very large; well-developed specimens measure from eighteen to twenty inches in length, and seven or eight inches in diameter. Flesh white, with red zones or rings; more colored than that of the last named. Leaves erect, green; the stems and nerves washed or stained with rose-red.

For agricultural purposes, this variety is superior to the Long Red, as it is larger, more productive and more easily harvested.

Root produced half above ground, nearly German Yeliow Mangel cylindrical for two-thirds its length, terminating wurzel. rather bluntly, and often branched or deformed GREWN MANGEL by small side roots. Size large; - when well MAGNE. Vii. grown, measuring sixteen or eighteen inches deep, six or seven inches in diameter, and weighing from twelve to fifteen pounds. Skin above ground, greenish brown; below, yellow. Flesh white, occasionally zoned or marked with yellow. Leaves of medium size, rather numerous, erect, very pale, or yellowish green; the stems and ribs light green. 
While young and small, the roots are tender and wellflavored; but this is a field rather than a table beet. In point of productiveness, it differs little from the Common Long Red, and should be cultivated as directed for that variety.

Half Long Root produced within the earth, of medium Blood.

DWARF BLood. size, or rather small ; - usually measuring about FINE DWARF RED.
EARY HALF J.ONG BLOOD. l.ovo BLood.
Rove NAIS.
Vil. or twelve inches. Skin smooth, very deep pur-

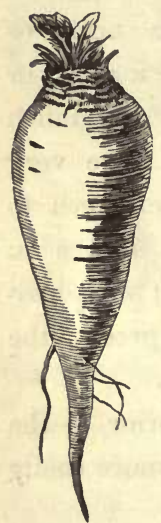
plish-red. Flesh deep blood-red, circled and rayed with paler red, remarkably fine grained, of firm texture, and very sugary. Leaves small, bright red, blistered on the surface, and spreading horizontally. Leaf-stems short.

An excellent, half-early, garden variety, sweet, and well flavored, a good keeper, and by many considered superior to the Common Long Blood. When full grown, it is still tender and finegrained, and much less stringy and fibrous than the last named, at an equally advanced stage of growth. It may be classed as one of the best Half Long Blood. table-beets, and is well worthy cultivation. Improved This is an improved variety of the Common
Long Blood.

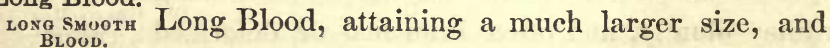
differing in its form, and manner of growth. When matured in good soil, its length is from eighteen inches to two feet; and its diameter, which is retained for more than half its length, is from four to five inches. It is seldom symmetrical in its form; for, though it has but few straggling side-roots, it is almost invariably bent and distorted. Skin smooth, very deep or blackish purple. Flesh 
dark blood-red, sweet, tender, and fine grained, while the

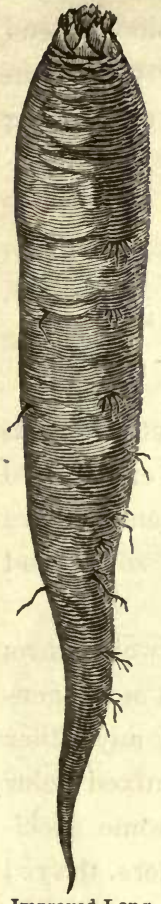

Improved Long Blood. root is young and small, but liable to be tough and fibrous when full grown. Leaves small, erect, red, and not very numerous. Leaf-stems blood-red.

This beet, like the Common Long Blood, is a popular winter sort, retaining its color well when boiled. It is of larger size than the last named, grows more above the surface of the ground, and has fewer fibrous and accidental small side-roots. While young, it compares favorably with the old variety; but, when full grown, can hardly be said to be much superior. To have the variety in its greatest perfection for winter use, the seed should not be sown before the 10th of June; as the roots of this, as well as those of nearly all the table varieties, are much more tender and succulent when very rapidly grown, and of about two thirds their full size.

Sow in drills fifteen inches apart, and thin to eight inches apart in the drills; or sow on ridges eighteen inches apart.

The roots of this familiar variety are long, Long Blood. tapering, and comparatively slender; the size Loxa BLood. varying according to the depth and richness of the soil. Skin dark purple, sometimes purplish-black. Flesh deep blood-red, very fine grained and sugary, retaining its color well after being boiled. Leaves rather numerous, of medium size, erect, deep purplish-red; the leaf-stems blood-red.

One of the most popular of winter beets; but, for late keeping, the seed should not be sown before the middle of June, as the roots, when large, are frequently tough and fibrous. 
The Improved Long Blood is a variety of this, and has, to a considerable extent, superseded it in the vegetable garden; rather, it would seem, on account of its greater size, than from any real superiority as respects its quality or keeping properties.

Root fusiform, contracted at the crown, which, Long Red in the genuine variety, rises six or eight inches Wurzel. above the surface of the ground. Size large; RED MANGE when grown in good soil often measuring inches in length, and six or seven inches in diameter. Skin below ground purplish-rose ; brownish-red where exposed to the air and light. Leaves green; the stems and nerves washed or stained with rose-red. Flesh white, zoned and clouded with different shades of red.

The Long Red Mangel Wurzel is hardy, keeps well, grows rapidly, is very productive, and in this country is more generally cultivated for agrieultural purposes than any other variety. According to Lawson, the marbled or mixed color of its flesh seems particularly liable to vary; in some specimens, it is almost of a uniform red; while, in others, the red is searcely, and often not at all, perceptible. These variations in color, are, however, of no importance as respects the quality of the roots.

The seed may be sown from the middle of April to the last of May. If sown in drills, they should be at least eighteen inches apart, and the plants should be thinned to ten inches in the drills. If sown on ridges, the sowing should be made in double rows; the ridges being three and a half or four feet apart, and the rows fifteen inches apart. The yield varies with the quality of the soil and the state of cultivation; thirty and thirty-five tons being frequently harvested from an acre.

While young, the roots are tender and well-flavored, and are sometimes employed for table use. 
An improved variety of the White Sugar Long White Bect. Root produced much above ground, and Green-Top Bect. Root produced much above ground, and Mangel. of very large size; if well grown, measuring GREBN-Tor nearly

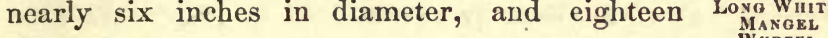
inches in depth, - the diameter often retained WURZEL.

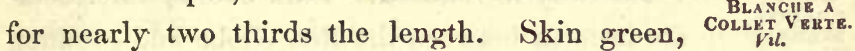
where exposed to light and air; below ground, white. Flesh white. Leaves green, rather large, and not so numerous as those of the White Sugar.

Productive, and superior to the last named for agricultural purposes; the quality being equally good, and the yield much greater.

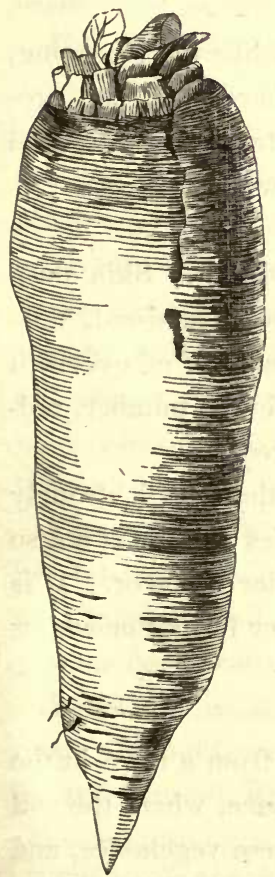

Ioot somewhat fusiform, Long Yelcontracted towards the crown, Wurzel. which rises six or eight inches GRossE. ${ }^{\text {JATER }}$. above the surface of the ground. Size remarkably large ; when grown in deep rich soil, often measuring twenty inches in length, and five or six inches in thickness. Skin yellow, bordering on orangecolor. Flesh pale yellow, zoned or circled with white, not closc-grained but sugary. Leaves comparatively large, pale green; the stems and nerves yellow; the nerves paler.

The variety is one of the most productive of the field-beets; but the roots are neither smooth nor symmetrical, a majority being forked or much branched.

In the vicinity of Paris it is extensively cultivated, and is much esteemed by dairy Long Yellow Mangel Wurzel. farmers, on account of the rich color which it imparts to milk when fed to dairy-stock. Com- 
pared with the German Yellow, the roots of this variety are longer, not so thick, more tapering; and the flesh is of a much deeper color. It has also larger foliage.

Oliveshaped Mangel Wurzel. Red.

Red OVAL MANGEL

Recently introduced. Bulb ovoid; intermediate in form between the Red Globe and common Red Mangel Wurzel; smooth and symmetrical. Flesh solid, somewhat variable in color, usually white, shaded or zoned with red, but sometimes with very little coloring. It is hardy, grows vigorously, and is said to yield quite as much to the acre as either of the last-named varieties.

Oliveshaped Mangel Wurzel. Yellow.

YeLLOW OVAL MANGEL WURZEL.
A recently introduced sort, like the foregoing, which it resembles in form, hardiness, and productiveness. Flesh solid, white, zoned or clouded with different shades of yellow.

Pine-Apple Root of medium size, fusiform. Skin deep Short-Trop. purplish-red. Flesh very deep blood-red, finegrained, as sweet as the Bassano, tender, and of excellent quality for table use. Leaves short and few in number, reddish-green; leaf-stems and nerves blood-red.

In its foliage as well as in the color of the root, it strongly resembles some of the Long Blood varieties; but it is not so large, is much finer in texture, and superior in flavor. It is strictly a garden or table beet, and, whether for fall or winter use, is well deserving of cultivation.

Red Castel- This beet derives its name from a town in the naudary.

Trans. province of Languedoc in France, where the soil is particularly adapted to the growth of these vegetables, and where this variety, which is so much esteemed in France for its nut-like flavor, was originally produced. 
The roots grow within the earth. The leaves are thickly clustered around the crown, spreading on the ground. The longest of the leaf-stems do not exceed three inches: these and the veins of the leaves are quite purple, whilst the leaves themselves are green, with only a slight stain of purple. The root is little more than two inches in diameter at the top, tapering gradually to the length of nine inches. The flesh, which is of a deep purple, and exhibits dark rings, preserves its fine color when boiled, is very tender and sweet, and presents a delicate appearance when cut in slices.

Being small in its whole habit, it occupies but little space in the ground, and may be sown closer than other varieties usually are.

Not generally known or much cultivated in this country.

Root nearly spherical, but tapering to pear- Red Globe shaped at the base; nearly one-third produced above ground. Size large; well-grown speciMangel Wurzel. BetTerave GLOBE mens measuring seven or eight inches in diameter, and nine or ten inches in depth. Skin smooth, and of a rich purplish rose-color below ground; brown above the surface where exposed to the sun. Flesh white, rarely circled with rosered. Leaves pale green, or yellowish green; the stems and ribs or nerves sometimes veined with red.

This variety is productive, keeps well, and, like the Yellow Globe, is well adapted to hard and shallow soils. It is usually cultivated for agricultural purposes, although the yield is comparatively less than that of the last named.

In moist soils, the Yellow Globe succeeds best; and, as its quality is considered superior, it is now more generally cultivated than the Red.

An improved variety of the Yellow Globe Mangel Wurzel, recommended for size, sym- Large Yelmetry of form, and solidity. It is also hardy, Marzel. 
yields abundantly, and appears to be adapted to all descriptions of soil.

White Globe A sub-variety of the Yellow and Red Globe, Wurzel. which, in form and manner of growth, it much resembles. Skin, above ground, green; below, white. Leaves green. Flesh white and sugary; but, like the foregoing sorts, not fine-grained, or suited for table use.

Productive, easily harvested, excellent and profitable for farm purposes, and remarkably well adapted for cultivation in hard, shallow soil.

White Su- Root fusiform, sixteen inches in length, six or WIIE.
SIIAR.
BET-

TRRAYE
BLANCHE. Vil. face of the soil, but nearly retaining its size for half the depth, and thence tapering regularly to a point.

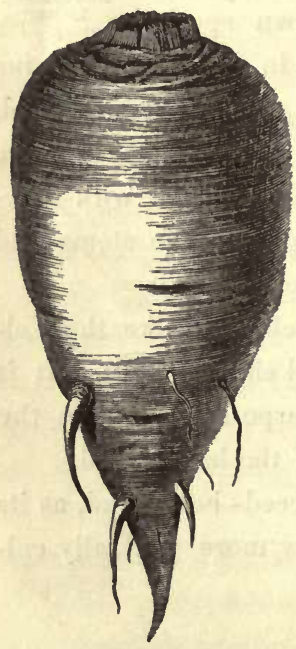

White Sugar Beet.

Skin white, washed with green or rose-red at the crown. Flesh white, crisp, and very sugary. Leaves green; the leaf-stems clear green, or green stained with light red, according to the variety.

The White Sugar Beet is quite extensively grown in this country, and is employed almost exclusively as feed for stock; although the young roots are sweet, tender, and well flavored, and in all respects superior for the table to many garden varieties. In France, it is largely cultivated for the manufacture of sugar and for distillation.

Of the two sub-rarieties, some cultivators prefer the 
Green-top; others, the Rose-colored, or Red-top. The latter is the larger, more productive, and the better keeper; but the former is the more sugary. It is, however, very difficult to preserve the varieties in a pure state; much of the seed usually sown containing, in some degree, a mixture of both.

- It is cultivated in all respects as the Long Red Mangel Wurzel, and the yield per acre varies from twenty to thirty tons. A variety of the Early Turnip-rooted Blood, White Turwith green leaves and white flesh; the size and form of the root, and season of maturity, being nearly the same. Quality tender, sweet, and well flavored; but, on account of its color, not so marketable as the last named.

Root sixteen inches long, five inches in diam- Wyatt's eter, fusiform, and somewhat angular in conse- Dark son. quence of broad and shallow longitudinal fur- DARK WRIMrows or depressions. Crown conical, brownish. Skin smooth, slate-black. Flesh deep purplish-red, circled and rayed with yet deeper shades of red, fine-grained, and remarkably sugary. Leaves deep red, shaded with brownish-red; those of the centre, erect; those of the outside, spreading or horizontal.

The variety is not early, but of fine quality; keeps remarkably well, and is particularly recommended for cultivation for winter and spring use. Much esteemed in England.

Root produced within the earth, broadest at Yellow Casthe crown, where its diameter is nearly three Trans. Vil. inches, and tapering gradually to a point; the length being about eight inches. Skin orange-yellow. Flesh clear yellow, with paler zones or rings. Leaves spreading, those on the 
outside being on stems about four inches in length; the inner ones are shorter, numerous, of a dark green color, and waved on the edges: the leaf-stems are green, rather than yellow.

An excellent table-beet, being tender, yet firm, and very sweet when boiled, although its color is not so agreeable to the eye.

Yellow Globe Man-

This is a globular-formed beet, measuring gel Wurzel. about ten inches in diameter, and weighing Glonge gel Wurzel. 3ETTERAVE JAUNE GLOBE. ten or twelve pounds; about one half of the root growing above ground. Skin yellow, where it is covered by the soil; and yellowish-brown above the surface, where exposed to light and air. Flesh white, zoned or marked with yellow, close-grained and sugary. Leaves not large or uumerous, rather erect, green ; the stems and ribs paler, and sometimes yellowish.

The Yellow Globe is one of the most productive of all the varieties; and, though not adapted to table use, is particularly excellent for stock of all descriptions, as the roots are not only remarkably sugary, but contain a considerable portion of albumen. It retains its soundness and freshness till

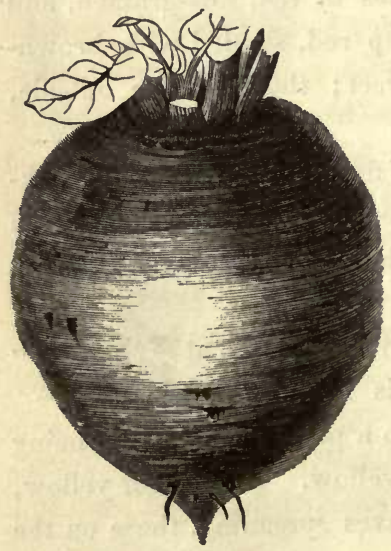

Yellow Globe Mangel Wurzel.

the season has far advanced, does not sprout so early in spring as many others, and is especially adapted for cultivation in hard, shallow soil.

The yield varies from thirty to forty tons per acre, according to soil, season, and culture; although crops are recorded of fifty tons and upwards.

Sow from the last of April to the last of May; but early sowings succeed best. If sown in drills, they should be made 
twenty inches apart, and the plants should be thinned to ten inches apart in the drills; if sown on ridges, sow in double rows, making the ridges three feet and a half, and the rows sixteen inches apart. On account of its globular form, the crop. can be harvested with great facility by the use of a common plough.

A sub-variety of the Blood Turnip-rooted, Yellow Turdiffering principally in color, but to some extent also in its form, which is less compressed. Leaves large, yellowish-green; the leaf-stems and nerves yellow. Flesh yellow, comparatively close-grained, sweet and tender.

Not much cultivated on account of its color ; the red varieties being preferred for table use.

\section{THE CAR R T .}

Daucus carota.

The Carrot, in its cultivated state, is a half-hardy biennial. It is indigenous to some parts of Great Britain, generally growing in chalky or sandy soil, and to some extent has become naturalized in this country, being found in gravelly pastures and mowing fields, and occasionally by road-sides, in loose places, where the surface has been disturbed or removed. In its native state, the root is small, slender, and fibrous, or woody, of no value, and even of questionable properties as an article of food.

Soil, Sowing, and Culture. - The Carrot flourishes best in a good, light, well-enriched loam. Where there is a choice of situations, heavy and wet soils should be avoided; and, where extremes are alternatives, preference should be given to the light and dry. If possible, the ground should be stirred to the depth of twelve or fifteen inches, incorporating 
a liberal application of well-digested compost, and well pulverizing the soil in the operation. The surface should next be levelled, cleared as much as possible of stones and hard lumps of earth, and made mellow and friable; in which state, if the ground contains sufficient moisture to color the surface when it is stirred, it will be ready for the seed. This may be sown from the first of April to the 20th of May; but early sowings succeed best. The drills should be made an inch in depth ; and for the smaller, garden varieties, about ten inches apart. The larger sorts are grown in drills, about fourteen inches apart; the plants in the rows being thinned to five or six inches asunder.

Harvesting. - The roots attain their full size by the autumn of the first year; and, as they are not perfectly hardy, should be dug and housed before the ground is frozen. When large quantities are raised for stock, they are generally placed in bulk in the cellar, without packing; but the finer sorts, when intended for the table, are usually packed in earth or sand, in order to retain their freshness and flavor. With ordinary precaution, they will remain sound and fresh until May or June.

Seed. - To raise seed, select good-sized, smooth, and symmetrical roots; and as early in spring as the frost is out of the ground, and the weather settled, transplant to rows three feet apart, and fifteen inches apart in the rows, sinking the crowns just below a level with the surface of the ground. The seed-stalks are from four to six feet in height, with numerous branches. The flowers appear in June and July; are white; and are produced at the extremities of the branches, in umbels, or flat, circular groups or clusters, from two to five inches in diameter. The seed ripens in August; but, as all the heads do not ripen at once, they should be cut off as they successively mature. The stiff, pointed hairs or bristles with which the seeds are thickly covered, and which 
cause them to adhere together, should be removed either by threshing or by rubbing between the hands; clearing them more or less perfectly, according to the manner of sowing. If sown by a machine, the seeds should not only be free from broken fragments of the stems of the plant, but the surface should be made as smooth as possible. For handsowing, the condition of the seed is less essential; though, when clean, it can be distributed in the drill more evenly and with greater facility.

The seeds of the several varieties differ little in size, form, or color, and are not generally distinguishable from each other. They will keep well two years; and if preserved from dampness, and placed in a cool situation, a large percentage will vegetate when three years old.

In the vegetable garden, an ounce of seed is allowed for one hundred and fifty feet of drill; and, for field culture, about two pounds for an acre.

An ounce contains twenty-four thousand seeds.

Use. - Though not relished by all palates, carrots are extensively employed for culinary purposes. They form an important ingredient in soups, stews, and French dishes of various descriptions ; and by many are much esteemed when simply boiled and served with meats or fish. They are also considered valuable for almost all descriptions of farm stock, and are more or less extensively cultivated throughout the country for this purpose. For horses, they are palatable and healthful; and for dairy cows, few kinds of food are better suited, as they are not only highly nutritious, but impart color and flavor to butter.

The varieties are as follow :-

The Altrincham Carrot measures about four- Altrincham. teen inches in length, by two inches in diameter. It retains its thickness for nearly two thirds Law. Altrineham. LONG RED ALits length: but the surface is seldom regular or smooth; 
the genuine variety being generally characterized by numerous crosswise elevations, and corresponding depressions. Neck small and conical, rising one or two inches above the surface of the soil. Skin nearly bright red; the root having a semi-transparent appearance. Flesh bright and lively, crisp and breaking in its texture; and the heart, in proportion to the size of the root, is smaller than that of the Long Orange. Leaves long, but not large or very numerous.

According to Lawson, it is easily distinguished from the Long Orange by the roots growing more above ground, by its more convex or rounded shoulders, and by its tapering more irregularly, and terminating more abruptly. It is, however, exceedingly difficult to procure the variety in its purity, as it is remarkably liable to sport, although the roots grown for seed be selected with the greatest care.

It is a good field-carrot, but less productive than the long Orange and some others; mild and well flavored for the table, and one of the best sorts for cultivation for market.

Thompson states that " it derives its name from a place called Altrincham, in Cheshire, Eng., where it is supposed to have originated. In seedsmen's lists, it is frequently, but erroneously, called the Altringham."

Early Frame. Root grooved or furrowed at the crown, EARLY FORCING
HORN. EARIIEST
SHORT FORCING
rHO Foundish, or somewhat globular; rather more

HORN. EARLY
SHORT SCARLT. than two inches in diameter, nearly the same in depth, and tapering suddenly to a very slender tap-root. Skin red, or reddish orange; brown or greenish where it

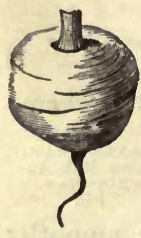
comes to the surface of the ground. Foliage small and finely cut or divided, not so large or luxuriant as that of the Early Horn.

The Early Frame is the earliest of all varieties, and is especially adapted for cultivation under

Early Frame. glass, both on account of its earliness, and the 
shortness and small size of its roots. It is also one of the best sorts for the table, being very delicate, fine-grained, mild, and remarkably well flavored.

Where space is limited, it may be grown in rows six inches apart, thinned to three inches apart in the rows; or sown broadcast, and the young plants thinned to three inches apart in each direction.

Root slender and tapering, measuring seven Early Halfor eight inches in length, and two inches in its $\begin{gathered}\text { Long Sarret. } \\ \text { HAOG RaD }\end{gathered}$ greatest diameter. Crown hollow. Skin red below the surface of the ground, green or brown above. Flesh reddish orange, fine-grained, mild, and well flavored. Foliage similar to that of the Early Frame, but not abundant.

The variety is remarkably productive; in good soil and favorable seasons, often yielding an amount per acre approaching that of the Long Orange. Season intermediate between the early garden and late field sorts.

Root six inches in length, two inches and a FarlyHorn. half in diameter, nearly cylindrical, and taper- $\begin{gathered}\mathrm{E}_{A R L Y} \mathrm{RCARLET} \\ \text { HoBN. }\end{gathered}$ ing abruptly to a very slender tap-root. Skin SOrcu Hurs. orange-red, but green or brown where it comes to the surface of the ground. Flesh deep orange-yellow, finegrained, and of superior flavor and delicacy. The crown of the root is hollow, and the foliage short and small.

The variety is early, and as a table carrot much esteemed, both on account of the smallness of its heart and the tenderness of its fibre. As the roots are quite short, it is well adapted for shallow soils; and on poor, thin land will often yield a greater product per acre than the Long Orange, or the White Belgian, when sown under

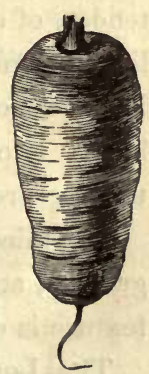

Early Horn Carrot. like circumstances. 
Sow in rows one foot apart, and thin to four inches in the rows.

Flander's Large Pale Scarlet. Vil. Flander's Pale RED.

Root produced within the earth, fourteen or fifteen inches long, three or four inches in diameter at the broadest part, fusiform, not very symmetrical, but often quite crooked and angular. The crown is flat, large, and nearly covered by the insertion of the leaves. Flesh reddish-yellow, and rather coarse-grained. foliage large and vigorous.

The roots are formed early and with great certainty. It is also productive, of large size, keeps remarkably well ; and, though of coarse texture, one of the best sorts for cultivation for farm purposes.

It originated in Flanders, and is comparatively an old variety, but is little disseminated, and not grown to any extent in this country.

Long Orange. Root long, thickest at or near the crown, and tapering regularly to a point. Size very variable, being much affected by soil, season, and cultivation: well-grown specimens measure fifteen inches in length, and three inches in diameter at the crown. Skin smooth, of a reddish orange color. Flesh comparatively close-grained, succulent, and tender, of a light-reddish vermilion or orange color, the heart lighter, and large in proportion to the size of the root. Foliage not abundant, but healthy and vigorous, and collected into a comparatively small neck. The roots are usually produced entirely within the earth.

If pulled while young and small, they are mild, finegrained, and good for table use; but when full grown, the texture is coarser, and the flavor stronger and less agreeable.

The Long Orange is more cultivated in this country for agricultural purposes than all other varieties. With respect 
to its value for stock, its great productiveness, and its keeping properties, it is considered the best of all the sorts for field culture. A well-enriched soil will yield from six hundred to eight hundred bushels per acre. The seed is usually

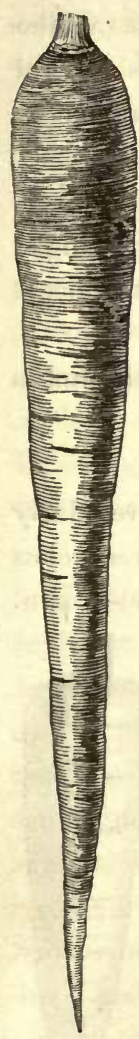

Long Red Belgian Carrot.

sown in drills, about fourteen inches apart, but sometimes on ridges, eighteen or twenty inches apart, formed by turning two furrows together; the ridges yielding the largest roots, and the drills the greatest quantity.

Two pounds of seed are usually allowed to an acre; but if sown by a well-regulated machine, about one half this quantity will be sufficient.

Root very long, fusiform, contracted Long Red a little towards the crown, but nearly $\begin{gathered}\text { Belgian. } \\ \text { YELL BEL- }\end{gathered}$ of uniform thickness from the top GREN-TOP BELdown half the length. Size large; when grown in deep soil, often measuring twenty inches in length, and nearly three inches in diameter. The crown rises four or five inches above the surface of the ground, and is of a green color; below the surface, the skin is reddish-yellow. Flesh orangered.

This variety, like the White, originated in Belgium. In Furope it is much esteemed by agriculturists, and is preferred to the White Belgian, as it is not only nearly as productive, but has none of its defects.

Root fusiform, three inches in diameter at the Long Yellow. crown, and from twelve to fourteen inches in LONG LeMON.

depth. Skin pale yellow, or lemon color, under ground; but greenish on the top, or crown, which rises a little above the surface of the soil. Flesh yellow, the heart paler, and, like 
that of the Long Orange, of large size. While young, the roots are delicate, mild, and well-flavored; but when full grown, valuable only for stock.

The Long Yellow is easily harvested, and is very productive, yielding nearly the same quantity to the acre as the Long Orange, which variety it much resembles in its geveral character, and with which it is frequently, to a greater or less extent, intermixed.

Long Surrey. 'This variety much resembles the Long Orange : I.NO RED.

JАM Е's SCARLE. the roots, however, are more slender, the heart is smaller, and the color deeper.

It is said to be popular in some parts of England, and is cultivated to a considerable extent on the continent.

Long White. Root produced entirely below ground, regularly fusiform, fifteen inches long, by about three inches in its largest diameter. Skin white, stained with russet-brown. Flesh white, and generally considered sweeter than that of the colored varieties.

The Common White has been but little cultivated since the introduction of the White Belgian; a variety much more productire, though perhaps not superior either in flavor or fineness of texture.

New Intermediate.

An English variety, comparatively of recent introduction. Root broadest at the crown, and thence tapering regularly to a point. Size full medium; well-grown specimens measuring nearly three inches in diameter at the broadest part, and about one foot in length. Skin bright orange-red: Flesh orange-yellow, finegrained, sweet, well flavored, and, while young, excellent for table use.

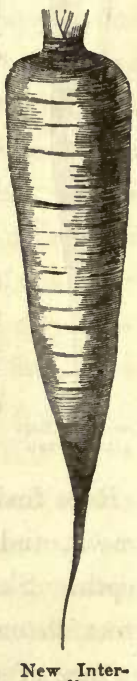

mediate. 
Very hardy, and productive; yielding, according to the best English authority, a greater weight per acre than any other yellow-fleshed variety.

Root fusiform, and very slender, fourteen inches Purple or in length, by two inches and a half in diameter Vloogrtr. at the top or broadest part. Skin deep purple, varying to some extent in depth of shade, but generally quite dark. Flesh purple at the outer part of the root, and yellow at the centre or heart; fine-grained, sugary, and comparatively well flavored.

Not much cultivated for the table, on account of the brown color it imparts to soups or other dishes of which it may be an ingredient. It is also inclined to run to seed the year it * is sown. It has, however, the reputation of flourishing better in wet, heavy soil than any other variety.

Root obtusely conical, seven or eight inches Short white. long, by about four inches in diameter at the BLAscre prs. crown, which is large, flat, greenish, and level with the surface of the ground. Skin white, tinted with amber, smooth and fine. Flesh yellowish-white, remarkably solid, and fine in texture; sweet and well flavored. Foliage rather finely divided, and as vigorous as the Long Orange.

The Short White yields well, retains its qualities during winter, and is well adapted for cultivation in soils that are hard and shallow.

Root fusiform, very long, and regular; the studley.

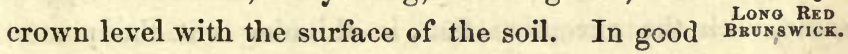
cultivation, the roots attain a length of sixteen inches, and a diameter of nearly two inches. Color bright reddish-orange, like the Altrincham.

An excellent table-carrot, but flourishes well only in deep, mellow soil. 
White Belgian. Root very long, fusiform, frequently measGREEN-TOP WHITr. uring eighteen or twenty inches in length, and four or five inches in diameter. In the genuine variety, the crown rises five or six inches from the surface of the ground; and, with the exception of a slight contraction towards the top, the full diameter is retained for nearly one half of the entire length. Skin green above, white below ground. Flesh white, tending to citron-yellow at the centre or heart of the root; somewhat coarse in texture. Foliage rather large and vigorous.

The White Belgian Carrot is remarkable for its productiveness, surpassing in this respect all other varieties, and exceeding that of the Long Orange by nearly one fourth. It - can be harvested with great facility, and gives a good return even on poor soils.

The variety is not considered of any value as a table esculent, and is grown almost exclusively for feeding stock; for which purpose it is, however, esteemed less valuable than the yellow-fleshed sorts, because less nutritious, and more liable to decay during winter.

Since its introduction, it has somewhat deteriorated; and, as now grown, differs to some extent from the description given above. The roots are smaller, seldom rise more than two or three inches above the soil, and taper directly from the crown to the point. A judicious selection of roots for seed, continued for a few seasons, would undoubtedly restore the variety to its primitive form and dimensions.

The same amount of seed will be required as of the Long Orange; and the general method of culture should be the same, with the exception that, in thinning out the plants, the White Belgian should have more space. Wite Belgian Root seven or eight inches in length, and two
Horn.

TRANSPAENT
WHIT. Vil. 
from the crown to the point. Skin fine, clear white. Flesh very white, and almost transparent, mild, tender, and delicate.

A French variety, remarkable for the peculiar, pure white color of its skin and flesh.

\section{TURNIP-ROOTED CHERVIL.}

Chærophyllum bulbosum.

A hardy biennial plant, from the south of Europe. The root is fusiform, four or five inches long, and nearly an inch and a half in diameter; skin, grayish-black; flesh, white. The leaves are compound, the leaflets deeply cut, and the divisions of the upper leaves narrow and slender. The flowers are white, and terminate the top of the plant in umbels, or large, circular, flat, spreading bunches. The seeds are long, pointed, furrowed, concave on one side, of a brownish Turnip-rooted color, and retain their power of germination but one year. An ounce contains sixty-five hundred seeds.

Soil and Cultivation. - The seeds may be sown in drills, in October or April, in the manner of sowing the seeds of the common carrot; preference to be given to rich, mellow soil. The roots will attain their full size by the following August or September, when they should be harvested. With a little care to prevent sprouting, they may be preserved until April.

Seed. - The roots intended for seed should be set in the open ground in autumn or in spring. The seeds will ripen in August, and should be sown within a month or two of the time of ripening, or, if kept till spring, should be packed in earth or sand; for, when these precautions are neglected, they will often remain dormant in the ground throughout the year. 
Use. - The Tuberous-rooted Chervil promises to be a valuable esculent root. M. Vilmorin considered it worthy to be classed with the potato, though not equally productive. On his authority, upwards of six tons have been produced on an acre ; an amount which he states may be greatly increased by a judicious selection of the best roots for seed.

The roots, which are eaten boiled, are nearly of the size and form of an Early Horn Carrot. The flesh is white, farinaceous, and of a flavor intermediate between that of a chestnut and a potato.

\section{CHINESE POTATO, OR JAPANESE YAM.}

Dioscorea batatas.

Stem twelve feet or more in length, of a creeping or climbing habit; leaves heart-shaped, though sometimes halberdformed; flowers small, in clusters, white. The roots are club-shaped, about two feet in length, two inches and a half in their largest diameter, of a rusty white or yellowish color without, remarkably white within, very mucilaginous, and so easily broken that they are rarely taken from the ground in a perfect state.

Propagation and Cultivation. - The Chinese Potato requires a deep, light, rather sandy, and tolerably rich soil; and this should be thoroughly stirred to the depth of at least two feet. No fresh manure should be used, but fine, welldecomposed compost applied, and deeply as well as thoroughly. incorporated with the soil; avoiding, however, if possible, its direct contact with the growing roots. It is propagated either by small roots; by the top or neck of the large roots, cut off to the length of five or six inches; or by the small bulbs, or tubers, which the plants produce in considerable numbers on the stem, in the axils of the leaves. These 
should be planted the last of April, or as soon as the ground is in good working condition. Lay out the land in raised ridges two feet and a half or three feet asunder, and on the summit set the bulbs, or tubers, with the point or shoot upwards, eight or ten inches apart, and cover about an inch deep. Cultivate in the usual manner during the summer; and late in autumn, after the tops are dead, and just before the closing-up of the ground, take up the roots, dry them a short time in the sun, and store in the cellar for use. The roots are perfectly hardy, and will sustain no injury from the coldest winter if left unprotected in the open ground. During the second season, the growth of the old root is not continued, but gradually decays as the new roots are formed.

Use. - The roots are eaten either boiled or roasted, and require rather more than half the time for cooking that is usually given to the boiling or roasting of the common potato. When cooked, they possess a rice-like taste and consistency, are quite farinaceous, and unquestionably nutritive and valuable for food.

Though strongly recommended as a vegetable likely to become a substitute for the potato, the cost of preparing

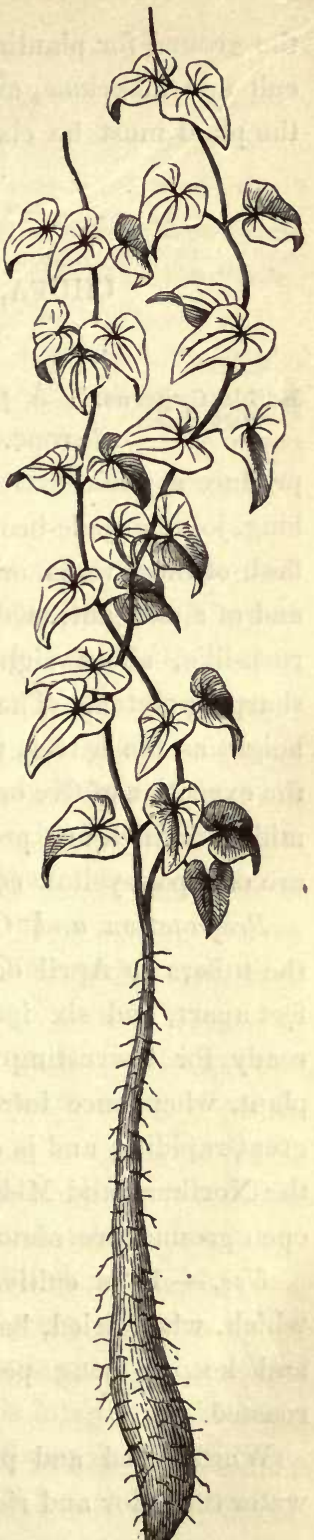


the ground for planting is so great, the harvesting is so difficult and laborious, and the yield is generally so small, that the plant must be classed as one not worthy of cultivation.

\section{CHUFA, OR EARTH ALMOND.}

Cyperus esculentus.

Edible Cyperus. A perennial plant, from the south of EuNut Rush. rope. The roots are long and filbrous, and produce at their extremities numerous small, rounded or oblong, jointed, pale-brown tubers, of the size of a filbert. The flesh of these roots, or tubers, is of a yellowish color, tender, and of a pleasant, sweet, and nut-like flavor. The leaves are rush-like, about eighteen inches high, a little rough, and sharply pointed. The flower-stalks are nearly of the same . height as the leaves, three-cornered, hard, and leafless, with the exception of five or six leaf-like bracts at the top, from the midst of which are produced the spikelets of flowers, which are of a pale-yellow color.

Propagation and Culture. - It is propagated by planting the tubers in April or May, two inches deep, in drills two feet apart, and six inches apart in the drills. They will be ready for harvesting in October. In warm climates, the plant, when once introduced into the garden, spreads with great rapidity, and is exterminated with much difficulty. In the Northern and Middle States, the tubers remaining in the open ground are almost invariably destroyed by the winter.

Use.- It is cultivated for its small, almond-like tubers, which, when dried, have somewhat the taste of the almond, and keep a long period. They are eaten either raw or roasted.

When dried and pulverized, they are said to impart to water the color and richness of milk. 


\section{GERMAN RAMPION.}

Enothera biennis.

The German Rampion, or Evening Primrose, Tree Prim-

common in this country to gravelly pastures and rose. Even. roadsides, is a hardy biennial plant, and, when rose.

in full perfection, measures three or four feet in height, with long, flat, pointed leaves, and large, yellow, fragrant flowers. The seed-pods are oblong, four-sided; the seeds are small, angular, of a brown color, and retain their germinative properties three years.

Sowing and Cultivation. - The seeds should be sown annually, in April, in a rich and shady situation; for if grown in a dry, sunny exposure, and sown very early in the season, the plants are inclined to run to flower during the summer, which renders the roots worthless; for they then become hard and fibrous. Sow in drills an inch deep, and fourteen inches apart; thin to six or eight inches in the rows; cultivate in the usual form; and, in September, the roots will be ready for use. For winter use, take up the roots before freezing weather, and pack in sand. For spring use, they may be taken directly from the ground.

To raise Seed. - Two or three plants, left in the ground through the winter, will yield an abundant supply of seeds the following summer.

Use. - The root is the only part used. This, when full grown, is generally from ten to twelve inches long, fusiform, occasionally with a few strong fibres, whitish on the outside, and white within. The thick, outer covering separates readily, and should be removed when the root is eaten in its crude state. It possesses a nutty flavor; but is inferior to the true Rampion, having a slight pungency. If required as a raw salad, it should be eaten while young. When the roots have 
attained their full size, they are usually dressed in the manner of Skirret and Scorzonera.

\section{JERUSALEM ARTICHOKE.}

Helianthus tuberosus.

The Jerusalem Artichoke is a hardy perennial. . In its manner of growth and flowering it much resembles the common sunflower, of which, as its scientific term suggests, it is really a species. Stem six to eight feet high, very rough, and much branched; leaves alternate, large, rough, heartshaped at the base, pointed at the ends, and indented on the borders; flowers large, yellow, produced on the top of the plant, at the extremities of the branches.

Soil, Propagation, and Culture. - The Artichoke thrives best in light, mellow soil, but will succeed wherever the common potato can be profitably grown. It is propagated by planting the tubers, divided in sections, as is generally practised with the potato. These may be set in spring or autumn, and should be covered about three inches deep. Whether planted in hills or rows, the plants will soon completely occupy the ground.

Extra fine tubers are sometimes raised by stirring the soil to the depth of twelve or fifteen inches before planting, and by a liberal application of manure; afterwards thinning out such plants as make a weakly growth, and weeding and cultivating thoroughly during the season.

Taking the Crop. - The new tubers will be suitable for use in the autumn. In digging, great care should be taken to remove the small as well as the full-grown; for those not taken from the ground will remain fresh and sound during the winter, and send up in the spring new plants, which, in 
turn, will increase so rapidly, as to encumber the ground, and become troublesome. In localities where the crop has once been cultivated, though no plants be allowed to grow for the production of fresh tubers, yet the young shoots will continue to make their appearance from time to time for many years.

Use. - The plant is cultivated for its tubers, which are pickled, like the cucumber, and sometimes eaten in their crude state, sliced as a salad. When cooked they have somewhat the flavor of the true artichoke.

McIntosh says that the tubers may be used in every way as the potato, and are suited to persons in delicate health, when debarred from the use of most other regetables.

Varieties. - For a long period there was but a single variety cultivated, or even known. Recent experiments in the use of seeds as a means of propagation have developed new kinds, varying greatly in their size, form, and color, possessing little of the watery and insipid character of the heretofore grown Jerusalem Artichoke, and nearly or quite equalling the potato in flavor and excellence.

Tubers large, and often irregular in form; skin Common and flesh white; quality watery, and somewhat White. insipid. It is unfit for boiling, but is sometimes served baked or roasted. It makes a very crisp and well-flarored pickle.

A French variety, produced from seed. PurpleTubers purplish rose-color; flesh dryer when cooked, and finer flavored, than that of the foregoing.

Like the purple-skinned, proauced from seed. Red-skinned. Skin red. Between this and the last named there are various intermediate sorts, differing in shades of color, as well as in size, form, and quality. 
Yellow-skin- The tubers of this variety are of a yellowish
ned. Law. color, and are generally smaller, and even more irregularly shaped, than those of the Common White. They are, however, superior in quality, and of a more agreeable taste when cooked.

\section{OXALIS, TUBEROUS-ROOTED. - Law.}

Tuberous-rooted Wood-sorrel. Oca. Oxalis crenata.

Of the Tuberous-rooted Oxalis there are two varieties, as follow :-

Whiterooted.

Stem two feet in length, branching, prostrate Oca вLANCA. Or trailing; the ends of the shoots erect; leaves trifoliate, yellowish-green, the leaflets inversely heart-shaped; flowers rather large, yellow, - the petals crenate or notched on the borders, and striped at their base with purple. The seeds are matured only in long and very favorable seasons. In its native state, the plant is perennial, but is cultivated and treated, like the common potato, as an annual.

Cultivation. - The tubers should be started in a hot-bed, in March, and transplanted to the open ground in May, or as soon as the occurrence of settled warm weather. They thrive best in dry, light, and medium fertile soils, in warm situations, and should be planted in hills two feet and a half apart, or in drills two feet and a half apart, setting the plants or tubers an inch and a half deep, and fifteen or eighteen inches apart in the drills, treating in all respects as potatoes.

The tubers form late in the season; are white, roundish, or oblong, pointed at the union with the plant, and vary in size according to soil, locality, and season, seldom, however, 
exceeding an inch in diameter, or weighing above four ounces. The yield is comparatively small.

Use. - The tubers are used as potatoes. When cooked, the flesh is yellow, dry, and mealy, of the flavor of the potato, with a slight acidity. The tender, succulent, stalks and foliage are used as salad.

Plant similar in habit to the White-rooted; Oxalis, Redbut the branches, as well as the under surface oca cozorad. of the leaves, are more or less stained with red. Tubers larger than those of the last named, roundish, tapering towards the connection with the plant, and furnished with numerous eyes, in the manner of the common potato; skin smooth, purplish-red; flesh often three-colored, - the outer portion of the tuber carmine-red, the central part marbled, and the intermediate portion yellow, - the colors, when the root is divided transversely, appearing in concentric zones, or rings. The flesh contains but little farinaceous matter, and possesses a certain degree of acidity, which, to many palates, is not agreeable.

It is propagated, and in all respects cultivated, like the White. Either of the varieties may also be grown from cuttings, which root readily.

According to a statement from the London Horticultural Society's Journal, the acidity may be converted into a sugary flavor by exposing the tubers to the action of the sun for eight or ten days, - a phenomenon which is analogous to what takes place in the ripening of most fruits. When treated in this form, the tubers lose all trace of acidity, and become as floury as the best descriptions of potatoes. If the action of the sun is continued for a long period, the tubers become of the consistence and sweet taste of figs. Mr. Thompson states that the disagreeable acid taste may also be removed by changing the water when they are three quarters boiled. 
The plants are tender, and are generally destroyed early in autumn by frost. The tubers must be taken up before freezing weather, packed in sand, and placed in a dry, warm cellar for the winter.

Deppe's Oxal- A perennial plant from Mexico, very distinct
is. Thomp.Vil. OxıLIs DEPREI. from the tuberous-rooted species before described. Stalk about one foot in height, smooth and branching; leaves four together, the leaflets wedge-shaped, pale yellowish-green, the upper surface marked by two brownish lines or stains in the form of two sides of a triangle; flowers terminal, of a carmine-rose or pink-red color, stained with green at the base of the petals. The roots are fusiform, three or four inches long, nearly an inch and a half in diameter, white and fleshy, and surmounted with numerous small scales or bulbs, which serve for propagation.

Soil and Culture. - The plant succeeds best in rich, warm, mellow soil ; and, though it may be raised from seed, is usually propagated from the small bulbs, which are set early in May, six or eight inches apart, in shallow drills fifteen inches asunder.

As the whole season will be required for their full perfection, the roots should be allowed to remain in the ground till danger from freezing, when they should be harvested, packed in dry sand, and stored in the cellar for the winter.

The plant has been cultivated with the most complete success with no especial preparation of the soil ; merely planting the bulbs in shallow drills, the ground being dug and manured as for other kitchen-garden crops.

Use. - The roots are eaten boiled, and served as asparagus; and the young leaves, which have a pleasant acid taste, are used as salad, as are also the flowers.

It is sometimes cultivated as an ornamental plant. 


\section{THE PARSNIP.}

Pastinaca sativa.

The Parsnip is a hardy biennial, indigenous to Great Britain and some parts of the south of Europe, and to a considerable extent naturalized in this country. In its native state the root is small and fibrous, and possesses little of the fineness of texture, and delicacy of flavor, which characterize the Parsnip in its cultivated state.

The roots are fusiform, often much elongated, sometimes turbinate, and attain their full size during the first year. The flowers and seeds are produced the second year, the plant then measuring five or six feet in height, with a grooved or furrowed, hollow, branching stem. The flowers are yellow, in large spreading umbels five or six inches in diameter. The seeds ripen in July and August; are nearly circular; about one fourth of an inch in diameter; flat, thin, very light, membranous on the borders, and of a pale yellowish-brown or yellowish-green color. They vary but little in size, form, or color, in the different varieties, and retain their vitality but two years. About six thousand seeds are contained in an ounce.

Half an ounce of seed is -usually allowed for one hundred feet of drill, and six pounds for an acre.

Soil, Sowing, and Cultivation. - The soil should be mellow, deep, of a rich vegetable texture, and not recently turned from the sward. As the roots of most of the varieties are long and comparatively slender, the deeper and more thoroughly the soil is stirred the better. Where the soil is thin, and the sub-soil clayey or hard and gravelly, the Parsnip rarely succeeds well, the roots being not only short and branched, but deficient in the mild, tender, and 
sugary properties which they possess when grown under more favorable conditions.

The Parsnip is always propagated from seeds sown annually. As early in April as the soil becomes dry and warm, prepare the land as for the carrot and other esculent roots, raking the surface fine and smooth, and sow the seeds rather thickly, in drills, fifteen inches asunder, and an inch and a half in depth. When the young plants are well up, thin them to five or six inches apart, and cultivate in the usual manner during the season.

The roots are sometimes drawn for use early in September, but they are at this season generally small, and comparatively flavorless. Their full size aud excellence are not acquired till the decay of the leaves, when they are ready for harvesting.

Harvesting. - The Parsnip sustains no injury when left in the open ground during winter; and it is a common practice to take up in the fall a certain quantity of roots to meet a limited demand in the winter months, allowing the rest to remain in the ground until spring. The roots thus treated are considered to have a finer flavor; that is to say, are better when recently taken from the ground.

In taking up the crop, be careful to remove the soil to a sufficient depth as not to injure the roots. The thrust of the spade that easily lifts a carrot without essential injury, will, if applied to the Parsnip, break the roots of nine in ten at scarcely half their length from the surface of the ground. As the roots keep much fresher, and retain their flavor much better, when taken up entire, the best method is to throw out a trench beside the rows, to the depth of the roots, when they can be easily, as well as perfectly, removed. They should be dug in pleasant weather, and laid on the ground exposed to the sun for a few hours to dry; after which remove the foliage, and pack in sand, dried leaves, or common 
loam, not too moist. Thus treated, they will remain comparatively fresh kept in almost any location, either in the cellar or storehouse.

If the roots which have remained in the ground during winter be taken up in spring, and the tops removed as before directed, they may be packed in sand or earth, and will remain fresh and in good condition for use until May or June.

To raise Seed. - In April thin out the roots, that have been in the ground during the winter, to about eighteen inches apart; or, at the same season, select a few good-sized and symmetrical roots from those harvested in the fall, and set them eighteen inches apart, with the crowns just below the surface of the ground. They will send up a stalk to the height and in the manner before described, and the seeds will ripen in August. The central umbel of seeds is always the largest, and is considered much the best.

Use. - The use of the Parsnip as an esculent is wellknown. The roots are considered healthful, and are esteemed for their delicate, pleasant flavor.

They contain a considerable portion of sugar, and are considered more nutritive than carrots or turnips. They also form a common ingredient in soups; and are sometimes used for making bread, and also a kind of wine said to resemble Malmsey or Madeira.

Aside from the value of the Parsnip as a table vegetable, $i t$ is one of the most economical roots for cultivation for farm purposes, as it not only produces an abundant and almost certain crop, but furnishes very nourishing food particularly adapted to and relished by dairy-stock.

Varieties. - The varieties, which are not numerous, are as follow : -

The leaves of the Common, or Dutch Parsnip, are strong 
Common, or and numerous; generally about two feet long Dutch. T'rans.
SwkLLive PARs- or high. The roots are from twenty to thirty
NIP LONA Sмоотичтсн inches in length, and from three to four inches in diameter at the shoulder, regularly tapering to the end, occasionally producing a few strong fangs. The crown is short and narrow, elevated, and contracting gradually from the shoulder, which is generally below the surface of the ground.

Seeds from America, Holland, and Germany, sown in the garden of the London Horticultural Society, all proved alike; though some were superior to others in the size of their roots, owing, it was thought, both to a careful selection of seed-roots and to the age of the seeds. It was found that new seeds uniformly produced the largest roots.

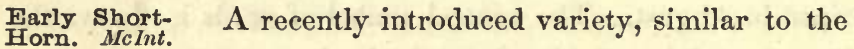
Turnip-rooted, but shorter. Very delicate and fiue-flavored.

Guernsey. The leaves of this variety grow much stronger PANa SMooris. and somewhat taller than those of the Common

TIK FRENCH. Parsnip. The leaflets are also broader. The only distinguishable difference in the roots is, that those of the Guernsey Parsnip are the larger and more perfect, being sometimes three feet long. Roots produced from seed obtained from Guernsey were evidently much superior to those which were grown from seed raised in other localities : from which it would appear that the Guernsey Parsnip is only an improved variety of the Common, arising from soil and cultivation in that island. Dr. McCulloch states that, in Guernsey, its roots grow to the length of four feet. In its flavor, it differs little from the Common Dutch Parsnip. 
In this variety, the leaves are shorter and not so numerous as those of the Common Parsnip. The roots are oblong, about eighteen inches in length, and four inches in diameter at

Hollowcrowned. Trans.

LONG JERSET.

HOLLOW-CROWN-

EU GUERNSEY.

HOLLOW-HKADED. the shoulder, more swollen at the top, and not tapering gradually, but ending somewhat abruptly with a small taproot. The crown is short, and quite sunk into the shoulder, so as to form a hollow ring around the insertion of the stalks of the leaves; and grows mostly below the surface of the ground.

It is a good sort for general cultivation, especially as it does not require so deep a soil as either the Common, or Guernsey. There is little difference in the flavor or general qualities of the three varieties.

This is said to be more tender and richer in Siam, or Yelflavor than any of the other varieties. It is low. Thomp. mentioned by Dr. Neill in the "Encyclopædia Britannica," and is described by M. Noisette as being yellowish in color, and in form intermediate between the Guernsey and Turniprooted Parsnips. He also states that it is the most esteemed. It does not, however, appear to be kuown at the present day in this country.

Root fusiform, varying in length from fifteen The Student. to twenty inches, according to soil and culture. The crown is broad and rounded, hollowed at the insertion of the leaves, and in well-grown specimens measures nearly three inches in diameter. Compared with the Common Dutch, or IIollow-crowned, the root is more free from fibres, and tapers more suddenly and with greater regularity from the crowu to the point. The flavor is peculiarly sweet, mild, and pleasant, and is described as excelling that of any other sort now in cultivation. 
This variety, so recently brought to notice and so strongly commended, is of English origin, and was obtained from the wild Parsnip by Prof. Buckman, of the Royal Agricultural College at Cirencester. It was introduced into this country soon after it was publicly offered into England, and is now quite generally disseminated.

- Turniprooted.
Trans. Panats Rond, of THE YKENCH. teen inches in length. The roots are from four to six inches in diameter, tunnel-shaped, tapering very abruptly, with a strong tap-root; the whole being from twelve to fifteen inches in length. The rind is rougher than either of the other sorts; the shoulder very broad, growing above the surface of the soil; convex, with a small, short crown. It is much the earliest of the Parsnips; and, if left in the

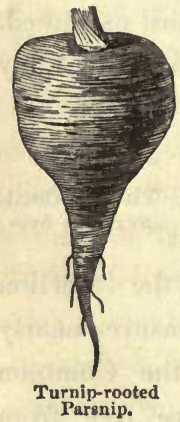
ground, is liable to rot in the crown. The leaves also decay much sooner than those of most other sorts.

It is particularly adapted to hard and shallow soils; and, from its coming into use much earlier than any other kind, very desirable. In flavor it is mild and pleasant, though less sugary than the long-rooted kinds. The flesh, when dressed, is more yellow than that of any other variety. 


\section{T H E POT A TO.}

Solanum tuberosum.

The Potato is a native of Central or Tropical America. In its wild or natural state, as found growing on the mountains of Mexico or South America, the tubers rarely exceed an inch in diameter, and are comparatively unpalatable. During the last half century its cultivation within the United States has greatly increased ; and it is now considered the most important of all esculent roots, and next to the cereals in value as an article of human subsistence.

Soil. - The soils best suited to the Potato are of the dryer and lighter descriptions; pasture lands, or new land, with the turf freshly turned, producing the most abundant as well as the most certain crops. On land of a stiff, clayey texture, or in wet soils, they are not only extremely liable to disease, but the quality is usually very inferior.

Where the land has been long under cultivation, they seldom produce well, and the quality, even when quite free from disease, is usually much inferior to that of tubers raised on comparatively new soil.

Fertilizers. - If the soil is good, but little manure will be required. In highly enriched soil the plants appear to be more liable to disease than when grown in soil that is naturally good.

The best fertilizers are those of a dry or absorbent nature, as plaster, lime, superphosphate of lime, and bone-dust. For wet soils these are particularly beneficial, as they not only promote growth, but prevent disease. On dry, warm land, muck-compost or barn-yard manure may be applied advantageously. Decaying leaves make an excellent fertil- 
izer, but all applications of very rich manure, particularly in the hill about the sets at the time of planting, should be avoided. Manures that are slow in their decomposition are well suited for the Potato, and experience has proved that these are quite as beneficial applied equally over the ground, as they are when brought more directly in contact with the growing plants. Ashes are a safe manure, and crops in England treated with these alone suffered very little from disease, while others, under the application of manure in the ordinary forms, were more than half destroyed.

Propagation. - The Potato is propagated from the tubers, which are either divided into sets or planted entire. Whichever of these practices may be adopted, experience has proved that plants from well-ripened tubers are not only more healthy and more productive, but actually come to perfection earlier than those produced from immature sets.

Experiments for the purpose of testing the comparative value of the tubers entire or divided into sets for planting, do not seem to be satisfactory. At the Chiswick Gardens, England, the divided tubers gave nearly one ton per acre more than those planted entire, this excess being the mean of two plantations, one made early in the season, and another four weeks later; while another experiment, continued through a series of years, gave a mean result in favor of medium-sized tubers, planted entire.

The part of the Potato used for planting has been regarded as important, the point or top being thought to produce the most healthy and productive plants. Though there appears to be a physiological difference between the extremities, and though the results of the experiment made by the London Horticultural Society gave a large amount in favor of the eye or top of the tuber, still, practically considered, the part of the tuber to be used for planting is comparatively unimportant-a paramount consideration being its complete development or full maturity. 
With regard to the quantity of seed per acre great diversity of opinion exists among cultivators. Much, of course, depends on the variety, as some sorts not only have more numerous eyes, but more luxuriant and stronger plants than others. Of such varieties a much less quantity will be required than of those of an opposite character. From a series of experiments carefully made for the purpose of ascertaining the amount of seed most profitable for an acre, it was found that from six to eight bushels, if planted in hills, answered better than more; for, when too much seed was used, there were many small tubers; and where the tubers had been divided into very small parts, or single eyes, the plants were more feeble, and the yield less in number and weight, though usually of larger size.

Methods of Planting and Cultivation. - Potatoes are usually planted either in hills or ridges, the former method being the more common in this country. If planted in hills, they should be made from three feet to three and a half apart; the distance to be regulated by the habit of the variety under cultivation. If in ridges or drills, they may be made from two and a half to three feet apart; although some of the earlier and smaller kinds may be successfully grown at eighteen or twenty inches.

Of sets formed by dividing a tuber of medium size into four parts, three may be allowed to a hill; if planted in drills, sets of this size should be placed about ten inches apart. On light, warm soil they require to be covered nearly four inches deep; but in cold, wet situations, two and a half or three inches will be sufficient.

Cultivation. - This should be commenced as soon as the young shoots are fairly above the surface. As the season advances, gather the earth gradually about the hills or along the drills, adding a little at each successive hoeing for the support of the growing plants, and to encourage the develop- 
ment of the side-roots ; for it is at the extremities of these that the tubers are formed. After the appearance of the blossoms cultivation should be discontinued, and no further attention will be required till the time for harvesting.

Forcing. - This should be commenced from three to four weeks before the season for planting in the open ground. The earliest varieties should be chosen for the purpose, selecting whole tubers of medium size, and placing them close together, in a single layer, among half-decayed leaves or very light loam, on the surface of a moderate hot-bed.

In a few wecks the eyes will have started sufficiently for planting out. Divide the tubers into sets as before directed, - being careful not to break or injure the young shoots, set them in hills or drills, and cover three inches deep. A light application of horse-manure at the bottom of the hills or drills will afford the warmth which may be needed early in the season, and afterwards give support and vigor to the growing crop.

Taking the Crop and Method of Preservation. - The season of maturity of the earlier sorts will be indicated by the decay of the plants. The later sorts will coutinue their growth until checked by frost - previous to which time they will not be ready for harvesting.

In summer weather, when it is practicable, the table should be supplied from day to day directly from the field or garden, as the tubers rapidly deteriorate after being taken from the ground, particularly if exposed to a warm, light atmosphere, or kept in a warm and dry cellar.

In the preservation of potatoes it is of the first importance that they be excluded from light. If this is neglected, they become not only injurious, but actually poisonous; and this is especially the fact when they are allowed to become of a green color, which they readily will do on exposure to the light. In a state of complete darkness they should, there- 
fore, be placed the day they are taken out of the ground; and it were even better that they were stored in rather a damp state, than that they should be exposed for a day to the light with a view to dry them. Drying has a bad effect on the skin of the Potato; for, if subjected to this, the skin and part of the epidermis are made to part with their natural juices, which ever afterwards renders them incapable of absorbing moisture, even if presented to them. Fermentation is also an important evil to be guarded against, as it changes the whole substance of the Potato, and, so far as seed potatoes are concerned, destroys their vegetative principle. As security against this, they should be stored either in barrels or boxes, or in long, narrow ridges, with partitions of earth between. Potatoes once dried should never be again moistened until just before using.

Varieties. - Messrs. Peter Lawson and Sons describe one hundred and seventy-five, and other foreign authors enumerate upwards of five hundred varieties, describing the habit of the plant; size, form, and color of the tubers; quality and general excellence; and comparative value for cultivation.

They are obtained from seeds, which are quite small, flat, lens-shaped, and retain their germinative properties three years; one hundred and five thousand are contained in an ounce.

They may be sown either in spring or autumn. If in autumn, collect the balls or berries, and plant them, either bruised or entire, in drills twelve or fifteen inches apart, and cover an inch deep. If in spring, the berries should be gathered in autumn, and the seeds extracted and dried, as is practised with the seeds of the tomato. In April, sow in shallow drills, half an inch deep and twelve or fifteen inches apart, as directed for the sowing in autumn. During the summer, treat the growing plants in the usual form, keeping 
the soil loose and clear of weeds, and in October, when the tops have been destroyed by frost, harvest the tubers, keeping those of the different plants distinct, and store in the cellar for the winter.

The following spring these tubers, some of which will measure nearly an inch in diameter, must be again planted, which may be done in drills fifteen inches apart, dropping the tubers about a foot asunder, and covering two inches deep. During the summer, earth up the drills to a moderate extent, and harvest in October, keeping the various kinds distinct as before.

The third season some estimate of the value of the different sorts may be formed. They will be found to vary, in a greater or less degree, in size, form, color, number and depth of the eyes, quality, season, productiveness, and liability to disease. Such as are of little value may be rejected, while such as appear promising should be reserved for further cultivation.

Ash-leaved

Stem nearly two feet in leight, erect, with Early. long, smooth, shining, and drooping foliage; flowers very seldom produced; tubers white, roundish, rough-skinned; flesh white, of medium quality. The variety is healthy and remarkably early, well suited to open culture, but not adapted for growing under glass, on account of its tall habit.

\footnotetext{
Ash-leaved

One of the earliest of the garden varieties, well Kidney. adapted for forcing under glass, or for starting in a hot-bed, and subsequent cultivation in the open ground. The plant is of spreading habit, and about eighteen inches in height; leaves small, recurved; tubers of medium size, kidney-shaped, white; flesh white, dry, and well-flavored. Very healthy. Introduced.
} 
Tubers of medium size, roundish, white ; flesh Atkinson's pure white, dry, and farinaceous, and of delicate Early. flavor. Plant dwarfish.

One of the earliest of all varieties, excellent for garden culture, and well adapted for forcing. Originated at Lynn, Mass.

Plant two feet and a half high, spreading; Biscuit. leaves rather rough, large, and of a pale-green Lav. color; flowers whitish; tubers rather small, round, smooth, and of a light-brownish color. A healthy variety, mealy, well-flavored, and quite produetive.

The plants do not decay, nor do the tubers attain full maturity, until nearly the close of the season: the latter are, however, of good quality, and in perfection for the table soon after being harvested.

Plant vigorous, and generally of healthy habit; Black Mertubers nearly of the form of the Lady's Finger, Chenango. but of larger size; skin very deep purple, or nearly black; flesh purple, both in its crude state and when cooked; quality good, usually dry, and of good flavor.

The Black Chenango is moderately productive, and withstands disease better than almost any other Potato; but its dark color is objectionable. Compared with many of the recent varieties, it has little merit, and is not a profitable sort for extensive cultivation.

A western variety; grown also to a consid- Buckeye. erable extent in some parts of the Middle States. "It is a handsome, round Potato; white throughout, except a little bright pink at the bottom of the eye ; very early, - ripening as early as the Chenango; attains a good marketable size as soon as the Dykeman; cooks dry and light; and is fine- 
flavored, particularly when first matured. It throws up a thick, vigorous, and luxuriant vine; grows compactly in the hill, and to a large size, yielding abundantly."

For planting for early use, it is a promising variety; but for a late or medium crop, upon strong, rich ground, is said to grow so rapidly, and to so great a size, that many of the tubers are liable to be hollow-hearted, which considerably impairs their value for table use.

Calico. Similar to the Pink-eyed; varying little except in color, which is mostly red, with occasional spots and splashes of white. It is in no respect superior to the last-named variety in quality, and cannot be considered of much value for agricultural purposes or for the table.

\section{California Red.}

A bright-red Potato from California. Tubers variable in form, from long to nearly round, rather smooth; eyes slightly depressed.

It is one of the most productive of all varieties; but, on account of its extreme liability to disease, cannot be recommended for general cultivation.

Carter. A medium-sized, roundish, flattened, white Potato, once esteemed the finest of all varieties, but at present nearly or quite superseded by the Jackson White, of which it is supposed to be the parent. Eyes rather numerous, and deeply sunk; flesh very white, remarkably dry, farinaceous, and well-flavored. Originated about thirty years ago, in Berkshire county, Mass., by Mr. John Carter.

Churchill. A variety said to have originated in Maine, and often sold in the market for the "State of Maine," which it somewhat resembles in size, form, and color. Flesh yellow. Not a desirable sort. 
It is much inferior to the "State of Maine," and, in many places, the latter variety has been condemned in consequence of the Churchill having been ignorantly cultivated in its stead.

An early sort, of good quality, but rather Cristy. unproductive. Shape somewhat long, though often nearly round; color white and purple, striped and blended together. It is of no value as an agricultural variety, and, for table use, cannot be considered superior to many other varieties equally healthy and more prolific.

Introduced. Plant upright, stocky, surviving Cups. till frost ; flowers pale purple ; tubers pink or reddish, large, oblong, often irregular; flesh dry and farinaceous. Very healthy and productive, but better suited for agricultural purposes than for the table.

Plant healthy and vigorous. The large, full- Danvers grown tubers are long; and the smaller, unde- DANVERs RED. veloped ones, nearly round. Color light red, with faint streaks of white; eyes moderately sunk; quality fair.

This variety originated in Danvers, Essex county, Mass. ; and, when first introduced, was not only of good size and quality, but remarkably productive. It has, however, much deteriorated; and is now, both as respects quality and yield, scarcely above an average. At one period it had the reputation of being one of the best varieties for keeping, and of entirely withstanding the attacks of the potato disease. -

This variety originated in the town of Sterling, Davis's Mass., and was early disseminated through the Seedling. influence of the Massachusetts Horticultural Society, at whose exhibitions it attracted much attention on account 


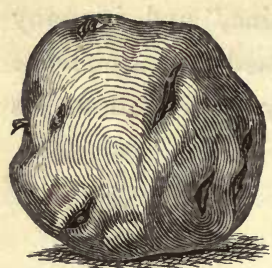

Davis's Seedling.

of its size and beauty. For general cultivation it is probably one of the most profitable sorts known, as it yields abundantly, even with ordinary attention. Under a high state of cultivation seven hills have produced a bushel of potatoes.

The tubers are of good size, red, nearly round, though sometimes more or less flattencd. Eyes deeply sunk, and not very numerous; flesh nearly white, slightly tinged with pink beneath the skin when cooked; quality good, being dry, farinaceous, and well-flavored. It requires the full season for its complete perfection, and resists disease better than most varieties.

As a winter Potato, or for extensive cultivation for market, it is one of the best of all varieties; and commends itself to the farmer, both as respects quality and yield, as being greatly superior to the Peach-blow, Pink-eye, Vermont White, and many similar varieties, which so abound in city markets.

Plant of medium strength and vigor, rarely Dykeman. producing seed or blossoms ; tubers large, round- EarLy Drkeman. ish, often oblong; color white, clouded at the stem-end and about the eyes (which are moderately sunk and rather numerous) with purple; flesh white, or yellowish-white; its quality greatly affected by season, and the soil in which the variety may be cultivated.

In certain descriptions of rather strong, clayey land, the yield is often remarkably great, and the quality much above medium. In such land, if warm and sheltered, the tubers attain a very large size quite early in the season, and find a ready sale in the market at greatly remunerative prices. Under other conditions, it frequently proves small, waxy, and 
inferior in quality, and profitless to the cultivator. Notwithstanding these defects, its size, earliness, and productiveness render it worthy of trial.

Tubers of medium size, roundish, of a bright Early Blue. purple or bluish color; eyes moderately deep; flesh, when cooked, white, or yellowish-white, mealy, and well flavored.

This old and familiar variety is one of the earliest of the garden potatoes, of fine quality, and one of the best for forcing for early crops. It retains its freshness and flavor till late in the spring; is of comparatively healthy habit; and, though but moderately productive, is worthy more general cultivation.

Plant of medium strength and vigor, recum- Early Cockney. bent, rarely blossoming, and usually ripening and decaying early in the season, or before the occurrence of frost; tubers white, large, roundish, rough; flesh yellowish-white, or nearly white, dry, farinaceous, and of good flavor. Hardy, moderately productive, and recommended as a desirable intermediate variety for the garden or for field culture. Introduced.

Plant medium or small, rarely blossoming, Farly Manly. and decaying early in the season; tubers of medium size, white, roundish ; flesh yellowish-white, dry, mealy, and mild flavored. It yields well, and is a good variety for early garden culture. Introduced.

Plant reclining, of rather slender habit, rarely Flour-Ball. blossoming; tubers of medium size, white, round, the skin quite rough or netted; flesh white, dry, farinaceous, and mild flavored. It yields abundantly, and is a good sort for the garden; but would prove less profitable for growing for the market than many other varieties of larger size. 
Fluke Kidney. Plant vigorous, with luxuriant, deep-green Cot. Gard.

foliage; continuing its growth till late in the season, or until destroyed by frost. The tuber is remarkable for its singular shape, of a flattened oval, frequently measuring eight or nine inches in length by nearly three inches in width. The peel is thin, and remarkably free from eyes; the surface, smooth and even; the flesh is dry, mealy, and farinaceous, exceedingly well flavored, and, in general excellence, surpassed by few, if any, of the late varieties. It is also healthy, hardy, and very productive; but is much better towards spring than when used soon after being harvested.

The variety originated near Manchester, Eng., about the year 1844 ; and appears to be a cross or hybrid between the Lapstone Kidney and Pink-eye.

In this country the variety has never reached the degree of excellence it appears to have attained in England. With us the yield has been small, and it has suffered greatly from disease. The flesh is also yellow when cooked, and quite strong flavored. Not recommended for cultivation.

Forty-Fold. An English variety. Plant healthy, ripening about the middle of September, rarely producing seed or blossoms; tubers white, of medium size, round; skin rough or netted; flesh white, comparatively dry, and well flavored. It yields abundantly ; is a good kind for forcing ; and, though the plants remain green until frost, the tubers attain a suitable size for use quite early in the season. An English sort, known as Taylor's Forty-fold, is quite distinct, the tubers being oval, much flattened, and of a reddish color.

Garnet Chili. Plant of medium height, rather erect, sturdy and branching ; flowers abundant, white or pale purple, showy, and generally abortive; tubers large, roundish or oblong, 
purplish-red or garnet-crlored; eyes not abundant, and of moderate depth ; flesh nearly white, dry and mealy when cooked, and, the size of the tubers considered, remarkably well flavored. Not early, but hardy, healthy, productive, and recommended for cultivation.

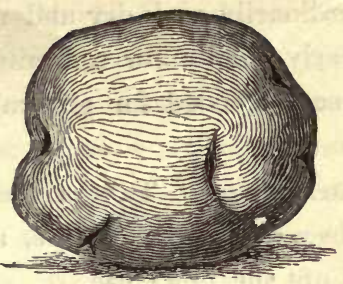

Garnet Chili.

The Garnet Chili, now very generally disseminated, was originated in 1853 by Rev. Chauncey E. Goodrich, of Utica, N. Y., from the seeds of a variety received from Chili, South America.

Tubers large, oval, or oblong, flattened, white, Gillyflower. and comparatively smooth; flesh white, dry, and of fair quality. The plants are healthy, and the variety is very productive; but it is inferior to many others for table use; though its uniform good size, and its fair form, and whiteness, make it attractive and salable in the market.

It is similar to, if not identical with, the St. Helena and the Laplander.

Plant strong and vigorous ; flowers dull white, Green-Top. generally abortive; tubers quite large, white, roundish, often irregular ; eyes deep-set; flesh white, comparatively dry, and well flavored. The variety is productive, and of healthy, hardy habit, but not early ; the plants continuing green till c.estroyed by frost. Introduced.

An old variety, very little, if at all, earlier Hill's Early. than the White Chenango. Quality not much above mediocrity, its chief recommendation being its earliness. Skin and flesh yellowish-white; eyes rather deeply sunk; size medium; form roundish; moderately productive. It does not 
ordinarily cook dry and mealy; and, though desirable as an early Potato for a limited space in the garden, cannot be recommended for general cultivation.

Irish Cups. 'Tubers nearly round, yellowish-white; eyes deep-set; flesh yellow, and strong flavored when cooked. Unfit for table use.

Aside from the difference in form, the variety somewhat resembles the Rohan.

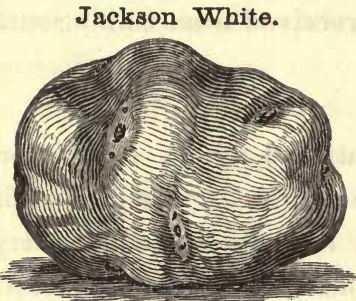

This comparatively new but very excellent variety originated in Maine; and is supposed to be a seedling from the celebrated Carter, which it much resembles. Tubers yellowish-white, varying in size from medium to large; form somewhat irregular, but generally roundish, though sometimes oblong and a little flattened; eyes rather numerous, and deeply sunk; flesh perfectly white when cooked, remarkably dry, mealy, farinaceous, and well flavored.

The variety unquestionably attains its greatest perfection when grown in Maine, or the northern sections of Vermont and New Hampshire; but is nevertheless of good quality when raised in the warmer localities of New England and the Middle States. It is earlier than the Davis Seedling; comparatively free from disease ; a good keeper ; commands the highest market price; and, every thing considered, must be classed as one of the best, and recommended for general cultivation.

The plants are very erect, the flowers nearly white; and the balls, or berries, are produced in remarkable abundance.

Like many other varieties, the plants seem to be more productive, and the tubers of better quality, when raised from 
seed obtained every year or two from Maine, Canada, or the Provinces. When grown for successive years from seed raised in the same locality, the variety becomes less productive, the plants less healthy and vigorous, and the tubers gradually lose the dry, floury character which they possess when in their full perfection, and for which they are so much esteemed.

A variety of comparatively recent introduc- Jenny Lind. tion. Plant very strong and vigorous; tubers $\begin{gathered}\text { RHODE-IsLAN } \\ \text { SEEDLING. }\end{gathered}$ of extraordinary size when grown in strong soils, long and somewhat irregular in form, thickly set on the surface with small knobs, or protuberances, above which the eyes are placed in rather deep basins, or depressions; color red and white intermixed; in some specimens mostly red, while in others white is the prevailing color; flesh yellow when cooked, and quite coarse, but esteemed by many as of good quality for table use.

One of the largest of all the varieties, remarkably productive, quite free from disease, keeps well, and, as an agricultural Potato, rivals the Rohan. Requires the full season. It sports more than any Potato; being exceedingly variable in size, form, and color.

Stem from a foot and a half to two feet high, Lady's Finof straggling habit of growth; leaves smooth, RUFFRT KaDand of a light-green color; blossoms rarely if ever produced; tubers white, smooth, long, and slender, and of nearly the same diameter throughout; eyes numerous, and slightly depressed.

An old variety, of pretty appearance, long cultivated, and much esteemed as a baking Potato; its peculiar form being remarkably well adapted for the purpose. It is, however, very liable to disease; and as many of the recently intro- 
duced seedlings are quite as good for baking, as well as far more hardy and productive, it cannot now be considered as a variety to be recommended for general culture.

Lapstone A variety of English origin. McIntosh deKidney

MrcInt. scribes it as being decidedly the best kidney poNichol's EARLY. tato grown, and an excellent cropper. 'Tubers sometimes seven inches in length, and three inches in breadth. It is longer in coming through the ground in spring than most other varieties, and the stems at first appear weakly; but they soon lose this appearance, and grow most vigorously. It is a good potato in August and September; and will keep in excelleut condition till May following, without losing either its mealiness or flavor.

Long Red. Form long, often somewhat flattened, - its general appearance being not unlike that of the Jenny Lind, though of smaller size; color red; flesh marbled or clouded with red while crude, but, when cooked, becoming nearly white. The stem-end is often soggy, and unfit for use ; and the numerous prongs and knobs which are often put forth on the sides of the tubers greatly impair their value for the table.

A few ycars since, this variety was exceedingly abundant in the market, and was esteemed one of the best sorts for use late in spring and early in summer. It was also remarkably healthy and productive, and was considered one of the most valuable kinds for general cultivation. It has somewhat improved in quality by age, although not now to be classed as a potato of first quality. The Jenny Lind and other varieties are now rapidly supcrseding it in most localities.

Mercer. An old and familiar variety; at one period

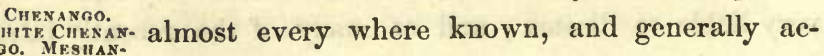
co. MEsi
NOCE. 
knowledged as the best of all varieties. As a Potato for early planting, whether for family use or for the market, it was a general favorite; but, within a few years past, it has not only greatly deteriorated

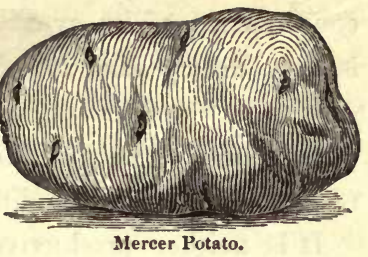
in quality and productiveness, but has been peculiarly liable to disease and premature decay of the plants.

When well grown, the tubers are of good size, rather loug, a little flattened, and comparatively smooth; eyes slightly sunk ; color white, with blotches of purple, - before cooking, somewhat purple under the skin; flesh, when cooked, often stained with pale purple; in its crude state, zoned with bright purple. Quality good; dry, mealy, and well flavored.

It originated in Mercer county, New York, whence the name. Mr. Paschal Morris, of Philadelphia, states that it went west, taking the name of Meshannock, from the name of the stream, in Mercer County, along which it originated. In Canada, the Provinces, and throughout most of New England, it is known as the Chenango, or White Chenango.

A handsome white variety, long and smooth, Mexican. like the St. Helena, but not quite so large ; eyes very slightly depressed. It is of poor quality, quite unproductive, rots badly, and not worthy of cultivation.

This old variety at one period was very ex- Nova-Scotia tensively cultivated, and for many years was conBlue. sidered the most profitable of all the sorts for raising for market or for family use.

Form nearly round, the larger specimens often somewhat flattened; color light blue; eyes moderately depressed; flesh white, dry, and good. It yields abundantly; but, in 
consequence of its great liability to disease, its cultivation is now nearly abandoned.

Old Kidney. Tubers kidney-shaped, white; flesh yellow, rather waxy, and of indifferent flavor.

It is neither productive, nor of much value in other repects, and is now little cultivated.

Peach-Blow. Tubers similar in form to the Davis Seedling, but rather more smooth and regular; color red, the eyes not deeply sunk; flesh yellow when cooked, dry and mealy, but only of medium quality, on account of its comparatively strong flavor.

It is hardy and quite productive; keeps well ; and is ex- tensively cultivated for market in the northern parts of New England and the State of New York, as well as in the Canadas. It is common to the markets of most of the large seaport cities; and, during the winter and spring, is shipped in large quantities to the interior and more southern sections of the United States.

The Davis Seedling - which is quite as productive, and much superior in quality for table use - might be profitably grown as a substitute.

Pink-Eyed. Tubers nearly round; eyes rather large and deep; color mostly white, with spots and splashes of pink, particularly about the eyes; flesh yellow.

The Pink-eyed is an old but inferior variety, hardly superior in quality to the Vermont White. Though quite productive, it is generally esteemed unworthy of cultivation.

Poggy, or A dark-colored variety, extensively cultivated
Porgee. Cow-Hons. in the British Provinces, particularly in Nova Scotia; and, during the autumn, imported in considerable 
quantities into the prineipal seaports of the United States. It is of excellent quality, and by some preferred to all others, especially for baking; for which purpose, on account of its size and remarkable form, it seems peculiarly adapted. It is moderately productive, and succeeds well if seed is procured every year or two from the East; but, if otherwise, it soon deteriorates, even under good cultivation.

Size above medium; form long, broadest, and somewhat flattened, at the stem-end, and tapering towards the opposite extremity, which is often more or less sharply pointed. It is also frequently bent, or eurved; whence the name "Cowhorn," in some localities. Skin smooth; eyes not depressed; color dark-blue outside, white within when cooked. Not remarkably hardy, and requires a full season for its complete perfection. Unless where well known its color is objectionable; and it is generally less salable than the whiteskinned varieties.

A large, white, roundish, English Potato, not Quarry. unlike the variety universally known and cultivated many years since in this country as the Orange Potato.

Plant vigorous, and of strong, stocky habit; flowers purple, generally abortive; flesh yellowish-white, of fair quality for table use. A hardy, produetive sort, which might be profitably grown for marketing and for agricultural purposes. The plants survive till frost. Not early.

Tubers very large, in form much resembling Rohan. the Jenny Lind, - the full-developed specimens being long, and the smaller or immature tubers nearly round; eyes numerous and deep-set; color yellowish-white, with clouds or patehes of pink or rose; flesh greenish-white when cooked, yellowish, watery, and strong flavored. The plant is strong and vigorous, and continues its growth till destroyed by frost. The flowers are generally abortive. 
Mr. Hyde describes it as a variety famous in history, but infamous as a table Potato, and fit only for stock. It formerly gave an immense yield, but now produces only moderate crops; and its cultivation is nearly abandoned.

Shaw's Early. An English variety, much employed for
Mc Int. forcing, and extensively cultivated in the vieinity of London for early marketing. It is, for an early sort, a large, beautiful, oblong, white-skinned Potato. Its only fault is its hollow eyes. It is very productive.

State of

Maine.

This variety, as implied by its name, is of Maine origin, and was introduced to general notice six or seven years ago. In form the tubers are similar to the White Chenango, being long, smooth, and

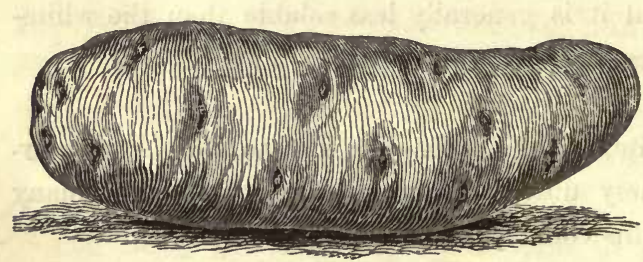

State of Maine.

somewhat flattened; though the smaller and uudeveloped bulbs are often nearly round. Eyes almost even with the surface, and quite numerous; color white, like the Jackson White. When cooked, the flesh is white, dry, mealy, and of good flavor.

It is quite early, but more liable to disease than the Davis Seedling and some other varieties. In Maine it is grown in great perfection, nearly equalling the Jackson White and Carter as a table Potato. On light soil, it is only moderately productive; but on strong land, in high cultivation, yields abundantly.

St. Helena. An old and productive variety. Plant erect, LAPLANDER. and of a bushy habit, about two feet and a half in height; foliage light green; flowers pale reddish-purple. 
The tubers are of an oblong form, and remarkably large; specimens having been produced measuring ten inches in length. Eyes numerous, but not deeply set; skin white and smooth ; flesh white when cooked, mealy, and of fair quality.

It is a healthy variety, and not easily affected by disease ; but belongs to that class of late field potatoes, the foliage of which does not in ordinary seasons decay until injured by frost, and the tubers of which generally require to be kept some time before they are fit for using to the greatest advantage.

Plant about one foot and a half high, slender, Taylor's Forand spreading in habit; foliage light green; $\begin{gathered}\text { Fostr-poLd. } \\ \text { tyold }\end{gathered}$ flowers rarely produced; tubers oval, much flattened, and of medium size; skin rough, and of a dull reddish color.

This variety is dry and starchy, well flavored, and suffers comparatively little from disease. It is also productive, and a good early sort for the garden; but not well adapted for field culture, or for cultivation for agricultural purposes.

Plant quite low and dwarf, decaying with the Tolon. season ; flowers lilac-purple, large and handsome, generally abortive ; tubers of medium size, roundish, of a pink or reddish color; flesh yellow, dry, but not of so mild a flavor as many of the more recent kinds. Moderately productive. Introduced.

A fair and good-sized, but poor variety, grown to a considerable extent in the northern Vermont
White. and more interior portions of New England. Color white outside ; but the flesh, when cooked, is yellow, soft, not dry, and strong flavored.

It is a strong grower, and quite productive, but rots badly, and commands only a low price in the market, on account of its inferior quality. Not recommended for cultivation. 
Veto, or Ab- Tubers long, resembling in form those of the ington Blue.

Long Red, and, like that variety, often watery at the stem-end after being cooked; color blue or purplish ; flesh white; quality fair as a table Potato.

This variety originally was remarkably productive, and at one period was in general cultivation; but now is rarely planted, as it is extremely liable to disease, and rots badly.

Western

Red.

Plant erect, stout and branching; stem and foliage deep green; flowers lilac-purple; tubers large, roundish or oblong, like those of the Garnet Chili; purplish red; eyes not numerous, set in shallow basius; flesh yellowish-white, and if well grown, dry and of fair quality.

The variety is hardy, yields abundantly, and is extensively grown in many sections of the country, but can hardly be considered superior in quality or productiveness to the Garnet Chili, besides being quite as liable to disease.

The variety is considerably affected by the soil in which it may be cultivated; in some localities, being much more colored than in others. It is now rapidly giving place to new seedling varieties of quite as good quality, and mich more healthy and productive.

White Cups. Tubers long and flattened, somewhat irregular; eyes deeply sunk; skin yellowish; flesh white.

It is a handsome variety, of Maine origin, but is only moderately productive. It is also of ordinary quality, rots easily, and will probably never become popular.

White Mountain.

Tubers large, long, white, smooth, uniformly fair and perfect. Appears to be nearly identical with the St. Helena and Laplander. It is very productive, and a good agricultural variety; but, for table use, can be considered only of second quality. 
Tubers of a pinkish-white color, and similar Worcester in form to the Jackson White. Eyes deep-set; Dovrz. RuLE. flesh white, more so than that of the Davis Seedling. It keeps well, and is an excellent variety for cultivation for family use, but less profitable than many others for the market. Stalks upright; blossoms pinkish, but not abundant.

In quality this comparatively old and well-known variety is nearly or quite equal to the Carter ; and, besides, is much more productive. As a garden Potato it deserves general cultivation. Requires the full season.

\section{THE RADISH.}

\section{Raphanus sativus.}

The Radish is a hardy annual plant, originally from China. The roots vary greatly in form; some being round or ovoid, some turbinate, and others fusiform, or long, slender, and tapering. When in flower, the plant rises from three to four feet in height, with an erect, smooth, and branching stem. The flowers are quite large, and, in the different kinds, vary in color from clear white to various shades of purple. The seed-pods are long, smooth, somewhat vesiculate, and terminate in a short spur, or beak. The seeds are round, often irregularly flattened or compressed; those of the smaller or spring and summer varieties being of a grayish-red color, and those of the winter or larger-rooted sorts of a yellowishred. An ounce contains from three thousand three hundred to three thousand six hundred seeds, and they retain their vitality five years.

Soil, Propagation, and Cultivation.-All the varieties thrive best in a light, rich, sandy loam; dry for early spring sowings, moister for the summer.

Like all annuals, the Radish is propagated by seeds, which 
may be sown either broadcast or in drills; but the latter method is preferable, as allowing the roots to be drawn regularly, with less waste. For the spindle-rooted kinds, mark out the drills half an inch deep, and five or six inches apart; for the small, turnip-rooted kinds, three quarters of an inch deep, and six inches asunder. As the plants advance in growth, thin them so as to leave the spindle-rooted an inch apart, and the larger-growing sorts proportionally farther.

Open Culture. - Sow in spring as soon as the ground can be worked. If space is limited, Radishes may be sown with onions or lettuce. When grown with the former, they are said to be less affected by the maggot. For a succession, a small sowing should be made each fortnight until midsummer, as the early-sown plants are liable to become rank and unfit for use as they increase in size.

Radishes usually suffer from the drought and heat incident to the summer, and, when grown at this season, are generally fibrous and very pungent. To secure the requisite shade and moisture, they are sometimes sown in beds of asparagus, that the branching stems may afford shade for the young radishes, and render them more crisp and tender. A good criterion by which to judge of the quality of a Radish is to break it asunder by bending it at right angles. If the parts divide squarely and freely, it is fit for use.

Production and Quantity of Seed. - To raise seed of the spring or summer Radishes, the best method is to transplant; which should be done in May, as the roots are then in their greatest perfection. Take them up in moist weather; select plants with the shortest tops and the smoothest and bestformed roots; and set them, apart from all other varieties, in rows two feet and a half distant, inserting each root wholly into the ground, down to the leaves. With proper watering, they will soon strike, and shoot up in branching stalks, producing abundance of seeds, ripening in autumn. 
An ounce and a half of seed will sow a bed five feet in width and twelve feet in length. Ten pounds are required for seeding an acre.

The excellence of a Radish consists in its being succulent, mild, crisp, and tender; but, as these qualities are secured only by rapid growth, the plants should be frequently and copiously watered in dry weather. The varieties are divided into two classes; viz., Spring or Summer, and Autumn or Winter, Radishes.

\section{Spring or Summer Radishes.}

These varieties are all comparatively hardy, and may be sown in the open ground as early in spring as the soil is in good working condition.

Early Radishes are easily grown in a common hot-bed, and as the plants will withstand cold and moisture, the seeds may be sown in February; or they may be successfully grown in frames with early lettuce, sowing the seeds in any of the winter months, or early in March. If the long-rooted sorts, as the Long Scarlet and the like, are grown, the depth of earth upon the surface of the bed should not be less than eight inches; while the Turnip-rooted varieties will succeed well on a depth of four inches. Sow the seeds in drills four or five inches apart, cover half an inch deep, and when well up, thin the young plants to two inches apart. On sunny days, give plenty of air, water sparingly, and in severe weather cover the sashes at night with garden mats, woollen carpets, or like material.

It is a good practice to sow a few rows across the bed at intervals of a fortnight, which will insure a succession of tender, medium-sized roots. When overgrown, whether under glass or in the open ground, most of the early sorts become pungent, dry, and fibrous, and are worthless for the table. 
Varieties. -

Early Black. Bulb nearly spherical, slightly elongated or Norr Hatir. Vil. tapering, nearly of the size and form of the Gray Turnip-rooted; skin dull-black, rough and wrinkled; flesh white, solid, crisp, and piquant; leaves of the size of those of the Gray Turnip-rooted. Season intermediate between that of the last named and the Black Spanish.

Early Long A sub-variety of the Long Purple, earlier and Purple.

RAYR VIOLETTR of smaller size.

HATIF, Vil.

Early Purple A few days earlier than the Scarlet Turnip-

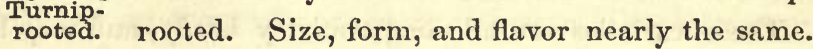

Early Scarlet Bulb spherical, or a little flattened, - often Turnip- bursting or cracking longitudinally before attain-

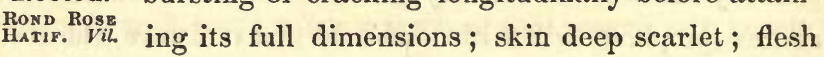
ose-colored, crisp, mild, and pleasant; neck small; leaves few in number, and of smaller size than those of the common Scarlet Turnip-rooted. Season quite early, - two or three days in advance of the last named.

As a variety for forcing, it is considered one of the best; but the small size of the leaves renders it inconvenient for bunching, and it is consequently less cultivated for the market than many other sorts.

Extensively grown in the vicinity of Paris.

Early White Skin and flesh white; form similar to that of rooted. the Scarlet Turnip-rooted. It is, however, of RONDBLANO
HATIF. Vil. lent sort, and much cultivated.

Gray Olive- Form similar to the Scarlet Olive-shaped. Shaped.

Skin gray; flesh white, crisp, and well flavored. 
The form of this variety may be called round, Gray Turnip-rooted. though it is somewhat irregular in shape. It grows large, and often becomes hollow, and

Grar Summer. ROUND BROWX. Trans. should, therefore, be used while young, or when not more than an inch or an inch and a half in diameter. The outside coat is mottled with greenish-brown, wrinkled, and often marked with transverse white lines. The flesh is mild, not so solid as that of many varieties, and of a greenish-white color. The leaves are similar to those of the Yellow Turniprooted, growing long and upright, with green foot-stalks. Half early, and a good variety for summer use.

Root long, a large portion growing above ground; $\begin{aligned} & \text { Long Pur- } \\ & \text { ple. Thomp. }\end{aligned}$ skin deep purple; flesh white, and of good flavor.

The seed-leaves, which are quite large, are used as a small salad. The variety is early, and good for forcing. When the green tops are required for salading, the seeds should be sown in drills, as mustard or cress.

This variety has been considered synonymous with the Long Scarlet; but it is really a disLong Salmon. Trans. tinct sort. The neck of the root rises about an LOXa SCARLET SALMON. inch above the ground, like that of the Scarlet, but it is of a paler red; and this color gradually becomes lighter towards the middle, where it is a pale-pink or salmon color. From the middle, the color grows paler downwards, and the extremity of the root is almost white.

In shape and size, this Radish differs little from the Scarlet; nor does it appear to be earlier, or to possess any qualities superior to the Searlet Radish, the beauty of which, when well grown, exceeds that of any other Long Radish.

Root long, a considerable portion growing above the surface of the ground, - outside, of a beautiful, deep-pink color, becoming paler 
towards the lower extremity ; flesh white, transparent, crisp,

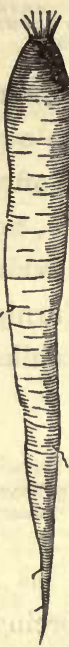
and of good flavor, having less pungency than that of the Scarlet Turnip; leaves small, but larger than those of the last named variety.

When of suitable size for use, the root measures seven or eight inches, in length, and five eighths or three-fourths of an inch in diameter at its largest part.

The Long Scarlet Radish, with its sub-varieties, is more generally cultivated for market in the Eastern, Middle, and Western States, than any other, or perhaps even more than all other sorts. It is extensively grown about London, and is every where prized, not only for its fine qualities, but for its rich, bright color. It is also one of the hardiest of the Radishes; and is raised readily in any comLong Scarlet
Radish. mon frame, if planted as early as February.

Long White. Root long and slender, nearly of the size and WHITE ITALIAN.
NAPLES WHITE
TRANSARENT. exposed to the light, tinged with green; flesh white, crisp, and mild.

It is deserving of cultivation, not only on account of its excellent qualities, but as forming an agreeable contrast at table when served with the red varieties.

Long White Purple-Top.

A sub-variety of the Long White; the portion of the root exposed to the light being tinged with purple. In size and form it differs little from the Long Scarlet.

New London Particular.

This is but a sub-variety of the Long ScarWOod's FRAM. let; the difference between the sorts being immaterial. The color of the New London Particular 
is more brilliant, and extends farther down the root. It is also said to be somewhat earlier.

The Oblong Brown Radish has a pear-shaped bulb, with an elongated tap-root. It does not

Oblong Brown. Trans. grow particularly large ; and, being hardier than most varieties, is well adapted for use late in the season. The outside is rough and brown, marked with white circles; the flesh is piquant, firm, hard, and white; the leaves are dark green, and rather spread over the ground; the foot-stalks are stained with purple.

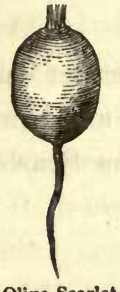

Olive-Scarlet Radish.
Bulb an inch and a half deep, three fourths of an inch in diameter, oblong, somewhat in the form of an shaped Scarlet. Oblono RossCOLORED. Thomp. olive, terminating in a very slim tap-root; skin fine scarlet; neck small; leaves not numerous, and of small size; flesh rose-colored, tender, and excellent. Early and well adapted for forcing and for the general crop.

This is a variety of the Scarlet Turniprooted ; the size, form, color, and quality bePurple Turnip-rooted. ing nearly the same. The skin is purple. It is considered a few days earlier than the last named.

Bulb spherical ; when in its greatest perfection measuring about an inch in diameter; skin

Scarlet Turnip-rooted. Crimson TuR-

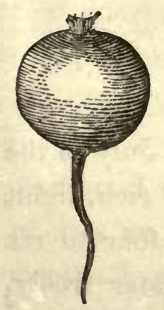

Scarlet Turnipfine, deep scarlet ; flesh white, sometimes stained with red; leaves rather large and numerous.

The variety is early, and deserves more general cultivation, not only on account of its rich color, but for the crisp and tender properties of its flesh. It is much esteemed in England, and is grown extensively for the London market. 
Small, Early, Bulb of the size and form of the Scarlet TurYellow Tur- nip-rooted. nip-rooted; skin smooth, yellow ; flesh white, fine-grained, crisp, and rather pungent; foliage similar to that of the scarlet variety; season ten or fifteen days later.

White Crooked. TorTILLEE Du MaNs. Vil.

Root very long; when suitable for use, measuring twelve inches and upwards in length, and an inch in diameter, nearly cylindrical, often irregular, and sometimes assuming a spiral or cork-screw form; skin white and smooth; flesh white, not so firm as that of most varieties, and considerably pungent; leaves very large.

Vhite Turnip-rooted.

Bulb of the form and size of the Scarlet Turnip-rooted; skin white; flesh white and semitransparent. It possesses less piquancy than the Scarlet, but is some days later.

Yellow Turnip-rooted. Trans. YelLow SUMmer.

Bulb nearly spherical, but tapering slightly towards the tap-root, which is very slender. It grows large, - to full four inches in diameter, when old; but should be eaten young, when about an inch in diameter. The flesh is mild, crisp, solid, and quite white. The skin is of a yellowish-brown color; and the leaves grow long and upright, with green foot-stalks.

Half early, and well adapted for summer cultivation.

\section{Autumn and Winter Radishes.}

These varieties may be sown from the 20th of July to the 10th of August; the soil being previously made rich, light, and friable. Thin out the young plants from four to six inches apart; and, in the absence of rain, water freely. 
During September and October, the table may be supplied directly from the garden. For winter use, the roots should be harvested before freezing weather, and packed in earth or sand, out of danger from frost. Before being used, they should be immersed for a short time in cold water.

To raise Seed. - Seeds of the Winter Radishes are raised by allowing the plants to remain where they were sown. As fast as they ripen, cut the stems; or gather the principal branches, and spread them in an open, airy situation, towards the sun, that the pods, which are quite tough in their texture, may become so dry and brittle as to break readily, and give out their seeds freely.

Use. - All the kinds are used as salad, and are served in all the forms of the spring and summer radishes.

\section{Varieties. -}

Bulb ovoid, or rather regularly pear-shaped, Black Spanwith a long tap-root. At first the root is slenish. Trans. der, and somewhat cylindrical in form; but it swells as it advances in age, and finally attains a large size, measuring eight or ten inches in length, and three or four inches in diameter. The outside is rough, and nearly black; the flesh is pungent, firm, solid, and white; the leaves are long, and inclined to grow horizontally; the leaf-stems are purple. It is one of the latest, as well as one of the hardiest, of the radishes, and is considered an excellent sort for winter use.

The large Purple Winter Radish is a beautiful Large Purple variety, derived, without doubt, from the Black Spanish; and may therefore be properly called Wrinters. PURPLE SPANISH. the Purple Spanish. In shape and character it much resembles the Black Spanish; but the outside, when cleaned, is of a beautiful purple, though it appears black when first drawn from the earth; and the coat, when cut through, 
shows the purple very finely. The footstalks of the leaves have a much deeper tinge of purple than those of the other kinds.

Long Black A sub-variety of the Black Spanish. Root
Winter. long and tapering. With the exception of its smaller size, much resembling a Long Orange Carrot. Long-leaved Root fusiform, sometimes inversely turbinate,

nese. Vil. about five inches in length, and an inch in diameter; skin white, and of fine texture; flesh fine-grained, crisp, and though somewhat pungent, yet milder flavored than that of the Black Spanish ; leaves large, differing from most other varieties in not being lobed, or in being nearly entire on the borders. Its season is nearly the same as that of the Rose-colored Chinese. The plants produce but few seeds.

Purple Chi- A sub-variety of the Scarlet, with little varianese.

tion except in color; the size, quality, and manner of growth, being nearly the same.

Rose-colored Bulb rather elongated,'somewhat cylindrical,
Chinese. Vil. SCARLET CHI-
NESE WINTKR.
contracted abruptly to a long, slender tap-root; size full medium; average specimens measuring about five inches in length, and two inches in diameter at the broadest part; skin comparatively fine, and of a bright rose-color; flesh firm, and rather piquant; leaves large, - the leaf-stems washed with rose-red. Season between that of the Gray Summer and that of the Black Spanish.

Winter Root somewhat fusiform, retaining its diameter
White Span-
ish.
AUTUM WHIR. for two thirds the length, sharply conical at the
BLANC D.AVGs- base, and, when well grown, measuring seven or
BourG. Pih
eight inches in length by nearly three inches in its fullest 
diameter; skin white, slightly wrinkled, sometimes tinged with purple where exposed to the sun; flesh white, solid, and pungent, though milder than that of the Black Spanish.

It succeeds best, and is of the best qualiiy, when grown in light sandy soil. Season intermediate.

\section{RAMPION.}

Campanula rapunculus.

The Rampion is a biennial plant, indigenous to the south of Europe, and occasionally found in a wild state in England. The roots are white, fusiform, fleshy, and, in common with the other parts of the plant, abound in a milky juice; the lower or root leaves are oval, lanceolate, and waved on the borders; the upper leaves are long, narrow, and pointed. Stem eighteen inches or two feet in height, branching; flowers blue, sometimes white, disposed in small, loose clusters about the top of the plant, on the ends of the branches. The seeds are oval, brownish, and exceedingly small - upwards of nine hundred thousand being contained in an ounce. They retain their germinative property five years.

The plant flowers in July of the second year, and the seeds ripen in autumn. There is but one variety.

Soil and Caltivation. - The finest roots are obtained from a rich, loamy soil, with a northern aspect; or in localities not exposed to the too direct influence of the sun. Stir the ground thoroughly to the depth of ten or twelve inches, rake the surface smooth and fine, and sow the seeds either in April or May, in very shallow drills ten inches asunder. When well up, thin to four inches apart in the lines.

In protracted dry and warm weather the plants sometimes run to seed the first season, when the roots become fibrous, strong flavored, and unfit for use. 
Taking the Crop. - The roots will be fit for use from October till April. They may be taken from the ground for immediate use ; or a quantity may be taken up in autumn, before the closing-up of the ground, and packed in sand, for use during the winter.

To raise Seed. - Leave or transplant some of the best yearling plants, and they will produce an abundance of seed in autumn.

Use. - The roots, as well as the leaves, have a pleasant, nut-like flavor, and are generally eaten in their crude state as a salad.

\section{RUTA-BAGA, OR SWEDE TURNIP.}

Russian Turnip. French Turnip. Brassica campestris Ruta-baga. De Cand.

The Ruta-baga, or Swede Turnip, is supposed by De Candolle to be analogous to the Kohl Rabi ; the root being developed into a large, fleshy bulb, instead of the stem. In its natural state the root is small and slender; and the stem smooth and branching, - not much exceeding two feet in height.

The bulbs or roots are fully developed during the first year. The plant flowers and produces its seed the second year, and then perishes. Although considered hardy, - not being affected by even severe frosts, - none of the varieties will withstand the winters of the Northern or Middle States in the open ground. The crop should therefore be harvested in October or November, and stored for the winter out of danger from freezing. Most of the sorts now cultivated retain their freshness and solidity till spring, and some even into the summer; requiring no particular care in their preservation, other than that usually given to the carrot or the potato. 
Soil and Cultivation. - All the varieties succeed best in a deep, well-enriched, mellow soil ; which, previous to planting, should be very deeply ploughed, and thoroughly pulverized by harrowing or otherwise. Some practise ridging, and others sow in simple drills. The ridges are usually formed by turning two furrows against each other; and, being thus made, are about two feet apart. If sown in simple drills, the surface should be raked smooth, and the drills made from sixteen to eighteen inches apart, the distance to be regulated by the strength of the soil.

Seed and Sowing. - About one pound of seed is usually allowed to an acre. Where the rows are comparatively close, rather more than this quantity will be required; while three fourths of a pound will be amply sufficient, if sown on ridges, or where the drills are eighteen inches apart. The sowing may be made from the middle of May to the 1st of July; the latter time being cousidered sufficiently early for growing for the table, and by some even for stock. Early sowings will unquestionably give the greatest product; while the later-grown bulbs, though of smaller dimensions, will prove of quite as good quality for the table.

To raise Seeds. - Select the smoothest and most symmetrical bulbs, and transplant them in April, two feet asunder, sinking the crowns to a level with the surface of the ground.

The seeds are similar to those of the common garden and field turnip, and will keep from five to eight years.

Varieties. - The varieties are as follow :-

Bulb of medinm size, ovoid, smooth and sym- Asheroft. metrical; neek very short, or wanting. Above ground, the skin is purple; below the surface, yellow. Flesh yellow, solid, fine-grained, and of excellent flavor. It forms its bulb quickly and regularly; keeps in fresh and sound condition until May or June; and well deserves cultivation, either for agricultural purposes or for the table. 


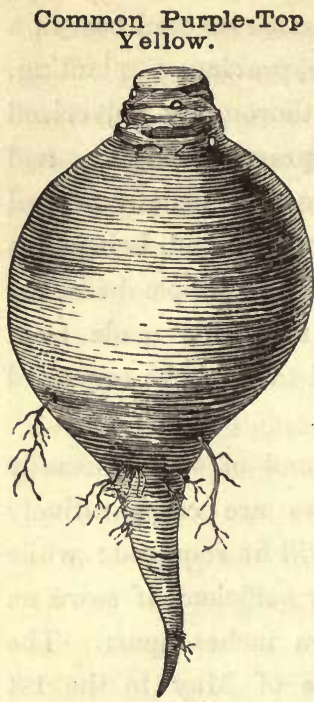

An old and long-cultivated sort, from which, in connection with the Green-top, have originated most of the more recent and improved yellowfleshed varieties. Form regularly egg-shaped, smooth, but usually sending out a few small, straggling roots at its base, near the tap-root; neck short; size rather large, - usually measuring six or seven inches in depth, and four or five inches in its largest diameter; skin purple above ground, - below the surface, yellow; flesh yellow, of close, firm texture, and of good quality. It is very hardy ; forms its bulb promptly and uniformly; and in rich, deep soils, yields abundantly. For thin and light soils, some of the other varieties should be selected. Drummond's A large, handsome, oval variety. Above the proved. surface of the ground the skin is bright purple; below, yellow.

It is described as being a vigorous grower and remarkably productive. New.

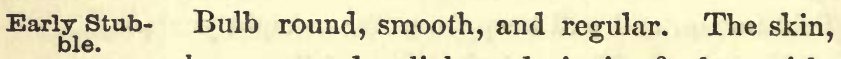
where exposed to light and air, is of a brownishgreen; but, where covered by the soil, yellow. The flesh is firm, and well flavored.

The Early Stubble is recommended as forming its bulbs quickly and uniformly, and as being well adapted for late sowing. It yields abundantly; keeps well; is a good sort for the table ; and, in some localities, is preferred to the Common Yellow for cultivation for farm purposes. 
In form and foliage this variety resembles the Common Purple-top; but usually attains a larger

Green-Top Yellow. size when grown in similar situations. Skin above the surface of the soil, green; below ground, yellow. The flesh is solid, sweet, and well-flavored, but inferior to that of the Purple-top. It keeps well, is of fair quality for the table, and, on account of its great productiveness, one of the best of all varieties for growing for feeding stock.

Bulb turbinate, smooth, and symmetrical. The Green-Top skin above ground is of a fine, clear, pea-green; White. often browned or mellowed where exposed to the direct influence of the sun; below the surface of the ground it is uniformly white. The flesh is also white, comparatively solid, sweet, and of fair quality for table use. It differs from the Purple-top White, not only in color, but in size and quality; the bulbs being larger, and the flesh not quite so firm or well flavored.

The Green-top White is productive; continues its growth till the season has far advanced; is little affected by severe weather; and, when sown in good soil, will yield an agricultural crop of twenty-five or thirty tons to an acre.

This variety differs from most, if not all, of Laings Imthe varieties of Swedish turnips, in having entire cabbage-like leaves, which, by their horizonproved Purple-Top. Law. and Gen. Farmer. tal growth, often nearly cover the surface of the ground. In form, hardiness, and quality, it is fully equal to any of the other sorts. Growing late in the autumn, it is not well adapted to a climate where the winter commences early. It has little or no tendency to run to seed in the fall; and even in the spring, when set out for seed, it is a fortnight later in commencing this function than other varieties of Ruta-bagas. It requires good land, in high condition; and, 
under such circumstances, will yield abundantly, and is worthy of cultivation.

The bulb, when well grown, has an almost spherical form; a fine, smooth skin, purple above ground, yellow below, with yellow, solid, and well-flavored flesh.

New Hardy A hardy, productive, white-fleshed variety, of
White. recent introduction.

When sown early, in strong soil, the roots attain a large size, and the flesh becomes coarse; bulbs from later sowings are fine grained, tender, and of good quality for table use.

It keeps remarkably well, and appears to be adapted to poor soil.

Purple-Top Bulb oblong, tapering towards the lower ex-
White. tremity, five or six inches in diameter, seven or eight inches in depth, and less smooth and regular than many of the yellow-fleshed varieties. The skin is of a clear rich purple where it comes to air and light, but below the ground pure white; flesh white, very solid and fine-grained, sugary, and well flavored.

The variety is hardy, productive, keeps remarkably well, is good for table use, and may be profitably grown for agricultural purposes, Upwards of twenty-eight tons, or nine hundred and sixty bushels, have been raised from an acre.

River's. Root regularly turbinate, or fusiform, of full medium size, smooth, and with few small or fibrous roots; neck two inches long; skin, above ground, green, washed with purplish-red where most exposed to the sun,-below ground, yellow; flesh yellow, firm, sweet and well flavored.

Esteemed one of the best, either for stock or the table. Keeps fresh till May or June. 
Bulb ovoid, or regularly turbinate, and rather Skirving's deeper in proportion to its diameter than the Sxrprive's

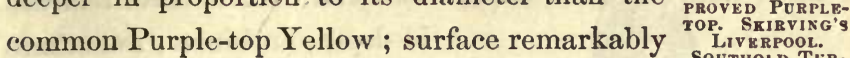

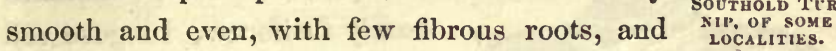
seldom deformed by larger accidental roots, although in unfavorable soils or seasons a few coarse roots are put forth in the vicinity of the tap-root; size full medium, - five to seven inches in length, and four or five inches in diameter. Sometimes, when sown early in good soil, and harvested late, the average will considerably exceed these dimensions. Neck short, but, when grown in poor soil, comparatively long; skin above ground fine, deep purple, below ground yellow, - the colors often richly blending together at the surface; flesh yellow, of solid texture, sweet, and well flavored.

This variety was originated by Mr. William Skirving, of Liverpool, Eng. In this country it has been widely disseminated, and is now more generally cultivated for table use and for stock than any other of the Swede varieties. The plants seldom fail to form good-sized bulbs; it is a good keeper; is of more than average quality for the table; and long experience has proved it one of the best sorts for cultivation on land that is naturally shallow and in poor condition. On soils in a high state of cultivation upwards of nine hundred bushels have been obtained from an acre.

In sowing, allow twenty inches between the rows, and thin to ten or twelve inches in the rows.

An English prize sort, said to have received Sutton's twelve silver cups in six years.

Champion.

Skin bright purple above, yellow below ground. Form smooth and regular; size large; flesh yellow, comparatively fine, and of good quality.

It yields abundantly, keeps well, and deserves cultivation, either for farm stock, or for the table. 
Sweet German.

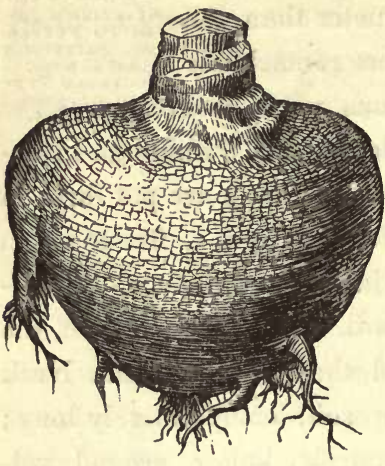

Bulb four or five inches in diameter, six or seven inches in depth, turbinate, sometimes nearly fusiform. In good soil and favorable seasons, it is comparatively smooth and regular ; but, under opposite conditions, often branched and uneven. Neck two or three inches in length; skin greenish-brown above ground, white beneath; flesh pure white, of extraordinary solidity, very sweet, mild, and well flavored.

It retains its solidity and freshness till spring, and often at midsummer has no appearance of sponginess or decay. As a table variety, it must be classed as one of the best, and is recommended for general cultivation.

White
French. The roots of this variety are LONG WIITR
FRENCH. produced entirely within the earth. They are invariably fusiform ; and, if well grown, measure four or five inches in diameter, and from eight to ten inches in length. Foliage not abundant, spreading; skin white; flesh white, solid, mild, sweet, and delicate. It is not so productive as some other varieties, and is therefore not so well adapted to field culture; but for table use it is surpassed by few, if any, of its class.

A rough-leaved, fusiform-rooted variety of the common garden-turnip : is known by the name of "White French" in many localities; but according to the most reli-

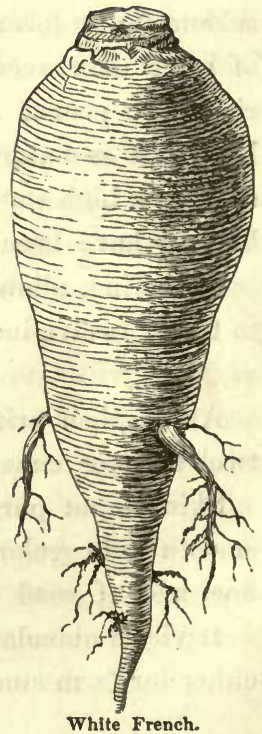

White French. 
able authority, the term has not only long been used in connection with, but properly belongs to, the white turnip above described.

\section{SALSIFY, OR OYSTER-PLANT.}

Leek-leaved Salsify. Vegetable Oyster. Purple Goat's Beard. Tragopogon porrifolius.

The Salsify is a hardy biennial plant, and is principally cultivated for its roots, the flavor of which resembles that of the oyster; whence the popular name.

The leaves are long and grass-like, or leek-like; the roots are long and tapering, white within and without, and, when grown in good soil, measure twelve or fourteen inches in length, and rather more than an inch in diameter at the crown.

Soil and Cultivation. - The Oyster-plant succeeds best in a light, well-enriched, mellow soil ; which, previous to sowing the seeds, should be stirred to the depth of twelve or fifteen inches. The seeds should be sown annually, in the same manner and at the same time as the seeds of the carrot and parsnip. Make the drills fourteen inches apart; cover the seeds an inch and a half in depth; and thin, while the plants are young, to four or five inches asunder.

Early sowings succeed best; as the seeds, which are generally more or less imperfect, vegetate much better when the earth is moist than when dry and parched, as it is liable to become when the season is more advanced. Cultivate in the usual manner during the summer; and, by the last of September or beginning of October, the roots will have attained their full growth, and be ready for use. The plants will sustain no injury during the winter, though left entirely unprotected in the open ground; and the table may be supplied 
directly from the garden, whenever the frost will admit of their removal. A portion of the crop should, however, be taken up in autumn, and stored in the cellar, like other roots; or, which is perhaps preferable, packed in earth or sand. Roots remaining in the ground may be drawn for use till April, or until the plants have begun to send up their stalks for flowering.

Seeds, - production and quantity. - For the produetion of seeds, allow a few plants to remain during the winter in the open ground where they were sown. They will blossom in June and July. When fully developed, the stem is about three feet in height, cylindrical, and branching. The flowers are large, of a very rich violet-purple, and expand only by day and in comparatively sunny weather. As the flowers are put forth in gradual succession, so the heads of seeds are ripened at intervals, and should be cut as they assume a brownish color.

The seeds are brownish, - lighter or darker as they are less or more perfectly matured, - long and slender, furrowed and rough on the sides, tapering to a long, smooth point at the top, often somewhat bent or curved, and measure about five eighths of an inch in length. They will keep four years.

An ounce contains three thousand two hundred seeds, and will sow a row eighty feet in length. Some cultivators put this amount of seed into a drill of sixty feet; but if the seed is of average quality, and the season ordinarily favorable, one ounce of seed will produce an abundance of plants for eighty or a hundred feet.

Use. - The roots are prepared in various forms; but, when simply boiled in the manner of beets and carrots, the flavor is sweet and delicate. The young flower-stalks, if cut in the spring of the second year and dressed like asparagus, resemble it in taste, and make an excellent dish. 
The roots are sometimes thinly sliced, and, with the addition of vinegar, salt, and pepper, served as a salad. They are also recommended as being remedial or alleviating in cases of consumptive tendency.

There is but one species or variety now cultivated.

\section{S C O L Y M U S.}

Spanish Scolymus. Spanish Oyster-plant. Scolymus Hispanicus.

In its natural state this is a perennial plant; but when cultivated it is generally treated as an annual or as a biennial. The roots are nearly white, fleshy, long, and tapering in their general form, and, if well grown, measure twelve or fifteen inches in length, and an inch in diameter at the crowu. When cut or bruised, or where the fibrous roots are broken or rubbed off, there exudes a thick, somewhat viscous fluid, nearly flavorless, and of a milk-white color. The leaf is large, often measuring a foot or more in length, and three inches in diameter, somewhat variegated with greeu and white, deeply lobed; the lobes or divisions toothed, and the teeth terminating in sharp spines, in the manner of the leaves of many species of thistles. When in flower the plant is about three feet in height. The flowers, which are put forth singly, are of án orange-yellow, and measure an inch and a half in diameter. The seeds are flat, and very thin, membranous on the borders, of a yellowish color, and retain their vitality three years. An ounce contains nearly four thousand seeds.

Soil and Cultivation. - Any good garden loam is adapted to the growth of the Scolymus. It should be well and deeply stirred as for other deep-growing root crops. The seeds should be sown from the middle of April to the 10th of May, in drills an inch deep, and fourteen inches asunder. 
Thin the young plants to five inches distant in the rows; and, during the summer, treat the growing crop as parsnips or carrots.

Use. - It is cultivated exclusively for its roots, which are usually taken up in September or October, and served at table, and preserved during the winter, in the same manner as the Salsify, or Oyster-plant. They have a pleasant, delicate flavor; and are considered to be not only healthful, but remarkably nutritious.

\section{SCORZONERA.}

Black Oyster-plant. Black Salsify. Scorzonera Hispanica.

This is a hardy perennial plant, introduced from the south of Europe, where it is indigenous. The root is tapering and comparatively slender, - when well developed, measuring about a foot in length, and an inch in diameter near the erown, or at the broadest part; skin grayish-black, coarse, somewhat reticulated, resembling the roots of some species of trees; flesh white; leaves long, ovate, broadest near the end, and tapering sharply to the stem. They are also more or less distinctly ribbed, and have a few remote teeth, or serratures, at the extremities. When in flower the plant measures about four feet in height; the stalk being nearly cylindrical, slightly grooved or furrowed, smooth, and branched towards the top. The flowers are large, terminal, yellow; the seeds are whitish, longer than broad, taper towards the top, and retain their vitality two years. An ounce contains about two thousand five hundred seeds.

Soil and Culture. - Though a perennial, it is generally cultivated as an annual or biennial, in the manner of the carrot or parsnip. The seeds may be sown in April or May; but in the warmer sections of the country they should not be 
sown too early, as in long, warm, and dry seasons, the plants are liable to flower and seed, which impairs or destroys the value of the roots. After thoroughly stirring the soil, and raking the surface clear of stones and lumps of earth, sow the seeds in drills fifteen inches apart, and half an inch deep. Thin the plants to six inches in the lines, cultivate in the usual form, and in October the roots will be ready for use. Such as are required for the table during winter, should be taken up and stored as salsify; the remainder may be left in the open ground, - as the parsnip and other hardy biennial roots, - and in spring, when the frost will admit, drawn as required for use.

To raise Seed. - Allow a few well-grown plants to remain in the ground during winter; or select a few good-sized roots from those harvested in autumn, and reset them in April, about eighteen inches apart, covering them to the crowns. The seed will ripen at the close of the summer or early in autumn. Seed saved from plants of the growth of two seasons is considered best; that produced from yearling plants being greatly inferior.

Use. - It is cultivated exclusively for its roots; no other portion of the plant being employed in domestic economy. The flesh of these is white, tender, sugary, and well flavored. They are boiled in the manner of the parsnip, and served plain at the table; or they may be cooked in all the forms of salsify or scolymus. Before cooking, the outer, coarse rind should be scraped off, and the roots soaked for a few hours in cold water for the purpose of extracting their bitter flavor. 


\section{S K IR R ET. \\ Crummock, of the Scotch. Sium sisarum.}

Skirret is a hardy perennial, and is cultivated for its roots, which are produced in groups, or bunches, joined together at the crown or neck of the plant. They are oblong, fleshy, of a russet-brown color without, white within, very sugary, and, when well grown, measure six or eight inches in length, and nearly an inch in diameter.

The leaves of the first year are pinnate, with seven or nine oblong, finely toothed leaflets. When fully developed, the plant measures from three to five feet in height; the stem being marked with fine, parallel, longitudinal grooves, or lines. The flowers are small, white, and are produced in umbels at the extremities of the branches. The seeds, eight thousand of which are contained in an ounce, are oblong, of a greenish-gray color, and closely resemble those of the common caraway. They will keep but two years; and, even when newly grown, sometimes remain in the ground four or five weeks before vegetating.

Soil and Culture. - Skirret succeeds best in light, mellow soil, and is propagated by suckers, or seeds. 'The best method is to sow the seeds annually, as, when grown from slips, or suckers, the roots are liable to be dry and woody; the seeds, on the contrary, producing roots more tender, and in greater perfection.

Sow the seeds in April, in drills one foot apart, and about an inch in depth; thin to five or six inches; and, in September, some of the roots will be sufficiently grown for use. Those required for winter should be drawn before the closing-up of the ground, and packed in sand.

To propagate by Slips, or Suckers. - In the spring remove the required number of young shoots, or sprouts, from the side of the roots that have remained in the ground 
during winter, not taking any portion of the old root in connection with the slips, and set them in rows ten inches asunder, and six inches apart in the rows. They will soon strike, and produce roots of suitable size for use in August or September.

T. raise Seeds. - The plants that have remained in the ground during the winter, if not disturbed, will send up stalks as before described, and ripen their seeds at the close of the summer. Two or three plants will yield all the seeds ordinarily required for a single garden.

Use. - The roots were formerly much esteemed, but are now neglected for those greatly inferior. When cooked and served as salsify or scorzonera, they are the whitest and sweetest of esculent roots, and afford a considerable portion of nourishment.

There are no varieties.

\section{SWEET POTATO.}

Spanish Potato. Carolina Potato. Convolvulus batatas. Ipomoea batatas.

The Sweet Potato is indigenous to both the East and West Indies. Where its growth is natural the plant is perennial; but, in cultivation, it is always treated as an annual. The stem is running or climbing, round and slender; the leaves are heart-shaped and smooth, with irregular, angular lobes; the flowers, which are produced in small groups of three or four, are large, bell-shaped, and of a violet or purple color ; the seeds are black, triangular, and retain their vitality two or three years, - twenty-three hundred are contained in an ounce.

The plants rarely blossom in the Northern or Middle States, and the perfect ripening of the seeds is of still more rare 
occurrence. The latter are, however, never employed in ordinary culture; and are sown only for the production of . new varieties, as is sometimes practised with the common potato.

Soil, Planting, and Cultivation. - In warm climates, the Sweet Potato is cultivated in much the same manner as the common potato is treated at the North. It succeeds best in light, warm, mellow soil, which should be deeply stirred and well enriched. The slips, or sprouts, may be set ou ridges four feet apart, and fifteen inches from plant to plant; or in hills four or five feet apart in each direction, three plants being allowed to a hill. During the summer give the vines ordinary culture; and late in September, or early in October, the tubers will have attained their growth, and be ready for harvesting. The slips or sprouts are generally obtained by setting the tubers in a hot-bed in March or April, and breaking off or separating the sprouts from the tubers as they reach four or five inches in height, or attain a suitable size for transplanting. In favorable seasons the plucking may be repeated three or four times. In setting out the slips the lower part should be sunk from one third to one half the entire length; and, if very dry weather occurs, water should be moderately applied.

Keeping. - The essentials for the preservation of Sweet Potatoes are dryness and a warm and even temperature. Where these conditions are not supplied, the tubers speedily decay. By packing in dry sand, and storing in a warm, dry room, they are sometimes preserved in the Northern States until the time of starting the plants in spring.

Varieties. - Though numerous other varieties, less marked and distinctive, are described by different authors, and are catalogued by gardeners and seedsmen, the principal are as follow :- 
Tubers red, or purplish-red, of medium size ; Kentucky flesh yellow, dry, sweet, and of good quality. A $\begin{gathered}\text { Early Red } \\ \text { N/rray. }\end{gathered}$ very prolific, hardy variety; recommended as RED Nansemoxd. the best red Sweet Potato for Northern culture.

Tubers from six to ten inches in length; Large White. thickest at the middle, where they measure from $\begin{gathered}\text { PATATR-BLANCHE } \\ \text { Or THE FENACH. }\end{gathered}$ two to nearly three inches in diameter; weight from six ounces to a pound and upwards; skin dusky white; flesh nearly white, but with a shade of yellow. Not so finegrained or so sweet as the Yellow or Purple, but quite farinaceous and well flavored.

It requires a long season in order to its full development ; but, being remarkably hardy, it will succeed well in any of the Middle States, and attain a fair size in the warmer sections of New England.

A rariety said to have originated in Nanse- Nansemond. mond county, $\mathrm{Va}$; whence the name. Tubers YrLLow NansBmond county, Va.; whence the name. Tubers Mosv. large, yellow, swollen at the middle, and tapering to the ends ; flesh yellow, dry, unctuous, sweet, and well flavored.

It is early fit for the table; matures in short seasons ; is very productive; succeeds well in almost any tillable soil ; and, having been long acclimated, is one of the best sorts for cultivation at the North, - very good crops having been obtained in Maine and the Canadas.

Tubers swollen at the middle, and tapering in Purple-skin-

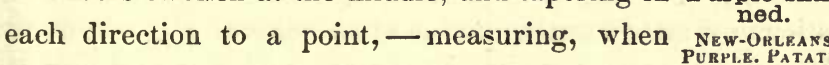

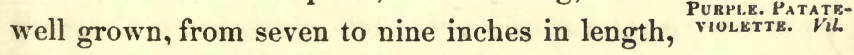
and from two to three inches in diameter; skin smooth, reddish-purple ; flesh fine-grained, sugary, and of excellent quality. The plants attain a remarkable length, and the tubers are rarely united about the neck as in most other varieties. 
The Purple-skinned is early and productive, but keeps badly. It would probably succeed much better in cool climates than either the White or the Yellow. It is much grown in the vicinity of Paris.

Red-skinned, Tubers fusiform, long, and comparatively or American
Red. inches, and the diameter rarely above two inches; weight from three to ten ounces; skin purplish-red, smooth and shining; flesh yellow, very fine-grained, unctuous, sugary, and farinaceous; plant long and slender.

This variety is early, quite hardy, productive, and excellent, but does not keep so well as the yellow or white sorts. It is well adapted for cultivation in the cooler sections of the United States, where, in favorable seasons, the crop has proved as certain, and the yield nearly as abundant, as that of the common potato.

Rose-colored. Tubers somewhat ovoid, or egg-shaped, often
Vil. grooved, or furrowed, and of extraordinary size. Well-grown specimens will measure eight or nine inches in length, and four inches or more in diameter; frequently weighing two and a half, and sometimes greatly exceeding three pounds. Skin rose-colored, shaded or rariegated with yellow; flesh sweet, of a pleasant, nut-like flavor, but less soft or unctuous than that of most varieties.

It is hardy, remarkably productive, and, its excellent keeping properties considered, one of the best sorts for cultivation.

Yellow-skin- Tubers from six to ten inches in length, thick-

ned.
YaLLOW CARO- est at the middle, where they measure from two
LINA. to three inches in diameter, and pointed at the extremities; weight varying from four to twelve ounces and 
upwards; skin smooth, yellow; flesh yellow, fine-grained, unctuous, and remarkably sugary, - surpassing, in this last respect, nearly all other varieties. Not so early as the Redskinned or the Purple.

When grown in the Southern States, it yields well; perfectly matures its crop; and, in color and flavor, the tubers will accord with the description above given. When grown in the Middle States, or in the warmer parts of New England, it decreases in size ; the tubers become longer and more slender; the color, externally and internally, becomes much paler, or nearly white ; and the flesh, to a great extent, loses the fine, dry, and sugary qualities which it possesses when grown in warm climates.

\section{TUBEROUS-ROOTED CHICKLING VETCH.}

Tuberous-rooted Pea. Eatable-rooted Pea. Lathyrus tuberosus.

Perennial; stem about six feet high, — climbing, slender, four-sided, smooth, and of a clear green color ; flowers rather large, in bunches, of a fine carmine rose-color, and somewhat fragrant; pod smooth; seeds rather large, oblong, a little angular, of a brown color, spotted with black; root spreading, furnished with numerous blackish, irregularly shaped tubers, which are generally from an ounce to three ounces in weight.

The roots are very farinaceous, and, when cooked, are highly esteemed. In taste, they somewhat resemble roasted chestnuts. Where the roots are uninjured by the winter, the plant increases rapidly, and is liable to become a troublesome inmate of the garden. 


\section{TUBEROUS-ROOTED TROPGEOLUM. Thomp.}

Ysano. Tropøolum tuberosum.

This is a perennial plant from Peru, and deserves mention as a recently introduced esculent. It produces an abundance of handsome yellow and red tubers, about the size of small pears, the taste of which is not, however, very agreeable. On this account, a particular mode of treatment has been adopted in Bolivia, where, according to M. Decaisne, they are treated in the following manner:-

The tubers designated "Ysano," at $\mathrm{La} \mathrm{Paz}$, require to be prepared before they are edible. Indeed, when prepared like potatoes, and immediately after being taken up, their taste is very disagreeable. But a mode of making them palatable was discovered in Bolivia; and the Ysano has there become, if not a common vegetable, at least one which is quite edible. The means of making them so consists in freezing them after they have been cooked, and they are eaten when frozen. In this state it is said that they constitute an agreeable dish, and that scarcely a day passes at La Paz without two lines of dealers being engaged in selling the Ysano, which they protect from the action of the sun by enveloping it in a woollen cloth, and straw. Large quantities are eaten sopped in treacle, and taken as refreshment during the heat of the day.

Propagation and Culture. - The plant may be propagated by pieces of the tubers, in the same manner ass potatoes; an eye being preserved on each piece. The sets should be planted in April or May, according to the season, about four feet apart, in light, rich soil. The stems may be allowed to trail along the ground, or pea-sticks may be placed for their support. In dry soils and seasons, the former method should be adopted; in those which are moist, the latter. The tubers are taken up in October, when the leaves begin to decay, and stored in sand. 


\section{THE TURNIP.}

English Turnip. Brassica rapa.

The common Turnip is a hardy, biennial plant, indigenous to Great Britain, France, and other parts of Europe. The roots of all the varieties attain their full size during the first year. The radical leaves are hairy and rough, and are usually lobed, or lyrate, but, in some of the sorts, nearly spatulate, with the borders almost entire. The flowers are produced in May and June of the second year, and the seeds ripen in July; the flower-stalk rises three feet or more in height, with numerous branches; the leaves are clasping, and much smoother and more glaucous than the radical leaves of the growth of the previous year; the flowers are yellow, and are produced in long, loose, upright, terminal spikes; the seeds are small, round, black, or reddish-brown, and are very similar, in size, form, and color, in the different varieties, - ten thousand are contained in an ounce, and they retain their vitality from five to seven years.

Propagation and Culture. - All the sorts are propagated by seeds; which should be sown where the plants are to remain, as they do not generally succeed well when transplanted. Sowings for early use may be made the last of April, or beginning of May; but as the bulbs are seldom produced in perfection in the early part of the season, or under the influence of extreme heat, the sowing should be confined to a limited space in the garden. The seeds may be sown broadcast or in drills : if sown in drills, they should be made about fourteen inches apart, and half an inch in depth. The young plants should be thinned to five or six inches asunder. For a succession, a few seeds may be sown, at intervals of a fortnight, until the last week in July; from which time, until the 10th of August, the principal sowing is usually made for the winter's supply. In the Middle States, 
and the warmer portion of New England, if the season is favorable, a good crop will be obtained from seed sown as late as the last week in August.

Harvesting. - Turnips for the table may be drawn directly from the garden or field until November, but must be harvested before severe freezing weather; for, though comparatively very hardy, few of the varieties will survive the winters of the Northern States in the open ground.

Seed. - As the various kinds readily hybridize, or intermix, only one variety should be cultivated in the same neighborhood for seed. Select the best-formed bulbs, and transplant them out in April, in rows two feet apart, and one foot apart in the rows, just covering the crowns with earth, or leaving the young shoots level with the surface of the ground.

An ounce of seed will sow eight rods of land, and a pound will be sufficient for an acre.

Varieties. - The varieties are numerous, as follow :Altrincham. This is a yellow-fleshed, field variety, of rather
Law.

Yrulow Altrix- less than average size. The bulb, however, is CHAM. ALTRING-

HAM. of a fine, globular shape, with a light-green top, very small neck and tap-root, and possessed of considerable solidity.

Border Imperial.

BORPER IMPERIAL PURPLE-TOP
YELLOW.

Bulb five or six inches in diameter, nearly spherical, sometimes flattened, and usually very smooth and symmetrical; skin yellow, the upper surface of a bright purple; flesh yellow, firm, and sugary; leaves large.

The variety is of English origin, and is recommended for its earliness and great productiveness.

Chivas's Or- Bulb of a handsome, round form, with a small ange Jelly. Thomp. top; the skin is pale orange; and the flesh yel- 
low, juicy, sweet, and tender. It has very little fibre; so that, when boiled, it almost acquires the consistence of a jelly. It originated in Cheshire, Eng.

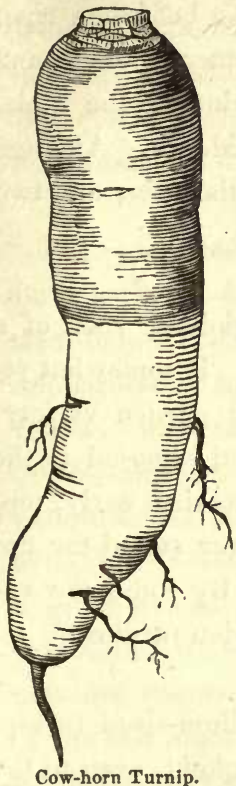

Root produced much above Cow-Horn. ground, nearly cylindrical, WHITEVARRTV rounded at the end, ten or twelve inches in length, nearly three inches in diameter, and weighing from one and a half to two pounds. The skin is smooth and shining, - white below the surface of the ground, and green at the top; the flesh is white, tender, and sugary. Early, very productive, and remarkable for its regular form and good quality. As a field-turnip, it is one of the best; and, when pulled young, good for table use. During winter the roots often become dry and spongy.

This variety is of English origin, and is said to be a hy-

Dales's Hybrid. tab.

brid from the Green-top Swede and the common White Globe. Its prevailing traits are, however, those of the White Globe; inasmuch as its roots are similar in form and texture.

Foliage strong and luxuriant; root large, oblong, pale yellow ; the upper surface light green; neck and tap-root small. The form of the bulb, though generally oblong, is sometimes nearly globular; but its more material characteristics, large size, and luxuriance of growth, are uniformly the same.

Its reputation as a turnip of very superior quality has not been sustained in this country.

An old and well-known early garden variety. Early Flat Bulb round, much flattened, and produced EARL Dutch. $_{\text {HITE }}$ 
mostly within the earth; skin white, somewhat washed with green at the insertion of the leaves, which are of medium size. Before the bulb has attained its full dimensions, the flesh is fine-grained, tender, and sweet; but when ripe, especially in dry seasons, it often becomes spongy and juiceless : in which condition, it is of no value for the table, and, even for stock, is comparatively worthless. Average specimens measure about four inches in diameter, and two inches and a half in depth. Early Yellow This variety has a small, globular root, of a
Dutch YrLLow Dutcu. pale yellow color throughout. It somewhat resembles the Yellow Malta, and is a good garden variety. The portion of the bulb above ground, and exposed to the sun, is washed with green. It is of medium size, early, tender, rather close-grained, and sugary; better suited for use in summer and autumn than for winter. By some the variety is esteemed the best of the yellow garden turnips.

Finland. Law. YELLOW FINLAND.

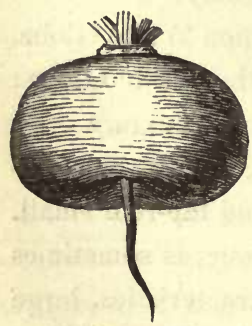

Finland Turnip.
This is a beautiful medium-sized turnip, of a bright yellow throughout, even to the neck; somewhat similar to a firm Yellow Malta, but of finer color. The under part of the bulb is singularly depressed: from this depression issues a small, mouse-taillike root. It is somewhat earlier, and also hardier, than the Yellow Malta.

The flesh is tender, close-grained, and of a sweet, sugary flavor; the leaves are small, and few in number; bulb about two inches in thickness by four inches in diameter, weighing eight or ten ounces. An excellent garden variety.

Freneuse.

Root produced within the earth, - long, taper- 
ing, and rather symmetrical; size small, - average specimens measuring five or six inches in length, an inch and a half in diameter at the crown, and weighing eight or ten ounces; skin white, or yellowish-white; flesh white, dry, very firm, and sugary; leaves small, deep green, spreading. Half early, and one of the best of the dry-fleshed varieties.

Bulb produced mostly within the earth, nearly Golden Ball.

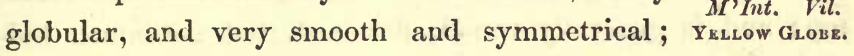
skin bright yellow below ground, greenish above; leaves comparatively small, spreading; flesh pale yellow, sweet, and well flavored, but not so fine-grained as that of many other varieties. It is a good table turnip; and with the Robertson's Golden Stone, which it greatly resembles, the most valuable for cultivation where large-sized garden turnips are required. Its size is about that

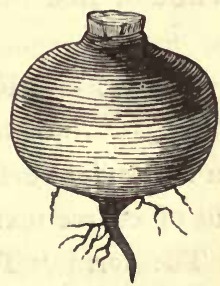

Golden Ball. of the last named. Average specimens measure four inches in diameter, nearly the same in depth, and weigh from twelve to fourteen ounces.

Roots of a fine, globular shape, with a small Green Globe. neck and tap-root; very white below, and green above, the surface of the ground; of GRERT-TOP
WIITE G GOBB medium size, hardy, and firm in texture, but scarcely so much so as the Green Round; than which it arrives at maturity rather earlier. It is somewhat larger than the White Norfolk ; has large, deep-green foliage ; grows strongly, and produces extraordinary crops; but it soon becomes spongy, and often decays in autumn or early in winter.

A sub-variety, of larger size and with softer flesh, is known by the name of Hungarian Green-top Globe. 
Green $\dot{N}$ or.

A sub-variety of the White Norfolk, of nearly

folk. Law.

GRERN-TOP NOR- the same form and size; the bulb differing YOLK. GREEN principally in the color of the top, which is green.

The Norfolk turnips are all of a peculiar flattish form; rather hollowed towards their neck, as also on their under side. When grown to a large size, they become more or less irregular, or somewhat angular. The Green-top variety possesses these characters in a less degree than the Whitetop; and is generally round, flattened, but not much hollowed, on the upper or under surface. It is hardier than the White or Red varieties.

Green Tank- Roots more than half above ground; oblong, or tankard-shaped; of a greenish color, except on the under surface, which is white ; flesh white and sweet, but of coarse texture.

The term "Tankard" is applied to such common field turnips as are of an oblong shape, and the roots of which, in general, grow much above the surface of the ground. Such oblong varieties, however, as approach nearest to a round or globular form, are sometimes termed "Decanter," or "Decanter-shaped turnips."

In good soils the Green Tankard sometimes attains a weight of eight or ten pounds. As a garden variety it is of little value. Green-Top Similar in size, form, and quality to the
Flat. common Purple-top Flat; skin, above ground, green.

Long grown in New England for feeding stock; and, in its young state, often used as a table turnip. Now very little cultivated. 
An old and esteemed variety, similar in size Green-Top and form to the Purple-top Yellow Aberdeen: erdeen. Law. the color of the top is bright green.

Gansex-ToP YaLL. LOW BULLOCK.

This variety is remarkable for its large, deep Lincolnshire green, luxuriant foliage. Bulb very large, Red Globe. roundish; skin, below ground, white, - above the surface, purple; flesh white, firm, and, when young, well flavored, and adapted to table use. It yields abundantly; is uniformly fair, and free from small roots; an average keeper; and deserving of cultivation, especially for agricultural purposes.

Except in the form of its roots, this variety Long Black. much resembles the Round Black. It possesses the same peculiar, piquant, radish-like flavor; and is served at table in the same manner.

Roots eight or nine inches in length, an inch Long White and a half in diameter, somewhat fusiform, and very smooth and symmetrical. The crown rises Maltese. Loxa Wutte Clalrfontaine. two or three inches above the surface of the ground, and is of a green color, except where exposed to the sun, when it often becomes purple or reddish-brown. Below the surface of the soil, the skin is of a dull or dirty white. Flesh white, moderately fine, tender, and of a sugary flavor. Half early.

The variety has some resemblance to the Cow-horn; but is smaller, and the flesh not so white.

Bulb of medium size, flattened, - comparatively smooth and regular; tap-root slender, Petros:woodsks. issuing from a basin; skin blackish-purple above and below ground, sometimes changing to yellow about the tap-root of large or overgrown bulbs; flesh yellow, fine-grained, and 
tender, if grown in cool weather, but liable to be fibrous and strong-flavored when grown during the summer months.

The variety is early, and must be classed as a garden rather than as a field turnip.

Pomeranian
Globe. Bulb globular, remarkably smooth and regular; the neck is small, and the skin white, smooth, and glossy; the flesh is white, close-grained, tender, and sweet; the leaves are large, and of a dark green color, with paler or whitish nerves. Half early.

When in perfection, the bulbs measure three and a half or four inches in diameter, about the same in depth, and weigh from fourteen to eighteen ounces. If sown early in good soil, and allowed the full season for development, the roots sometimes attain a weight of eight or ten pounds. It is generally cultivated as a field turnip, but is also sown as a garden variety; the roots being of good quality for the table, if pulled when about half grown.

Preston, or

An early sort, somewhat resembling the YelLiverpool foliage is stronger, and the basin, or depression, about the tap-root less deeply sunk.

Purple-Top Bulb round, flattened, nearly one-half grow-
Flat. RED-TOP FLAT. ing above ground; neck and tap-root small; skin reddish-purple where exposed to light and air, and white below the surface of the soil ; flesh very white, closegrained while young, and of a sugary but often bitter taste. During winter it usually becomes dry and spongy. Average specimens measure two and a half inches in depth, four or five inches in diameter, and weigh from sixteen to twenty ounces.

This old and well-known variety, at one period, was the 
principal field as well as garden turnip of the Northern and Middle States. It is now, however, very little cultivated; being superseded by the Strap-leaved and other more desirable sorts.

Bulb very flat, smooth, and regular in form, Purple-Top produced almost entirely above ground; tap- leaved. root slender; leaves few, upright, broad, rounded at the ends, and tapering to the neck, which is very small; skin above, clear, bright purple, - below, pure white, often finely clouded or shaded at the union of the colors; flesh clear white, firm, solid, sugary, mild, and remarkably well-flavored; size medium, - measuring about two inches and a half in depth by four or five inches in diameter, and weighing from ten to twelve ounces. Field- Purple-top Strap-leaved Turnip. grown roots, with the benefit of a long season and rich soil, attain much greater dimensions; often, however, greatly deteriorating in quality as they increase over the average size.

This variety is unquestionably one of the best of the flat turnips, either for the garden or field. It is early, hardy, very prolific, will thrive in almost any description of soil, is of excellent quality, and rarely fails to yield a good crop. It is the best of all the flat turnips for sowing among corn or potatoes, or upon small patches of the garden from which early peas or beans have been harvested.

Bulb globular, reddish-purple above, and Purple-Top deep yellow below; tap-root small; leaves deep $\begin{gathered}\text { Yellow } \mathrm{Ab} \\ \text { erdeen. }\end{gathered}$

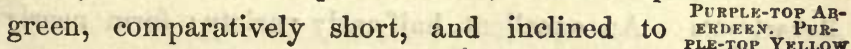
grow horizontally. BULLOCE. 
In rich soil and long seasons the bulbs sometimes attain a weight of eight or ten pounds; but specimens of average size measure about four inches in depth, nearly five inches in diameter, and weigh from sixteen to twenty ounces. The flesh is pale yellow, tender, sugary, and nearly equal to that of the Swedes in solidity.

The variety is hardy, and, although generally grown for farm purposes, is really superior to many sorts cultivated exclusively for table use.

Red Globe. An old, medium-sized, globular turnip, well Law. suited for cultivation in light soil and on exposed or elevated situations. Skin red, where exposed to the sun, - below ground, white; flesh white, and finer in texture than that of the White Globe. It is not suited for table use ; and is generally field-grown, and fed to stock.

Red Norfolk. This is a sub-variety of the White Norfolk, the RED-TOP NOR-
FOLK. KED
ROUND. washed, or clouded with red where exposed to the light. It is firmer in texture, and more regular in its form, than the last named; and, if there be any difference in size, this is the smaller variety.

Red Tankard. Bulb produced partially above ground, pyriform, eight or nine inches in depth, four or five inches in diameter, and weighing about three pounds; below ground the skin is white, - above, purple or violet; flesh white, rather firm, sugary, and well flavored; foliage large.

It is recommended for its earliness and productiveness, but must be considered a field rather than a table variety.

Robertson's An excellent, half-early variety; form nearly Golden Stone. Vilobular; color deep orange throughout, some- 
times tinged with green on the top; size above medium, average specimens measuring nearly four inches in depth, four inches in diameter, and weighing from sixteen to eighteen ounces; flesh firm, and well flavored.

The Robertson's Golden Stone is remarkably hardy, keeps well, and is one of the best of the Yellows for autumn or winter use.

Leaves few, small, and comparatively smooth ; Round Black. bulb produced almost or altogether under ground, Law. of an irregular, roundish form, often divided, or terminating in thick branches at its lower extremity; skin black, and very tough; flesh white.

The varicty is extensively cultivated in some parts of Europe, and is much esteemed for its peculiar, piquant, somewhat radish-like flower. It is someimes served in its crude state as a salad.

Bulb produced much above ground, rather Six Weeks.

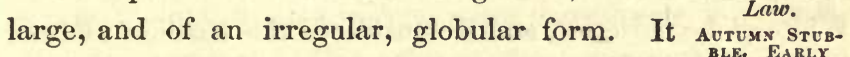
soon arrives at maturity; but, on account of its BLE. EARL natural softness of texture, should always be sown late, and used before severe frosts. As descriptive of its earliness, it has received the above names, being suited for very late sowing, after the removal of early crops, or for making up blanks in turnip-fields, where the first sowing may have partially failed.

It is well flavored, but soon becomes dry and spongy, and is unsuitable for use during winter. Skin white below the surface of the ground, greenish above. Field-grown specimens sometimes weigh three pounds and upwards.

Leaves small, and spreading; root generally Smaul Long entirely under ground, small, and of an oblong Yellow. 
or carrot shape, terminating abruptly at the point; skin pale yellow; flesh yellow, firm, dry, and sugary, with some degree of piquancy. It is a good variety for the table, and also a good keeper.

Snow-Ball. The bulb of this variety is nearly spherical, DAVET BOULE E. 'smooth and regular; size medium, - the average dimensions being four inches in diameter, four and a half in depth, and the weight about a pound. The neck is small, and the skin white. 'The flesh of the young bulbs is white, fine-grained, tender, and sugary; but, if overgrown or long kept, it is liable to become dry and spongy.

The variety is early, and, though classed by seedsmen as a garden turnip, is well adapted for field culture ; as it not only yields abundantly, but succeeds well when sown late in the season on land from which early crops have been harvested.

Stone Globe. Bulb globular, and regularly formed, growing mostly beneath the surface of the ground. It belongs to the White-globe varieties, and is considered the hardiest and the best suited for winter use of any of its class. The leaves are larger, stronger, and deeper colored, than any of the White-globe sorts.

Skin and flesh white; texture moderately close; flavor sweet, and its keeping properties good; size rather large.

Teltow, or This is said to be the smallest of turnips; its Small Berlin.
TrLtav. leaves not exceeding in number those of the radish. The root is fusiform or spindle-shaped, not very regular, and produced entirely under ground; skin dusky white; flesh dry, dull white, fine-grained, piquant, and sugary; leaves erect, yellowish-green. Early. 'The roots measure three inches long by about an inch and three fourths at their largest diameter, and weigh from three to four ounces. 
The Teltow Turnip is much esteemed on account of its excellent qualities, and is one of the best early garden varieties.

According to Loudon, it is in high repute in France, Germany, and Holland; and is grown in the sandy fields around Berlin, and also near Altona, whence it is imported to the London market. It is, or was extensively grown in the neighborhood of Moscow.

The peculiar flavor is in the outer rind. When used, it should not be peeled. It bears transplanting well ; and may be set in rows one foot apart, and nine inches apart in the rows.

A recent variety, of English origin, introduced Waite's Hyby Mr. John G. Waite, a seed-merchant of Lonbrid Eclipse. don. As figured and described, it is of large size, richly colored, and remarkably smooth and symmetrical. At the crown, it is broad and round-shouldered, and measures about six inches in diameter; which size is nearly retained to a depth of eight or nine inches, when it contracts in a conical form to a tap-root. The color of the upper portion is clear purple, richly clouded, and contrasts finely with the yellow on the lower part. It is recommended as a turnip of excellent quality, and as being very productive, but when cultivated in this country has generally fallen short of the excellence it is represented as attaining in England. It is apparently not adapted to the dry and warm summers of the United States.

Root globular; skin smooth, perfectly white; White Globe. flesh also white; neck and tap-root small. Al- commox Fisı. though this description embraces the principal characters of the White Globe, there is considerable variety in the turnips to which this name is applied; arising from the 
degree of care and attention bestowed by growers in selecting their seed-roots; and the shape is often not a little affected by the soil in which they are grown. Thus Globes of any kind, and particularly those of this variety, when grown on a very superior, rich soil, may be said to be forced beyond their natural size, and thereby acquire somewhat of a monstrous or overgrown appearance; losing, in a great measure, their natural symmetry.

This variety is better adapted to field culture than to the garden, as it is altogether too coarse in texture for table use. It is a poor keeper, and, in unfavorable seasons, sometimes decays before the time of harvesting. Specimens have been grown weighing fifteen and even eighteen pounds. White Nor- A large English variety, somewhat irregular
folk. Wrixr Rourd. in form, but usually more or less compressed, and sometimes pyriform; the upper portion of the root being produced four or five inches above ground. Specimens sometimes measure ten or twelve inches in diameter. The leaves are large, and rather numerous; the skin is white below the surface, and often white above, but sometimes washed with green; flesh white and coarse-grained, but sweet. Very. late.

It is but a sub-variety of the Common Flat Turnip, and oftentimes attains a most extraordinary size. For the garden it possesses no value. It is grown exclusively as an agricultural or field turnip; but is very liable to rot, soon becomes spongy, and can only be classed as third-rate even for feeding stock.

White Stone. EARLY STONe. WHITE GARDEN
STONE.
This common and well-known garden turnip somewhat resembles the White Dutch; but has stronger foliage, is rounder in form, and finer in texture. A carefully selected and improved variety of this 
is known by the name of Mouse-tail Turnip; and, in addition, some catalogues contain varieties under the name of Red-topped Mouse-tail, \&c.

Skin and flesh white; size full medium, measuring three and a half to four inches in depth by four and a half or five inches in diameter.

Bulb pyriform, cylindrical at the crown, White Tankwhich, like that of the Red Tankard, rises MAVErG two or three inches from the ground; skin white in the earth, green above; flesh white, tender, sweet, rather firm, and close-grained. Early.

Vilmorin mentions two varieties; one having entire leaves, the other with lyrate or lobed leaves; giving preference, however, to the one with entire leaves.

Like most of the Tankards, the variety seems better adapted to agricultural than to horticultural purposes.

Bulb similar in size and form to the Green- White-Top top Flat; leaves few and small ; skin uniformly Flat. white; flesh white, firm, sugary, and well flavored. As a table variety it is superior to the Purple-top Flat or the Green-top.

This is a sub-variety of the Purple-top Strap- White-Top leaved; differing little, except in color. The leaved. leaves are erect, few and small, somewhat lanceolate, and nearly entire on the borders; the bulb is of medium size, much flattened, pale green above ground, white below, and remarkably smooth and regular in form; tap-root very small; the flesh is white, very fine-grained, saccharine, mild, and excellent.

Early, productive, and recommended as one of the best varieties for field or garden culture. 
The Strap-leaved Turnips appear to be peculiarly adapted to the climate of the Northern States, and are greatly superior in all respects to the Common White and Purple-top Flat varieties. Though of comparatively recent introduction, they have been widely disseminated; and, wherever grown, are highly esteemed.

Yellow Malta. MCInt. MALTESE. GOLD-
EN MALTESE.

A beautiful, symmetrical, small bulbed, early

variety, slightly flattened above, somewhat concave about the tap-root, which, as well as the neck, is remarkably small ; skin very smooth, bright orangeyellow; foliage small, and not abundant, - on which account the plants may be grown quite close to each other; flesh pale-yellow, fine-grained, and well-flavored. It is a good garden variety, and one of the best of the Yellows for summer use. Average bulbs measure two inches in depth, four inches in diameter, and weigh about ten ounces.

Yellow Bulb flattened, smooth, and regular; neck Scarisbrick.

small; skin pale yellow, - above ground, green; flesh yellowish-white, tender, and sweet; leaves of medium size, pale green. Season late. Well-grown specimens measure four inches in diameter, and about three inches in depth.

Yellow Stone. Similar to the Golden Ball or Yellow Globe. Compared with these varieties, the bulb of the Yellow Stone is produced more above ground, and the upper surface is more colored with green. One of the best of garden turnips.

Yellow Tankard. Vil. the ground. Average specimens measure seven or eight 
inches in length, three inches and a half in diameter, and weigh about twenty-four ounces. Skin yellowish-white below ground, green above; flesh pale yellow, firm, and sugary; leaves large. It is esteemed for the solidity of its flesh, and for its earliness and productiveness. A good variety for either field or garden.

$10 *$ 


\section{CHAPTER II.}

\section{ALLIACEOUS PLANTS.}

The Cive. Garlic. Leek. Onion. Rocambole. Shallot. Welsh Onion.

THE CIVE.

Chive. Allium schœenoprasum.

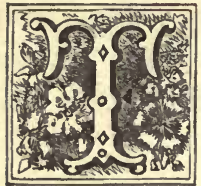

HE Cive is a hardy, bulbous-rooted, perennial plant, indigenous to France and Great Britain. The leaves, which are produced in tufts, are seven or eight inches in length, erect and cylindrical, or awl-shaped. The bulbs are white, oval, and of small size; usually measuring about half an inch in diameter. 'The flower-stalk rises to the height of the leaves, and produces, at its extremity, a globular group of purplish, barren flowers.

Propagation and Culture. - As the plant seldom, if ever, produces seeds, it is always propagated by a division of the roots, or bulbs. These are produced in compact groups, or bunches, seven or eight inches in diameter.

The bulbs are planted in May, two or three together, in rows fifteen or eighteen inches apart, twelve or fifteen inches apart in the rows, and covered two or three inches deep. They require little attention, increase rapidly, and will be ready for use the following spring. If not cut to excess, a plantation will continue ten years.

Use. - The young leaves are the parts of the plant used; 
but, whether used or not, to keep them in a fresh and tender condition, the plants should be frequently shorn to the ground. They possess the flavor peculiar to the onion family; and are principally used in flavoring soups, and as an ingredient in spring salads. The leaves and bulbs are sometimes taken together, and eaten crude, as a substitute for young onions. In omelets, the Cive is considered almost indispensable.

There are no varieties.

\section{COMMON GARLIC.}

Allium sativum.

This is a perennial plant, from the south of Europe. The root is composed of from ten to fifteen small bulbs, called "cloves," which are enclosed in a thin, white, semi-transparent skin, or pellicle. The leaves are long and narrow. The flower-stem is cylindrical, about eighteen inches in height, and terminates in an umbel, or group, of pale pink flowers, intermixed with small bulbs 'The seeds are black, and, in form, irregular; but are seldom employed for propagation; the cloves, or small bulbs, succeeding better.

Planting and Cultivation. - Garlic thrives

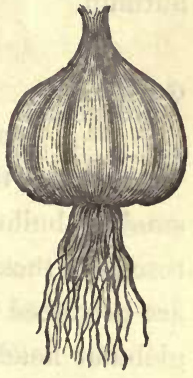

Garlic. best in a light, well-enriched soil; and the bulbs should be planted in April or May, an inch deep, in rows or on ridges, fourteen inches apart, and five or six inches apart in the rows. Keep the soil loose, and the plants clear of weeds, and when the tops wither, the bulbs will have attained their growth, and be ready for harvesting.

Use. - It is cultivated for its bulbs, or cloves, which possess more of the flavor of the onion than any other alliaceous plant. These are sometimes employed in soups, stews, and 
other dishes; and, in some parts of Europe, are eaten in a crude state with bread.

The bulbs of the Common Garlic, as seen in the markets of this country, generally average about an inch in diameter, but McIntosh states that where they are skilfully treated they sometimes attain a circumference of seven and a half inches. Twenty well grown bulbs weigh one pound. Early Rose This is a sub-variety of the Common Garlic.
Garlic.

EarLY Pixx. The pellicle in which the small bulbs are enclosed is rose-colored; and this is its principal distinguishing characteristic. It is, however, nearly a fortnight earlier.

For culinary purposes, it is not considered superior to the Common Garlic. Propagation and cultivation the same; though, in warm climates, the bulbs are sometimes planted in autumn.

Great-head- This species is a hardy perennial, and is reed Garlic.

ALLiUM AMPELOmarkable for the size of its bulbs; which, as in the foregoing species and variety, separate into smaller bulbs, or cloves. The leaves and stem somewhat resemble those of the leek; the flowers are rose-colored, and are produced at the extremity of the stalk, in large, regular, globular heads, or umbels ; the seeds are similar to those of the Common Garlic, but are seldom used for reproduction the cloves, or small bulbs, being generally employed for this purpose. It is used and cultivated as the Common Garlic.

\section{THE LEEK.}

Allium porrum.

The Leek is a hardy biennial, and produces an oblong, tunicated bulb; from the base of which, rootlets are put forth 
in great numbers. The plant, when full grown, much resembles what are commonly known as "Scallious;" the lower, blanched portion being the part eaten. This varies in length from four to eight inches, and in diameter from less than an inch to more than three inches. The leaves are long, narrow, smooth, and pointed; and spread in opposite directions, somewhat in the form of a fan. The flower-stem proceeds from the centre of this collection of leaves, and is about four feet, in height. The flowers are white, with a stripe of red, and are produced in terminal, globular groups, or umbels; the seeds are black, irregular, but somewhat triangular in form, and, with the exception of their smaller size, are similar to those of the onion. About twelve thousand seeds are contained in an ounce; and they retain their vitality two years.

Soil, Sowing, and Cultivation. - The Leek is very hardy, and easily cultivated. It succeeds best in a light but wellenriched soil. When fine leeks are desired, it can hardly b3 made too rich. It should also be thoroughly spaded over, and well pulverized to the depth of at least twelve inches. The seed should be sown in April, at the bottom of drills made six or eight inches deep, and eighteen inches asunder. Sow the seeds thinly, cover half an inch deep, and thin the young plants to nine inches distant in the drills. As the plants increase in size, draw the earth gradually into the drills, and around the stems of the leeks, until the drills are filled. By this process the bulbs are blanched, and rendered tender and mild flavored. The seeds are sometimes sown broadcast, and in July transplanted to trenches, and subsequently cultivated as before directed. The plants are also sometimes set on the surface, and afterwards earthed up to the height of six or eight inches in the process of cultivation. In October the leeks will be suitable for use; and, until the closing-up of the ground, may be drawn from time to time 
as required for the table. For winter use, they should be preserved in earth or sand.

Early leeks may be obtained by sowing the seeds in a hotbed in February or March, and transplanting to the open ground in June or July.

Seed. - To obtain seed, some of the finest plants of the growth of the previous year should be set out in April, fifteen inches apart, and the stems sunk to the depth of three or four inches.

The flower-stem, which, as before described, is often four feet high, should be supported by stakes, as is practised with the onion, to prevent injury from wind. The seeds ripen in September, and are said to retain their vitality best if left in the heads, which should be exposed in a dry, airy situation.

Use. - The whole plant has the flavor and general properties of the onion; but the lower or blanched portion is the part generally eaten, and this is used in soups, or boiled and served as asparagus.

Varieties. -

Common Flag. Vil. is about six inches in depth, and an inch in diameter. The leaves are put forth in opposite directions, are comparatively erect, and of a glaucous-green color.

The variety is remarkably hardy, and well suited for open culture.

Large Rouen. Leaves very dark green, broad, and of thick
Thomp. substance; stem rather short, but remarkably thick, sometimes measuring nearly four inches in diameter. It is now the variety most cultivated near Paris; and, since its general dissemination, has been much approved by all who have grown it. It is found to be the best kind for for- 


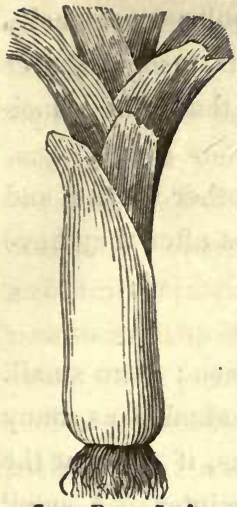

cing, as it acquires a sufficient thickness of stem sooner than any other. In England, it is pronounced one of the best, if not the best, of all varieties.

Stem short and slender ; foli- Little Monage deeper green than that of the Common Flag. It is the smallest of the leeks. Not much cultivated.

Stem about four inches in London Large Rouen Leek. length, and nearly an inch and LARGE FLAG. a half in diameter. The leaves are larger, of a ENOLISFAG. paler color, and softer in their texture, than those of the Common Flag.

The London-flag Leek is hardy, and of good quality, and is more generally cultivated in this country than any other variety.

Stem somewhat shorter than that of the Lon- Musselburgh. don Flag, but of equal thickness. The swelling sсотстр. at the base has the same form. The leaves are Improved. broad and tall, and spread regularly in a fan-like manner. Their color is deeper than that of the Long Flag or the Large Rouen, but paler than the London Flag. Hardy, and of excellent quality. It originated in England.

This is a viviparous variety of the common Proliferous leek, producing young plants on its flower-stalk Leek. Trans. instead of flowers. The leaves are similar to those of the London Flag; and the plant, in its young state, before it runs to flower, exactly resembles it. The flower-scape is from two to three feet high, and supports a compact, irregular, globose umbel, composed of numerous small bulbs, 
intermixed with flowers. Some of these bulbs occasionally produce a second umbel, on scapes of from six to eight inches in length, but of much smaller dimensions than the principal one.

The variety is cultivated in rows, like other leeks; and the bulbs will remain sound several months after they have ripened.

Small Early Leaves long, narrow, dark green; stem small.

Netherland.
Thomp.

SMALL SUMMER On this account, it is not so valuable as many BRABANT. others for a main crop: besides, if sown at the same time, it is liable to run to seed before winter. A small sowing, however, may be made with advantage for early use.

Yellow Poitou. A remarkably large variety; the leaves hav-
Thomp. ing sometimes measured five feet in length, and six inches in breadth. They are of a yellowish-green color. The underground or blanched portion of the stem is yellowish-white, and is more tender than that of any other variety. On this account, and also for its large size, it deserves cultivation. The great length of the leaves makes it important that more space should be allowed between the plants than is usually allotted to other varieties.

\section{THE ONION.}

\section{Allium cepa.}

The Onion is a half-hardy biennial plant: the roots and leaves, however, are annual, as they usually perish during the first year. The bulbs, for which the plant is generally cultivated, are biennial, and differ to a considerable extent in their size, form, and color. The flower-stalk, which is 
developed the second year, is from three to four feet in height, leafless, hollow, swollen just below the middle, and tapers to the top. The flowers are either white or rosecolored, and are produced at the extremity of the stalk in a regular, globular group, or umbel. The seeds ripen in August. They are deep blue-black, somewhat triangular, and similar in size and form in all the varieties. An ounce contains about seventy-five hundred seeds, which retain their vitality two years.

Soil and Cultivation. - The Onion requires a light, loamy, mellow soil ; and, unlike most kinds of garden or field vegetables, succeeds well when cultivated on the same land for successive years. With the exception of the Top and the Potato Onion, all the varieties are raised from seed. Previous to sowing, the ground should be thoroughly spaded over or deeply ploughed, and the surface made smooth and even. The seed should be sown as early in spring as the soil may be in good working condition. Sow in drills fourteen inches apart, and half an inch in depth. When the plants are three or four inches high, thin them to two inches asunder; and, in the process of culture, be careful not to stir the soil too deeply, or to collect it about the growing bulbs. The onions will ripen in August, or early in September, and their full maturity will be indicated by the perfect decay of the leaves, or tops. The bulbs may be drawn from the drills by the hand, or by the use of a common garden-rake. After being exposed for a few days to the sun for drying, they will be ready for storing or the market.

Preservation. - The essentials for the preservation of the bulbs are a low temperature, freedom from frost, dryness, and thorough ventilation.

Seed. - For the production of seed, select the ripest, firmest, and best-formed bulbs ; and, in April, transplant them to lines two feet and a half or three feet distant, and from nine 
to twelve inches apart in the lines, sinking the crowns just below the surface of the ground. As the plants advance in height, tie them to stakes for support. The seeds ripen in August, and the heads, or umbels, should be cut off when they assume a brown color; for then the capsules begin to open, and shed their seeds. After being threshed out, the seed should be exposed to the action of the sun until it is thoroughly dried; for, when stored in a damp state, it is extremely liable to generate heat, and consequently to lose its vitality. An ounce of seed will sow two hundred feet of drill, and three pounds are usually allowed to an acre.

Varieties. - Few of the numerous varieties are cultivated to any extent in this country. Many of the kinds succeed only in warm latitudes, and others are comparatively unimportant. The Danvers, Large Red, Silver-skin, and the Yellow seem peculiarly adapted to our soil and climate. The annual product of these varieties greatly exceeds that of all the other sorts combined. Blood-Red. Bulb middle-sized, or rather large, flattened;
Thomp.

FRExom BLoop- skin dull red, - the coating next within glossy, RED. DUTCH

BLOOD-RED.
ST. THOMA. and very dark red. The internal layers are palest at the base; and, except at the top, are only colored on their outsides. Each layer is paler than the one which surrounds it; till the centre is reached, which is white.

It is a good keeper, but one of the strongest flavored of all varieties. It imparts to soups, or other dishes of which it may be an ingredient, a brownish or blackish color.

Brown Portugal. Thomp.
BroWN SPAISH. neck small ; skin yellowish-brown, - next inteCAMRAI.
OPORTO. variety in some parts of France; and is remarkable for its productiveness, excellent quality, and keeping properties. 
This comparatively recent variety was obtained by selection from the Common Yellow. It is somewhat above medium size, and inclined to globular in its form. Average bulbs measure three inches in diameter, and two inches and three fourths in depth. The skin is yellowish-brown, but becomes darker by age, and greenishbrown if long exposed to the sun; the flesh Danvers.

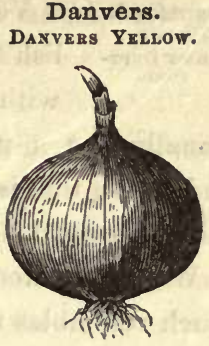

Danvers Onion. is similar to that of the Yellow, - white, sugary, comparatively mild, and well flavored.

The superiority of the Danvers Onion over the last named consists principally, if not solely, in its greater productiveness. When grown under like conditions, it yields, on the average, nearly one fourth more; and, on this account, the variety is generally employed for field eulture. It is, however, not so good a keeper; and, for shipping purposes, is decidedly inferior to the Yellow, its globular form rendering it more liable to decay from the heat and dampness incident to sea voyages.

When cultivated for the market, the land is thoroughly ploughed, and well enriched with fine decomposed manure. The surface is then harrowed, and next raked free of stones and lumps of earth. The seed is sown in April, usually by machines, in rows fourteen inches apart, and three fourths of an inch in depth; three pounds of seed being allowed to an acre. The crop is treated in the usual form during the summer, and ripens the last of August, or early in September. When the tops have entirely withered, the bulbs are raked from the drills, and spread a few days in the sun for drying; after which they are sorted, and barrelled for storing or the market. The yield varies from five to eight hundred bushels per acre. 
Dentford.

Thomp.

BROWN DEPT-

FORD.

Very similar to, if not identical with, the English Strasburg. "It sometimes exactly agrees with the description of that variety; but it occasionally has a pale-brown skin, without any tinge of red; and, when this is the case, its flavor is milder than that of the last named."

With the exception of its more globular form, the bulb much resembles the Yellow Onion of this country.

Early Silver This is a small variety of the Early SilverNocera.

$\underset{\substack{\text { EARLY SMALL } \\ \text { SIIVER NOCKRA. }}}{\text { skin, with an occasionally roundish, but gener- }}$ SILVER NOCERA.
WHITE NOCERA.

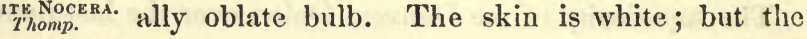
layers beneath are striped with bright-green lines. The leaves are very small. 'Sometimes the bulb has only a single leaf, frequently but two; and, if there are more than four, the plant has not its true character.

It is an excellent sort for pickling, and is the smallest and earliest variety known, - being fifteen or twenty days earlier than the Early Silver-skin ; but it is liable to increase in size, and to degenerate. Very little known or cultivated in this country.

Early Red Wethersfield.

A sub-variety of the Large Red Wethersfield, and the earliest of the red onions. Form and color nearly the same as the Large Red ; bulb small, measuring about two inches and a half in diameter, and about an inch and a half in depth. It is close-grained, mild, a good keeper ; forms its bulbs, with few exceptions, and ripens, the last of July, being three or four weeks earlier than the Large Rerl. Cultivated to a limited extent in various places on the coast of New England, for early consumption at home, and for shipment to the South and West.

This variety and the Intermediate are liable to degenerate: they tend to grow larger and later, approaching the original 
variety, and can be preserved in a pure state only by a careful selection of the buibs set for seed.

This is a small, early variety of the Silver-skin, Early Silvermeasuring two inches and three fourths in diameter, and an inch and three fourths in depth. The neck is small, and the skin silvery-white. It is much esteemed for its earliness and mild flavor, and is one of the best of all varieties for pickling. When cultivated for the latter purpose, it should be sown and treated as directed for the Silver-skin.

This is a large onion, growing from eight Fusiform, or inches to a foot in length. It tapers rather Cow-Hilorn. regularly from the base to the top, and is frequently bent or curved in the form of a horn; whence the name. Skin copper-red. It is late, lacks compactness, is liable to degenerate, decays soon after being harvested, and must be considered more curious than useful.

An early variety of the common Large Red. Intermediate Bulb of medium size, flattened; neck small; $\begin{gathered}\text { Red } \text { ersfield. } \\ \text { (n) }\end{gathered}$ color deep purple.

It is rather pungent, yet milder than the Large Red; keeps well, and is grown to a considerable extent, in certain localities in New England, for shipping.

This is an English hybrid, said to have been originated by a Mr. James, an extensive market-gardener in Surrey, England. The bulb is

James's Keeping. JAMES'S LoxG KEEPING. pyriform, or pear-shaped, and measures four inches and upwards in depth, and two inches or more at its broadest diameter. Skin copper-yellow, - the coating next under it reddish-brown; flavor strong. It is not early, but is much 
prized for its long keeping; the bulbs not sprouting so early in spring as those of most varieties.

Large Red. Bulb sometimes roundish, but, when pure, WETHERSFIELD comparatively flat. It is of very large size ; and, when grown in favorable soil, often measures five inches or more in diameter, and three inches in depth. Skin

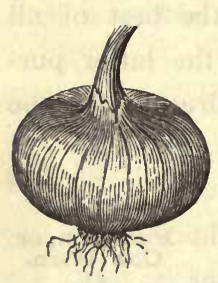

Wethersfield Large Red Onion. deep purplish-red; neck of medium size; flesh purplish-white, moderately fine-grained, and stronger flavored than that of the Yellow and earlier Red varieties. It is quite productive; one of the best to keep; and is grown to a large extent, in many places on the sea-coast of New England, for shipping to the South and West. It is almost everywhere seen in vegetable markets; and, with perhaps the exception of the Yellow or Danvers, is the most prominent of the sorts employed for commercial purposes. It derives its name from Wethersfield, Conn.; where it is extensively cultivated, and where it has the reputation of having originated.

A sub-variety of the foregoing is cultivated in some localities, with nearly the same variation in form that exists between the Danvers and Common Yellow. It will probably prove somewhat more productive; but it is neither better flavored, nor to be preferred for its superior keeping properties.

Madeira.

LAROE GLOBE TRIPOLI. ROMAIN. half in depth

large; skin reddish-brown, - the layer next within, pale red.

The variety is much prized for its extraordinary size, and for its mild, sugary flavor. The plants, however, often fail 
to form good bulbs; and, even when well matured, the latter are liable to decay soon after being harvested. It requires a long, warm season for its greatest perfection. The seed should be sown early, in drills sixteen inches apart; and the plants should be thinned to eight inches apart in the rows.

Not suited to New England or the cooler sections of the United States.

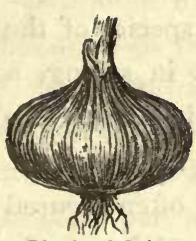

Bulb small, flattened, - two inches and a quarter in diameter, and an inch and a half in

New Deep Blood-Red. Brunswick DeEP BLOOD depth; neck small; skin deep violet-red, approaching black. A half early variety, reBlood-red Onion. markable for its intense purplish-red color.

Bulb roundish, flattened on the upper side, Pale-Red. but not so much so as the Blood-red, of which this may be considered a variety; size medium, two inches and a half in diameter, one inch and three quarters in depth; neck small; skin copper-red, much paler than that of the Blood-red. Compared with the last named, it is earlier and of milder flavor. This and the Blood-red are much esteemed by some for their extreme pungency and for their diuretic properties.

A large, somewhat flattened variety, much cultivated about Paris ; skin fine russet-yellow ; Paris Straw-
colored. Vil. neck small. It is not early, but productive, and of excellent quality.

Bulb pyriform, measuring four inches and a half in depth, and two inches in diameter at Pearthe broadest part; neck small; skin copper red. It is quite late, but of good quality, and keeps well. 
Potato On- Bulb flattened, from two and a half to three ion.

Undergrourd inches in diameter, and about two inches in ONION.

depth ; skin copper-yellow ; flavor sugary, mild, and excellent. It does not keep so well as many other varieties; but remains sound longer, if the leaves are cut two or three inches above the top of the bulb at the time of harvesting.

The Potato Onion produces no seeds, neither small bulbs upon its stalks, in the manner of many of the species of the onion family; but, if a full-grown bulb be set in spring, a number of bulbs of various sizes will be formed beneath the surface of the ground about the parent bulb. By means of these it is propagated, and an abundant supply often secured in localities where the varieties raised from seed frequently wholly fail, either from the maggot, effects of climate, or other causes.

Like other varieties of onions, it requires a rich, deep soil, well manured, and dry at the bottom. This should be deeply and thoroughly stirred, and then raised in ridges of moderate height, fifteen inches apart. In April, select the large bulbs, and set them on the ridges, ten inches apart, with the crown of the bulbs just below the surface of the ground. The subsequent culture consists in keeping them clean from weeds, and gathering a little earth about them from time to time in the process of cultivation. As soon as the tops are entirely dead, they will be ready for harvesting.

It is very prolific, yielding from four to six fold. Such of the crop as may be too small for the table should be preserved during the winter, to be set in the following spring; planting them out in April, in drills one foot apart and three inches from each other in the drills, and sinking the crowns just below the surface of the ground. They attain their full size by September. 
Bulb of medium size, flattened, - average Silver-Skin.

White Portuspecimens measuring about three inches in OAL, OF REW diameter, and an inch and a half or two inches in thickness; neck very small; skin silvery-white. After the removal of the outer envelope, the upper part of the bulb is often veined and clouded with green, while the portion produced below ground is generally clear white. Flesh white, fine-grained, sugary, and remarkably mild flavored.

It forms its bulb early and regularly, ripens off well, and is quite productive; an average yield being about four hundred

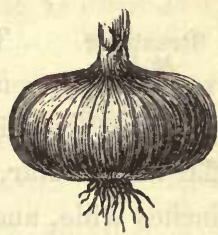

Silver-Skin Onion. bushels per acre. It is a poor keeper; and this is its most serious objection. It is always preserved through the winter with much difficulty, and almost invariably decays if kept from light and exposed to dampness. The best method for its preservation is to spread the roots in a dry, light, and airy situation.

The Silver-skin Onion is much esteemed in the middle and southern sections of the United States, and is cultivated to a considerable extent in New England. It is well adapted for sowing in August, or the beginning of September, for early use, and for marketing during the ensuing spring. Where the winters are mild, the crop, with slight protection, will sustain no injury in the open ground. In Europe it is much esteemed, and extensively grown for pickling, as its "white color, in contrast with the fine green veins, or lines, gives it a very agreeable appearance. For pickling, the seed should be sown thickly, then slightly covered with fine soil, and afterwards rolled. If the seed is covered more deeply, the bulb, from not being quite on the surface, has a larger and thicker neck; so that it loses its finely rounded form, and is, moreover, less compact."

This variety, erroneously known in New England as the 
"White Portugal," is unquestionably the true Silver-skin, as described both by English and French authors. The application of the term "Silver-skin" to the Common Yellow Onion, as extensively practised by seedsmen and marketmen in the Eastern States, is neither pertinent nor authorized. Strasburg. This is the variety most
McInt.

YELLOW STRAs-
BURG. FLANBURG. FLAN-
DERS. DUTCH.
ESSSEX. flat to globular, or oval; bulb large, three inches wide, and full two inches in depth; outside coating brown, of firm texture. Divested of this, the color is reddish-brown,

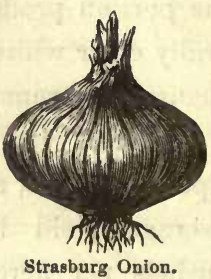
tinged with green. Flavor comparatively mild. It is a very hardy sort, succeeds in cold localities, and keeps well.

The Strasburg and Deptford Onions much resemble the common Yellow Onion of New England; and the difference between the sorts is not great, when English-grown bulbs of the first-named varieties are compared with the bulbs of the Yellow Onion, American-grown; but seeds of the Strasburg or Deptford, raised in England and sown in this country, almost invariably fail to produce plants that form bulbs so generally or so perfectly as American-grown seeds of the Yellow Onion.

Top or Tree Bulb large, a little flattened; producing, inOnion.

Eoxprin. stead of seeds, a number of small bulbs, or onions, about the size of a filbert, which serve as a substitute for seeds in propagation. The flesh is coarse ; and the bulbs are liable to decay during winter, unless kept in a cool and dry situation. The variety has been considered rather curious than useful.

Propagation and Culture. - It is propagated from the bulbs, which are set in April or May, in rows fifteen inches 
apart, and ten inches asunder in the rows. The small bulbs produced upon the stalk are sometimes used for propagation, and are set at the same season with the underground bulbs, in rows one foot apart, and four inches apart in the rows. These small bulbs are obtained by setting mature or fully developed bulbs in April or May, and treating as directed for raising the seeds of the Common Onion.

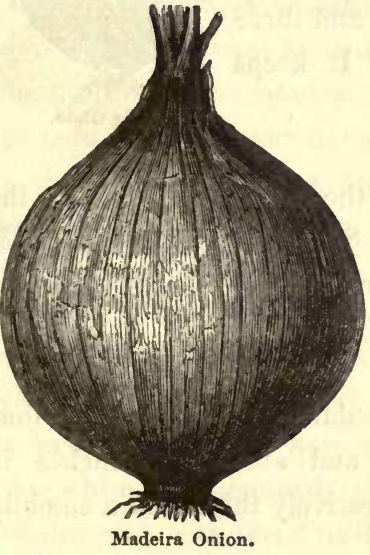

This is one of Tripoli. the largest varieties. FLA MADEIRA. The bulb tapers abruptly from the middle to the neck, and almost equally so to the base. It is five inches and upwards in diameter; color light reddish-brown, - beneath the skin, pale brownish-red, tinged with green.

It requires the whole season, and in some localities is considered excellent for a late crop. The flesh is soft, and the bulbs soon perish after being taken from the ground. In its season it is much esteemed for its mild and delicate flavor. Like the Madeira Onion, the plants fail to form bulbs so generally as other varieties. Not adapted to the climate of the Northern States.

This variety derives its name from the fact Two-Bladed. that the small bulbs have generally but two Thomp. leaves. The larger ones have more, rarely, however, exceeding four ; but, unless by far the greater portion have only two leaves, either the seed or the cultivation is at fault.

The bulbs are small, flat, light-brown, very firm, and attain maturity early; the neck is small, and the top of the bulb is 
depressed or hollowed around the stem. It keeps well, and is an excellent variety.

White Globe. Form nearly ovoid, very Thomp. regular and symmetrical ; skin greenish-yellow, marked with rose-colored lines, - the pellicle changing to white on drying. The bulb measures about four inches in depth, and two inches and three fourths in its largest diameter. It keeps well, and is an excellent variety.

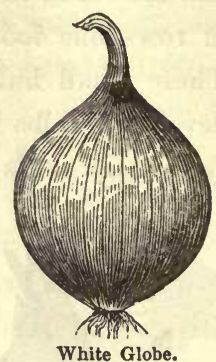

Yellow Globe. Nearly allied to the preceding variety; the size and form being the same. Skin reddish-yellow. It is hardy, productive, of good flavor, keeps well, and deserves general cultivation.

White Lis- A very large, globular onion, measuring four

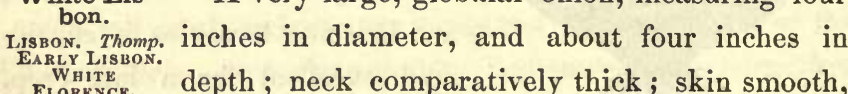

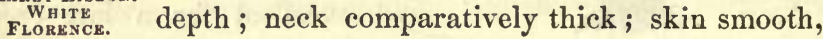
thin, clear, and white.

It is a late variety; and, although comparatively hardy, requires a long, warm season for its full development. Under the most favorable conditions, both with regard to soil and exposure, many of the plants fail to form a good bulb. On account of its hardiness, it is a good sort for sowing in the autumn for a supply of young onions for spring salads; or, if these young bulbs be set in the open ground in April, fine, large onions will be formed towards the end of summer. The variety is better suited to the climate of the Middle States than to that of the Northern and Eastern.

White Portugal, or

Spanish. Thomp.
A large, flat onion, measuring three inches and upwards in width by about two inches in 
depth ; skin loose, of a pale-brown or yellowish- WHitr SPANrst. brown, falling off spontaneously, and exhibiting the next coating, which is greenish-white. It has a small neck, and is particularly mild-flavored. One of the best for early winter use, but early decays.

Quite distinct from the White Portugal of the NewEngland markets.

One of the oldest varieties, and, as a market onion, probably better known and more generally cultivated in this country than any other sort.

Yellow

Onion.

SILVER-SKIN OF New ENGLaNd. The true Yellow Onion has a flattened form and a small neck. Its size is rather above medium, measuring, when well grown, from three inches to three inches and a half in diameter, and from two inches to two inches and a half in depth. Skin yellowishbrown, or copper-yellow, - becoming

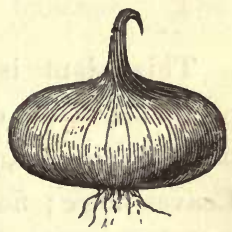

Yellow Onlon. somewhat deeper by age, or if exposed long to the sun; flesh white, fine-grained, comparatively mild, sugary, and well flavored. It keeps well, and is very prolific : few of the plants, in good soils and seasons, fail to produce good-sized and well-ripened bulbs. For the vegetable garden, as well as for field culture, it may be considered a standard sort.

The Danvers Onion, which is but a sub-variety of the common Yellow, may prove somewhat more profitable for extensive cultivation, on account of its globular form; but neither in its flavor nor in its keeping properties can it be said to possess any superiority over the last named.

The term "Silver-skin," by which this onion is very generally though erroneously known throughout New England, has created great confusion between seedsmen and dealers. Much perplexity might be avoided if its application to the Yellow Onion were entirely abandoned. The genuine Silver- 
skin, as its name implies, has a skin of pure, silvery whiteness ; and is, in other respects, very dissimilar to the present variety.

When extensively cultivated for the market, it should be sown and subsequently treated as directed for the Danvers Onion. The yield per acre varies from four to six hundred bushels.

\section{ROCAMBOLE.}

Allium scorodoprasum.

This plant is a half-hardy perennial from Denmark, partaking of the character of both the leek and garlic. The bulbs or cloves are similar to those of the common garlic. Leaves large ; flower-stalk about two feet high, contorted or coiled towards the top, and producing at its extremity a group of bulbs, or rocamboles, intermixed with flowers.

Propagation and Culture. - It is propagated by planting either the underground bulbs, or the small cloves, or bulbs, that are produced upon the stem of the plant. These should be set in April, in drills ten inches apart, and four or five inches asunder in the drills. In the following August they will have attained their full size, and may be used immediately ; or they may be taken up, spread to dry, tied in bunches, and housed, for future consumption. All the culture required is the removal of weeds, and the occasional stirring of the soil.

Use. - The bulbs or cloves have the odor and flavor common to alliaceous plants, and are used as the shallot and garlic.

There is but one variety. 


\section{SHALLOT.}

\section{Allium Ascalonicum.}

The Shallot (sometimes written Eschalot) is a native of Palestine, - the specific term "Ascalonicum" being derived from Ascalon, a town in Syria : hence also the popular English name, "Scallion."

The root of the plant is composed of numerous small bulbs, united at their base; the whole being enclosed in a thin skin, or pellicle, varying in color in the different varieties. Leaves fistulous, or hollow, produced in tufts, or groups; flowers reddish, in terminal, compact, spherical bunches. The plants, however, very seldom blossom.

Soil. - The Shallot will thrive in any soil naturally adapted to the growth of the onion. In wet and cold soil it is said to be more liable to the attacks of the maggot, than when grown in that which is light and warm.

Propagation and Culture.-The roots of the Shallot, which are bulbous, are readily increased by offsets. The bulbs are oblong, but somewhat irregular in their form, and seldom attain a large size. As they increase into clusters, they do not swell like roots that grow singly.

They are propagated by dividing these clustered roots into separate offsets, and planting the divisions in April, in shallow drills one foot apart, placing them about six inches apart in the drills, and covering them lightly with earth. Soot mixed with the surface-soil has been found of much service to prevent the maggot from committing extensive depredations upon this plant. The only after-culture required is that of keeping them clean from weeds, and occasionally stirring the ground.

Harvesting. - The ripening of the crop will be indicated by the decay of the leaves. After being thoroughly dried, 
the bulbs should be stored in a light and warm situation. Under the influence of a damp cellar, or by exposure to frost, they rapidly decay.

Use. - The flavor of the Shallot is mild and pleasant, and resembles that of the leek. The largest of the bulbs are selected, and employed in the same manner as the garlic or onion.

Varieties. -

Common or Bulbs about three fourths of an inch in diamSmall Shallot. Vil. eter at the base, elongated, and enclosed in a reddish-yellow skin, or pellicle; leaves small, ten or twelve inches high.

This variety is early, keeps well, and is one of the best for cultivation.

Jersey. Vil. Bulbs of large size, often measuring two inches in length, and more than an inch in diameter at the base; grouped like the other varieties, and enclosed in a light-brown pellicle, as fine in texture as the skin of an onion, - which this Shallot much resembles in form and odor. Compared with the Common Shallot, it is more round, the neck is smaller, and it is also more close or compact. Leaves remarkably glaucous, not tall, but of good substance, - quite distinct in these respects from the Small or the Large sort. It also sometimes produces seeds; which is, perhaps, a recommendation, as these, when sown, frequently produce new varieties. It is one of the earliest of all the sorts; but is comparatively tender, and decays early.

Large Alen- Bulb remarkably large, exceeding in size that of the Jersey Shallot, which it much resembles in form and color, and in being tender, decaying early, and sometimes running to seed. It is, however, not quite so 
early ; and the leaves are longer and more glaucous. Flavor mild and pleasant.

At the time of harvesting, the bulbs should be long exposed to the sun, in order that they may be thoroughly dried before packing away. "The bulbs are slow in forming, and the worst keepers, as, when stored, they soon begin to sprout."

This variety and also the Jersey Shallot closely resemble the onion. It is possible they may constitute a distinct species.

Bulbs about two inches in diameter at the Large Shalbase, elongated, and enclosed in a brownish-yellow skin, or pellicle; leaves fifteen to eighteen inches high.

This variety, in size, much exceeds that of the Common or Small Shallot; and, though later in ripening, is nevertheless the first to be found in the market, as it forms its bulbs early in the season. Its keeping properties are inferior to the last named. This resembles the Common Shallot; but is Long Keepconsidered superior to that variety in its keeping properties, and in being less subject to the attack of the maggot. It is said that the variety may be kept two years.

\section{WELSH ONION.}

Ciboule, of the French. Allium fistulosum.

The Welsh Onion is a hardy perennial from Siberia. It is quite distinct from the Common Onion, as it forms no bulbs, but produces numerous elongated, angular, tunicated stems, not unlike scallions, or some of the smaller descriptions of leeks. The flower-stem is about eighteen inches high, swollen near the middle, and terminates in a globular 
umbel of greenish-white flowers. The seeds are small, black, somewhat irregular in form, and retain their vitality two years. About thirty-six thousand are contained in an ounce.

Sowing and Cultivation. - The seeds are sown in drills about half an inch in depth, and the crop subsequently treated as the Common Onion.

There are two varieties : -

Common or Skin, or pellicle, reddish-brown, changing to

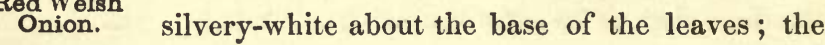
latter being fistulous, and about a foot in height. Its principal recommendation is its remarkable hardiness. The seeds are sometimes sown in July and August for the young stems and leaves, which are used during winter and early in spring as salad.

White Welsh This is a sub-variety of the Common Red. Onion. Vil. The skin is rose-white, and, like that of the last named, changes to silvery-white about the upper portion of the stem, or bulb; the leaves are longer, deeper colored, firmer, and less subject to wither or decay at their extremities, than those of the Common Red. The White is generally considered the better variety, as it is more tender, and milder in flavor, though much less productive.

The Welsh Onions are of little value, except in cold latitudes; and are rarely found in the vegetable gardens of this country. 


\section{CHAPTER III.}

ASPARAGINOUS PLANTS.

The Artichoke. Asparagus. Cardoon. Hop. Oosung. Phytolacca.

\section{THE ARTICHOKE.}

Cynarus scolymus.

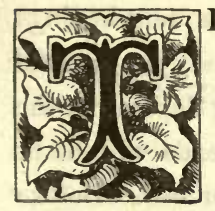

HE Artichoke is a hardy perennial. The stem is from four to five feet in height, with numerous branches; the leaves are of remarkable size, frequently measuring three feet, and sometimes nearly four feet in length, pinnatifid, or deeply cut on the borders, and more or less invested with an ash-colored down; the mid-ribs are large, fleshy, and deeply grooved, or furrowed; the flowers are large, terminal, and consist of numerous blue florets, enclosed by fleshy, pointed scales; the seeds (eight hundred and fifty of which are contained in an ounce) are of a grayish color, variegated with deep brown, oblong, angular, somewhat flattened, and retain their vitality five years.

Soil. - Select a light, rich, and rather moist soil, and trench it well; incorporating in the process a liberal portion of old, well-decomposed compost. Sea-weeds, kelp, rockweed, and the like, where they can be obtained, are the best fertilizers; but, where these are not accessible, a slight application of salt will be beneficial.

Propagation. - Artichokes may be propagated either by seeds, or by slips, or suckers, from established plants. If 
by slips, they should be taken off in May, when they have grown five or six inches in height, and transplanted four or

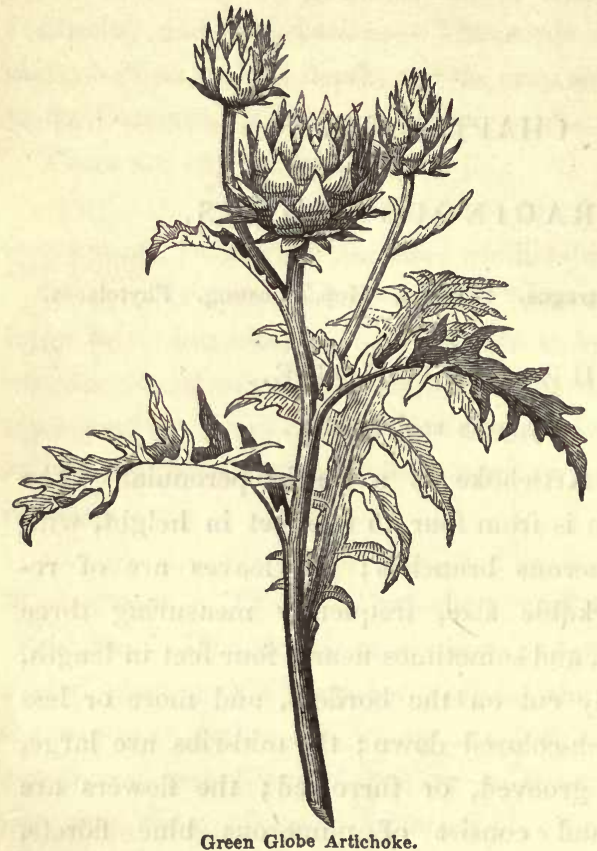

five.inches deep, in rows four feet apart, and two feet apart in the rows. Water freely, if dry weather occurs before the young plants are established. Keep the ground loose by frequent hoeings and in August or September the heads will be fit for use. Before severe weather, the plants should be covered with straw or stablelitter.

As plants of one year's growth produce but few heads, and are also later in their development of these than established plants, it is the practice of many cultivators to set a few young slips, and to destroy an equal part of the old plantation, yearly.

When propagated from seeds, a few are sown broadcast, and covered about an inch deep; or they may be sown in drills eight or ten inches apart. When the plants are well up, transplant, and subsequently treat as directed for slips or suckers.

To raise Seeds. - Allow a few of the largest central heads 
to remain; and, just as the flowers expand, bend over the stalk so as to allow the rain to run from the buds, as the seeds are often injured by wet weather. In favorable seasons, they will ripen in September. According to English authority, little dependence can be placed on seedling plants : many produce small and worthless heads, whilst others produce those of large size and good quality.

Taking the Crop. - The buds or heads, which furnish the scales for which the plant is generally cultivated, should be cut as they attain a suitable size, and before the appearance of the blossom. After the opening of the calyx and the expansion of the flower, the scales become tough and woody and are unfit for the table. For what are called bottoms, the buds are allowed to remain on the plant until they are fully developed.

Use. - The portions of the plant used are the lowest parts of the leaves, or scales, of the calyx; and also the fleshy receptacles of the flower, freed from the bristles and seeddown. The latter are commonly called the "choke," on account of their disagreeable character when eaten.

Sometimes, particularly in France, the central leaf-stalk is blanched, and eaten like cardoons. The bottom, which is the top of the receptacles, is fried in paste, and enters largely into fricassees and ragouts. They are sometimes pickled, and often used in a raw state as a salad. The French also cut them into thin slices; leaving one of the scales, or calyx leaves, attached, by which the slice is lifted, and dipped in oil and vinegar before using. The English present the head whole, or cut into quarters, upon a dry plate; the guests picking off the scales one by one, which have a fleshy substance at the base. These are eaten after being dipped in oil and vinegar.

What is called "artichoke chard" is the tender leaf-stalks blanched, and cooked like cardoons. The Italians and 
French often eat the heads raw with vinegar, oil, salt, and pepper; but they are generally preferred when boiled.

Varieties. -

Dark-Red Spined.

Bud very small. The variety is remarkable for the long spines in which the scales terminate. For cultivation it is inferior to the other sorts.

Early Purple. Vil. PURPLE. PURPLE short and broad, pointed, green at the base,
GLOBE. tinged with purplish-red on the outside, towards their extremities, moderately succulent, and of good quality. The variety is early, but not hardy. In France, it is considered excellent in its crude state, served with vinegar and oil; but not so good cooked.

Green Globe. A large sort, much esteemed, and generally LARGE ROUND-
HEADED. GLOBE. cultivated in England. Heads, or buds, nearly round, and with a dusky, purplish tint. The scales turn in at the top, and the receptacle is more fleshy than that of most varieties. It is generally preferred for the main crop, as the scales, or edible parts, are thicker and higher flavored than those of any other artichoke. It is not a hardy variety, and requires ample protection during winter.

Green, or Common.

FreNCH.
Bud very large, of a conical or oval form; scales deep-green, thick, and fleshy, pointed at the tips, and turned outwards. Though it has not the same thickness of flesh as the Green Globe Artichoke, it is much hardier, more prolific, and one of the best sorts for cultivation.

Green Provence.

Bud large; scales comparatively long and narrow, of a lively green color, erect, fleshy at the base, and terminating in a sharp, brownish spine, or 
thorn; leaves of the plant deep green. Most esteemed in its crude state, eaten as a salad in vinegar and oil.

Similar to the Common Green Artichoke, but Laon. Vil. of larger size. Scales rather loose and open, deep green, fleshy, and pointed. Much cultivated in the vicinity of Paris, and there considered the best.

Bud of medium size, somewhat globular, but flattened at the top; scales closely set together,

Large Flat Brittany. green, brownish on the borders, - short, thick, and fleshy at the base. Earlier than the Laon, but not so fleshy. Much grown in Anjou and Brittany.

Bud conical ; scales green towards their tips, and purplish-red at their base. Not very Purplish-
red. fleshy, and in no respect superior to the preceding varieties.

\section{A S P A RA GUS. \\ Asparagus officinalis.}

Asparagus is a hardy, perennial, maritime plant. It rises to the height of five feet and upwards, with an erect, branching stem; short, slender, nearly cylindrical leaves; and greenish, drooping flowers. The seeds, which are produced in globular, scarlet berries, are black, somewhat triangular, and retain their germinative powers four years. Twelve hundred and fifty weigh an ounce.

It is indigenous to the shores of various countries of Europe and Asia; and, since its introduction, has become naturalized to a considerable extent in this country. It is frequently seen in mowing-fields upon old farms; and, in some instances has found its way to the beaches and marshes of the sea-coast. 
Propagation. - It is propagated from seed, which may be sown either in autumn, just before the closing up of the ground, or in spring, as soon as the soil is in good working condition. The nursery, or seed-bed, should be thoroughly spaded over, the surface levelled and raked smooth and fine, and the seed sown, not very thickly, in drills twelve or fourteen inches apart, and about an inch in depth. An ounee of seed is sufficient for fifty or sixty feet of drill.

When the plants are well up, thin them to three inches asunder; as they will be much stronger, if growu at some distance apart, than if allowed to stand closely together. Cultivate in the usual manner during the summer, and give the plants a light covering of stable-litter during the winter.

Good plants of one year's growth are preferred by experienced growers for setting; but some choose those of two years, and they may be used when three years old.

Soil and Planting. - $\mathbf{A}$ deep, rich, mellow soil is best adapted to the growth of asparagus. In the forming of a plantation, cold and wet situations should be avoided, and a sandy subsoil, where it can be obtained, should be preferred to a subsoil of clay or gravel.

Before planting out the roots, the ground should be thoroughly trenched two feet or more in depth. As the soil can hardly be made too rich, incorporate in the process of trenching a very liberal quantity of well-decomposed manure with a free mixture of common salt.

Lay out the land in beds five feet apart, and rumning north and south or east and west, as may be most convenient. Along these beds set three rows of roots, the outer rows being one foot from the borders of the bed, and the roots one foot from each other in the rows.

The roots may be set in April, or early in May. Throw out a trench, along the length of the bed, ten inches or a foot in width, and deep enough to allow the crowns to be covered 
three or four inches beneath the surface. There are various methods of placing the roots in the trench. Some spread them out like a fan against the side; some form little hillocks of fine soil, over which the roots are spread, extending like the sticks of an umbrella; others make a ridge along the centre of the trench, and spread the roots on either side; while others remove the soil from the bed, rake the surface smooth, and spread out the roots at right angles on the level, afterwards replacing the soil, covering to the depth of about three inches.

During the summer nothing will be necessary but to keep the plants clear of weeds; and, in doing this, the hoe should be dispensed with as much as possible, to avoid injuring the roots. In the autumn, when the tops have completely withered, they should be cut down nearly level with the surface of the ground, and burned. The beds should then be lightly dug over, and two or three inches of rich loam, intermixed with well-digested compost, and salt at the rate of two quarts to the square rod, should be applied; which will leave the crowns of the roots about five inches below the surface.

Second Year. - Early in spring, as soon as the frost leaves the ground, dig over the beds, taking care not to disturb the roots; rake the surface smooth; and, during the summer, cultivate as before directed: but none of the shoots should be cut for use. In the autumn, after the stalks have entirely withered, cut down and burn as in the previous year; stir the surface of the bed, and add an inch of soil and manure, which will bring the crowns six or seven inches below ground, - a depth preferred, by a majority of cultivators, for established plantations.

Third Year. - Early in spring stir the ground as directed for the two previous years. Some cultivators make a slight cutting during this season; but the future strength of the plants will be increased by allowing the crop to grow natu- 
rally as during the first and second years. In autumn cut and burn as before; dig over the surface; add a dressing of manure; and, in the ensuing spring, the beds may be cut freely for use.

Instead of transplanting the roots, asparagus-beds are sometimes formed by sowing the seeds where the plants are to remain. When this method is adopted the beds should be laid out and trenched, as before directed, and about three inches of soil removed from the entire surface. The seed should then be sown in drills an inch deep, at the distances marked out for the rows, and covered with rich, light soil. When the seedlings are two or three inches high, they should be thinned to nine or twelve inches apart; and, in thinning, the weakest plants should be removed. In the autumn, cut down the plants after they have withered, stir and smooth the surface, and add a dressing of manure. In the spring of the second year stir the surface again; and, during the summer, cultivate as before. In the autumn the plants will be ready for the dressing, which consists of the soil previously taken from the bed, with sufficient well-digested compost added to cover the crowns of the roots five or six inches in depth. The after-culture is similar to that of beds from transplanted roots.

" Asparagus-beds should be enriched every autumn with a liberal application of good compost containing some mixture of salt; the benefit of which will be evident, not only in the quantity, but in the size and quality, of the produce. The dressing should be applied after the removal of the decayed stalks, and forked in, that its enriching properties may be washed to the roots of the plants by winter rains.

"In general, transplanted Asparagus comes up quite slender the first year; is larger the second; and, the third year, a few shoots may be fit for cutting. It is nearly in perfection the fourth year; and, if properly managed, will annually give 
an abundant supply during the life of the maker of a bed or plantation."

Cutting. - "The shoots should be cut angularly, from two to three inches below the surface of the ground; taking care not to wound the younger buds. It is in the best condition for cutting when the shoots are four or five inches above ground, and while the head, or bud, remains close and firm.

"It is the practice to cut off all the shoots as they appear, up to the period when it is thought best to leave off cutting altogether. The time for this depends on the climate, season, nature of the soil, and strength of the plants. Where the climate is good, or when the season is an early one, cutting must be commenced early; and of course, in such a case, it ought not to be continued late, as the plants would thereby be weakened."

In the Middle States the cutting should be discontinued from the 10th to the 15th of June; and from the 15th to the 25th of the same month in the Easteru States and the Canadas.

"If the plants are weak, they should be allowed to grow up as early as possible, to make foliage, and consequently fiesh roots, and thus to acquire more vigor for the ensuing year. It is also advisable to leave off at an early period the cutting of some of the best of the beds intended for early produce, in order that the buds may be well matured early in autumn, and thus be prepared to push vigorously early in spring."

Asparagus-beds will continue from twenty to thirty years; and there are instances of beds being regularly cut, and remaining in good condition for more than fifty years.

Use. - The young shoots are boiled twenty minutes or half an hour, until they become soft; and are principally served on toasted bread, with melted butter. It is the practice of some to boil the shoots entire; others cut or break the 
sprout just above the more tough or fibrous part, and cook only the part which is tender and eatable. This is snapped or cut into small sections, which are boiled, buttered, seasoned, and served on toast in the usual form. "The smaller sprouts are sometimes cut into pieces three-eighths of an inch long, and cooked and served as green peas." The sprouts are also excellent when made into soup.

It is one of the most productive, economical, and healthful of all garden vegetables.

Varieties. - "The names of numerous varieties occur in the catalogues of seedsmen; but there seems to be little permanency of character in the plants; such slight variations as appear from time to time being caused, to a considerable extent, by the nature of the soil, or by the situation in which the plants are grown. What are called the Red-topped and Green-topped may perhaps be somewhat distinct, and considered as varieties." - Glenny.

Soil and location have unquestionably much influence, both as respects the quality and size of the sprouts. A bed of Asparagus in one locality produced shoots seldom reaching a diameter of half an inch, and of a very tough and fibrous character; while a bed in another situation, formed of plants taken from the same nursery-bed, actually produced sprouts so large and fine as to obtain the prize of the Massachusetts Horticultural Society.

If any variety really exists peculiar in size, form, color, or quality, it cannot be propagated by seed. Large sprouts may afford seeds, which, as a general rule, will produce finer Asparagus than seeds from smaller plants; but a variety, when it occurs, can be propagated only by a division of the roots.

Mr. Thompson states that on one part of Mr. Grayson's extensive plantation, on the south side of the Thames, near London, the so-called Grayson's Giant was produced; and 
in another section, the common sort; but, when both were made to change places, the common acquired the dimensions of the giant, whilst the latter diminished to the ordinary size.

Seeds of the following named and described sorts may be obtained of seedsmen, and will undoubtedly, in nearly all cases, afford fine asparagus ; but they will not produce plants which will uniformly possess the character of the parent variety : -

Battersea is famed for producing fine Asparagus, and the name is applied to the particular Battersea. Rog.

variety there grown. The heads are large, full, and close, and the tops tinted with a reddish-green color. It is probably intermediate between the Green and Purple-topped.

Originated and named under like circum- Gravesend. stances with the Battersea. The top is greener, Rog. and not generally so plump and close; but it is considered finer flavored. Both varieties are, however, held in great estimation.

This variety, as also the Deptford, Mortlake, Grayson's and Reading, all originated and were named Giant. under the same conditions as the varieties before described. All are fine sorts; but the difference between them, and indeed between all of the kinds, if important, is certainly not permanent, so long as they are offered in the form of seeds for propagation.

Mr. Grayson, the originator of this variety, produced a hundred sprouts, the aggregate weight of which was fortytwo pounds, - the largest ever raised in Britain.

This variety resembles the Giant Purple-topped, German. but is a little earlier, and the top is deeper colored. 
Giant Purple- Sprout white; the top, as it breaks ground, Duтсн. RzD-тор. purple; size very large, sometimes measuring an inch and three fourths in diameter, but greatly affected by soil and cultivation.

A hundred sprouts of this variety have been produced, which weighed twenty-five pounds.

Green-Top. This variety, when grown under the same conditions as the Giant Purple-top, is generally smaller or more slender. The top of the sprout and the scales on the sides are often slightly tinged with purple. The plant, when full grown, is perceptibly more green than that of the Giant Purple-top. From most nursery-beds plants of both varieties will probably be obtained, with every intervening grade of size and color.

\section{CA R DOON.}

Chardon. Chardoon. Cynara cardunculus.

In its general character and appearance the Cardoon resembles the Artichoke. Its full size is not attained until the second year, when it is "truly a gigantic herbaceous plant," of five or six feet in height. The flowers, which are smaller than those of the Artichoke, are produced in July and August of the second year, and are composed of numerous small blue florets, enclosed by somewhat fleshy, pointed scales. The seeds are oblong, a little flattened, of a grayish or grayish-green color, spotted and streaked with deep brown ; and, when perfectly grown, are similar in size and form to those of the apple. About six hundred are contained in an ounce; and they retain their vitality seven years.

Soil, Propagation, and Culture. - The best soil for the Cardoon is a light and deep but not over-rich loam. It is 
raised from seed ; which, as the plant is used in the first year of its growth and is liable to be injured by the winter, should be sown annually, although the Cardoon is really a perennial. It succeeds best when sown where the plants are to remain; for, if removed, the plants recover slowly, are more liable to run to seed, and, besides, seldom attain the size of those that have not been transplanted.

The seed should be sown as early in spring as the weather becomes warm and settled, in drills three feet apart, an inch and a half in depth, and the young plants afterwards thinned to twelve inches asunder in the drills. The leaves are blanched before being used.

It is sometimes raised and blanched as follows: Sow the seed at the bottom of trenches made about six inches deep, twelve inches wide, three feet apart, and of a length according to the supply required. At the bottom of the trench thoroughly mix a small quantity of well-digested compost, and sow the seeds in small groups, or collections (three or four seeds together), at about twelve or fifteen inches apart, and cover them an inch or an inch and a half deep. When the young plants have acquired three or four leaves, they should be thinned out to single plants. During the summer keep them free from weeds; and, as they require much moisture, it is well to water frequently, if the weather is very dry. In September the plants will have attained their growth for the season, and be ready for blanching; which should be commenced in a dry day, and when the plants are entirely free from dampness. It is thus performed: The leaves of each plant are carefully and lightly tied together with strong matting, keeping the whole upright, and the ribs of the leaves closely together. The plant is then bound with twisted hay-bands, or bands of straw, about an inch and a half in diameter ; beginning at the root, and continuing the winding until two thirds or three fourths of the height are covered. 
If there is no heavy frost the leaves will blanch quickly and finely without further pains; but, if frosty weather occurs, it will be necessary to earth up about the plants, as is practised with celery; but care should be taken not to raise the earth higher than the hay-bands.

One method of blanching is simply to tie the leaves together with matting, and then to earth up the plants from time to time like celery; beginning early in September, and adding gradually every week until they are sufficiently covered. Those, however, blanched by the banding process, are superior, both in respect to color and in the greater length of the parts blanched.

Another practice is to earth up a little about the base of the plant, tie the leaves together with thread or matting, and then envelop the whole quite to the top with a quantity of long, clean wheat or rye straw, placed up and down the plant, and tied together with small cord or strong matting. The leaves will thus blanch without being earthed up, and speedily become white. This process is a good one, is economical, and presents a neat appearance.

In about three weeks after being tied up the cardoons will be fit for use.

Harvesting. - When the stems and midribs of the leaves are thoroughly blanched they arc ready for use. Until the occurrence of severe weather the table may be supplied directly from the garden; but, before the closing up of the ground, "the plant should be taken up, roots and leaves entire, and removed to the cellar, where they should be packed in sand, laying the plants down in rows, and packing the sand around them, one course over another, till finished. In this way they not only keep well, but become more perfectly blanched."

To raise Seed. - Allow two or three plants to remain 
unblanched, and leave them in the ground during the winter, protected by straw or other convenient material. They will grow to the height, and flower and seed, as before described. One plant will afford sufficient seed for any common garden.

Use. - The plant is cultivated for the stems and mid-ribs of the large leaves, which, after being blanched, are used in various forms of cookery and as winter salad.

In France, the flowers are gathered, and dried in the shade; and, when so preserved, are used as a substitute for rennet, to coagulate milk.

\section{Varieties. -}

This kind grows from four to five feet high. Common, or The leaves are large and strong, though somewhat smaller than those of the Tours or Prickly Large Smooth. Trans. Cardoon. They are of a shining green color, SMOoth LARGE Solid. with little appearance of loariness on the upper surface, and generally destitute of spines; though some of the plants occasionally have a few small ones at the base of the leaflets.

The Cardon Plein Inerme of the French, which is described in the "Bon Jardinier" as a novelty, corresponds nearly with the Large Smooth or Common Cardoon.

Stem five or six feet high. The divisions of Large Spanthe leaflets are rather narrower, and somewhat more hoary, than those of the Common Cardoon. The ribs are longer, and the whole plant stronger and generally more spiny; though on the whole comparatively smooth. It is not, however, always readily distinguished from the Common or Large Smooth Cardoon. It runs up to seed quicker than the other varieties. 
Puvis.

The Puvis Cardoon is remarkable for its

Thomp.

strong growth, the large size it attains, and the LEAVED. LANCE-

LEAVED.

thickness of the midribs of the leaves, which are almost solid. The leaves are thick, and not at all prickly, or very slightly so. The terminal lobe is large and lance-formed; whence the name. It is a fine variety, and of more tender substance than the Tours Cardoon.

Red. Trans. BLOOD-RIBBED. RKD-STKMMED. Thomp.

The leaves of this variety are green, without any hoariness ; long, narrow, and more sharply pointed than those of most of the other kinds. The ribs are large, solid, and tinged with red. A recent sort, excellent in quality, but wanting in hardiness.

Tours. Trans. The leaves of this variety are very hoary on LARog Tours
SoutD. the upper surface; the divisions are broad, sharply pointed, and terminate with rigid, sharp spines. Spines also grow in clusters of from three to five at the base of the leaflets, and are very strong, and of a yellowish color. This variety is not so tall as the Spanish or Large Smooth. The ribs are large and solid.

The Tours Cardoon is cultivated by the market-gardeners around Paris ; and, notwithstanding the inconvenience arising from its numerous and rigid spines, it is considered by them as the best, because of its thick, tender, and delicate ribs.

\section{TH E H O P.}

\section{Humulus lupulus.}

The Hop is considered a native of this continent, and is found wild in all parts of the United States. The root is perennial, but the stems are annual. The latter are from ten to twenty-five feet in length, angular, rough, and twine 
from right to left. The leaves are placed opposite each other on the stem, on long, winding footstalks; the smaller ones are heart-shaped; the larger ones three or five lobed, veiny, and rough. The barren and fertile flowers are produced on separate plants; the former being very numerous and paniculated, the latter in the form of an ament, or collection of small scales, which are more or less covered with a fine, yellow powder called "lupulin."

While several distinct sorts of the fertile or hop-bearing plant have been long in cultivation, only one variety of the male or barren plant is known.

Soil and Location. - Though it may be cultivated with success in a variety of soils, the Hop prefers a rich, deep loam, which should be thoroughly ploughed, and, if necessary, enriched with well-digested compost. In general, it may be said that "good corn-land is good hop-land." Hops, however, are reputed to be of better quality when raised on comparatively thin soils.

Propagation and Culture. - It is propagated by a division of the roots early in spring. When extensively cultivated, the plants are set in hills, five to seven feet apart, and three or four cuttings or slips allowed to a hill; but in garden culture, to procure the young shoots, the plants are set in rows about three feet apart, and one foot from plant to plant in the rows.

Use. - The plant is principally cultivated for its flowers, which are largely employed in the manufacture of malt liquors. The young shoots are cut in spring, when they are five or six inches in height, and eaten as salad, or used as asparagus, which they somewhat resemble in taste. 
HOOSUNG, OR OOSUNG. Hov. Mag.

A lettuce-like plant from Shanghai. Stems cylindrical, from two to three feet high, erect, light green, with a green, succulent pith; leaves oblong, tapering to the base, the uppermost clasping; the flowers are small, yellow, in panicles slightly drooping. If sown in April or May, the plants will ripen their seed in August.

Sowing and Cultivation. - Sow in a cool frame, in either April or May, or continuously, for a succession, at intervals during May, and transplant into the open ground in the usual manner of treating lettuces; making the rows about eighteen inches apart, and placing the plants about the same distance apart in the rows. The plants will be fit for use early in June.

Use. - The succulent stem is the part used. This is divested of its outer rind, and either simply boiled, with a little salt in the water, and dressed as asparagus, or stewed in soy, with salt, pepper, and butter added, or boiled in soup as okra. It is a very agreeable and pleasant addition to the list of vegetable esculents, and worthy of trial.

The plant is little cultivated, and there are no described varieties.

\section{PERENNIAL PHYTOLACCA.}

Garget. Poke. Pigeon Berry. Phytolacca decandra.

A hardy, herbaceous, perennial plant, common by roadsides, in waste places, and springing up spontaneously on newly burned pine-lands. It has a branching, purplish stem, five to seven feet in height; and large, oval, pointed, entire leaves. The flowers are produced in July and August, in long clusters; and are of a dull white color. The fruit consists of a flat, purple, juicy berry; and is sometimes used for dyeing purple. 
Soil and Culture. - It will thrive in almost any soil or situation; and can be easily propagated from seed, or by dividing the roots. The plant requires little cultivation, and is so abundant in many localities as to afford an ample supply for the mere labor of gathering.

Use. - The young shoots are eaten early in the season, as a substitute for asparagus, which they resemble in taste. When treated in the manner of sea-kale, the flavor of the sprouts is scarcely distinguishable from that of asparagus. The root has reputed important medicinal properties; and, when taken internally, acts as a violent emetic.

\section{ANNUAL PHYTOLACCA.}

Phytolacca esculenta.

An annual species, with foliage similar to the foregoing. It is much less vigorous and stocky in habit. The seed should be sown in April, in drills fifteen inches apart. The young shoots, or plants, are used in the manner of the species before described. 


\section{CHAPTER IV. \\ CUCURBITACEOUS PLANTS.}

The Cucumber. Egyptian Cucumber. Globe Cucumber. Gourd, or Calabash. The Melon. Muskmelon. Persian Melons. Watermelon. Papanjay, or Sponge Cucumber. Prickly-fruited Gherkin. Pumpkin. Snake Cucumber. Squash.

\section{THE CUCUMBER.}

Cucumis sativus.

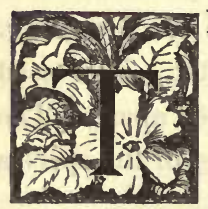

HE Cucumber is a tender, annual plant, and is a native of the East Indies, or of tropical origin. It has an angular, creeping stem; large, somewhat heart-shaped, leaves; and axillary staminate or pistillate flowers. The fruit is cylindrical, generally elongated, often somewhat angular, smooth, or with scattering black or white spines; the flesh is white or greenish-white, and is divided at the centre of the fruit into three parts, in each of which the seeds are produced in great abundance. These seeds are of an elliptical or oval form, much flattened, and of a pale yellowishwhite color. About twelve hundred are contained in an ounce, and they retain their vitality ten years.

Soil and Culture. - Cucumbers succeed decidedly best in warm, moist, rich, loamy ground. The essentials to their growth are heat and a fair proportion of moisture. They should not be planted or set in the open air until there is a prospect of continued warm and pleasant weather; as, when 
planted early, not only are the seeds liable to decay in the ground, but the young plants are frequently cut off by frost.

The hills should be five or six feet apart in each direction. Make them fifteen or eighteen inches in diameter, and a foot in depth; fill them three fourths full of thoroughly digested compost, and then draw four or five inches of earth over the whole, raising the hill a little above the level of the ground ; plant fifteen or twenty seeds in each, cover half an inch deep, and press the earth smoothly over with the back of the hoe. When all danger from bugs and worms is past, thin out the plants, leaving but three or four of the strongest or healthiest to a hill.

Taking the Crop. - As fast as the cucumbers attain a suitable size, they should be plucked, whether required for use or not. The imperfectly formed, as well as the symmetrical, should all be removed. Fruit, however inferior, left to ripen on the vines, soon destroys their productiveness.

Seed. - As cucumbers readily intermix or hybridize when grown together, it is necessary, in order to retain any variety in its purity, to grow it apart from all other sorts. When a few seeds are desired for the vegetable garden, two or three of the finest-formed cucumbers should be selected early in the season, and allowed to ripen on the plants. In September, or when fully ripe, cut them open, take out the seeds, and allow them to stand a day or two, or until the pulp attached to them begins to separate; when they should be washed clean, thoroughly dried, and packed away for future use.

For Pickling. - The land for raising cucumbers for pickling may be either swarded or stubble; but it must be in good condition, and such as is not easily affected by drought. It should be deeply ploughed, and the surface afterwards made fine and friable by being thoroughly harrowed. The hills should be six feet apart, and are generally formed by furrowing the land at this distance in each direction. Ma- 
nure the hills with well-digested compost, level off, draw over a little fine earth, and the land is ready for planting.

This may be done at any time from the middle of June to the first week in July. The quantity of seed allowed to an acre varies from three fourths of a pound, upwards. In most cases, growers seed very liberally, to provide against the depredation of worms and bugs; usually putting six or eight times as many seeds in a hill as will be really required for the crop. When the plants are well established and beyond danger, the field is examined, and the hills thinned to three or four plants; or, where there is a deficiency of plants, replanted.

As fast as the cucumbers attain the proper size, they should be plucked; the usual practice being to go over the plantation daily. In gathering, all the fruit should be removed, - the misshapen and unmarketable, as well as those which are well formed; for, when any portion of the crop is allowed to remain and ripen, the plants become much less productive.

In favorable seasons, and under a high state of cultivation, a hundred and twenty-five thousand are obtained from an acre; while, under opposite conditions, the crop may not exceed fifty thousand. The average price is about a dollar and twenty-five cents per thousand.

Varieties. -

Early Cluster.

Early Greex

Cluster.

whence the name. The plant is healthy, hardy, and vigorous; fruit comparatively short and thick. Its usual length is about five inches, and its diameter about two inches ; skin prickly, green, - at the blossom-end, Early Cluster Cucumber.

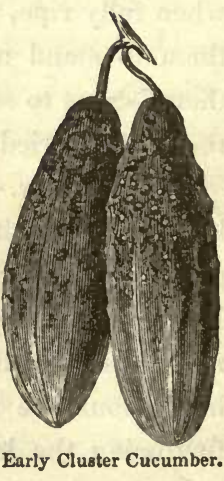


often paler, or nearly white, - brownish-yellow when ripe ; flesh white, seedy, tender, and well flavored, but less crispy or brittle than that of many other varieties.

It is a good early garden sort, and is quite productive; but is not well adapted for pickling, on account of the soft and seedy character of its flesh.

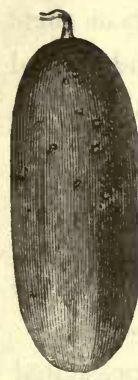

Early Frame Cucumber.

One of the oldest of the garden Early Frame. sorts, justly styled a standard variSHORT GREEN. ety. Plant healthy and vigorous, six to ten feet in length; fruit straight and well formed, five inches and a half long, and two inches and a half in diameter; skin deep green, paler at the blossom-end, changing to clear yellow as it approaches maturity, and, when fully ripe, of a yellowish, russet-brown color; flesh greenishwhite, rather seedy, but tender, and of an agreeable flavor. It is a few days later than the Early Cluster.

The variety is universally popular, and is found in almost every vegetable garden. It is also very productive; succeeds well, whether grown in open culture or under glass; and, if plucked while young and small, makes an excellent pickle.

This comparatively new variety resembles, Early Rusin some respects, the Early Cluster. Fruit

sian.

from three to four inches in length, an inch and a half or two inches in diameter, and generally produced in pairs; flesh tender, crisp, and well flavored. When ripe, the fruit is deep yellow or yellowish-brown.

Its merits are its hardiness, extreme earliness, and great productiveness. It comes into use nearly ten days in advance of the Early Cluster, and is the earliest garden variety now cultivated. Its small size is, however, considered an 
objection; and some of the larger kinds are generally preferred for the main crop.

Gondon Long Fruit about a foot in length, tapering towards the extremities; skin very deep green while the fruit is young, yellow when it is ripe ; flesh greenish-white, firm, and crisp ; flavor good.

This variety is nearly related to the numerous prize sorts which in England are cultivated under glass, and forced during the winter. There is little permanency in the slight variations of character by which they are distinguished; and old varieties are constantly being dropped from the catalogues, and others, with different names, substituted. Amongst the most prominent of these sub-varieties are the following:-

Carter's Champion. - Recently introduced. Represented as one of the largest and finest of the forcing varieties.

Coleshill. - A recent sort, measuring on the average about twenty inches in length. With the exception of the neck, which is short and handsome, the fruit is perfectly cylindrical. The skin is smooth, pale green, and thickly covered . with bloom. Hardy, productive, and of excellent quality.

Conqueror of the West. - Eighteen to twenty inches in length. It is a fine prize sort, and succeeds well in open culture.

Cuthill's Black Spine. - Six to nine inches in length, hardy, early, and productive. An excellent sort for starting in a hotbed. Fruit very firm and attractive.

The Doctor. - Sixteen to eighteen inches in length, and contracted towards the stem in the form of a neck. In favorable seasons, it will attain a good size, if grown in the open ground. Crisp, tender, and well flavored.

Eggleston's Conqueror. - "Very prolific, good for forcing, of fine flavor, hardy, and a really useful sort. Specimens 
have been grown measuring twenty-eight inches in length, nine inches and a half in circumference, and weighing five pounds."

Flanigan's Prize. - An old, established variety; having been grown in England upwards of thirty years. Length fifteen inches.

Giant of Arnstadt. - Length twenty-four inches; fine rich color, and productive.

Henderson's Number One Black-spined.Length seventeen inches, straight and even. Color deep and fine. Of a hundred and eighteen varieties fruited at the Chiswick Gardens, England, this proved one of the best.

Hunter's Prolific. - Length eighteen inches. Very crisp and excellent, but requires more heat than most other varieties. Spines white; fruit covered with a good bloom, and not liable to turn yellow at the base.

Improved Sion House. - This variety has received many prizes in England. Not only is it well adapted for the summer crop, but it succeeds remarkably well when grown under glass.

Irishman. - Length twenty-two to twentyfive inches. Handsome, and excellent for exhibition.

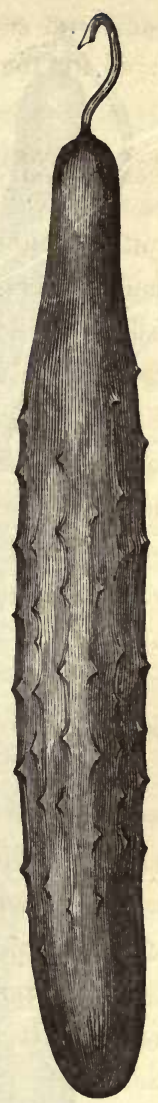

The Doctor - Cucumber.

Lord Kenyon's Favorite. - Length twelve to eighteen inches. A fine sort for winter forcing.

Manchester Prize. - This, like the Nepal, is one of the largest of the English greenhouse prize varieties. It sometimes measures two feet in length, and weighs twelve pounds. In fayorable seasons it will attain a large size in open cul. ture, and sometimes perfect its seed. 


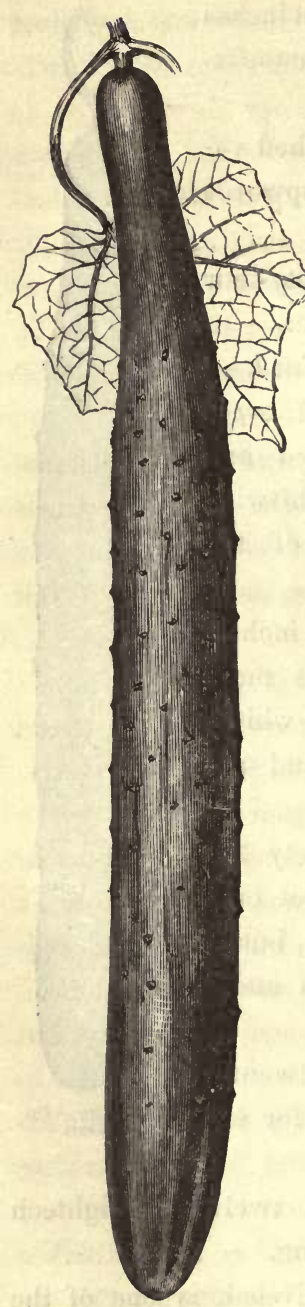

Manchester Prize Cucumber.

Napoleon III. - Hardy and very prolific. A fine new sort.

Nepal. - One of the largest of all varieties; length about twenty-four inches; weight ten to twelve pounds.

Norman's Stitchworth-Park Hero.A recently introduced variety, hardy, long, handsome, very prolific, and fine flavored.

Old Sion House. - Length about nine inches. This is a well-tried, winter, forcing variety. Like the Improved Sion House, it also succeeds well in open culture. Quality good, though the extremities are sometimes bitter.

Prize-fighter. - Length about sixteen inches. Good for the summer crop or for exhibition.

Rifleman. - This variety is described as one of the best prize cucumbers. It has a black spine; always grows very even from stem to point, with scarcely any handle; carries its bloom well; keeps a good fresh color; and is not liable to turn yellow as many other sorts. Length twenty-four to twenty-eight inches. An abundant bearer.

Ringleader. - A prominent prize sort, about fifteen inches in length. It succeeds well, whether grown under glass or in the open ground.

Roman Emperor. - Length twelve to fifteen inches. 
Star of the West. - Long, hardy, handsome; described as extra fine.

Stockwood.-One of the best sorts for forcing. It is remarkably hardy and prolific, and succeeds well grown in a common hotbed. Length fifteen to twenty inches. It sometimes produces three or four fruit at a joint.

Southgate. - This variety has been pronounced the most productive, and the best for forcing, of all the prize sorts. It is not so late as many of the English varieties, and will frequently succeed well if grown in the open ground.

Sugden's Aldershott. - Remarkably large and handsome, one of the finest of the prize sorts. The fruit sometimes attains a length of three feet.

Victory of Bath. - Length about seventeen inches. Well adapted for forcing or for the general crop.

This is a large-sized variety, and somewhat Long Green later than the White-spined. The plant is a Prickly. strong grower, and the foliage of a deep green GREEN PBICKLY. color; the fruit is about seven inches in length, straight, and generally angular; skin dark green, changing to yellow as the fruit approaches maturity, - when fully ripe, it is reddish-brown, and is often reticulated about the insertion of the stem; prickles black; flesh white, somewhat seedy, but crisp, tender, and well flavored.

The Long Green Prickly is hardy and productive; makes a good pickle, if plucked while young; and is well deserving of cultivation. It differs from the London Long Green and the Long Green Turkey in its form, which is much thicker in proportion to its length; and also in the character of its flesh, which is more pulpy and seedy.

A distinct and well-defined variety; when full grown, sometimes measuring nearly eigh-

Long Green Turkey. 
teen inches in length. Form long and slender, contracted towards the stem in the form of a neck, and swollen towards the opposite extremity; seeds few, and usually produced nearest the blossom-end. The neck is generally solid. While the fruit is young, the skin is deep green; afterwards it changes to clear yellow, and finally assumes a rusty yellow or yellowish-brown. Flesh remarkably firm and crisp; exceeding, in these respects, that of any other variety. Very productive and excellent.

Its remarkably firm and crispy flesh, and the absence of seeds, render it serviceable for the table after it has reached a very considerable size. For the same reasons it may be pickled at a stage of its growth when other more seedy and pulpy sorts would be comparatively worthless.

Short Prickly. This variety somewhat resembles the Long SHORT GREEN
PRICKLY ERARY
SHORT GREEN PRICKLY.

thicker. Its length, when suitable for use, is about four inches. Skin prickly, green, changing to yellow at maturity; flesh transparent greenish-white, rather seedy, but tender, crisp, and fine flavored.

The variety is hardy and productive, comes early into fruit, and is one of the best for pickling. It is a few days later than the Early Cluster.

Underwood's Short Prick$1 y$.
This is an improved variety of the common Short Prickly, and is the best of all the sorts for extensive cultivation for pickling. The plant is hardy and productive. The fruit, when young, is very symmetrical, and of a fine deep green color. Its flesh is characterized by extraordinary crispness and solidity. When more advanced the color becomes paler, and the flesh more soft and seedy. The fruit, at maturity, is yellow. 
The form of this variety is similar to that White Spanof the White-spined. The fruit measures about

five inches in length, two inches in diameter, and is generally somewhat ribbed. When suitable for use, the skin is white; a characteristic by which the variety is readily distinguished from all others. The flesh is crisp, tender, and well flavored. At maturity, the fruit is yellow.

This very distinct variety is extensively grown for marketing, both at the North and South. The plants grow from six to ten feet in length;

Whitespined.

EARLY WHITESPINED, NEW YOBK MAREET. and, like those of the Early Frame, are of a healthy, luxurious habit. The fruit is of full medium size, straight, and well formed; about six inches in length, and two inches and a half in diameter. Skin deep green; prickles white ; flesh white, tender, crispy, and of remarkably fine flavor. As the fruit ripens, the skin gradually becomes paler; and, when fully ripe, is nearly white; by which peculiarity, in connection with its white spines, the variety is always readily distinguishable.

The White-spined is one of the best sorts for the table; and is greatly prized by market-men on account of its color, which is never changed to

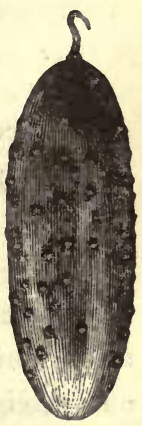

White-spined Cucumber. yellow, though kept long after being plucked. It is generally thought to retain its freshness longer than any other variety, and consequently to be well fitted for transporting long distances; though, on account of its peculiar color, the freshness may be less real than apparent.

For the very general dissemination of this variety, the public are, in a great degree, indebted to the late Isaac Rand, Esq., of Boston, whose integrity as a merchant, and whose skill as a practical vegetable cultivator and horticulturist, will be long remembered. 


\section{EGYPTIAN CUCUMBER.}

Hairy Cucumber. Round-leaved Egyptian. Cucumis chate.

This is a tender, anuual plant, with an angular, creeping stem, and alternate, somewhat heart-shaped, leaves. The flowers are axillary, about an inch in diameter, and of a pale yellow color; the fruit is small, oblong, and very hairy.

It is of little value as an esculent, and is rarely cultivated. The fruit is sometimes eaten in its green state, and also when cooked. According to Duchesne, the Egyptians prepare from the pulp an agreeable and refreshing beverage.

Plant and cultivate as directed for melons or cucumbers.

\section{GLOBE CUCUMBER.}

Concombre des prophètes. Vil. Cucumis prophetarum.

A tender annual from Arabia. Stem slender, creeping, and furnished with tendrils, or claspers. The leaves are about three inches in diameter, five-lobed, and indented on the borders; the flowers are axillary, yellow, and nearly three fourths of an inch in diameter; the fruit is round, and rarely measures an inch in thickness; skin striped with green and yellow, and thickly set with rigid hairs, or bristles; the seeds are small, oval, flattened, and of a yellowish color.

Planting and Culture. - The seeds should be planted, at the time of planting cucumbers or melons, in hills four or five feet apart, and covered about half an inch deep. Thin to two or three plants to a hill.

Use. - The fruit is sometimes eaten boiled; but is generally pickled in its green state, like the common cucumber.

As a table vegetable, it is comparatively unimportant, and not worthy of cultivation. 


\section{CALABASH, OR COMMON GOURD.}

Bottle Gourd. Cucurbita lagenaria.

The Calabash, or Common Gourd, is a climbing or creeping annual plant, frequently more than twenty feẹt in height or length. The leaves are large, round, heart-shaped, soft and velvety to the touch, and emit a peculiar, musky odor, when bruised or roughly handled. The flowers, which are produced on very long stems, are white, and nearly three inches in diameter. They expand towards evening, and remain in perfection only a few hours; as they are generally found drooping and withering on the ensuing morning. The young fruit is hairy, and quite soft and tender; but, when ripe, the surface becomes hard, smooth, and glossy. The seeds are five eighths of an inch in length, somewhat quadrangular, of a fawn-yellow color, and retain their vitality five years. About three hundred are contained in an ounce.

Cultivation. - The seeds are planted at the same time and in the same manner as those of the Squash. The Gourd succeeds best when provided with a trellis, or other support, to keep the plant from the ground ; as the fruit is best developed in a pendent or hanging position.

Use. - The fruit, while still young and tender, is sometimes pickled in vinegar, like cucumbers. At maturity the flesh is worthless : but the shells, which are hard, light, and comparatively strong, are used as substitutes for baskets; and are also formed into water-dippers, and various other articles both useful and ornamental. The varieties are as follow:-

Fruit about a foot in length, contracted at BottleGourd. the middle, largest at the blossom-end, but Vil. swollen also at the part next the stem.

There is a sub-variety, very much larger ; but it is'also later. 
Hercules Club.

Fruit very long, frequently measuring upwards of five feet in length. It is smallest towards the stem, and increases gradually in size towards the opposite extremity, which is rounded, and near which, in its largest diameter, it measures from four to five inches. Its form is quite peculiar, and is not unlike that of a massive club; whence the name.

It is frequently seen at horticultural and agricultural shows; and, though sometimes exhibited as a "cucumber," has little or no value as an esculent, and must be considered much more curious than useful. It is of a pea-green color while growing, and the skin is then quite soft and tender; but, like the other varieties, the surface becomes smooth, and the skin hard and shell-like, at maturity. Powder- $\quad$ Fruit long and slender, broadest at the base,
Horn. HOrn.
COURGE POIREA tapering towards the stem, and often more or
POUDRE. Vil.

less curved. In its general form it resembles a common horn, as implied by the name. Its usual length is twelve or fourteen inches; and its largest diameter nearly three inches.

Siphon

Fruit rounded, and flattened at the blossomGourd. Covrag Siprios. end; then suddenly contracted to a long, slender neck. The latter often bends or turns suddenly at nearly a right angle; and, in this form, the fruit resembles a siphon. Pea green while young, pale green when mature. Shell thick and hard.

\section{THE MELON.}

Of the Melon there are two species in general cultivation, - the Musk-melon (Cucumis melo) and the Water-melon 
(Cucurbita citrullus), - each, however, including many varieties. Like the Squash, they are tender, annual plants, of tropical origin, and only thrive well in a warm temperature. "The climate of the Middle and Southern States is remarkably favorable for them; indeed, far more so than that of England, France, or any of the temperate portions of Europe. Consequently, melons are raised as field crops by market-gardeners; and, in the month of August, the finest citrons or green-fleshed melons may be seen in the markets of New York and Philadelphia in immense quantities; so abundant, in most seasons, as frequently to be sold at half a dollar per basket, containing nearly a bushel of fruit. The warm, dry soils of Long Island and New Jersey are peculiarly favorable to the growth of melons; and, even at low prices, the product is so large, that this crop is one of the most profitable." - Downing.

Through the extraordinary facilities now afforded by railroads and ocean steam-navigation, the markets of all the cities and large towns of the northern portions of the United States, and even of the Canadas, are abundantly supplied within two or three days from the time of gathering: and they are retailed at prices so low, as to allow of almost universal consumption; well-ripened and delicious green-fleshed eitron-melons being often sold from six to ten cents each.

Soil and Cultivation. - Both the Musk and the Water Melon thrive best in a warm, mellow, rich, sandy loam, and in a sheltered exposure. After thoroughly stirring the soil by ploughing or spading, make the hills six or seven feet apart in each direction. Previous to planting, these hills should be prepared as directed for the Squash; making them a foot and a half or two feet in diameter, and twelve or fifteen inches in depth. Thoroughly incorporate at the bottom of the hill a quantity of well-digested compost, equal to three fourths of the earth removed; and then add sufficient 
fine loam to raise the hill two or three inches above the surrounding level. On the top of the hill thus formed, plant twelve or fifteen seeds; and, when the plants are well up, thin them out from time to time as they progress in size. Finally, when all danger from bugs and other insect depredators is past, leave but two or three of the most stocky and promising plants to a hill. When the growth is too luxuriant, many practise pinching or cutting off the leading shoots ; and, when the young fruit sets in too great numbers, a portion should be removed, both for the purpose of increasing the size and of hastening the maturity of those remaining. " Keep the fruit from being injured by lying on the ground; and if slate, blackened shingles, or any dry, dark material, be placed beneath it, by attraction of the sun's rays, the fruit will ripen earlier and better."

The striped bug (Galeruca vittata) is the most serious enemy with which the young melon-plants have to contend. Gauze vine-shields, though the most expensive, are unquestionably the most effectual preventive. Boxes either round or square, twelve or fifteen inches in depth, and entirely uncovered at the top, if placed over the hills, will be found useful in protecting the plants. The flight of the bug being generally nearly parallel with the surface of the ground, very few will find their way within the boxes, if of the depth required. Applications of guano, ashes, dilutions of oil-soap, and plaster of Paris, applied while the plants are wet, will be found of greater or less efficacy in their protection. The pungent smell of guano is said to prevent the depredation of the flea-beetle, which, in many localities, seriously injures the plants early in the season, through its attacks on the seed-leaves. 


\section{THE MUSKMELON.}

Cucumis melo.

Plant running, - varying in length from five to eight feet; leaves large, angular, heart-shaped, and rough on the upper and under surface; flowers yellow, one-petalled, fivepointed, and about an inch in diameter; seeds oval, flat, generally yellow, but sometimes nearly white, about four tenths of an inch in length, and three sixteenths of an inch in breadth, - the size, however, varying to a considerable extent in the different varieties. An ounce contains from nine hundred to eleven hundred seeds; and they retain their germinative properties from eight to ten years.

Varieties. - These are exceedingly numerous, in consequence of the great facility with which the various kinds intermix or hybridize. Varieties are, however, much more easily produced than retained; consequently, old names are almost annually discarded from the catalogues of seedsmen and gardeners, and new names, with superior recommendations, offered in their stead. The following list embraces most of the kinds of much prominence or value now cultivated either in Europe or this country:-

Fruit nearly spherical, but rather longer than Beechwood. broad, - usually five or six inches in diameter; skin greenish-yellow, thickly and regularly netted; flesh green, melting, sugary, and excellent. An early and fine variety.

A large-fruited, late variety; form variable, but generally round, and flattened at the ends;

Black-Rock Cantaloupe. size large, - ten inches in diameter, eight inches deep, and weighing eight or ten pounds. The skin varies in color from grayish-green to deep green; becomes yellow at maturity, and is thickly spread with knobby bunches, or small 
protuberances. Rind very thick ; flesh reddish-orange, melting, and sugary. It requires a long season for its full perfection.

Christiana. This variety was originated by the late Captain Josiah Lovett, of Beverly, Mass. Form roundish ; size rather small, - average specimens measuring nearly the same as the Green Citron; skin yellowish-green; flesh yellow, sweet, juicy, and of good quality. Its early maturity is its principal recommendation; the Green Citron, Nutmeg, and many other varieties, surpassing it in firmness of flesh, sweetness, and general excellence.

It would probably ripen at the North, or in short seasons, when other sorts generally fail.

Citron. Fruit nearly round, but flattened slightly at

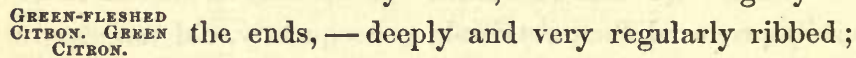
size medium, or rather small, - average specimens measuring about six inches in diameter, and five inches and a half in depth; skin green, and thickly netted, - when

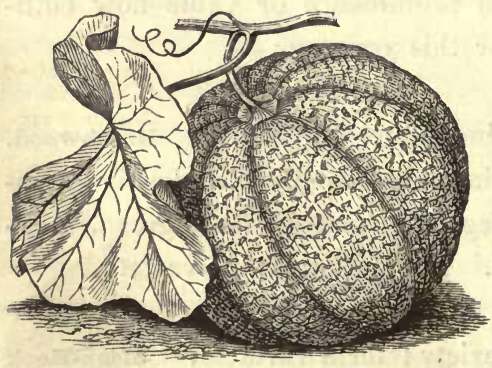

Green Citron Melon. fully mature, the green becomes more soft and mellow, or of a yellowish shade; flesh green, quite thick, very juicy, and of the richest and most sugary flavor. It is an abundant bearer, quite hardy, and remarkably uniform in its quality. It is deservedly the most popular as a market sort; and for cultivation for family use, every thing considered, has few superiors.

In common with the Carolina Watermelon, the Green 
Citron is extensively grown at the South for shipping to the northern portions of the United States; appearing in the markets of New York and Boston three or four weeks in advance of the season of those raised in the same vicinity in the open ground.

This variety possesses little merit aside from Early Cantaits very early maturity. It is a roundish melon, loupe. flattened a little at the ends, ribbed, and of comparatively small size; usually measuring about five inches in diameter. Skin yellowish, often spotted with green, and sometimes a little warty; rind quite thick; flesh reddish-orange, sweet, and of good flavor.

It is exceedingly variable in size, form, and color.

Fruit rather small, round, depressed, strongly Hardy Ridge. ribbed, and irregularly warted all over its surLoud. face; skin dull yellow, mottled with dull green; flesh an inch thick, bright orange-red, sweet, and well flavored; rind thick; weight from three to four pounds. Not an early, but a productive variety.

Fruit very oval, large, strongly ribbed; skin Large-ribbed yellow, very thickly netted, sometimes so closely common Muskas to cover nearly the entire surface; flesh salMELON. mon-yellow, remarkably thick and sweet, but not fine-grained or melting, when compared with the more recent and improved varieties.

Hardy and productive. In good soil and favorable seasons, the fruit some-

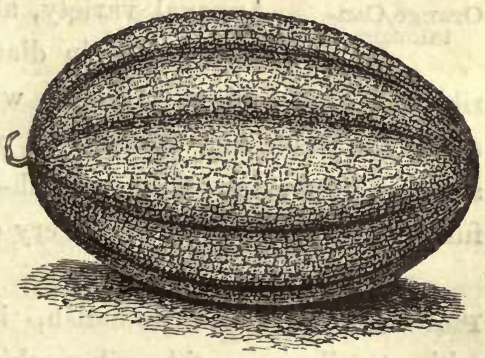

Large Netted Muskmelon. 
times attains a length of fifteen inches, and weighs upwards of twenty pounds.

Monroe's A comparatively new variety. The fruit is Green Filesh.

nearly spherical, but tapers slightly towards the stem, and is rather regularly as well as distinctly ribbed. Its diameter is about five inches. Cicatrix large; skin greenish-yellow, thickly and finely netted over the entire surface; rind thin; flesh green, remarkably transparent, comparatively thick, very melting, and highly perfumed.

Nutmeg. Fruit oval, regularly ribbed, eight or nine inches in length, and about six inches in its broadest diam-

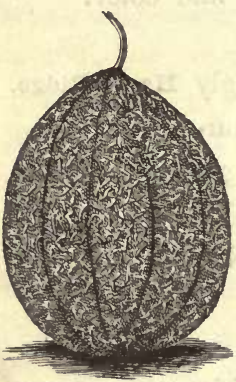

Nutmeg Melon. eter; skin pale green, and thickly netted; rind thin; flesh light green, rich, sweet, melting, and highly perfumed.

The Nutmeg Melon has been long in cultivation, and is almost every where to be found in the vegetable garden, though seldom in a perfectly unmixed state. When the variety is pure, and the fruit perfectly ripened, it is of most delicious excellence, and deservedly ranked as one of "the best."

Orange Can- An oval variety, about six inches in length taloupe.

by five inches in diameter, rather prominently ribbed. Skin yellow, marbled with green, thickly netted about the stem, and sparsely so over the remainder of the surface ; rind thick; flesh reddish-orange, sweet, highly perfumed, and of good flavor. Very early and productive.

Pine-Apple. Form roundish, inclining to oval, either without ribs or with rib-marking faintly defined; size 
small, - the average diameter being about five inches and a lalf; skin olive-green, with net-marketings more or less abundant; rind thin; flesh green melting, sweet, and perfumed. Season early.

It is an excellent sort, easily grown, and very productive.

Fruit generally somewhat flattened, but vari- Prescott Canable in form, deeply ribbed; size large, - welltaloupe. Vil. grown specimens measuring eight or ten inches in diameter, and weighing from seven to nine pounds; skin thickly covered with small tubercles; color varying from grayish-green to clear green, more or less deep, changing to yellow at maturity; rind very thick; flesh orauge-red, sugary and melting, and of delicious flavor.

There are numerous sub-varieties, as grown by different gardeners, varying somewhat in form, color, and time of maturity; all, however, corresponding nearly with the above description, though known by different names, as the "White," "Gray," "Black," "Prescott," \&c. Much esteemed in France, and extensively grown by market-gardeners in the vicinity of Paris.

This variety much resembles the Pine-apple. Form rounded, flattened slightly at the ends; Skillman's Fine-netted. flesh green, sugary, melting, and excellent. It has been pronounced "the earliest of the green-fleshed sorts."

A recently introduced variety of English origin. Fruit egg-shaped, faintly ribbed, rounded Victory of
Bath. at the blossom-end, and slightly contracted towards the stem, - at the insertion of which, it is flattened to a small, plane surface; size medium, - about six inches deep, and five inches in diameter; skin green, clouded with yellow, and sparsely covered with fine net-markings; skin thin; flesh green. 
White Japan. A recently introduced, roundish, mediumsized, or rather small variety; skin cream-white and very

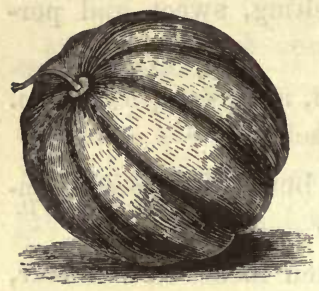

White Japan Melon. thin; flesh thick, remarkably sweet and fine flavored, - if the fruit is well matured, almost rivalling that of the Green Citron. It ripens early, and is quite productive.

Of the numerous new sorts that have been offered to the public within the past two or three years, this appears to be one of the most desirable.

\section{PERSIAN MELONS. Trans.}

These differ remarkably from the varieties commonly cultivated. They are destitute of the thick, hard rind which characterizes the common sorts, and which renders so large a portion of the fruit useless. On the contrary, the Persian melons are protected by a skin so thin and delicate, that they are subject to injury from causes that would produce no perceptible effect on the sorts in general cultivation. As a class, they are not only prolific, but their flesh is extremely tender, rich, and sweet, and flows copiously with a cool juice, which renders them still more grateful. They are, however, not early; and, for their complete perfection, require a long and warm season.

\section{Varieties : -}

Dampsha.

Flesh dark green near the skin, rather whitish towards the centre, quite melting, and of excellent flavor. The first-produced fruit in the season is somewhat cylindrical, bluntly pointed at both ends; the whole surface being prominently netted, and of a pale yellow or 
dark olive color. The secondary crop has the fruit more pointed and less netted, and the skin becomes much darker. Like the other varieties of winter melons, it may be preserved a long time after being taken from the vines, if suspended in a dry room. Weight four to five pounds.

This resembles the Geree Melon in color, as Daree. Trans. well as in many other respects. It is of the same form; but the rind, when netted, exhibits coarser reticulations. The flesh is white, thick, crisp, and melting; when fully ripened, very sweet, but rather insipid if imperfectly matured. It is always, however, cool and pleasant.

A handsome green fruit. In shape, it is Geree. Trans. oval, or ovate; and measures eight inches in length by four inches and a half in breadth. The skin is closely mottled with dark sea green upon a pale ground, and is either netted or not. In the former case, the meshes are very close; by which character, it may be readily distinguished from the Daree. Stalk very short; flesh an inch and a half or two inches thick, bright green, melting, very sweet, and highly flavored. Though perhaps equally rich, it is not so beautiful or so juicy as the Melon of Keiseng. A good bearer, but requires a warm, long season.

A handsome large-sized, ribbed fruit, shaped Germek. like a compressed sphere; usually six inches in LAвав Gвкавк. length, and from seven to nine inches in diameter. Skin deep green, closely netted; flesh from an inch and a half to two inches thick, clear green, firm, juicy, and high flavored. This is an excellent variety, an abundant bearer, ripens early, and exceeds in size any of the Persian melons.

A handsome egg-shaped fruit, five inches long Green Hoo- 
by four inches broad; when unripe, of a very deep green; but, in maturity, acquiring a fine, even, light green, regularly netted surface, which, on the exposed side, becomes rather yellow. The flesh is pale greenish-white, tender and delicate, full of a highly perfumed, pleasant, sweet juice; the rind is very thin; the seeds are unusually large.

It is a variety of much excellence, a great bearer, and one of the hardiest of the Persian melons.

Green Valen- A winter sort. Although not rich in flavor, cia. McInt. it is firm, saccharine, and juicy; and upou the whole, if fully ripened, a more desirable melon than many of the summer varieties.

Ispahan. This has been pronounced "the most deliTrans.
SwEEx IsPAHAN. cious of all melons." The fruit is egg-shaped, varying in length from eight to twelve inches, and weighing from six to eight pounds; skin nearly smooth, of a deep sulphur-yellow; flesh nearly white, extending about half way to its centre, crisp, sugary, and very rich.

It is a variety of much excellence, but is fully perfected only in favorable seasons.

Melon of Keiseng. Loud.

A beautiful egg-shaped fruit, eight inches long, five inches wide in the middle, six inches wide at the lower extremity; very regularly and handsomely formed. Color pale lemon-yellow; flesh from an inch and a half to two inches and a quarter thick, nearly white, flowing copiously with juice, extremely delicate, sweet, and high flavored, very similar in texture to a well-ripened Beurré pear; rind thin, but so firm that all the fleshy part of the fruit may be eaten.

It differs from the Sweet Ispahan in being closely netted. 
A fruit of regular figure and handsome appearance, seven inches long by five inches wide.

Melon of Seen.

Shape ovate, with a small mamelon at the apex; surface pale dusky yellow, regularly and closely netted, except the mamelon, which is but little marked; rind very thin; flesh from an inch and a half to two inches thick, pale green, sometimes becoming reddish towards the inside, exceedingly tender and juicy; juice sweet, and delicately perfumed. A good bearer, but requires a long season. Named from Seen, a village near Ispahan; where the variety was procured.

This ripens about a week earlier than the Small GerLarge Germek, but is not so valuable a fruit. mek. Trans. In form it is a depressed sphere, with about eight rounded ribs. It measures four inches in depth by four inches and a half in width. The skin is even, yellowish, with a little green about the interstices, obscurely netted; the flesh is green, inclining to reddish in the inside, an inch and a half thick, juicy, and high flavored; skin very thin. The pulp in which the seeds are immersed is reddish. It is not a great bearer, and the vines are tender.

Fruit oval and much netted, dark green in striped Hoobroad stripes, with narrow intervals of dull samee. Trans. white, which become faintly yellow as the fruit ripens; pulp externally green, but more internally pale red, excessively juicy, and more perfectly melting than that of the famous Ispahan Melon.

It is sweeter and higher flavored than any other Persian variety, but requires a long, warm season for its full perfection. 


\section{THE WATERMELON.}

Cucurbita citrullus.

Plant running, - the length varying from eight to twelve feet; leaves bluish-green, five-lobed, the lobes rounded at the ends; flowers pale yellow, about an inch in diameter; fruit large, roundish or oblong, green, or variegated with different shades of green; seeds oval, flattened, half an inch long, five sixteenths of an inch broad, - the color varying according to the variety, being either red, white, black, yellowish or grayish brown. An ounce contains from a hundred and seventy-five to two hundred seeds, and they retain their vitality eight years.

The Watermelon is more vigorous in its habit than the Muskmelon, and requires more space in cultivation; the hills being usually made eight feet apart in each direction. It is less liable to injury from insects, and the crop is consequently much more certain. The seed should not be planted till May, or before established warm weather; and but two good plants allowed to a hill.

The varieties are as follow:-

Apple-

A rather small, nearly round sort, deriving its name from its small, peculiar seeds, which, in form, size, and color, are somewhat similar to those of the apple. Skin deep, clear green; rind very thin; flesh bright red to the centre, sweet, tender, and well-flavored. It is hardy, bears abundantly, seldom fails to ripen perfectly in the shortest seasons, and keeps a long time after being gathered.

Black

Spanish.

SPANISH.

Fruit of large size, roundish or oblong, generally more or less distinctly ribbed; skin very dark or blackish green; rind half an inch thick; flesh deep 


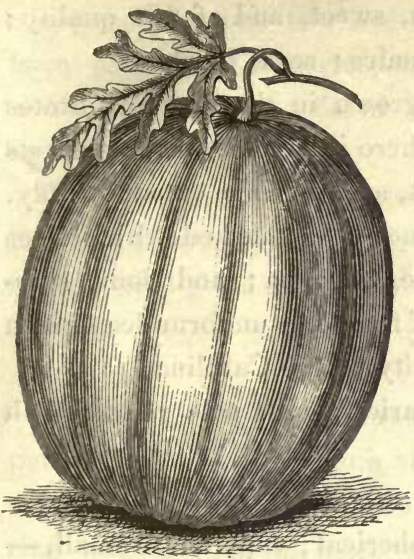

Black Spanish Water-melon.

red (contrasting finely with the deep green color of the skin), fine-grained, sugary, and of excellent flavor. 'The variety is hardy, productive, thrives well, matures its fruit in the Northern and Eastern States, and is decidedly one of the best for general cultivation. Seeds dark brown, or nearly black.

The Bradford Bradford. is a highly prized, W.D. Brinckle.

South Carolina variety ; size large ; form oblong; skin dark green, with gray, longitudinal stripes, mottled and reticulated with green; rind not exceeding half an inch in thickness; seed yellowish-white, slightly mottled, and with a yellowishbrown stripe around the edge; flesh fine red to the centre; flavor fine and sugary ; quality "best."

Fruit of large size, and of an oblong form, Carolina.

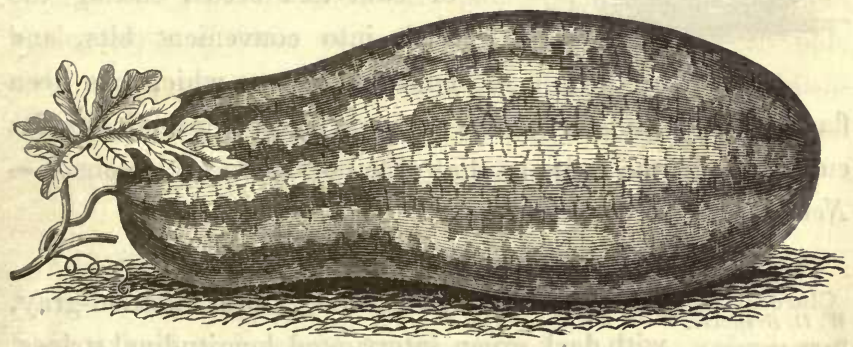

Carolina Water-melon.

usually somewhat swollen towards the blossom-end; skin deep green, variegated with pale green or white; flesh deep 
red, not fine-grained, but crisp, sweet, and of fair quality; fruit frequently hollow at the centre; seeds black.

This variety is extensively grown in the Southern States for exportation to the North, where it appears in the markets about the beginning of August, and to some extent in July. Many of the specimens are much less marked with stripes and variegations than the true Carolina; and some shipments consist almost entirely of fruit of a uniform deep green color, but of the form and quality of the Carolina.

Downing mentions a sub-variety with pale yellow flesh and white seeds.

Citron Water- Form nearly spherical; size rather small, melon.

average specimens measuring six or seven inches in diameter; color pale green, marbled with darker shades of green; flesh white, solid, tough, seedy, and very

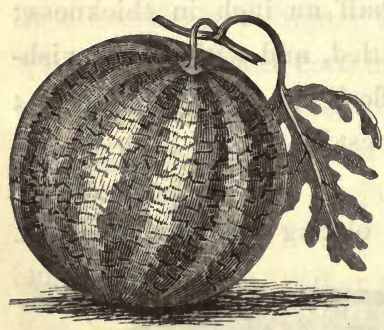

Citron Watermelon. squashy and unpalatable in its crude state. It ripens late in the season, and will keep until December. "It is employed in the making of sweetmeats and preserves, by removing the rind or skin and seeds, cutting the flesh into convenient bits, and boiling in sirup which has been flavored with ginger, lemon, or some agreeable article. Its cultivation is the same as that of other kinds of melons." New American Cyclopoedia.

Clarendon. Size large ; form oblong; skin mottled-gray, W. D. Brinckle.
DARK-SPECKLED. with dark green, interrupted, longitudinal stripes, irregular in their outline, and composed of a succession of peninsulas and isthmuses; rind thin, not exceeding half an inch; seed yellow, with a black stripe extending round the 
edge, and from one to three black spots on each side, - the form and number corresponding on the two sides; flesh scarlet to the centre; flavor sugary and exquisite, and quality "best."

This fine melon originated in Clarendon county, South Carolina; and, when pure, may at all times be readily recognized by the peculiarly characteristic markings of the seeds.

A large, pale green sort; when unmixed, Ice-Creas. readily distinguishable from all other varieties. Form nearly round, but sometimes a little depressed at the extremities; rind thicker than in most varieties: flesh white, sweet and tender, and of remarkably fine flavor; seeds white.

It is prolific, and also early; and is remarkably well adapted for cultivation in cold localities, or where the seasons are too short for the successful culture of the more tender and late kinds. Its pale green skin, white flesh, and white seeds, are its prominent distinctive peculiarities.

This variety is said to have been introduced Imperial. from the Mediterranean. Fruit round, or obDown. late, and of medium size; skin pale green, with stripes and variegations of white or paler green; rind thin; flesh pale red, crisp, sweet, and of excellent flavor; seeds reddishbrown. Very productive, but requires a warm situation and a long season for its complete perfection.

This variety is similar to the Mountain Sweet. Mountain It is of large size, long, and of an oval form. Sprout. Skin striped and marbled with paler and deeper shades of green; rind thin, - measuring scarcely half an inch in thickness; flesh scarlet, a little hollow at the centre, crisp, sugary, and of excellent flavor. 
Like the Mountain Sweet, it is a favorite market sort. It is not only of fine quality, but very productive. Seeds russet-brown.

Mountain

Sweet.
A large, long, oval variety, often contracted towards the stem in the form of : $s$ neck; skin striped and marbled with different shades of green; rind

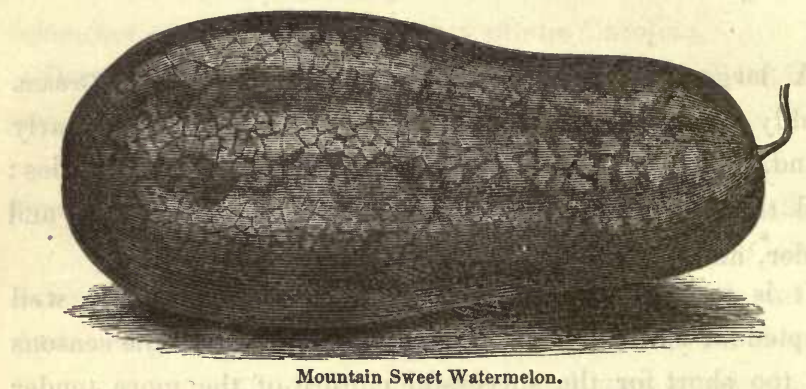

rather thin, measuring scarcely half an inch in thickness; flesh scarlet, and solid quite to the centre; seeds pale russetbrown, but often of greater depth of color in perfectly matured specimens of fruit.

A popular and extensively cultivated variety, quite hardy, productive, and of good quality. "For many years it was universally conceded to be the best market sort cultivated in the Middle States, but of late has lost some of the properties that recommended it so highly to favor. This deteriorat:on has probably been owing to the influence of pollen from inferior kinds grown in its vicinity."

Odell's Large A remarkably large variety, the fruit someWhite. W.D. Brinckle. times weighing sixty pounds; form round; skin gray, with fine green network spread over its uneven surface; rind nearly three fourths of an inch in thickness; seeds large, grayish-black, and not numerous; flesh pale 
red; flavor fine; quality very good. Productiveness said to exceed that of most other kinds.

This remarkably large melon originated with a negro man on the property of Colonel A. G. Sumner, of South Carolina. Its large size, and long keeping quality after being separated from the vine, will recommend the variety, especially for the market.

Form oval, of medium size; skin pale green, Orange. marbled with shades of deeper green; rind half an inch in depth, or of medium thickness; flesh red, not fine-grained, but tender, sweet, and of good quality. When in its mature state, the rind separates readily from the flesh, in the manner of the peel from the flesh of an orange.

When first introduced, the variety was considered one of the best quality; but it appears to have in some degree deteriorated, and now compares unfavorably with many other sorts.

Plant running, - the foliage and general habit Pie-Melon. resembling the Common Watermelon, but yet $\begin{gathered}\text { California } \\ \text { MELON. }\end{gathered}$ distinguishable by its larger size, more hairy stem, and its more stocky and vigorous character; fruit oblong, very large, often sixteen inches and upwards in length, and from eight to ten inches in diameter; skin yellowish-green, marbled with different shades of light green or pea green ; flesh white, succulent, somewhat tender, but quite unpalatable, or with a squash-like flavor, in its crude state. As intimated by the name, it is used only for culinary purposes.

This melon should be cooked as follows : After removing the rind, cut the flesh into pieces of convenient size, and stew until soft and pulpy. Lemon-juice, sugar, and spices should then be added; after which, proceed in the usual manner of making pies from the apple or any other fruit. 
If kept from freezing, or from dampness and extreme cold, the Pie-melon may be preserved until March.

Ravenscroft. Size large; form oblong; skin dark green, W. D. Brinckle. faintly striped and marked with green of a lighter shade, and divided longitudinally by sutures from an inch and a quarter to two inches apart; rind not more than half an inch in thickness; seed cream-color, tipped with brown at the eye, and having a brown stripe around the edge; flesh fine red, commencing abruptly at the rind, and extending to the centre; flavor delicious and sugary; quality "best."

This valuable watermelon originated with Colonel A. G. Sumner, of South Carolina.

Souter.
W. Drinckle. Size large, sometimes weighing twenty or thirty pounds ; form oblong, occasionally roundish; skin peculiarly marked with finely reticulated, isolated gray spots, surrounded by paler green, and having irregular, dark green, longitudinal stripes extending from the base to the apex; rind thin, about half an inch thick; seed pure cream-white, with a faint russet stripe around the edge; flesh deep red to the centre; flavor sugary and delicious; quality "best." Productiveness said to be unusually great. This excellent variety originated in Sumter District, South Carolina.

\section{PAPANJAY, OR SPONGE CUCUMBER.}

Cucumis acutangulus.

This is an East Indian plant, with a creeping stem, and angular, heart-shaped leaves. The flowers (several of which are produced on one stem) are yellow; the fruit is ten or twelve inches in length, about an inch and a half in diameter, 
deeply furrowed or grooved in the direction of its length, forming ten longitudinal, acute angles; the skin is hard, and of a russet-yellow color; the seeds, five hundred of which are contained in an ounce, are black, hard, and rough, and quite irregular in form.

Use. - The fruit is eaten while it is quite young and small, served in the manner of cucumbers, or like vegetable marrow. When fully ripened it is exceedingly tough, fibrous, and porous, and is sometimes used as a substitute for sponge ; whence the name.

\section{PRICKLY-FRUITED GHERKIN.}

Gherkin. West Indian Cucumber. Jamaica Cucumber. Cucumis anguria.

This species is said to be a native of Jamaica. The habit of the plant is similar to that of the Globe Cucumber, and its season of maturity is nearly the same. The surface of the fruit is thickly set with spiny nipples, and has an appearance very unlike that of the Common Cucumber. It is comparatively of small size, and of a regular, oval form, generally measuring about two inches in length by an inch and a third in its largest diameter ; color pale green ; flesh greenish-white, very seedy and pulpy. The seeds are quite small, oval, flattened, yellowish-white, and retain their vitality five years.

It is somewhat later than the Common Cucumber, and requires nearly the whole season for its full development. Plant in lills about five feet apart; cover the seeds scarcely half an inch deep, and leave three plants to a hill.

The Prickly-fruited Gherkin is seldom served at table sliced in its crude state. It is principally grown for pickling; for which purpose it should be plucked when about half grown, or while the skin is tender, and can be easily broken 
by the nail. As the season of maturity approaches, the rind gradually hardens, and the fruit becomes worthless., In all stages of its growth, the flesh is comparatively spongy; and, in the process of pickling, absorbs a large quantity of vinegar.

\section{THE PUMPKIN.}

Cucurbita pepo.

Under this head, on the authority of the late Dr. T. W. Harris, should properly be included "the common New England field-pumpkin, the bell-shaped and crook-necked winter squashes, the Canada crook-necked, the custard squashes, and various others, all of which (whether rightly or not, cannot now be determined) have been generally referred by botanists to the Cucurbita pepo of Linnæus."

The term "pumpkin," as generally used in this country by writers on gardening and agriculture, and as popularly understood, includes only the few varieties of the Common New England Pumpkin that have been long grown in fields in an extensive but somewhat neglectful manner; the usual practice being to plant a seed or two at certain intervals in fields of corn or potatoes, and afterwards to leave the growing vines to the care of themselves. Even under these circumstances, a ton is frequently harvested from a single acre, in addition to a heavy crop of corn or potatoes.

The Pumpkin was formerly much used in domestic economy; but, since the introduction of the Crook-necks, Boston Marrow, Hubbard, and other improved varieties of squashes, it has gradually fallen into disuse, and is now cultivated principally for agricultural purposes.

Varieties. - The following are the principal varieties, although numerous intermediate sorts occur, more or less distinct, as well as more or less permanent in character :- 
The Canada Pumpkin is of an oblate form, Canada inclining to conic, and is deeply and regularly $\underset{\text { Vumporr Puxp- }}{\text { Pump. }}$ ribbed. When well grown, it is of comparaBIN. tively large size, and measures thirteen or fourteen inches in diameter, and about ten inches in depth. Color fine, deep orange-yellow; skin or shell rather thick and hard; flesh yellow, fine-grained, sweet, and well flavored. Hardy and productive.

Compared with the common field variety, the Canada is much more flattened in its form, more regularly and deeply ribbed, of a deeper and richer color; and the flesh is generally much sweeter, and less coarse and stringy in its texture. It seems adapted to every description of soil ; thrives well in all climates; and is one of the best sorts for agricultural purposes, as well as of good quality for the table.

The plants of this variety are remarkably strong and vigorous, with large, deep green Cheese
Pumpkin. leaves. The fruit is much flattened, deeply and rather regularly ribbed, broadly dishing about the stem, and basin-like at the opposite extremity. It is of large size; and, when well grown, often measures fifteen or sixteen inches in diameter, and nine or ten inches in depth. Skin fine, deep reddish-orange, and, if the fruit is perfectly matured, quite hard and shell-like; flesh very thick, yellow, fine-grained, sweet, and well flavored. The seeds are not distinguishable from those of the Common Field Pumpkin.

The Cheese Pumpkin is hardy, remarkably productive, and much superior in all respects to most of the field-grown sorts. Whether the variety originated in this country, cannot probably now be determined; but it was extensively disseminated in the Middle States at the time of the American revolution, and was introduced into certain parts of New England by the soldiers on their return from service. After 
a lapse of more than serenty-five years, - during which time it must have experienced great diversity of treatment and culture, - it still can be found in its original type; having the same form, color, size, and the same thickness and quality of flesh, which it possessed at the time of its introduction.

Common Yellow Field

Pumpkin.

Plant of vigorous, stocky habit, extending rounded, usually a little more deep than broad, flattened at the ends, and rather regularly, and more or less prominently, ribbed. Its size is much affected by soil, season, and

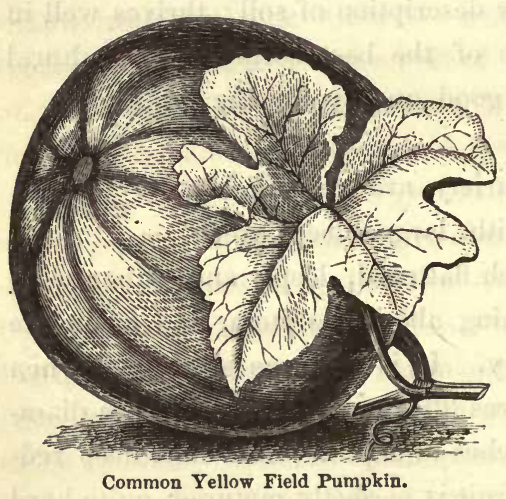
the purity of the seed. Average specimens will measure about fourteen inches in length, and eleven or twelve inches in diameter. Color rich, clear orange - yellow ; skin, or rind, if the fruit is well matured, rather dense and hard; flesh, variable in thickness, but averaging about an inch and a half, of a yellow color, generally coarse-grained, and often stringy, but sometimes of fine texture, dry, and of good quality; seeds of medium size, cream-yellow.

The cultivation of the Common Yellow Field Pumpkin in this country is almost coeval with its settlement. For a long period, few, if any, of the numerous varieties of squashes, now so generally disseminated, were known; and the Pumpkin was not only extensively employed as a material for pies, but was much used as a vegetable, in the form of squash, at the table. During the struggle for national independence, 
when the excessively high prices of sugars and molasses prevented their general use, it was the practice to reduce by evaporation the liquid in which the pumpkin had been cooked, and to use the saccharine matter thus obtained as a substitute for the more costly but much more palatable sweetening ingredients. When served at table in the form of a vegetable, a well-ripened, fine-grained pumpkin was selected, divided either lengthwise or crosswise ; the seeds extracted; the loose, stringy matter removed from the inner surface of the flesh ; and the two sections, thus prepared, were baked, till soft, in a common oven. The flesh was then scooped from the shell, pressed, seasoned, and served in the usual form. By many it is still highly esteemed, and even preferred for pies to the squash, or the more improved varieties of pumpkins; but its cultivation at present is rather for agricultural than for culinary purposes.

A large, yellow, field variety, not unlike the Common Yellow in form, but with a softer Connecticut Field Pumpkin. skin, or shell. It is prolific, of fair quality as an esculent, and one of the best for cultivating for stock or for agricultural purposes.

Plant hardy and vigorous, not distinguishable Long Yellow from that of the Common Yellow variety; fruit Field Pun. oval, much elongated, the length usually about twice the diameter ; size large, - well-grown specimens measuring sixteen to twenty inches in length, and nine or ten inches in diameter; surface somewhat ribbed, but with the markings less distinct than those of the Common Yellow ; color bright orange-yellow; skin of moderate thickness, generally easily broken by the nail ; flesh about an inch and a half in thickness, yellow, of good but not fine quality, usually sweet, but watery, and of no great value for the table. 
It yields abundantly; is well adapted for planting among corn or potatoes; may be profitably raised for feeding out to stock; keeps well when properly stored; and selected specimens will afford a tolerable substitute for the squash in the kitchen, particularly for pies.

Between this and the Common Yellow there are various intermediate sorts; and, as they readily hybridize with each other, it is with difficulty that these varieties can be preserved in a pure state. Only one of the sorts should be cultivated, unless there is sufficient territory to enable the cultivator to allow a large distance between the fields where the different varieties are grown.

Nantucket. Form flattened or depressed, but sometimes "NARD-GEELL. medium or rather small; color deep green, somewhat mellowed by exposure to the sun, or at full maturity; skin or shell thick and hard, and more or less thickly covered with prominent, wart-like excrescences ; flesh comparatively thick, yellow, sweet, fine-grained, and of excellent flavor, - comparing favorably in all respects with that of the Sugar Pumpkin. It is a productive sort, and its flesh much drier and more sugary than the peculiar, green, and warty appearance of the fruit would indicate.

When cooked, it should be divided into pieces of convenient size; the seeds, and loose, stringy parts removed from the inner surface of the flesh, and then boiled or baked in the skin or shell; afterwards scooping out the flesh, as is practised with the Hubbard Squash, or other hard-shelled varieties of pumpkins. It is an excellent pie-variety, and selected specimens will be found of good quality when served as squash at the table. Season from February to March.

Striped Field Habit of the plant, and form of the fruit,
Pumpkin. 
similar to the Common Yellow Field Pumpkin. The size, however, will average less; although specimens may sometimes be procured as large as the dimension given for the Common Yellow. Color yellow, striped and variegated with green, - after being gathered, the green becomes gradually softer and paler, and the yellow deeper; flesh yellow, moderately thick, and, though by some considered of superior quality, has not the fine, dry, and well-flavored character essential for table use ; seeds similar to the foregoing sorts.

The Striped Field Pumpkin is a hardy sort, and yields well. It is, however, exceedingly liable to hybridize with all the varieties of the family, and is with difficulty preserved in an unmixed condition.

Plant similar in its character and general appearance to the Common Field Pumpkin; fruit small, eight or nine inches at its broadest diam-

SugarPumpkin.

Small SugarPUMPKIN. eter, and about six inches in depth; form much depressed, usually broadest near the middle, and more or less distinctly ribbed; skin bright orange-yellow when the fruit is well ripened, hard, and shell-like, and not easily broken by the nail ; stem quite long, greenish, furrowed, and somewhat reticulated ; flesh of good thickness, light yellow, fine-grained, sweet, and well flavored; seeds of smaller size than, but in other respects similar to, those of the Field Pumpkin.

The variety is the smallest of the sorts usually employed for field cultivation. It is, however, a most

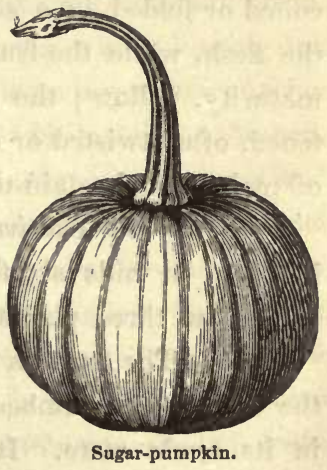
abundant bearer, rarely fails in maturing its crops perfectly, is of first-rate quality, and may be justly styled an acquisition. For pies, it is not surpassed by any of the family; 
and it is superior for table use to many of the garden squashes. The facility with which it hybridizes or mixes with other kinds renders it extremely difficult to keep the variety pure; the tendency being to increase in size, to grow longer or deeper, and to become warty; either of which conditions may be considered an infallible evidence of deterioration.

Varieties sometimes occur more or less marbled and spotted with green; the green, however, often changing to yellow after harvesting.

\section{SNAKE OR SERPENT CUCUMBER.}

Cucumis flexuosus.

Though generally considered as a species of cucumber, this plant should properly be classed with the melons. In its manner of growth, foliage, flowering, and in the odor and taste of the ripened fruit, it strongly resembles the muskmelon. The fruit is slender and flexuous; frequently measures more than three feet in length; and is often gracefully coiled or folded in a serpent-like form. The skin is green; the flesh, while the fruit is forming, is greenish-white, - at maturity, yellow; the seeds are yellowish-white, oval, flattened, often twisted or contorted like those of some varieties of melons, and retain their vitality five years.

Planting and Cultivation. - The seeds should be planted in May, in hills six feet apart. Cover half an inch deep, and allow three plants to a hill.

Use. - The fruit is sometimes pickled in the manner of the Common Cucumber, but is seldom served at table sliced in its crude state. It is generally cultivated on account of its serpent-like form, rather than for its value as an esculent.

Well-grown specimens are quite attractive; and, as curi- 
ous vegetable productions, contribute to the interest and variety of horticultural exhibitions.

\section{THE SQUASH.}

All the varieties are tender annuals, and of tropical origin. They only thrive well in a warm temperature; and the seed should not be sown in spring until all danger from frost is past, and the ground is warm and thoroughly settled; as, aside from the tender nature of the plant, the seed is extremely liable to rot in the ground in continued damp and cold weather.

Any good, well-enriched soil is adapted to the growth of the Squash. The hills should be made from eight to ten inches in depth, two feet in diameter, and then filled within three or four inches of the surface with well-digested compost; afterwards adding sufficient fine loam to raise the hill an inch or two above the surrounding level. On this plant twelve or fifteen seeds, covering about three fourths of an inch deep. Keep the earth about the plants loose and clean, and from time to time remove the surplus vines, leaving the most stocky and vigorous. Three plants are sufficient for a hill; to which number the hills should ultimately be thinned, making the final thinning when all danger from bugs and other vermin is past. The dwarfs may be planted four feet apart; but the running sorts should not be less than six or eight. The custom of cutting or nipping off the leading shoot of the running varieties is now practised to some extent, with the impression that it both facilitates the formation of fruitful laterals and the early maturing of the fruit. Whether the amount of product is increased by the process, is not yet determined.

In giving the following descriptions, no attempt has been 
made to present them under scientific divisions; but they have been arranged as they are in this country popularly understood :-

\section{Summer Varieties. -}

Apple

Plant running, not of stocky habit, but Squash.
EARLY APPLE. healthy and vigorous ; fruit obtusely conical, three inches broad at the stem, and two inches and a half in depth; skin yellowish-white, thin and tender while the fruit is young, hard and shell-like when ripe; flesh dry and well flavored in its green state, and often of good quality at full maturity.

The fruit is comparatively small; and on this account the variety is very little cultivated.

Bush Summer Warted Crookneck.

EARLY SUMMER

CROOKNECK.

YELLOW SUM-

MER WARTED

CrOOKNECK.

Cucurbita VerRUCOSA.

Plant dwarfish or bushy in habit, generally about two feet and a half in height or length; fruit largest at the blossom-end, and tapering gradually to a neck, which is solid, and more or less curved; size medium, - average specimens, when suitable for use, measuring about eight inches in length, and three inches in diameter at the broadest part; the neck is usually about two inches in thickness ; color clear, brightyellow; skin very warty, thin, and easily broken by the nail while the fruit is young, and suitable for use, - as the season of maturity approaches, the rind gradually becomes firmer, and, when fully ripe, is hard and shell-like; flesh greenish-yellow, dry, and well flavored; seeds comparatively small, broad in proportion to the length, and of a pale yellow color. About four hundred are contained in an ounce.

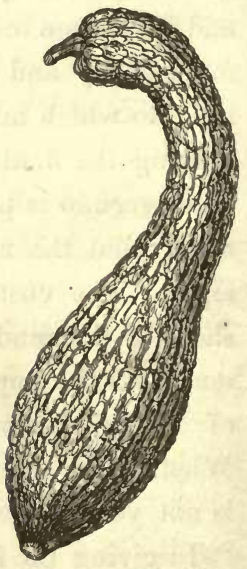

Bush Summer Warted Crookneck Squash. 
The Bush Summer Crookneck is generally esteemed the finest of the summer varieties, but is used only while young and tender, or when the skin can be easily pierced or broken by the nail. After the fruit hardens, the flesh becomes watery, coarse, strong-flavored, and unfit for table use.

On account of the dwarfish character of the plants, the hills may be made four feet apart. Three plants will be sufficient for a hill. This is a sub-variety of the Early Yellow Early White Scalloped. The plant has the same dwarf habit, and the fruit is nearly of the same size and form. The principal distinction between loped. Wirte PattrPAN. CYMLING. WHITE SUMMER SCALLOPED. the varieties consists in the difference of color.

By some the white variety is considered a little inferior in fineness of texture and in flavor to the yellow; though the white is much the more abundant in the markets. Both of the varieties are hardy and productive; and there is but little difference in the season of their maturity.

In the month of June, large quantities are shipped from the Southern and Middle States to the North and East, where they anticipate from two to three weeks the products of the home-market gardens ; the facilities afforded by steam transportation rendering nearly profitless the efforts of gardeners to obtain an early crop. As the variety keeps well, and suffers little from transportation, the squashes are generally found fresh and in good order on their arrival.

Plant dwarf, of rather erect habit, and about Early Yellow two feet and a half in height; leaves large, clear green ; fruit somewhat of a hemispherical form, expanded at the edge, which is deeply Bush Scalloped.

CrMLING. YELLOW PATYPAN
YELDY SUMMER SCALLOP. and very regularly scalloped. When suitable for use, it measures about five inches in diameter, and three inches in 


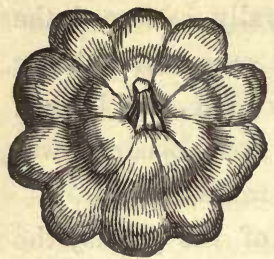

Early Yellow Bush Scalloped.

depth; but, when fully matured, the diameter is often ten or twelve inches, and even upwards. Color yellow; skin, while young, thin, and easily pierced, at maturity, hard and shell-like; flesh pale yellow, tolerably fine-grained, and well flavored, - not, however, quite so dry and sweet as that of the Summer Crookneck; seeds broader in proportion to their length than the seeds of most varieties, and of comparatively small size. Four hundred and twenty-five weigh an ounce.

This variety has been common to the gardens of this country for upwards of a century, during which period the form and general character have been very slightly, if at all, changed. When grown in the vicinity of the Bush Summer Crookneck, the surface sometimes exhibits the same wart-like excrescences; but there is little difficulty in procuring seeds that will prove true to the description above given.

Like the Summer Crookneck, the scalloped squashes are used while young or in a green state. After the hardening of the skin, or shell, the flesh generally becomes coarse, watery, strong-flavored, and unfit for the table.

The hills should be made about four feet apart, and three plants allowed to a hill. Season from the beginning of July to the middle or last of August.

Egg Squash. CUCURBITA OVIFERA.

An ornamental variety, generally cultivated for its peculiar, egg-like fruit, which usually measures about three inches in length, and two inches or two and a half in diameter. Skin, or shell, white. It is seldom used as an esculent; though, in its young state, the flesh is quite sirnilar in flavor and texture to that of the scalloped varieties. "If trained to a trellis, or when allowed to cover a dry brauching tree, it is quite orna- 
mental, and, in its ripened state, is quite interesting, and attractive at public exhibitions." Increase of size indicates mixture or deterioration.

"It has been generally supposed, that the Egg-squash was a native of Astrachan, in Tartary. Dr. Loroche included it in a list of plants not natives of Astrachan, but cultivated only in gardens where it is associated with such exotics as Indian corn, or maize, with which it was probably introduced directly or indirectly from America. We also learn from Loroche that this species varied in form, being sometimes pear-shaped; that it was sometimes variegated in color with green and white, and the shell served instead of boxes. Here we have plainly indicated the little gourd-like, hardshelled, and variegated squashes that are often cultivated as ornamental plants.

"From these and similar authorities it is evident that summer squashes were originally natives of America, where so many of them were found in use by the Indians when the country began to be settled by Europeans." - Dr. T. W. Harris, in Pennsylvania Farm Journal.

Fruit similar in size and form to the Yel- Green Bush low or White Bush Scalloped; skin or shell Scalloped. bottle green, marbled or clouded with shades of lighter green. It is comparatively of poor quality, and is little cultivated.

"Plant dwarf, but of strong and vigorous Green-Striped habit; fruit of small size, bell-shaped; colors Bergen. dark green and white, striped.

"An early but not productive sort, little cultivated at the North or East, but grown to a considerable extent for the New York market. It is eaten both while green and when fully ripe." 
Large Summer Warted Crookneck.

A large variety of the Bush or Dwarf Summer Crookneck. Plant twelve feet and upwards in length, running; fruit of the form of the last named, but of much greater proportions, - sometimes attaining a length of nearly two feet; skin clear, bright yellow, and thickly covered with the prominent wart-like excrescences peculiar to the varieties; flesh greenish yellow, and of coarser texture than that of the Dwarf Summer Crookneck. Hardy and very productive. The hills should be made six feet apart.

Orange.

Cucurbita AuRANTIACA.
Fruit of the size, form, and color of an orange. Though generally cultivated for ornament, and considered more curious than useful, "some of them are the very best of the summer squashes for table use; far superior to either the scalloped or warted varieties." When trained as directed for the Egg-squash, it is equally showy and attractive.

Variegated Bush Scalloped.

Pale yellow, or nearly white, variegated with green. Very handsome, but of inferior quality.

\section{Autumn and Winter Varieties. -}

Autumnal

Marrow.

J. M. Ives.

Boston Makrow.

COURGR DE
LOHO. Vil. tremities, eight or nine inches in length, and seven inches in diameter; stem very large, fleshy, and contracted a little at its junction with the fruit, - the summit, or blossomend, often tipped with a small nipple or wart-like excresence; skin remarkably thin, easily bruised or broken, cream-ye!low at the time of ripening, but changing to red after harvesting, or by remaining on the plants after full maturity; flesh rich, salmon-yellow, remarkably dry, fine-grained, and in sweetness and excellence surpassed by few varieties. 
The seeds are large, thick, and pure white; the surface, in appearance and to the touch, resembles glove-leather or dressed goat-skin. About one hundred are contained in an ounce.

In favorable seasons the Autumnal Marrow Squash will be sufficiently grown for use early in August, and, if kept from cold and dampness, may be preserved till March.

Mr. John M. Ives, of Salem, who was awarded a piece of sil-

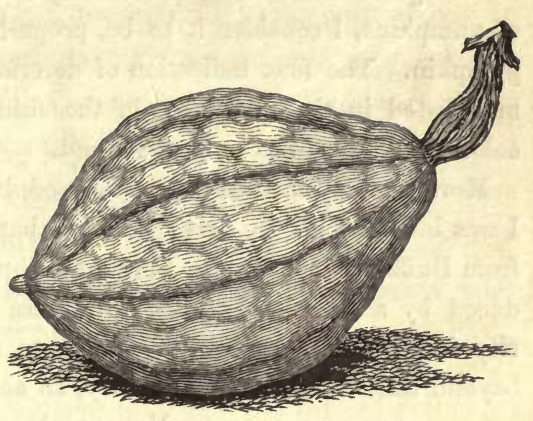

Autumnal Marrow Squash. ver plate by the Massachusetts Horticultural Society for the introduction of this valuable variety, has furnished the following statement relative to its origin and dissemination:-

SALEm, MAss., Feb. 7, 1858.

DEAR Sir, - As requested, I forward you a few facts relative to the introduction of the Autumnal Marrow Squash, the cultivation of which has extended not only over our entire country, but throughout Europe. In succeeds better in England than the Crooknecks, and may be seen in great abundance every season at Corent-Garden Market, in London.

Early in the spring of 1831, a friend of mine from Northampton, in this State, brought to my grounds a specimen of this vegetable, of five or six pounds' weight, which he called "Vegetable Marrow." As it bore no resemblance to the true Vegetable Marrow, either in its form or color, I planted the seeds, and was successful in raising eight or ten specimens. Finding it a superior vegetable, with a skin as thin as the inner envelope of an egg, and the flesh of fine texture, and also that it was in eating early in the fall, I ventured to call it "Autumnal Marrow Squash." Soon a drawing was made, and forwarded, with a description, to the 
"Horticultural Register" of Fessenden, and also to the "New England Farmer."

In cultivating this vegetable, I found the fruit to average from eight to nine pounds, particularly if grown on newly broken-up sod or grass land. From its facility in hybridizing with the tribe of pumpkins, I consider it to be, properly speaking, a fine-grained pumpkin. The first indication of deterioration or mixture will be manifested in the thickening of the skin, or by a green circle or coloring of green at the blossom-end.

More recently, I have been informed, by the gentleman to whom I was indebted for the first specimen, that the seeds came originally from Buffalo, N. Y., where they were supposed to have been introduced by a tribe of Indians, who were accustomed to visit that city in the spring of the year. I have not been able to trace it beyond this. It is, unquestionably, an accidental hybrid.

\section{Yours truly,}

Mr. F. BURr, Jun.

JoHN M. Ives.

Bush, or Dwarf Vege-

A sub-variety of the Vegetable Marrow, with table Marrow. a dwarf, reclining stem, two and a half or three feet in height or length. The fruit has the form and color of the running variety, but is of smaller size, generally measuring six or seven inches in length, and about three inches in diameter.

The variety is hardy, productive, comes early into use, and will keep through the winter, though much inferior to the Boston Marrow, Hubbard, and like sorts, as a table vegetable; it is excellent as a pie-squash, and is well suited for cultivation in humid climates, or cold latitudes, as the fruit forms early in the season, and is soon ripened.

Canada Crookneck.

The plants of this variety are similar in habit to those of the Common Winter Crookneck; but the foliage is smaller, and the growth less luxuriant. In point of size the Canada Crookneck is the smallest 
of its class. When the variety is unmixed the weight seldom exceeds five or six pounds. It is sometimes bottleformed; but the neck is generally small, solid, and curved in the form of the Large Winter Crooknecks. The seeds are contained at the blossom-end, which expands somewhat abruptly, and is often slightly ribbed. Skin of moderate thickness, and easily pierced by the nail ; color, when fully ripened, cream-yellow, but, if long kept, becoming duller and darker; flesh salmon-red, very close-grained, dry, sweet, and fineflavored; seeds comparatively small, of a grayish or dull white color, with a rough and uneven yellowish-brown border; three hundred are contained in an ounce.

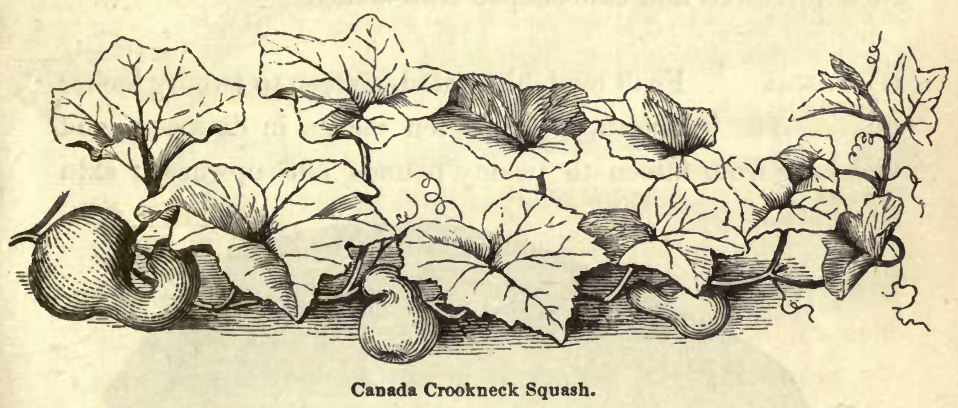

The Canada is unquestionably the best of the Crooknecked sorts. The vines are remarkably hardy and prolific, yielding almost a certain crop both North and South. The variety ripens early; the plants suffer but little from the depredations of bugs or worms; and the fruit, with trifling care, may be preserved throughout the year. It is also quite uniform in quality; being seldom of the coarse and stringy character so common to other varieties of this class.

Somewhat of the form and color of the Common Winter Crookneck. Two prominent vari-

Cashaw. Cushaw PumpKIN. eties, however, occur. The first is nearly round; the other 
curved, or of the shape of a hunter's horn. The latter is the most desirable. It is not cultivated or generally known in New England or in the northern portions of the United States; for though well suited to Louisiana and other portions of the South, where it is much esteemed, it is evidently too tender for cultivation where the seasons are comparatively short and cool.

In an experimental trial by the late Dr. Harris, specimens raised from seed received from New Jersey " did not ripen well, and many decayed before half ripe."

The Crooknecks of New England " may be distinguished from the Cashaw by the want of a persistent style, and by their furrowed and club-shaped fruit-stems."

Cocoa-Nut Fruit oval, elongated, sixteen to twenty inches
Squask. Cocos SquAsr. in length, eight or ten inches in diameter, and weighing from fifteen to twenty pounds and upwards; skin

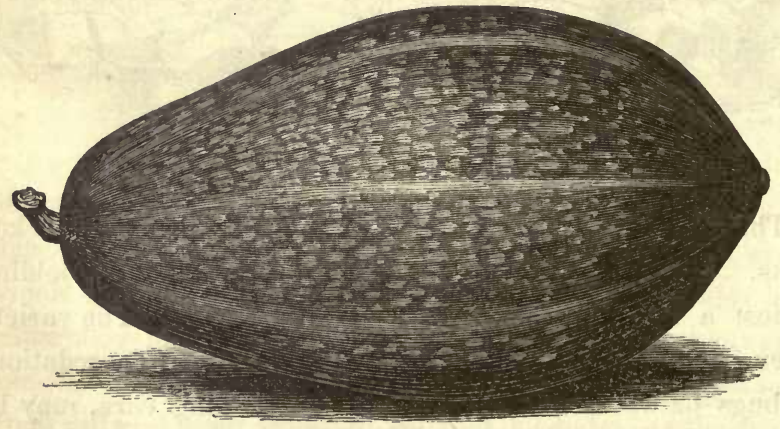

Cocoa-nut Squash.

thin, easily pierced or broken, of an ash-gray color, spotted, and marked with light drab and nankeen-brown, - the furrows dividing the ribs light drab; stem small; flesh deep orange-yellow, of medium thickness; seeds pure white, broader in proportion to their length than those of the Hubbard or Boston Marrow. 
The quality of the Cocoa-nut Squash is extremely variable. Sometimes the flesh is fine-grained, dry, sweet, and of a rich, nut-like flavor; but well-developed and apparently well-matured specimens are often coarse, fibrous, watery, and unfit for table use. The variety ripens in September, and will keep till March or April.

Plant healthy and of vigorous habit, often Custard twenty feet and upwards in length; fruit obSquash. long, gathered in deep folds or wrinkles at the stem, near

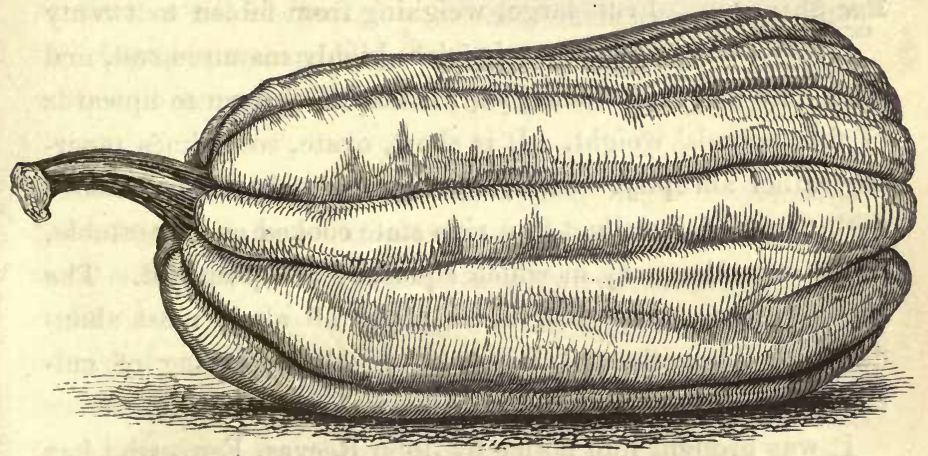

Custard Squash.

which it is the smallest, abruptly shortened at the opposite extremity, prominently marked by large, rounded, lengthwise elevations, and corresponding deep furrows or depressions; skin, or shell, cream-white; flesh pale yellow, not remarkable for solidity, or fineness of texture, but well flavored; the seeds are yellowish-white, and readily distinguished from those of other varieties by their long and narrow form. Under favorable conditions of soil and season, the Custard Squash attains a large size; often measuring twenty inches and upwards in length, eight or ten inches in diameter, and weighing from eighteen to twenty-five pounds. 
It is one of the hardiest and most productive of all varieties. Crops are recorded of fourteen tons from an acre. It is esteemed by some for pies; but, as a table squash, is inferior to most other sorts. Its great yield makes it worthy the attention of agriculturists, as it would doubtless prove a profitable variety to be cultivated for stock.

From the habit of the plant, the form and character of the fruit, and its great hardiness and productiveness, it appears to be allied to the Vegetable Marrow.

Fgg-Shaped, Fruit large, weighing from fifteen to twenty or Reeves.

Thomp.

pounds; but in rich, highly manured soil, and with only a few on each plant, it may be grown to upwards of fifty pounds' weight. It is short, ovate, sometimes tapering rather abruptly. Skin, or shell, hard, of a reddish color ; flesh firm, red, excellent in a ripe state cooked as a vegetable, or in any other way in which squashes are prepared. The stems run to a great length, and bear all along most abundantly. Altogether, it is a sort highly deserving of cultivation.

It was brought into notice by John Reeves, Esq., who has contributed to horticulture many valuable plants from China, where he resided for many years.

Plant in hills eight feet apart, and thin to two plants to a hill.

Honolulu. Plant twelve feet or more in length, remarkably strong and vigorous; leaves very large, - leaf-stems often three feet and upwards in length; fruit large, oblate, depressed about the stem, broadly, and sometimes deeply, but in general faintly, ribbed; skin moderately thick, but not shell-like, of an ash-green color, often striped and variegated with drab or lighter shades of green; flesh reddish-orange, very thick, of good flavor, but less dry and 
sweet than that of the Hubbard or Boston Marrow; seeds large, white.

This recently introduced variety is hardy, productive, a good keeper, excellent for pies, and by some esteeined for table use.

Specimens frequently occur of a reddish cream color, striped and marked

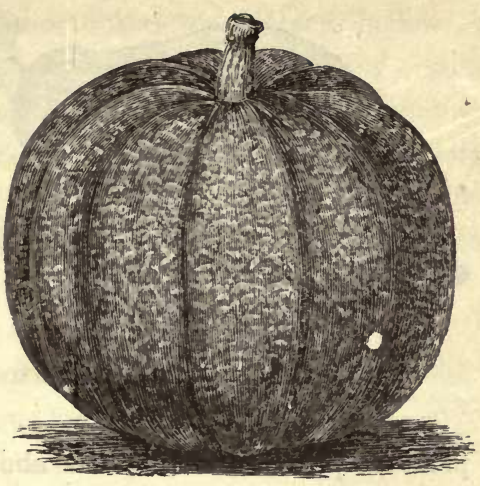

Honolulu Squash. with drab or pale yellow.

Plant similar in character and appearance to Hubbard. that of the Autumnal Marrow ; fruit irregularly J.J.H.Gregory. oval, sometimes ribbed, but often without rib-markings, from eight to ten inches in length, seven or eight inches in diameter, and weighing from seven to nine pounds, - some specimens terminate quite obtusely, others taper sharply towards the extremities, which are frequently bent or curved; skin, or shell, dense and hard, nearly one eighth of an inch thick, and overspread with numerous small protuberances; stem fleshy, but not large ; color variable, always rather dull, and usually clay-blue or deep olive-green, - the upper surface, if long exposed to the sun, assuming a brownish cast, and the under surface, if deprived of light, becoming orange-yellow ; flesh rich salmon-yellow, thicker than that of the Autumnal Marrow, fine-grained, sweet, dry, and of most excellent flavor, - in this last respect resembling that of roasted or boiled chestnuts; seeds white, - similar to those of the Autumnal Marrow. Season from September to June; but the flesh is dryest and sweetest during autumn and the early part of winter. 


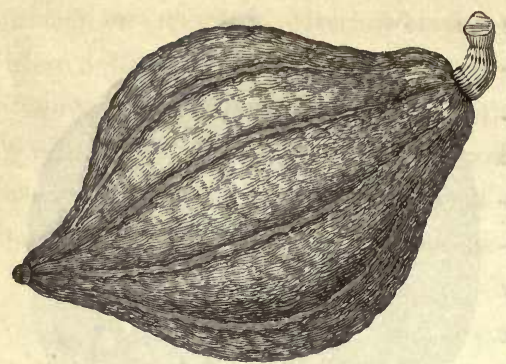

Hubbard Squash.

The Hubbard Squash should be grown in hills seven feet apart, and three plants allowed to a hill. It is essential that the planting be made as far as possible from similar varieties, as it mixes, or hybridizes, readily with all of its kind. In

point of productiveness it is about equal to the Autumnal Marrow. The average yield from six acres was nearly five tons of marketable squashes to the acre.

Mr. J. J. H. Gregory, of Marblehead, Mass., who brought this excellent variety to notice, and through whose exertions it has become widely disseminated, states that it was introduced into Marblehead about sixty years since by an elderly man, who followed marketing, from the vicinity of Boston. Though there appears to be nothing in its history that forbids its having been previously cultivated elsewhere, very few have claimed this to have been the fact, and none who have done so seem to have stood the test of a fair criticism.

The original squash was green, and the blue sub-variety is believed to have been produced by a cross with the Sweet Potato Squash. In the color of the shell of these hybrids, in the lighter orange tint of the flesh, and sometimes in the form, the old Sweet Potato variety can yet be traced.

Italian Veg- Plant dwarf, bushy, with short, reclining row. Thomp. stems, and upright leaves, which are deeply five-lobed. The fruits are used when the flowers are about to drop from their ends. They are then from four to five inches long, and an inch and a half to two inches in diameter. 
When ripe, the fruit is from fifteen to eighteen inches in length, and about six inches in diameter. It is of a pale yellow, striped with green, and should be used in the young, green state; when mature, it is less esteemed than many other sorts. The plants bear abundantly, and, as they do not run, may be grown in smaller compass than the true Vegetable Marrow.

This is the largest-fruited variety known. In Mammoth. a very rich compost, and under favorable con- MIN. LATH PQMP. a very rich compost, and under favorable COn- MIN. LARGE ditions of climate, it grows to an enormous size. Fruit weighing a hundred and twenty pounds $\begin{gathered}\text { Coctrita. } \\ \text { IM. }\end{gathered}$ is not uncommon ; and instances, though exceptional, are recorded of weights ranging from two hundred to nearly two hundred and fifty pounds.

The leaves are large, and the stems thick, running along the ground to the distance of twenty or thirty feet, if not stopped, and readily striking root at the joints.

The fruit is round, or oblate; sometimes flattened on the under side, owing to its great weight; sometimes obtusely ribbed, yellowish, or pale buff, and frequently covered to a considerable extent with a gray netting. Flesh deep yellow ; seeds white.

It is used only in its full-grown or ripe state, in which it will keep for several months, and even during the winter, if stored in a dry, warm situation. The flesh is sweet, though generally coarse-grained and watery. It is used in soups and stews, and also for pies; but is seldom served like squash at the table.

Plant running; leaves small, smooth, striped Neapolitan. and marked with white along the nerves; fruit nearly two feet in length, and rather more than five inches in its smallest diameter, bent at the middle, and broadly but faintly ribbed, 
- it increases in size towards the extremities, but is largest at the blossom-end, where it reaches a diameter of eight or ten inches; skin bright green; stem small; flesh bright, clear yellow; the neck is entirely solid, and the seed-end has an unusually small cavity; seeds dull white.

The late Rev. A. R. Pope, in a communication to the Massachusetts Horticultural Society, describes it as follows : "New, very heavy; having a large, solid neck, and a small cavity for the seeds. Flesh sweet, dry, and somewhat coarse, but not stringy. Very superior for pies, and a good keeper."

Patagonian. A large, long Squash, prominently ribbed. It differs little in form or size from the Custard. Skin deep green; flesh pale yellow; seeds of medium size, yellowishwhite.

The plant is a vigorous grower, and the yield abundant; but its quality is inferior, and the variety can hardly be considered worthy of cultivation for table use. It may, however, prove a profitable sort for growing for agricultural purposes.

Puritan. Plant ten feet and upwards in length; leaves clear green, of medium size ; fruit bottle-formed, fourteen or fifteen inches long, and about ten inches in diameter at the broadest part; neck solid, four or five inches in diameter; average weight eight to ten pounds; skin thin, usually white or cream-white, striped, and marked with green, though specimens sometimes occur, from unmixed seed, uniformly green; flesh pale yellow, dry, sweet, mild, and well flavored; seeds of medium size, white. Season from August to January.

This variety, long common to gardens in the vicinity of the Old Colony, retains its distinctive character to a re- 
markable degree, even when grown . under the most unfavorable circumstances. Seeds, obtained from a gardener, who had cultivated the variety indiscriminately among numerous summer and winter kinds for upwards of twenty years, produced specimens uniformly true to the normal form, color, and quality. It is hardy and productive, good for table use, excellent for pies, and well deserving of cultivation.

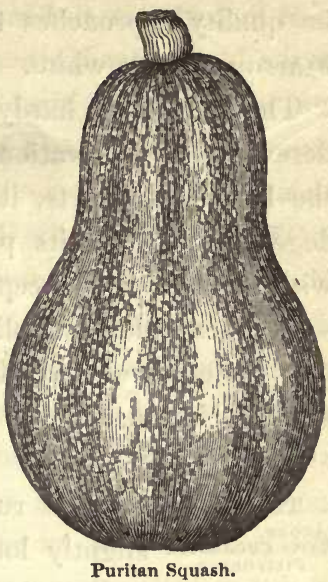

Plant similar in character to that of the Hub- Sweet-Potato bard or Autumnal Marrow; fruit twelve or Squash. fourteen inches long, seven or eight inches thick, sometimes ribbed, but frequently without rib-markings; oblong,

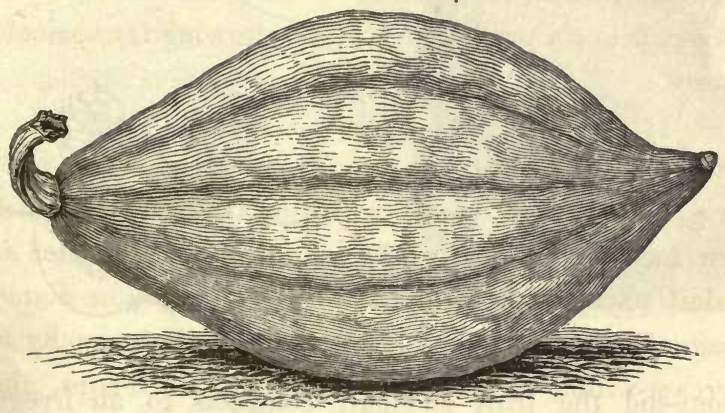

Sweet Potato Squash.

tapering to the ends, which are often bent or curved in the inanner of some of the types of the Hubbard ; stem of medium size, striated; skin ash-green, with a smooth, polished surface; flesh salmon-yellow, thick, fine-grained, dry, and sweet, - if the variety is pure, and the fruit well matured, 
its quality approaches that of the Hubbard and Autumnal Marrow ; seeds white.

The variety is hardy and productive, keeps well, and is deserving of cultivation. When grown in the vicinity of the last-named sorts, it often becomes mixed, and rapidly degenerates. In its purity it is uniformly of one color; with perhaps the exception of the under surface, which is sometimes paler or yellowish. It has been suggested that this variety and the Hubbard may have originated under similar circumstances.

Turban.

Plant running; leaves of medium size, soft, AcORN. TURK's
CAP. CUCURBIA slightly lobed on the borders; fruit rounded,
PILIFORMIS. flattened, expanding about the stem to a broad, plain, brickred surface, of ten or twelve inches in diameter. At the

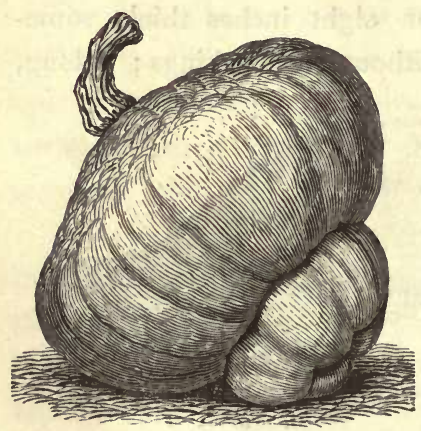

Turban Squash.

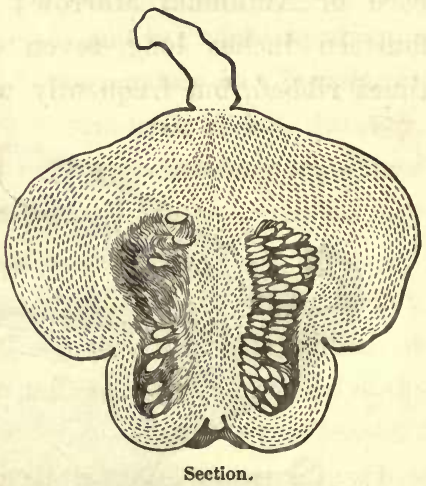

Section.

blossom-end the fruit suddenly contracts to an irregular, cone-like point, or termination, usually of a greenish color, striped with white, but sometimes yellowish-white without the stripes or variegations; and thus, in form and color, somewhat resembles a turban, whence the name. Flesh orange-yellow, thick, fine-grained, sugary, and well flavored ; seeds white, comparatively short, and small. 
The Turban Squash is not early, and should have a rich, warm soil, and the advantage of the whole season. Though its keeping properties are not particularly good, it is early fit for the table; and for use in autumn or early in winter must be classed as one of the best of all varieties. The weight varies from five to eight pounds, and the specific gravity is said to exceed that of any other known sort.

After harvesting, the fruit should be immediately stored in a dry and warm situation, laid upon the side to avoid injury to the seed or acorn end, which is peculiarly liable to decay, and in this position remain undisturbed till required for use.

In favorable situations, and under high culture, six tons have been obtained from an acre.

A sub-variety - probably the result of acclimation - is known as the Improved Turban. Compared with the original, the plant is hardier, yields more abundantly, and the fruit, besides being quite as sweet and delicate, is a much better keeper, and nearly or

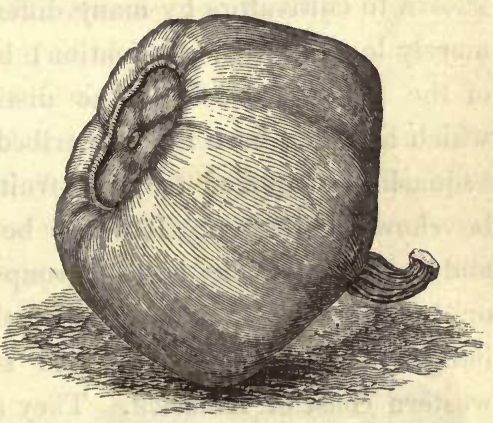

Improved Turban Squash. quite equal in quality to that of the best Autumnal Marrow.

Plant running; leaves large, not lobed, but Valparaiso.

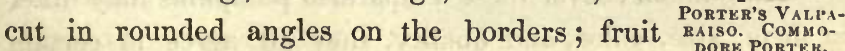
oval, about sixteen iuches in length, ten or eleven inches in diameter, slightly ribbed, and largest at the blossom-end, which often terminates in a wart-like excrescence; skin cream-white, sometimes smooth and polished, but often more or less reticulated, or netted ; flesh comparatively thick, orange-yellow, generally dry, sweet, and well 
flavored, but sometimes fibrous and watery; seeds rather large, nankeen-yellow, smooth and glossy.

The variety requires the whole season for its perfection. It hybridizes readily with the Autumnal Marrow and kindred sorts, and is kept pure with considerable difficulty. It is in use from September to spring. The variety, if obtained in its purity, will be found of comparative excellence, and well deserving of cultivation. Stripes and clouds of green upon the surface are infallible evidences of mixture and deterioration.

The late Dr. Harris, in a communication to the "Pennsylvania Farm Journal," remarks as follows : "The Valparaiso squashes (of which there seem to be several varieties, known to cultivators by many different names, some of them merely local in their application) belong to a peculiar group of the genus Cucurbita, the distinguishing characters of which have not been fully described by botanists. The word ' squash,' as applied to these fruits, is a misnomer, as may be shown hereafter. It would be well to drop it entirely, and to call the fruits of this group 'pompions,' 'pumpkins,' or 'potirons.' It is my belief that they were originally indigenous to the tropical and sub-tropical parts of the western coast of America. They are extensively cultivated from Chili to California, and also in the West Indies; whence enormous specimens are sometimes brought to the Atlantic States.

"How much soever these Valparaiso pumpkins may differ in form, size, color, and quality, they all agree in certain peculiarities that are found in no other species or varieties of Cucurbita. Their leaves are never deeply lobed like those of other pumpkins and squashes, but are more or less fiveangled, or almost rounded and heart-shaped, at base; they are also softer than those of other pumpkins and squashes. The summit, or blossom-end, of the fruit has a nipple-like 
projection upon it, consisting of the permanent fleshy style. The fruit-stalk is short, nearly cylindrical, never deeply fivefurrowed, but merely longitudinally striated or wrinkled, and never clavated, or enlarged with projecting angles, next to the fruit. With few exceptions, they contain four or five double rows of seeds. To this group belongs Mr. Ives's Autumnal Marrow Squash (or Pumpkin) ; Commodore Porter's Valparaiso Squash (Pumpkin); the so-called Mammoth Pumpkin, or Cucurbita maxima of the botanists; the Turban or Acorn Squash ; Cucurbita piliformis of Duchesne ; the Cashew Pumpkin; Stetson's Hybrid, called the 'Wilder Squash ;' with various others."

Plant twelve feet and upwards in length; leaves deeply five-lobed; fruit about nine inches long, and of an elliptic shape, - but it is some-

Vegetable

Marrow.

Thomp.

Succade Gourd. times grown to twice that length, and of an oblong form; surface slightly uneven, by irregular, longitudinal, obtuse ribs, which terminate in a projecting apex at the extremity of the fruit. When mature, it is of a uniform pale yellow or straw color. The skin, or shell, is very hard when the fruit is perfectly ripened; flesh white, tender, and succulent, even till the seeds are ripe. It may be used in every stage of its growth. Some prefer it when the flower is

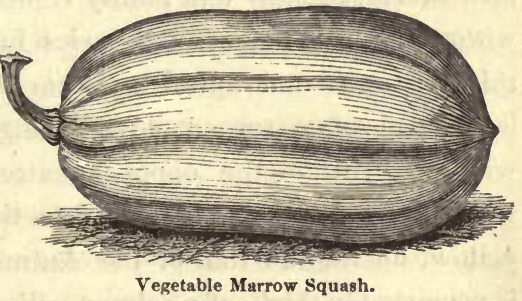
still at the extremity of the fruit; others like it older. When well ripened, it will keep throughout the winter, if stored in a perfectly dry place, out of the reach of fros', and not exposed to great changes of temperature.

To have Vegetable Marrows large and fine for winter, the 
young fruit should be regularly taken off for use ; and, when the plant has acquired strength, a moderate quantity should be allowed to set for maturity. Sufficient for this purpose being reserved, the young fruit that may be subsequently formed should be removed for use in a very young state. The vines, or shoots, may be allowed to run along the surface of the ground, or they may be trained against a wall, or on palings or trellises.

The seed should be planted at the same time and in the same manner as those of the Winter Crookneck or Boston Marrow.

Wilder. Stetson's IIY BRID.
The Wilder Squash was produced, about twelve years since, from the Valparaiso and the Autumnal Marrow, by Mr. A. W. Stetson, of Braintree, Mass.; and was named for the Hon. Marshall P. Wilder, a gentleman widely known for his patriotic devotion to the advancement of agricultural and pomological science in the United States.

The plant is a strong grower, and resembles that of the Valparaiso. The fruit is somewhat ovoid, but rather irregular in form, broadly and faintly ribbed (sometimes, however, without rib-markings), and varies in weight from twelve to thirty pounds and upwards; stem large, striated or reticulated, and often turned at right angles near its connection with the fruit, - the opposite extremity terminates in the wart-like excrescence peculiar to the class; skin reddishyellow, not unlike that of the Autumnal Marrow; the flesh is remarkably thick, of a salmon-yellow color, sweet and wellflavored. In some forms of cookery, and especially for pies, it is esteemed equal, if not superior, to any other variety. When served in the customary manner of serving squash at table, it is inferior to the Hubbard or Autumnal Marrow. 'The seeds are white. 
This is one of the oldest and most familiar of the winter varieties. Plant hardy and vigoWinter
Crookneck Cucraw. rous; fruit somewhat irregular in form, the neck solid and nearly cylindrical, and the blossom-end more or less swollen. In some specimens the reck is nearly straight; in others, sweeping or circular; and sometimes the extremities nearly or quite approach each other. Size very variable, being affected greatly both by soil and season; the weight ranging from six to forty pounds and upwards. A specimen was raised by Captain Josiah Lovett, of Beverly, Mass., and exhibited before the Massachusetts Horticultural Society, the weight of which was nearly seventy pounds. Color sometimes green, but, when fully mature, often cream-yellow. The color, like that of the Canada Crookneck, frequently changes after being harvested. If green when plucked, it gradually becomes paler; or, if yellow when taken

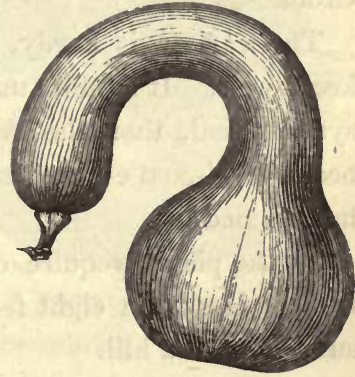

Winter Crookneck Squash. from the vines, it becomes, during the winter, of a reddish cream-color. Flesh salmon-yellow, not uniform in texture or solidity, sometimes close-grained, sweet, and fine-flavored, and sometimes coarse, stringy, and nearly worthless for the table ; seeds of medium size, grayish-white, the border darker, or brownish. About two hundred are contained in an ounce.

It is a hardy and productive variety; ripens its crop with great certainty; suffers less from the depredations of insects than most of the winter sorts; and, if protected from cold and dampness during the winter months, will keep the entire year.

This is a sub-variety of the common Winter

Crookneck. Fruit of large size, varying in Crookneck. 
weight from six to twenty-five pounds; neck large and solid; sced-end of medium size, and usually smooth; skin thin, pale green or light cream-white, diversified with lengthwise stripes and plashes of bright green, - the colors becomin's gradually softer and paler after gathering; flesh bright orange, and, like that of the Common Winter Crookneck, not uniform in texture or in flavor. Different specimens vary greatly in these respects; some are tough and stringy, others fine-grained and well-flavored. Seeds not distinguishable, in size, form, or color, from those of the Winter Crookneck.

The variety is hardy, grows luxuriantly, is prolific, and keeps well. It is more uniform in shape, aud generally more symmetrical, than the Winter Crookneck; though varieties occur of almost every form and color between this and the last named.

As the plants require considerable space, the hills should not be less than eight feet apart. Two or three plants are sufficient for a hill.

"'The 'Crookneck Squash,' as it is commonly but incorreetly called, is a kind of 'pumpkin,' - perhaps a genuine species; for it has preserved its identity, to our certain knowledge, ever since the year 1686, when it was described by Ray. Before the introduction of the Autumnal Marrow, it was raised in large quantities for table use during the winter, in preference to pumpkins, which it almost entirely superseded. Many farmers now use it instead of pumpkins for cattle, - the vine being more productive, and the fruit containing much more nutriment in proportion to its size. It varies considerably in form and color. The best kinds are those which are very much curved, - nearly as large at the stem as at the blossom-end, - and of a rich cream-color. It is said to degenerate in the Middle and Southern States, where, probably, the Valparaiso or some 
kindred variety may be better adapted to the climate." Dr. Harris.

A new variety, recently introduced into this Yokohama. country from Japan. Stem running, attaining a length of twelve feet and upwards; fruit roundish, much flattened, strongly ribbed, deeply sunk at the blossom-end and about the stem, eight or ten inches at its largest diameter, and weighing from six to twelve pounds. Skin warted, green while the fruit is young, but afterwards gradually changing to yellow or dull orange ; stem long and slender, woody, clavated and furrowed, resembling that of the Sugar Pumpkin. Flesh orange-yellow, fine-grained, dry and

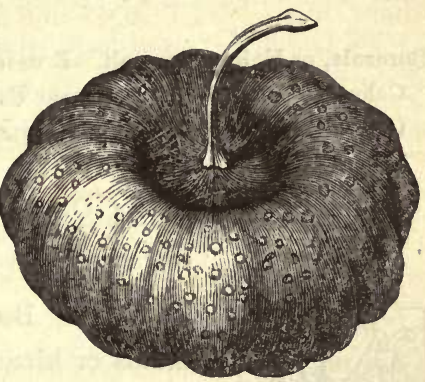

Yokohama Squaeh. sweet. Seeds small, somewhat resembling those of the Scalloped, or Warted Crookneck. Season from July to March.

Disseminated by Mr. James Hogg, of Yorkville, New York City, from seeds received from his brother, $\mathrm{Mr}$. Thomas Hogg, at Japan. 


\section{CHAPTER V.}

\section{BRASSICACEOUS PLANTS.}

Borecole, or Kale. Broccoli. Brussels Sprouts. Cabbage. Cauliflower. Colewort. Couve Tronchuda, or Portugal Cabbage. Kohl Rabi. PakChoi. Pe-Tsai, or Chinese Cabbage. Savoy. Sea-kale.

\section{BORECOLE, OR KALE.}

Brassica oleracea sabellica.

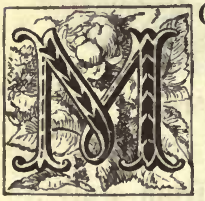

OST of the Borecoles or Kales are either annuals or biennials. As a class they form neither heads as the Common Cabbage, nor eatable flowers like the Broccoli and Cauliflower. Some of the varieties attain a height of six or seven feet; but while a few are compact and symmetrical in their manner of growth, and of good quality for table use, many are "ill-colored, coarse, ramblinggrowing, and comparatively unpalatable and indigestible."

Propagation and Culture.-They are propagated from seeds, which, in size, form, and color, resemble those of the Cabbage, and which are sown at the time of sowing the seeds of the Cabbage or Cauliflower, and in the same manner. Early plants may be started in a hot-bed, or the seeds may be sown in the open ground in April or May. In transplanting, treat the plants like young cabbages, setting them more or less remote, according to the size or habit of the variety.

Though they are extremely hardy, and will endure quite a 
low temperature, they are generally harvested in autumn, before the closing-up of the ground. If reset in the following spring, they will furnish an abundance of tender sprouts, which, when cooked, are superior in flavor and delicacy to the Cabbage, and resemble Coleworts or Brussels Sprouts.

Seed. - 'To raise seed, select, at the time of harvesting, two or three well-grown plants; take them up entire and store them in the cellar for the winter. In April, or as soon as the weather becomes mild, transplant them two feet and a lialf or three feet apart in each direction. When in flower, the plant resembles the Cabbage at a similar stage of growth, and should be staked, or otherwise supported to prevent injury from wind.

J. E. Teschemacher gives the following directions for culture and use :-

"Sow, the middle or last of May, a small bed on a moderately rich soil, but in a well-exposed situation. When the young plants have six or eight leaves, plant them six or eight inches asunder, water well, and shade for a few days against the hot sun. Towards the latter end of July, or middle of August, they should be thick, stocky plants, fit for final transplanting to the spots where they are to remain. The ground must be well manured, and the plants moved singly and carefully, with as much earth attached to the roots as possible. They will not show much signs of growth until the cool nights prevail ; after that, they will grow rapidly."

Use. - "The tender, upper part alone is eaten. They are often, but not always, frozen when cut; and, when this is the case, they should be put into a cool cellar, or in cold water, until the frost is out of them. The beautiful curled leaves are quite ornamental.

"From one hundred plants, pluckings for the table were made twice a week, from the middle of November to the middle of January; and these fresh from the open garden, 
although the thermometer in the time had indicated a temperature approaching to zero." - Hov. Mag.

Varieties. - The varieties, which are numerous, and in many instances not well marked or defined, are as follow :-

Buda Kale, or Borecole. Thomp.

Russian Kale. ASPARAOUS KaLe. MaNcues. TER BORECOLE. DWARF FEATHER

KALE. UAKLEA VED KALK.
The Buda Kale somewhat resembles the Purple; but the stalk is shorter. The leaves are purplish, somewhat glaucous, cut and fringed. The variety is not only hardy and well flavored, but continues to produce sprouts longer than any other sort. It is sometimes blanched like sea-kale.

Cabbaging Kale, or Borecole. Thomp. ImPYRAa IIEART- general appearance of the leaves; the heartleaves, however, fold over each other, somewhat like those of a cabbage, but, on account of the curls of the margin, not so compactly. The quality is excellent.

Cockscomb Kale.

Curled ProlifEROUS KALE.

Stalk about twenty inches high. The leaves differ to a considerable extent in size, and are of a glaucous-green color. From the upper surface of the ribs and nerves, and also from other portions of the leaves, are developed numerous small tufts, or fascicles of leaves, which, in turn, give rise to other smaller but similar groups. The foliage thus exhibits the form of a cock's comb; whence the name.

The variety is hardy, but more curious than useful.

Cow-Cabbage. This variety generally grows to the height Tree-Cabiaz. Thonk- CEAAREA
ThOREC OLE. CESAREAN CABBAOK. 
and even upwards. The leaves are large, - measuring from two and a half to nearly three feet in length, - smooth, or but slightly curled.

It is generally grown for stock; but the young sprouts are tender and mild-flavored when cooked. - Its value for agricultural purposes appears to have been greatly overrated; for, when tried in this country against other varieties of cabbages, the produce was not extraordinary.

The plants should be set three feet or three feet and a half apart.

A new vegetable, the result of a cross between the common heading Cabbage and BrusDalmeny Sprouts. sels Sprouts. The stem is a foot and upwards in height, and is not only thickly set with sprouts, or small cabbages, like the Brussels Sprouts, but terminates in a Cabbage of medium size.

The seeds are sown, and the plants are treated in all respects as Borecole, or as Brussels Sprouts.

Stalk four or five feet in height or length. The Daubenton's leaves are nearly two feet long, deep green; the Breeping leaf stems are long and flexible. It sometimes takes root where the stem rests upon the surface of the ground, and, on this account has been called perennial.

The variety is hardy, and yields abundantly; though, in this last respect, it is inferior to the Thousand-headed.

The Dwarf Green Curled is a hardy but comparatively low-growing variety, the stem seldom exceeding sixteen or eighteen inches in height. The leaves are finely curled, and the crowns of the plants, as well as the young

Dwarfed Green Curled Borecole. Thomp. DWARF CURLed KAlE. GREEN SCOTCH KALE. DWARY CURLIES. CANADA DWARF Curled. 
shoots, are tender and delicate, especially after having been exposed to the action of frost.

The plants may be set eighteen inches apart.

Field Cab- Leaves sixteen to eighteen inches in length, bage. Vil.
FIELD KAIE, ror dark green, deeply lobed or lyrate, and hairy or hispid, on the nerves and borders. The leaf-stems are nearly white.

The variety produces small tufts, or collections of leaves, which are excellent for fodder, and which may be cut several times during the season. It is sometimes cultivated for stock, but as a table vegetable is of little value.

Flanders This is a sub-variety of the Tree-cabbage, Kale. Thomp.

from which it is distinguished by the purplish color of its foliage. Its height is nearly the same, and the plant has the same general appearance. It is, however, considered somewhat hardier.

Green Marrow-Stem

Borecole. Vil.

Stem green, about five feet high, clavate, or club-formed; thickest at the top, where it measures nearly two inches and a half in diameter. This stem, or stalk, is filled with a succulent pith, or marrow, which is much relished by cattle; and, for this quality, the plant is sometimes cultivated. The leaves are large, and nearly entire on the edges; the leaf-stems are thick, short, white, and fleshy.

It is not so hardy as most of the other varieties. The plants should be grown about three feet apart in one direction, by two feet or two feet and a half in the opposite.

Lannilis Borecole. Vil.

LANNILIS TrEECabBag.
Stem five feet high, thicker and shorter than that of the Cow or Tree Cabbage ; leaves long, entire on the borders, pale green, thick, and 
fleshy. The leaf-stems are also thicker and shorter than those of the last named varieties.

The stalk is largest towards the top, and has the form of that of the Marrow-stem. It sometimes approaches so near that variety as to be scarcely distinguishable from it.

The Neapolitan Borecole is remarkable for its peculiar manner of growth, but is hardly worthy of cultivation as a table vegetable, or

Neapolitan Borecole. Trans.

NeAPOLITAN Curled Kale. even for stock. The stem is short and thick, and terminates in an oval bulb, somewhat in the manner of the Kohl Rabi. From all parts of this bulb are put forth numerous erect, small leaves, finely curled on their edges. The whole plant does not exceed twenty inches in height. The leaves are attached to footstalks six or seven inches long. They are obovate, smooth on the surface, with an extraordinary number of white veins, nearly covering the whole leaf. The fringed edges are irregularly cut and finely curled, and so extended as nearly to conceal the other parts of the leaf. As the plant gets old it throws out numerous small branches from the axils of the leaves on the sides of the bulb.

The swollen portion of the stem is of a fleshy, succulent character, and is used in the manner of Kohl Rabi, between which and the Cabbage it appears to be intermediate.

Stalk six feet in height, terminating at the Palm Kale. top in a cluster of leaves, which are nearly enPaLM Borgcole. tire on the borders, blistered on the surface like those of the Savoys, and which sometimes measure three feet in length by four or five inches in width.

As grown in France, the plant is remarkable for its fine appearance, and is considered quite ornamental, though, as an article of food, it is of little value. In England, it is said to have a tall, rambling habit, and to be little esteemed. 
The plants should be set three feet and a half apart in each direction.

Purple Bore- With the exception of its color, the Purple
cole. RED Borecols. Borecole much resembles the Tall Green Curled. TALL PURPLE

KALE. CURED
BROWN KALE. to green; but the veins still retain their purple hue. When cooked, the color nearly or quite disappears.

It is remarkably hardy, and is much cultivated in Germany. Red Marrow- Stalk purplish red, four and a half or five
stem Borecole.

RED-STALKED KALE. feet high, and surmounted by a cluster of large, fleshy leaves, on short, thick stems. The stalk is much larger than that of the Green Marrow-stem, and sometimes measures more than three inches in diameter. It is cultivated in the same manner, and used for the same purposes, as the last-named variety.

Tall Green Curled. Thomp.

TALL Scotch

KALE. TALL GREEN BORECOLE.

TAI,L GERMAN GreENS.
This variety, if unmixed, may be known by its bright green, deeply lobed, and curled leaves. Its height is two feet and a half and upwards. Hardy and productive.

The parts used are the crowns of the plants, and also the tender side-shoots, which are produced in great abundance. These boil well, and are sweet and delicate, especially after frost, though the quality is impaired by protracted, dry, freezing weather.

Thousandheaded Bore-

The Thousand-headed Borecole much resemcole. Thomp. bles the Tree or Cow Cabbage, but is not so tall-growing. It sends out numerous side-shoots from the main stem, and is perhaps preferable to the last-named sort. It is chiefly valuable as an agricultural plant, and is occa- 
sionally grown in gardens on account of its great hardiness; but it is inferior in flavor to all other varieties.

This is a sub-variety of the Purple Borecole, Variegated growing about a foot and a half high. The Thomp. leaves vary much in size, and are lobed and KALE. VARED finely curled. They are also beautifully variegated, sometimes with green and yellowish white, or green and purple, and sometimes with bright red and green.

It is frequently grown as an ornamental plant, is occasionally employed for garnishing, and is sometimes put into bouquets. It is very good cooked after frost, but is not quite so hardy as the Purple Borecole.

A variety of the Common Cockscomb Kale, with the leaves more or less variegated with Variegated Cockscomb Kalo. purple and white. It is not of much value as an esculent.

This is a tall variety of the Purple Borecole, Woburn Perwith foliage very finely divided or fringed. $\begin{gathered}\text { onnial Kale. } \\ \text { Thomp. }\end{gathered}$ The plant lasts many years, and may be propagated by cuttings, as it neither flowers readily nor perfects well its seeds. Its produce is stated to have been more than four times greater than that of either the Green or Purple Borecole on the same extent of ground. The weight of produce from ten square yards was a hundred and forty-four pounds ten ounces; but some of the large kinds of Cabbages and Savoys will exceed this considerably, and prove of better quality. The Woburn Perennial Kale can therefore only be recommended where the climate is too severe for the more tender kinds of the Cabbage tribe. 


\section{BROCCOLI.}

\section{Brassica oleracea var.}

In its structure and general habit the Broccoli resembles the Cauliflower. Between these vegetables the marks of distinction are so obscurely defined that some of the white varieties of Broccoli appear to be identical with the Cauliflower. Botanists divide them as follows :-

The Cauliflower has generally a short stalk, and whiteribbed, oblong leaves. The stem by which the flower is supported unites at the head of the primary branches into thick, short, irregular bundles, in the form of a corymb. It appears to be a degeneration of the Brassica oleracea costata, or Portugal Cabbage.

In the Broccoli the stalk is more elevated, the leaf-nerves less prominent, the pedicles, or stems, connected with and supporting the flower, or head, less thick and close. They are also longer; so that, on becoming fleshy, they resemble in shape the young shoots of asparagus; hence the name of "Asparagoides," given by ancient botanists to Broccoli. It seems to be a degeneration of the "Chou cavalier," or tall, open Cabbage.

Cultivation, by improving the finer kinds of White Broccolis, is narrowing the distinctive marks; but, although so nearly alike, they must ever remain really distinct, inasmuch as they derive their origin from two very distinct types, viz., the Portugal Cabbage and the Tall Curled Kale. The Cauliflower also originated in the south of Europe, and the Broccoli in the north of Europe, either in Germany or Britain.

Seed. - Broccoli-seeds are rarely raised in this country; most of the supply being received from France or England. In size, form, and color, they are similar to those of the Cabbage or Cauliflower. An ounce may be calculated to pro- 
duce about five thousand plants, although it contains nearly twice that number of seeds.

Sowing and Cultivation. - In New England, as well as in the Middle and Western States, the seeds of the later sorts should be sown in March or April, in the manner of early cabbages; whilst the earlier varieties may be sown in the open ground, from the middle to the last of May. If the sowing be made in the open ground, prepare a small nurserybed not too directly exposed to the sun, and sow in shallow drills six or eight inches apart. The last of June, or as soon as the plants have attained sufficient size, transplant them into soil that is well enriched, and has been deeply stirred, setting them at the distance directed for the variety. If possible the setting should be performed when the weather is somewhat dull, for then the plants become sooner established; but, if planted out in dry weather, they should be immediately and thoroughly watered. If the plants have been started in a hot-bed, they should be set out at the time of transplanting cabbages.

The after-culture consists in hoeing frequently to keep the ground loose and clean, and in earthing up slightly from time to time about the stem.

Some of the early varieties will be fit for use in September; whilst the latter sorts, if properly treated, will supply the table till spring.

The difficulties attending the growing of Broccoli in this country arise mainly from the extreme heat and dryness of the summer, and the intense cold of the winter. Whatever will tend to counteract these will promote the growth of the plants, and secure the development of large and well-formed heads.

"When the heads of White Broccoli are exposed to light, and especially to the direct influence of the sun, the color is soon changed to a dingy or yellowish hue. It is, therefore, 
necessary to guard against this as much as possible by frequently examining the plants; and, when any heads are not naturally screened, one or two of the adjoining side-leaves should be bent over the flower-head to shade it from the light, and likewise to protect it from the rain. Some kinds are almost self-protecting, whilst the leaves of others spread, and consequently require more care in shading." - Thomp.

Taking the Crop. - "Broccoli should not be allowed to remain till the compactness of the head is broken, but should always be cut while the 'curd,' as the flowering mass is termed, is entire, or before bristly, leafy points make their appearance through it. In trimming the head, a portion of the stalk is left, and a few of the leaves immediately surrounding the head, the extremities being cut off a little below the top of the latter." - Thomp.

Preservation. - The heads will keep well in a light, dry cellar, if set in earth as far as the lower leaves. They are also sometimes treated as the Cabbage, by selecting a dry situation, setting out the plants late in autumn, and erecting over them a temporary shed; afterwards adding a thick covering of straw to prevent severe freezing.

Seeds. - The seeds of Broccoli are not distinguishable from those of the Cauliflower. They, however, rarely ripen well in this country, and seedsmen are generally supplied from abroad.

Use. - The heads, or flowers, are cooked and served in all the forms of the Cauliflower.

Varieties. - These are exceedingly numerous; although the distinctions, in many instances, are neither permanent nor well defined.

In 1861-62, a hundred and three nominally distinct sorts were experimentally cultivated at the Chiswick Gardens, near London, Eng., under the direction of Robert Hogg, Esq. In reporting the result, he says, "It is quite evident 
that the varieties of Broccoli, as now grown, are in a state of great confusion. The old varieties, such as Grange's and the Old Early White, have entirely disappeared, or lost their original character; whilst the distinctive names of Early White and Late White seem now to be possessed of no value, as, in some cases, the one is used for the other, and vice versa."

The kinds catalogued by seedsmen, and recommended for cultivation, are the following, viz.:-

Similar to Mitchinson's Penzance, but easily Ambler's distinguished by its winged leaves, those of Early White. the last named being interrupted. It is remarkable hardy, and produces a large, creamy-white head, very uniform in size.

A large and fine sort, earlier than the Portsmouth; flower cream-yellow. Sow in the open ground in May, and transplant three feet apart Chappell's Large Cream colored.

Chappell's Nrw in each direction.

The leaves of this variety are long, narrow, and much undulated; the leaf-stems are tinged with purple; the heads are of medium size, Danish, or Late Green. Late Danish. SIBERIAN. compact, exposed, and of a greenish color. It is one of the latest and hardiest of all varieties.

This variety resembles the Sulphur-colored; from which it probably originated. It is, howBrowarf Brown Closeheaded. ever, earlier, and differs in the form, as well as Trans. in the color, of the flower. The leaves are small, not much waved, dark green, with white veins; they grow erect, and afford no protection to the head. Most of the crowns are 
green at first, but they. soon change to large, handsome, brown heads.

The plants should be set two feet apart in each direction.

Early Purple. Trans. EarLy PURPLE SPROUTING.

An excellent kind, of a deep purple color. When the variety is unmixed, it is close-headed at first ; afterwards it branches, but is liable to be too much branched, and to become green. The plant is from two to three feet high, and a strong grower; the leaves are comparatively short, spreading, and of a purplish-green color; the head is quite open from the leaves. Small leaves are sometimes intermixed with the head, and the plant produces sprouts of flowers from the alæ of the leaves.

It succeeds best in rich soil, and the plants should be set three feet apart.

Early Sprouting. IfCInt.

Asparagus Broccoli. NORTI'S EARLY PuRple. Italian PURPLE. TTALAN
LPOUTING. EAR-
LYANCHING.
A strong-growing, hardy sort, from two to three feet high. The leaves are spreading, much indented, and of a purplish-green color. The flower is close-headed, and, in the genuine variety, of a rich purple on its first appearance. It is, however, liable to lose its color, and to become greenish; and sometimes produces numerous small, green leaves, intermixed with the flower, particularly if grown in soil too rich.

The variety is extensively grown by the market-gardeners in the vicinity of London.

Elletson's Gigantic Late White. ELLETSON's МАммотн.

Fine Early White. Thomp.

EARLY WHITE. DEVONGHIRE DEVONSHIRE
WHITE. AUTUMN WHITE.
One of the largest and latest of the White Broccolis. Leaves spreading; stem short.

Plant tall, with erect, dark green, nearly entire leaves. The heads are very white and close. . 
This variety, in common with a few others, is sometimes cut in considerable quantities by market-gardeners previous to heavy frost, and preserved in cellars for the supply of the market.

Head pure white, scarcely distinguishable from the finest Cauliflower; size large, - when Frogmore Protecting. well formed, measuring from seven to nine inches in diameter.

A recently introduced sort, promising to be one of the best. The plants are extremely hardy and vigorous, and rarely fail to develop a large and fine head, having a rich, curdy appearance, and, as before observed, similar to a wellgrown Cauliflower. It is of dwarf growth; and the outer leaves, closing over the large head of flowers, protect it from the action of severe weather.

A fine, white, early autumn variety, much grown about Edinburgh.

Gillespie's Broccoli. Thomp.

This is an old variety, and, when pure, still Grange's Earstands in high estimation, having a head near- er Broccoli. ly as large and as white as a Cauliflower. The Grange's Earry TIITE. HOPleaf-stems are long and naked; the leaves are WOOD'S EARLY somewhat ovate, lobed at the base, slightly WHLL. EARLY waved, and, incurving a little over the flower, WHITE. INVISIBLE. defend it from the frost and wet. It is not a large grower; and, being upright in habit, may be grown at two feet distant.

Hardy, and well deserving of cultivation. The London market-gardeners cultivate four varieties, of which this is the principal.

Leaves long and narrow; the veins and mid- Green Cape. 


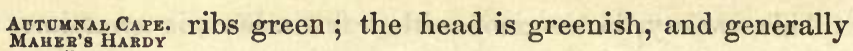
CAPE. covered by the leaves.

This variety and the Purple Cape often become intermixed, and are liable to degenerate. They are, however, quite distinct, and, when pure, very beautiful. Green Close- This new and excellent Broccoli is appa-
headed Winter. Trans. rently a seedling from the Green Cape. The Late Grien. SIBRRIAN. DWARE ROMAN. plants are dwarf; the leaves are large and numerous, with white veins. The flower grows exposed, is not of large size, and resembles that of the Green Cape. Its season immediately follows that of the last-named variety.

Hammond's White Cape.

An excellent, pure white variety, obtained in England by cultivation and selection.

Kent's Late White.

R. Hogg.

A remarkably hardy, dwarf-growing variety, with dark green foliage. Bouquet white, of good size, and well protected. Kiddermin- Head large and handsome, of pure whiteness,
ster.

R. Hogg. and much exposed. It is evidently a form of "Willcove," and has, undoubtedly, emanated from that variety; but it is somewhat earlier.

Knight's Protecting. R. Hogg.

EARLT GEM. THE GEM. LAKE'S

GEM. WATERLOO Dilite WIITH's Lite WHITR. HAMPTON Court. Invisibl

LATE White.

When pure, this variety is of a dwarfish habit of growth, with long, pointed, and winged leaves, which have a spiral twist about the head, and turn in closely over it, so as effectually to protect it from the effect of frost, and preserve it of a fine white color.

It is remarkably hardy; and as the plants are of small size, with comparatively large heads, a great product is realized from a small piece of ground. 
This is the latest Purple Broccoli. The plants Late Dwarf seldom rise above a foot in height. The flower, Dwarr Swrodsh. at first, shows small and green, but soon en- DWAAY DANISH. larges, and changes to a close, conical, purple head. The leaves are short and small, dark green, with white veins, much sinuated, deeply indented, and form a regular radius round the flower. The whole plant presents a singular and beautiful appearance.

This is an old variety; but is considered by Miller's Late some to be the best late sort, if it can be obtained true. Hardy. Transplant two feet apart. White.

Thomp. MiLleR's DWARF.

Hardy, and of a dwarf habit; leaves smooth, Te Plus Un. glaucous, protecting the head, which is cream- tra. Thomp. colored, large, and compact. Transplant two feet apart.

One of the best of the Spring Whites. The Mitchinson's leaves are much waved on the margin, and en- Penzance. close large and fine heads, which are nearly of CoRMISH. MITCH a pure white color. Very hardy. IXSOK'B EARLY White.

Leaves large, broad, with white veins, spread- Portsmouth. ing; although the central ones partially cover CRRAM-COLORE. the flower, or head, which is buff, or cream- $\begin{gathered}\text { SoUTHAMProx. } \\ M A B R B\end{gathered}$ colored. It is a hardy sort; and the flower, which is produced near the ground, is said to exceed in size that of any other variety. The plants should be set three feet apart.

This variety produces a close, compact head, Purple Cape. of a purple color, which, in favorable seasons, EARLY Puppis comes as large as a Cauliflower. The plants SLILSIAS. How comes as large as a Cauliflower. The plants grow from a foot to a foot and a half in height, GaAORE with short, erect, concave leaves, regularly sur- 
rounding the head. The veins and midribs are stained with purple. The head is exposed to view in growing; and, as it enlarges, the projecting parts of the flower show a greenish-white mixed with the purple color. When boiled, the whole flower becomes green.

Excellent for general culture, as it is not only one of the finest varieties for the table, but the plants form their heads much more generally than many other kinds. It is the earliest of the Purple Broccolis.

The seeds should not be sown before the middle or last of May, and the plants will require a space of two feet and a half in each direction.

Reading Giant.

A remarkably large, white-flowered variety, recently introduced by Messrs. Sutton and Sons of the Royal Berkshire Seed Establishment, Reading, Eng. It is described as sometimes attaining a weight of seventeen pounds, and measuring, when divested of foliage, four feet in circumference. Though somewhat coarse, and wanting in compactness, it is quite free from fibre, and as tender and delicate as many of the smaller and close-flowered Broccolis.

Snow's Superb White

Winter.

Thomp.

GILL'S YARMOUTH WHITE.

This variety is of dwarfish habit. The leaves are broad, with short stems; the heads are large, white, compact, well protected by the incurved leares, and equal in quality to those of the Cauliflower. By many it is considered superior to Grange's Early Cauliflower Broccoli. White, or Broccoli. Trans.

NAPLES WHITE. EARLY WHITE. ADAMS'S EARLX WAX WHTE. IMPE- when ready for cutting, and thus protect it
TIALEAKLYWHTE. strong grower. The leaves are large, thickveined, flat, and narrow, and generally compress the head, so as to render it invisible 
from rain and the effects of frost. Head Graxar's Catlilarge, perfectly white.

COVENTGADEN

MARKET.

Leaves with long stems; heads large, compact, somewhat conical, sulphur-colored, sometimes tinged with purple. Hardy.

Sulphur, or

Brimstone

Broccoli. Trans.

LATE BRIMSTONE. FINE LATE SULPHUR. EDISBURGH SULPHUR.

Comparatively new, and so closely resembling a Cauliflower as to be scarcely distinguishWalcheren Broccoli. McInt. able from it. The leaves, however, are more curled, and its constitution is of a hardier nature, enduring the cold, and also withstanding heat and drought better. Much esteemed in England, where, by successive sowings, it is brought to the table at every season of the year.

'This is a form of Knight's Protecting, but is Ward's Sufrom two to three weeks later. It is of a $\begin{gathered}\text { perb. } \\ \text {. Hogg. }\end{gathered}$ dwarfish habit of growth, closely protected by the spirally compressed leaves, with a good-sized and perfectly white head. One of the best of the late White Broccolis.

Heads of medium size, white, and compact. White Cape.

The true Willcove is a variety perfectly dis- Willeove. tinct from every other of its season. The LATE Wogg. heads are large, firm, even, and fine, and of a pure whiteness. They are fully exposed, and not protected by the leaves, as most other Broccolis are. On this account the variety is more liable to be injured by the weather than any other late sort; and therefore, in severe seasons, it must be regarded as deficient in hardiness.

"It derives its name from a small village near Devenport, Eng., where it originated, and where the Broccoli is said to be grown in great perfection." 


\section{BRUSSELS SPROUTS.}

Thousand-headed Cabbage. Brassica oleracea var.

In its general character this vegetable is not unlike some of the varieties of Kale or Borecole. Its stem is from a foot to four feet in height, and from an inch and a half to upwards

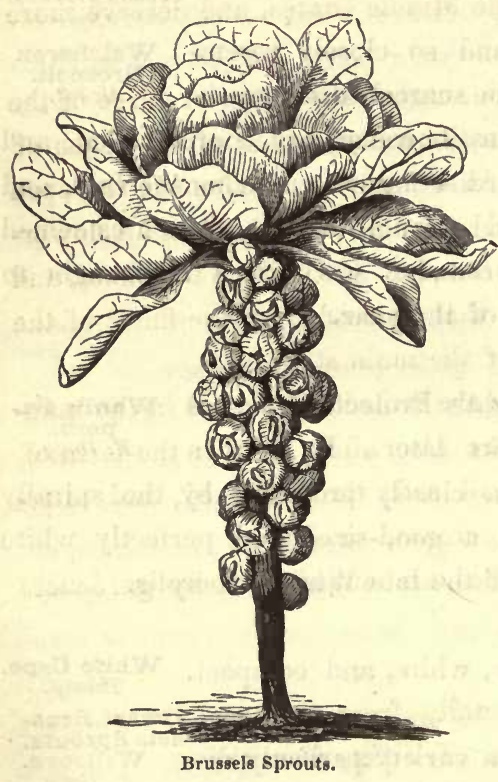
of two inches in diameter. It is remarkable for the production of numerous small axillary heads, or sprouts, which are arranged somewhat in a spiral manner, and which are often so closely set together as entirely to cover the sides of the stem. " $\quad$ These small heads are firm and compact like little cabbages, or rather like hearted Savoys in miniature. A small head, resembling an open Savoy, surmounts the stem of the plant, and maintains a circulation of sap to the extremity. Most of the original side-leaves drop off as these small buds, or heads, enlarge." - Thomp.

Culture. - The plant is always raised from seeds, which, in size, form, or color, are scarcely distinguishable from the seeds of the Common Cabbage. These should be sown at the time and in the manner of the Cabbage, either in hotbeds in March or April, or in the open ground in April or May. When three or four inches high, transplant two feet apart in each direction, and cultivate as directed for cabbages 
and Cauliflowers. In September, the early plantings will be fit for gathering; whilst the later plants will afford a succession that will supply the table during the winter. For the latter purpose, they should be harvested before severe freezing weather, and preserved in the cellar as Cauliflowers and Broccolis. They are quite hardy, easily grown, thrive well in New England or in the Middle States, and deserve more general cultivation.

To raise Seeds. - In the autumn select two or three of the finest plants ; keep them in the cellar, or out of the reach of frost, during winter; and in the spring set them in the open ground, two feet apart, and as far as possible from all flowering plants of the Cabbage family. Cut off the top shoot, and save the branches of pods that proceed from the finest of the small heads on the sides of the main stem.

Use. - The small heads are boiled and served in the manner of Cabbages. They are also often used in the form of the Cauliflower, boiled until soft, then drained, and afterwards stewed with milk, cream, or butter.

Varieties. - Two varieties are enumerated by gardeners and seedsmen, viz.:-

A low-growing sort, usually from eighteen Dwarf Brusinches to two feet in height. It differs from the sels Sprouts. following variety principally in size, though it is somewhat earlier. The dwarf stems are said to produce heads which are more tender and succulent when cooked than those obtained from taller plants.

Stem nearly four feet in height; plant healthy Tall or Giant and vigorous, producing the small heads pecu- $\begin{gathered}\text { Brussels } \\ \text { Sprouts. }\end{gathered}$ liar to its class in great abundance. It is somewhat hardier than the foregoing variety, and, on account of its greater length of stalk, much more productive. 
There is, however, very little permanency to these sorts. Much of the seed found in the market will not only produce plants corresponding with both of the varieties described, but also numerous intermediate kinds.

\section{THE CABBAGE.}

\section{Brassica oleracea capitata.}

The Cabbage is a biennial plant; and, though comparatively hardy, - growing at all seasons unprotected in England, - will not withstand the winters of the Northern States in the open ground.

When fully developed, it is from four to five feet in height. The flowers are cruciform, generally yellow, but sometimes white or yellowish-white. The seeds, which ripen in July and August of the second year, are round, reddish-brown or blackish-brown, and retain their vitality five years. About ten thousand are contained in an ounce.

Soil. - Cabbages are best grown in deep, rich, loamy soil. On land that has been long under cultivation, or in dry situations, they rarely succeed well. Ashes, with a mixture of salt, may be advantageously applied, not only for the promotion of growth, but for protection against the attack of the maggot, to which the roots are liable. They may be mixed in the hill at the time of transplanting, or applied about the plant from time to time in the process of cultivation.

Propagation. - All of the varieties are propagated from seed sown annually. For early use, a sowing may be made in a hot-bed in February or March; and, for winter use, the seed may be sown in a nursery-bed in the open ground in May or June. When five or six inches high, transplant to the distance directed in the description of the variety. In 
the hot-bed or nursery-bed, the plants should not be allowed to stand too thickly together, as this causes them to draw up weak and feeble.

To raise Seed. - At the time of harvesting, select a few of the most compact and best-formed heads possessing the characters of the pure variety; and, in the following April, set the plants entire, three feet apart in each direction. As they progress in growth, remove all of the side-shoots, and encourage the main sprout, that will push up through the centre of the head. Seeds from the side-shoots, as well as those produced from decapitated stems, are of little value. No cabbage-seed is really reliable that is not obtained from firm and symmetrical heads; and seed thus cultivated for a few successive seasons will produce plants, ninety per cent. of which will yield well-formed and good-sized Cabbages.

American grown seed is generally considered superior to that of foreign growth; and, when it can be obtained from a reliable seedsman or seeds-grower, the purchaser should not be induced by the difference in price to select the nominally cheaper, as there are few vegetables with which the character of the seed is of greater importance.

Varieties. - The varieties are numerous, and the distinction, in many instances, well-defined and permanent. Between some of the sorts, however, the variations are slight, and comparatively unimportant.

This is a variety of the Early York; the head, however, is smaller and more conical,

Atkins's Matchless: McInt. and the leaves are more wrinkled, - somewhat similar to those of the Savoys. It is of tender texture and delicate flavor; and, with the exception of its smaller size, is considered equal, if not superior, to the last-named variety.

It is comparatively a recent sort, and seems to be desirable 
rather for its precocity and excellent quality than for its size or productiveness.

Transplant to rows fifteen inches apart, and twelve inches asunder in the rows.

Barnes's

Early.

BABNES'S EARLY

DWARF.

This variety, in respect to season, size, form, and general habit, seems to be intermediate between, or a hybrid from, the York and Oxheart. Head ovate, rather compact; texture fine and tender ; flavor mild and good.

Set in rows two feet apart, and eighteen inches apart in the rows.

Bergen

Drumhead.

LARGR BERGEN. GREAT AMERICAN

QUINTAL. Vil.

LARGE GERMAN

DRUMHEAD.

Head remarkably large, round, flattened at the top, compact; the leaves are of a peculiar, glaucous-green color, of thick texture, firm, and rather erect; the nerves large and prominent; the outer leaves of the head are usually revoluted on the borders; the loose leaves are numerous, and rarely rise above a level with the summit of the head; the stalk is short.

The Bergen Drumbead is one of the largest and latest of all the cabbages, and, when not fully perfected before being harvested, has the reputation, if reset in earth in the cellar, of heading, and increasing in size during winter. It is a popular market sort; and, notwithstanding its extraordinary proportions, is tender, well flavored, and of more than average quality for family use. The plants should be set three feet apart. Champion of One of the largest of the recently introduced
America.

sorts; the whole plant sometimes attaining a weight of forty pounds and upwards. Head flattened, somewhat resembling the Drumheads; outer leaves very few, 
succulent, and tender; stalk short; quality tender, mild, and well flavored.

As a market variety, it has few, if any, superiors. It heads with great uniformity, and bears. transportation well ; but its large size is objectionable when required for the use of families numbering but few members.

The type of the Early Battersea is very old. Early BatterWhen fully grown, the four outside or lower DWARy BAтrkgleaves are about sixteen inches in diameter; and, when taken off and spread out, their general outline is nearly circular. The stem is dwarfish, and the leaf-stalks come out quite close to each other; so that scarcely any portion of the stem is to be seen between them. The whole cabbage measures about three feet in circumference. The heart is shortly conical, with a broad base; near which it is about two feet in circumference, when divested of the outside leaves. The ribs boil tender.

It is one of the best sorts for the general crop of early cabbages; is not liable to crack; and, when cut close to the stem, often puts forth a number of fresh heads, of fair size and good quality.

This is an intermediate sort, both in respect Early Corto size and season, and is said to derive its nish. name from a village in Devonshire, Eng., where PERTOX, PAIITVILLR. it has been cultivated for ages. The head is of full medium size, somewhat conical in form, and moderately firm and solid. The outside leaves are rather numerous, long, and of a pale or yellowish-green color. Its texture is fine and tender, and its flavor mild and agreeable. It is three or four weeks later than the Early York.

If reset in spring, this variety, like the Vanack, sends out from the stalk abundant tender sprouts, which will supply 
the table with the best of coleworts, or greens, for several weeks of the early part of the season.

As the plants are somewhat leafy and spreading, the rows should be three feet apart, and the distance between the plants in the rows full two feet.

Early Drum- This is an intermediate variety, about the size of the Early York, and a little later. The head is round, flattened at the top, firm and well formed, tender in texture, and well flavored.

It is a good sort for the garden, as it heads well, occupies but little space in cultivation, and comes to the table immediately after the earlier sorts.

The plants should be set in rows two feet apart, and eighteen inches apart in the rows.

Early Dutch An excellent cabbage, of the smallest size. It Twist. is early and delicate, and may be planted almost as close together as a crop of cabbage lettuce.

The first sowing should be made early; afterwards, sowings should be made at intervals of two or three weeks, which will secure for the table a constant supply of fresh and tender heads from July till winter.

Early IIope. A small, solid, oval-headed, early sort, nearly of the season of the Early York. The leaves are bright green, erect and firm. In quality it is not unlike the Small Early Ox-heart, and requires the same space in cultivation.

The variety is comparatively new, and, though found on the catalogues of seedsmen, is little disseminated.

Early Low Dutch. EARLY DUTCH

This well-known and standard variety has a round, medium-sized, solid head, sometimes tinted with brown at its top. The outside and loose 
leaves are few in number, large, rounded, clasping, blistered, and of a glaucous-green color; the ribs and nerves are small; the stalk is thick and short. It is early, tender, of good quality, heads well, and one of the best sorts for growing in a small garden for early table use. The plants should be allowed a space of two feet and a half between the rows, and nearly two feet in the rows.

Head of medium size, bright green, ovoid Early Nonor egg-shaped, solid; the leaves are generally pareil. erect, roundish, concave, and of thick, firm texture; the stalk is comparatively short, and the spare leaves few in number; flavor mild and pleasant. By some it is considered the best of the intermediate varieties.

In many respects it resembles the Small Ox-heart.

The color of this variety, and the form of its Early Sugarhead, distinguish it from all others. The plant, when well developed, has an appearance not unlike some of the varieties of Cos lettuces; the head being round and full at the top, and tapering thence to the base, forming a tolerably regular inverted cone. The leaves are erect, of a peculiar ashy or bluish-green hue, spoon-shaped, and clasp or cove over and around the head in the manner of a hood or cowl.

Though an early cabbage, it is thought to be more affected by heat than most of the early varieties; and is also said to lose some of its qualities if kept late in the season. Head of medium size, seldom compactly formed, and, when cut and cooked in its greatest perfection, tender and well flavored.

Transplant in rows two feet apart, and from eighteen to twenty-four inches apart in the rows. 
Early Wake- Head of medium size, generally somewhat
field. conical, but sometimes nearly round, compact; leaves glaucous-green; stalk small.

A fine, early variety, heading readily. As the plants occupy but little space, it is recommended as a desirable sort tor early marketing.

Early York. According to Rogers, the Early York Cabbage was introduced into England from Flanders, more than a hundred years ago, by a private soldier named Telford, who was there many years in the reign of Queen Anne. On his return to England, he settled as a seedsman in Yorkshire; whence the name and celebrity of the variety.

In this country it is one of the oldest. most familiar, and, as an early market sort, one of the most popular, of all the kinds now cultivated. The head is of less than medium size, roundish-ovoid, close, and well-formed, of a deep or ash-green color, tender, and well flavored. 'The loose leaves are few in number, often revoluted on the border, and comparatively smooth on the surface; nerves greenish white. The plants of the true variety have short stalks, occupy but little space, and seldom fail to produce a well-formed, and, for an early sort, a good-sized head. They require a distance of about eighteen inches between the rows, and fifteen or eighteen inches in the rows.

Its earliness and its unfailing productiveness make it a favorite with market-gardeners; and it still retains its longestablished popularity, notwithstanding the introduction of numerous new sorts, represented as being as early, equally prolific, and surpassing it in general excellence.

East Ham. From East Ham, in Essex, Eng. It is not a large, but a fine, early sort, not unlike the Ox-heart. The head is of an oval form, compact, and rather regular; the 
leaves are firm in texture, sometimes reflexed, or curved backward, but generally erect and concave; nerves pale greenish-white; stem short. It is mild and delicate, and a desirable early variety.

In setting the plants, allow two feet and a half between the rows, and two feet between the plants in the rows.

Head large, loose and open; the leaves are numerous, large, rounded, waved on the bor- $\begin{gathered}\text { GMERCANGRES } \\ \text { GLAZDD. }\end{gathered}$ ders, and slightly blistered on the surface; stalk comparatively long. Its texture is coarse and hard, and the variety really possesses little merit; though it is somewhat extensively grown in warm latitudes, where it appears to be less liable to the attacks of the cabbage-worm than any other sort.

A distinguishing characteristic of this cabbage is the deep, shining-green color; the plants being readily known from their peculiar, varnished, or glossy appearance.

Head large, round, sometimes flattened a lit- Large Late the at the top, close and firm; the loose leaves Drumhead. are numerous, broad, round, and full, clasping, HEAD.

blistered, and of a sea-green color; the ribs and nerves are of medium size, and comparatively succulent and tender; stem short. The variety is hardy, seldom fails to form a head, keeps well, and is of good quality.

In cultivation, it requires more than the average space, as the plants have a spreading habit of growth. The rows should not be less than three feet apart; and two feet and a half should be allowed between the plants in the rows.

There are many varieties of this cabbage, introduced by different cultivators and seedsmen under various names, differing slightly, in some unimportant particulars, from the 
foregoing description, and also differing somewhat from each other, "but agreeing in being large, rounded, cabbaging uniformly, having a short stem, keeping well, and in being tender and good flavored."

Large York. This is a larger cabbage than the Early York, which variety it somewhat resembles. The head, however, is broader in proportion to its depth, and more firm and solid; the leaves not connected with the head are more erect, of a firmer texture, not quite so smooth and polished, and the surface slightly bullated, or blistered. The stalk is also shorter, and it is two or three weeks later.

The Large York seems to be intermediate between the Early York and the Large Late Drumheads, as well in respect to form and general character as to its season of maturity. It is recommended as being less affected by heat than many other kinds, and, for this reason, well adapted for cultivation in warm climates. It seldom fails in forming its head, and is tender and well flavored.

Large Oxheart. LARGE FRENCH OX-HEART.

This is a French variety, of the same form and general character as the Small Ox-heart, but of larger size. The stalk is short; the head firm and close, and of a light green color; the spare leaves are few in number, generally erect, and concave. It is a week or ten days later than the Small Ox-heart, forms its head readily, and is tender and well flavored. One of the best of the intermediate sorts.

The plants should be set two feet apart in each direction.

Little Pixie. A recent sort, remarkable for its earliness, Том Тнимв. and for its diminutive size, and generally dwarfish character, - the whole plant, when full grown, being scarcely larger than a colewort, or some varieties of cabbage lettuce. 
It is of tender texture; the flavor is mild and delicate; and as an early variety, particularly where space is limited, is recommended for cultivation.

One of the largest of the Cabbage family, produced from the Mason, or Stone-mason, by Mr. Alley, and introduced by Mr. J. J. H.

Marblehead Mammoth Drumbead. J.J. H. Gregory. Gregory; of Marblehead, Mass.

Heads not uniform in shape, - some being nearly flat, while others are almost hemispherical ; size very large, varying from fifteen to twenty inches in diameter, - although specimens have been grown of the extraordinary dimensions of twenty-four inches. In good soil, and with proper culture, the variety is represented as attaining an average weight of thirty pounds. Quality tender and sweet.

Cultivate in rows four feet apart, and allow four feet between the plants in the rows. For early use, start in a hot-bed; for winter, sow in the open ground from the first to the middle of May. Sixty tons of this variety have been raised from a single acre.

The Mason Cabbage, in shape, is nearly Mason. J.J. hemispherical ; the head standing well out from H. Gregory. among the leaves, growing on a small and short stalk. Under good cultivation, the heads will average about nine inches in diameter and seven inches in depth. It is characterized for its sweetness, and for its reliability for forming a solid head. It is also an excellent rariety for cultivation in ex-

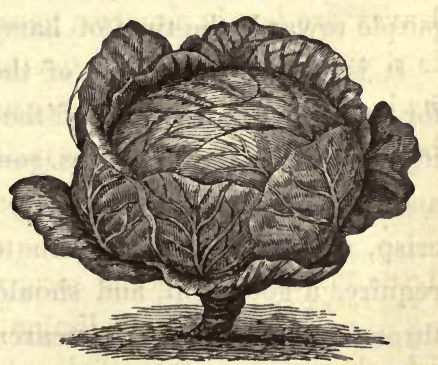

Mason Cabbage. treme Northern latitudes, where, from the shortness of the 
season, or in those sections of the South, where, from excessive heat, plants rarely cabbage well. Under good cultivation, nearly every plant will set a marketable head.

Originated by Mr. John Mason, of Marblehead, Mass.

Pomeranian. This variety is of comparatively recent introduction. The head, which is of medium size, has the form of an elongated cone, and is regular and symmetrical. It is quite solid, of a pale or yellowish-green color, tender and well flavored, and remarkable for the peculiar manner in which the leaves are collected, and twisted to a point, at its top. The loose, exterior leaves are numerous, large, and broad; stalk rather high.

It is an intermediate variety, and excellent either as an autumnal or winter cabbage. As it heads promptly and almost invariably, and, besides, is of remarkable solidity, it makes a profitable market cabbage, keeping well, and bearing transportation with little injury.

Premium Flat Dutch.

Large Flat DUTCH.
Head large, bluish-green, round, solid, broad and flat on the top, and often tinted with red or brown. The exterior leaves are few in number, roundish, broad and large, clasping, blistered on the surface, bluish-green in the early part of the season, and tinged with purple towards the time of harvesting; stalk short.

It is one of the largest of the cabbages, rather late, good for autumn use, and one of the best for winter or late keeping, as it not only remains sound, but retains its freshness and flavor till late in spring. The heads open white and crisp, and, when cooked, are tender and well flavored. It requires a good soil, and should be set in rows not less than three feet apart, and not nearer together than thirty inches in the rows.

As a variety for the winter market, the Premium Flat 
Dutch has no superior. It is also one of the best sorts for extensive culture, as it is remarkably hardy, and seldom fails in forming a good head. An acre of land, well set and cultivated, will yield about four thousand heads.

Head of large size, round, a little flattened, solid; the exterior leaves are numerous, glau-

St. Denis. Vil. cous-green, clasping at their base, and often reflexed at the ends; the ribs and nerves are large and prominent; stem long.

This variety is of good quality, seldom fails to form a head, and yields a large crop in proportion to the quantity of land it occupies. The plants should be set two feet and a half apart in each direction.

A half-early variety, intermediate in form and size between the York and Ox-heart. As Shilling's Queen. a "second early," it is one of the best. It compares favorably with the Early Nonpareil, and is tender, mild, and delicate.

Transplant in rows two feet and a half apart, and eighteen inches apart in the rows.

Head below medium size, ovate or egg-shaped, obtuse, broad at the base, compact. The leaves Small Oxheart. are of the same bright green as those of the York Cabbage, round, of firm texture, sometimes revolute, but generally erect, and concave; the nerves are white, more numerous and less delicate than those of the last-named variety; the stalk is short, and the leaves not composing the head few in number.

The Ox-heart cabbages - with respect to character, and period of maturity - are intermediate between the Yorks and Drumheads; more nearly, however, resembling the 
former than the later. The Small Ox-heart is about ten days later than the Early York.

As not only the heads, but the full-grown plants, of this rariety are of small size, they may be grown in rows two feet apart, and sixteen inches apart in the rows.

Stone-mason. An improved variety of the Mason, origiory. nated by Mr. John Stone, Jun., of Marblehead, Mass. Head larger than that of the original, varying in size from ten to fourteen inches in diameter, according to the strength of the soil and the cultivation given it. The form of the head is flatter than that of the Mason, and but little, if any, inferior to it in solidity. Stem short and small. Under good culture, the heads, exclusive of the outer foliage, will weigh about nine pounds. Quality exceedingly sweet, tender, and rich. A profitable variety for market purposes; the gross returns per acre, in the vicinity of Boston, Mass., often reaching from two hundred dollars to three hundred and fifty.

The Mason, Stone-mason, and the Marblehead Mammoth, severally originated from a package of seeds received from England, under the name of the "Scotch Drumhead," by Mr. John M. Ives, of Salem, Mass.

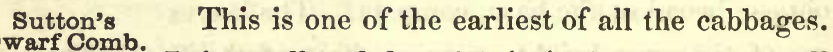
Dwarf Comb.

It is small and dwarfish in its habit, hearts well early in the season, and will afford a good supply of delicate sprouts throughout a large part of the summer.

The plants require a space of only twelve inches between the rows, and the same distance between the plants in the rows.

The seed of this variety, in common with other dwarfish and early sorts, should be sown more frequently than the larger growing kinds, so as to keep up a succession
} 
of young and delicate heads, much after the manner of sowing lettuce.

This variety was introduced into England from Holland, more than a century ago, by a Vanack. Lind. wealthy Dutch farmer of the name of Vanack. Though often found upon the catalogues of our seedsmen, it has not been extensively grown in this country, and perhaps is really but little known.

Head somewhat irregular in shape, broad at the base, and terminating in rather a sharp point; color palish-green, the ribs and nerves of the leaves paler. The exterior leaves are large, spreading, deep green, and strongly veined.

It is tender in texture, sweet and delicate in flavor, cabbages early and uniformly, and, when kept through the winter and reset in spring, pushes abundant and fine sprouts, forming excellent early coleworts, or greens. Lindley pronounces its quality inferior to none of the best cabbages. Transplant to rows two feet and a half apart, and two feet apart in the rows.

A large, late, but coarse, French variety. The head is generally round; leaves deep Vaugirard Cabbage. green, - those of the outside having the veins sometimes tinged with red.

The plants should be set three feet apart in each direction.

Heads small, but solid and uniform in shape. Waite's New It has little of the coarseness common to the Hov.Mag. larger varieties, and the flavor is superior.

One of the finest early cabbages, and one of the best sorts for the market. It occupies but little space compared with some of the older kinds, and a large number of plants may be grown upon a small piece of ground. 
Winnigstadt. This is a German variety, somewhat similar Pointed Head. to the Ox-heart, but more regularly conical. Head broad at the base, and tapering symmetrically to a point, solid, and of the size of the Ox-heart; leaves of the head pale or yellowish green, with large nerves and ribs; the exterior leaves are large, short, and rounded, smooth, and of firm texture; the stalk is short.

It is an intermediate sort, immediately following the Early York. A large proportion of the plants will form good heads; and as these are not only of remarkable solidity, but retain their freshness well during winter, it is a good variety for marketing, though rather hard, and somewhat deficient in the qualities that constitute a good table cabbage.

It requires a space of about eighteen inches by two feet.

Red Varieties. - These are comparatively few in number, and generally used as salad or for pickling. When cooked, they are considered less mild and tender than the common varieties, besides retaining a portion of their color, which, by many, is considered an objection.

Early Dwarf Head nearly round, generally of a deep red $\underset{\substack{\text { RERY BLOoD } \\ \text { RED. SMALL RED. }}}{\text { Rer dark purple color. The leaves on the out- }}$

side of the plant are not numerous, rather rigid, or stiff, green, much washed or clouded with red; stalk short.

It is about ten days earlier than the Large Red Dutch, and is quite variable in form and color.

The seed should be sown early; and, when transplanted, the rows should be about two feet apart, and the plants eighteen inches in the rows.

The variety is seldom served at the table cooked in the manner of other sorts ; for, when boiled, it has a dark and unattractive appearance. It is usually shredded, and with 
the addition of vinegar, olive-oil, mustard, or other seasoning, served as a salad.

The most familiar, as well as the most popular, of the red varieties. The head is rather

Läge Red Dutch. large, round, hard, and solid; the leaves composing the head are of an intense purplish-red; the outer leaves are numerous, red, with some intermixture or shades of green, firm in texture, and often petioled at the union with the stalk of the plant, which is of medium height.

On account of its dark color when cooked, it is seldom used in the manner of the common cabbages, but is chiefly used for pickling, or, like the other red sorts, cut in shreds, and served as a salad; though any solid, well-blanched, smallribbed, white-headed sort will answer for the same purpose, and perhaps prove equally tender and palatable.

The Large Red Dutch is one of the latest of cabbages, and should receive the advantage of nearly the entire season. Make the sowing, if in the open ground, as soon as the soil is in good working condition, and transplant or thin to rows two and a half or three feet apart, and two feet apart in the rows.

The heads may be kept fresh and sound until May.

Small, like the Utrecht Red, but of a still deeper color. When pickled, however, the dark Superfine Bhomp. coloring matter is greatly discharged, so that the substance is left paler than that of others originally not so dark. It is, therefore, not so good for pickling as other sorts which retain their color and brightness.

A small, but fine, dark-red cabbage.

Utrecht Red. Thomp. 


\section{THE CAULIFLOWER.}

Brassica oleracea var.

The Cauliflower, like the Broccoli, is strictly an annual plant, as it blossoms and perfects its seed the year in which it is sown. When fully grown or in flower, it is about four feet in height, and in character and general appearance is similar to the Cabbage or Broccoli at a like stage of growth. The seeds resemble those of the Cabbage in size, form, and color, although not generally so uniformly plump and fair. From ten to twelve thousand are contained in an ounce, and they retain their germinative properties five years.

Soil. - The Cauliflower, like the Cabbage, requires a deep, rich soil, and seldom succeeds well when grown on land long under cultiration. Applications of lime and sulphur have a beneficial effect, not only in preventing the ravages of insects, but in promoting the growth of the plants. The best fertilizers appear to be those of a saline character, and excellent Cauliflower's have been produced by liberal applications of kelp and sea-weed. Where these cannot be obtained, a good substitute will be found in the use of common salt, which may be sprinkled about the plant at the time of setting, or applied from time to time in the process of cultivation.

Sowing and Culture. - The seed may be sown in a hotbed in March, at the same time and in the same manner as early cabbages, and the plants set in the open ground late in May; or the seed may be sown in the open air in April or the beginning of May, in a common nursery-bed, in shallow drills six or eight inches apart; and, when sufficiently grown, the plants may be set where they are to remain. They need not all be transplanted at one time; nor is it important when, except that, as soon as they are large enough, the first opportunity should be improved for beginning the sctting. 
The after-culture should be similar to that bestowed upon the Cabbage. The dry, sunny weather which so often prevails in the summer months is unfavorable to the full development of the Cauliflower, and in such seasons liberal applications of water or liquid manure may be beneficially made, and will often produce fine flowers from plants that would otherwise prove abortive.

The leaves are sometimes gathered, and tied loosely over the tops of the heads, to facilitate the blanching.

Taking the Crop. - Cauliflowers raised by open culture will generally come to the table in October. Such as have not fully perfected their heads may, just as the ground is elosing, be taken up by their roots, and suspended, with the top downward, in a light cellar, or other place secure from frost; by which process the heads will increase in size, and be suitable for use the last of December or first of January.

Like the Broccoli, Cauliflowers should be cut for use while the head, or what is known as the "curd," is still close and compact. As the plants advance in growth the head opens, separates into branches, and soon becomes coarse, fibrous, strong flavored, and unfit for the table.

Preservation during Winter. - The best way to preserve them during winter is to take them up late in the fall, with as much earth as possible about their roots, and reset them in earth, in a light, dry cellar, or in any other light and dry location secure from frost.

Use. - The methods of cooking and serving are almost numberless. When well grown and seasonably cut, the flavor is peculiarly mild and agreeable. Few brassicaceous plants are more ornamental, or more generally esteemed.

Varieties. - These are comparatively few in number; the distinctions, in many instances, being quite unimportant. In the color, foliage, general habit, and even in the quality, of the entire list, there is great similarity. 
Early London Stem tall; leaves of medium size. It has a Caunon Parrict- fine, white, compact "curd," as the unexLAR. FITCH'S EARLY LONDON.

panded head is termed, and is the sort grown in the vicinity of London for the early crop. It is comparatively hardy, and succeeds well when grown in this country. The plants should be set two feet and a half apart.

Early Paris Cauliflower.

Head rather large, white, and compact; leaves large; stalk short. An early sort. In France it is sown in June, and the heads come to table in autumn.

Erfurt's Early Cauliflower. ERfurt's Extra EARLY.

Leaves large, long, waved, and serrated on the borders; stalk of medium height; head large, - measuring from seven to ten inches in diameter, - close, and compact.

From the experience of a single season, this variety promises to be one of the best for cultivation in this country. Specimens exhibited under this name before the Massachusetts Horticultural Society measured fully ten inches in diameter, the surface being very close, and the heads possessing the peculiar white, curdy character so rarely attained in the climate of the United States. The plants seldom fail to form a good-sized and symmetrical head, or flower.

Frogmore Early Forcing.

Stem quite short, and plant of compact habit. The heads are large and close, and their color clear and delicate. Recommended as one of the best for forcing, as well as an excellent sort for open culture.

Iarge Asiatic Cauliflower. Thomp.

Originally from Holland. It is a fine, large, white, compact variety, taller and later than the Early London Cauliflower; it has also larger leaves. If sown at the same time, it will afford a succession. 
Plant about fifteen inches high, with winged Le Normand. leaves, which are broad, and taper abruptly R. Hogg. towards the base. They are toothed and waved on the margin, and expose a head which is about nine inches in diameter, and of a creamy color.

It is earlier than the Walcheren, and is readily distinguished from it by the waved and toothed margin of the foliage.

The plants are hardy and vigorous growers, and rarely fail to develop a flower, even in dry and unfavorable seasons.

A new variety. Bouquet not large, but hand- Mitchell's some and compact. It is so firm, that it re- Cauliflower. mains an unusual length of time without running to seed or becoming pithy. A desirable sort for private gardens and for forcing.

A recent sort, with large, clear white flowers, New Erfurt of superior quality.

Dwarf Mam. moth.

The plants are low and compact, and generally form a head, even in protracted dry and warm weather. It appears to be one of the few varieties adapted to the climate of this country, and is recommended for cultivation.

A recent variety, introduced from Holland. Stadtholder. The plants are strong growers, producing large, compact, pure white flowers. In the vicinity of London, where it is largely cultivated for the market, it is considered equal, if not superior, to the Walcheren.

A new variety, represented as being of large Waite's Alma size, and firm; surpassing in excellence the Cauliflower. Walcheren. 
Walcheren Caulifiower. Thomp.

EARLY J,EYDE. LEGGE'S WAL-
CHEREN BROCCOLI.

This has been cultivated as a Broccoli for more than ten years, though originally introduced by the London Horticultural Society, under the name of Early Leyden Cauliflower. Stem comparatively short; leaves broad, less pointed and more undulated than those of the Cauliflower usually are. The difference in constitution is, however, important; as it not only resists the cold in winter, but the drought in summer, much better than other cauliflowers. In hot, dry summers, when scarcely a head of these could be obtained, the Walcheren Cauliflower, planted under similar circumstances, formed beautiful heads, - large, white, firm, and of uniform closeness.

Wellington Messrs. Henderson and Son describe this Cauliflower. Cauliflower as the finest kind in cultivation; pure white; size of the head over two feet; in growth very dwarfish, - the stem not more than two or three inches from the soil.

It is one of the hardiest varieties known, and is said to withstand the extreme variations of the climate of the United States. An excellent sort for early planting and for forcing.

\section{COLEWORT', OR COLLARISS. Loud.}

Collet.

The Colewort, strictly speaking, is a plant distinct from the other varieties of Cabbage. It is of small habit, and at:ains sufficient size for use in a few weeks. It is eatable from the time it has four or six leaves until it has a hard heart. Loudon says the original Colewort seems to be lost, and is now succeeded by what are called "Cabbage Coleworts." These are cabbage-plants in their young state, 
and, when cooked, are quite as tender and good as the true Colewort. In growing these, all that is necessary is to sow the seed of almost any variety of the common green cabbages in drills a foot apart, and half an inch deep. For a. succession, sowings may be made at intervals of two weeks, from the last of April to the last of August. In the Southern States, the sowings might be continued through the winter.

When cultivated for sale, simply allow them to stand till there is enough to be worth bunching and eating. They are boiled and served ąt table as greens.

A small but remarkably neat variety; the whole plant, when well grown, measuring Rosette Colewort. twelve inches in diameter, and having the form of a rose not completely expanded, - the head, corresponding to the bud, still remaining at the heart, or centre; stalk small and short. The plants may be grown twelve inches asunder.

COUVE TRONCHUDA, OR PORTUGAL CABBAGE. Trans.

Portugal Borecole. Large-ribbed Borecole. Trauxuda Kale.

Though a species of Cabbage, the Couve 'Tronchuda is quite distinct from the common head varieties. The stalk is short and thick; the outer leaves are large, roundisl, of a dark bluish-green, wrinkled on the surface, and slightly u:.dulated on the borders; the midrib of the leaf is large, thick, nearly white, and branches into veins of the same color; the plant forms a loose, open head, and, when full grown, is nearly two feet high.

Culture. - It should be planted and treated like the Common Cabbage. The seeds may be sown early in frames, and the plants afterwards set in the open ground; or the sowing 
may be made in the open ground in May. The plants require two feet and a half between the rows, and two feet between the plants in the rows. The seeds, in size, form, and color, resemble those of the Cabbage, and will keep five years. One fourth of an ounce will produce about a thousand plants.

To raise Seed. - In the autumn, before severe weather, remove two or three plants entire to the cellar, and in April following reset them about two feet apart. Cut off the lower and smaller side-sprouts as they may appear, and allow only the strong, central shoot to grow. The seeds will ripen in August.

Use. - Different parts of the Couve Tronchuda are applicable to culinary purposes. The ribs of the outer and larger leaves, when boiled, somewhat resemble sea-kale in texture and flavor. The heart, or middle of the plant, is, however, the best for use. It is peculiarly delicate and agreeably flavored, without any of the coarseness which is so often found in plants of the Cabbage tribe.

Dwarf Couve Much earlier and smaller throughout than Tronchuda.

Trans. the Common Couve Tronchuda. Stem from

MURCIANA.
DWARF PORTVAL
CABRAER DWARY
Cifteen to eighteen inches high. The leaves are DABRAGE. DWARY
TRAUXUDA KALE.

TraUXUda Kale. of medium size, rounded, smooth, and collected at the centre of the plant into a loose heart, or head. When the lower leaves are taken off for use, the plant, unlike the former variety, throws out numerous sprouts, or shoots, from the base of the stem, which make excellent coleworts, or greens. It is, however, wanting in hardiness, and appears to be better adapted for early use than for late keeping.

Soil and Cultivation. - Both of the varieties require a well-manured soil. The seeds of the Dwarf Couve Tronchuda may be sown early in frames, and the plants afterwards set in the open ground; or the sowing may be made, 
in May or June, where the plants are to remain. They should be two feet apart in each direction.

Stem short; leaf-stems thicker and larger Fringed than those of the Common Couve Tronchuda, Tronchuda. but not so fleshy and succulent. The leaves expand towards their extremities into a spatulate form, the edges being regularly lobed and curled. They are of a glaucous or bluishgreen color, and form a sort of loose heart, or head, at the centre of the plant. Its only superiority over the common varieties consists in its more hardy character.

The Fringed Tronchuda is, however, quite succulent, and of good quality, and is cultivated to some extent in France, particularly in the vicinity of Paris.

This variety nearly resembles the Dwarf Portugal Cabbage, or Dwarf Couve Tronchuda, if it is not identical. It has white ribs, and forms a close heart.

Whiteribbed Tronchuda.

WHITE-RIBBED

AVILES CABBAGR. WHITE-RIBBED

Portugal CabBAGE.

It should be planted, and in all respects treated, as the Dwarf Portugal Cabbage.

\section{KOHL RABI.}

Turnip Cabbage. Brassica caulo-rapa.

The Kohl Rabi is a vegetable intermediate between the cabbage and the turnip. The stem, just above the surface of the ground, swells into a round, fleshy bulb, in form not unlike a turnip. On the top and about the surface of this bulb are put forth its leaves, which are similar to those of the Swede turnips, being either lobed or entire on the borders, according to the variety. The seeds are produced 
the second year; after the ripening of which the bulb perishes.

Sowing and Cultivation. - The seeds may be sown, in May or June, in a nursery bed, as is practised with the Cabbage, afterwards removing the young plants to rows eighteen inches or two feet apart, and fifteen inches apart in the rows; and they are sometimes sown, like the seeds of the Ruta Baga, in rows where they are to remain. When the latter course is followed, the plants taken up in thinning are reset in rows, as directed for setting plants raised in the nursery bed.

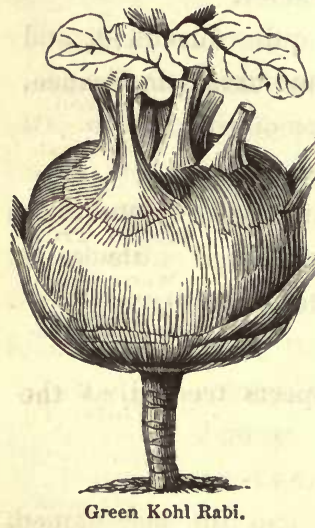

The growing crop is treated in all respects as the Ruta Baga or Cabbage.

Seed. - Take up a few plants entire in autumn; preserve them during winter in the manner of cabbages or turnips; and transplant to the open ground in April, two feet apart in each direction. The seeds are not distinguishable from those of the Swede or Ruta Baga 'Turnip, and retain their vitality from five to seven years.

Use. - The part chiefly used is the turnip-looking bulb, formed by the swelling of the stem. This is dressed and eaten with sauce, or with meat, as turnips usually are. 
While young, the flesh is tender and delicate, possessin'r the combined flavor of the cabbage and turnip.

They are said to keep better than any other bulb, and to be sweeter and more nutritious than the cabbage or white turnip. "In the north of France they are extensively grown for feeding cattle - a purpose for which they seem admirably adapted, as, from having a taste similar to the leaves of others of the species, they are found not to impart any of that peculiar, disagreeable taste to the milk, which it acquires when cows are fed on turnips."

Varieties. - These are as follow :-

Of German origin, deriving its name from the resemblance of the leaves to those of the Artichoke. Bulb small, and not smooth or

Artichokeleaved. Thomp. Iitl. Cut-leaved. symmetrical. The leaves are beautifully cut, and are very ornamental; but the bulb is comparatively of little value. Not much cultivated.

Bulb white, smaller than that of the Common Early Dwarf White, and supported close to the ground. The leaves are also smaller and less numerous.

It is earlier, and finer in texture, than the last named, and, while young, excellent for the table.

Transplant in rows fifteen inches apart, and ten inches asunder in the rows.

This corresponds with the Early White Vien- Early Purple na, except in color, which, in this variety, is a Thomp. Vil. beautiful purple, with a fine glaucous bloom. The leafstems are slender, and the leaves smooth, and few in number.

These two Vienna sorts are by far the best for table use. When taken young, and properly dressed, they form 
an excellent substitute for turnips, especially in dry seasons, when a crop of the latter may fail, or become of inferior quality.

Early White

Dwarf, small, early ; bulb handsome, firm, Thomp.

glossy, white, or very pale green. The leaves are few, small, with slender stems, the bases of which are dilated, and thin where they spring from different parts on the surface of the bulb. 'The flesh is white, tender, and succulent whilst the bulb is young, or till it attains the size of an early white Dutch turnip; and at or under this size it should be used.

Set the plants in rows fifteen inches apart, and ten inches from plant to plant in the lines.

Green. Similar to, if not identical with, the Common White. The bulbs are pale green, attain a large size, and the variety is hardy and productive. Not suited to garden culture, but chiefly grown for farm purposes.

Purple. Thomp. Vil.

This variety differs little from the White, except in color; the bulb being purple, and the leaf-stems and nerves also tinged with purple.

Like the White, it attains a large size, and is only adapted for field culture; the flesh being too coarse and strongflavored for table use.

White. Bulb large, - when full grown, measuring Thomp. Vil. seven or eight inches in diameter, and weighing from eight to ten pounds; leaves rather large and numerous ; skin very pale, or whitish-green; stem about six inches high. Hardy, quite late, and chiefly employed for farm purposes.

The variety should be cultivated in rows eighteen inches apart, and the plants should stand one foot apart in the rows. 


\section{PAK-CHOÏ. Vil.}

Chinese Cabbage. Brassica sp.

An annual plant, introduced from China. The root-leaves are oval, regular, smooth, deep green, with long, naked, fleshy, white stems, somewhat similar to those of the Swiss Chards, or Leaf-beets.

When in blossom the plant measures about four feet in height, and the stem is smooth and branching. The flowers are yellow; the seeds are small, round, blackish-brown, and, in their general appearance, resemble those of the Turnip or Cabbage. An ounce contains about ten thousand seeds, aud they will keep five years.

Sowing and Cultivation. - The seed should be sown in April or May, and the plants may be grown in hills or drills. They are usually sown in rows, and thinned to twelve inches apart.

Use. - The leaves are eaten boiled, like Cabbage; but they are much more tender, and of a more agreeable flavor.

\section{PE-TSAI.}

Chinese Cabbage. Brassica chinensis.

The Pe-Tsai, like the Pak-Choï, is an annual plant, originally from China. The leaves are of an oval form, rounded at the ends, somewhat blistered on the surface, and at the centre are collected together into a long and rather compact tuft, or head. The plant, when well grown and ready for use, has somewhat the appearance of a head of Cos Lettuce, and will weigh six or seven pounds; though in its native country it is said to reach a weight of upwards of twenty pounds. 
Towards the end of the summer the flower-stalk shoots from the centre of the head to the height of three feet, producing long and pointed leaves, and terminating in loose spikes of yellow flowers. The seeds are small, round, brownish-black, and resemble those of the Common Cabbage. They retain their vitality five years. An ounce contains eight thousand seeds.

Cultivation. - Sow in April or May, and thin or transplant to rows eighteen inches apart, and a foot apart in the rows.

Use. - It is used like the Common Cabbage, and is sweet, mild-flavored, and easy of digestion. 'The young plants are also boiled like coleworts or spinach.

\section{SAVOY.}

Savoy Cabbage. Brassica oleracea, var. bullata. Dec.

This class of Cabbages derives its popular name from Savoy, a small district adjoining Italy, where the variety originated, and from whence it was introduced into England and France more than a hundred and fifty years ago. The Saroys are distinguished from the common head or closehearted Cabbages by their peculiar, wrinkled, or blistered leaves. According to Decandole, this peculiarity is caused by the fact that the pulp, or thin portion of the leaf, is developed more rapidly than the ribs and nerves.

Besides the distinction in the structure of the leaves, the Savoys, when compared with the Common Cabbages, are slower in their development, and have more open or less compactly formed heads. In texture and flavor they are thought to approach some of the Broccolis or Cauliflowers ; having, generally, little of the peculiar musky odor and 
taste common to some of the coarser and larger varieties of Cabbages.

None of the family are hardier or more easily cultivated than the Savoys; and though they will not quite survive the winter in the open ground, so far are they from being injured by cold and frosty weather, that a certain degree of frost is considered necessary for the complete perfection of their texture and flavor.

Soil. - They succeed best in strong, mellow loam, liberally enriched with well-digested compost.

Sowing. - The first sowing may be made early in a hotbed, and the plants set in the open ground in May, or as soon as the weather will admit. Subsequent sowings may be made in drills, in the open ground, in May, or early in June. When the seedlings are five or six inches high, thin or transplant to about three feet apart.

Harvesting. - During the autumn, take the heads directly from the garden, whenever they are required for the table; but they should all be taken in before the ground is deeply frozen, or covered with snow. No other treatment will be required during the winter than such as is usually given to the Common Cabbage.

To raise Seed. - In April, select a few well-formed, goodsized heads, as near types of the variety as possible, and set them entire, about two feet apart. If small shoots start from the side of the stalk, they should be removed, as only the sprout that comes from the centre of the head produces seed that is really valuable. All varieties rapidly deteriorate if grown from seeds produced by side-shoots, or suckers.

The sceds, when ripe, in form, size, and color, are not distinguishable from those of the Common Cabbage. An o:anes contains ten thousand seeds, which will generally produce about three thousand plants. 
Varieties. -

Bloemendaal. New. Head of medium size, firm and compact, yellow-hearted, and of mild, delicate flavor.

Drumhead Head large, round, compact, yellowish at the Savoy. Cape Savor. centre, and a little flattened, in the form of some of the Common Drumhead Cabbages, which it nearly approaches in size. The exterior leaves of the plant are round and concave, clasping, sea-green or bluish-green, rise above a level with the top of the head, and are more finely and less distinctly fretted or blistered on the surface than the leaves of the Green Globe. Stalk of medium length.

The Drumhead Savoy seldom fails to heart well, affords a good quantity of produce, is hardy, and when brought to the table, is of very tender substance, and finely flavored. It is considered one of the best of the large kinds, and, wherever cultivated, has become a standard sort. It keeps well during winter, and retains its freshness late into the spring.

As it requires nearly all of the season for its complete development, the seed should be sown comparatively early.

Transplant to rows at least three feet apart, and allow nearly the same distance between the plants in the row. Farly Dwarf Head small, flattened, firm, and close; leaves
Savoy.

EarLy Grikx
SAYOY. finely but distinctly blistered, broad and rounded at the top, and tapering towards the stalk or stem of the plant, which is short. It is not quite so early as the Ulm Savoy; but it hearts readily, is tender and of good quality, and a desirable sort for early use.

It requires a space of about twenty inches in each direction. 
A middle-sized, dwarf, flat-headed variety; Early Flat color deep green; quality tender and good.

The plants should be set fifteen or eighteen Green Curled Savoy. Thomp. inches asunder.

Similar to the Golden Savoy, and, like it, an early sort. It has, however, a longer head,

Farly Long. Yellow Savoy. and does not heart so firmly. In flavor and texture, as well as in its peculiar color, there is little difference between the varieties.

Cultivate in rows eighteen inches apart, and fifteen or eighteen inches apart in the rows.

A dwarfish, early sort. Head small, round, Farly Ulm solid; leaves rather small, thick, fleshy, and NEw ULM S Svor. somewhat rigid, of a fine deep green, with nu- SAvox. Mclnt. merous prominent blister-like elevations. The loose leaves are remarkably few in number; nearly all of the leaves of the plant contributing to the formation of the head.

It very quickly forms a heart, which, though not of large size, is of excellent quality. It is, however, too small a sort for market purposes, but for private gardens would, no doubt, be an acquisition. In the London Horticultural Society's garden, it proved the earliest variety in cultivation.

Being one of the smallest of the Savoys, it requires but a small space for its cultivation. If fifteen inches between the rows, and about the same distance in the rows, be allowed, the plants will have ample room for their full development.

This curious and useful variety has been in existence for several years, and is said to be a Featherstem Savoy. NICInt. cross between the Savoy and the Brussels Sprouts. It is what may be called a sprouting Savoy; producing numerous shoots, or sprouts, along the stem. 
A sowing should be made the last of April, and another from the middle to the 20th of May, and the plants set out as soon as they are of suitable size, in the usual manner of Savoys and other winter greens.

- Golden Savoy.

EARLY YeLLOW SAYOY. McInt.
A middle-sized, roundish, rather loose-headed variety, changing during the winter to a clear, bright yellow. The exterior leaves, at the time of harvesting, are erect, clasping, of a pale green color, and coarsely but not prominently blistered on the surface; stalk short.

The Golden Savoy comes to the table early, hearts readily, is of tender substance wher cooked, and of excellent quality, though its peculiar color is objectionable to many.

It requires a space of about eighteen inches between the rows, and fifteen to eighteen inches between the plants in the rows.

Green Globe Savoy.

Grken Curled SAVOY. LARGE GKEEN SAVOY.
One of the best and one of the most familiar of the Savoys, having been long in cultivation, and become a standard sort. The head is of medium size, round, bluish or sea-green on the outside, yellow towards the centre, and loosely formed. The interior leaves are fleshy and succulent, with large and prominent midribs, - the exterior leaves are round and large, of a glaucous or sea-green color, and, in common with those of the head, thickly and distinctly blistered in the peculiar manner of the Savoys ; stalk of medium height. The variety possesses all the

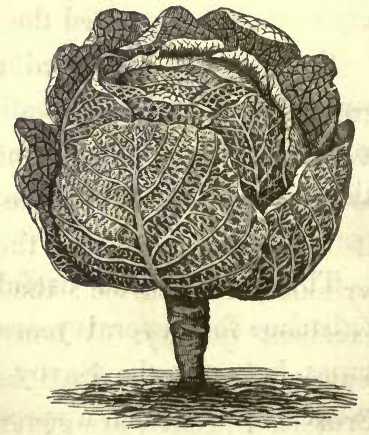

Savoy Cabbage. 
qualities of its class ; the texture is fine, and the flavor mild and excellent. On account of its remarkably fleshy and tender character, the inner loose leaves about the head will be found good for the table, and to possess a flavor nearly as fine as the more central parts of the plant.

It is remarkably hardy, and attains its greatest perfection only late in the season, or under the influence of cool or frosty weather. As the plants develop much less rapidly than those of the Common Cabbage, the seed should be sown early. Transplant in rows two and a half or three feet apart, and allow a space of two feet and a half between the plants in the rows.

A comparatively small variety, with an oval, Long-headed long, yellowish-green, but compact head ; leaves erect, inclining to bluish-green, long and narrow, revoluted on the borders, and finely fretted or blistered on the surface; stem rather high.

It is hardy and of excellent quality, but yields less than many other sorts. It is, however, a good kind for gardens of limited size, as it occupies little space and cabbages well. The plants may be set eighteen inches apart in one direction by about fifteen inches in the opposite.

A new sort, allied to the Early Ulm, but Marcelin Sagrowing somewhat larger. Though not so early, voy. Thomp. it is next to it in point of earliness; and, if both sorts are sown at the same time, the Marcelin will form a succession. It is a low grower; the leaves are dark green, finely wrinkled and curled; the head is round, compact, and of excellent quality. When cut above the lower course of leaves, about four small heads, almost equal in delicacy to Brussels Sprouts, are generally formed. This sort is exceedingly hardy, and, on the whole, must be considered a valuable acquisition. 
The plants should be set eighteen inches by twelve inches apart.

Tour's Savoy.

DWARF GREeN

CURLED SAYOY. Mclnt.

Head small, loose, and irregular; leaves numerous, bright green, rigid, concave or spoon-shaped; the neryes and ribs large, and the entire surface thickly and finely covered with the blisterlike swellings peculiar to the Savoys.

It has some resemblance to the Early Dwarf Savoy, but is larger, less compact, and slower in its development.

A useful, hardy, smallish sort, adapted to small gardens, requiring only eighteen or twenty inches space each way. Excellent for use before it becomes fully cabbaged.

Yellow Curled Savoy. Thomp. at first, but quite yellow in winter; the heart is YARGE LATE
YELLOW SAYOY. not so compact as some, but of tender quality,
WHITE SAYOY. WHITE SAYOY. and by many preferred, as it is much sweeter than the other kinds. It is later and hardier than the Yellow Savoys before described.

\section{SEA-KALE.}

Crambe maritima.

Sea-kale is a native of the southern shores of Great Britain, and is also abundant on the sea-coasts of the south of Europe. There is but one species cultivated, and this is perennial and perfectly hardy. The leaves are large, thick, oval or roundish, sometimes lobed on the borders, smooth, and of $\dot{a}$ peculiar bluish-green color; the stalk, when the plant is in flower, is solid and branching, and measures about four feet in height; the flowers, which are produced in groups, or clusters, are white, and have an odor very similar 
to that of honey. The seed is enclosed in a yellowish-brown shell, or pod, which, externally and internally, resembles a pit, or cobble, of the common cherry. About six hundred seeds, or pods, are contained in an ounce; and they retain their germinative powers three years. "They are large and light, and when sold in the market, are often old, or imperfectly formed; but their quality is easily ascertained by cutting them through the middle; if sound, they will be found plump and solid." They are usually sown without being broken.

Preparation of the Ground, and Sowing. - The ground should be trenched to the depth of from a foot to two feet, according to the depth of the soil, and well enriched throughout. The seeds may be sown in April, where the plants are to remain; or they may be sown at the same season in a nursery-bed, and transplanted the following spring. They should be set or planted out in rows three feet apart, eighteen inches apart in the rows, and the crowns covered three inches deep.

Culture. - Keep the plants clear of weeds; nip off the shoots of such as tend to run to flower; and in the autumn, when the leaves have decayed, add a liberal dressing of compost, or stable manure. Very early in spring, stir or rake over the bed, being careful not to injure the crowns of the roots, and cover eight or ten inches deep with the material intended for blanching. This may be beach sand, dry peat, common gravel, or whatever of like character can be conveniently obtained.

In England the plants are blanched by inverting over them pots made for the purpose, aud known as "sea-kale pots," and sometimes by using as a substitute ten or twêlve inch flower-pots.

Cutting. - The sprouts are cut for use when they are from three to six inches high, and the season continues about 
six weeks. Like Asparagus, the roots are injured by excessive cutting, and some of the shoots should be allowed to make their natural growth, that strength may be secured for the crop of the following spring. A plantation, with good culture and moderate use, will continue from seven to ten years.

Seeds. - The seeds, which are best preserved in the pods, may be obtained plentifully by allowing a few strong plants to make their natural growth.

Use. - The blanched sprouts are used cooked as Asparagus, or as Broccoli and the Cauliflower.

No varieties of this vegetable have been introduced. 


\section{CHAPTER VI,}

\section{SPINACEOUS PLANTS.}

Amaranthus. Black Nightshade. Leaf-beet, or Swiss Chard. Malabar Nightshade. Nettle. New Zealand Spinach. Orach. Patience Dock. Quinoa. Sea-beet. Shepherd's Purse. Sorrel. Spinach. Wild or Perennial Spinach.

\section{A M A R A N THUS.}

Chinese Amaranthus. Chinese Spinach.

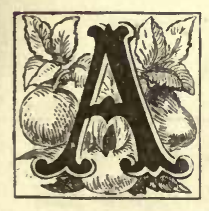

HARDY, annual plant, introduced from China; stem three feet in height, much branched, and generally stained with red; leaves varicgated with green and red, long, and sharply pointed; the leaf-stems and nerves are red; the flowers, which are produced in axillary spikes, are greenish, and without beauty; the seeds are small, black, smooth, and shining. Twenty-three thousand are contained in an ounce, and they retain their power of germination four or five years.

Soil and Cultivation. - Any good garden soil is adapted to the growth of the Amaranthus. Before sowing, the grouid should be thoroughly pulverized, and the surface made smooth and even. The seed may be sown in April, or at any time during the month of May, in shallow drills, fourteen to sixteen inches apart, and covered with fine, moist earth. When the plants are two inches high, thin to five or six inches apart, and cultivate in the usual manner. They will yield abundantly during most of the summer. 
Use. - The leaves are used in the manner of Spinach, and resemble it in taste.

\section{Varieties. -}

Farly Ama-

This plant is a native of the East Indies, ranthus. Vil.

and in height, color, and general habit, resembles the Chinese Amaranthus. It is, however, somewhat earlier, and ripens its seed perfectly in climates where the Chinese often fails. Its uses and mode of cultivation are the same.

Hantsi

Shanghai

Introduced from China by Mr. Fortune, and Amaranthus. disseminated by the London Horticultural So-
Vil. ciety. It differs little from the preceding species, and is cultivated in the same manner, and used for the same purposes. Annual.

\section{BLACK NIGHTSHADE.}

Morelle of the French. Solanum nigrum

An unattractive, annual plant, growing spontaneously as a weed among rubbish, in rich waste places. Its stem is from two to three feet high, hairy, and branching; the leaves are oval, angular, sinuate, and bluntly toothed; the flowers are white, in drooping clusters, and are succeeded by black, spherical berries, of the size of a small pea; the seeds are small, lens-shaped, pale yellow, and retain their vitality five years. Twenty-three thousand are contained in an ounce.

Propagation and Culture. - It is raised from seed, which may be sown in April or May, or in autumn. Sow in shallow drills, fifteen or eighteen inches apart, and thin to six or eight inches in the drills; afterwards keep the soil loose, and free from weeds, in the usual manner. 
Use. - The French, according to Vilmorin, eat the leaves in the manner of Spinach ; while Dr. Bigelow asserts that it has the aspect and reputation of a poisonous plant.

On the authority of American botanists, it was introduced into this country from Europe. By European botanists, it is described as a plant of American origin.

\section{LEAF-BEET, OR SWISS CHARD.}

Sicilian Beet. White Beet. Beta cicla.

The Leaf-beet is a native of the sea-coasts of Spain and Portugal. It is a biennial plant, and is cultivated for its leaves and leaf-stalks. The roots are much branched or divided, hard, fibrous, and unfit for use.

Propagation and Cultivation. - It is propagated, like other beets, from seed sown annually, and will thrive in any good garden soil. The sowing may be made at any time in April or May, in drills eighteen inches apart, and an inch and a half deep. When the plants are well up, thin them to ten or twelve inches apart, and treat during the season as the common Red Beet, stirring the surface frequently, and keeping clear of weeds. The excellence of this vegetable consists in the succulent character of the stems and nerves of the leaves; and these properties are best acquired in moist and warm seasons, or by copious watering in dry weather.

Taking the Crop. - "The largest and fullest grown leaves should be gathered first; others will follow. If grown for Spinach, the leaves should be rinsed in clean water, and afterwards placed in a basket to drain dry; if for Chard, or for the leaf-stalks and veins, these should be carefully preserved, and the entire leaves tied up in bundles of six or eight in each." - McInt.

Seed.-During the first season, select a few vigorous 
plants, and allow them to grow unplucked. Just before the closing up of the ground in autumn, take up the roots; and, after removing the tops an inch above the crown, pack them in dry sand in the cellar. The following spring, as soon as the ground is in working order, set them out with the crowns level with the surface of the ground, and about two feet and a half apart. As the plants increase in height, tie them to stakes, to prevent injury from wind; and in August, when the seed is ripe, cut off the stems near the ground, and spread them entire, in an airy situation, till they are sutficiently dried for threshing out.

The seed, or fruit, has the appearance peculiar to the family, although those of the different varieties, like the seeds of the Red Beet, vary somewhat in size, and shade of color.

An ounce of seed will sow a hundred feet of drill, or be sufficient for a nursery-bed of fifty square feet.

Use. — "This species of Beet - for, botanically consii.ered, it is a distinct species from Beta vulgaris, the Common or Red Beet - is cultivated exclusively for its leaves; whereas the Red Beet is grown for its roots. These leaves are boiled like Spinach, and also put into soups. The midribs and stalks, which are separated from the lamina of the leaf, are stewed and eaten like Asparagus, under the name of "Chard." As a spinaceous plant, the White Beet might be grown to great advantage in the vegetable garden, as it affords leaves fit for use during the whole summer." - McInt.

The thin part of the leaves is sometimes put into soups, together with sorrel, to correct the acidity of the latter.

The varieties are as follow :-

Green or

Stalks and leaves large, green; the roots are Leaf-Beet. tough and fibrous, and measure little more than an inch in diameter; the leaves are tender, and of good quality. If a sowing be made as soon in spring as the frost will 
permit, another in June, and a third the last of July, they will afford a constant supply of tender greens, nearly or quite equal to Spinach. For this purpose the rows need be but a foot apart.

Stalks white; leaves pale yellowish-green, Large-ribbed with broad midribs, large nerves, and a blis- CurLrolenetered surface, like some of the Savoys. It may BEET. be grown, as a substitute for Spinach, in the manner directed for the Common or Green-leaved variety. Leaf-stalks bright purplish-red ; leaves green, Large-ribbed blistered on the surface; nerves purplish-red. A beautiful sort, remarkable for the rich and zilian. Red Stalk LeavBEKT. brilliant color of the stems and nerves of the leaves.

A variety with bright yellow leaf-stalks and yellowish leaves. The nerves of the leaves are yellow, like the leaf-stalks; the color is pecuLarge-ribbed
Yellow Bra zilian. YELLOW-STALKED liarly rich and clear; and the stalks are quite attractive, and even ornamental. Quality tender and good.

Stalks large; leaves of medium size, erect, Silver-leaf with strong, white ribs and veins. The leaf- Grgat Wurtestalks and $\begin{aligned} & \text { I.EAF BEET. } \\ & \text { SWISS CUARD. }\end{aligned}$ stalks and nerves are cooked and served like $\begin{gathered}\text { SWISS CUIARD. } \\ \text { SEA-KALEBET. }\end{gathered}$ Asparagus, and somewhat resemble it in tex- SILVER-LEAY ture and flavor. It is considered the best of the Leaf-beets.

\section{MALABAR NIGHTSHADE (WHITE).}

Climbing Nightshade. White Malabar Spinach. Basella alba.

From the East Indies. Though a biennial plant, in cultivation it is generally treated as an annual. Stem five feet 
and upwards in length, slender, climbing; leaves alternate, oval, entire on the borders, green and fleshy; flowers in clusters, small, greenish ; seeds round, with portions of the pulp usually adhering, eleven to twelve hundred weighing an ounce. They retain their vitality three years.

Large-leaved Chinese Malabar Nightshade.

LARGE-LEAVED MARGE-LEAVED ACH. BASELLA

A Chinese species, more vigorous and much stronger in its general habit than the Red or the White. Leaves as large as those of Lettuce, green, round, thick, and fleshy; flowers small, greenish; seeds round, nearly of the same form and color as those of the White variety, but rather larger.

The species is slow in developing its flower-stem, and is the best for cultivation.

\section{RED MALABAR NIGHTSHADE.}

Red Malabar Spinach. Basella rubra.

From China. Properly a biennial plant, but, like the White species, usually cultivated as an annual. It is distinguished from the last named by its color, the whole plant being stained or tinted with purplish-red. In the size and color of the seeds, and general habit of the plant, there are oo marks of distinction, when compared with the White.

Propagation and Cultivation. - All of the species are easily grown from seeds, which may be sown in a hot-bed in March, or in the open ground in May. They take root readily when transplanted, and may be grown in rows, like the taller descriptions of peas, or in hills, like running beans. Wherever grown, they require a trellis, or some kind of support; otherwise the plants will twist themselves about other plants, or whatever objects may be contiguous. All are comparatively tender, and thrive best, and yield the most produce, in the summer months. 
Use. - The leaves, which are put forth in great profusion, are used in the form of Spinach. The juice of the fruit affords a beautiful but not permanent purple color.

\section{COMMON NETTLE.}

Large Stinging Nettle. Urtica dioica.

The Common Nettle is a hardy, herbaceous perennial, growing naturally and abundantly by waysides and in waste places, " but is seldom seen where the hand of man has not been at work, and may, therefore, be considered a sort of domestic plant." The stem is erect, branching, four-sided, and from three to five feet in height; the leaves are opposite, heart-shaped at the base, toothed on the borders, and thickly set with small, stinging, hair-like bristles; the flowers are produced in July and August, and are small, green, and without beauty; the seeds are very small, and are produced in great abundance, a single plant sometimes yielding nearly a hundred thousand.

Propagation and Culture. - The Nettle will thrive in almost any soil or situation. Though it may be propagated from seeds, it is generally increased by a division of the roots, which may be made in spring or autumn. These should be set in rows two feet apart, and a foot apart in the rows.

Use. - "Early in April the tops will be found to have pushed three or four inches, furnished with tender leaves. In Scotland, Poland, and Germany, these are gathered, as a pot-herb for soups or for dishes, like Spinach ; and their peculiar flavor is by many much esteemed. No plant is better adapted for forcing; and in winter or spring it may be made to form an excellent substitute for Cabbage, Coleworts, or Spinach. Collect the creeping roots, and plant them either 
on a hot-bed or in pots to be placed in the forcing-house, and they will soon send up an abundance of tender tops: these, if desired, may be blanched by covering with other pots. If planted close to a flue in the vinery, they will produce excellent nettle-kale or nettle-spinach in January and February."

Lawson states that "the common Nettle has long been known as affording a large proportion of fibre, which has not only been made into ropes and cordage, but also into sewing-thread, and beautiful, white, linen-like cloth of very superior quality. It does not, however, appear that its cultivation for this purpose has ever been fairly attempted. The fibre is easily separated from other parts of the stalk, without their undergoing the processes of watering and bleaching; although by such the labor necessary for that purpose is considerably lessened. Like those of many other common plants, the superior merits of this generally accounted troublesome weed have hitherto been much overlooked."

\section{NEW ZEALAND SPINACH. Loud.}

Tetragonia expansa.

This plant, botanically considered, is quite distinct from the common garden Spinach; varying essentially in its foliage, flowers, seeds, and general habit.

It is a hardy annual. The leares are of a fine green color, large and broad, and remarkably thick and fleshy; the branches are numerous, round, succulent, pale green, thick, and strong; the stalks recline upon the ground for a large proportion of their length, but are erect at the extremities; the flowers are produced in the axils of the leaves, and, except that they show their yellow anthers when they expand, are quite inconspicuous; the fruit is of a dingy-brown color, 
three eighths of an inch deep, three eighths of an inch in diameter at the top or broadest part, hard and wood-like in texture, rude in form, but somewhat urn-shaped, with four or five horn-like points at the top. Three hundred and twentyfive of these fruits are contained in an ounce; and they are generlly sold and recognized as the seeds. They are, however, really the fruit, - six or eight of the true seeds being contained in each. They retain their germinative powers five years.

Propagation and Culture. - It is always raised from seed, which may be sown in the open ground from April to July. Select a rich, moist soil, pulverize it well, and rake the surface smooth. Make the drills three feet apart, and an inch and a half or two inches deep, and sow the seed thinly, or so as to secure a plant for each foot of row. In five or six weeks from the planting, the branches will have grown sufficiently to allow the gathering of the leaves for use. If the season should be dry, the plants will require watering. They grow vigorously, and in good soil will extend, before the end of the season, three feet in each direction.

Gathering. - The leaves, which are the parts of the plant used, are gathered as they are developed, leaving the ends of the young shoots uninjured. If not cut to excess, the plants will yield abundantly till destroyed by frost. The leaves retain their fresh, succulent character after they are fully grown, and even under the influence of the heat and drought incident to the summer months. No one of the family of Spinaceous Plants is more easily raised, and few, if any, are more productive.

Anderson, one of its first cultivators, had but nine plants, which furnished a gathering for the table every other day from the middle of June. A bed of a dozen healthy plants will afford a daily supply for the table of a large family.

Seed. - To raise seed, leave two or three plants in the 
poorest soil of the garden, without cutting the leaves. The seeds will ripen successively, and should be gathered as they mature.

Use. - It is cooked and served in the same manner as Common Spinach.

There are no described varieties.

\section{ORACH.}

Arrach. French Spinach. Mountain Spinach. Atriplex hortensis.

Orach is a hardy, annual plant, with an erect, branching stern, varying in height from two to four feet, according to the variety. The leaves are variously shaped, but somewhat oblong, comparatively thin in texture, and slightly acid to the taste; the flowers are small and obscure, greenish or reddish, corresponding in a degree with the color of the foliage of the plant; the seeds are small, black, and surrounded with a thin, pale yellow membrane; they retain their vitality three years.

Soil and Culture. - It is raised from seed sown annually. As its excellence depends on the size and succulent character of the leaves, Orach is always best when grown in a rich, deep, and moist soil. The first sowing may be made as soon in spring as the ground is in proper condition; afterwards, for a succession, sowings may be made, at intervals of two weeks, until June.

When the ground has been thoroughly dug over, and the surface made fine and smooth, sow the seed in drills eighteen inches or two feet apart, and cover three fourths of an inch deep. When the young plants are two or three inches high, thin them to ten or twelve inches apart, and cultivate in the usual manner. Orach is sometimes transplanted, but gener- 
ally succeeds best when sown where the plants are to remain. In dry, arid soil it is comparatively worthless.

To raise Seed. - Leave a few of the best plants without cutting, and they will afford a plentiful supply of seeds in September.

Use. - Orach is rarely found in the vegetable gardens of this country. The leaves have a pleasant, slightly acid taste, and, with the tender stalks, are used boiled in the same manner as Spinach or Sorrel, and are often mixed with the latter to reduce the acidity.

A few plants will afford an abundant supply.

Varieties. -

The leaves of this variety are of a dark Green Orach. grass-green color, broad, much wrinkled, slightly Drans. toothed, and bluntly pointed; the stalk of the GRENOBRACH. plant and the leaf-stems are strong and sturdy, and of the same color as the leaves. It is the lowest growing of all the varieties.

Leaves pale purple, tinged with dark green; Lurid Orach. the under surface light purple with green veins, PALE RED OBACH. slightly wrinkled, terminating rather pointedly, and toothed on the borders only towards the base, which forms two acute angles; the stalk of the plant and the stems of the leaves are bright red, slightly streaked with white between the furrows; height three feet and upwards.

Plant from three to four feet in height; Purple leaves dull, dark purple, more wrinkled and more deeply toothed than those of any other Orach. Trans.

Dark Purple OBACH. variety. They terminate somewhat obtusely, and form two acute angles at the base. The stalk of the plant and the 
stems of the leaves are deep red, and slightly furrowed. The leaves change to green when boiled.

Red Orach. Leaves oblong, heart-shaped, somewhat wrinDarm RED ORACH. kled, and slightly toothed on the margin; the upper surface is very dark, inclining to a dingy purple; the under surface is of a much brighter color. The stems are deep red, and slightly furrowed; height three feet and upwards.

This is an earlier but a less vigorous sort than the White. The leaves of this variety, as also those of most of the colored sorts, change to green in boiling.

Red-stalked Green Orach. Trans.

Leaves dark green, tinged with dull brown, much wrinkled, toothed, somewhat curled, terminating rather obtusely, and forming two acute angles at the base; the stalk and the stems of the leaves are deep red, and slightly furrowed; the veins are very prominent. It is of tall growth.

Red-stalked WhiteOrach. Trans.

PURPLE-BORPURPLE-BOR-
DERED GREN ORACH. Hiller.
Leaves somewhat heart-shaped, of a yellowish-green, tinged with brown. Their margin is stained with purple, and a little dentated or toothed in some cases, but not in all. The stalk and the stems of the leaves are of a palish red, and are slightly furrowed, as well as streaked with pale white between the furrows. The plant is of dwarfish growth.

WhiteOrach. Leaves pale green or yellowish-green, much Trans.

PaLE GREEN ORACHE. Neill. WHITE FRENCH
SPINACH. YELLOW ORACH. wrinkled, with long, tapering points, strongly cut in the form of teeth towards the base, which forms two acute angles; the stalk of the plant and the stems of the leaves are of the samo color as the foliage. It is comparatively of low growth. 


\section{PATIENCE.}

Herb Patience. Patience Dock: Garden Patience. Rumex patientia.

This plant is a native of the south of Europe. It is a hardy perennial, and when fully developed, from four to five feet in height. The leaves are large, long, broad, pointed; the leaf-stems are red; the flowers are numerous, small, axillary, and of a whitish-green.color; they are put forth in June and July, and the seeds ripen in August. The latter are triangular, of a pale brownish color, and will keep three years.

Soil and Cultivation. - No peculiarity of soil or culture is requisite for the production of this vegetable. The seeds are sown in April or May, or immediately after ripening, in drills fifteen inches apart and an inch deep, and the young plants afterwards thinned to ten or twelve inches apart in the rows. It is also sometimes grown in hills, setting two or three plants together, and making the hills two feet and a half apart. Though it may be propagated by dividing the roots, it is generally raised from seeds.

The leaves are more abundant, attain a much larger size, and are more succulent and tender, if the flowering shoots are cut or pinched off as they make their appearance.

The plant is perfectly hardy, and, if cut over regularly, will continue healthy and productive for several years. In the vicinity of gardens where it has been cultivated, it is frequently found growing spontaneously, and sometimes becomes troublesome.

Use. - The leaves are used as Spinach. Though at one period it was cultivated and used to some extent, it is now rarely to be found in the gardens of this country.

Its present neglect, however, may arise from a want of knowledge of the proper method of using it. The leaves 
are put forth quite early in spring. They should be cut while they are young and tender, and about a fourth part of Common Sorrel mixed with them. In this way, Patience Dock is much used in Sweden, and may be recommended as forming an excellent spinach dish.

\section{QUINOA (WHITE). Law.}

White-seeded Quinoa. Goosefoot. Chenopodium quinoa.

An annual plant from Mexico or Peru. The stem is five or six feet in height, erect and branching; the leaves are triangular, obtusely toothed on the borders, pale green, mealy while young, and comparatively smooth when old; the flowers are whitish, very small, and produced in compact clusters; the seeds are small, yellowish-white, round, a little flattened, about a line in diameter, and, on a cursory glance, might be mistaken for those of millet; they retain their vegetative powers three years; about twelve thousand are contained in an ounce.

Sowing and Cultivation. - It is propagated from seeds which are sown, in April or May, in shallow drills three feet apart. As the seedlings increase in size, they are gradually thinned to a foot apart in the rows. The seeds ripen in September. In good soil, the plants grow vigorously, and produce seeds and foliage in great abundance.

Use. - The leaves are used as Spinach or Sorrel, or as greens. In some places, the seeds are employed as a substitute for corn or wheat in the making of bread, and are also raised for feeding poultry.

\section{Varieties. -}

The stalks of this variety are more slender, and the leaves smaller, than those of the White- 
seeded. The plant is also stained with brownish-red in all its parts. Seeds small, grayish-black.

It is sown, and in all respects treated, like the White. The seeds and leaves are used in the same manner. This variety, or, perhaps, more properly spe- Red-seeded cies, is quite distinct from the White-seeded. It grows to the height of six or eight feet, and Law.

even more, with numerous long, spreading branches. The leaves are more succulent than those of the last named, and are produced in greater abundance. When sown at the same time, it ripens its seeds nearly a month later.

Its foliage and seeds are used for the same purposes as the White. Sow in rows three feet apart, and thin to fifteen inches in the rows.

\section{SEA-BEET. Trans.}

Beta maritima.

The Sea-beet is a hardy, perennial plant. The roots are not eaten; but the leaves, for which it is cultivated, are an excellent substitute for Spinach, and are even preferred by many to that delicate vegetable. If planted in good soil, it will continue to supply the table with leaves for many years. The readiest method of increasing the plants is by seeds; but they may be multiplied to a small extent by dividing the roots.

The early-produced leaves are the best, and these are fit for use from May until the plants begin to run to flower; but they may be continued in perfection through the whole summer and autumn by cutting off the flower-stems as they arise, and thus preventing the blossoming.

There are two varieties:- 
Fnglish Seabeet.

The English Sea-beet is a dwarfish spreading or trailing plant, with numerous angular, leafy branches. The lower leaves are ovate, three or four inches in length, dark green, waved on the margin, and of thick, fleshy texture; the upper leaves are smaller, and nearly sessile.

Sow in April, or May, in rows sixteen or eighteen inches apart, and an inch in depth; thin to twelve inches in the rows. The leaves should not be cut from seedling plants during the first season, or until the roots are well established.

Irish Seabeet.

This differs from the preceding variety in the greater size of its leaves, which are also of a paler green; the stems are not so numerous, and it appears to be earlier in running to flower. The external differences are, however, trifling; but the flavor of this, when dressed, is far superior to that of the last named.

It requires the same treatment in cultivation as the English Sea-beet.

\section{SHEPHERD'S PURSE.}

Thlaspi Bursa pastoris.

A hardy, annual plant, growing naturally and abundantly about gardens, road sides, and in waste places. The rootleaves spread out from a common centre, are somewhat recumbent, pinnatifid-toothed, and in good soil attain a length of eight or ten inches; the stem-leaves are oval, arrow-shaped at the base, and rest closely upon the stalk. When in blossom, the plant is from twelve to fifteen inches in height ; the flowers are small, white, and four-petaled ; the sceds are small, of a reddish-brown color, and retain their vitality five years.

Propagation and Cultivation. - It is easily raised from 
seed, which should be sown, in May, where the plants are to remain. Sow in shallow drills twelve or fourteen inches apart, and cover with fine mould. Thin the young plants to four inches asunder, and treat the growing crop in the usual manner during the summer. Late in autumn cover the bed with coarse stable-litter, and remove it the last of February. In March and April the plants will be ready for the table.

Use. - It is used as Spinach, and has a mild, pleasant flavor, not unlike that of Broccoli or the Cauliflower. Under high cultivation the plants sometimes attain a diameter of nearly twenty inches. Blanched and served as Endive, it makes an agreeable early salad.

In April and May it may be gathered, growing spontaneously about cultivated lands, and, though not so excellent as the cultivated plants, will yet be found of good quality.

\section{SORREL.}

\section{Rumex, sp. et var.}

Sorrel is a hardy perennial. The species, as well as varieties, differ to a considerable extent in height and general habit; yet their uses and culture are nearly alike.

Soil and Cultivation. - All of the sorts thrive best in rich, moist soil, but may be grown in almost any soil or situation. The seeds are sown, in April or May, in drills fifteen or eighteen inches apart, and covered half an inch in depth. The young plants should be thinned to twelve inches apart; and in July and August the leaves will be sufficiently large for gathering.

The finest sorts are obtained from seedlings, which often vary to a considerable extent in the size and form of the leaves, as well as in their general habit. These varieties are propagated by dividing the roots, and this method must 
be adopted, in the propagation of the diøecious kinds, when male plants are required.

All of the varieties, whether produced from seeds or by parting the roots, will send up a flower-stalk in summer; and this it is necessary to cut out when first developed, in order to render the leaves larger and more tender.

The plants will require no special protection or care during the winter, though a slight covering of strawy stable litter may be applied after the forking over of the bed in the autumn, just before the closing up of the ground.

Use. - It enters into most of the soups and sances for which French cookery is so famed, and they preserve it in quantities for winter use. It forms as prominent an article in the markets of Paris as does Spinach in those of this country; and it has been asserted, that, amongst all the recent additions to our list of esculent plants, we have not one so wholesome, so easy of cultivation, or one that would add so much to the sanitary condition of the community, particularly of that class who live much upon salt provisions.

The species and varieties are as follow :-

Alpine Sor- A new, perennial species, found upon the
rel. Romex Nivasis. Alps, near the line of perpetual snow. The root-leaves are somewhat heart-shaped, thick, and fleshy; stem simple, with verticillate branches; flower diøecious.

It is one of the earliest as well as the hardiest of the species, propagates more readily than Alpine plants in general, and is said to compare favorably in quality with the Mountain Sorrel or Patience Dock.

Common Sor- This is a hardy perennial, with an erect,
rei. r. Ackross. branching stem, about two feet in height. The flowers, which are small, numerous, and of a reddish color, 
are diœcious, the fertile and barren blossoms being produced on separate plants; the seeds are small, triangular, smooth, of a brownish color, and retain their germinative properties two years. An ounce contains nearly thirty thousand seeds.

Of the Common Sorrel there are five varieties, as follow :-

Leaves ten or twelve inches long by six inches in diameter; leaf-stems red at the base.

Belleville Sorrel. Vil. BROAD-LEAVED. Compared with the Common Garden Sorrel, the leaves are larger and less acid.

The variety is considered much superior to the last-named sort, and is the kind usually grown by market gardeners in the vicinity of Paris.

It should be planted in rows eighteen inches apart, and the plauts thinned to a foot apart in the rows.

Radical léaves nine inches long, four inches wide, oval-hastate or halberd-shaped, growing Blisteredleaf Sorrel. Trans. on long footstalks. The upper leaves are more blistered than those attached to the root; the flower-stems are short. The principal difference between this variety and the Common, or Broad-leaved, consists in its blistered foliage.

It is slow in the development of its flower-stem, and consequently remains longer in season for use. The leaves are only slightly acid in comparison with those of the Common Sorrel. It is a perennial, and must be increased by a division of its roots; for being only a variety, and not permanently established, seedlings from it frequently return to the Belleville, from whence it sprung.

An excellent sort, with large, yellowish-green, blistered leaves and red leaf-stems. It is com- 
paratively hardy, puts forth its leaves early, and produces abundautly.

The rows should be eighteen inches apart.

Green or Common Gar-

Root-leaves large, halberd-shape, and supden Sorrel. ported on stems six inches in length. The upper leaves are small, narrow, sessile, and clasping. A hardy sort, but, on account of its greater acidity, not so highly esteemed as the Belleville.

Sow in rows fifteen inches apart, and thin to eight or ten inches in the rows.

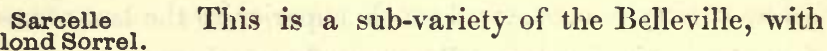
Blond Sorrel.

longer and narrower leaves and paler leafstems. It puts forth its leaves earlier in the season than the Common Sorrel, and is of excellent quality. The seed rarely produces the variety in its purity, and it is generally propagated by dividing the roots.

Round-leaved or French

Sorrel.

Thomp.

ROMAN SORREL.

R. scutatus.

This is a hardy perennial, a native of France and Switzerland. Its stem is trailing, and from twelve to eighteen inches in height or length; the leaves vary in form, but are usually roundish-heart-shaped or halberd-shaped, smooth, glaucous, and entire on the borders; the flowers are hermaphrodite, yellowish; the leaves are more acid than those of the varieties of the preceding species, and for this reason are preferred by many.

It requires eighteen inches' space between the rows, and a foot in the rows. There is but one variety.

Mountain Sorrel.

The leaves of this species are large, oblong,

R. sostasis. of thin texture, and of a pale green color; the root-leaves are numerous, about nine inches long and four 
inches wide, slightly blistered. It is later than the Common Garden Sorrel in running to flower, and is generally propagated by dividing the roots, but may also be raised from seeds. The leaves are remarkable for their acidity.

This is the Rumex montanus of modern botanists, though formerly considered as a variety of $R$. acetosa.

This variety is distinguished from the Green BlisteredMountain Sorrel by its larger, more blistered, tain Sorrel. and thinner leaves. The leaf-stems are also longer, and, as well as the nerves and the under surface of the leaf, finely spotted with red. It starts early in spring, and is slow in running up to flower.

This is an improved variety of the Mountain Green MounSorrel, and preferable to any other from the tain Sorrel. greater size and abundance of its leaves, which possess much acidity. It is also late in running to flower.

The leavès are large, numerous, ovate-sagittate, from ten to eleven inches long, and nearly five inches in width; the radical leaves are slightly blistered, and of a dark, shining green color. It can only be propagated by dividing the roots.

The plants require a space of eighteen inches between the rows, and a foot from plant to plant in the rows.

\section{SPINACH.}

Spinacia oleracea.

Spinach is a hardy annual, of Asiatic origin. When in flower, the plant is from two to three feet in height; the stem is erect, furrowed, hollow, and branching; the leaves are smooth, succulent, and oval-oblong or halberd-shaped, - the 
form varying in the different varieties. The fertile and barren flowers are produced on separate plants, - the former in groups, close to the stalk at every joint; the latter in long, terminal bunches, or clusters. The seeds vary in a remarkable degree in their form and general appearance, those of some of the kinds being round and smooth, while others are angular and prickly; they retain their vitality five years. An ounce contains nearly twenty-four hundred of the prickly seeds, and about twenty-seven hundred of the round or smooth.

Soil and Cultivation. - Spinach is best developed, and most tender and succulent, when grown in rich soil. For the winter sorts, the soil can hardly be made too rich.

It is always raised from seeds, which are sown in drills twelve or fourteen inches apart, and three fourths of an inch in depth. The seeds are sometimes sown broadcast; but the drill method is preferable, not only because the crop can be cultivated with greater facility, but the produce is more conveniently gathered. For a succession, a few seeds of the summer varieties may be sown, at intervals of a fortnight, from April till August.

Taking the Crop. - "When the leaves are two or three inches broad they will be fit for gathering. This is done either by cutting them up with a knife wholly to the bottom, drawing and clearing them out by the root, or only cropping the large outer leaves, - the root and heart remaining to shoot out again. Either method can be adopted, according to the season or other circumstances." - Rogers.

To raise Seed. - Spinach seeds abundantly; and a few of the fertile plants, with oue or two of the infertile, will yield all that will be required for a garden of ordinary size. Seeds of the winter sorts should be saved from autumn sowings, and from plants that have survived the winter.

Use. - The leaves and young stems are the only parts of 
the plant used. They are often boiled and served alone; and sometimes, with the addition of sorrel-leaves, are used in soups, and eaten with almost every description of meat. "The expressed juice is often employed by cooks and confectioners for giving a green color to made dishes. When eaten freely, it is mildly laxative, diuretic, and cooling. Of itself it affords little nourishment. It should be boiled without the addition of water, beyond what hangs to the leaves in rinsing them; and, when cooked, the moisture which naturally comes from the leaves should be pressed out before being sent to the table. The young leaves were at one period used as a salad." - McInt.

\section{Varieties. -}

This is a winter. Spinach, and is considered superior to the Prickly or Common Winter

Flanders Spinach. Trans. Spinach, which is in general cultivation during the winter season in our gardens. It is equally hardy, perhaps hardier.

The leaves are doubly hastate or halberd-shaped, and somewhat wrinkled; the lower ones measure from twelve to fourteen inches in length, and from six to eight in breadth. They are not only larger, but thicker and more succulent, than those of the Prickly Spinach. The whole plant grows more bushy, and produces a greater number of leaves from each root; and it is sometimes later in running to seed. The seeds are like those of the Round or Summer Spinach, but larger; they are destitute of the prickles which distinguish the seeds of the Common Winter Spinach.

For winter use, sow at the time directed for sowing the Large Prickly-seeded, but allow more space between the rows than for that variety; subsequent culture, and treatment during the winter, the same as the Prickly-seeded. 
Large Prick- Leaves comparatively large, rounded at the Iy-seeded

Spinach.

LARGE WINTER SPINACH. ends, thick and succulent. In foliage and general character it is similar to some of the round-seeded varieties, but is much hardier, and slower in running to seed. It is commonly known as "Winter Spinach," and principally cultivated for use during this portion of the year. The seeds are planted towards the last of August, in drills a foot apart, and nearly an inch in depth. When well up, the plants should be thinned to four or five inches apart in the drills; and, if the weather is favorable, they will be stocky and vigorous at the approach of severe weatlier. Before the closing up of the ground, lay strips of joist, or other like material, between the rows, cover all over with clean straw, and keep the bed thus protected until the approach of spring, or the crop has been gathered for use.

Iettuceleaved Spinach.

EPINARD GAUDRY.

Leaves large, on short stems, rounded, deep green, with a bluish tinge, less erect than those of the other varieties, often blistered on the surface, and of thick substance. It is neither so early nor so hardy as some others; but it is slow in the development of its flower-stalk, and there are few kinds more productive or of better quality. The seeds are round and smooth. For a succession, a sowing should be made at intervals of two weeks.

Sorrel-leaved Leaves of medium size, halberd-formed, deep Spinach.

green, thick, and fleshy. A hardy and productive sort, similar to the Yellow or White Sorrel-leaved, but differing in the deeper color of its stalks and leaves.

Summer or Round-leaved Spinach. Round DUtch.
Leaves large, thick, and fleshy, rounded at the ends, and entire, or nearly entire, on the borders. 
This variety is generally grown for summer use; but it soon runs to seed, particularly in warm and dry weather. Where a constant supply is required, a sowing should be made every fortnight, commencing as early in spring as the frost leaves the ground. The seeds are round and smooth. Plants from the first sowing will be ready for use the last of May or early in June.

- In Belgium and Germany a sub-variety is cultivated, with smaller and deeper-colored foliage, and which is slower in running to flower. It is not, however, considered preferable to the Common Summer or Round-leaved.

Leaves seven or eight inches long, halberd- Winter or shaped, deep green, thin in texture, and nearly Prickly Spinerect on the stalk of the plant; seeds prickly.

From this variety most of the improved kinds of Prickly Spinach have been obtained ; and the Common Winter or Prickly-seeded is now considered scarcely worthy of cultivation.

The leaves of this variety are similar in form and appearance to those of the Garden Sorrel. They are of medium size, entire on the bor- IEAVED SPIIACCH. der, yellowish-white at the base, greener at the tips, and blistered on the surface.

New. Represented as being hardy, productive, slow in the development of its flower-stalk, and of good quality.

\section{WILD OR PERENNIAL SPINACH.}

Good King Henry. Tota Bona. Goosefoot. Blitum Bonus Henricus.

A hardy perennial plant, indigenous to Great Britain, and naturalized to a limited extent in this country. Its stem is 
two feet and a half in height; the leaves are arrow-shaped, smooth, deep green, undulated on the borders, and mealy on their under surface; the flowers are numerous, small, greenish, and produced in compact groups, or clusters; the seeds are small, black, and kidney-shaped.

Propagation and Culture. - It may be propagated either from seeds or by dividing the roots; the more common method, however, is from seeds, which are sown in April or May in a nursery-bed, and the seedlings afterwards transplanted to rows fifteen inches apart, and eight or ten inches apart in the rows. They are sometimes twice transplanted, the second setting being made in August or early in September.

The leaves, which are the parts of the plant used, will be fit for gathering in May and June of the following year, and are generally cut as they attain a sufficient size.

Use. - The same as Spinach. 


\section{CHAPTER VII.}

\section{SALAD PLANTS.}

Alexanders. Brook-lime. Buckshorn Plantain. Burnet. Caterpillar. Celery. Celeriac, or Turnip-rooted Celery. Chervil. Chiccory, or Succory. Corchorus. Corn Salad. Cress, or Peppergrass. Cuckoo Flower. Dandelion. Endive. Horse-radish. Lettuce. Madras Radish. Mallow, Curled-leaf. Mustard. Nasturtium. Garden Picridium. Purslain. Rape. Roquette, or Rocket. Samphire. Scurvy-grass. Snails. Sweet-scented Chervil, or Sweet Cicely. Tarragon. Valeriana. Water-cress. Winter-cress, or Yellow Rocket. Wood-sorrel. Worms.

\section{A L E X A N I) ER S.}

Alisanders. Smyrnium olusatrum.

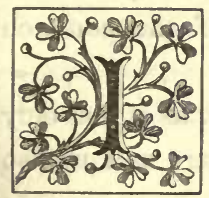

$\mathrm{N}$ foliage and habit this plant somewhat resembles Celery. It is a hardy biennial, with a branching stem, three to four feet in height; the radical leaves are pale green, compound, - those of the stem similar in form, but of smaller size. The branches of the plant terminate in large umbels, or spherical bunches of yellowish flowers, which are succeeded by roundish fruits, each of which contains two crescent-shaped seeds.

Sowing and Culture. - It thrives best in light, deep loam, and is raised from seed sown annually. Make the drills two and a half or three feet apart, and cover the seeds an inch deep. When the plants are two or three inches high, thin to twelve inches apart; or sow a few seeds in a nursery-bed, and transplant. 
Blanching. - When the plants are well advanced, they should be gradually earthed up about the stems in the process of cultivation, in the manner of blanching Celery or Cardoons; like which they are also gathered for use, and preserved during winter.

To raise Seed. - Leave a few plants unblanched; protect with stable-litter, or other convenient material, during winter, and they will flower, and produce an abundance of seeds, the following summer.

Use. - It was formerly much cultivated for its leaf-stalks, which, after being blanched, were used as a pot-herb and for salad. They have a pleasant, aromatic taste and odor; but the plant is now rarely grown, Celery being almost universally preferred.

Perfoliate Alexanders. SMrRNiUm PERF- three feet in height, grooved or furrowed, holLATUM.

low; leaves many times divided, and of a yellowish-green color; flowers, in terminal bunches, yellowishwhite; seeds black, of the form of those of the common species, but smaller.

It is considered superior to the last named, as it not only blanches better, but is more crisp and tender, and not so harsh-flavored.

\section{BROOK-LIME.}

American Brook-lime. Marsh Speedwell. Veronica beccabunga.

Brook-lime is a native of this country, but is also common to Great Britain. It is a hardy perennial, and grows naturally in ditches and streams of water, but is rarely cultivated. The stem is from ten to fifteen inches in height, thick, smooth, and succulent, and sends out roots at the joints, by which the plant spreads and is propagated; the 
leaves are opposite, oval, smooth, and fleshy; the flowers are produced in long bunches, are of a fine blue color, and stand upon short stems; they are more or less abundant during most of the summer, and are followed by heart-shaped seed-vessels, containing small, roundish seeds.

Cultivation. - It may be propagated by dividing the roots, and setting the plants in wet localities, according to their natural habit. It will thrive well when grown with Watercress.

Use. - The whole plant is used as a salad, in the same manner and for the same purposes as Water-cress. It is considered an excellent anti-scorbutic.

\section{BUCKSHORN PLANTAIN.}

Star of the Earth. Plantago coronopus.

A hardy annual, indigenous to Great Britain, France, and other countries of Europe. The root-leaves are put forth horizontally, and spread regularly about a common centre, somewhat in the form of a rosette; the flower-stem is leafless, branching, and from eight to ten inches high; the flowers are yellow; the seeds are quite small, of a clear, brown color, and retain their power of germination three years. Nearly two hundred and thirty thousand are contained in an ounce.

Soil and Cultivation. - It succeeds best in a soil comparatively light; and the seed should be sown in April. Sow thinly, broadcast, or in shallow drills eight inches apart. When the plants are about an inch high, thin them to three or four inches apart.

Use. - The plant is cultivated for its leaves, which are used as a salad. They should be plucked while still young and tender, or when about half grown. 


\section{BURNET.}

Poterium sanguisorba.

Burnet is a hardy, perennial plant, indigenous to England, where it is found on dry, upland, chalky soils. When fully developed, it is from a foot and a half to two feet in height. The leaves proceeding directly from the root are produced on long stems, and are composed of from eleven to fifteen smaller leaves, which are of an oval form, regularly toothed, and generally, but not uniformly, smooth. The branches, which are somewhat numerous, terminate in long, slender stems, each of which produces an oval or roundish bunch of purplish-red, fertile and infertile flowers. The fertile flowers produce two seeds each, which ripen in August or September. These are oblong, four-sided, of a yellowish color, and retain their vitality two years. Thirty-five hundred are contained in an ounce.

Sowing and Culture. - The plant is easily propagated by seeds, which may be sown either in autumn or spring. Sow in drills ten inches apart, half or three fourths of an inch deep, and thin, while the plants are young, to six or eight inches in the row. If the seeds are allowed to seatter from the plants in autumn, young seedlings will come up plentifully in the following spring, and may be transplanted to the distances before directed. In dry soil the plants will continue for many years, requiring no further care than to be occasionally hoed, and kept free from weeds. It may also be propagated by dividing the roots.

Use. - The leaves have a warm, piquant taste, and when bruised resemble cucumbers in odor. They are sometimes used as salad, and occasionally form an ingredient in soups. The roots, after being dried and pulverized, are employed in cases of internal hemorrhage.

It is little used in this country, and rarely seen in gardens. 
Varieties. - There are three varieties; the distinctions, however, being neither permanent nor important.

Leaves and stems comparatively rough or Hairy-leaved hairy; in other respects similar to the SmoothBurnet. leaved. This, like the others, is a sub-variety, and Large-seeded probably but a seminal variation.

Leaves and stems of the plant comparatively smooth, but differing in no other particular Smooth-
leaved Burnet. from the Hairy-leaved. Seeds from this variety would probably produce plants answering to both descriptions.

\section{CATERPILLAR.}

Scorpiurus.

All of the species here described are hardy, annual plants, with creeping or recumbent stems, usually about two feet in length. The leaves are oblong, entire on the borders, broadest near the ends, and taper towards the stem; the flowers are yellow, and quite small; the seeds are produced in caterpillar-like pods, and retain their vitality five years.

Cultivation. - The seeds may be planted in the open ground in April or May; or the plants may be started in a hot-bed, and set out after settled warm weather. The rows should be fifteen inches apart, and the plants twelve or fifteen inches apart in the rows; or the plants may be grown in hills two feet and a half apart, and two or three plants allowed to a hill.

Use. - No part of the plant is eatable; but the pods, in their green state, are placed upon dishes of salads, where 
they so nearly resemble certain species of caterpillars as to completely deceive the uninitiated or inexperienced.

Species. - The species cultivated are the following, viz. :-

Common Pod, or fruit, comparatively large. The inCaterpillar.
Vil. ScorpiUrus ver-
miculata. quite wanting; the exterior grooves are ten in number, and well defined. Along the summit of these furrows are produced numerous small, pedicelled tubereles, quite similar to those of some species of worms or caterpillars; and these small tufts, in connection with the browuishgreen color and peculiar coiling of the pods, make the resemblance nearly perfect, especially if seen from a short distance. The seeds are large, oblong, flattened at the ends, and of a yellowish color. A well-developed fruit will measure about three eighths of an inch in diameter, and, when uncoiled, nearly an inch and a half in length.

Furrowed Fruit rather slender, furrowed, grayish-green Caterpillar. Scorpiurus sulCATA. mits. Four of the exterior furrows are surmounted with numerous small, obtuse, or rounded tubercles; and the pods are coiled in the manner peculiar to the class. The seeds resemble those of the Prickly Caterpillar, but are of larger size.

Prickly Cater- Pod, or fruit, a fourth of an inch in diampillar. Vil.
SMALL CATERPL- eter, brownish-red, with shades of green. The LAR. SCORPIURUS MURICATA. seeds are large, long, wrinkled, and of a yellowish color.

Villous or Hairy Caterpillar.

SCORPIURUS SUBVILLOSA.
This species resembles the Prickly Caterpillar, but is a little larger. The most marked distinction, however, is in the small points, or 
tubereles, placed along the longitudinal ridges, which in this species are recurved, or bent at the tips. The seeds are larger than those of the foregoing species.

\section{CELERY.}

Smallage. Apium graveolens.

Celery, or Smallage, is a hardy, umbelliferous, biennial plant, growing naturally " by the sides of ditches and near the sea, where it rises with wedge-shaped leaves and a furrowed stalk, producing greenish flowers in August." Under cultivation, the leaves are pinnatifid, with triangular leaflets ; the leaf-stems are large, rounded, grooved, succulent, and solid or hollow according to the variety. The plant flowers during the second year, and then measures from two to three feet in height ; the flowers are small, yellowish-white, and are produced in umbels, or flat, spreading groups, at the extremities of the branches; the seeds are small, somewhat triangular, of a yellowish-brown color, aromatic when bruised, and of a warm, pleasant flavor. They are said to retain their germinative powers ten years, but by seedsmen are not considered reliable when more than five years old. An ounce contains nearly seventy thousand seeds.

Soil. - Any good garden soil, in a fair state of cultivation, is adapted to the growth of Celery.

Propagation. - It is always propagated by seed, a fourth of an ounce of which is sufficient for a seed-bed five feet wide and ten feet long. The first sowing is usually made in a hot-bed in March ; and it may be sown in the open ground in April or May, but when so treated vegetates slowly, often remaining in the earth several weeks before it comes up.

Some recommend putting a bushel or two of stable ma- 
nure into a hole made broad and deep, and covering it with rich fine mould to the depth of three or four inches. If this method is practised, sprinkle the seed thinly over the surface of the loam, stir the soil to the depth of half an inch, and press the earth flat and smooth with the back of a spade. Sufficient plants for any family may be started in a large flower-pot or two, placed in the sitting-room, giving them plenty of light and moisture.

Cultivation. - As soon as the young plants are about three inches high, prepare a small bed in the open air, and make the ground rich and the earth fine. Here set out the plants for a temporary growth, placing them four inches apart. This should be done carefully; and they should be gently watered once, and protected for a day or two against the sun. A bed ten feet long and four feet wide will contain three.hundred and sixty plants.

Corbett directs that the plants should remain in this nursery-bed till the beginning or middle of July, when they should be removed into trenches. Make the trenches a foot or fifteen inches deep, a foot wide, and not less than five feet apart, and lay the earth into the middle of the space between the trenches, so that it may not be washed into them by heavy rains ; for it will, in such case, materially injure the crop by covering the hearts of the plants. At the bottom of the trench put some good, rich, but well-digested compost manure; for, if too fresh, the Celery will be rank and pipy, or hollow, and will not keep nearly so long or so well. Dig this manure in, and make the earth fine and light; then take up the plants from the temporary bed, and set them out carefully in the bottom of the trenches, six or eight inches apart.

It is the practice of some cultivators, at the time of setting in the trenches, to remove all the suckers, to shorten the long roots, and to cut the leaves off, so that the whole plant shall 
be about six inches in length. But the best growers in England have abandoned this method, and now set the plants', roots and tops, entire.

Blanching. - "When the plants begin to grow (which they will quickly do), hoe on each side and between them with a small hoe. As they grow up, earth their stems; that is, put the earth up against them, but not too much at a time, and always when the plants are dry; and let the earth put up be finely broken, and not at all cloddy. While this is being done, keep the stalks of the outside leaves close up, to prevent the earth getting between the stems of the outside leaves and inner ones ; for, if it gets there, it cliecks the plant, and makes the Celery bad. When the earthing is commenced, take first the edgres of the trenches, working backwards, time after time, till the earth is reached that was taken from the trenches; and by this time the earth against the plants will be above the level of the land. Then take the earth out of the middle, till at last the earth against the plants forms a ridge, and the middle of each interval a sort of gutter. Earth up very often, not putting up much at a time, every week a little; and by the last of September, or beginning of October, it will be blanched sufficiently for use." - Corb.

Another (more recent) method of cultivation and blanching is to take the plants from the temporary bed, remove the suckers, and set them with the roots entire, ten inches apart in the trenches. They are then allowed to grow until they have attained nearly their full size, when the earth for blanching is more rapidly applied than in the previous method.

"Many plant on the surface, - that is, marking out the size of the bed on ground that has been previously trenched; digging in at least six or eight inches of rich, half-decayed manure, and planting either in single lines four feet apart, 
or making beds six feet broad, and planting across them, setting the rows fourteen inches apart, and the plants eight inches apart in the lines. They may be earthed up as they advance, or not until they have attained the height of a foot." - McInt.

McIntosh gives the following method, practised by the Edinburgh market-gardeners : "Trenches, six feet wide and one foot deep, are dug out; the bottom is loosened and well enriched, and the plants set in rows across the bed, fourteen inches asunder, and the plants nine inches apart in the rows. By this means space is economized, and the plants attain a fair average size and quality. The same plan is very often followed in private gardens; and, where the new and improved sorts are grown, they arrive at the size most available for family use. This is one of the best methods for amateurs to grow this crop. They should grow their plants in the temporary or nursery beds until they are ten inches or a foot high, before planting in the trenches, giving plenty of water, and afterwards earthing up once a fortnight."

Some allow the plants to make a natural growth, and earth up at once, about three weeks before being required for use. When so treated, the stalks are of remarkable whiteness, crisp, tender, and less liable to russet-brown spots than when the plants are blanched by the more common method.

Taking the Crop. - Before the closing up of the ground, the principal part of the crop should be carefully taken up (retaining the roots and soil naturally adhering), and removed to the cellar, where they should be packed in moderately moist earth or sand, without covering the ends of the leaves.

A portion may be allowed to remain in the open ground; but the hearts of the plants must be protected from wet weather. This may be done by placing boards lengthwise, 
in the form of a roof, over the ridges. As soon as the frost leaves the ground in spring, or at any time during the winter when the weather will admit, Celery may be taken for use directly from the garden.

Seed.-Two or three plants will produce an abundance. They should be grown two feet apart, and may remain in the open ground during the winter. The seeds ripen in August.

Use. - The stems of the leaves are the parts of the plant used. These, after being blanched, are exceedingly crisp and tender, with an agreeable and peculiarly aromatic flavor. They are sometimes employed in soups, but are more generally served crude, with the addition of oil, mustard, and vinegar, or with salt only. The seeds have the taste and odor of the stems of the leaves, and are often used in their stead for flavoring soups.

With perhaps the exception of Lettuce, Celery is more generally used in this country than any other salad plant. It succeeds well throughout the Northern and Middle States, and in the vicinity of some of our large cities is produced of remarkable size and excellence.

\section{Varieties. -}

A medium-sized, white variety ; hardy, crisp, Boston-marsucculent, and mild flavored. Compared with ket Celery. the White Solid, the stalks are more numerous, shorter, not so thick, and much finer in texture. It blanches quickly, and is recommended for its hardiness and crispness, the stalks rarely becoming stringy or fibrous, even at, an advanced stage of growth. Much grown by market-gardeners in the vicinity of Boston. Mass.

This is comparatively a new sort, of much Cole's Superb excellence, and of remarkable solidity. It is 
not of large size, but well adapted for cultivation in the kitchen garden and for family use; not so well suited for marketing, or for exhibition purposes. It has the valuable property of not piping, or becoming hollow or stringy, and remains long without running to seed. The leaf-stalks are of a fine purple color, tender, crisp, and fine flavored. A well-grown plant will weigh about six pounds.

Cole's Superb Much like Cole's Superb Red; differing little, except in color. An excellent sort, hardy, runs late to seed, and is one of the most crisp and tender of the white sorts. Stalks short and thick.

DwarfCurled Leaves dark green, curled, resembling those
White. Vil. $\quad$ of Parsley, and, like it, might be employed for garnishing. The leaf-stalks are rounded and grooved, comparatively crisp and solid, but not fine flavored. It is quite hardy, and, in moderate winters, will remain in the open ground without injury, and serve for soups in spring. Its fine, curled foliage, however, is its greatest recommendation.

Early Dwarf Solid White. Thomp.

Rather dwarf, but thick stemmed. The heart is remarkably full; the leaf-stalk solid, blanching promptly. There is, in fact, much more finely blanched substance in a plant of this variety than in one of the tall sorts, and the quality is excellent. It comes into use rather early, and is one of the hardiest of the White varieties.

Italian Celery. Thomp. IARGE UPRIGHT.
Giant PATAG0NIAN.

serratures. It is not so crisp as the Common White Solid, and is suitable only for soups, or where very tall Celery is desirable. 
This is considered the largest variety yet pro- Laing's Imduced; specimens have been grown in England of the extraordinary weight of eight or ten proved Mammoth Red

Celery. pounds, and at the same time perfectly solid. It is nearly perennial in its habit, as it will not run to seed the first year, and is with difficulty started to blossom even during the second, when planted out for the purpose. Color bright red; flavor unsurpassed, if equalled.

This variety scarcely differs from the Red Manchester Solid. It has, however, a coarser habit, with a somewhat rounder stalk; and, this being the Red Celery. Thomp. Manchester RED GIANT. case, the heart is not so compact. It is grown largely for marketing, and is excellent for soups and stewing.

Originated with Mr. Nutt, of Sheffield. Nutt's ChamIt attains, under good management, in good soil, a large size, and, this considered, is of expion White Celery. McInt. cellent quality; very white, and not apt to run to seed.

The plant grows to a large size, full hearted, Red Solid. with a thick stem. Leaf-stalks thick, deeply NEw LARGE RED furrowed, and remarkably solid, of a dark red $\begin{gathered}\text { NEW PLE TOURS } \\ \text { PURPLE. }\end{gathered}$ or purplish hue where exposed, rose-colored where partially blanched; but the perfectly blanched portion is pure white, more so than the blanched part of the White varieties of Celery. It is also crisp, of excellent flavor, and unquestionably the best variety of Red Celery.

A large-sized, vigorous-growing variety; in good soils, often attaining a height of nearly three feet. The stalks are solid; flat at the base, where they overlap, and form a compact, Seymour's Superb White. Thomp.

SEYMOUR'S SUPERB WHITE SOLID. crisp, and, with ordinary care, a well-blanched heart of ex- 
cellent quality. It succeeds best, as most other sorts do, in rich, moist soil ; and when so grown, and properly blanched, will yield a large proportion of Celery, of a pure white color, and of the best quality.

It is one of the best sorts for extensive culture for the markets, as it is also one of the best varieties for small gardens for family use. It blanches readily, and, with little care, will supply the table from the last of September through most of the winter.

Seymour's A variety represented as being superior to pion.

Seymour's Superb White. The stalks are broad, flat at the base, and form a compact, well-blanched, crisp heart.

Shepherd's Much like the Manchester Red, but has flatRed. Thomp.

SHEPHERD's ter stems; consequently, it is more compact, GIANT RED.

and blanches sooner and more perfectly, than that variety; to which, for these reasons, it is preferred by growers for competition.

Small Dutch

Leaf-stems small, hollow, crisp, and succuCelery. Vil.

lent; sprouts, or suckers, abundant. It is seldom blanched; but the leaves are sometimes used for flavoring soups.

The seeds should be sown thickly, and on level beds. The plants often resprout after being cut. Not much cultivated.

Sutton's White Solid. McInt:

Turkey or Prussian Celery.

GIANT White. TURKISH GIANT Solid.
A very large yet solid-growing variety, exceedingly white and crisp.

A remarkably large variety, resembling the Common White Solid. Leaf-stalks long, large, erect, fleshy, and solid; leaves large, with rounded serratures, and of a glossy green color. 
It is one of the largest of the White sorts, and is considered superior to the Common White Solid.

An improved variety of the Italian, esteemed by growers for competition, where quantity, Wall's
White Celenot quality, is the principal consideration.

A short, broad, flat-stalked variety, of excellent quality; crisp and white. Its short, flat, spreading habit gave rise to its name. ry. Thomp.

This variety is of strong and rather tall White Solid.

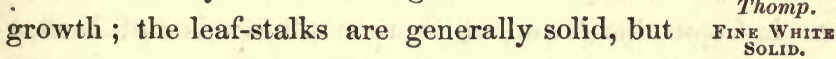
when grown in rich, highly manured soil, they White
Lion's-Paw Celery. McInt.

L10N's-PAw. sometimes become slightly hollow; the leaves are large, smooth, and bright green; serratures large and obtuse. It blanches readily, is crisp, of excellent quality, and comes into use earlier than the Red sorts. It is generally cultivated in the Northern States, not only on account of its hardiness, but for its keeping qualities. As a market variety, it is one of the best.

\section{CELERIAC, OR TURNIP-ROOTED CELERY.}

This variety forms at the base of the leaves, near the surface of the ground, a brownish, irregular, rounded root, or tuber, measuring from three to four inches in diameter. The leaves are small, with slender, hollow stems. In favorable exposures and rich soil, the roots sometimes attain a weight of more than three pounds. It is much hardier than the common varieties of Celery.

Propagation. - It is propagated from seeds, which may be sown in the open ground in April or May, in shallow drills six or eight inches apart. As soon as the seed- 
lings are three or four inches high, take them up, remove the small side-shoots, or suckers, and set the plants in rows eighteen inches or two feet apart, and a foot apart in the rows.

Subsequent Cultivation. - The growing crop will require no peculiar treatment. When the bulbs are two thirds grown, they are earthed over for the purpose of blanching, and to render the flesh crisp and tender. Cool and humid seasons are the most favorable to their growth. In warm and dry weather, the bulbs are small, comparatively tough, and strong flavored.

Taking the Crop. - Some of the bulbs will be ready for use in September, from which time till the last of November, the table may be supplied directly from the garden. Before severe weather, the quantity required for winter should be drawn, packed in damp earth or sand, and stored in the cellar.

To save Seed. - Give to a few plants, taken up in the autumn, as much light and air as possible during the winter, keeping them cool, but not allowing them to freeze; and in April set them in the open ground, eighteen inches apart. The seed will ripen the last of the season. It is often used, in the manner of the seed of the Common Celery, for seasoning soups.

Use. - The root, or bulb, is the part of the plant eaten; the flesh of this is white, and comparatively tender, with the flavor of the stalks of Common Celery, though generally less mild and delicate. It is principally valued for its remarkable hardiness and for its keeping properties. Where the common varieties of Celery are grown or pre-seirved with difficulty, this might be successfully cultivated, and afford a tolerable substitute. The bulbs are sometimes eaten boiled, and the leaves are occasionally used in soups. 
This is a variety of the Common Celeriac, Curledor Turnip-rooted Celery; like which, it forms leaved Cele-

a sort of bulb, or knob, near the surface of the TURNIP-BOoteD. ground. It is, however, of smaller size, usually measuring about three inches in diameter. The skin is brown, and the flesh white and fine grained; leaves small, spreading, curled.

It is in no respect superior to the Common Turnip-rooted, and possesses little merit aside from the peculiarity of its foliage. Cultivate, preserve during winter, and use as directed for the common variety.

An early variety. Root, or bulb, not large, Early Erfurt but regular in form. Its earliness is its prinVil. cipal merit.

\section{CHERVIL.}

Common or Plain-leaved. Chærophyllum cerefolium.

A hardy, annual plant, from the south of Europe. Stem eighteen inches to two feet in height; the leaves are many times divided, and are similar to those of the Common Plain Parsley; the flowers are small, white, and produced in umbels at the extremities of the branches; the seeds are black, long, pointed, longitudinally grooved, and retain their vitality but two years. Nearly nine thousand are contained in an ounce.

"This is the most common sort, but, except that it is hardier than the Curled varieties, is not worthy of cultivation." A variety of the Common Chervil, with Curled Cherfrilled or curled leaves; the distinction between the sorts being nearly the same as that between the 
Plain-leaved and Curled-leaved varieties of Parsley. The foliage is delicately and beautifully frilled, and, on this account, is much employed for garnishing, as well as for the ordinary purposes for which the plain sort is used.

Being a larger grower, it requires more room for its development; and the plants should stand a foot apart each way. When intended for winter use, it should have the protection of hand-glasses, frames, or branches of trees placed thickly around or amongst it. In unfavorable situations, it is well to pot a dozen or two of the plants, and shelter them under glass during the winter.

Frizzled- An improved variety of the Curled Chervil, leaved or French Cher- - even more beautiful, but wanting in hardi-
vil. AICInt. Double-curLed. ness. It succeeds best when grown in the summer months.

Propagation and Cultivation. - Chervil is raised from seeds ; and, where it is much used, sowings should be made, at intervals of three or four weeks, from April till July. The seeds should be sown thinly, in drills a foot apart, and covered nearly an inch in depth.

Use. - It is cultivated for its leaves, which have a pleasant, aromatic taste, and, while young and tender, are employed for flavoring soups and salads.

\section{CHICCORY, OR SUCCORY.}

Wild Endire. Cichorium intybus.

- A hardy, perennial plant, introduced into this country from Europe, and often abounding, as a troublesome weed, in pastures, lawns, and mowing-lands. The stem is erect, stout, and branching, and, in its native state, usually about three feet in height, - under cultivation, however, it sometimes 
attains a height of five or six feet; the radical leaves are deep green, lobed, and, when grown in good soil, measure ten or twelve inches in length, and four inches in width; the flowers are large, axillary, nearly stemless, of a fine blue color, and generally produced in pairs; the seeds somewhat resemble those of Endive, though ordinarily smaller, more glossy, and of a deeper brown color. They will keep ten years. The plants continue in blossom from July to September; and the seeds 'ripen from August to October, or until the plants are destroyed by frost.

Soil, Sowing, and Cultivation. - As the roots of Chiccory are long and tapering, it should be cultivated in rich, mellow soil, thoroughly stirred, either by the plough or spade, to the depth of ten or twelve inches. The seed should be sown in April or May, in drills fifteen inches apart, and three fourths of an inch deep. When the young plants are two or three inches high, thin them to eight inches apart in the rows, and, during the summer, cultivate frequently, to keep the soil light, and the growing crop free from weeds.

Blanching. - Before using as a salad, the plants arc blanched, either by covering with boxes a foot in depth, or by strips of boards twelve or fourteen inches wide, nailed together at right angles, and placed lengthwise over the rows. They are sometimes blanched by covering with earth, the leaves being first gathered together, and tied loosely at the top, which should be left exposed to light.

To save Seed. - In the autumn, leave a few of the best plants unblanched; let them be about eighteen inches asunder. Protect with stable litter; or, if in a sheltered situation, leave them unprotected during winter, and they will. yield abundantly the ensuing summer.

Taking the Crop. - When the leaves are properly blanched, they will be of a delicate, creamy white. When they are about a foot high, they will be ready for use; and, as soon 
as they are cut, the roots should be removed, and others brought forward to succeed them.

Use. - It is used as Endive, its flavor and properties being much the same. Though rarely grown in this country, it is common to the gardens of many parts of Europe, and $i$; much esteemed. The blanched leaves are known as Barbe de Capucin, or "Friar's Beard."

\section{Varieties. -}

Improved Chiccory, or

Succory.

Leaves larger than those of the Common Chiccory, and produced more compactly, forming a sort of head, or solid heart, like some of the Endives.

The plant is sometimes boiled and served in the manner of Spinach.

Variegated or Spotted Chiccory. Vil.

This is a variety of the preceding, distinguished by the color of the leaves, which are veined, and streaked with red. In blanching, the red is not changed, but retains its brilliancy, while the green becomes nearly pure white, the two eolors blending in rich contrast. In this state they form a beautiful, as well as tender and well-flavored, salad.

Improved Variegated Chiccory. Vil.

A sub-variety of the Spotted Chiccory, more constant in its character, and more uniform and distinct in its stripes and variegations. When blanched, it makes an exceedingly delicate and beautiful garnish, and a tender and excellent salad.

The improved sorts are as hardy, and blanch as readily, as the Common Chiccory.

Large-rooted or Coffee Chiccory. TURNIP-ROOTED CHiccory.
This variety is distinguished by its long, fleshy roots, which are sometimes fusiform, but generally. much branched or divided; when 
well grown, they are twelve or fourteen inches in length, and about an inch in their largest diameter. The leaves have the form of those of the Common Chiccory, but are larger and more luxuriant.

Though the variety is generally cultivated for its roots, the leares, when blanched, afford a salad even superior to some of the improved sorts before described.

Vilmorin mentions two sub-varieties of the Large-rooted or Coffee Chiccory, viz.:-

Roots shorter than those of the Magdebourg, Brunswick but of greater diameter; leaves spreading.

Largerooted.

Roots long, and comparatively large; leaves Magdebourg erect.

Largerooted.

After several years' trial, preference was given to this variety, which proved the more productive.

Sowing and Cultivation. - For raising Coffee Chiccory, the ground should first be well enriched, and then deeply and thoroughly stirred by spading or ploughing. The seeds should be sown in April or May, in shallow drills a foot apart, and the young plants thinned to three or four inches apart in the rows. Hoe frequently; water, if the weather is dry ; and in the autumn, when the roots have attained sufficient size, draw them for use. After being properly cleaned, cut them into small pieces, dry them thoroughly in a kiln or spent oven, and store for use or the market. After being roasted and ground, Chiccory is mixed with coffee in various proportions, and thus forms a pleasant beverage; or, if used alone, will be found a tolerable substitute for genuine coffee.

The roots of any of the before-described varieties may be used in the same manner, but as they are much smaller, and 
consequently less productive, are seldom cultivated for the purpose.

It is an article of considerable commercial importance. and large quantities are annually imported from the south of Europe to different seaports of the United States. As the plant is perfectly hardy, of easy culture, and quite productive, there appears to be no reason why the home demand for the article may not be supplied by home production. Of its perfect adaptedness to the soil and climate of almost any section of this country, there can scarcely be a doubt.

\section{CORCHORUS.}

Corchorus olitorius.

An annual plant from Africa; also indigenous to the West Indies. Stem about two feet high, much branched; the leaves are deep green, slightly toothed, and vary in a remarkable degree in their size and form; some are spearshaped, others oval, and some are nearly heart-shaped; the leaf-stems are long and slender; flowers nearly sessile, small, yellow, five-petaled; seeds angular, pointed, and of a greenish color. Fourteen thousand are contained in an ounce, and they retain their vitality four years.

Soil, Propagation, and Culture. - The plant requires a light, warm soil, and should have a sheltered, sunny place in the garden. It is grown from seed sown annually. The sowing may be made in March in a hot-bed, and the plants set in the open ground in May; or the seed may be sown the last of April, or first of May, in the place where the plants are to remain. The drills, or rows, should be fifteen inches apart, and the plants five or six inches apart in the rows. No further attention will be required, except the ordinary labor of keeping the soil loose and the plants clear from weeds. 
Use. - The leaves are eaten as a salad, and are also boiled and served at table in the form of greens or spinach. They may be cut as soon as they have reached a height of five or six inches.

\section{CORN SALAD.}

Fetticus. Lamb's Lettuce. Valeriana locusta.

This is a small, hardy, annual plant, said to derive its name from its spontaneous growth, in fields of wheat, in England. It is also indigenous to France and the south of Europe.

When in flower, or fully grown, it is from twelve to fifteen inches in height. The flowers are small, pale blue; the seeds are rather small, of a yellowish-brown color, unequally divided by two shallow, lengthwise grooves, and will keep six or eight years.

Soil and Culture. - It is always grown from seed, and flourishes best in good vegetable loam, but will thrive in any tolerably enriched garden soil. Early in April, prepare a bed four feet wide, and of a length according to the quantity of salad required; having regard to the fact, that it is better to sow only a small quantity at a time. Rake the surface of the bed even, make the rows across the bed about eight inches apart, sow the seed rather thinly, and cover about one fourth of an inch deep with fine, moist soil. If dry weather occurs after sowing, give the bed a good supply of water. When the young plants are two inclies high, thin them to four inches apart, and cut or draw for use as soon as the leaves have attained a suitable size.

As the peculiar value of Corn Salad lies in its remarkable hardiness, a sowing should be made the last of August or beginning of September, for use during the winter or early in spring; but, if the weather is severe, the plants must be pro- 
tected by straw or some other convenient material. Early in March, or as soon as the weather becomes a little mild, remove the covering, and the plants will keep the table supplied until the leaves from fresh sowings shall be grown sufficiently for cutting.

Seed. - To raise seed, allow a few plants from the spring sowing to remain without cutting. They will grow up to the height and in the manner before described, and blossom and ripen their seed during the summer. An ounce of seed will sow a row two hundred feet in length, and about five pounds will be required for an acre.

Use. - The leaves, while young, are used as a salad, and in winter, or early in spring, are considered excellent. They are also sometimes boiled and served as Spinach.

\section{Varieties. -}

Common Corn
Salad.

Root-leaves rounded at the ends, smooth, three or four inches long by about an inch in width. The younger the plants are when used, the more agreeable will be their flavor.

Large Round- Leaves larger, of a deeper green, thicker, leaved. and more succulent, than those of the foregoing variety. It is the best sort for cultivation. The leaves are most tender, and should be cut for use while young and small.

Large-seeded This is a sub-variety of the Large Round, Round. Vil. and is much cultivated in Germany and Holland. The leaves are longer, narrower, and thinner, and more tender when eaten; but the Large Round is preferred by gardeners for marketing, as it bears transportation better. The seeds are about twice as large. 
The Italian Corn Salad is a distinct species, Italian Corn and differs from the Common Corn Salad in its valertanzela foliage, and, to some extent, in its general habit.

It is a hardy annual, about eighteen inches high. The radical leaves are pale green, large, thick, and fleshy, those of the stalk long, narrow, and pointed; the flowers are small, pale blue, washed or stained with red; the seeds are of a light brown color, somewhat compressed, convex on one side, hollowed on the opposite, and retain their vitality five years. Nearly twenty-two thousand are contained in an ounce.

It is cultivated and used in the same manner as the species before described. It is, however, earlier, milder in flavor, and slower in running to seed. The leaves are sometimes employed early in spring as a substitute for Spinach ; but their downy or hairy character renders them less valuable for salad purposes than those of some of the varieties of the Common Corn Salad.

\section{CRESS, OR PEPPERGRASS.}

Lepidium sativum.

The Common Cress of the garden is a hardy annual, and a native of Persia. When in flower, the stem of the plant is smooth and branching, and about fifteen inches high. The leaves are variously divided, and are plain or curled, according to the variety; the flowers are white, small, and produced in groups, or bunches; the seeds are small, oblong, rounded, of a reddish-brown color, and of a peculiar, pungent odor. About fourteen thousand are contained in an ounce, and they retain their germinative properties five years.

Soil and Cultivation.-Cress will flourish in any common 
garden soil, and is always best when grown early or late in the season. The seed vegetates quickly, and the plants grow rapidly. As they are milder and more tender while young, the seed should be sown in succession, at intervals of about a fortnight, making the first sowing early in April. Rake the surface of the ground fine and smooth, and sow the seed rather thickly, in shallow drills six or eight inches apart. Half an ounce of seed will be sufficient for thirty feet of drill.

To raise Seed. - Leave a dozen strong plants of the first sowing uncut. They will ripen their seed in August, and yield a quantity sufficient for the supply of a garden of ordinary size.

Use. - The leaves, while young, have a warm, pungent taste, and are eaten as a salad, either separately or mixed with lettuce or other salad plants. The leaves should be cut or plucked before the plant has run to flower, as they then become acrid and unpalatable. The curled varieties are also used for garnishing.

\section{Varieties. -}

Broad-leaved A coarse variety, with broad, spatulate Cress.

leaves. It is sometimes grown for feeding poultry, and is also used for soups; but it is less desirable as a salad than most of the other sorts.

Common or Plain-leaved Cress.

This is the variety most generally cultivated. It has plain leaves, and consequently is not so desirable a sort for garnishing. As a salad kind, it is tender and delicate, and considered equal, if not superior, to the Curled varieties.

Curled Cress. Leaves larger than those of the common plain Garnishina CREss. variety, of a fine green color, and frilled and 
curled on the borders in the manner of some kinds of Parsley. It is used as a salad, and is also employed as a garnish.

It is very liable to degenerate by becoming gradually less curled. To keep the variety pure. select only the finest curled plants for seed. This variety is of slower growth than the Golden Cress. Common Cress. The leaves are of a yellowishgreen, flat, oblong, scalloped on the borders, sometimes entire, and of a much thinner texture than any of the varieties of the Common Cress. It is very dwarf, and is consequently short when cut as a salad herb for use. It has a mild and delicate flavor. When run to flower it does not exceed eighteen inches in height.

It deserves more general cultivation, as affording a pleasant addition to the varieties of small salads.

The seeds are of a paler color, or more yellow, than those of the other sorts.

An excellent variety, introduced by Mr. Normandy Charles McIntosh, and described as being re- Curled McInt. markable hardy, and therefore better adapted for sowing early in spring or late in summer.

The leaves are finely cut and curled, and make not only a good salad, but a beautiful garnish. The seed should be sown thinly, in good soil, in drills six inches apart. In gathering, instead of cutting the plants over, the leaves should be picked off singly. After this operation, fresh leaves are soon put forth.

It is difficult to procure the seed true, the Common Curled being, in general, substituted for it. 


\section{CUCKOO FLOWER.}

Small Water-cress. Cardamine pratensis.

A hardy, perennial plant, introduced from Europe, and naturalized to a limited extent in some of the Northern States. Stem about fifteen inches high, erect, smooth; leaves deeply divided, - the divisions of the radical or root leaves rounded, those of the stalk long, narrow, and pointed; the flowers are comparatively large, white, or rose-colored, and produced in erect, terminal clusters; the seeds are of a brown color, small, oblong, shortened on one side, rounded on the opposite, and retain their vegetating powers four years. Nearly thirty thousand are contained in an ounce.

Soil. - It succeeds best in moist, loamy soil, and should have a shady situation.

Propagation and Cultivation. - It may be propagated from seeds, or by a division of the roots. The seeds are sown in April or May, in shallow drills a foot asunder. The roots may be divided in spring or autumn.

Use. - The leaves have the warm, pungent taste common to the Cress family, and are used, in their young state, like Cress, as a salad. Medically, they have the reputation of being highly antiscorbutic and of aiding digestion. There are four varieties:-

White Flowering. - A variety with white, single flowers. Purple Flowering. - Flowers purple, single. Either of these varieties may be propagated from seeds, or by a division of the roots.

Double Flowering White.-Flowers white, double.

Double Flowering Purple. - A double variety, with purple blossoms. These varieties are propagated by a division of the roots. Double-flowering plants are rarely produced from seeds. 


\section{THE DANDELION.}

\section{Leontodon taraxacum.}

The Dandelion, though spontaneously abundant, is not a native of this country. Introduced from Europe, it has become extensively naturalized, abounding in gardens, on lawns, about cultivated lands, and, in May and June, often, of itself alone, constituting no inconsiderable portion of the herbage of rich pastures and mowing-fields.

It is a hardy, perennial plant, with an irregular, branching, brownish root. The leaves are all radical, long, runcinate, or deeply and sharply toothed; the flower-stem is from six to twelve inches and upwards in height, leafless, and produces at its top a large, yellow, solitary blossom; the seeds are small, oblong, of a brownish color, and will keep three years.

Soil and Cultivation. - Although the Dandelion will thrive in almost any description of soil, it nevertheless produces much the largest, most tender, and best flavored leaves, as well as the greatest crop of root, when grown in mellow, well-enriched ground. Before sowing, stir the soil, either by the spade or plough, deeply and thoroughly; smooth off the surface fine and even; and sow the seeds in drills half an inch deep, and twelve or fifteen inches apart. If cultivated for spring greens, or for blanching for salad, the seed must be sown in May or June. In July, thin out the young plants to two or three inches apart; cultivate during the season in the usual form of cultivating other garden productions, and in April and May of the ensuing spring the plants will be fit for the table.

For early use, select a portion of the bed equal to the supply required, and, in November, spread it rather thickly over with coarse stable manure. About the beginning of February, remove the litter, and place boards or planks on 
four sides of a square or parallelogram, in the manner of a common hot-bed, providing for a due inclination towards the south. Over these put frames of glass, as usually provided for hot-beds ; adding extra protection by covering with straw or other material in intensely cold weather. Thus treated, the plauts will be ready for cutting two or three weeks earlier than those in the open ground.

When grown for its roots, the ground must be prepared in the manner before directed; and the seeds should be sown, in October, in drills fourteen or fifteen inches asunder. In June following thin out the young plants to two or three inches apart; keep the ground loose, and free from weeds, during the summer, and in October the roots will have attained their full size, and be ready for harvesting, which is usually performed with a common subsoil plough. After being drawn, they are washed entirely clean, sliced, and dried in the shade, when they are ready for the market.

Use. - The Dandelion resembles Endive, and affords one of the earliest, as well as one of the best and most healthful, of spring greens. It is also sometimes blanched and used as salad. The roots, after being dried as before directed, constitute an article of considerable commercial importance, being extensively employed as a substitute for, or mixed in various proportions with, coffee.

It may be grown for greens at trifling cost; and a bed twelve or fourteen feet square will afford a family an abundant supply.

Under cultivation, and even in its natural state, the leaves of different plants vary in a marked degree from each other, not only in size and manner of growth, but also in form. Judicious and careful cultivation would give a degree of permanency to these distinctions ; and varieties might undoubtedly be produced, well adapted for the various purposes for which the plant is grown, whether for the roots, for blanching, or for greens. 


\section{ENDIVE.}

Chicorium endivia.

Endive is a hardy annual, said to be a native of China and Japan. When fully developed, it is from four to six feet in height. The leaves are smooth, and lobed and cut upon the borders more or less deeply, according to the variety; the flowers are usually of a blue color, and rest closely in the axils of the leaves; the seeds are small, long, angular, and of a grayish color; their germinative properties are retained for ten years. Nearly twenty-five thousand are contained in an ounce.

Soil. - All of the varieties thrive well in any good, mellow garden soil. Where there is a choice of situations, select one in which the plants will be the least exposed to the effects of drought and heat.

Propagation. - The plants can be raised only from seed, which may be sown where the plants are to remain, or in close drills in a nursery-bed for transplanting. If sown where the plants are to remain, sow thinly in shallow drills a foot apart for the smaller, curled varieties, and fifteen inches for the larger, broad-leaved sorts. Thin out the plants to a foot asunder as soon as they are large enough to handle, and keep the ground about them, as well as between the rows, loose, and free from weeds, by repeated hoeings. If required, the plants taken out in thinning may be reset in rows at the same distances apart.

If sown in a nursery-bed, transplant when the young plants have eight or ten leaves, setting them at the distances before directed. This should be done at morning or evening; and the plants should afterwards be watered and shaded for a few days, until they are well established.

The first sowing may be made as early in spring as the weather will permit; and a sowing may be made a month or 
six weeks after, for a succession; but as it is for use late in autumn, or during the winter and spring, that.Endive is most required, the later sowings are the most important. These are usually made towards the end of July.

Blanching. - Before using, the plants must be blanched, which is performed in various ways. The common method is as follows: When the root-leares have nearly attained their full size, they are taken when entirely dry, gathered together into a conical form, or point, at the top, and tied together with matting, or any other soft, fibrous material, by which means the large, outer leaves are made to blanch the more tender ones towards the heart of the plant.

After being tied in this manner, the plants are sometimes blanched by earthing, as practised with Celery or Cardoons. This process is recommended for dry and warm seasons; but in cold, wet weather they are liable to decay at the heart; and blanching-pots, or, in the absence of these, common flower-pots, inverted over the plants, will be found a safe and effectual means of rendering them white, crisp, and mild flavored.

Time required for Blanching. - In summer weather, when vegetation is active, the plants will blanch in ten days; but in cool weather, when the plants have nearly attained their growth, or are slowly developing, three weeks will be required to perfect the operation.

Harvesting, and Preservation during Winter. - "Before frost sets in, they must be tied up in a conical form, as before directed, and all dead or yellow leaves must be taken off. Then take them up with a ball of soil to each, and put them into light earth in a cellar or some warm building. Put only the roots into the earth. Do not suffer the plants to touch each other; and pour a little water round the roots after they are placed in the earth. If they are perfectly dry when tied up, they will keep till spring." - Corb. 
Seed. - Two or three vigorous plants, left unblanched, will yield sufficient to supply a garden of ordinary size for years. Half an ounce will sow a seed-bed of forty square feet.

Use. - "The leaves are the parts used, and these only when blanched, to diminish their natural bitterness of taste. It is one of the best autumn, winter, and spring salads." McInt.

Varieties. - The descriptions of many of the varieties have been prepared from an interesting paper read before the London Horticultural Society by Mr. Matthews, clerk of the society's garden.

The different sorts are divided into two classes - the "Batavian" and the "Curled-leaved."

Batavian Endives. - Under the Batavian Endives are included all the varieties with broad leaves, generally rounded at the points, with the margin slightly ragged or torn, but not curled. These are called, by the French, Scarolles. As most of the sorts require more room than the Curledleaved kinds, the rows should be about fourteen inches apart, and the plants thinued out from nine to twelve inches in the rows.

Leaves yellowish-green, large, long and broad, Broad-leaved thick and fleshy, the edges slightly ragged;

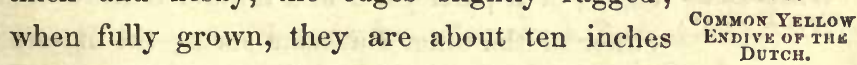
long, and an inch wide at the base, increasing Batavian Endive. regularly in width towards the end, and measuring five or six inches in diameter at the broadest part. The leaves of the centre of the plant are of the same form, but shorter and much paler. The plants form but little heart of themselves, but the length of the outer leaves is such that they tie up well for blanching. 
In quality, as well as in appearance, it is inferior to the curled varieties. Curled Bata- The leaves of this variety are neither so large
vian Endive. Thomp. nor so broad as those of the Broad-leaved Batavian Endive; they grow, flat on the ground, and are curled at their edges. The whole appearance of the plant is very different from the Common Broad-leaved, approaching the Curled Endives in general character. The heart, which forms of itself, is small, and lies close to the ground.

The plants require twelve or fourteen inches' space between the rows, and eight or ten inches in the row.

Large Bata- This differs from the Small Batavian Endive vian Endive. in the size and shape of its leaves, which are broader and more rounded; they are a little darker, but yet pale. The inner ones are turned over like the small variety, though not so regularly, but form a large, well-blanched heart, of good flavor. This and the Small Batavian will blanch perfectly if a mat is laid over them, and do not require to be tied up. Both the Small and the Large sorts are considered hardier than the Curled varieties.

Lettuceleaved or

Leaves broad and large, obtuse, ragged at the White Bata- edges, of a paler color and thinner texture than
vian Endive.

either of the other Batavian sorts ; the exterior leaves are spreading, fourteen inches long, two inches wide at the base, and growing regularly broader to the end, measure six or seven inches in diameter at the widest part; the central leaves are short, and the head is less compact than that of the Common Broad-leaved; the seeds are of a paler color than those of the Green Curled Endive.

To blanch it, the leaves must be tied up; and it should be grown for summer use, as it is comparatively tender, and 
will not endure severe weather. It is best if used while young; when fully developed, the leaves are not tender, and, if not well blanched, are liable to have a slightly bitter taste.

Sow in May or June, in rows fifteen inches apart, and thin to a foot in the rows; or transplant, giving the plants the same space.

Leaves whitish-green, broad, of moderate Small Batalength, and slightly cut at the edges. The vian Endive. inner leaves are numerous, and turn over like a hood at the end, forming a larger head than any of the other kinds. It is one of the best of the Endives, and a valuable addition to our winter salads. It blanches with little trouble, and is mild and sweet without being bitter.

Curled Endives. - Curled Endives are those with narrow leaves, more or less divided, and much curled. They are usually full in the heart. The French call them, by way of distinction, Chicorées.

This approaches the Large Green Curled En- Dutch Green dive in appearance and growth; but the di- $\begin{gathered}\text { Curled dive. } \\ \text { dive }\end{gathered}$ visions of the leaves are deeper, the outer leaves are broader, not so much curled, and the inner ones more turned into the heart; the outer leaves are about ten inches long. It blanches well, and is hardy.

Leaves six or seven inches long, finely cut, Green Curled and beautifully curled; the outer leaves lying $\begin{gathered}\text { Endive. } \\ \text { SMALL GREN }\end{gathered}$ close to the ground, the inner ones thickly set, forming a compact heart. Easily blanched, very hardy, and well adapted for winter use. The leaves are longer, and of a darker green color, than those of the Green Curled Sum- 
mer Endive, and will tie up much better for blanching. It is a fortnight later.

Sow in rows a foot or fourteen inches apart, and thin to six or eight inches in the row.

It may be quickly blanched by simply covering the plant with a deep flower-pot saucer. In summer, while the plants are growing vigorously, the process will be completed in about a week; later in the season, two weeks, or even more, may be necessary. Green Curled Leaves not quite so large as those of the Green
Summer Endive.

Curled; finely and deeply cut; the outer ones are five or six inches long, and grow close to the ground; the inner are short, numerous, curled, and form a close, full heart. It is much the smallest of any of the kinds, and is somewhat tender. The outer leaves are so short that they will not tie up, but blanch well by being covered simply with a flat garden-pan, as directed for the Green Curled.

This variety is distinguished from the last named by its shorter, broader, deeper cut, and less curled leaves; the head is more solid at the centre, and is also much harder. The seeds should be sown early; if sown late, the plants are liable to be affected by dampness and wet weather, and to rot at the heart.

Cultivate in rows twelve or fourteen inches apart, and eight or ten inches apart in the rows.

Italian Green Leaves from ten to twelve inches long, deep Curled En-
dive. green, narrow, and divided to the midrib. They grow erect, and the segments are much cut and curled.

It is a well-marked variety, readily distinguished by the length of the leaf-stalks, and the pinnatifid character of the leaves. It blanches well, and is of good quality. 
A sub-variety of the Common Green Curled, Large Green of stronger growth, and larger hearted. The dive.

exterior leaves are ten or twelve inches long, looser and more erect than those of the last named; the inner ones are less numerous, and not so much divided.

It is hardy, blanches quickly, and is not liable to decay at the heart.

Leaves long, deeply divided, and more upright Long Italian in their growth than those of the Large Green Curled.

Curled; the divisions of the leaves are large, and toothed, or cut, but are not curled; the heart-leaves are few and short.

The variety is quite distinct; and, though not so neat and regular as some others, it is of excellent quality, and recommended for cultivation.

Exterior leaves seven or eight inches long, Picpus Fine deeply lobed; the lobes divided in the same dive. Vil. manner as those of the Common Green Curled. The inside leaves are finely eut and much curled, and form a kind of head more compact than that of the Green Curled, but comparatively loose-hearted.

It blanches well and quickly, and is a good variety, though neither its foliage nor its general habit presents any very distinctive peculiarities.

This variety attains a remarkable size, much exceeding that of the Common Green Curled. Ruffec The leaves sometimes measure nearly a foot and a half in length. Quality tender and good.

A recently introduced variety. The leaves Staghorn Enare deep green, divided into numerous segments, not frilled or curled, but much cut or jagged 
at the points, the borders having a branched appearance; whence the name. The leaves gradually shorten towards the centre of the plant, are more finely cut, and become closer together, thus forming a moderately firm heart, or head; less compact, however, than that of the Green Curled Summer Endive.

It is well adapted to humid climates, is hardier than the Common Green Curled, and is preferred by market-gardeners for cultivation in autumn and winter.

Triple-curled Moss Endive. NCInt. Winter Moss ENDIVE.

This is a sub-variety of the Staghorn Endive, and comparatively of recent introduction. It is a unique sort, exceedingly well curled, and, when the variety is genuine and the plant well developed, has an appearance not unlike a tuft of moss.

It is liable to degenerate, and, though sometimes classed as a Winter Endive, is less hardy than many other sorts.

It may be grown in rows a foot apart, six inches being allowed between the plants in the rows.

White Curled Leaves pale yellowish-green, nearly white blanched En- when young, ten inches long, rather narrow,
dive. Vil. lobed, eut, and beautifully frilled, or curled, on the borders; the upper surface of the midribs generally tinged with red. The leaves of the centre are not numerous, and much curled; resting upon those of the exterior, they form no head, but leave the heart loose and open.

It is distinguished from all others by its color, both the leaves and the seeds being paler than those of any other sort. Its principal recommendation is signified in the name; but it should be used while young, cut and served in the form of lettuce. It is then tender and of good quality, though the plants yield a small amount of salad, compared with many other sorts. When fully grown, the leaves become tough, 
and often bitter. As a variety for winter culture, it is of little value.

\section{HOR S E-R A I) ISH.}

Cochlearia armoracia. Nasturtium armoracia.

Horse-radish is a hardy perennial, introduced from Europe, and growing naturally along old roads, and about gardens and waste places in long-settled towns. The root is white within and without, long, nearly cylindrical, and from an inch to two inches and a half in diameter; stalk two feet or more in height, smooth and branching; the radical leaves are from fifteen to eighteen inches in length, oval-oblong, and toothed on the margin, - those of the stalk narrow, pointed, smooth, and shining; the flowers are white, and are put forth in June; the seed-pods are globular, but are very rarely formed, the flowers being usually abortive.

There are no varieties.

Soil, Propagation and Culture. - Horse-radish will not thrive in dry, gravelly soil, neither will it succeed well where the subsoil is of a hard, clayey character. The finest roots are obtained from a deep, naturally rich, mellow soil, and it is only in such situations that the yield will repay the cost of planting and cultivation.

It is always propagated by planting the crowns of the roots, which may be set either in spring or autumn. Trench the ground eighteen inches or two feet deep, and set the crowns or leading buds of old roots, cut off about three inches in length, in rows a foot apart, and nine inches from each other in the rows; cover six inches deep, and cultivate in the usual manner during the summer. The shoots will soon make their appearance, and the large leaves of the plant completely occupy the surface of the bed. After two seasons' growth the roots will be fit for use. 
Taking the Crop. - Its season of use is from October till May; and, whenever the ground is open, the table may be supplied directly from the garden.

For winter use take up the requisite quantity of roots in November, pack them in moist sand or earth, and store in the cellar, or in any situation out of reach of frost.

Use. - The root shredded or grated, with the addition of vinegar, is used as a condiment with meats and fish. It has an agreeable, pungent flavor, and, besides aiding digestion, possesses other important healthful properties.

It has been truthfully remarked that "there is scarcely another culinary vegetable, of equal importance, in which cultivation is, in general, so greatly neglected as in this. It is often found planted in some obscure corner of the garden, where it may have existed for years, and is only visited when needed for the proprietor's table. The operation of hastily extracting a root or two is too often all that is thought of, and the crop is left to fight its. way amongst weeds and litter as best it may."

\section{LETTUCE.}

Lactuca sativa.

Lettuce is said to be of Asiatic origin. It is a hardy, annual plant, and, when fully developed, from two to three feet in height, with an erect, branching stem. The flowers are compound, yellow, usually about half an inch in diameter; the seeds are oval, flattened, and either white, brown, or black, according to the variety. Nearly thirty thousand are contained in an ounce, and their vitality is retained five years.

Soil. - Lettuce succeeds best in rich and comparatively moist soil, and is also best developed, and most crisp and 
tender, if grown in cool, moist weather. A poor soil, and a hot, dry exposure, may produce a small, tolerable lettuce early in spring, or late in autumn; but if sown in such situations during the summer months, it will soon run to seed, and prove nearly, if not entirely, worthless for the table. The richer the soil may be, and the higher its state of cultivation, the larger and finer will be the heads produced; and the more rapidly the plants are grown, the more tender and brittle will be their quality.

Propagation. - It is always grown from seeds, which are small and light; half an ounce being sufficient to sow a nursery-bed of nearly a hundred square feet. It is necessary that the ground should be well pulverized and made smooth before it is sown, and the seeds should not be covered more than a fourth of an inch deep.

Cultivation. - Some recommend sowing where the plants are to remain, in drills from ten to fifteen inches apart, and thinning the plants to nearly the same distance in the lines; adapting the spaces between the drills, as well as between the plants in the drills, to the habit and size of the variety in cultivation. Others recommend sowing in a small nursery-bed, and transplanting. The process of transplanting unquestionably lessens the liability of the plants to run to seed, and produces the largest and finest heads. The first sowing in the open ground may be made as soon in March or April as the frost leaves the ground; and, if a continued supply is desired, a sowing should afterwards be made, at intervals of about four weeks, until September.

Forcing. - Lettuce is now served at table the year round; not, of course, of equal excellence at all seasons. Sowings are consequently required for each month; those intended for the spring supply are made from December to February, about twelve weeks being required for its full development when reared in the winter months. The seed is sown rather 
thinly, broadcast, in a hot-bed; and, when the plants have made two or three leaves, they are pricked out to three or four inches apart in another portion of the bed, - thus affording them more space for growth, and opportunity to acquire strength and hardiness. When two or three inches high, they are finally transplanted into yet another part of the bed, at distances corresponding with the size of the variety, varying from ten to fourteen inches in each direction. As the plants increase in size, the quantity of air should be increased; and water should be given, whenever the surface of the bed becomes dry. In severe cold or in cloudy weather, and almost always at night, straw matting (made thick and heavy for the purpose), woollen carpeting, or a similar substitute, should be extended over the glass for the retention of heat.

Some practise transplanting directly from the nursery-bed to where the plants are to remain; but the finest Lettuce is generally obtained by the treatment above described.

"Lettuces are sometimes required for cutting young, or when about two inches high. These are termed, by the French, Laitues à couper. The small, early sorts (such as the Hardy Hammersmith and Black-seeded Grotte) are preferred for this purpose; but any sort that is green or pale green, and not brown or otherwise colored, will do. They should be sown in the open ground about once a week, or every ten days, from April, throughout the season. In winter they are best raised on heat. They should be sown rather thickly in drills six inches apart." - Thomp.

To save Seed. - "This should be done from plants raised from early sowings. The finest specimens should be selected, avoiding, however, those that show a disposition to run quickly to seed. Those that heart readily, and yet are slow to run up, are to be preferred. Care should be taken that no two different varieties be allowed to seed near each other, 
in order that the sorts may be kept true. The seed which ripens first on the plant is the best; therefore it should be secured, rather than wait for the general ripening. The branchlets which first ripen their seed should be cut off, and laid on a cloth in the sun; or, when the forward portion of the seed is as near maturity as will safely bear without shaking off, the plants should be carefully pulled up, and placed upright against a south wall, with a cloth under them to perfect their ripening. The seed should in no case be depended on without trial. Plants from seeds two years old heart more readily than those from one-year-old seed." Thomp.

Use. - "Lettuce is well known as one of the best of all salad plants. It is eaten raw in French salads, with cream, oil, vinegar, salt, and hard-boiled eggs. It is also eaten by many with sugar and vinegar; and some prefer it with vinegar alone. It is excellent when stewed, and forms an important ingredient in most regetable soups. It is eaten at almost all meals by the French ; by the English after dinner, if not served as adjuncts to dishes during the repast, and by many even at supper. In lobster and chicken salads, it is indispensable; and some of the varieties furnish a beautiful garnish for either fish, flesh, or fowl.

"In a raw state, Lettuce is emollient, cooling, and in some degree laxative and aperient, easy of digestion, but containing no nourishment."

Varieties. - Thcse are exceedingly numerous. Some are of English origin ; many are French and German ; but comparatively few are American. The number of kinds grown to any considerable extent in this country is quite limited. Cultivators generally select such as appear to be best adapted to the soil and climate of their particular locality ; and, by judicious management, endeavor to give vigor and hardiness to the plants, and to increase the size, compactness, and 
crispy quality of the head. Some of the varieties have thus been brought to a remarkable degree of perfection, the plants producing heads with as much certainty, and nearly as well proportioned and solid, as those of the Common Cabbage.

They are generally divided into two classes, viz., Cabbage Lettuces and Cos Lettuces.

\section{Cabbage Lettuces. -}

Brown Dutch. Head of medium size, rather long and loose; BLACK-SEEDED. the leaves, which coil or roll back a little on
Vil. the borders about the top of the head, are yellowish-green, washed or stained with brownish-red; the surplus leaves are large, round, waved, green, washed with bronze-red, and coarsely, but not prominently, blistered; diameter twelve to fourteen inches; weight about eight ounces.

This Lettuce cabbages readily, forms a good-sized head, is tender, of good quality, hardy, and tolerably early. It does not, however, retain its head well in dry and warm weather; and, as it is little affected by cold, seems best adapted to winter or very early culture. It resembles the Yellow-seeded Brown Dutch, but is not so early, and the head is looser and larger.

Brown Silesian or Marseilles Cab. bage. Vil. Brow N BATAVIAN.
Head green, tinted with brown, remarkably large, - not compactly, but regularly, formed; ribs and nerves of the leaves large and prominent; the leaves disconnected with the head are large, bronze-green, coarsely blistered, and frilled and curled on the margin. The diameter of a well-grown plant is about eighteen inches, and its weight twenty-eight ounces. The seeds are white.

This Lettuce, though somewhat hard, is brittle and mildflavored, but is better when cooked than when served in its 
crude state as a salad. It is a hardy, late sort, succeeds well in winter, and retains its head a long period, but is rarely employed for forcing, on account of its size, - one of the plants occupying, in a frame or hot-bed, the space of two plants of average dimensions.

Head of medium size, green, washed or Brown Winstained with brownish-red, regularly formed, and moderately compact; the exterior leaves ter Cabbage. Vil.

LARGE BROWN WINTER. are round and short, much wrinkled, and coarsely blistered. When grown in winter or in cool weather, the plants measure fourteen inches in diameter, and weigh from fourteen to sixteen ounces. The seeds are white.

Hardy, and well adapted for winter culture. The heads are not so firm as those of some varieties; but they are well retained, blanch white and tender, and are of excellent flavor.

Head roundish, usually well formed, and moderately close and firm; the outer leaves are large, loose, golden-green, undulated, and Early or Summer Cape. RoYal CAPE. coarsely blistered; the interior leaves are more finely blistered, and nearly of the same color as those of the outside; head, when divided, yellowish to the centre; the plants, when fully grown, measure nearly a foot in diameter, and weigh from six to ten ounces.

The variety is not well adapted for forcing or for early culture in the open ground. As a summer Lettuce, it is one of the best, enduring the heat well, and not running soon to seed. Though not so crisp and brittle as some of the winter or spring grown varieties, it is comparatively well flavored and of good quality. It is similar to the Summer or Royal Cabbage. 
Early Simp- Head large, pale green, a little irregular in
son. Vil. its form, and only of medium solidity; the outside leaves are large and broad, plaited, and much blistered; diameter fourteen or fifteen inches ; weight twelve or fourteen ounces; seeds white.

This Lettuce is brittle, and of excellent flavor; but its head is not compactly formed. Its season is near that of the Versailles Cabbage, but it earlier runs to seed. It is said to be an American variety, and is much grown in the vicinity of New York city for marketing.

Early White A small spring Cabbage Lettuce growing
Spring or Black-seeded close to the ground. Its heart is hard and Gotte.

Trans. firm, and measures about four inches in diameter when stripped of its outer leaves; color pale green; the leaves are thin, nearly round, rugose, and waved on the margin.

This Lettuce comes early into use, and, besides, is of excellent flavor; but its chief merit is, that it remains longer than almost any other sort before running to seed, and even sometimes bursts before the flower-stem is formed. It is one of the smallest of the Cabbage Lettuces, and somewhat resembles the Tennis-ball, from which, however, it differs in the leaves being more curled and of a lighter green color, and by not running to seed so soon by three weeks or a month.

The variety has black seeds; and this fact should be particularly attended to in obtaining it from seedsmen, as the White-seeded Gotte Lettuces run much sooner to flower. Various other Gotte Lettuces are described by authors. "All are of great merit, but are little cultivated in the United States. Where small, hard, compact, and delicate sorts are required, this class should be selected." 
This variety forms no head. The leaves are Endivefinely frilled and curled, and spread regularly leaved. Vil. from a common centre in the form of a rosette. A welldeveloped plant resembles Curled Endive. It appears to be nearly identical with the Green Curled Lettuce.

The seeds are black, and smaller than those of any other variety.

Like the Common Green Curled Lettuce, English Enthis variety forms no head. The plant has the dive-like form of a rosette, and the foliage a silveryleaved. Vil. gray appearance. The leaves are short, undulated on the border, but not frilled and curled like the Common variety; nerves purplish; the heart of the plant is large and full; seeds black.

This Lettuce is hardy, tender, and well flavored, and equal, if not superior, to the Common Green Curled, both in respect to quality and its adaptation to winter culture.

The Green Curled strongly resembles, if it is Green Curled. not identical with, the Endive-leaved. When $\begin{gathered}\text { CURLED. ERDIVE- } \\ \text { LEAED. } \\ \text { BosTor }\end{gathered}$ well grown, the plant measures about ten inches in diameter, and is one of the most beautiful of all the Lettuces. The exterior leaves are finely frilled and curled, and of a rich, goldengreen color; the central leaves are smaller, but frilled and curled like those of the exterior. When in perfection, the plants have the form of a rosette, and make an excellent garnish. The seeds are

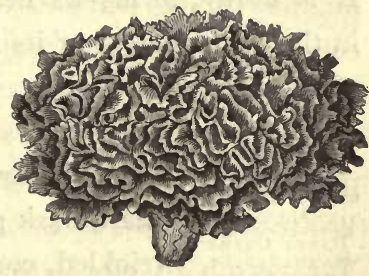

Green Curled Lettuce. white.

It is hardy, well adapted for forcing, and is extensively grown in the vicinity of Boston, Mass., for early marketing. 
As respects its value for the table, it cannot be considered equal to many of the Cabbage varieties, as it is deficient in crispness, and tenderness of texture - qualities essential in all salad plants. Its recommendations are its hardiness, its adaptation to early culture and forcing, and particularly its beautiful appearance.

Market-gardeners and cultivators make three sub-varieties, which are known as "Single-curled," " Double-curled," and "Triple-curled;" the difference consisting in the finer frilling, or curling, of the last named. A well-grown plant resembles some varieties of Enclive; whence the term "Endive-leaved."

Green Winter Cabbage. HARDY WINTER CABbage.

Head pale green, of medium size, round and regular, firm and solid; leaves of the head much wrinkled and coarsely blistered; the outside leaves are broad and large, glossy green, wrinkled and blistered like those composing the head. Winter-grown plants will measure in their full diameter about twelve inches, and weigh from fourteen to sixteen ounces. Seeds white.

The Green Winter Cabbage Lettuce is tender, and of excellent flavor, particularly if cultivated in cool weather. It is hardy, forms its head promptly and uniformly, is slow in the development of its flowers, and must be classed as one of the best of the hardy, winter varieties.

Hammersmith Hardy. ICInt. HARDY GREEN HAMMERSHITI. EArLY Frame. EABLY DWARF Dutch. Greer DUTCH.

A popular, old variety, with a comparatively small, dark green head. The leaves are much wrinkled, concave, thick, and fleshy; the seeds are white.

It is considered the hardiest sort in cultivation, and is one of the best for growing in winter or for forcing. When raised in spring, late in autumn, or in cool, 
moist weather, the plants attain a diameter of nearly ten inches, and weigh from six to eight ounces; but summergrown specimens are much smaller, rarely measuring more than six or seven inches in diameter, or weighing above three or four ounces. In warm, dry weather, it soon ruas to seed.

This variety belongs to the division of the Ice Cabbage. Silesian or Batavian Lettuces, and must not be

Trans.

confounded with the White Cos. The leaves are of a light shining green, blistered on the surface, much undulated and slightly jagged on the edges, nearly erect, eight inches long, and five or six inches broad; the outer leaves spread a little at the top, but grow close at the heart. It blanches without tying up, and becomes white, crisp, and tender.

The Ice Cabbage Lettuce comes into use with the White Silesian, from which it differs, as it also does from any other of its class, in being much more curled, having a lucid, sparkling surface (whence probably its name), and not turning in so much at the heart. It lasts as long in crop as the White Silesian.

A large and excellent variety, but inferior to Imperial the Versailles or the Ice Cabbage. Head large, $\begin{gathered}\text { TURKEY CAB- } \\ \text { BAGE. UNION. }\end{gathered}$ regular, a little oblong, of a dull, pale green color, and not compactly formed; the outside leaves are large, rounded, undulated or waved on the borders, thin in texture, and of a soiled or tarnished light green color; diameter fourteen inches; weight twelve to fifteen ounces; seeds white.

This is a crisp and tender Lettuce, though sometimes slightly bitter. It is not early, and soon shoots up to seed; but is quite hardy, and well adapted for winter cultivation. 
The Imperial Head, or Imperial Cabbage Lettuce, with white seeds, was at one period more generally cultivated in small gardens than any other variety, and though some of the recently introduced sorts excel it, not only in size, but in tender consistency and flavor, the Imperial is still extensively cultivated and much esteemed.

With the exception of the color of its seeds, it resembles the Turkey Cabbage.

India. This variety somewhat resembles the White LARGE INDIA.

Silesian or White Batavian. The leaves are large and numerous, smoother and of a paler green than those of the last-named sort. The plants attain a large size, frequently measuring sixteen or eighteen inches in diameter. The heads are not remarkable for solidity, but are white within, crisp and tender, with little of the bitter flavor common to many other varieties. The seeds are white.

The India Lettuce, like the White Silesian, withstands heat and drought, and is a favorite market sort in various parts of the Middle States. It is one of the best for summer culture, and, aside from its large size, one of the best for forcing.

Large Brown Head remarkably large, round, regularly Mogul. ${ }^{-}$formed, grayish-green, tinted or washed with LARGR Gray

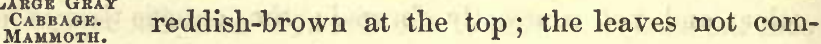
posing the head are large, plaited, coarsely blistered, of a grayish-green color, stained here and there with spots of pale brown. The diameter of a well-grown plant is about fourteen inches, and its weight nearly a pound. Seeds black.

The Large Brown Cabbage Lettuce is crisp and tender, but is sometimes slightly bitter. Its season is near that of the Versailles, but it is slower in forming its head, and sooner runs to flower. It is hardy, good for forcing, and well 
adapted for cultivation during winter. In summer, the heads are comparatively small, and loosely formed. Head green, washed with red, of medium Large Red size, regularly but loosely formed; the exterior Vil. leaves are large, undulated, blistered, and stained with brownish-red, like those of the head; diameter thirteen or fourteen inches; weight twelve ounces; seeds black.

Its season is near that of the Large Brown Cabbage. When grown in warm weather, the head is small, and the plant soon runs to seed; in winter, the head is much larger, more solid, and longer. retained. It resembles the Brown Dutch, but differs in the deeper color of the leaves.

Head of medium size, regular, but not com- Large Winpact, green, washed with red at the top; the or Madeira. leaves not composing the head are broad and large, a little undulated or waved on the border, plaited or folded at the base, thin in texture, somewhat blistered, and stained with spots of clear brown. When grown in winter, or in cool, moist weather, the plants will measure about a foot in diameter, and weigh nearly a pound. The seeds are white.

It is quite brittle, though not remarkable for tenderness of texture; hardy; succeeds well when grown in cold weather, and remains long in head before shooting up to seed. Season, the same with that of the Green Winter Cabbage.

In its general character this variety resem- Malta or Ice bles The The. bles the White Silesian. The head is remark- Icr Cos. Drimably large, somewhat flattened, compact, pale HEAD. WHITE green without, and white at the centre; the outer leaves are large and broad, glossy green, and coarsely blistered; the midribs and nerves are large and prominent. The extreme 
diameter of a full-grown plant is about sixteen inches, and the weight from twenty to twenty-four ounces. The seeds are white.

The variety heads readily, blanches naturally, and is crisp, tender, and well flavored. It is hardy, but not early, and remains long in head without running to seed.

It is extensively cultivated in England, and in some localities succeeds better, and is of finer quality, than the White Silesian or Marseilles Cabbage. The name is derived from the glazed or polished surface of the leaves.

Neapolitan. Plant dwarfish; head of large size, round, $\underset{\text { BАGE. }}{\text { NAPLES }}$ - regularly formed, solid, - when in perfection, resembling a well-developed cabbage ; the exterior leaves are broad and large, green, frilled on the margin, and coarsely blistered. If well grown, the plants will measure sixteen inches in diameter, and weigh from twenty to twenty-four ounces. Seeds white.

The Neapolitan Lettuce blanches naturally, is well flavored, and so slow in the development of its flower-stalk, that the heads are sometimes artificially divided at the top to facilitate its growth, and to secure the seeds, a supply of which is always obtained with difficulty, as, aside from the tardiness of the plant in flowering, the yield is never abundant.

It is not so good for foreing as many others, and must be classed as a summer rather than as a winter variety.

Palatine. Vil. A variety of medium size, with a round, Brown СаввAGR. somewhat depressed head, stained with red about the top. The foliage is yellowish-green, strongly marked or clouded with brownish-red. Extreme diameter of the plant ten or eleven inches; weight about twelve ounces. The seeds are black. 
It is remarkably crisp and tender; of excellent flavor; yields a large quantity of salad in proportion to its size; flourishes well at all seasons, even during winter; and must be classed as one of the best, and recommended for general cultivation.

The heads of this variety are of medium size, Spotted Cabround, regular, and comparatively solid; the saeded.) (Black sides are brownish-red, but at the crowns the color is changed to clear, bright red; the outer leaves are short, broad, and round, and strongly marked or clouded with brownish-red, like those composing the head. If grown in winter or in cool weather, the plants attain a diameter of about twelve inches, and will weigh twelve ounces.

It retains its head longer than almost any other variety, and, though sometimes slightly bitter, is considered superior to the White-seeded. Compared with the last named, the head is not so well formed, the foliage is deeper colored, and it is not so well adapted for forcing or for cultivation during winter.

Head yellowish-green, spotted and clouded spotted Cabwith brownish-red, of medium size, round and regular. The surplus leaves are small and nubage.
(White-
seeded.) merous, round, prominently blistered, copper-green, stréaked and variegated with brownish-red. Summer-grown plants will measure ten inches in diameter, and weigh about eight ounces. Wințer-grown plants, or those grown in cool and moist weather, will give an increase of the diameter, and weigh nearly a pound.

It is a brittle, well-flavored lettuce, hardy, and well adapted for growing in frames during winter. When grown in the summer months, the head is seldom well formed, and the plants soon run to seed. 
Plant quite small, with a uniformly green, Stone Tenregular, solid head, all of the leaves to the heart nis-ball. Vil. being strongly wrinkled and coarsely blistered. The exterior leaves are comparatively few and small, green, undulated, and prominently blistered. Summer-grown plants measure six or seven inches in diameter, and weigh about three ounces. When grown early or late in the season, or under the influence of cool and moist weather, the plants attain a larger size, often measuring nine or ten inches in diameter, and weighing eight ounces. The seeds are black.

The Stone Tennis-ball hearts well, is of excellent quality, and, in proportion to its size, yields a large quantity of salad. It retains its head a long period, even in warm weather, without shooting up to seed; and, as most of the leaves of the plant are embraced in the head, it occupies but a small space of ground in cultivation. Hardy and early. Summer Cab- Foliage pale yellowish-green; head of medi-
bage.

LARGE CABBAGE. ROYAL MERBAOE. SUM- close; the leaves composing it are wrinkled and SUGAR CABBAGK.

blistered; those of the outside are frequently torn and broken on the margins about the crown. The entire diameter of a well-grown plant is about twelve inches, and the weight from ten to twelve ounces. The seeds are white.

It is one of the best sorts for summer cultivation, as it not only forms its head readily in warm and dry weather, but remains long in head before running to flower. For forcing, or for sowing early in the season, some other varieties would succeed better. Though sometimes slightly bitter, it is crisp, tender in texture, appears to be adapted to our climate, and is recommended for cultivation. 
One of the oldest and most esteemed of the Cabbage Lettuces. The head is below medium size, dark green, remarkably solid if grown in Tennis-ball. Grark Ball. Butron. CAPvCHIX. HARDY cool weather, but often loose and open-hearted vil. if cultivated during the summer months; the surplus leaves are few in number, deep green, slightly curled, and broadly, but not prominently, blistered; the seeds of the genuine variety are black.

The Tennis-ball Lettuce is remarkable for its extreme hardiness. Winter-grown plants, or those raised in cool, moist weather, will measure about ten inches in diameter, and weigh eight ounces; whilst those raised under opposite conditions rarely exceed seven or eight inches in diameter, or weigh more than four or five ounces.

It is slow in running to seed, and the head blanches white and tender. "It requires little room in frames in winter, and yields a great return in spring, as almost the whole plant is eatable." A large Cabbage Lettuce, tinted with brown about the head, is erroneously known in some localities as the "Tenuis-ball."

Similar to the Imperial Head; the principal Turkey Cabif not only difference consisting in the color of bage. the seeds, which are black.

Head pale yellowish-green, large, long, and Versailles. compactly formed; the exterior leaves are swrpiss. Buoxp

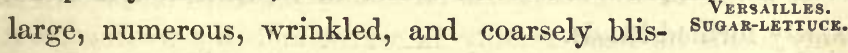
tered. When in its greatest perfection, the extreme diameter of the whole plant is about fourteen inches, and its weight twelve or fourteen ounces. The seeds are white.

This variety forms its head quickly and uniformly; cabbages white and crisp; is slow in shooting up to seed; flourishes in almost every description of soil, and at all 
seasons, except, perhaps, in extreme cold, and, though sometimes slightly bitter, is crisp, tender, and of good quality.

With the exception of its paler color, it resembles the Neapolitan. It is one of the best of all varieties for summer cultivation.

Victoria or Red-bor-

An excellent early and hardy variety. The dered. Vil. head is of medium size, tinted or washed with red at the top, round and regular in form, and comparatively solid; leaves large, yellowish-green, wrinkled, and blistered. If grown in summer, the plants measure eight or nine inches in diameter, and weigh four ounces. In cool weather, the plants attain a diameter of twelve inches, and weigh from ten to twelve ounces. Seeds white.

The Victoria Lettuce is larger than the Tennis-ball, heads freely, and is crisp and well flavored. When sown in summer, it soon runs to flower; but in cool weather, the heads are well retained. White Gotte. A small, low-growing, yellowish-green Cab-
(Black-seeded.) Vil. bage Lettuce, with a comparatively loose head. The plants rarely measure more than six inches in their full diameter, or weigh above four ounces.

It is one of the earliest of all the Lettuces, crisp, of good flavor, and well adapted for forcing or for frame culture. Besides the distinction in the color of the seeds, it differs from the White-seeded White Gotte in its smaller and more loosely formed heads.

Whito Gotte. This variety has a small, long, firm, and seeded.) Vil. close head, and is uniformly of a yellowishWhite TENNIS-

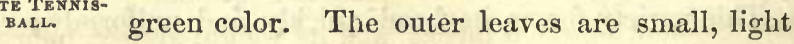
greenish-yellow, waved on the borders, and prominently blistered. The plant is of small dimensions, and rarely meas- 
ures more than six or seven inches in diameter, or weighs above three ounces. The variety is early, crisp, and well flavored, but soon runs to seed, and is much better adapted for growing in winter, or for forcing, than for cultivation in the summer months.

One of the largest of the Cabbage Lettuces. White SileHead golden-green, tinted with brownish-red white, BataIlead goldengreen, tinted with brow. about the top, regularly but not compactly DRUMHEADCAAformed. The outer leaves are large and broad, yellowish-green bordered with brown, wrinkled, and coarsely blistered. When well grown, the entire diameter of the plant is about eighteen inches, and its weight twenty ounces. The seeds are white.

This variety appears to be adapted to all seasons, is hardy, retains its head well, withstands heat and drought, blanches white and crisp, and is of excellent flavor. It succeeds well in frames, but, on

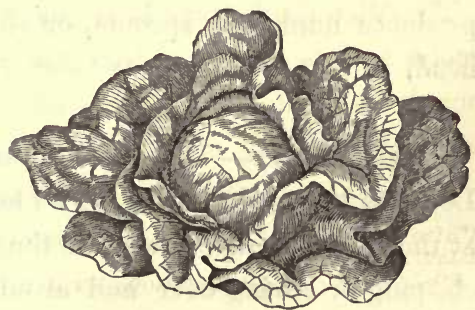

White Silesian Lettuce. account of its large size, is not a profitable sort for forcing.

A variety known as the "Tennis-ball" in some localities much resembles this; and the "Boston Cabbage" of New England, if not identical, seems to be but an improved form of the White Silesian.

Head of medium size, yellowish-green, stained white Stone with brownish-red firm and solid. When Cabbage. When LARGEGOLDEX fully developed, the entire diameter of the plant is about fourteen inches, and its weight sixteen ounces. The seeds are white.

This lettuce is brittle, of tender texture and good qual- 
ity, though it is sometimes slightly bitter. It is hardy, heads readily, is slow in running to flower, succeeds well in warm and dry weather, and is also well adapted for frame culture or for forcing.

Yellowseeded Brown Dutch. Vil. White DuTCH. AMERICAN BROWN DUTCH.
Head of medium size, yellowish-green variegated with red, rounded at the top, and tapering to a point at the base; compact; seeds yellow.

A half-early sort, of good quality, hardy, and well adapted for winter culture, or for sowing early in spring. It somewhat resembles the Black-seeded Brown Dutch; but, apart from the difference in the color of the seeds, its foliage is more blistered, and more colored with red, and the plant produces numerous sprouts, or shoots, about the base of the head.

Cos Lettuces. - These are quite distinct from the Cabbage Lettuces before described. The heads are long, erect, largest at the top, and taper towards the root, - the exterior leaves clasping or coving over and around the head in the manner of a hood, or cowl. As a class, they are remarkable for hardiness and vigor; but the midribs and nerves of the leaves are comparatively coarse and hard, and most of the kinds will be found inferior to the Cabbage Lettuces in crispness and flavor. They are ill adapted for cultivation in dry and hot weather, and attain their greatest perfection only when grown in spring or autumn, or in cool and humid seasons.

\section{Varieties. -}

Alphange or Florence Cos. (Blackseeded.) Vil.
In the form of the head, and in its general character, this variety resembles the Whiteseeded. Both of the sorts are remarkable for 
size, for hardiness and healthy habit, for the length of time they remain in head before running to seed, and for the brittle and tender character of the ribs and nerves of the leaves.

Besides the difference in the color of the seeds, the head of this variety is smaller, and the foliage paler, than that of the White-seeded.

Head large, long, not compact, and forming Alphange or well only when the exterior leaves are tied loosely together. The midribs and nerves of Masum Bonum the leaves are large, but brittle, and of tender Florence Cos. texture.

It is ten or twelve days later than the Green Paris Cos, retains its head well, is hardy and of healthy habit, but is deficient in flavor, and inferior to either of the Paris sorts. This variety forms no head, and, in its foliage Artichokeand general habit, is quite distinct from all of the Cos varieties. The leaves are numerous, twelve or fourteen inches long, of a lively-green color, often stained with brownish-red; erect, narrow, pointed, and toothed on the margin, like those of the Artichoke. Before blanching, the leaves are slightly bitter, but mild, crisp, and tender, with no savor of bitterness after being blanched. The seeds are black.

The plant grows uprightly, groups its leaves together, and thus blanches the interior parts spontaneously; but a much larger portion will be fit for use if the leaves are collected and tied loosely about the tips in the manner of treating Cos Lettuces.

It is remarkably hardy, slow in running to flower, and the seeds may be sown till August. Late in the season, it is mild 
and pleasant, and furnishes a tender salad. when most of the Cos Lettuces become bitter and strong flavored.

Bath Green

Cos. MrInt.

This variety has much merit as a hardy, winter, green sort, and is nearly related to the Brown Cos. It is, however, less brown on the outer leaves, and while that has white seeds, the seeds of this variety are black. Hence there are found, upon the catalogues of seedsmen, Black-seeded Bath, or Brown Cos, and White-seeded Bath, or Brown Cos; the latter seeming to be the hardiest, while the former appears to be the best.

Brown Cos. This is one of the oldest of the Cos Lettuces, BATH COS. SET-
TON'SBRRKSHRE and considered the hardiest of the class. The
BROW COS.

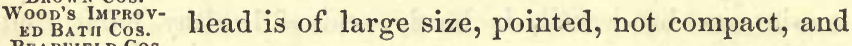

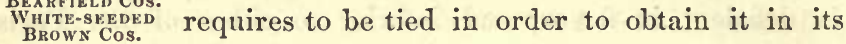
greatest perfection; the leaves are of a copper-green color, stiff and firm, toothed and blistered; the seeds are white.

The Brown Cos blanches white and tender, and is exceedingly crisp and well flavored; but the dark brownish color of the exterior leaves is deemed an objection, and it is often displaced by really inferior varieties. In weight and measurement, it differs little from the Green Paris Cos. Extensively cultivated and much esteemed in England.

\section{Gray Paris}

Head of the form of an inverted cone; green, with a grayish tone about the top; compact, and forming well without tying. The exterior leaves are numerous, deep-green, erect, firm, and prominently blistered. The full diameter of the plant is nearly twelve inches, and its weight about twenty ounces. The seeds are white.

The Gray Paris Cos is brittle, and of tender texture, but is considered inferior to the other Paris Cos sorts, and is but little cultivated. 
Head inversely conical, compact ; leaves Green Paris deep green, erect, firm, hooded or cowl-formed Cos. Vil. towards the ends, and serrated on the margin. Cos. SUTrrox's towards the ends, and serrated on the margin ; Cos. WERLINGthe ribs and nerves are large and prominent. ${ }^{\text {TOX. }}{ }_{\text {LAROE. }}^{\text {AD'S }}$ When full grown, the entire diameter of the plant is fifteen or sixteen inches, and its weight twenty-four ounces. The seeds are white.

It is considered one of the best of the Cos Lettuces, and, though not so hardy as the Brown Cos, is a good variety for forcing, and furnishes a tender, well-flavored head during summer. Whether for spring, summer, or autumn, it is an excellent sort. It attains a large size, is of a fine green color, and, "from the manner in which the outer leaves cove over the interior ones, blanches well without having to be tied together."

It has a tender, brittle leaf; is some days earlier than the White Paris; and is the principal variety employed by the market-gardeners of Paris for cultivating under glass.

Head elongated, somewhat of the form of Green Winthe preceding variety; deep green, and not. ter Cos. $\nu \bar{i}$. forming well, unless the exterior leaves are tied together at the tips; the outer leaves are large, erect, concave, toothed on the margin, and prominently blistered. The seeds are black.

It blanches well, but the ribs and nerves of the leaves are comparatively coarse and hard. Well adapted to winter culture, but as a summer lettuce, of little value.

Head of remarkable size, long, loose, and open; leaves large, equalling in size those of the Alphange or Florence Cos; green washed Monstrous Brown Cos. Vil. TwO-HEADED. with brown; pointed; seeds white. 
The plant sends out numerous side-shoots, or suckers, and sometimes produces several distinct heads; these, however, are generally loosely formed, and not of the fine, tender quality of the Paris varieties.

Oak-leaved The Oak-leaved Lettuce produces no head, Cos. Vil.

but forms a loose and open heart at the centre of the plant. The leaves are numerous, bronze-green, and deeply cut, or lobed, on the margin, in the form of the leaves of some species of the oak. The seeds are black.

The plants put forth fresh sprouts after having been cut; but the quality is inferior, and the variety is rarely cultivated.

Red Winter Foliage deep brown, smooth, and glossy, -
Cos. gathered at the centre of the plant into a loose heart, rather than head. Seeds black.

The hardiness of this lettuce is its principal merit. It is little affected by severe weather, and, as a sort for winter culture, is desirable. When grown in summer, it is of poor quality.

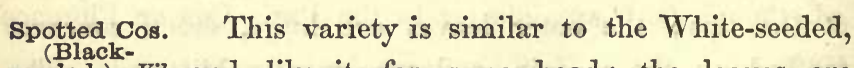
seeded.) Vil. and, like it, forms no head; the leaves are RED-SPOTTED. BLOODY. green, much stained or clouded with brownish-red, erect, firm, rounded at the ends, concave or spoonshaped, and grouped at the centre into a long and comparatively close heart.

It is crisp and well flavored, but attains its greatest perfection only when the outer leaves are tied loosely together about the top of the plant.

Spotted Cos. Like the preceding, this variety forms no (White- vil. head; but the interior leaves are formed into 
an erect, oblong, close heart, which, by tying the exterior leaves together, becomes white, crisp, and of excellent flavor.

Though late, it is hardy, remains long in head before running to seed, and is well worthy of cultivation.

An excellent variety, apparently intermediate between the Green Paris and White Paris ; not

Waite's White Cos. McInt. of quite so deep a green as the former, yet deeper than the latter. With regard to its comparative excellence, it is considered fully equal to the Paris Cos varieties, as it is grown as easily, and is equally crisp and tender. Size and weight nearly the same.

Leaves of large size, yellowish-green, pointed, slightly undulated, entire on the borders, and often revoluted like those of the White-seeded.

White Brunoy Cos.

(Blackseeded.) Vil. It rarely produces a head; or, if so, it is loose and open. Its greatest perfection is obtained by collecting the exterior leaves about the top of the plant, and tying them loosely together.

The variety is not considered superior to the White-seeded, though both are inferior to the Paris Cos or Florence sorts.

The heads of this variety are long and loose, and rarely form well unless the exterior leaves are tied loosely together. It somewhat resem-

White Brunoy Cos. (Whiteseeded.) Vil. bles the Alphange in the form and character of its foliage, though the head is longer and larger.

The plant attains a remarkable size, is hardy, and of good quality, but soon runs to seed, and appears to be a winter rather than a summer Lettuce. 
White Paris Cos.

Iil. IIcInt.

rondor WHITE

Cos. Sutron's

SUPERB WHITR

Cos.

The head of this variety has the form of the Green Paris, and blanches well without tying; the outside leaves are erect, yellowishgreen, and rather numerous. The extreme diameter of the entire plant, when well grown, is about fourteen inches, and its weight nearly twenty-four ounces. The seeds are white.

This is the sort most generally grown by the London market-gardeners, millions of it being produced annually within a few miles of London alone, and it has been adopted almost exclusively, by the gardeners of Paris, for cultivation in the open air. Next to the Green Paris Cos, this is the best, the largest, and the longest in running to seed, of all the summer Lettuces. It is tender, brittle, and mild flavored, less hardy and a few days later than the Green Paris Cos.

Endiveleaved Iettuce. Trans. LACTUCA intyBACEA.

The leaves of this species have the form of those of some of the varieties of Endive; whence the name. They are small, pale green, broad towards the ends, cut and irregularly lobed on the borders. While young, the plants have the appearance of Green Curled Endive.

As it runs to flower much earlier than the Spinach Lettuce, it is less esteemed than that variety. The seeds should be sown thickly, in shallow drills ten or twelve inches apart, and the plants should be cut for use when they are three or four inches high.

Perennial Iettuce. Vil. LACtuca peren. NIS.

This species is a native of Europe, and, in habit and duration, is distinct from all others. The leaves are about ten inches long, of a glaucous or sea-green color, thick and fleshy, deeply cut or divided on the margin, and spread regularly from the centre of the plant in the form of a rosette. When fully devel- 
oped, the plant is two feet and a half high, separating into numerous branches, which terminate in large purple flowers.

The seeds, which are of a brownish-black color, are sown in drills fifteen inches apart, and the plants should be thinned to six inches apart in the drills.

The leaves are eaten as salad; but when so used, they should be blanched, either by earthing up or by tying the plant together. They are also sometimes eaten boiled as Spinach or Endive.

The leaves of this species are six inches long, Spinach Letpale yellowish-green, lyrate, with obtuse and tuce. Trans entire divisions; when fully developed, they TUCA QUERCINA. somewhat resemble those of the oak, as implied by the name. The plants form no heart, or head, and are never cultivated singly, like the Cabbage or Cos Lettuces. The leaves are produced in moderate abundance, and are crisp and well flavored.

The seeds should be sown, like those of the Endive-leaved, thickly, in drills, and, when the lower leaves are four or five inches long, they may be cut for use. If not taken off too closely, the plants will afford a second cutting. The seeds are sown early with other spring salads.

\section{MADRAS RADISH.}

Raphanus sp.

The roots of the Madras Radish are sometimes eaten while they are quite young and small; but they soon become fibrous, strong flavored, and unfit for use. The plant is generally cultivated for its pods, which sometimes measure ten or twelve inches in length; these are solid, crisp, and 
tender, and, while young, are used for pickling and for salad, being much superior for these purposes to those of the Common Radish.

When cultivated for its pods, the seeds should be sown in drills two feet apart, and the plants thinned to nine inches in the drills.

\section{MALLOW, CURLED-LEAVED.}

Malva crispa.

An annual plant, introduced from Europe, and occasionally found growing spontaneously in the vicinity of gardens where it has been once cultivated. The stem is frequently more than six feet in height; the leaves are nearly five inches in diameter, smooth, and of a rich green color, lobed, and beautifully frilled or curled on the borders; flowers axillary, white, and small; the seeds are somewhat kidneyshaped, of a yellowish-brown color, and retain their powers of germination five years.

Cultivation. - The seeds are sown the last of April or beginning of May, and covered about an inch deep. The plants require much space, and should be grown at least eighteen inches asunder. The best method is to drop a few seeds where the plants are to grow, or to rake in a few seeds sown broadcast, and transplant.

Use. - No part of the plant is considered suitable for food, but the elegantly curled leaves are employed for garnishing desserts.

\section{MUSTARD.}

Black Mustard. Brown Mustard. Red Mustard. Sinapis nigra.

Black Mustard is a hardy, annual plant, introduced from Europe. In some localities, it grows naturally in great 
abundance, and is regarded as a troublesome weed, though its seeds furnish the common table mustard. The stem is four or five feet in height, round, smooth, and branching; the leaves are lobed and toothed on the margin, - the radical or lower ones rough, those of the upper portion of the stalk smooth; the flowers are numerous, rather large, bright yellow ; the pods are erect, somewhat four-sided, and are set closely against the sides of the stalk; the seeds are small, round, brownish-black, and retain their germinative powers many years. Nearly eighteen thousand are contained in an ounce.

Propagation and Cultivation. - It is raised from seeds, about four quarts of which will be required for sowing an acre. It is sometimes grown in the vegetable garden, but is generally cultivated in fields for its seeds, which, as before remarked, furnish the common table mustard. The sowing is usually made from the middle of April to the middle of May. After making the surface of the ground fine and smooth, sow broadcast, or thinly in shallow drills fourteen or fifteen inches apart; cultivate during the season in the usual manner, and in August the crop will be ready for harvesting. Cut the stalks at the ground before the pods shed their seeds, and spread in a dry, light, and airy situation, till they are sufficiently dried for threshing.

When grown for salad in the regetable garden, it should be sown, and cut for use, as directed for White Mustard.

Lawson says, if the seeds are covered to the depth of three inches or more, they will lie dormant, and retain their powers of vegetation for ages ; from which circumstance, together with the liability of the seeds to become shaken out in the harvesting of the crop, such lands as are once employed for the growing of mustard cannot be fairly cleaned of it for a considerable length of time, and only by judicious fallowing or fallow-cropping, with repeated hoeing and weeding. 
Use. - Besides the use of the flour of the seeds as a condiment, the seed-leaves are used as salad, in the manner of those of the White species; and the young plants, cut to the ground, are used as spring greens, either boiled alone or mixed with Spinach.

Chinese or Pekin Mustard. Sinapis PekinENSIS.

A hardy annual, introduced from China. Stem four feet high, with remarkably large leaves; the flowers, which are produced in loose, terminal spikes, are yellow and showy; the seeds are small, and retain their vitality five years.

Cultivation. - The seeds are sown in April or May, in shallow drills ten or twelve inches apart. If cultivated for its seeds, the drills should be eighteen inches or two feet apart, and the plants thinned to six or eight inches in the drills.

Use. - The leaves are employed in salads, in the manner of Cress ; and they are also sometimes boiled and served as Spinach.

Cabbage-
leaved hardy, annual, Chinese plant, similar in leaved Mus- habit to the species last described. Stem from
tard. SINAPIS BP. three to four feet high; leaves large, roundish, lobed, and wrinkled; flowers yellow; the seeds are small, reddish-brown or black, and retain their powers of germination a long period.

Cultivation and Use. - This species is cultivated in the same manner, and is used for the same purpose, as the Chinese Mustard. Curled Mus- A comparatively small species. Stem two
tard.

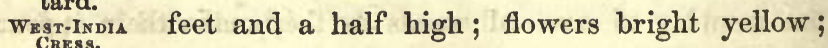
seeds small, blackish-brown, - scarcely distinguishable from those of the Black Mustard. The leaves are 
of medium size, greenish-yellow, broadest near the ends, deeply and finely cut on the borders, and beautifully frilled, or curled; they make an excellent garnish; and, when used as salad, have a pleasant, cress-like flavor.

\section{In its general character, this species resem- Cut-leaved Mustard.} bles the Chinese or Pekin Mustard ; the leaves, however, are much smaller, and divided quite to the midrib.

When young, the leaves make an excellent small salad, having the warm, pleasant flavor of Cress.

White Mustard is a hardy annual, introduced White Musfrom Europe, and occasionally found growing SisAPIS LLBA. spontaneously in the vicinity of fields and gardens where it has been once cultivated. The stem is three feet and upwards in height; the leaves are large, deeply lobed, and of a rich, deep green color; the flowers are large, yellow, produced in loose, terminal spikes; the seeds are yellow, much larger than those of the preceding species, and retain their vitality five years. Seventy-five hundred are contained in an ounce.

Propagation. - White Mustard is always raised from seeds, about four quarts of which will be necessary for seeding an acre. When grown for salad, an ounce will sow forty feet of drill.

Soil and Cultivation. - It succeeds best in rich, loamy soil, which, previously to sowing, should be thoroughly pulverized. When cultivated in the vegetable garden for salad or greens, the first sowing may be made as early in the season as the frost will admit. Sow the seeds thickly, in drills eight or ten inches apart, and cover half an inch deep with fine mould. Remove all weeds as they make their appearance, and in continued dry weather water freely.

The plants should be cut for use while in the seed-leaf; 
when much developed, they become strong, rank, and illflavored.

For a succession, a small sowing may be made every week until September.

In field culture, the seeds are sometimes sown broadcast, but the more common method is to sow in drills fifteen or eighteen inches apart. When the crop is ready for harvesting, the plants are cut to the ground, stored and threshed, as directed for Black Mustard.

Use. - The plants, before the development of the rough leaves, are used as salad; when more advanced, they are boiled and eaten as Spinach. The flour of the seeds furnishes a table mustard of good quality, though the seeds of the Black species possess greater piquancy, and are generally employed for the purpose. The seeds of both species are much used in medicine, and are considered equally efficacious.

\section{NASTURTIUM.}

Indian Cress. Capucine, of the French. Tropæolum, sp. et var.

This plant is a native of Peru, and, though generally treated as an annual, is a tender perennial. When cultivated for its flowers or seeds, it should be planted in poor, light soil ; but when foliage and luxuriant growth are desired, for the covering of arbors, trellises, and the like, the soil can hardly be made too rich.

The planting should be made in April or May. As the seeds are quite large, they should be covered two inches deep. When planted in drills, they are made three feet apart, and the young plants thinned to six inches apart in the drills. The growing crop may be supported by staking or bushing, as practised with peas, or the taller-growing 
sorts may be shortened in, which will induce a strong, stocky habit of growth.

While the plants are young, they will require some attention in order that they may be properly attached to the stakes or trellises provided for their support ; after which little care need be bestowed, beyond the ordinary stirring of the soil, and keeping the ground free from weeds.

Use. - The unexpanded flower-buds, and the seeds while young and succulent, have a warm, aromatic taste, and are pickled and used as capers. The young shoots are eaten as salad, and the flowers, which are large and richly colored, are used for garnishing. Few ornamental plants are better known or more generally cultivated than the Nasturtium.

The species and varieties are as follow :-

Stem from six to eight feet high, succulent; Tall Nasturleaves alternate, smooth, rounded, - the leaf- Trium. stems being attached to the disk, or under surface ; flowers large, on long stems, yellow, - the two upper petals streaked and marked with purple; the seeds are large, somewhat triangular, convex on one of the sides, of a drab or pale brown color, and retain their germinative properties five years. From a hundred and eighty to two hundred are contained in an ounce.

A variety of the preceding, differing only in Dark-flowerthe brown color of the flowers. Cultivation ing. and uses the same.

Also a sub-variety of the Tall Nasturtium, Variegated. with orange-yellow flowers; each of the petals being stained or spotted with purple.

Other varieties occur, differing in color, but equally useful for the purposes before described. 
Small Nas- Much smaller, in all respects, than the comturtium.

DWARF CAPUCINE. TROP.éLUM MINUS. mon Dwarf variety of Tropaeolum majus; the stem rarely measuring more than two feet in length, or rising above a foot in height. The flowers are yellow; the lower petals with a blotch of scarlet at their base, and the upper ones delicately striped with the same color.

It yields abundantly, and, though the pods are comparatively small, they are generally preferred to those of the Tall Nasturtium for pickling.

\section{PICRIDIUM.}

Garden Picridium. Picridium vulgare.

A hardy, annual plant, from the south of Europe. Stem eighteen inches high ; leaves six to eight inches long, irregular in form, but generally broad at the ends, and heart-shaped and clasping at the base; flowers yellow, compound, produced in clusters; the seeds are long, slightly curved, foursided, brown or blackish-brown, and retain their vitality five years.

Sowing and Cultivation. - The seeds should be sown in April or May, in drills a foot apart, and half an inch in depth. As the plants, when allowed to run to seed, produce but little foliage, it is necessary, in order to secure a continued supply of fresh leaves, to cut or nip off the flowering shoot as it makes its appearance. Under proper management, the leaves grow rapidly, and are produced in great abundance.

Use. - The leaves have a pleasant, agreeable flavor, and, while young and tender, are mixed in salads. 


\section{PURSLA I N.}

\section{Portulaca.}

Purslain is a hardy, annual plant. Most of the cultivated kinds are but improved forms of the Common Purslain ( $P$. oleracea), introduced into this country from Europe, and so troublesome as a weed in most vegetable gardens.

The stem is usually about a foot in length, succulent and tender; the leaves are flesliy, broad and round at the ends, and taper to the stalk; the flowers are yellow, and rest closely in the axils of the leaves; the seeds are black, exceedingly small, and retain their germinating powers ten years.

Soil, Propagation, and Culture.-Purslain thrives well in all soils, - dry, wet, or intermediate, - and is propagated by seeds sown in shallow drills at any time from April to July.

Use. - The plants may be cut for use when they have made a growth of four or five inches. They are mixed in salads, eaten boiled as Spinach, or pickled.

The species and varieties are as follow:-

Abundant in gardens, cultivated fields, and waste grounds. The Green and the Golden Purslain are improved sub-varieties. The

Common Purslain. Portulaca OLERACRA.

Common Purslain is used in all the forms in which the cultivated sorts are used, and, though some of the latter are considered more succulent, the difference in quality will scarcely repay the cost of cultivation, where the present variety would be the ceaseless competitor for the supremacy.

Similar to the Green Purslain, but differing Golden Pursin the paler or yellowish color of the stalks P. OLERACBA VAR. and leaves. 
Green Purslain

Leaves an inch and three fourths in length, and upwards of an inch in width; deep green.

Large-leaved Golden Purslain.

P. sativa.

Leaves pale yellowish-green, larger than those of the preceding sorts. The plant is a strong grower, and the leaves attain a remarkable size; but the stalks are often comparatively tough and hard, and, for salad purposes, much inferior to those of the Green or Golden variety.

\section{R A P E.}

This plant is generally cultivated for its seeds, like Mustard. It is, however, sometimes grown for salad; the seeds being sown in April, and, for a succession, once in three or four weeks till August or September. Sow thickly, in drills ten or twelve inches apart, and cover half an inch deep. The soil should be rich and moist, in order to induce a rapid growth, and thus to give a tender, succulent character to the young leaves, which are the parts eaten. They are served like Lettuce, or boiled and treated as Coleworts or Spinach. For mixing with Cress or Lettuce, the plants are cut to the ground before the development of the second leaves.

The species are as follow :-

Annual Root fusiform, small, hard, and woody ; the Rough-
aved Sum- radical leaves are lyrate, vivid green, and withmer Rape. Law. TURNIP RAPE. out any appearance of the glaucous bloom for BRASSICA AAPA. which the biennial sorts are so distinguished; the stem-leaves are slightly glaucous, smooth, or nearly so, the lower ones cut on the borders, the upper entire; the seeds are small, and similar to those of the common field turnip, of which it seems to be either a variety or the source from which the latter has been derived. 
Biennial; root long, tapering, hard, and Common or ; Winter Rape. woody, like that of the species before de- Law. scribed. The leaves are smooth, thick, and BRASSICA NAPUS. fleshy, and of much the same form as those of the Annual Rough-leaved Summer Rape ; this species, however, is readily distinguished, when young, by its uniformly smooth leaves. The seeds, also, are larger than those of the lastnamed species; but this is not to be relied upon as a distinguishing characteristic, as the size of the seeds, in this as in most other plants, is liable to be materially altered by the soil as well as by the previous culture of the seedstock.

The seeds are sown in summer, and the crop ripens the following year. It is not adapted to the climate of the Northern States.

In England, the foregoing species are extensively cultivated both for forage and for seeds; the latter are used to a limited extent for feeding birds, but chiefly for the production of rape-seed oil.

The German Rape somewhat resembles the German Common or Winter. It differs in being of an- Rape. Law.

nual duration, in its more deeply divided leaves, SMOOHELEAVRD more erect pods, and smaller seeds.

Brassica PRA-

It would unquestionably succeed well in almost any part of the Northern or Middle States, and might prove as remunerative a crop as coin or wheat. The seeds should be sown in May, and the plants should be treated and the crop harvested, in all respects, as Mustard. It is sometimes sown broadcast, but generally in drills. When sown broadcast, eight or ten pounds of seed will be required for an acre; if in drills, three or four pounds will be sufficient. The yield varies from twenty to forty bushels per acre. 
Summer Rape. Law. Colza. WILD NAVEW. BRASSICA CAMPESTIS. and roughish when young; those of the stem clasping, or heart-shaped, at base, and of an oblong form, - all somewhat fleshy, of a dark green color, with a glaucous bloom. The seeds are larger than those of the Ruta-baga, or Swedish Turnip, but in other respects not distinguishable.

This species is sometimes termed Brassica campestris olifer, or Oil-rape, from its being considered the best sort of rape for cultivating for oil, and to distinguish it from the Campestris Ruta-baga, or Swedish Turnip, which is only a variety of this species.

It is not sufficiently hardy for cultivation in the Northern States.

\section{ROCKET. Vil.}

Garden Rocket. Roquette, of the French. Brassica eruca.

A hardy, annual plant, from the south of Europe. Stem about two feet high; leaves long, lobed or lyrate, smooth and glossy, succulent and tender; flowers pale citron-yellow, with blackish-purple veins, very fragrant, having the odor of orange-blossoms; the seeds are small, roundish, brown, or reddish-brown, and retain their vitality two years. Fifteen thousand are contained in an ounce.

Sowing and Cultivation. - The seeds are sown thinly, in shallow drills a foot asunder. The first sowing may be made as early in spring as the frost will permit ; afterwards, for a succession, a few seeds may be sown at intervals of three or four weeks. In poor soil and dry seasons, the leaves are liable to be tough and acrid; the seeds should, therefore, be sown in rich loam, and the plants thoroughly 
watered in dry weather; as, the more rapid and vigorous the growth, the more succulent and mild-flavored will be the foliage.

Use. - The leaves, while young and tender, are eaten as salad.

SAMPHIRE. Thomp. Mill.

Sea-fennel. Parsley-pert. St. Peter's Herb. Crithmum maritimum.

This is a half-hardy, perennial plant, common to rocky localities on the sea-coast of Great Britain. Stalk from a foot to two feet in height, tender and succulent; leaves half an inch long, somewhat linear, glaucous-green, fleshy ; flowers in terminal umbels, - small, white, or yellowish-white; the seeds are oblong, yellowish, and, though somewhat larger, resemble those of Fennel. They retain their germinative power but one year.

The plant blossoms in July and August, and the seeds ripen in September and October.

Soil and Culture. - The plant requires peculiar soil, exposure, and culture; but, however skilfully treated, it is rarely raised in that perfection which it reaches in its native localities. It may be propagated by dividing the roots ; but the better method is to sow the seeds in autumn as soon as they ripen.

Samphire thrives best in sandy or gravelly soil, and the growing crop should be frequently and copiously watered with weak solutions of soda and salt. The leaves may be gathered for use in August and September.

Use. - The leaves have a warm, pleasant, aromatic flavor, and, when pickled in vinegar, are used in salads and as a seasoning. 
Golden Sam. phire. Thomp. INULA CRITHMIFOLLA.
A hardy perennial, growing, like the preceding, naturally, on the marshes and sea-coast of Great Britain. The stalk is a foot and a half in height, erect, with clusters of small, fleshy leaves; flowers yellow, in small, umbel-like clusters.

Propagation and Cultivation. - It may be propagated by seeds, or by a division of the roots. It thrives best in a shady situation, and requires frequent watering. If salt be occasionally dissolved in the water, it will promote the growth of the plants, and render the branches and foliage more succulent and tender.

Use. - The fleshy leaves and the young branches are pickled in vinegar, and added to salads as a relish. The plant, however, has none of the pleasant aromatic flavor of the true Samphire, though often sold under the name, and used as a substitute.

\section{SCURVY-GRA S S.}

Cochlearia officinalis.

This is a hardy, annual, maritime plant, common to the sea-coast of France and Great Britain. The root-leaves spread regularly from a common centre, are heart-shaped, fleshy, smooth, and glossy, - those of the stem sessile, oblong, and toothed on the margin; the stalks are numerous, and from six inches to a foot in height; the flowers are small, white, and produced in compact groups or clusters ; the seeds are small, oval, a little angular, and retain their vitality three years.

Soil, Soving, and Cultivation.-It succeeds best in moist, sandy soil, and flourishes in shady situations. Sow the seeds in August, soon after they ripen, in shallow drills eight or ten inches apart, and, while the plants are young, thin them to five or six inches apart in the rows. The plants taken up in 
thinning may be transplanted, and new beds formed if occasion require. The growing crop should be kept free from weeds, and liberally watered in dry weather. In the following spring, the leaves will be fit for the table. Those plants not cut for use will flower in June, and the seeds will ripen in July. The seeds seldom vegetate well if sown late in spring, or during warm, dry weather.

Use. - The radical leaves are used as a salad, and are sometimes mixed with Cress. When bruised, they emit an unpleasant odor, and have an acrid, bitter taste when eaten. The plant is more generally used for medicinal purposes than as an esculent.

\section{SNAILS.}

Snail Trefoil. Medicago orbicularis.

From the south of Europe. It is a hardy, annual plant, with reclining stems, compound or winged leaves, and yellow flowers. The pods, or seed-vessels, are smooth, and coiled in a singular and remarkably regular manner. As they approach maturity, they gradually change to a dark brown color, and, seen from a short distance, have the appearance of snails feeding on the plant.

The seeds are large, flat, somewhat kidney-shaped, of a yellowish-brown color, and retain their powers of germination five years. They are usually sold in the pods, but should be taken out before planting.

Sowing and Culture. - It is propagated by seeds, which should be sown in April or May where the plants are to remain. Sow in drills fifteen inches apart. The plants should be thinued out where they are too close, and kept free from weeds, which is all the culture they require. They will blossom in July, and the seeds will ripen in autumn. 
Use. - Though entirely inoffensive, no part of the plant is used for food. The pods resemble some species of snails in a remarkable degree, and are placed on dishes of salad for the purpose of exciting curiosity, or for pleasantly surprising the guests at table.

\section{SWEET CICELY.}

Sweet-scented Chervil. Osmorrhiza odorata. Scandix odorata.

A hardy perennial. When fully grown, the stalk is three feet or more in height; the leaves are large, and many times divided; the stems and nerves downy; the flowers are white, fragrant, and terminate the stalks in flat, spreading bunches, or umbels; the seeds are large, brown, and retain their vitality but one year.

Sowing and Culture. - It is usually growu from seeds, and is of easy cultivation, as it thrives in almost any soil or situation. When allowed to scatter its seeds after ripening in the autumn, the plants will spring up spontaneously in great numbers in the following April or May, and may then be transplanted where they are to remain; or the seed may be sown in October, in beds, making the rows fifteen or eighteen inches apart, and thinning the plants to a foot apart in the rows. When practicable, the seed should be sown in the autumn, as it seldom vegetates well, unless subjected to the action of the winter. After the plants have become established, they will require only ordinary treatment, and yield abundantly.

Use. - "In England the leaves were formerly put into salads; but the strong flavor of anise-seed, which the whole plant possesses, renders them disagreeable to most persons. It is now not cultivated in Britain, but the leaves and roots are still used in France; the former for the same purposes as 
those of Chervil ; the latter in soups, to which they are said to communicate an agreeable taste." - Thomp.

In this country it is sometimes cultivated with other aromatic plants; but its use in soups, or as a seasoner or garnish, is very limited.

\section{TARRAGON.}

Artemesia dracunculus.

A hardy, perennial plant, said to be a native of Siberia. Stalk herbaceous, about three feet in height; the leaves are long, narrow, pointed, smooth, and highly aromatic; the flowers are small, somewhat globular, greenish, and generally infertile. There is but one variety.

Soil, Planting, and Culture. - As the plants seldom produce seed, Tarragon is usually propagated by dividing the roots. Select a warm and comparatively dry situation; stir the ground deeply and thoroughly, and in April set the roots in rows fifteen inches apart, ten or twelve inches apart in the rows, and cover two or three inches deep. They will soon send up vigorous shoots, which may be cut for use the first season.

It is sometimes increased by cuttings, set three or four inches deep in moist earth. If seeds can be obtained, they should be sown in April or May, in a nursery-bed or in a common frame. Sow in shallow drills six or eight inches apart, and when the plants are three or four inches high, set them out as directed for the roots. They will early become strong and stocky, and may be used in August or September. The plants are more healthy, yield more abundantly, and are of finer quality, when not allowed to run to flower.

Use. - "Tarragon is cultivated for its leaves and the points of its young shoots, both of which are used as ingredients in salads, soups, stews, pickles, and other compounds. 
Tarragon vinegar, so much estecmed as a fish-sauce, is made by infusion of the leaves in common vinegar. It is also added to most salads to correct their coldness. Three or four plants will be sufficient for a family." - McInt.

\section{VALERIANA. Vil.}

Fedia cornucopiæ. Valeriana cornucopiæ.

This is an annual plant, with a smooth, branching stem about fifteen inches high. The leaves are oblong, stemless, thick, and fleshy, and of a bright, glossy green color; the flowers are numerous, large, rose-colored, showy, and ornamental; the seeds are oblong, yellowish, somewhat vesiculous, and retain their vitality five years. Twenty-two hundred are contained in an ounce.

Soil and Culture. - It succeeds best in a light, warm soil. Prepare a bed four feet and a half wide, spade it thoroughly over, rake the surface smooth and fine, and sow the seed in drills fourteen inches apart. The first sowing should be made the last of April, or early in May ; and afterwards, for a succession, sow a row or two every fortnight till July.

Use. - It is used as a salad, and is said to be superior to the Common Fetticus, or Corn-salad.

When in blossom, the plant presents a beautiful appearance, and well deserves a place in the flower-garden.

\section{WATER-CRESS.}

Sisymbrium nasturtium. Nasturtium officinale.

Water-cress is a hardy, aquatic perennial, and is found growing naturally, in considerable abundance, about ponds, and in ditches and small running streams. When in blos- 
som, the plant is about two feet in height, or length; the leaves are winged, with five or six pairs of rounded leaflets, and, in deep water, are often immersed, or float upon the surface ; the flowers are small, white, four-petaled, and terminate the stalks in loose spikes; the seeds are very small, reddishbrown, and retain their powers of germination five years. Nearly a hundred and twenty thousand are contained in an ounce.

Planting and Culture. - Water-cress is of the best quality when grown in running streams and gravelly soil. The roots may be planted in spring, in situations where the water is from four to eight inches deep. After they are established, the plants will rapidly increase, both from the natural distribution of the seeds and the spreading of the roots, and soon entirely cover the surface of the water with foliage. It may be grown with trifling cost in any small collection of water, and can be easily introduced by dropping a few plants about the borders, at the time of the ripening of the seeds. In many localities it is found growing in spontaneous abundance, and one of the best and most healthful of salads may be obtained for the mere labor of gathering.

Varieties. - There are three described varieties, - the Green-leaved, the Small Brown-leaved, and the Large Brown-leaved. These differ slightly, if at all, in flavor, though the Brown-leaved is generally preferred: having a fine appearance, and a small proportion of stalk to the leaves, it is most salable in the market. The variations in foliage and habit do not appear to be caused by the quantity or quality of the water in which the plants are grown, as the three kinds are found growing together. The Green-leaved is said to be the easiest of cultivation, but the Small Brownleaved is the hardiest. The Large Brown-leaved is the best, and is the only one which can be well grown in situations where shallow water is not to be obtained. 
Gathering and Use. - "The shoots are cut for market, not broken off, as is the usual mode of gathering Cress in its natural state, and which is found to be very injurious to the plants in the beds. After they have been cut about three times, they begin to stock; and then, the oftener they are cut the better. In summer, it is necessary to keep them very closely cut; and in water of a proper depth, and with a good soil, each bed supplies a gathering once a week."

It is extensively employed as an early spring salad, and, on account of its warm and pleasant taste, is by many persons preferred to all other salad plants.

\section{WINTER-CRESS.}

American Winter-cress. Belle-Isle Cress. Scurvy-grass, of some localities. Barbarea præcox. •

Stems from twelve to fifteen inches high; leaves lyrate, the terminal lobe round; flowers small, in erect, loose, terminal spikes, or groups; the seeds are small, wrinkled, of a grayish color, and retain their vitality three years. Introduced from Europe, and naturalized in the Northern States.

Common This species somewhat resembles the foreWinter--
low kocket. going, and, like it, grows naturally in moist, low ROCkEt.
BARIS.

longer, more erect, and more slender pods.

Soil and Cultivation. - Both of the species are hardy, perennial plants, and are raised from seeds, which should be sown in April or May, in shallow drills a foot apart. For a succession, a few seeds may be sown at intervals of three or four weeks till August. For winter use, sow, and, subsequently cultivate, as Winter Spinach.

Use. - As soon as the plants have made sufficient growth, 
they may be cut for use. The outer leaves should be first gathered, and the flower-stalks cut or nipped off as they make their appearance, in order to render the plants strong and stocky, and to promote the growth of the leaves, which are the parts of the plants used. They are served as Cress, which they resemble in flavor.

WOOD-SORREL.

Oxalis acetocella.

Wood-sorrel is a hardy, perennial plant, growing naturally in woods, in cool and shaded situations. The leaves are radical, inversely heart-shaped, and produced three together at the extremity of quite a long stem, or petiole; the flowerstalk is entirely leafless, and supports a solitary bell-shaped flower, the petals of which are white, finely lined or striped with purple; the seed-vessels are of an oblong form, fiveangled, and, when ripe, burst open. by the touch, in the manner of those of the Impatiens noli me tangere, or Common Balsam, of the flower-garden; the seeds are quite small, and of a reddish-brown color.

The flowers are produced in May and June, and the seeds ripen in July.

Propagation and Culture. - It may be propagated either by seeds or by dividing the roots. The soil should be rich and moist, and the seeds may be sown in April or May, in shallow drills ten or twelve inches apart; or the roots may be divided in spring or autumn, and set in rows the same distance asunder.

Use. - The leaves possess a pleasant acid taste, and are mixed with salads, to which they impart an agreeable, refreshing flavor. The plant is considered one of the most valuable of all vegetables cultivated for their acid properties. 


\section{WORMS.}

Astragalus hamosus.

A hardy, annual plant, indigenous to the south of Europe. Stem ten or twelve inches long, recumbent; leaves pinnate, with ten or twelve pairs of small leaflets; flowers yellow, produced five or six together at the extremity of quite a long stem, or peduncle; the seed-pods are about two inches long, nearly a fourth of an inch thick, peculiarly bent or curved, and contain ten or twelve brown seeds.

There is but one species or variety cultivated.

Sowing and Culture. - The plants may be started by sowing the seeds in a hot-bed in March, or the seeds may be sown in the open ground in May. They are cultivated in rows fourteen inches apart, and ten or twelve inches apart in the rows, and are also grown in groups, or hills, three or four together. The plants blossom in July, and the pods attain their growth in August and September.

Use. - The pods, in their green state, much resemble some descriptions of worms, and, like Caterpillars (Scorpiurus) and Snails (Medicago), are sometimes placed on dishes of salad to excite curiosity, or for pleasantly surprising the guests at table. Though inoffensire, they are seldom eaten. 


\section{CHAPTER VIII.}

\section{OLERACEOUS PLANTS.}

Angelica. Anise. Balm. Basil. Borage. Caraway. Clary. Coriander. Costmary. Cumin. Dill. Fennel. Lavender. Lovage. Marigold. Marjoram. Nigella. Parsley. Peppermint. Rosemary. Sage. Savory. Spearmint. Tansy. Thyme.

\section{A N G E L I C A.}

Angelica archangelica.

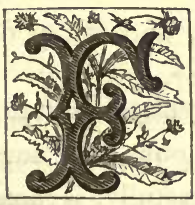

ROM Central Europe, but also indigenous to Great Britain. It is a hardy, biennial plant, with a cylindrical, hollow, herbaceous stem four or five feet high. The radical leaves are from two to three feet long, compound, or divided in threes, purplish-red at the base; flowers small, pale yellow, in large, terminal, spherical umbels; the seeds are of a yellowish color, oblong, flattened on one side, convex on the opposite, ribbed, thin, and membraneous on the borders, and retain their germinative power but a single season. Nearly six thousand are contained in an ounce

Soil and Culture. - The plants thrive best in damp, and even wet, localities, but may be grown in any good, wellenriched soil. As the seeds soon lose their vitality, they should be sown in August, immediately after ripening. Make a small bed, sow the seeds in drills ten inches apart, and cover three fourths of an inch deep. In this seed-bed 
allow the young plants to remain until the following spring, when they should be set out two feet asunder in each direction. The stalks will be fit for use in May and June of the following year. If the flower-stem is removed as it makes its appearance, the plants will put forth fresh sprouts from the sides of the root, and survive three years; but when allowed to blossom, and to perfect their seeds, the plants soon after perish.

Use. - Angelica was formerly used, after being blanched, as a salad, like Celery. In the vicinity of London, it is raised to a considerable extent for confectioners, - the tender leaf-stalks and flowering-shoots serving as a basis for sweetmeat. The seeds are sometimes employed for flavoring liquors.

\section{A NISE.}

Pimpinella anisum.

This is an annual plant, originally from Egypt. Though but little cultivated in this country, neither our soil nor climate is unsuitable; and it might be successfully, if not profitably, grown in the middle and warmer parts of the Northern States. Large quantities of the seeds are raised on the Island of Malta and in some parts of Spain, and thence exported to England and America for the purpose of distillation or expression.

The stem is from a foot and a half to two feet high, and separates into numerous slender branches; the leaves are twice pinnate, - those of the upper part of the stalk divided into three or four narrow segments; the flowers are small, yellowish-white, produced in large, loose umbels, at the extremities of the branches; the seeds are of a grayish-green color, oblong, slightly bent or curved, convex and ribbed on one side, concave on the opposite, and terminate in a small 
bunch or knob. Nearly nine thousand are contained in an ounce, and they retain their vitality three years.

Culture. - Anise is raised from seeds sown annually, and thrives best in light, rich, comparatively dry soil, and in a warm, sunny situation. As early in spring as the appearance of settled warm weather, lay out a bed four feet and a half wide, and as long as may be desired; spread on a thin dressing of well-digested compost, and spade it thoroughly in with the soil; then rake the surface fine and even, and sow the seed thinly in drills twelve inches apart and an inch deep, allowing an ounce of seed for a hundred and fifty linear feet. When the plants are an inch high, thin them to five or six inches apart, and as they increase in size keep the ground between the rows loose, and the spaces between the plants free from weeds. Towards the close of the season, the seed will be ripened sufficiently for harvesting, when the plants should be pulled up, and spread in a sunny place until dry. The seed should then be threshed from the heads, riddled and winnowed, and again exposed to the sun, or spread in a dry, airy room, to evaporate any remaining moisture, when they will be ready for use or the market.

In field culture, the grower should follow substantially the same method, with the exception of laying out the ground, omitting, in this particular, its division into beds. After the land has been well prepared, the seed can be sown with great facility by a common sowing-machine, adjusted as when employed for sowing carrots. At the time of harvesting, the plants may be cut near the surface of the ground, or even mowed, thereby avoiding much of the inconvenience arising from the soil that adheres to the roots when the plants are pulled up.

There are no varieties.

Use. - The seeds and leaves are used both in medicine 
and cookery. The green leaves are employed in salads, and for seasoning and garnishing, like Fennel. The seeds have a fragrant odor, a pleasant, warm taste, and are highly carminative. Large quantities are used for distillation and in flavoring liquors, and also for expressing for their essential oil.

\section{B A L M.}

Melissa officinalis.

A hardy, perennial plant, from the south of Europe. The stalk is four-sided, branching, and from two to three feet ligh ; leaves opposite, in pairs, ovate, toothed on the borders ; the flowers are small, nearly white, produced in spikes, or clusters, at or near the top of the plant.

Soil, Propagation, and Culture. - Any warm, mellow, garden soil is suited to its growth. It is generally propagated by dividing the roots, which may be done either in spring or in autumn. After thoroughly stirring the soil, set the roots in rows fifteen inches apart, and a foot apart in the rows. Under good management, the plants will soon completely cover the surface of the ground, and the bed will not need renewal for many years.

Gathering. - If required for drying, the plants should be cut as they come into flower, separating the stems at the surface of the ground. They should not be exposed to the sun in drying, but spread in an airy, shady place, and allowed to dry gradually. The leaves, in their green state, may be taken directly from the plants as they are required for use.

Use. - The plant has a pleasant, lemon-like odor, an agreeable, aromatic taste, and, in flavoring certain dishes, is used as a substitute for lemon-thyme. It is beneficial in hemorrhage and other diseases of the lungs, and, in the 
form of tea, constitutes a cooling and grateful diluent in fevers. A mixture of balm and honey, or sugar, is sometimes applied to the interior of beehives, just previous to reeeiving the swarm, for the purpose of "attaching the colony to its new settlement."

\section{B A S I L.}

Ocymum.

There are two species of Basil cultivated in gardens; viz., the Common Sweet Basil (O. basilicum) and the Small Bush Basil ( $O$ minimum). Of the Common Sweet Basil, there are three varieties, and of the Bush Basil, two varieties. They are all annuals, and are grown from seeds, which are black, small, oblong, and retain their vitality from six to ten years.

Stem from a foot to a foot and a half in Common

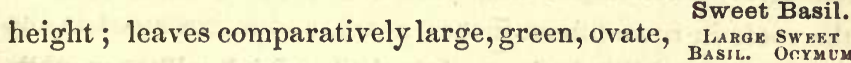
sharply pointed; flowers white, in whorls at BASILCYM the extremities of the stems and branches. The whole plant, when bruised, is highly aromatic, having the odor and flavor of cloves.

The seeds of the Common Sweet Basil, and also those of the two following varieties, may be sown in a hot-bed in March, and the plants set out in May in rows a foot apart, and five or six inches apart in the rows; or the seeds may be sown in the open ground the last of April or early in May, and the plants thinned while young, as directed for transplanting. In removing the plants from the hot-bed, retain as much of the earth about the roots as possible; water freely as soon as transp?anted, and also in dry weather; 
and they will soon yield an abundance of tender stems and leaves.

\section{Varieties. -}

Purple Basil. Leaves and flowers purple. When grown in sunny situations, the leaf-stems and young branches are also purple. In other respects, the variety is similar to the Common Sweet Basil. Its properties and uses are the same.

Lettuce- The leaves of this variety are large, pale
aved Basil. Vil. green, wrinkled and blistered like those of some kinds of Lettuce; whence the name. It resembles the foregoing varieties in taste and odor, and is used for the same purpose.

Bush Basil. The Bush Basils are small, low-growing, OCYMUM MINIMUM. ${ }^{-1}$ branching plants, and are propagated and cultivated like the Common Sweet Basil.

Green Bush Stem about eight inches high; leaves small, green, oval ; flowers white, produced in whorls about the upper portion of the principal stalk and towards the extremities of the branches.

Purple Bush Leaves purple. In other respects, similar to the Greeu Bush Basil.

Use. - The leaves and young branches have a strong, clove-like taste and odor, and are used in highly-seasoned soups and meats. They are also sometimes added to salads. For winter use, the stalks are cut while in flower, dried, powdered, and preserved, like other pot-herbs. 


\section{BORAGE.}

Borago officinalis.

Borage is generally classed as a hardy annual, though it is sometimes biennial. Stem two feet high; the leaves are oval, alternate, and, in common with the stalk and branches, thickly set with stiff, bristly hairs; the flowers are large and showy, - they are red, white, or blue, and often measure more than an inch in diameter; the seeds are large, oblong, slightly curved, and retain their germinative property three years.

Soil and Cultivation. - Borage thrives best in light, dry soil. The seeds are sown in April or May, in drills ten or twelve inches apart, and half an inch deep. They should be sown quite thinly, or so as to secure a plant for every six or eight inches, to which distance they should be thinned. When a continued supply is required, a second sowing should be made in July. The plants seed abundantly, and, when once introduced into the garden, spring up spontaneously.

Use. - The plant is rarely cultivated, and little used in this country. It is sometimes employed as a pot-herb, and the young shoots are occasionally mixed in salads. They are also sometimes boiled and used as Spinach. The flowers make a beautiful garnish, and it is well worthy of cultivation as an ornamental plant. "The stalks and foliage contain a large proportion of nitre, and, when dried, burn like match-paper."

Varieties. - There are several varieties, differing slightly, except in the color of the flowers; the Red-flowering, White-flowering, and Blue-flowering being the principal. A variety with variegated foliage is described by some authors. Miller states that they generally retain their distinctions from seeds. 


\section{CARA W A Y.}

Carum carui.

The Common Caraway is a hardy, biennial plant; a native of various parts of Europe, and to a considerable extent naturalized in this country. The root is long and tapering, of a yellowish-white color, and about three fourths of an inch in diameter near the crown, or at its broadest part; the flesh of the root is white, fine-grained, with a flavor not unlike that of the carrot; the flower-stalks are put forth the second season, and are about two feet and a half in height, with numerous spreading branches; the leaves are finely cut, or divided, and of a deep green color; the flowers are small, white, and produced in umbels at the ends of the branches; the seeds, which ripen quite early in the season, are of an oblong form, somewhat curved, furrowed, slightly tapering towards the extremities, of a clear olive-brown color, and pleasant, aromatic flavor and odor. Nearly eight thousand five hundred seeds are contained in an ounce, and they retain their vitality three years.

Soil and Cultivation. - Caraway is one of the hardiest of plants, and succeeds well in almost any soil or situation. In the coldest parts of the United States, and even in the Canadas, it is naturalized to such an extent about fields and mowing lands, as to be obtained in great abundance for the mere labor of cutting up the plants as the ripening of the seeds takes place.

When cultivated, the sowing may be made in April or May; but, if sown just after ripening, the seeds not only vegetate with greater certainty, but the plants often flower the ensuing season, thus saving a summer's growth. Sow in drills twelve or fifteen inches apart, and cover half an inch deep. When the plants are well up, thin to six or eight inches apart, and keep the ground loose, and free from 
weeds. The seeds will ripen in the July of the year after sowing. For other methods of culture, see Coriander.

Use. - It is principally cultivated for its seeds, which constitute an article of some commercial importance; a large proportion, however, of the consumption in this country is supplied by importation from Europe. They are extensively employed by confectioners, and for distillation. They are also mixed in cake, and, by the Dutch, introduced into cheese.

It is sometimes cultivated for its young leaves, which are used in soups and salads; or as a pot-herb, like Parsley. The roots are boiled in the manner of the Carrot or Parsnip, and by some are preferred to these vegetables, the flavor being considered pleasant and delicate.

There are no described varieties.

\section{CLARY. Loud.}

Clary Sage. Salvia sclarea.

Clary is a hardy, biennial plant. It is indigenous to the south of Europe, and has been cultivated in gardens for upwards of three centuries. The radical leaves are large, rough, wrinkled, oblong-heart-shaped, and toothed on the margin; stalk two feet high, four-sided, clammy to the touch; flowers pale blue, in loose, terminal spikes; seeds round, brownish, and, like others of the family, produced four together. They retain their vitality two years.

Sowing and Culture. - It is generally grown from seeds, which are sown annually in April or May, in drills fifteen or eighteen inches apart, and half or three fourths of an inch deep. When the young plants are two or three inches high, they are thinned to ten or twelve inches apart, and the growing crop is treated in the usual form during summer. The 
leaves are in perfection in the ensuing autumn, winter, and spring, and the plants blossom, and produce their seeds, in the following summer.

Use. - The leaves are used for flavoring soups, to which they impart a strong, peculiar flavor, agreeable to some, but unpleasant to most persons. It has some of the properties of Common Sage, and is occasionally used as a substitute.

The plant is seldom employed in American cookery, and is little cultivated.

\section{CORIANDER. Law.}

Coriandrum sativum.

A hardy annnal, supposed to have been introduced from the sonth of Europe, but now naturalized in almost all temperate climates, where it has once been cultivated.

Stem about two feet in height, generally erect, but, as the seeds approach maturity, often acquiring a drooping habit; stem-leaves more finely cut or divided than those proceeding directly from the root, and all possessed of a strong and somewhat disagreeable odor. The generic name is derived from Koris (a bug), with reference to the peculiar smell of its foliage. Flowers white, produced on the top of the plant, at the extremities of the branches, in flat, spreading umbels, or bunches; seeds globular, about an eighth of an inch in diameter, of a yellowish-brown color, with a warm, pleasant, aromatic taste: they become quite light and hollow by age, and are often affected by insects in the manner of seed-peas. Though they will sometimes vegetate when kept for a longer period, they are not considered good when more than two years old.

Propagation and Cultivation. - Like all annuals, it is propagated from seed, which should be sown in April or May, in good, rich, mellow soil, well pulverized. Sow in drills made 
fourteen or sixteen inches asunder, and about three fourths of an inch in depth, and thin to nine inches in the rows. It soon runs to flower and seed, and will be ready for harvesting in July or August.

In the south of England, Coriander is generally cultivated in connection with Caraway; eighteen pounds of Caraway seed being mixed with fifteen pounds of Coriander for an acre. As the Coriander is an annual, it yields its erop the first season. After being cut, it is left on the field to dry, and the seeds are afterwards beaten out on cloths, the facility with which these are detached not admitting of the usual method of harvesting.

An unquestionably preferable mode of cultivation would be to sow them both in drills alternately, by which means the Caraway would be more easily hoed and cleaned after the removal of the Coriander.

Use. - It is generally cultivated for its seeds, which are used to a considerable extent by druggists, confectioners, and distillers. In the garden, it is sometimes sown for its leaves, which are used as Chervil in soups and salads; but, when so required, a sowing should be made at intervals of three or four weeks.

There are no varieties.

\section{COSTMARY, OR ALECOST.}

Balsamita vulgaris.

Costmary is a hardy, perennial plant, with a hard, creeping root, and an erect, branching stem two or three feet high. The radical leaves, which are produced on long footstalks, are oval, serrated, and of a grayish color, - those of the stalk are sessile, smaller than the radical ones, but similar in form ; the flowers are deep yellow, in erect, terminal, spread- 
ing corymbs; the seeds are small, slightly curved, and of a grayish-white color.

Hoary-leaved Costmary.

Loud. leaves, less fragrant than the preceding.

Propagation and Cultivation. - Costmary may be cultivated in almost any description of soil or situation. It is sometimes grown from seeds, but is generally propagated by dividing the roots, which increase rapidly, and soon entirely occupy the ground. They are taken up for planting out either in spring or autumn, and should be set two feet apart in each direction. By occasionally thinning out the plants as they become too thick, a bed may be continued many years.

Use. - The plant has a soft, agreeable odor, and is sometimes used as a pot-herb for flavoring soups. The leaves are used in salads, and also for flavoring ale or beer; hence the name "Alecost."

\section{CUMIN.}

Cuminum cyminum.

Cumin is a native of Egypt. It is a tender, annual plant, from nine to twelve inches high. The leaves are deep green, and divided into long, linear segments, not unlike those of Fennel; the flowers are white or pale bluc, and are produced in small umbels at the extremities of the branches; the seeds are long, furrowed, of a pale brownish color, and somewhat resemble those of Anise. About seven thousand are contained in an ounce, and they retain their power of germination three years.

Soil and Cultivation. - Cumin requires a light, warm, loamy soil. The seed should be sown about the beginning 
of May, in drills fourteen inches apart and half an inch deep. When the plants are well up, they should be thinned to three or four inches apart in the lines. The treatment of the growing crop, and the usual method of harvesting, are the same as directed for Anise or Coriander.

The seed is sometimes sown broadcast, the soil being first finely pulverized, and raked smooth and even. This may be successfully practised upon land naturally light and warm, if free from weeds.

Though a native of a warm climate, Cumin may be successfully grown throughout the Middle States, and in the warmer portions of the Northern and Eastern.

Use. - The plant is cultivated for its seeds, which are carminative, and used as those of Caraway and Coriander. They are sometimes employed for flavoring spirits.

The plant is rarely grown, and the seeds are but little used, in the United States. There are no varieties.

\section{DILL. Loud.}

Anethum graveolens.

Dill is a hardy, biennial plant. There is but one species cultivated, and there are no varieties. The stem is erect and slender, and the leaves are finely divided; the flowers are produced in June and July of the second year, and the seeds ripen in August. The plant resembles Fennel in its general character, though smaller and less vigorous.

Propagation and Cultivation. - Dill flourishes best in light soil, and is propagated from seeds sown annually. As these retain their vitality but a single year, and, even when kept through the winter, vegetate slowly, they are frequently sown late in summer, or early in autumn, immediately after ripening. The drills are made a foot apart, and the seeds 
covered half an inch deep. The young plants should be thinned to six inches apart in the rows, and the leaves may be gathered for use from July till winter, and in the following spring till the plants have run to flower.

Use. - The whole plant is strongly aromatic. Its leaves are used to give flavor to pickles, particularly cucumbers, and occasionally are added to soups and sauces; the seeds are also employed for flavoring pickles. All parts of the plant are used in medical preparations.

\section{FEN NEL.}

Foeniculum.

Three species of Fennel are eultivated, differing not only in habit, but, to some extent, in their properties. The stems vary in height from two to four feet, and are. smooth and branching; the flowers are yellow, in terminal umbels; the seeds are oval, ribbed, or furrowed, generally of a light yellowish-brown color, and retain their vitality from three to five years.

Soil, Sowing, and Culture. - A light, dry soil is best adapted to the growth of Fennel; though it will thrive well in any good garden loam. It is generally raised from seeds, which may be sown in August, just after they ripen, or in April and May. They are generally sown in drills fifteen or eighteen inches apart, and about three fourths of an inch deep, - the young plants being afterwards thinned to twelve or fifteen inches apart in the drills; or a few seeds may be scattered broadcast on a small seed-bed, raked in, and the seedlings, when two or three inches high, transplanted to rows, as before directed.

Fennel is sometimes propagated by a division of the roots and by offsets. This may be performed either in spring, 
summer, or autumn. Set the roots, or shoots, fifteen inches apart in each direction, and they will soon become stocky plants, and afford an abundance of leaves for use. When cultivated for its foliage, the flowering shoots should be cut off as they may make their appearance, to encourage the production of fresh shoots, and to give size and succulency to the leaves.

The species and their peculiar uses are as follow : -

A perennial species, with deep, strong, fleshy roots; stem three or four feet high, with finely divided leaves. The flowers are put forth in

Common or Bitter Fennel.

Faniculum vulOARK. July, and the seeds ripen in August; the latter are about one sixth of an inch long, of a greenish-brown color, and, in common with the leaves, of a decidedly bitter taste.

Soil, Sowing, and Culture. - This species may be grown in almost any soil or situation. Sow the seeds soon after ripening, or early in spring. 'The plants require no other care than to be kept free from weeds.

Use. - The young leaves are used for flavoring soups and sauces, and are sometimes mixed in salads. The seeds are carminative, and the roots and leaves have reputed medicinal properties.

A variety with deep green foliage. Its uses and modes of culture are the same as those of Dark Green Leaved. the foregoing species.

Quite distinct from the Common Fennel, and generally cultivated as an annual. The stem,. which is about eighteen inches high, expands Florence or Italian Fennel. Mill.

Finochio. near the surface of the ground, and, when divided SWEET AZORIAN CULUM DULCE. horizontally, presents an oval form, measuring four or five inches in one direction, and two inches in the opposite. 
The flowers are produced in umbels, as in the other species. The seeds are slender, yellow, somewhat curved, sweet and pleasant to the taste, and of an agreeable anise-like odor.

Sowing and Culture. - The plant should be grown in wellenriched, mellow soil. Sow the seeds in April or May, thinly, in shallow drills from eighteen inches to two feet apart. Half an ounce of seeds will be sufficient for fifty feet of drill; or, by transplanting when they spring up too thickly, will furnish seedlings for a hundred feet.

The plants should be eight or ten inches apart; and, when the stems have attained a sufficient size, they should be earthed up for blanching, in the manner of Celery. Two or three weeks will be required to perfect this; and, if properly treated, the stems will be found white, crisp, tender, and excellent.

Plants from the first sowing will be ready for use in July and August. For a succession, a few seeds may be sown in June, or early in July.

Use. - The blanched portion of the stem is mixed in soups, and also used as a salad. It is served like Celery, with various condiments, and possesses a sweet, pleasant, aromatic taste.

It is a popular vegetable in some parts of Europe, but is rarely cultivated in this country. Sweet Fen- By some writers this has been described as
nel. Mill.

MALTA FENAEL. a variety of the Common Fennel; but its disFOENICULUM UYFI-

tinctive character appears to be permanent under all conditions of soil and culture. The leaves are long and narrow, and, compared with those of the last named, less abundant, and not so pointed. The stem is also shorter, and the seeds are longer, more slender, and lighter colored. 
Sowing and Cultivation. - It is propagated and cultivated as the Common Fennel.

Use. - It is used in all the forms of the last named. The seeds. have a sweet, pleasant, anise-like taste and odor, are strongly carminative, and yield an essential oil by distillation.

\section{A V E N D E R.}

Lavendula spica.

Lavender is a hardy, low-growing, shrubby plant, originally from the south of Europe. There are three varieties; and they may be propagated from seeds, by dividing the roots, or by slips, or cuttings.

The seeds are sown in April or May. Make the surface of the soil light and smooth, and sow the seeds in very shallow drills six inches apart. When the seedlings are two or three inches high, transplant them in rows two feet apart, and a foot apart in the rows.

The slips, or cuttings, are set in April, two thirds of the length in the soil, and in rows, as directed for transplanting seedlings. Shade them for a few days, until they have taken root; after which little care will be required beyond the ordinary form of cultivation.

The roots may be divided either in spring or autumn. Though Lavender grows most luxuriantly in rich soil, the plants are more highly aromatic, and less liable to injury from severe weather, when grown in light, warm, and gravelly situations.

Use. - Lavender is sometimes used as a pot-herb, " but is more esteemed for the distilled water which bears its name, and which, together with the oil, is obtained in the greatest proportion from the flower-spikes which have been gathered in dry weather, and just before the flowers are fully expanded. 
The oil of lavender is obtained in the ratio of an ounce to sixty ounces of dried flowers." - Law.

In the neighborhood of Mitcham, in Surrey, England, upwards of two hundred acres are occupied with Lavender alone.

\section{Varieties. -}

Broad-leaved Compared with the Common Lavender, the Lavender. Mill.

SPIKE LAVENDER.

branches of this variety are shorter, more sturdy, and thicker set with leaves, the latter being short and broad.

The Broad-leaved Lavender rarely blossoms; but, when this occurs, the leaves of the flower-stalk are differently formed from those of the lower part of the plant, and somewhat resemble those of the Common variety. The stalks are taller, the spikes lower and looser, and the flowers smaller, than those of the last named.

Common or A shrubby, thickly-branched plant, from a Blue-flower-
ing Lavender. foot to upwards of three feet high, according NARROW-LEAVED
BLUE-FLOWERING. is cultivated. The leaves are opposite, long, and narrow ; flowers blue or purple, in spikes.

The whole plant is remarkably aromatic; but the flowers have this property in a greater degree than the foliage or branches. The plants are in perfection in July and August, and are cut, for drying or distillation, close to the stem, as the blossoms on the lower part of the spikes begin to change to a brown color. Narrow- A sub-variety of the Common Lavender, with white-flow- white flowers. It is of smaller growth and less ering.

liardy than the last named, though not so generally cultivated. Its properties and uses are the same. 


\section{OVA GE.}

\section{Ligusticum levisticum.}

Lovage is a hardy, perennial plant, with a hollow, channelled, branching stem six or seven feet high. The leaves are winged, smooth, deep glossy-green, and somewhat resemble those of Celery; the flowers are yellow, and produced in large umbels at the extremities of the branches; the seeds are oblong, striated, of a pale yellowish-brown color, and retain their germinative powers but one year.

Soil, Propagation, and Culture. - Lovage requires a deep, rich, moist soil, and is propagated either by seeds or dividing the roots. The seeds should be sown in August, or immediately after ripening, as, when sown in spring, they seldom vegetate well. When the young plants have made a growth of two or three inches, they should be transplanted three feet apart in each direction, and, when well established, will require little care, and continue for many years.

The roots may be divided in spring or autumn, and should be set three feet apart, as directed for seedling plants, covering the crowns three inches deep.

Use. - Lovage was formerly cultivated as an esculent; but its use as such has long been discontinued. It is now cultivated for its medicinal properties, both the seeds and roots being used. The latter are large, fleshy, dark brown without, yellowish within, and of a peculiar, warm, aromatic taste. They are sliced and dried, and in this state are used to some extent by confectioners. The seeds are similar to the roots in taste and odor, but have greater pungency. In appearance and flavor the plant is not unlike Celery.

There are no varieties. 


\section{MARIGOLD.}

Pot Marigold. Calendula officinalis.

This hardy annual is a native of France and the south of Europe. Aside from its value for culinary purposes, its large, deep orange-yellow. flowers are showy and attractive; and it is frequently cultivated as an ornamental plant. The stem is about a foot in height; the leaves are thick and fleshy, rounded at the ends, and taper to the stalk; the flowers are an inch and a half or two inches in diameter, yellow, differing, however, in depth of color, - and single or double, according to the variety; the seeds are large, light brown, much curved and contorted, and very irregular both in their size and form.

Sowing and Cultivation. - The plant is of easy culture. The seeds are sown in autumn, just after ripening, or in April, May, or June. Make the drills a foot apart; cover the seed three fourths of an inch deep, and, when the plants are an inch or two inches high, thin them to eight or ten inches apart. Plants from the first sowing will blossom early in July, and continue in bloom until destroyed by frost.

Gathering. - The flowers are gathered when fully expanded, divested of their calyxes, and spread in a light, airy, shaded situation until they are thoroughly dried. They are gathered as they come to perfection; when the plants are allowed to ripen their seeds, they become much less productive.

To raise Seed. - Leave one or two of the finest plants, without cutting the flowers, and, when the heads of seed begin to change from a green to a brownish color, cut them off, spread them a short time, as directed for drying the flowers, and pack away for use.

Use. - The flowers are used in various parts of Europe 
for flavoring soups and stews, and are much esteemed. Though often grown as an ornamental plant, the flowers are but little used in this country for culinary purposes.

The varieties are as follow:

Flowers single, deep orange-yellow, highflavored. It is considered the best variety Common Orange-flowered. for cultivation.

This differs from the foregoing in the paler Lemon-flowcolor of the flowers, which are also less aroered. matic. The plants are not distinguishable from those of the Common Orange-flowered.

Of the same color with the first named, but with fine, large, double ornamental flowers. Double OrangeThe petals are flat, and rest in an imbricated manner, one on the other, as in some varieties of the Anemone. It is more productive, but less aromatic, than the Singleflowering.

A variety of the second named sort, with double flowers, like those of the preceding.

Double Lemonflowering.

To raise good seeds of either of the double-flowering kinds, all plants producing single flowers must be removed as soon as their character is known. When the single and double-flowering plants are suffered to grow together, the latter rapidly deteriorate, and often ultimately become single-flowering.

This variety produces numerous small flowers from the margin of the calyx of the large central flowers. It is quite ornamental, but of litChilding, or Proliferous Marigold. Loud. tle value as an esculent. 


\section{MA R J O A M.}

Origanum.

Commom

Marjoram.

Origanum vul- sided stem, a foot and a half high; leaves GARE.

oval, opposite; at the union of the leaves with the stalk, there are produced several smaller leaves, which in size and form resemble those of the Common Sweet Marjoram; the flowers are pale red, or flesh-colored, and produced in rounded, terminal spikes; the plants blossom in July and August, and the seeds ripen in September.

Propagation and Culture. - It may be grown from seeds, but is generally propagated by dividing the roots, either in spring or autumn. Set them in a dry and warm situation, in rows fifteen inches apart, and ten or twelve inches from plant to plant in the rows.

The seeds may be sown in a seed-bed in April or May, and the seedlings transplanted to rows, as directed for setting the roots; or they may be sown in drills fifteen inches apart, afterwards thinning out the young plants to ten inches apart in the drills.

There is a variety with white flowers, and another with variegated foliage.

Use. - The young shoots, cut at the time of flowering and dried in the shade, are used as Sweet Marjoram for seasoning soups and meats. The whole plant is highly aromatic.

Sweet Marjo- Sweet Marjoram is a native of Portugal. ram.

KNatred Marjo- Though a biennial, it is always treated as an

RAM. ORIGANUM annual, as it is not sufficiently hardy to withstand the winters of the Middle or Northern States in the open ground. The plant is of low growth, with a branching stem, and oval or rounded leaves. The flowers, which appear in July and August, are of a purplish color, and 
produced in compact clusters, or heads, resembling knots; whence the term "Knotted Marjoram" of many localities. The seeds are brown, exceedingly small, and retain their germinative properties three years.

Sowing and Cultivation. - Sweet Marjoram is raised from seeds sown annually in April, May, or June. Its propagation, however, is generally attended with more or less difficulty, arising from the exceeding minuteness of the seeds, and the liability of the young seedlings to be destroyed by the sun before they become established. The seeds are sown in drills ten or twelve inches apart, and very thinly covered with finely pulverized loam. Coarse, light matting is often placed over the bed immediately after sowing, to facilitate vegetation, and, if allowed to remain until the plants are well up, will often preserve a crop which would otherwise be destroyed.

The seeds are sometimes sown in a hot-bed, and the plants set out in May or June, in rows twelve inches apart, and six inches apart in the rows.

Gathering. - The plants, when in flower or fully developed, are cut to the ground, and, for winter use, are dried and preserved as other pot-herbs.

Use. - Sweet Marjoram is highly aromatic, and is much used, both in the green state and when dried, for flavoring broths, soups, and stuffings.

A perennial species, from Sicily. Stem a Pot Marjofoot or more in height, branching; leaves Oram. oval, comparatively smooth; the flowers are small, of a purplish color, and produced in spikes.

Propagation and Cultivation. - The species is propagated, and the crop in all respects should be treated, as directed for Common Marjoram. The properties and uses of the plant 
are also the same. Both, however. are much inferior to the Sweet Marjoram last described. Winter A half-hardy perennial, from the south of
Sweet Marjo-
ram. Corb. Europe. Stem eighteen inches high, purplish;
ORIGANUM HERA-
CLEOTICUM. ends, and resemble those of Sweet Marjoram; the flowers are white, and are put forth in July and August, in spikelets about two inches in length; the seeds ripen in September.

Propagation and Culture. - It may be grown from seeds, but is generally propagated by dividing the roots either in the spring or fall, and planting the divisions ten inches apart, in rows eighteen inches asunder. It succeeds best in dry localities, and requires no other attention than to have the soil kept loose, and free from weeds.

There is a variety with variegated leaves, but differing in no other respect from the foregoing.

Use. - The leaves and young branches are used in soups, and stuffing for meats, and should be cut when just coming into flower, and dried in the shade.

\section{AROMATIC NIGELLA.}

Four Spices. Allspice. Black Cumin. Nigella sativa.

A hardy, annual plant from the East Indies. Stem twelve to eighteen inches high, with alternate, sessile, finely divided leaves; the flowers are large, white, variegated with blue; the seeds, which are produced in a roundish capsule, are somewhat triangular, wrinkled, of a yellowish color, and pungent, aromatic taste. About thirteen thousand are contained in an ounce, and they retain their vitality three years. There is a species cultivated, the seeds of which are black. 
Soil and Cultivation. - It is always raised from seed, and thrives best in light, warm soil. The seed may be sown from the middle of April to the middle of May. Pulverize the soil well, make the surface smooth and even, and sow in drills twelve or fourteen inches apart, and about half an inch deep. When the plants are two inches high, thin them to five or six inches apart in the rows. During the summer, cultivate in the usual manner, keeping the soil loose, and watering occasionally if the weather be dry; and in August or September, or when the seed ripens, cut off the plants at the roots, spread them in an airy situation, and, when sufficiently dried, thresh out; after which spread the seed a short time, to evaporate any remaining moisture, and they will be ready for use.

Use. - The seeds have a warm, aromatic taste, and are employed in French cookery, under the name of quatre épices, or "four spices."

\section{PAR S LEY.}

Apium petroselinum.

Parsley is a hardy, biennial plant from Sardinia. The leaves of the first year are all radical, compound, rich, deep green, smooth, and shining. When fully developed, the plant measures three or four feet in height; the flowers are small, white, in terminal umbels; the seeds are ovoid, somewhat three-sided, slightly curved, of a grayish-brown color and aromatic taste. Seven thousand are contained in an ounce, and they retain their vitality three years.

Soil and Propagation. - Parsley succeeds best in rich, mellow soil, and is propagated from seeds sown annually; an ounce of seed being allowed to a hundred and fifty feet of drill.

Sowing. - As the seed vegetates slowly, - sometimes re- 
maining in the earth four or five weeks before the plants appear, - the sowing should be made as early in spring as the ground is in working condition. Lay out the bed of a size corresponding to the supply required, spade it decply and thoroughly, level the surface (making it fine and smooth), and sow the seed in drills fourteen inches apart, and half an inch deep. When the plants are two or three inches high, thin them to eight or ten inches apart, being careful, in the thinning, to leave only the best curled plants.

According to Lindley, the finest curled kinds will rapidly degenerate, and become plain, if left to themselves; while, on the other hand, really excellent sorts may be considerably improved by careful cultivation.

The best curled Parsley is obtained by repeated transplantings. When the seedlings are two inches high, they are set in rows ten inches apart, and six inches apart in the rows. In about four weeks, they should be again transplanted to where they are to remain, in rows eighteen inches apart, and fourteen inches apart in the rows. When thus treated, the plants become remarkably close, of a regular, rosette-like form, and often entirely cover the surface of the ground. When grown for competition or for exhibition, this process of transplanting is thrice, and often four times, repeated.

Seed. - In autumn, select two or three of the finest curled and most symmetrical plants; allow them to remain unplucked; give a slight protection during winter, and in the following summer they will yield abundantly. Much care is requisite in keeping the varieties true. This is especially the case with the curled sorts. The seed-growers, who value their stock and character, select the best and finest curled plants, and allow no others to flower and seed. When the object is to improve a variety, but few seeds are saved from a plant, and in some cases but few seeds from a head. 
Use. - The leares of the curled varieties afford one of the most beautiful of garnishes; they are also used for flavoring soups and stews. The seeds are aromatic, and are sometimes used as a substitute for the leares, though the flavor is much less agreeable.

\section{Varieties. -}

A fine, dwarfish, curled variety, long culti- DwarfCurled vated in England. In Parsley. vated in England. In some gardens it is CURLD ParsLer.

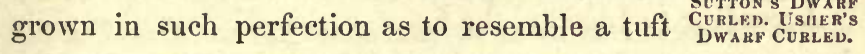
of finely curled green moss.

It is hardy, and slow in running to seed, but liable to degenerate, as it constantly tends to increase in size, and to become less curled.

From the Dwarf Curled Parsley, by judicious cultivation and a careful selection of plants for seed, have originated many excellent sorts of stronger growth, yet retaining its finely curled and beautiful leaves.

A fine, curled sort, larger than the Dwarf Curled, and, on account of its remarkable hardiness, recommended as one of the best

Mitchell's Matchless Winter. Thomp. for winter culture.

The leaves of this variety are large and spreading, bright green above, paler beneath. When true, the foliage is nearly as finely curled as that of the Dwarf, though the plant is much larger and stronger in its habit.

Myatt's Triplecurled. MYATT's GarNISIIINO. Myat's Extra Fine Curled. WiNDSUR Curled.

The leaves of this sort are plain, or not curled, and the plant produces them in greater quantity than the curled sorts. It is also somePlain Parsley. Thomp. Comxion PARSwhat hardier. 
For many years it was the principal variety grown in the gardens of this country, but has now given place to the curled sorts, which, if not of better flavor, are generally preferred, on account of their superior excellence for garnishing.

Rendle's Treble Garnishing. Trans.
A variety of the Dwarf Curled, of larger size, the leaves being as finely curled and equally beautiful.

Hamburg or Large-rooted Parsley. McInt.

TURNIP-ROOTED Parsley.
A variety of the Common Plain Parsley, with stronger foliage. Though the leaves are sometimes used in the manner of those of the Common Parsley, it is generally cultivated for its fusiform, fleshy roots.

To obtain these of good size and quality, the soil should not be too rich, but deeply and thoroughly trenched. Sow the seeds in April or May, in drills a foot or fourteen inches apart, and three fourths of an inch deep; and when the seedlings are two or three inches high, thin them to six or eight inches apart in the rows. Cultivate during the season as carrots or parsnips, and in October the roots will have attained their growth, and be suitable for use. Take them up before the ground closes, cut off the tops within an inch or two of the crowns, pack in earth or sand, and store in the cellar for winter.

To raise Seeds. - Reset a few roots in April, two feet apart; or leave a few plants in the open ground during the winter. They will blossom in June and July, and ripen their seeds in August.

Use. - The roots are eaten boiled as carrots or parsnips. In connection with the leares, they are also mixed in soups and stews, to which they impart a pleasant, aromatic taste and odor. 
This variety somewhat resembles Celery, Naples or and, by writers on gardening, is described as leaved Parsa hybrid between some of the kinds of Celery prapoutin and the Large-rooted or Hamburg Parsley. With the exception of their larger size, the leaves are similar to those of the Common Plain Parsley.

Use. - The leaves are sometimes employed for garnishing, but are generally blanched, and served as Celery.

Sowing and Cultivation. - The plants are started in a hotbed in March, or the seeds may be sown in a seed-bed in the open ground in May. When the seedlings are four or five inches high, transplant to trenches two feet apart, and six or eight inches deep, setting the plants a foot apart in the trenches; afterwards gather the earth gradually about the stems, in the process of cultivation, and when they are sufficiently grown and blanched, harvest and preserve as Celery.

To raise Seeds. - Leave two or three plants unblanched. They should be eighteen inches asunder, and may remain in the open ground during winter. They will flower, and yield a plentiful supply of seeds, the following summer.

\section{PE P PER M IN T.}

Mentha piperita.

Peppermint is a hardy, perennial plant, introduced from Europe, and growing naturally in considerable abundance along the banks of small streams, and in rich, wet localities. Where once established, it spreads rapidly, and will remain a long period.

Stem smooth, erect, four-sided, and from two to three feet in height; leaves opposite, ovate, pointed, toothed on the margin; flowers purplish, or violet-blue, in terminal spikes ; 
the seeds are small, brown, or blackish-brown, and retain their vitality four years.

Propagation and Culture. - It may be grown from seeds; but this method of propagation is rarely practised, as it is more readily increased by dividing the roots.

The agreeable odor, and peculiar, warm, pleasant flavor, of the leaves are well known. The plant, however, is little used as a pot-herb, but is principally cultivated for distillation. For the latter purpose, the ground is ploughed about the middle of May, and furrowed in one cirection, as for drill-planting of potatoes, making the furrows about eighteen inches apart. The best roots for setting are those of a year's growth, and an acre of these will be required to plant ten acres anew. These are distributed along the furrows in a continuous line, and covered sometimes with the foot as the planter drops the roots, and sometimes by drawing the earth over them with a hoe. In about four weeks, the plants will be well established, and require hoeing; this is usually performed three times during the season, and is finished early in August.

"The cutting and distilling commence about the 25 th of August, except in very dry seasons, when it stands two or three weeks longer, and continues until the 1st of October, during which period the plant is in full inflorescence, and the lower leaves begin to grow sear. It is raked together in small heaps, when it is suffered to wilt ten or twelve hours, if convenient.

"The next year, little is done to the mint-field but to cut and distil its product. During this (the second) year, a few weeds make their appearance, but not to the injury of the crop, though the most careful of the mint-growers go through their fields, and destroy them as much as possible. The second crop is not so productive as the first.

"The third year, little labor is required other than to har- 
vest and distil the mint. The stem is coarser than before, and the leaves still less abundant. The weeds this year abound, and are not removed or destroyed, half or more of the product of the field often being weeds.

"The fourth year, the field is ploughed up early in the spring; and this ' renewing' is sometimes done every third year.

" The fifth year, without any further attention, produces a crop equal to the second; after which the field is pastured and reclaimed for other crops.

"The first year produces the best quality of oil, the highest yield per acre, and the greatest amount to the quantity of herbage." $-F$. Stearns.

\section{ROSEMARY.}

Rosmarinus officinalis.

Rosemary is a half-hardy, shrubby plant, from three to six feet in height. The leaves vary in form and color in the different varieties; the flowers are small, generally blue, and produced in axillary clusters ; the seeds are brown, or blackish-brown, and retain their vitality four years.

Propagation and Cultivation.-Like most aromatic plants, Rosemary requires a light, dry soil; and, as it is not perfectly hardy, should have a sheltered situation. The Common Green-leaved and the Narrow-leaved are best propagated by seeds; but the variegated sorts are propagated only by cuttings or by dividing the roots. The seeds are sown in April, in a small nursery-bed, and the seedlings, when two or three inches high, transplanted in rows two feet apart, and eighteen inches apart in the rows.

When propagated by cuttings, they should be taken off in May or June, six inches long, and set two thirds of the 
length in the earth, in a moist, shady situation; when well rooted, transplant as directed for seedlings. The roots may be divided in spring or autumn.

Use. - It is sometimes employed, like other pot-herbs, for flavoring meats and soups. It is used in the manufacture of " eau de Cologne," and its flowers and calyxes form a principal ingredient in the distillation of "Hungary Water." Infusions of the leaves are made in some drinks, and the young stems are used as a garnish.

There are four varieties, as follow:-

Common or Leaves narrow, rounded at the ends, - the Greenleaved. upper and under surface green; the flowers are comparatively large, and deep-colored.

The plant is of spreading habit, and in all its parts is more strongly aromatic than the Narrow-leaved. It is decidedly the best sort for cultivation.

Gold-striped. A variety of the Common or Green-leaved, with foliage striped, or variegated with yellow.

This and the Silver-leaved are generally cultivated as ornamental plants. The Gold-striped is much the hardier sort, and will succeed in any locality where the Common Greenleaved is cultivated.

Narrow-

The plants of this variety are smaller and leaved.

less branched than those of the Common or Green-leaved, and are also less fragrant; the leaves are hoary beneath, and the flowers are smaller and of a paler color.

It is used in all the forms of the Common or Green-leaved, but is less esteemed. 
Green-leaved, and the most tender of all the sorts. It is principally cultivated for its variegated foliage, the leaves being striped, or variegated with white.

Like the Gold-striped, it can only be propagated by slips, or by dividing the roots, and must be well protected during winter.

\section{S A G E.}

\section{Salvia.}

Sage is a low-growing, hardy, evergreen shrub, originally from the south of Europe. Stem from a foot and a half to two feet high, - the leaves varying in form and color in the different species and varieties; the flowers are produced in spikes, and are white, blue, red, purple, or variegated ; the seeds, of which seven thousand are contained in an ounce, are round, of a blackish-brown color, and retain their power of germination three years.

Soil and Propagation. - Sage thrives best in light, rich, loamy soil. 'Though easily grown from slips, or cuttings, it is, in this country, more generally propagated from seeds. These may be sown on a gentle hot-bed in March, and the plants set in the open ground in June, in rows eighteen inches apart, and a foot asunder in the rows; or the seeds may be sown in April, where the plants are to remain, thinly, in drills eighteen inches apart, and three fourths of an inch deep. When the plants are two inches high, thin them to a foot apart in the rows, and, if needed, form fresh rows by resetting the plants taken up in thinning.

If grown from cuttings, those from the present year's growth succeed best. These should be set in June. Cut them fonr or five inches in length, remove the lower leaves, and set them two thirds of their length in the earth. Water freely, and shade or protect with hand-glasses. By the last 
of July, or first of August, they will have taken root, and may be removed to the place where they are to remain.

It may also be propagated by dividing the roots in spring or autumn, in the manner of other hardy shrubs.

Gathering and Use. - Sage should be gathered for drying before the development of the flowering-shoots; and, when cultivated for its leaves, these shoots should be cut out as they make their appearance. When thus treated, the product is largely increased, as the leaves are put forth in much greater numbers, and attain a larger size.

It is sometimes treated as an annual, the seeds being sown in April, in drills fourteen inches apart, and the plants cut to the ground when they have made sufficient growth for use.

The leaves are employed, both in a green and dried state, for seāsoning stuffings, meats, stews, and soups. Sage is also used for flavoring cheese, and, in the form of a decoction, is sometimes employed for medical purposes.

\section{Species and Varieties. -}

\section{Broad- leaved Green \\ Sage. Barsamic Sage.}

Stems shrubby, less erect and more downy than those of the succeeding species; the leaves are comparatively large, broad, heart-shaped, woolly, toothed on the margin, and produced on long footstalks, - those of the flower-stalks are oblong, sessile, and nearly entire on the borders; the flowers are small, pale blue, and much less abundant than those of the Common Sage.

It is rarely employed in cookery, but for medical purposes is considered more efficacious than any other species or variety.

Common or Red-leaved.

Purple-top.

RED-TOP. SALVIA OFFICINALIS.
This is the Common Sage of the garden, and with the Green-leaved, which is but a subvariety, the most esteemed for culinary pur- 
poses. The young stalks, the leaf-stems, and the ribs and nerves of the leaves, are purple; the young leaves are also sometimes tinged with the same color, but generally change by age to clear green.

The Red-leaved is generally regarded as possessing a higher flavor than the Green-leaved, and is preferred for cultivation; though the difference, if any really exists, is quite unimportant. The productiveness of the varieties is nearly the same. The leaves of the Green Sage are larger than those of the Red, but the latter produces them in greater numbers.

A variety of the preceding; the young shoots, Greenthe leaf-stalks, and the ribs and nerves of the leaved. leaves, being green.

There appears to be little permanency in the characters by which the varieties are distinguished. Both possess like properties, and are equally worthy of cultivation. From seeds of either of the sorts, plants answering to the description of the Red-leaved and Green-leaved would probably be produced, with almost every intermediate shade of color.

Leaves narrow, hoary, toothed towards the Narrowbase; the spikes of flowers are long, and leaved Green nearly leafless; flowers deep blue; the seeds are similar to those of the Red-leaved, and produced four together in an open calyx. Compared with the Common Red-leaved or Green-leaved, the leaves are much narrower, the spikes longer and less leafy, and the flowers smaller and of a deeper color.

The variety is mild flavored, and the most esteemed of all the sorts for use in a crude state, as it is also one of the best for decoctions. 
"At one period, the Dutch carried on a profitable trade with the Chinese by procuring the leaves of this species from the south of France, drying them in imitation of tea, and shipping the article to China, where, for each pound of sage, four pounds of tea were received in exchange." McInt.

Variegated- A sub-variety of the Green-leaved, with
leaved Green Sage. variegated foliage. It is not reproduced from seeds, and must be propagated by slips or by dividing the roots.

Variegatedleaved Red Sage.

This is but an accidental variety of the Common Red-leaved Sage, differing only in its variegated foliage. It can be propagated only by cuttings or by a division of the roots.

\section{S A V O R Y.}

Saturjea.

The cultivated species are as follow:-

Headed Savory.

SATURJEA CAPITATA.

A perennial plant, with a rigid, angular, branching stem a foot and a half high. The leaves are firm, pointed, and, when bruised, emit a strong, pleasant, mint-like odor; the flowers are white, and are produced in terminal, globular heads; the seeds are quite small, of a deep brownish color, and retain their vitality three years.

It may be propagated from seeds or by dividing the roots, the latter method, however, being generally practised. The young shoots are used in all the forms of Summer Savory. 
A shrub-like, perennial species, cultivated Shrubby Sain the same manner as the Winter Savory. SA voryeA. vimThe plant has the pleasant, mist-like odor of XEA. the species first described, but is little used either in cookery or medicine.

An annual species, from the south of Europe. Summer Sa-

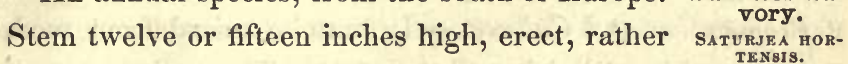
slender, and producing its branches in pairs; the leaves are opposite, narrow, rigid, with a pleasant odor, and warm, aromatic taste; the flowers are pale pink, or flesh-colored, and are produced at the base of the leaves, towards the upper part of the plant, each stem supporting two flowers; the seeds are quite small, deep brown, and retain their vitality two or three years.

Propagation and Cultivation. - Summer Savory is always raised from seeds, sown annually in April or May. It thrives best in light, mellow soil, and the seed should be sown in shallow drills fourteen or fifteen inches apart. When the plants are two or three inches high, thin them to five or six inches apart in the rows, and cultivate in the usual manner during the summer.

When the plants have commenced flowering, they should be cut to the ground, tied in small bunches, and dried in an airy, shady situation.

For early use, the seeds are sometimes sown in a hot-bed on a gentle heat, and the seedlings afterwards transplanted to the open ground in rows, as directed for sowing.

Use. - The aromatic tops of the plant are used, green or dried, in stuffing meats and fowl. They are also mixed in salads, and sometimes boiled with peas and beans. It is sold in considerable quantities, at all seasons of the year, in a dried and pulverized state, packed in hermetically sealed bottles or boxes. 
Winter Savo. ry. Thomp. SATURJEA MONTANA.
A hardy, evergreen shrub, with a low, branching stem about a foot in height. The leaves are opposite, narrow, and rigid, like those of

the preceding species; the flowers resemble those of the Summer Savory, but are larger and of a paler color; the seeds, which ripen in autumn, are small, dark brown, and retain their vitality three years.

Propagation and Culture. - It may be raised from seed, or increased by a division of the roots. The seeds are sown in April or May, in shallow drills, fifteen inches apart; and the roots may be divided in spring or autumn. The plants should be set one foot apart in the rows, to which distance the seedlings should also be thinned as soon as they are well up.

After they are established, the shrubs are treated as sage, - trimmed in September or October, and replanted once in three or four years.

Use. - It is used for the same purposes as Summer Savory. The leaves and tender parts of the young branches are mixed in salads; they are also boiled with peas and beans; and, when dried and powdered, are used in stuffings for meats and fowl.

\section{S PEARMINT.}

Green Mint. Mentha viridis.

A hardy, perennial plant, introduced from Europe, and generally cultivated in gardens, but growing naturally in considerable abundance about springs of water, and in rich, wet localities. The stem is erect, four-sided, smooth, and two feet or more in height; the leaves are opposite, in pairs, stemless, toothed on the margin, and sharply pointed; the flowers are purple, and are produced in August, in long, 
slender, terminal spikes; the seeds are small, oblong, of a brown color, and retain their vitality five years. They are generally few in number, as most of the flowers are abortive.

Soil, Propagation, and Culture. - It may be grown from seed, but is best propagated by a division of the roots, which are long and creeping, and readily establish themselves wherever they are planted. Spearmint thrives best in rich, moist soil, but may be grown in any good garden loam. The roots may be set either in the autumn or spring.

Where large quantities are required for marketing in the green state, or when grown for distillation, lay out the land in beds three or four feet in width, and make the drills two or three inches deep, and a foot apart. Having divided the roots into convenient pieces, spread them thinly along the drills, and earth them over to a level with the surface of the bed. Thus treated, the plants will soon make their appearance, and may be gathered for use in August and September. Just before severe weather, give the beds a slight dressing of rich soil, and the ensuing season the plants will entirely occupy the surface of the ground.

Use. - Mint is sometimes mixed in salads, and is used for flavoring soups of all descriptions. It is often boiled with green peas, and, with the addition of sugar and vinegar, forms a much esteemed relish for roasted lamb. It has also much reputed efficacy as a medicinal plant.

A variety with curled foliage. It is a good sort for garnishing, but, for general use, is Curled-
leaved Spearmint. inferior to the Common or Plain-leaved species before described. Propagated by dividing the roots. 


\section{T A N S Y.}

Tanacetum vulgare.

Tansy is a hardy, perennial, herbaceous plant, naturalized from Europe, and abundant by road-sides and in waste places. The stem is from two to three feet high; the leaves are finely cut and divided, twice toothed on the margin, and of a rich, deep green color ; flowers in corymbs, deep yellow, and produced in great abundance; the seeds are small, of a brownish color, and retain their vitality three years.

Soil and Cultivation. - Tansy may be grown in almost any soil or situation, and is propagated from seeds or by dividing the roots, the latter method being generally practised. In doing this, it is only necessary to take a few established plants, divide them into small pieces or collections of roots, and set them six inches apart, in rows a foot asunder, or in hills two feet apart in each direction. They will soon become established, and, if not disturbed, will completely occupy the ground. In most places when once introduced, it is liable to become troublesome, as the roots not only spread rapidly, but are very tenacious of life, and eradicated with difficulty.

When cultivated for its leaves, the flowering-shoots should be cut off as they make their appearance. It is but little used, and a plant or two will afford an abundant supply.

Use. - The leaves have a strong, peculiar, aromatic odor, and a bitter taste. They were formerly employed to give color and flavor to various dishes, but are now rarely used in culinary preparations. The plant possesses the tonic and stomachic properties common to bitter herbs.

There are three cultivated varieties, as follow : -

This differs from the Common Tansy in the

DodBle TANSY: frilled or curled character of the leaves, which GARE, VAR. CRIS PUM. 
have some resemblance to the leaves of the finer kinds of Curled Cress or Parsley. They are of a rich green color, and are sometimes employed for garnishing. In the habit of the plant, color of the flowers, odor and flavor of the leaves, the variety differs litte, if at all, from the Common Tansy. It is more beautiful than the last named, and, in all respects, much more worthy of cultivation.

Propagated only by dividing the roots.

Leaves larger than those of any other vari- Large-leaved ety, but much less fragrant. It is of little Tansy. value, and rarely cultivated.

A variety with variegated foliage. Aside Variegatedfrom the peculiar color of the leaves, the plant leaved. differs in no respect from the Common Tansy; it grows to the same height, the flowers are of the same color, and the leaves have the same taste and odor.

It must be propagated by dividing the roots, as the variegated character of the foliage is not reproduced from seeds.

T H Y M E.

Thymus.

Two species of Thyme are cultivated for culinary purposes - the Common Garden Thyme ( $T$. vulgaris) and the Lemon or Evergreen Thyme (T. citriodorus).

They are hardy, perennial plants, of a shrubby character, and comparutively low growth. They are propagated from seeds and by dividing the roots, but the finest plants are produced from seeds.

Of the Common Garden Thyme there are three varieties : - 
Broatleaved.
The Broad-leaved Thyme is more cultivated in this country than any other species or variety. The stem is ten or twelve inches high, shrubby, of a brownish-red color, and much branched; the leaves are small, narrow, green above, and whitish beneath, flowers purple, in terminal spikes ; the seeds are black, and exceedingly small. Two hundred and thirty thousand are contained in an ounce, and they retain their vitality two years.

Propagation and Cultivation. - When propagated by seeds, they are sown in April or May, thinly, in shallow drills ten or twelve inches apart. When the plants are up, they should be carefully cleared of weeds, and thinned to eight or ten inches apart, that they may have space for development. They may be cut for use as soon as they have made sufficient growth ; but, for drying, the stalks are gathered as they come into flower.

If propagated by dividing the roots, the old plants should be taken up in April, and divided into as many parts as the roots and tops will admit. They are then transplanted about ten inches apart, in beds of rich, light earth, and, if the weather be dry, watered till they are well established. They may be cut for use in August and September.

Use. - The leaves have an agreeable, aromatic odor, and are used for flavoring soups, stuffings, and sauces. Narrow- The stalks of this variety are shorter than
leaved. Mill.

those of the Broad-leaved; the leaves also are longer, narrower, and more sharply pointed; and the flowers are larger.

It is propagated, cultivated, and used as the Broadleaved.

Variegatedleaved.

A sub-variety of the Broad-leaved, with vari- . egated foliage. It is gencrally cultivated as an 
ornamental plant, and is propagated only by dividing the roots, as directed for the Broad-leaved.

A low, evergreen shrub, with a somewhat Lemon trailing stem, rarely rising more than six or $\begin{gathered}\text { Thyme. Loud. } \\ \text { Thrusus crrrt- } \\ \text { oDorus. }\end{gathered}$ eight inches high. It is readily distinguished from the Common or Broad-leaved by the soft, pleasant, lemon-like odor of the young shoots and leaves.

It is used for flavoring various dishes, and by some is preferred to the Broad-leaved.

The species is propagated from seeds by dividing the roots, and by layers and cuttings. Seedling plants, however, are said to vary in fragrance; and, when a choice stock can be obtained, it is better to propagate by dividing the plants. 


\section{CHAPTER IX.}

\section{LEGUMINOUS PLANTS.}

American Garden-bean. Asparagus-bean. Lima Bean. Scarlet-runner.

Sieva. Chick-pea. Chickling Vetch. English Bean. Japan Pea. Lentil. Lupine. Pea. Pea-nut. Vetch, or Tare. Winged Pea.

\section{AMERICAN GARDEN-BEAN.}

French Bean. Kidney Bean. Haricot, of the French. Phaseolus vulgaris.

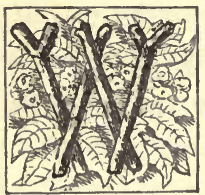

ITH the French or Kidney Bean of England and France, the Common Garden-bean of the United States is identical, but is quite distinct from the English or Garden-bean of French and English catalogues.

The American Garden-bean is a tender, annual plant from the East Indies, with a dwarfish or climbing stem and trifoliate leaves. The flowers are variable in color, and produced in loose clusters; the seeds are produced in long, flattened, or cylindrical, bivalved pods, and differ, in a remarkable degree, in their size, form, and color. Their germinative powers are retained three or four years.

As catalogued by seedsmen, the varieties are divided into two classes - the Dwarfs, and the Pole or Running sorts.

Dwarfs. - The plants of this class vary from a foot to two feet in height. They require no stakes or poles for their support, and are grown in hills or drills, as may suit the taste or convenience of the cultivator. 
All of the varieties are comparatively tender, and should not be planted before settled, mild weather. They succeed best in warm, light soil, but will flourish in almost any soil or situation, unless it be shaded or very wet.

When planted in drills, they are made from fourteen to twenty inches apart, and from an inch to two inches in depth. The seeds are planted from three to six inches apart; the distance in the drills, as well as the space between the drills, being regulated by the habit of the variety cultivated.

If planted in hills, they should be three feet apart in one direction, and about two feet in the opposite. If the variety under cultivation is large and vigorous, four or five plants may be allowed to a hill; if of an opposite character, allow twice this number.

To raise Seed. - Leave a row or a few hills entirely unplucked. Seed is of little value when saved at the end of the season from a few scattered pods accidentally left to ripen on plants that have been plucked from time to time for the table.

\section{Varieties. -}

A half-dwarf, French variety. Plant strong Bagnolet. and vigorous, with remarkably large, deep green foliage; flowers bright lilac; the pods are straight, seven inches long, half an inch wide, streaked and spotted with purple when sufficiently grown for shelling in their green state, nankeenyellow when fully ripe, and contain six seeds, which are nearly straight, rounded at the ends, a little flattened on the sides, three fourths of an inch long, a fourth of an inch thick, and of a violet-black color, variegated or marbled with drab.

About sixteen hundred beans are contained in a quart; and, as the plants are vigorous growers, this amount of seed 
will be sufficient for three hundred feet of drill, or for nearly three hundred hills. If planted in drills, they should be made twenty inches apart, and two plants allowed to a linear foot.

The variety is not carly, and requires the entire season for its full perfection. When sown as soon as the weather is suitable, the plant will blossom in about seven weeks. In sixty days, pods may be plucked for use; and the crop will be ready for harvesting in fifteen weeks from the time of planting. For its green pods the seeds may be planted until the middle of July.

The Bagnolet is of little value as a shelled-bean, either green or ripe. As a string-bean, it is deservedly considered one of the best. The pods are produced in great abundance, and are not only tender, succulent, and well flavored, but remain long on the plants before they become tough and unfit for use. If the pods are plucked as they attain a suitable size, new pods will rapidly succeed, and the plants will afford a continued supply for several weeks.

Black-eyed

Plant fifteen inches high, less strong and vigorous than that of the Common Red-eyed China; the flowers are white; the pods are comparatively short, usually about five inches long, green and straight while young, straw-yellow when sufficiently advanced for shelling, yellow, thick, hard, and parchment-like when ripe, and contain five or six seeds, - these are white, spotted and marked about the eye with black, of an oblong form, usually rounded, but sometimes shortened at the ends, slightly compressed on the sides, and measure half an inch in length, and three eighths of an inch in thickness.

A quart contains fifteen lundred beans, and will plant a drill, or row, of two hundred feet, or a hundred and fifty hills. 
The variety is early. Sown at the commencement of the season, the plants blossomed in six weeks, produced pods for the table in seven weeks, pods for shelling in ten weeks, and ripened in eighty-seven days. It yields well, ripens off at once, and, on account of the thick, parchment-like character of the pods, suffers much less from wet and unfavorable seasons than many other sorts.

As a string-bean, it is of fair quality, good when shelled in the green state, and farinaceous and mild flavored when ripe.

A half-dwarf variety, growing from two to Blue Pod. three feet high, with a branching stem, deep green foliage, and white flowers. The pods are five inches long, pale green while young, light yellow as the season of maturity approaches, cream-white when fully ripe, and contain five or six seeds.

Its season is intermediate. The plants blossomed in seven weeks, afforded pods for stringing in eight weeks, green beans in ten or eleven weeks, and ripened in ninetyseven days from the time of sowing. It is a week earlier than the White Marrow, and ten days in advance of the Pea-bean. Plantings may be made as late as the last week in June, which will yield pods for the table in seven weeks, and ripen the middle of September, or in about twelve weeks.

The ripe seed is white, oblong, flattened, rounded on the back, often squarely or angularly shortened at the ends, half an inch long, and a fourth of an inch thick. Twenty-seven hundred will measure a quart.

It is a field rather than a garden variety, though the green pods are tender and well flavored. If planted in drills two feet apart, five pecks of seed will be required for an acre; or four pecks for the same quantity of ground, if the rows are 
two feet and a half apart. If planted in hills, six or eight seeds should be put in each, and, if the hills are three feet apart, twelve quarts of seed will plant an acre.

The Blue Pod is the earliest of the field varieties; more prolific, more generally cultivated, and more abundant in the market, than either the Pea-bean or the White Marrow. It is, however, much less esteemed, and, even in its greatest perfection, is generally sold at a lower price.

On account of its precocity, it is well suited for planting in fields of corn, when the crop may have been partially destroyed by birds or insects, and the season has too far advanced to admit of a replanting of corn. In field culture, Blue-pod beans are planted till the 25th of June.

Canada Yel- The plants of this variety are from fourteen low.

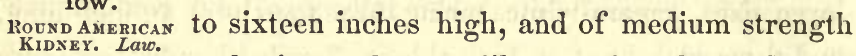

and vigor; flowers lilac-purple; the pods are five inches long, nearly straight, green while young, yellow at maturity, and contain from four to six seeds.

Season intermediate. If sown early, the plants will blossom in six or seven weeks, supply the table with pods in eight weeks, green shelled beans in ten weeks, and ripen off in ninety days. When planted after settled warm weather, the variety grows rapidly, and ripens quickly; blossoming in less than six weeks, and ripening in seventy days, from the time of planting. For green shelled beans, the seeds may be planted till the middle of July.

The ripe seeds are of an ovoid or rounded form, and measure half an inch in length and three eighths of an inch in thickness. They are of a yellowish-drab color, with a narrow, reddish-brown line about the eye; the drab changing, by age, to dull nankeen-yellow. About seventeen hundred are contained in a quart, and this amount of seeds will plant two hundred and fifty feet of drill, or a hundred and seventyfive hills. 
The variety is quite productive, and excellent as a shelledbean, green or dry. The young pods are not so tender as those of many other sorts, and are but little used.

Plant sixteen or eighteen inches high, sturdy Chilian. and vigorous, with large, deep green, wrinkled foliage; flowers pale lilac; the pods are five inches and a half long, slightly curved, pale green while young, yellowish-white when ripe, and contain five seeds.

Planted early in the season, the variety blossomed in seven weeks, yielded pods for the table in about eight weeks, and ripened in a hundred days, from the time of planting.

The ripe seeds are of a clear, bright pink, or rose color, gradually becoming duller and darker from the time of harvesting. They are kidney-shaped, a little flattened, and of large size; generally measuring three fourths of an inch long, and three eighths of an inch thick. Twelve hundred and fifty are contained in a quart, and will be sufficient for planting a row, or drill, of two hundred feet, or for a hundred and twenty-five hills.

The variety is healthy and productive; much esteemed for the tender, pulpy character of the young pods, and worthy of cultivation for the large size and good quality of the beans, which, either in the green or ripe state, are quite farinaceous and mild flavored.

Height fourteen or fifteen inches; flowers white, - the upper petals slightly stained with Crescenteyed. HALF Moov. red; the pods are five inches and a half long, pale green and somewhat curved when young, yellowish-white when fully ripe, and contain five seeds.

Season intermediate. If planted early, the variety will blossom in seven weeks, yield pods for stringing in eight weeks, supply the table with green beans in eleven weeks, 
and ripen in about ninety days. When planted and grown under the influence of summer weather, pods may be plucked for the table in fifty days, and the crop will ripen in about twelve weeks.

The beans, when ripe, are white, with a large, rose-red patch about the eye, the colored portion of the surface being striped and marked with brownish-red. The fine rose-red changes by age to a brownish-red, and the red streaks and markings become relatively duller and darker; they are somewhat kidney-shaped, and measure three fourths of an inch in length and three eighths of an inch in thickness. A quart contains nearly thirteen hundred seeds, and will plant a hundred and fifty hills, or a row of two hundred feet.

The variety yields well, and the green pods are tender and well flavored. It is, however, generally cultivated for its seeds, which are of large size and excellent quality, whether used in a green or ripe state.

Drab Tam-

Plant eighteen inches to two feet in height, pico.

producing slender, barren runners in the manner of the Turtle Soup and Newington Wouder, to which class the variety evidently belongs.

The flowers are purple; the pods are five inches long, green while young, brownish-yellow when ripe, and contain from six to eight seeds, which, with the exception of their light drab color, resemble those of the Turtle Soup.

Planted May 20th; the variety blossomed July 12th, and was ready for harvesting August 20th.

The Drab Tampico is very productive, and the young pods are tender and excellent for the table. The green seeds are of little value, but the ripe beans may be used in all the forms of the Turtle Soup and Newington Wonder.

Dun-colored. Plant of vigorous, branching habit, sixteen 
inches in height, with broad, deep green foliage and purplishwhite flowers; the pods are five inches and a half long, half an inch broad, green and nearly straight while young, yellow and slender when fully ripe, and contain five or six beans.

The ripe seeds are dun-colored or dark drab, usually with a greenish line encircling the eye, kidney-shaped, five eighths of an inch long, and about a fourth of an inch thick. A quart contains about seventeen hundred beans, and will plant a row of two liundred and twenty-five feet, or a hundred and seventy-five hills.

It is one of the earliest of the dwarf varieties. The plants blossomed in six weeks, produced young pods in seven weeks, and ripened in eighty-five days, from the time of sowing. Planted after settled warm weather, pods were gathered for use in six weeks; and for these the seeds may be sown until the 1st of August.

As a shelled-bean, green or dry, it is of little value, and hardly worthy of cultivation. As an early string-bean, it is one of the best. The pods are not only succulent and tender, but suitable for use very early in the season. It is also quite prolific, and, if planted at intervals of two weeks till the last of July, will supply the table to the last of September.

The variety has long been cultivated in England and other parts of Europe, and is much esteemed for its hardiness and productiveness.

Plant vigorous; and, if the variety is pure, Dwarf Cranstrictly a Dwarf, growing about sixteen inches berry. ligh. As generally found in gardens, the plants send out slender runners, eighteen inches or two feet in length. The flowers are pale purple; the pods are five inches long, sickle-shaped, pale green in their young state, nearly white when ripe, and contain five or six seeds.

The ripe seeds are smaller than those of the running vari- 
ety, but of the same form and color. Sixteen hundred are contained in a quart, and will plant nearly two hundred feet of drill, or a hundred and seventy-five hills.

The genuine Dwarf Cranberry is not one of the earliest varieties, but rather an intermediate sort. Sown as soon as the weather was suitable, the plants were in flower in seven or eight weeks, and young pods were gathered for use in nine weeks. In favorable seasons, the crop will be ready for harvesting in about ninety days. If planted in June, the variety will ripen in ten weeks.

It is hardy and productive, and the young pods are not only succulent and tender, but are suitable for use at a more advanced stage of growth than those of most varieties. The beans, in their green state, are farinaceous and well flavored, but, after ripening, are little used, the color being objectionable.

A variety with a brownish-red, oval, flattened seed, half an inch in length, is extensively known and cultivated as the Dwarf Cranberry. It is ten or twelve days earlier, the plants are smaller and less productive, the young pods less tender and succulent, and the seeds (green or ripe) less farinaceous, than those of the true variety. With the exception of its earlier maturity, it is comparatively not worthy of cultivation. Dwarf Horti-
cultural.

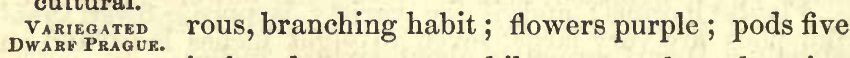
inches long, green while young, but changing to. yellow, marbled and streaked with brilliant rose-red, when sufficiently advanced for shelling in their green state. At maturity, the clear, pale yellow is changed to brownishwhite, and the bright red variegations are either entirely obliterated, or changed to dull, dead purple. If well formed, the pods contain five (rarely six) seeds. 
It is a medium or half-early sort; planted at the commencement of favorable weather, it blossomed in seven weeks, produced pods for the table in eight weeks, and ripened in ninety-five or a hundred days. Planted and grown in summer weather, the variety produced green pods in seven weeks, and ripened in ninety days.

The ripe seeds resemble those of the running variety in form and color; but they are smaller, a little more slender, and usually flattened slightly at the sides. When pure, they are egg-shaped; and a much compressed or a longer and more slender form is indicative of degeneracy. Fourteen hundred beans are contained in a quart; and this quantity of seed will be sufficient for planting a row of a hundred and seventy-five feet, or a hundred and forty hills.

The Dwarf Horticultural Bean is quite productive, and the young pods are tender and of good quality. It is, however, not so generally cultivated for its young pods as for its seeds, which are much esteemed for their mild flavor and farinaceous quality. For shelling in the green state, it is one of the best of the Dwarfs, and deserves cultivation.

A half-dwarf, French variety, two and a half Dwarf Sabre. to three feet high. As the running shoots are DWarp Casequite slender, and usually decay before the crop

KNIFE. DWARF Cimeter. matures, it is always cultivated as other Dwarf sorts. Foliage large, wrinkled, and blistered; the flowers are white; the pods are very large, seven to eight inches long, and an inch in width, often irregular and distorted, green while young, paler as the season of maturity approaches, brownish-white when ripe, and contain seven or eight seeds.

The ripe bean is white, kidney-shaped, flattened, often twisted or contorted, three fourths of an inch in length, and three eighths of an inch in width. About twelve hundred are contained in a quart. As the variety is a vigorous 
grower, and occupies much space, this quantity of seed will plant a row of two hundred feet, or two hundred and twentyfive hills.

Season intermediate. The plants biossomed in seven weeks, produced young pods in about eight weeks, pods for shelling in their green state in twelve weeks, and ripened in ninety-seven days, from the time of sowing. If cultivated for its green pods, the seeds may be planted to the middle of July.

The Dwarf Sabre is one of the most productive of all varieties, yielding its long, broad pods in great profusion. From the spreading, recumbent character of the plants, the pods often rest or lie upon the surface of the ground; and, being unusally thin and delicate, the crop often suffers to a considerable extent from the effects of rain and dampness in unfavorable seasons.

The young pods are remarkable for their tender and sueculent character; and the beans, both in a green and dried state, are mild and well flavored. It is hardy, productive, of good quality, and recommended for cultivation.

\section{Dwarf Sois- A half-dwarf, French bean, similar in habit sons.}

to the Dwarf Sabre. While young, the plants produce slender runners, two feet or more in length; but, as they are generally of short duration, the variety is cultivated as a Common Dwarf. The flowers are white; pods six inches long, pale green at first, cream-yellow when sufficiently advanced for shelling, dull cream-white when fully ripe, and contain five, and sometimes six, beans.

The variety is comparatively early. Plants, from seeds sown in spring, blossomed in six weeks, produced pods for use in seven weeks, and ripened in ninety days. Planted and grown in the summer months, the crop was ready for harvesting in eleven weeks; sowings for the ripe seeds may be made till the beginning of July. 
The seeds are white, kidney-shaped, flattened, often bent or distorted, five eighths of an inch long, three eighths of an inch wide, and a fourth of an inch thick. Fifteen hundred are contained in a quart, and will plant a drill two hundred and twenty-five feet in length, or about two hundred hills.

The variety is productive, and the young pods are of fair quality; the seeds are excellent, whether used green or ripe; the skin is thin, and they are much esteemed for their peculiar whiteness, and delicacy of flavor.

Plant fifteen inches high, with yellowish- Early China. green, wrinkled foliage, and white flowers; CHINA. REDthe pods are five inches long, green and straight while young, yellowish-green as they approach maturity, yellow when fully ripe, and contain five (rarely six) beans.

The ripe seeds are white, colored and spotted about the eye with purplish-red, oblong, nearly cylindrical at the centre, rouncel at the ends, six tenths of an inch long, and three eighths of an inch thick. Sixteen hundred and fifty measure a quart, and will plant two hundred feet of drill, or two hundred hills.

Plants from seeds sown early in the season blossomed in six weeks, afforded young pods for use in seven weeks, green beans in ten weeks, and ripened in eighty-five days. Planted and grown in summer, the crop ripened in eleven weeks; and plants from seeds sown as late as the first of August afforded an abundant supply of tender pods from the middle to the close of September.

The Early China is very generally disseminated, and is one of the most popular of the Dwarf varieties. It is hardy and productive; but the young pods, though succulent and tender, are inferior to those of some other varieties. The seeds, green or ripe, are thin skinned, mealy, and mild flavored. 
Early Rachel. A low-growing, branching variety, twelve to fifteen inches high; flowers white; the pods are five inches and a half long, green while young, becoming paler or greenish-yellow as they approach maturity, cream-white when ripe, and contain five seeds.

Planted early in the seasou, the variety blossomed in about seven weeks; and in eight weeks the young pods were fit for use. Pods for shelling were plucked in ten weeks, and the crop ripened in eighty days. For the green pods, the seeds may be planted till the middle or twentieth of July.

The ripe seed is yellowish-brown, white at one of the ends, kidney-shaped, often abruptly shortened, five eighths of an inch long, and a fourth of an inch thick. Nearly two thousand are contained in a quart.

The Early Rachel is hardy, and moderately productive, and, as an early string-bean, may be desirable; but as a shell-bean, green or dry, it is of little value. In common with many other early sorts cultivated as string-beans, the pods, though crisp and tender at first, soon become too tough and parchment-like for use. In general, the pods of the later sorts remain crisp and tender a much longer period than those of the earlier descriptions. Early Valen- Plant about sixteen inches high, with small,
tine.

valenting. yellowish-green leaves and white flowers; the pods are comparatively short, usually four and a half or five inches long, sickle-shaped, almost cylindrical, green while young, yellow when ripe, and contain five seeds.

The variety is productive, and quite early, though not one of the earliest. Sown at the commencement of the season, the plants blossomed in six weeks, produced pods for use in about seven weeks, and ripened in thirteen weeks, or ninety days, from the time of planting. Planted after the 
beginning of summer weather, pods were gathered for the table in fifty days, and the beans ripened in eleven weeks.

The seeds, when ripe, are of a pale pink color, marbled or variegated with rose-red, becoming duller and browner by age, oblong, nearly straight, sometimes distorted and irregular as if pressed out of their natural shape, often more or less shortened at the ends, five eighths of an inch long, three eighths of an inch wide, and about the same in thickness. A quart will contain eighteen or nineteen hundred seeds, which will be sufficient for a hundred and seventy-five hills, or for a drill, or row, of two hundred or two hundred and twenty-five feet.

The Early Valentine has little merit as a shelled-bean, green or ripe; but of nearly seventy of the most popular of the native, as well as foreign sorts, experimentally grown, no one excelled it in the tender and succulent character of the pods in the green state. Though these are of moderate size, they are remarkable for their thick, fleshy sides, and for the length of time required for the development of the seeds within. Few, if any, of the dwarfs harden their pods so slowly, or continue longer in condition for use, and few are more productive.

It has long been grown in England and other parts of Europe, and is common to gardens in almost every section of the United States.

A variety, imported from France, about twenty years since, and known as the "Excelsior," strongly resembles, if it is not identical with, the Early Valentine. The plants are similar in habit; the pods have the same form, and solid, fleshy character; and the seeds, in their ripe state, are of the same size and color.

Height about sixteen inches ; flowers purple ; Golden Cranthe pods are five inches and a half long, five ROUDADANE KIDNEY. 
eighths of an inch broad, somewhat irregular in form, yellow when ripe, and contain five seeds.

Season intermediate. Early plantings blossomed in seven weeks, yielded pods for the table in eight weeks, and ripened in ninety days.

The ripe seeds are pale greenish-yellow, with an olivegreen line encircling the eye; roundish-ovoid, three eighths of an inch long, and nearly the same in thickness. A quart contains nearly eighteen hundred seeds, and will plant a row, or drill, of two hundred feet, or two hundred and twenty-five hills.

As a string-bean, or for shelling in the green state, it is inferior to many other varieties, and is little cultivated for use in these forms ; but as a variety for baking, or for cooking in any form when ripe, it is much esteemed, and recommended for cultivation.

Hardy and productive.

Long Yellow The plants of this familiar variety are of Six-weeks.

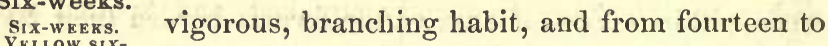
YELLOW SIX-

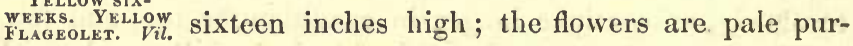
ple; the pods are five inches long, six tenths of an inch broad, often curved or sickle-shaped, green at first, gradually becoming paler, cream yellow when ripe, and contain five (rarely six) beans.

It is one of the earliest of the Dwarf varieties. Spring plantings were in blossom in six weeks, produced pods for the table in seven weeks, and ripened in eighty-seven days. Sown in summer, the plants afforded pods for the table in about six weeks, and ripened in sixty-three days. Planted as late in the season as the last of July or first of August, the variety afforded an abundant supply of tender pods from the middle to the last of September.

The ripe seeds are pale yellowish-drab, with an olive-green 
line about the eye, the drab rapidly changing by age to dull yellowish-brown. They are kidney-shaped, rather straight, three fourths of an inch long, and three tenths of an inch thick. About fourteen hundred beans are contained in a quart, and will plant a row of two hundred feet, or a hundred and fifty hills.

It is quite productive, and an excellent early string-bean, but less valuable as a green shelled-bean, or for cooking when ripe. On account of the tender and delicate character of the pods, the ripe seeds are often injured by damp or continued rainy weather. A popular, early garden-bean, much cultivated both in this country and in Europe.

Stem about eighteen inches high, sturdy and Mohawk. branching; foliage large, deep green, wrinkled, EARLY MOHAW. and blistered; flowers pale lilac; the pods are five inches and a half long, five eighths of an inch wide, and generally contain fiye seeds. While young they are green, and nearly straight; as they approach maturity they become paler, and, when ripe; are frequently streaked and spotted with purple.

The ripe seeds are variegated with drab, dull purple, and different shades of brown, the brown and dull purple prevailing; they are kidney-shaped, and measure nearly three fourths of an inch in length, and three eighths of an inch iu width. A quart contains about fourteen hundred and fifty seeds, and will plant a hundred and seventy-five feet of drill, or a hundred and seventy-five hills.

It is about a week later than the earliest varieties. Plants from seeds sown early in spring were in blossom in about seven weeks, produced pods for the table in eight weeks, and ripened in a hundred days, from the time of sowing. In ordinary seasons, the variety will ripen perfectly if planted the last week in June, and will yield an abundance of pods 
for the table, if the planting be made as late in the season as the last of July.

The Early Mohawk is quite productive, and one of the hardiest of the Dwarf varieties. It is well adapted for early planting, and is extensively grown by market-gardeners as an early string-bean. The young pods are comparatively tender, and of good quality, and, if gathered as they become of suitable size, the plants will continue to yield them in great abundance. The shelled-beans, green or dry, are less esteemed, and considered inferior to many other varieties.

Negro Long- Plant strong and vigorous, about two feet pod.

high, sending out a few slender, running shoots, like the Rob Roy and Newington Wonder. The flowers are purple; the pods are from six to seven inches long, rather narrow, but of even breadth, uniformly green till near maturity, brownish-yellow when ripe, and contain from six to eight slender, rather small, nearly straight, but somewhat kidney-shaped, glossy-black seeds, about half an inch in length.

Planted May 20th, the variety blossomed July 8th, and the crop ripened August 10th.

The Negro Long-pod is one of the most productive of all the Dwarfs, yielding its long, slender, and succulent pods in profuse abundance. The green seeds, however, are seldom used, but the ripe seeds would probably furnish an excellent substitute for the Turtle-soup and Tampico, though of little value in other forms of cookery.

The variety is of foreign origin, and is common to gardens, both in France and England. A sub-variety, known as the Dwarf Negro, less stocky in habit, and with much smaller pods, is also a favorite in the markets of London. The Long-podded, however, is considered much superior to the old Dwarf; but both are highly prized for the narrow, 
handsome form of the young pods, and for their uniformly fine green color.

A healthy, vigorous variety, with deep green foliage and bright purple flowers. The plants Newington
Wonder. often produce slender, barren runners, eighteen inches or two feet in length; but they are generally of short duration, and the variety is treated as other Dwarfs.

The pods are small and straight, usually about four inches long, and nearly half an inch broad. They are pale green at first, and afterwards change to yellowish-white, tinted or washed with bright pink. At maturity they are dusky drab, sometimes clouded or shaded with purple, and contain six or seven beans.

The ripe seeds are pale brownish-drab, with a yellowishbrown line about the eye, oblong, flattened, shortened at the ends, nearly half an inch long, and a fourth of an inch deep. About thirty-six hundred are contained in a quart. As the seeds are comparatively small, and the plants of spreading habit, this amount of seeds will plant a row four hundred feet in length, or four hundred hills.

The variety is not early, and, when cultivated for its seeds, should have the benefit of the whole season; though, with favorable autumnal weather, the crop will ripen if planted the middle of June. Spring plantings blossomed in eight weeks, produced young pods in nine weeks, and ripened in a hundred and six days.

The Newington Wonder is remarkably prolific, and, in its manner of growth and general character, resembles the Tampico, or Turtle-soup. As a string-bean, it is one of the best. The pods, though not large, are crisp, succulent, and tender, and produced in great abundance throughout most of the season. The seeds, in their green state, are small, and of little value for the table; when ripe, they afford an excellent 
substitute for the Tampico, or Turtle-soup, the difference, aside from the color, being scarcely perceptible.

The Newington Wonder of English and French authors appears to be, in some respects, distinct from the American variety. It is described as very dwarf, about a foot high, early and productive ; pods dark green, moderately long, not broad, thick, and fleshy ; seeds quite small, light chestnutcolored.

Nonpareil. The plants of this variety are strong and vigorous, and somewhat resemble the Mohawk, or White Kidney, growing about eighteen inches high, with numerous, erect branches; the flowers are white; the pods are five and a half or six inches long, green at first, cream yellow at maturity, and contain five or six seeds.

Planted the 20th of May, the variety was in flower July 9th, and ripened August 12th, or in eighty-four days from the time of planting.

The ripe seeds are strongly kidney-shaped, nearly three fourths of an inch long, white, with a broad and somewhat irregular patch of red about the eye, and numerous spots of the same color upon the back and sides. About fourteen hundred are contained in a quart, and this amount of seed will plant a hundred and seventy-five feet of drill, or a hundred and fifty hills.

The variety is comparatively new. It is not only hardy and remarkably productive, but the young pods are tender and excellent, and the seeds, green or ripe, are surpassed by few, if any, of the Dwarf sorts, in mildness and delicacy of flavor.

Pea-bean. Plant vigorous, much branched, and, like the Blue Pod and White Marrow, inclined to send up running shoots; foliage comparatively small, deep green; flowers 
white; the pods are about four inches long, half an inch wide, nearly straight, green when young, paler as they approach the season of ripening, yellowish when fully ripe, and contain five beans.

It is comparatively a late variety. When planted early in spring, it blossomed in fifty days, afforded green pods in fifty-eight days, and ripened in about fifteen weeks. In favorable autumns, it will ripen if planted as late as the 20th of June; but it is not so early as the Blue Pod or White Marrow, and, when practicable, should have the advantage of the entire season.

The ripe seeds of the pure variety are quite small, roundish-ovoid, five sixteenths of an inch long, a fourth of an inch in width and thickness, and of a pure, yet not glossy, white color. About forty-four hundred seeds are contained in a quart.

As a garden variety, it is of little value, though the young pods are crisp and tender. It is cultivated almost exclusively as a field-bean. If planted in rows or drills two feet apart, three pecks of seeds will be required for an acre; or eighteen quarts will seed this quantity of land, if the rows are two feet and a half apart. When planted in hills, eight seeds are allowed to a hill; and, if the hills are made three feet apart, eight quarts will plant an acre. The yield varies from fourteen to twenty bushels, according to soil, season, and cultivation.

The Pea-bean, the White Marrow, and the Blue Pod are the principal, if not the only, kinds of much commercial importance; the names of other varieties being rarely, if ever, mentioned in the regular reports of the current prices of the markets. If equally well ripened, and, in their respective varieties, equally pure, the Pea-bean and the White Marrow command about the same prices; the former, however, being more abundant in the market than the latter. 
By many, and perhaps by a majority, the Pea-bean is esteemed the best of all baking varieties.

Pottawottomie.

The plants of this variety are remarkable for their strong, vigorous habit, and large, luxuriant foliage. The flowers are flesh-white; the pods are six inches long, green at first, then mottled and streaked with lively rose-red on a cream-white ground (the markings changing to purple at maturity), and contain five (rarely six) seeds.

The variety is comparatively late. Plants from seeds sown early in the season were in flower in seven weeks, afforded pods for shelling in eleven weeks, and ripened in a hundred days, from the time of planting.

The ripe seeds are of a light creamy pink color, streaked and spotted with red or reddish-brown; the soft, flesh-like color, however, soon becomes duller and darker, and at last gives place to a dull, cinnamon-brown. They are kidneyshaped, fully three fourths of an inch long, and about three eighths of an inch broad. About a thousand will measure a quart, and will plant a row two hundred feet in length, or a hundred and twenty-five hills. On account of the large size and spreading habit of the plants, five seeds will be sufficient for a hill, and in the rows they should be dropped five or six inches from each other.

The young pods are inferior to most varieties in crispness, and tenderness of texture, and are comparatively but little used. The seeds are remarkably large, separate easily from the pods, and, green or ripe, are very farinaceous and well flavored, nearly or quite equalling the Dwarf and Running Horticultural.

A half-dwarf, French Bean, two to three feet Scartet Flage- high; flowers pale purple; the pods are six 
inches and a half long, somewhat curvęd, green while young, pale yellow at maturity, and contain five or six seeds.

It is one of the latest of the Dwarf varieties. Plants from seeds sown early in the season were in flower in seven weeks, and pods were gathered for use in nine weeks; in thirteen weeks the pods were sufficiently advanced for shelling, and the crop was ready for harvesting in a hundred and ten days. For its full perfection it requires the whole season; but for its young pods, or for green beans, plantings may be made to the last week in June.

The ripe beans are blood-red when first harvested, but gradually change by age to deep purple; they are kidneyshaped, nearly straight, slightly flattened, three fourths of an inch long, three eighths of an inch broad, and nearly the same in thickness. Fifteen hundred seeds are contained in a quart.

The Red Flageolet yields abundantly, and the young pods are not only of good size, but remarkably crisp and tender. If plucked as they become fit for use, the plants continue to produce fresh pods for many weeks. The green beans are farinaceous, and excellent for table use, but are seldom cooked in their ripened state.

Plant branching, and of strong growth, nearly a foot and a half high; foliage reRedspeckled. markably large; flowers pale purple; the pods are five inches and a half long, nearly straight, green while young, paler, with occasional marks and spots of purple, when more advanced, yellowish-white when ripe, and contain five (rarely six) seeds.

Season intermediate. Plants from seeds sown after settled warm weather blossomed in six weeks, and green pods were plucked for use in fifty days. Pods for shelling in their green state were gathered in ten weeks, and the crop ripened 
off in ninety days. For its young pods, or for green beans, plantings may be made to the last week in June; but the crop will not mature, unless the weather continues favorable, till the first of October.

The ripe seeds are variegated with deep red and pale drab, the red predominating; kidney-shaped, nearly straight, three fourths of an inch long, and three tenths of an inch deep. A quart contains fourteen hundred and fifty seeds, and will plant a row of two hundred and twenty-five feet, or a hundred and fifty hills.

The variety is hardy and productive. It is extensively cultivated as a garden-bean in England and France, and has been common to the gardens of this country for nearly two centuries. The young pods are of medium quality; but the seeds, green or dry, are mealy and well flavored. On account of the parchment-like character of the pods, the seeds seldom suffer from the effects of wet weather.

Refugee. Plant sixteen to eighteen inches high, and Thougand To ONE.

readily distinguished from most varieties by its small, smooth, deep green, and elongated leaves; flowers purple; pods five inches long, nearly cylindrical, pale green while young, greenish-white streaked with purple when sufficiently advanced for shelling, yellow when ripe, and usually yielding five beans.

The Refugee is not an early sort. The plants blossomed in seven weeks, produced young pods in eight weeks, and ripened in eighty-seven days, from the time of sowing. Plantings for the ripened product may be made till the middle of June, and for the green pods, to the middle of July.

The ripe seeds are light drab, with numerous spots and broad patches of bright purple, nearly straight, cylindrical at the middle, tapering to the ends (which are generally rounded), five eighths of an inch long, and three tenths of au 
inch thick. Eighteen hundred and fifty are contained in a quart, and will plant a row two hundred and fifty feet in length, or two hundred hills.

The variety is hardy, yields abundantly, and the young pods are thick, fleshy, and tender in texture. As a stringbean, or for pickling, it is considered one of the best of all varieties, and is recommended for general cultivation. The seeds are comparatively small, and are rarely used either in a green or ripened state.

Half-dwarf, about two feet high ; flowers Rice. vil. white; the pods are very small, scarcely more than three inches in length, only two fiftls of an inch in width, and usually contain six seeds.

The variety requires a full season for its perfection. Plants from seeds sown early in spring were in flower in seven weeks, yielded young pods in ten weeks, and ripened in a hundred and twelve days.

The ripe seeds are very small, and of a peculiar yellowishwhite, semi-transparent, rice-like color and appearance. They are quite irregular in form, usually somewhat oblong or ovoid, often abruptly shortened at the ends, three eighths of an inch long, and a fourth of an inch thick. Nearly five thousand are contained in a quart.

The young pods are tender and excellent; but the green beans are small, and rarely used. The ripe seeds are peculiar, both in consistency and flavor; they are quite brittle and rice-like, and, when cooked, much relished by some, and little esteemed by others.

Plant lialf-dwarf, - early in the season, proRob Roy. ducing slender, transient, barren runners two or three feet in length ; flowers purplish-white; the pods are five inches long, often produced in pairs, yellow as they approach ma- 
turity, yellowish-white when ripe, and contain five or six seeds.

It is one of the earliest of the Dwarfs. Spring plantings blossomed in six weeks, produced pods for the table in seven weeks, and ripened in eighty-two days. Planted in June, pods were plucked for use in six weeks, and the crop was ready for harvesting in sixty-eight days.

The ripe seeds are clear bright yellow; the surface being generally veined, and the eye surrounded with an olive-green line. They are of an oblong form, nearly straight on the side of the eye, rounded at the back, five eighths of an inch long, and three tenths of an inch deep. Fifteen hundred seeds are contained in a quart, and will be sufficient to plant a row of two hundred feet, or a hundred and fifty hills.

The Rob Roy generally matures in great perfection, being seldom stained or otherwise injured by rain or the dampness of ordinary seasons. It is also one of the earliest of the Dwarf varieties, but desirable as a string-bean rather than for its qualities as a green shelled-bean, or for cooking when ripe. If cultivated for its pods only, plantings may be made until the first of August.

Round Yel- Fourteen to sixteen inches high ; flowers pale low Six-

Weeks.
Round YELLow. purple; the pods are about five inches long, half DWARE YELLOW. an inch broad, pale yellowish-green as they approach maturity, and, when fully ripe, remarkably slender, and more curved than in their green state. They contain five or six beans.

The variety is early, blossoming in six weeks, producing young pods in seven weeks, and ripening in ninety days, from the time of planting. When planted in June, pods may be plucked for use in seven weeks, and the crop will be ready for harvesting in eighty days. For its green pods, plantings may be made to the last of July. 
The ripe seeds are orange-yellow, with a narrow, reddishbrown belt, or line, encircling the eye ; oblong or ovoid; half an inch long, and three tenths of an inch thick. A quart contains two thousand seeds, and will plant a row two hundred and twenty-five feet in length, or two hundred and twenty-five hills.

As an early string-bean, the variety is worthy of cultivation, but is little used, and is really of little value, as a shelled-bean, green or ripe. It has been common to the gardens of this country for more than a century; and, during this period, no apparent change has taken place in the character of the plant, or in the size, form, or color of the seed.

A French variety. The ripe seeds are sim- Solitaire. ilar to those of the Refugee; but the plants are quite distinct in foliage and general habit. Its height is about eighteen inches; the flowers are purple; the pods are six inches long, slender, nearly cylindrical, green at first, paler and streaked with purple when more advanced, and contain six seeds.

It is not early. Spring plantings were in blossom in sixty days, produced pods for the table in seventy days, and ripened in about fifteen weeks. It may be planted for its green pods until the first of July.

The beans, when ripe, are variegated with light drab and deep purple, the purple prevailing. They are often straight, sometimes curved, nearly cylindrical at the eye, usually rounded, but sometimes shortened, at the ends, three fourths of an inch long, and a fourth of an inch thick. Two thousand measure a quart.

On account of the size and branching character of the plants, more space must be allowed in cultivation than is usually given to Common Dwarf varieties. If planted in 
rows, they should be at least eighteen inches apart, and the plants eight or ten inches from each other in the rows; and, if planted in hills, they should be thinned to four or five plants, and the hills should not be less than three feet apart.

It is not much esteemed as a shelled-bean, either green or ripe. As a string-bean, it is one of the best. Its pods are long, cylindrical, remarkably slender, succulent, and tender. It is also a very prolific variety, and the pods remain for an unusual period without becoming tough or too hard for the table. Recommended for cultivation.

Swiss Crim- Plant vigorous, often producing running son. straight, six inches long, pale green while young, yellow streaked with brilliant rose red as they approach maturity, and containing five (rarely six) seeds.

It is comparatively a late variety. If planted as early as the weather will permit, the plants will blossom in seven weeks, the young pods will be ready for use in nine weeks, and the crop will be ready for harvesting in a hundred and five days. Planted and grown in summer weather, it produced young pods in sixty days, and ripened in thirteen weeks. Plantings for the green seeds may be made to the first of July.

The ripe seeds are clear bright pink, striped and spotted with deep purplish-red; the pink changes gradually to dull, dark red, and the variegations to dark brown. They are kidney-shaped, comparatively straight, somewhat flattened, three fourths of an inch long, and three eighths of an inch broad. Thirteen hundred seeds are contained in a quart, and will plant a row two hundred feet in length, or a hundred and fifty hills.

It is hardy and productive, and, as a shelled-bean, of 
excellent quality, either in its green or ripened state. As a variety for stringing, it is not above medium quality.

Plant vigorous, producing numerous, slender, Turtle-soup. barren runners two feet or more in length;

TAMPICO.

flowers rich deep purple; the pods are five inches long, green and sickle shaped while young, pale greenish-white stained with purple when more advanced, yellow clouded with purple when ripe, and contain five or six seeds.

The variety is quite late, and requires most of the season for its full perfection. Plants from early sowings blossomed in eight weeks, the young pods were sufficiently grown for use in ten weeks, and the crop ripened in a hundred and eight days. As the young pods are tender and of excellent quality, and are also produced in great abundance, a planting for these may be made as late as the last week in June, which will supply the table from the last of August till the plants are destroyed by frost.

The ripe seeds are small, glossy-black, somewhat oblong, and much flattened. Thirty-six hundred are contained in a quart, and will plant four hundred feet of drill, or three hundred and fifty hills.

It is very productive, and deserving of cultivation for its young and tender pods, but is of little or no value for shelling while green. The ripened seeds are used, as the name implies, in the preparation of a soup, which, as respects color and flavor, bears some resemblance to that made from the green turtle.

This is one of the earliest of the Dwarf va- Victoria. rieties. Plants from early sowings were in blossom in six weeks, yielded pods for the table in seven weeks, produced pods of suitable size for shelling in ten weeks, and ripened in eighty-four days. When planted after the season had 
somewhat advanced, - the young plants thus receiving the benefit of summer temperature, - pods were gathered for the table in about six weeks, and the crop ripened in sixtythree days.

Stalk fourteen to sixteen inches high, with comparatively few branches; flowers purple; pods four and a half to five inches long, streaked and spotted with purple, tough and parchment-like when ripe, and containing five or six seeds.

The ripe seeds are flesh-colored, striped and spotted with purple (the ground changing by age to dull reddish-brown, and the spots and markings to chocolate-brown), oblong, somewhat flattened, shortened or rounded at the ends, five eighths of an inch long, and three tenths of an inch thick. Fourteen hundred are contained in a quart.

The variety is remarkably early, and on this account is worthy of cultivation. For table use, the young pods and the seeds, green or dry, are inferior to many other sorts. Farly.

FEJEx.
White's

A remarkably hardy and vigorous variety, eighteen to twenty inches high. Flowers white, tinged with purple; pods five inches and a half long, curved or sickle-shaped, green at first, yellowish-white striped with purple when fully ripe, and containing five seeds.

Early plantings will blossom in about six weeks, young pods may be plucked for use in seven weeks, and the crop will ripen in eighty-two days. If planted as late in the season as the first week in July, the variety will generally ripen perfectly; and, when cultivated for its green pods, plantings may be made at any time during the month.

The ripe seeds are either drab or light slate, - both colors being common, - marked and spotted with light drab. In some specimens, drab is the prevailing color. They are kidney-shaped, irregularly compressed or flattened, nearly three fourths of an inch long, and three eighths of an inch deep. 
A quart contains about sixteen hundred seeds, and is sufficient for planting a row two hundred and fifty feet in length, or two hundred hills.

This variety, as an early string-bean, is decidedly one of the best, and is also one of the hardiest and most prolific. The pods should be plucked when comparatively young, and, if often gathered, the plants will continue a long time in bearing. As a shelled-bean, either in its green or ripened state, it is only of medium quality.

The long peduncles, or stems, that support its spikes of flowers, its stocky habit, and fine, deep green, luxurious foliage, distinguish the variety from all others.

From sixteen to eighteen inches high, of strong and branching habit. Flowers white; White Flageolet. the pods are five inches and a half long, sickle-shaped, green while young, yellowish-white at maturity, and contain six (rarely seven) seeds.

It is a half-early variety; blossoming in six weeks, yielding pods for the table in seven weeks, pods for shelling in eleven weeks, and ripening in ninety days, from the time of plantiug. Later plantings will ripen in a shorter period, or in about eighty days, and, if cultivated as a string-bean, seed sown as late in the season as the last week of July will supply the table from the middle of September with an abundance of well-flavored and tender pods.

The ripe bean is white, kidney-shaped, flattened, three fourths of an inch long, and three tenths of an inch broad. About twenty-two hundred are contained in a quart, and will plant a drill, or row, of two hundred and seventy-five feet, or nearly three hundred hills.

The White Flageolet is very productive, and is recommended for cultivation; the young pods are crisp and tender, and the seeds, green or ripe, are farinaceous, and remarkable for delicacy of flavor. 
White Kid- The plants of this variety are from sixteen to ney.

\section{KIDNEY.}

LARGE WHITE

KIDNEY.

eighteen inches high, and readily distinguishable, from their large and broad leaves, and strong, branching habit of growth; the flowers are white; the pods are somewhat irregular in form, six inches long, green at first, yellow when ripe, and contain five (rarely six) beans.

The White Kidney-bean is not early; it blossomed in seven weeks, produced young pods in nine weeks, pods for shelling in eleven weeks, and ripened in a hundred and ten days, from the time of planting.

The ripe seeds are white, more or less veined, pale yellow about the hilum, kidney-shaped, nearly straight, slightly flattened, fully three fourths of an inch long, and about three eighths of an inch thick. From twelve to thirteen hundred are contained in a quart, and this quantity of seeds will plant a hundred and seventy-five feet of drill, or a hundred and forty hills.

As a string-bean, the variety has little merit; but as a shelled-bean, green or ripe, it is decidedly one of the best of the Dwarfs, and well deserving of cultivation. The seeds are of large size, pure white, separate readily from the pods, and are tender and delicate. White Mar- Plants vigorous, much branched, and inclined
row.

WHTE MARRow- to produce running shoots; flowers white ; pods

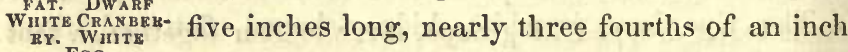
broad, pale green at first, then changing to clear yellow, afterwards becoming pure waxen-white, cream-yellow when ripe, and containing five seeds.

Planted at the commencement of favorable weather, the variety blossomed in seven weeks, yielded pods for the table in eight weeks, and ripened in a hundred and five days. When grown for the ripened product, the planting should not 
be delayed beyond the 20 th of June. Planted at this season, or the last week in June, the crop will blossom the first week in August, and about the middle of the month, pods may be gathered for the table. By the second week in September, the pods will be of sufficient size for shelling; and, if the season be ordinarily favorable, the crop will ripen the last of the month. It must not, however, be regarded as an early variety, and, when practicable, should be planted before the 10th of June.

The ripe seeds are clear white, ovoid or egg-shaped, nine sixteenths of an inch long, and three eighths of an inch thick. In size, form, or color, they are scarcely distinguishable from those of the White Running Cranberry. If well grown, twelve hundred seeds will measure a quart.

As a string-bean, the White Marrow is of average quality; but for shelling in the green state it is surpassed by few, if any, of the dwarf varieties, as the large seeds not only separate readily from the pod, but are remarkably white and well flavored. As a garden-bean, it deserves more general cultivation. When ripe, it is very farinaceous, of a delicate fleshy-white when properly cooked, and by many preferred to the Pea-bean.

In alınost every section of the United States, as well as in the Canadas, it is largely cultivated for market, and is next in importance to the last named for commercial purposes.

In field culture, it is planted in drills two feet apart, the seeds being dropped in groups, three or four together, a foot apart in the drills. Some plant in hills two and a half or three feet apart by eighteen inches in the opposite direction, seeding at the rate of forty-four quarts to the acre ; and others plant in drills eighteen inches apart, dropping the seeds singly, six or eight inches from each other in the drills.

The yield varies from twenty to thirty bushels to the acre, though crops are recorded of nearly forty bushels. 
Yellow-eyed

Plant sixteen to eighteen inches high, more China.

branched and of stronger habit than the Black or Red-eyed; flowers white; the pods are six inches long, nearly straight, pale green while young, cream-white at maturity, and contain five or six seeds.

It is an early variety. Sown in May, or at the beginning of settled weather, the plants blossomed in six weeks, afforded string-beans in seven weeks, pods for shelling in ten or eleven weeks, and ripened in ninety days, from the time of planting. From sowings made later in the season (the plants thereby receiving more directly the influence of summer weather), pods were plucked for the table in about six weeks, and ripened beans in seventy-five days. Plantings for supplying the table with string-beans may be made until the last week in July.

The ripe beans are white, spotted and marked about the eye with rusty yellow, oblong, inclining to kidney-shape, more flattened than those of the Red or Black-eyed, five eighths of an inch long, and three eighths of an inch in breadth. Fifteen hundred and fifty are contained in a quart, and will plant two hundred feet of drill, or a hundred and fifty hills. The plants are large and spreading, and most productive when not grown too closely together.

The Yellow-eyed China is one of the most healthy, vigorous, and prolific of the Dwarf varieties; of good quality as a string-bean, and, in its ripened state, excellent for baking, or in whatever manner it may be cooked. It also ripens its seeds in great perfection; the crop being rarely affected by wet weather, or injured by blight or mildew.

Pole or Running Beans.

As a class, these are less hardy than the Dwarfs, and are not usually planted so early in the season. The common 
practice is to plant in hills three feet or three and a half apart; though the lower growing sorts are sometimes planted in drills fourteen or fifteen inches apart, and bushed in the manner of the taller descriptions of peas.

If planted in hills, they should be slightly raised, and the stake, or pole, set before the planting of the seeds. The maturity of some of the later sorts will be somewhat facilitated by cutting or nipping off the leading runners when they have attained a height of four or five feet.

Plant of healthy, vigorous habit, attaining a California. height of six feet and upwards. The flowers are white; the pods are long, comparatively broad and flat, green at first, cream-yellow at maturity, and contain from six to eight seeds.

Planted May 20th, the variety blossomed July 12th, green pods were plucked for use July 24 th, and the crop ripened the middle of August.

The ripe seeds are of a clear ochre-yellow color, broadly kidney-shaped, five eighths of an inch long, and three eighths of an inch in width. If well grown, one thousand will measure a quart; and this amount of seed will be sufficient for a hundred hills.

The California Bean is hardy and productive, yielding its long and broad pods in great abundance till destroyed by frost. Though much used as a string-bean, it is principally valued for the excellent quality of the seeds in their green state.

From reliable authority, the variety is grown to a considerable extent on the Pacific coast of South America, in some parts of California, and also in the Sandwich Islands.

The true name appears to be wanting. Though it is popularly known in this section of the country as the "California," the name seems to have been given in accordance 
with a custom, much too prevalent, of applying the term to whatever fruits, flowers, or vegetables may have been originally received from the State of California.

Case-knife. This variety, common to almost every garden, is readily distinguished by its strong and tall habit of growth, and its broad, deep green, blistered leaves. The flowers are white; the pods are remarkably large, and often measure nine or ten inches in length, and nearly an inch in width; they are of a green color till near maturity, when they change to yellowish-green, and, when fully ripe, to creamwhite. A well-formed pod contains eight or nine seeds.

Early plantings blossomed in seven or eight weeks, yielded pods for stringing in about ten weeks, green beans in twelve or thirteen weeks, and ripened in a hundred and five days. Later plantings, with the exclusive advantage of summer weather, yielded green pods in seven weeks, pods for shelling in eight or nine weeks, and ripened in ninety-six days. Plantings for the green beans may be made till nearly the middle of July, and for the young pods to the 25th of the month.

The ripe seeds are clear white, kidney-shaped, irregularly flattened or compressed, often diagonally shortened at one or both of the ends, three fourths of an inch long, and three eighths of an inch deep. A quart contains about fifteen hundred seeds, and will plant a hundred and seventy-five hills.

It is one of the most prolific of the running varieties. As a shelled-bean, it is of excellent quality in its green state, and when ripe, farinaceous, and well flavored in whatever form prepared. The large pods, if plucked early, are succulent and tender, but coarser in texture than those of many other sorts, and not so well flavored.

The Case-knife, in its habit and general appearance, much 
resembles the Sabre, or Cimeter, of the French, and perhaps is but a sub-variety. Plants, however, from imported Sabre-beans, were shorter, not so stocky, a little earlier, and the pods, generally, less perfectly formed.

Plant six feet and upwards in height, of Concord. healthy, vigorous habit; flowers white; the pods are comparatively short and broad, measuring about four inches in length, and three fourths of an inch in breadth; they are green at first, afterwards greenish-yellow, brownish-white at maturity, and contain five seeds, which have the form of the Horticultural, from which variety the Concord appears to have been derived; these seeds are white with a patch of yellowish-drab about the eye, the colored portion of the surface being spotted and marked with bright rose-red.

It is one of the earliest of the running sorts. Planted May 20th, the variety was in flower July $8 \mathrm{th}$, and began to ripen August 10th.

The young pods are comparatively tough and stringy, and less valuable for the table than many other sorts; but as a shelled-bean, green or ripe, it is one of the best of the running varieties. The plants are healthy growers, attach themselves readily to the poles, and yield very abundantly; the seeds separate easily from the pods, are farinaceous and of pleasant flavor. Recently introduced, and recommended for cultivation.

Stem six feet and upwards in height; flowers Corn-bean. bright lilac; the pods are five inches and a half long, green while young, cream-white at maturity, and contain six or seven seeds.

The variety is late, but remarkable for hardiness and productiveness. The shelled-beans, green or ripe, are little used; the young pods are crisp, succulent, and excellent for 
the table, and the variety deserves more general cultivation. If plucked as fast as they become of suitable size, the plants will continue to produce them in abundance for six or eight weeks.

The ripe seeds are chocolate-brown, somewhat quadrangular, flattened, half an inch long, and three eighths of an inch broad. In size and form they somewhat resemble grains of Indian corn, whence the name. Twelve hundred and fifty seeds are contained in a quart, and will plant a hundred and twenty-five hills.

Horticultural.

MaRBLed

Prafue. Vil.

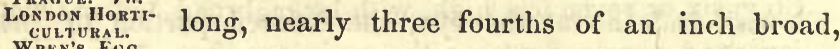
WREN'S EQG.

pale green while young, greenish-white streaked and blotched with brilliant rose-red when more advanced, much contorted, hard, parchment-like and very tenacious of their contents when ripe, and enclose five or six seeds.

Planted at the commencement of the season, the variety blossomed in about seven weeks, produced pods for stringing in nine weeks, green beans in twelve weeks, and ripened in a hundred days. Plantings made during the last week in June will mature their crop, if the season be favorable. For the green beans, plantings may be made until the last of June, and for the young pods until the first of July.

The ripe beans are flesh-white, streaked and spotted with bright pink, or red, with a russet-yellow line encircling the eye. They are egg-shaped, rather more than half an inch in length, and four tenths of an inch in width and depth. From the time of ripening, the soft, flesh-like tint gradually loses its freshness, and finally becomes cinnamon-brown, the variegations growing relatively duller and darker. A quart contains about eleven hundred seeds, and will plant a hundred and twenty-five hills. 
The Horticultural Bean was introduced into this country from England about the year 1825. It has now become very generally disseminated, and is one of the most popular of the running sorts. As a string-bean, it is of good quality; shelled in its green state, remarkably farinaceous and well flavored, and, when ripe, one of the best for baking or stewing. It is hardy and productive, but is liable to deteriorate when raised many years in succession from seed saved in the vegetable garden from the scattered pods accidentally left to ripen on the poles. To raise good seed, leave each year a few hills unplucked, allowing the entire product to ripen.

Stem six or seven feet high, with large, broad Indian Chief. foliage and purple flowers; the pods are five inches long, nearly as thick as broad, sickleWAX-BEAN. BUTTER-BEAN. Algerian. FRKNCH. shaped, green at first, but soon change to a fine, waxen, semitransparent cream-white, - the line marking the divisions being orange-yellow. At this stage of growth, the color indicates approaching maturity; but the pods will be found crisp and succulent, and are in their greatest perfection for the table. When ripe, they are nearly white, much shrivelled, and contain six or seven seeds.

When cultivated for the ripened product, the seed should be planted as early in the season as the weather will permit. The plants will then blossom in eight or nine weeks, afford young pods in about eleven weeks, pods for shelling in thirteen or fourteen weeks, and ripen in a hundred and twenty-four days. Plantings for green pods may be made until the first of July.

At the time of harvesting, the seeds are deep indigo-blue, the hilum being white. They are oblong, often shortened abruptly at the ends, half an inch long, nearly the same in depth, and three tenths of an inch thick. Fourteen hundred 
seeds measure a quart, and will plant a hundred and seventyfive hills.

The Indian-chief Bean is remarkable for its fine, tender, succulent, and richly-colored pods, and for these it is well worthy of cultivation. They are not only produced in profuse abundance, but continue fit for use longer than those of most varieties. In moist seasons, they remain crisp and tender till the seeds have grown sufficiently to be used in the green state. The ripe seeds are of little value.

The real merits of the variety appear to be little known; yet of all the running sorts cultivated for the green pods, it must be classed as one of the best.

Mottled Case-knife.

Plant six feet and upwards in height, but much less stocky and vigorous than the true Case-knife; the foliage is also smaller, and less wrinkled or blistered; the flowers are white, stained or clonded with purple; the pods have the form of those of the Case-knife, but are neither so long nor so broad.

The variety is comparatively early. Planted May 30th, the vines blossomed July 17th, green pods were plucked July 26th, and the crop ripened the middle of August, or in eighty days from the time of planting.

The seeds are strongly kidney-shaped, white or creamwhite striped and spotted with bluish-slate, and of the size of those of the White Case-knife.

Though less productive than the last named, it is nearly two weeks earlier, and the green pods are more succulent and tender. The seeds separate easily from the pods, and in their green state are esteemed for mildness and delicacy of flavor. variety. The flowers are white; the pods are 
short and broad, four inches and a half long, three fourths of an inch wide, yellow at maturity, and contain four or five seeds.

If planted early, the variety will blossom in seven weeks, yield pods for the table in eight or nine weeks, green beans in eleven weeks, and ripen in a hundred days. When planted after settled warm weather, it will ripen in ninety days.

The ripe seeds are white, the eye surrounded with a broad patch of purple, which is also extended over one of the ends; they are of a rounded-oval form, half an inch long, and three eighths of an inch in width and thickness. A quart contains fourteen hundred and fif:y seeds, and will plant a hundred and fifty hills. As the plants are of dwarfish character, the seeds are sometimes sown in drills, a quart being required for two hundred feet.

The Mottled Cranberry is moderately productive, and the young pods are tender and well flavored; the seeds, while green, are farinaceous, and, though of good quality when ripe, are but little used.

Plant branching, healthy, and vigorous, six Mottled feet or more in height; flowers purple; the Prolific. pods are four inches and a half long, usually produced in pairs, green at first, washed with purple when more advanced, light brown at maturity, and contain six seeds.

It is a late variety. Plantings made during the first of the season will not produce pods for use until the last of July, or beginning of August; but, if these are plucked as they become of suitable size, the plants will continue in bearing until destroyed by frost.

The ripe beans are drab, thickly and minutely spotted with black, and also distinctly marked with regular lines of the same color. They are of an oblong form, flattened, often 
squarely or diagonally shortened at the ends, nearly half an inch in length, and three tenths of an inch in width. A quart contains thirty-one hundred seeds, and will plant about three hundred hills.

As a shelled-bean, in its green or ripened state, the variety has little merit. Its recommendations are its fine, tender pods, its remarkable productiveness, and its uniformly healthy habit.

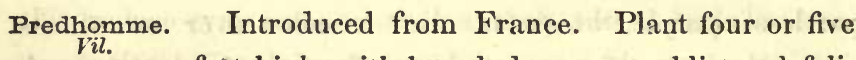

feet high, with broad, deep green, blistered foliage, and white flowers; the pods are nearly cylindrical, three inches long, green while young, cream-white when ripe, and contain from six to eight seeds, set very closely together.

The ripe beans are dull white, veined, oblong, often shortened at the ends, a third of an inch long, and nearly a fourth of an inch in width and thickness. A quart contains about thirty-five hundred seeds, and will plant three hundred and fifty hills.

Early plantings blossomed in eight weeks, afforded pods for the table in about ten weeks, and ripened in a hundred and eight days. It may be planted for its green pods to the first of July.

It is of little value as a shelled-bean in its green state. When ripe, it is of good quality, and, as a string-bean, one of the best, the pods being very brittle, succulent, and fine flavored. They remain long upon the plants without becoming tough and hard, and are tender, and good for use, until almost ripe. On account of their thin and delicate eharacter, the seeds, in unfavorable seasons, are often stained and otherwise injured by dampness at the time of ripeuing.

Princess.

Vil.

A French variety. Plant six feet or more in height, with lively green foliage and white 
flowers; the pods are five inches long, pale green while young, yellow at maturity, and contain six or seven, and sometimes eight, seeds.

The ripe bean is white, egg-shaped, two fifths of an inch long, and a fourth of an inch thick. Nearly three thousand are contained in a quart, and will plant three hundred and fifty lills.

The variety somewhat resembles the Prédhomme; but the seeds are larger and brighter, the pods are longer, the seeds are less close in the pods, and it is some days earlier. It ripens in about three months from the time of planting. A good sort for stringing, and of excellent quality when ripe.

This is one of the oldest and most familiar of garden-beans, and has probably been longer

Red Cranberry.

and more generally cultivated in this country than any other variety.

The plants are five or six feet high, of medium strength and vigor; flowers pale lilac. The pods are quite irregular in form, - often reversely curved, or sickle-shaped; four inches and a half long; yellowish-green while young; clear white when suitable for shelling; yellowish-white, shrivelled, and contorted, when ripe; and contain five or six seeds.

Its season is intermediate. Planted the 10th of May, the variety blossomed in seven weeks, yielded young pods in nine weeks, green beans in eleven weeks, and ripened in ninety-five days. In favorable seasons, the erop will ripen if the seeds are planted the last of June; but, for the young pods or for green beans, plantings may be made to near the middle of July.

Seeds clear, deep purple, the hilum white, round-ovoid, slightly compressed, half an inch long, and about three eighths of an inch in depth and thickness. Fourteen hun- 
dred and fifty seeds are contained in a quart, and will plant a hundred and fifty hills.

It is a hardy and productive variety, principally grown as a string-bean. The pods are succulent and tender; and these qualities are retained to a very advanced stage of growth, or until quite of suitable size for shelling. The dark color of the bean, which is to some extent imparted to the pods in the process of cooking, is by some considered an objection, and the White Cranberry, though perhaps less prolific, is preferred. As a shelled-bean, it is of good quality in its green state, but in its ripened state little used, though dry and farinaceous.

Red Orleans. Five to six feet high; flowers white; the SCARLET ORLEASS. pods are sickle-shaped, five inches long, green when young, often tinged with red when more advanced, yellow at full maturity, and contain five or six seeds, packed closely together.

It is one of the earliest of the running varieties. Spring plantings blossomed in about seven weeks, afforded pods for the table in eight weeks, green beans in eleven weeks, and ripened in eighty-five days. Planted later in the season, pods sufficiently large for stringing were gathered in six weeks, and the crop began to ripen in about seventy days. As a string-bean, the variety may be planted until the first of August.

At the time of harvesting, the ripe seeds are of a bright blood-red color, but change rapidly by age to brownish-red. They are of an oblong form, often squarely or diagonally shortened at the ends by contact with each other in the pods, half an inch long, and three tenths of an inch broad. A quart, which contains nearly twenty-four hundred seeds, will plant about two hundred and seventy-five hills.

The Red Orleans is quite prolific, and a desirable sort for 
soups and stews. The young pods are tender and well flavored; but its remarkable precocity must be considered its chief recommendation.

French writers describe the ripe seeds as exceeding the above dimensions; but specimens received from Paris seedsmen correspond in size, form, and color with the description before given.

Plant seven feet and upwards in height, with Rhode Island large, broad, deep green, wrinkled foliage ; flowers rose-white; the pods are six inches long, nearly three fourths of an inch broad, green while young, paler when more advanced, cream-white and much shrivelled when ripe, and contain seven seeds.

If planted early in the season, green pods may be plucked for the table in nine or ten weeks, pods for shelling in twelve weeks, and the crop will ripen in a hundred and twenty-three days. Planted early in June, the pods will generally all ripen; but, if the planting is delayed to the last of the month, the crop will but partially mature, unless the season prove more than usually favorable. The vines will, however, yield a plentiful supply of pods, and also of green beans.

The seeds, at maturity, are cream-yellow, with welldefined spots and stripes of deep yellowish-buff. They are broad-kidney-shaped, flattened, five eighths of an inch long, and nearly half an inch broad. The cream-yellow gradually changes by age to brown, and the markings become relatively darker. Fourteen hundred seeds are contained in a quart, and will plant a hundred and fifty hills.

The variety yields abundantly, and the large pods are tender, succulent, and excellent for table use. The beans, in their green state, are of good quality, though little used when ripe. 
Sabre, or Stem seven or eight feet high; leaves broad, Cimeter. large, deep green, and much wrinkled or corrugated; flowers white; the pods are large, broad, and thin, curved at the ends in the form of a sabre, or cimeter, green when young, cream-white when ripe, and contain eight beans.

The variety blossomed in eight weeks, afforded young pods for the table in ten weeks, green beans in eleven weeks, and ripeued in a hundred days, from the time of planting. Sown in June, the crop matured in ninety days. Plantings for the green seeds may be made till the last of June, and for the young pods to the middle of July.

The ripe seeds are clear white, kidney-form, three fourths of an inch long, and three eighths of an inch broad. Sixteen hundred are contained in a quart, and will plant a hundred and sixty hills.

The Sabre Bean is remarkably productive : the young pods are crisp and tender, excellent for table use, and good for pickling; the seeds, green or dry, are farinaceous, and of delicate flavor and appearance.

In height and foliage, size and form of the pods, color and size of the ripe seeds, it resembles the Case-knife. The principal difference between the varieties is in the carlier maturity of the Sabre.

Soissons.

Introduced from France. Stem six feet or Vil. more high; foliage large, broad, wrinkled; flowers white; the pods are eight inches long, three fourths of an inch broad, sword-shaped, yellowish-green when near maturity, yellowish-white when ripe, and contain six or seven seeds.

The variety requires the whole season for its full perfection. If planted early, it blossoms in nine weeks, produces young pods in eleven weeks, and ripens off in gradual succession till the plants are destroyed by frost. If cultivated 
for its young pods, plantings may be made to the last week in June.

The ripe seeds are remarkably large, - often measuring nearly an inch in length, and half an inch in breadth, - pure, glossy white, kidney-shaped, and generally irregularly compressed. Seven hundred are contained in a quart, and will plant about eighty hills.

The young pods, while quite young and small, are crisp and tender, and the ripe seeds are farinaceous and well flavored. It is also an excellent sort for shelling in the green state; but the plants are not hardy, and thrive well only in warm soil and sheltered situations. Under ordinary culture, many of the pods are imperfect, and frequently contain but two or three seeds.

Stem five or six feet high ; flowers white; White Cranthe pods are five inches and a half long, pale berry. green while young, striped and marbled with red when near maturity, yellowish-buff when ripe, and contain five or six beans.

It is not an early variety. From plantings made at the usual season, young pods were gathered in about nine weeks, pods for shelling green in twelve weeks, and ripened beans in a hundred and five days. For stringing, or for shelling in a green state, the variety may be planted the first of July; but in ordinary seasons few of the pods will reach maturity.

The ripe seeds are white, egg-shaped, sometimes nearly spherical, half an inch long, and three eighths of an inch in breadth and thickness. In size, form, and color, they strongly resemble the Dwarf White Marrow, and are not easily distinguished from the seeds of that variety. About twelve hundred and fifty are contained in a quart, and will plant a hundred and twenty-five hills. 
The White Cranberry is hardy, yields well, and the young pods are tender and well flavored. For shelling green, it is decidedly one of the best of all varieties, and for baking, or otherwise cooking, is, when ripe, fully equal to the Pea-bean or White Marrow.

wild-goose. Plant seven or eight feet high, of healthy, vigorous habit; flowers bright purple; the pods are sickleshaped, pale green at first, cream-yellow streaked and marbled with purple when ripe, and contain six seeds, closely set together.

The variety requires the entire season for its full perfection. When planted early, it will blossom in nine weeks, produce young pods in eleven weeks, green beans in thirteen weeks, and ripen in a hundred and twenty days. If planted and grown under the influence of summer weather, the plants will blossom in seven weeks, yield young pods in nine weeks, green beans in twelve weeks, and ripen in a hundred days. Plantings for the green seeds may be made to the middle of June, and for the young pods to the first of July.

The ripe beans are pale cream-white, spotted with deep purplish-black (the cream-white gradually changing by age to cinnamon-brown), round-ovoid, four tenths of an inchlong, and about three eighths of an inch in width and thickness. A quart contains nearly seventeen hundred seeds, and will plant two hundred hills.

The variety has been long cultivated both in Europe and this country. It is hardy and productive. The young pods are of fair quality, and the seeds, green or ripe, are excellent for table use, in whatever form prepared. Yellow Cran- Five to six feet high, with yellowish-green
berry.

foliage and pale purple flowers; the pods are five inches long, three fourths of an inch broad, often sickle- 
shaped; pale green at first; cream-yellow, shrivelled, and irregular in form, like those of the Red variety, at maturity, and contain five or six seeds.

It is a few days later than the White Cranberry, and nearly two weeks later than the Red. Planted at the commencement of the season, it blossomed in eight weeks, yielded pods for the table in about ten weeks, pods for shelling in twelve or thirteen weeks, and ripened in a hundred and ten days. Early summer plantings blossomed in seven weeks, produced pods for the table in less than nine weeks, and ripened in about a hundred days. When grown for the ripened crop, it should have the advantage of the entire season; but, when cultivated for its young pods, plantings may be made till the first of July.

The seeds are yellow, with a narrow, dark line encircling the hilum, round-ovoid, half an inch long, and three eighths of an inch in breadth and thickness. Thirteen hundred and fifty are contained in a quart, and will plant a hundred and twenty-five hills.

The variety is hardy and prolific, of good quality as a string-bean, or for shelling in the green state. When ripe, the seeds are nearly equal to the White Marrow for baking, though the color is less agreeable.

\section{ASPARAGUS-BEAN.}

Long-podded Dolichos. Dolichos sesquipedalis.

The Asparagus-bean, in its manner of growth, inflorescence, and in the size and character of its pods, is quite distinct from the class of beans before described. It is a native of tropical America, and requires a long, warm season for its full perfection.

The stem is from six to seven feet high; the leaves are 
long, narrow, smooth, and shining; the flowers are large, greenish-yellow, and produced, two or three together, at the extremity of quite a long peduncle; the pods are nearly cylindrical, pale green, pendent, and grow with remarkable rapidity, - when fully developed, they are eighteen or twenty inches long, and contain eight or nine seeds.

These should be sown as early in spring as the appearance of settled warm weather, and the plants will then blossom in ten or eleven weeks, afford pods for use in fourteen weeks, and ripen off their crop in gradual succession until destroyed by frost.

The ripe seeds are cinnamon-brown, with a narrow, dark line about the hilum; kidney-shaped, half an inch long, and a fourth of an inch broad. Nearly four thousand are contained in a quart, and will plant four hundred and fifty hills.

The seeds are quite small, and are rarely eaten, either in a green or ripe state. The variety is cultivated exclusively for its long, peculiar pods, which are crisp, tender, of good flavor, and much esteemed for pickling. It is, however, much less productive than many of the running kinds of garden-beans, and must be considered more curious than really useful.

A species or variety, known as the Chinese Long Pod, produces pods of much greater length, often measuring nearly three feet.

\section{LIMA BEAN.}

Phaseolus lunatus.

Stem ten feet or more in height; leaves comparatively long and narrow, smooth and shining; flowers small, greenish-yellow, in spikes; the pods are four inches and a half long, an inch and a quarter broad, much flattened, green 
and wrinkled while young, yellowish when ripe, and contain three or four beans.

The Lima is one of the latest, as well as one of the most tender, of all garden-beans, and seldom, if ever, entirely perfects -its crop in the Northern States. Little will be gained by very early planting, as the seeds are not only liable to decay before vegetating, but the plants suffer greatly from cold, damp weather. In the Northern and Eastern States, the seeds should not be planted in the open ground before the beginning of May; nor should the planting be delayed beyond the tenth or middle of the month. In ordinary seasons, the Lima Bean will blossom in eight or nine weeks, and pods may be plucked for use the last of August, or beginning of September. Only a small proportion of the pods attain a sufficient size for use; a large part of the crop being prematurely destroyed by frost.

The ripe seeds are dull white or greenish-white, with veins radiating from the eye; broad-kidney-shaped, much flattened, seven eighths of an inch long, and two thirds of an inch in width. A quart contains about seven hundred seeds, and will plant eighty hills.

The pods are tough and parchment-like in all stages of their growth, and are never eaten. The seeds, green or ripe, are universally esteemed for their peculiar flavor and excellence, and by most persons are considered the finest of all the garden varieties. If gathered when suitable for use in their green state, and dried in the pods in a cool and shaded situation, they may be preserved during the winter. When required for use, they are shelled, soaked a short time in clear water, and cooked as green beans; thus treated, they will be nearly as tender and well flavored as when freshly plucked from the plants.

The seeds are sometimes started on a hot-bed, in thumbpots, or on inverted turf, or sods, cut in convenient pieces, 
and about the last of May, if the weather is warm and pleasant, transplanted to hills in the open ground.

By the following method, an early and abundant crop may be obtained in comparatively favorable seasons :-

"As soon in spring as the weather is settled, and the soil warm and in good working condition, set poles about six feet in length, three feet apart each way, and plant five or six beans in each hill, - being careful to set each bean with its germ downward, and covering an inch deep. After they have grown a while, and before they begin to run, pull up the weakest, and leave but three of the most vigorous plants to a hill. As these increase in height, they should, if necessary, be tied to the stakes, or poles, using bass-matting, or other soft, fibrous material, for the purpose. When they have ascended to the tops of the poles, the ends should be cut or pinched off, as also the ends of all the branches, whenever they rise above that height. This practice checks their liability to run to vines, and tends to make them blossom earlier, and bear sooner and more abundantly, than they otherwise would do."

When cultivated in the vicinity of the Sieva, the varieties readily intermix or hybridize; and unless a fresh supply of seed is procured every year or two, the Lima rapidly degenerates. If raised for a succession of years, in northern latitudes, from seeds of northern growth, the variety gradually becomes earlier; but the plants decline in stockiness and vigor, and the pods and seeds yearly decrease in size, until the Lima is little, if at all, superior to some of the improved forms of the Sieva.

Plants from seeds of southern growth are generally healthy and vigorous, and produce beans of remarkable size and excellence; but the pods develop slowly, and comparatively few reach full maturity.

In tropical climates, the Lima Bean is perennial. 
A sub-variety of the Common Lima, differing Green Lima. principally in the pea-green color of the seeds.

As generally found in the market, the seeds of the Common and Green Lima are more or less intermixed. By some, the Green is considered more tender, and thought to remain longer on the plants without becoming hard, than the White. The habits of the plants are the same, and there is no difference in the season of maturity. A careful selection of seeds for planting, and skilful culture, would undoubtedly give a degree of permanency to this difference in color, which appears to be the principal, if not the only, point of variation.

This, like the Green, is a sub-variety of Mottled the Common Lima. The ripe seeds are dullLima. white, or greenish-white, mottled and clouded with purple.

In the habit of the plant, in the foliage, pods, form, or size of the seeds, or season of maturity, there are no marks of distinction when compared with the Common Lima.

\section{SCARLET-RUNNER.}

Phaseolus multiflorus.

From South America. Though nearly allied to the Common Kidney-bean, it is considered by botanists a distinct species, differing in its inflorescence, in the form of its pods, and particularly in the fact that the cotyledons, or lobes of the planted seed, do not rise to the surface of the ground in the process of germination. It is, besides, a perennial plant. The roots are tuberous, and, though small, not unlike those of the Dahlia.

If taken up before frost in the autumn, they may be preserved in a conservatory, or warm parlor or sitting-room, 
during winter, and reset in the open ground on the approach of warm weather, when new shoots will soon make their appearance, and the plants will blossom a second time early and abundantly.

The plants are twelve feet or more in height or length, with deep green foliage and brilliant scarlet flowers; the latter being produced in spikes, on long footstalks. The pods are six inches long, nearly an inch broad, somewhat hairy while young, sickle-shaped and wrinkled when more advanced, light reddish-brown when ripe, and contain four $\mathrm{Or}^{\circ}$ five seeds.

It requires the whole season for its perfection, and should be planted as early as the weather will admit. The plants will then blossom in seven or eight weeks, produce young pods in nine weeks, green seeds in twelve weeks, and ripen in a hundred and fifteen days.

The ripe seeds are lilac-purple, variegated with black, or deep purplish-brown, - the edge, or border, little, if any, marked; lilum long and white ; form broad-kidney-shaped; size large, - if well grown, measuring seven eighths of an inch long, six tenths of an inch broad, and three eighths of an inch thick. About five hundred and fifty are contained in a quart, and will plant eighty hills.

In this country, it is usually cultivated as an ornamental, climbing annual; the spikes of rich, scarlet flowers, and its deep green foliage, rendering the plant one of the most showy and attractive objects of the garden.

Though inferior to some of the finer sorts of garden-beans, its value as an esculent has not been generally appreciated. The young pods are tender and well flavored; and the seeds, green or ripe, are much esteemed in many localities. "In Britain, the green pods only are used; on the Continent, the ripened seeds are as much an object of culture; in Holland, the Runners are grown in every cottage-garden for both pur- 
poses; while in France and Switzerland, they are grown chiefly for the ripened seeds. In England, they occupy a place in most cottage-gardens, and are made both ornamental and useful. They cover arbors, are trained over pales and up the walls of cottages, which they enliven by the brightness of their blossoms, while every day produces a supply of wholesome and nutritious food for the owner. The French, now enthusiastically fond of this legume, at one time held it in utter detestation."

A sub-variety of the Scarlet-runner, with variegated flowers, the upper petals being Painted Lady-runner. scarlet, the lower white. The ripe seeds are paler, and the spots and markings duller. Cultivation and uses the same.

A variety of the Scarlet-runner. The plants White-Runare less vigorous, the pods are longer and less ner. wrinkled, and the flowers and seeds pure white.

The green pods are used in the same manner as those of the Scarlet-runner, and are similar in texture and flavor; but the shelled-beans, either green or ripe, are generally considered superior to those of the Scarlet variety. They are sometimes seen in vegetable markets under the name of the "Lima," and are probably often cultivated, as well as purchased and consumed, as the Lima. The White-runner beans, however, are easily distinguished by their greater thickness, more rounded form, and especially by their uniform whiteness. 


\section{S I E V A.}

Carolina. Saba. West-Indian. Small Lima. Carolina Sewee. Phaseolus lunatus var.

The Sieva is a variety of the Lima, and attains a height of ten or twelve feet. The leaves and flowers resemble those of the Common Lima. 'The pods, however, are much smaller, and remarkable for their uniform size, generally measuring three inches in length, and about seven eighths of an inch in width; they are green and wrinkled while young, pale yellowish-brown when ripe, and contain three, and sometimes four, seeds.

Though several days earlier than the Lima, the Sieva Bean requires the whole season for its complete maturity; and even when planted early, and receiving the advantage of a warm summer and a favorable autumn, it is seldom fully perfected in the Northern States; for, though much of the crop may ripen, a large portion, almost invariably, is prematurely destroyed by frost.

The variety blossomed in eight weeks from the time of planting, afforded pods for shelling in twelve weeks, and ripened from near the middle of September till destroyed by frost.

The seeds are white or dull yellowish-white, broad-kidney-shaped, much flattened, five eighths of an inch long, and nearly half an inch broad. A quart contains about sixteen hundred, and will plant a hundred and fifty hills.

The Sieva is one of the most productive of all varieties. The young pods, however, are tough and hard, and are never eaten. The beans, in their green or ripe state, are similar to the Lima, and are nearly as delicate and richly flavored. It is from two to three weeks earlier than the last named, and would yield a certain abundance in seasons when the Lima would uniformly fail. As a shelled-bean, green or 
dry, it must be classed as one of the best, and is recommended for cultivation.

A sub-variety of the Common Sieva; the Mottled principal, if not the only, mark of distinction is Sieva. in the variegated character of the seeds, which are dullwhite, spotted and streaked with purple.

It is sometimes described as being earlier than the Common variety; but, from various experiments in the cultivation of both varieties, there appears to be little if any difference in their seasons of maturity. The color and form of the flower are the same as the Sieva; the pods are of the same size and shape, and the leaves have the same elongated form, and smooth, glossy appearance.

Mr. John M. Ives states that the variety originated in Danvers, Essex County, Mass.

\section{CHICK-PEA.}

Egyptian Pea. Cicer arietinum.

The Chick-pea is $a^{\cdot}$ hardy, annual plant, originally from the south of Europe, but also indigenous to the north of Africa and some parts of Asia. The stem is two or three feet high, erect and branching; the leaves are pinnate, with from six to nine pairs of oval, grayish, toothed leaflets; the flowers resemble those of the Common Pea, and are produced on long peduncles, generally singly, but sometimes in pairs; the pods are about an inch long, three fourths of an inch broad, somewhat rhomboidal, hairy, inflated or bladder-like, and contain two or three globular, wrinkled, pea-like seeds.

Sowing and Cultivation. - The seed should be sown in April, in the manner of the Garden-pea; making the drills 
about three feet apart, an inch and a half deep, and dropping the seeds two inches asunder in the drills. All the culture required is simply to keep the ground between the rows free from weeds. The crop should be harvested before the complete maturity of the seeds.

Use. - "The Peas, though not very digestible, are largely employed in soups, and form the basis of the purée aux croutons, or bread and pea soup, so highly esteemed in Paris." They are also extensively used, roasted and ground, as a substitute for coffee.

There are three varieties, as follow :-

Red Chickpea. White Chick-
pea. similar to those of the other varieties.

Yellow Chick-pea. habit, differs little from the White or the Red-seeded.

\section{CHICKLING VETCH. Law.}

Lentil, of Spain. Cultivated Lathyrus. Lathyrus sativus.

Stem three or four feet high or long, attaching itself to trellises, branches, or whatever may be provided for its support, in the manner of Peas; the leaves are small and grasslike; the flowers are solitary, smaller than those of the Common Pea, and generally bright blue; the pods are an inch and a half long, three fourths of an inch broad, flattened, winged along the back, and enclose two compressed but irregularly shaped seeds, of a dun or brownish color, and p!easant flavor. 
Cultivation and Use. - The seeds are sown at the time and in the manner of the taller kinds of Garden-peas. The plant is principally cultivated for its seeds, the flour of which is mixed with that of wheat or rye, and made into bread. It is also fed to stock; and, in some localities, the plants are given as green food to horses and cattle.

"In 1671 , its cultivation and use were prohibited on account of its supposed pernicious properties, as it was thought to induce rigidity of the limbs, and to otherwise injuriously affect the system."

A variety with white flowers and seeds. The White-flowfoliage is also much paler than that of the Com- ered Chickmon Chickling Vetch.

Other species of the genus also produce farinaceous seeds suitable for food, but in too small quantities to admit of being profitably cultivated in this country.

\section{ENGLISH BEAN.}

Horse-bean. Garden-bean of the English. Vicia faba.

The English Bean differs essentially from the Common American Garden or Kidney Bean usually cultivated in this country, and is classed by botanists under a different genus, and not as a distinct species, as intimated in the "American Gardener." Aside from the great difference in their general appearance and manner of growth, the soil, climate, and mode of cultivation, required by the two classes, are very dissimilar; the American Garden-bean thrives best in a light, warm soil, and under a high temperature, and the English Bean in stiff, moist soil, and in cool, humid seasons.

The English Bean is a native of Egypt, and is said to be the most ancient of all the now cultivated esculents. It is 
an annual plant, with an upright, smooth, four-sided, hollow stem, dividing into branches near the ground, and growing from two to four feet and upwards in height. The leaves are alternate, pinnate, and composed of from two to four pairs of oval, smooth, entire leaflets; the flowers are large,

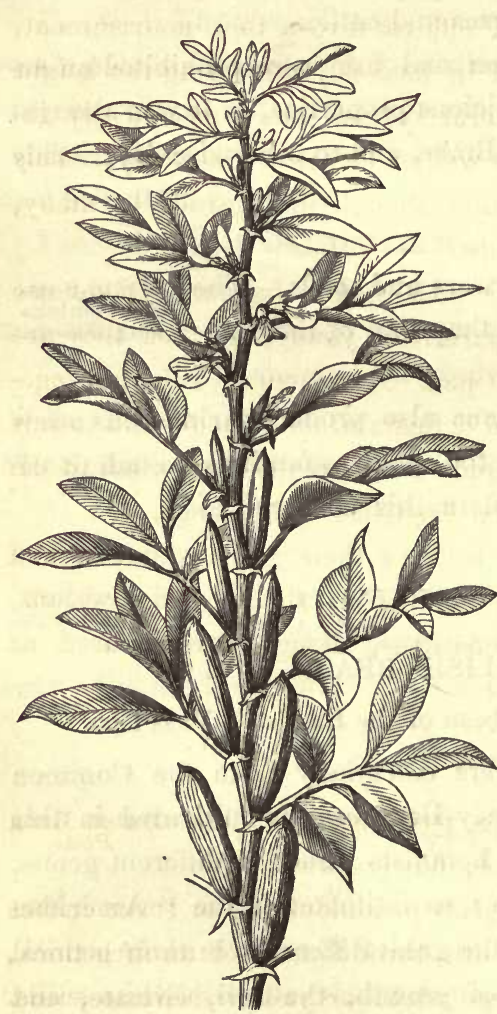

English Bean. nearly stemless, purple or white, veined and spotted with purplishblack ; the pods are large and downy; the seeds are rounded, or reniform, flattened, and vary to a considerable extent in size and color in the different varieties, - they will vegetate until more than five years old.

Soil and Planting. As before remarked, the English Bean requires a moist, strong soil, and a cool situation; the principal obstacles in the way of its successful cultivation in this country being the heat and drought of the summer. The seeds should be planted early, in drills two feet asunder for the smaller-growing varieties, and three feet for the larger sorts, - dropping them about six inches from each other, and covering two inches deep. A quart of seed will plant about a hundred and fifty feet of row or drill. 
Cultivation. - "When the plants have attained a height of five or six inches, they are earthed up slightly for support, and, when more advanced, they are sometimes staked along the rows, and cords extended from stake to stake to keep the plants erect. When the young pods appear, the tops of the plants should be pinched off, to throw that nourishment, which would be expended in uselessly increasing the height of the plant, into its general system, and consequently increase the bulk of crop, as well as hasten its maturity. This often recommended operation, though disregarded by many, is of very signal importance." - McInt.

Taking the Crop. - The pods should be gathered for use when the seeds are comparatively young, or when they are of the size of a marrowfat pea. As a general rule, all vegetables are most tender and delicate when young; and to few esculents does this truth apply with greater force than to the class of plants to which the English Bean belongs.

Use. - The seeds are used in their green state, cooked and served in the same manner as shelled kidney-beans. The young pods are sometimes, though rarely, used as string-beans.

\section{Varieties. -}

Plant from four to five feet high, dividing Dutch Long into two or three branches; flowers white; the pods are horizontal, or slightly pendulous, six or seven inches long, about an inch in width, three fourths of an inch thick, and contain five or six large white or yellowish-white seeds.

The variety is not early, but prolific, and of good quality.

A remarkably dwarfish, early variety, much employed in forcing. The stem is about a foot high, and separates near the ground into two or three branches; the flowers are white; the pods, which

\section{Dwarf Fan,} or Cluster.

EARLY DWART. BOG-BEAN. 
are produced in clusters near the top of the plant, are almost cylindrical, three inches long, three fourths of an inch thick, and contain three or four small, oblong, yellow seeds.

It is one of the smallest and earliest of the English Beans, and yields abundantly.

Early Dwarf Plant sixteen inches high, separating into Crimsonseeded.

VILMORIN's

DWARY REDtwo or three divisions, or branches; the flowers SEEDED. resemble those of the Common varieties, but are somewhat smaller; the pods are erect, three inches and a half long, three fifths of an inch wide, half an inch thick, and contain three or four seeds, closely set together, and nearly as large in diameter as the pod.

The ripe seeds 'are bright brownish-red or crimson, thick, shortened at the back, and depressed at the sides. Six hundred and fifty will measure a quart.

The variety is principally esteemed for its dwarfish habit and early maturity.

Early Maza-

This variety, though originally from Maza-

gan.
EarLy Malta. gan, on the coast of Africa, is one of the hardiest sorts now in cultivation. Stem from two to three feet high, and rather slender; pods four to five inches long, containing four or five whitish seeds.

The Early Mazagan is much less productive than many other sorts; but its hardiness and earliness have secured it a place in the garden, and it has been cultivated more or less extensively for upwards of a century.

Evergreen Long Pod. IICInt.

Green Genos.

GRER N LONG

Pod. GREEN

NONPAREIL.
This variety grows from three to four feet high. The pods are long, somewhat flattened, and generally contain four rather small, oblong, green seeds. It is an excellent bearer, of good quality, and but a few days later than the Common Long 
Pod. The variety is much esteemed on account of the fine green color of the beans, which, if gathered at the proper time, retain their green color when dressed.

In planting, make the drills three feet apart, and two inches and a half deep, and allow two plants for each linear foot.

From two to two feet and a half high; the Green China. pods are long, cylindrical, and contain three or four beans, which remain of a green color when dry. It is recommended for its great productiveness and late maturity.

Plant about three feet and a half high, usually divided into four branches; the pods are Green Julierect, four inches long, three fourths of an inch thick, and contain two or three small, oblong, green seeds.

Early and of good quality.

Stem three feet high, separating into two, Green Windand sometimes three, branches; the flowers are $\begin{gathered}\text { sor. } \\ \text { Torgr. }\end{gathered}$ white; the pods are erect, often horizontal, four inches and a half long, au inch and a quarter wide, and contain three large, green, nearly circular, and rather thick seeds.

The latter retain their fresh, green color till near maturity, and, to a considerable extent, when fully ripe, and on this account are found in the market, and used at table, after most other varieties have disappeared.

The variety resembles the Common Broad Windsor; but the seeds are smaller, and retain their green color after maturity. Eleven or twelve well-developed seeds will weigh an ounce.

- Stem from three to five feet high ; flowers variable in color; the ripe seeds are from a

Horse-bean. Law. 
half to five eighths of an inch in length by three eighths in breadth, generally slightly compressed on the sides, and frequently a little hollowed or flattened at the end, of a whitish or light brownish color, occasionally interspersed with darker blotches, particularly towards the extremities; eye black; average weight per bushel sixty-two pounds.

An agricultural sort, generally cultivated in rows, but sometimes sown broadcast. It is not adapted to the climate of the United States, though extensively and profitably grown in England and Scotland.

Johnson's Wonderful. Law.

An improved variety of the Broad Windsor, recently introduced, and apparently of excellent quality. The pods are long, and contain six or eight beans, which are similar in size and form to the Windsor.

Long-podded. Stems from three to five feet high; the pods
Law. LisBon. HANG- are six to seven inches long, an inch and a DOWN LONG POD.
EARLY LONO POD. fourth broad, rather pendulous, and contain
SANDWICH. TOR- for KEY LONO POD. four or five whitish, somewhat oblong, flat-
SWORD LONG POD. four tened seeds, about an inch in length, and five eighths of an inch in breadth.

The variety has been long in cultivation, is remarkably productive, and one of the most esteemed of the English Beans. It is about a week later than the Early Mazagan.

Marshall's Early Dwarf Prolific. McInt.

Plant from eighteen inches to two feet high, separating into numerous branches. It resembles the Early Mazagan, but is two weeks earlier, and much more productive. The pods are produced in clusters near the ground, and contain four or five seeds, which are larger than those of the last named. 
Stem three or four feet high, separating near Red or Scarthe ground into four branches; flowers gen- somed. erally bright red, approaching scarlet, but varying from pale to purplish-red and blackish-purple, and sometimes to nearly jet black; the pods, which differ from all other varieties in their dark, rusty-brown color, are erect, four inches long, nearly an inch broad, and contain three, and sometimes four, seeds.

The variety is remarkably hardy and productive, but less esteemed than many others, on account of its dark color. It deserves cultivation as an ornamental plant.

This variety resembles the Violet or Purple, Red Windand grows about four feet high. The pods are scakLer Windnarrower than those of the Broad Windsor, and contain about the same number of seeds; in the green state, these are darker than those of the Violet, but change to scarlet when full grown, and to deep red when ripe.

The Red Windsor is late, but prolific, and of good quality. It is, however, little cultivated, on account of its dark and unattractive appearance. The seed weighs about thirty-one grains.

A very Dwarf, and comparatively new vari- Royal Dwarf ety, growing only twelve or fourteen inches McInt. high. It produces its pods in clusters, three or four beans in each pod, which are smaller than Marshall's Early Prolific. On account of its branching habit, it should not have less than ten or twelve inches in the line, which is nearly its proper distance between the rows. It is much esteemed for the delicacy and small size of the beans while young, and considered one of the best of the early Dwarf sorts. 
Toker. Lav. Height about five feet; the pods are rather Large Toker. long, quite broad, and contain three or four beans of a whitish color, but which differ from the Common Windsor in being of an elongated, oval form.

This is a medium late sort, and an excellent bearer, though considered somewhat coarse, and therefore not so much esteemed as the Windsor. The ripe seed weighs thirty-six grains.

Violet or Purple.
Stem about four feet high, with two or three ramifications ; flowers white ; the pods are generally erect, sometimes at right angles, a little curved, four. inches or upwards in length, an inch and a fourth in width, four fifths of an inch thick, and contain two, and sometimes three, seeds. When ripe, the beans are large, not regular in form, rather thin, of a violet red color, changing by age to a mahogany red; the size and shape being intermediate between the Long Pod and Broad Windsor.

The variety is of good quality and productive, but less desirable than many other sorts, on account of its dark color.

White-blos-

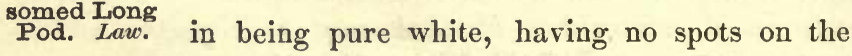

The flowers of this sort differ from all others large upper petal, or on the wings or smaller side petals. It is liable to degenerate, but may easily be distinguished, when in flower, by the above characters. Stem about four feet high ; pods long, nearly cylindrical, and slightly pendulous, generally containing four and sometimes five seeds, which are black or blackish-brown, three fourths of an inch long, and half an inch broad.

It is a moderate bearer, and of excellent quality, but not used in an advanced state, on account of its color. The variety possesses the singular anomaly of having the whitest 
flowers and the darkest seeds of any of the English Beans. The seed weighs about twelve grains.

Stem about four feet high; flowers white; Windsor. the pods are generally horizontal or inclined, WINDSOB. five inches long, an inch and a fourth wide, WISDOR KKNTfive inches long, an inch and a fourth wide, seven eighths of an inch thick, and contain $\begin{gathered}\text { WRECPR IM- } \\ \text { PROVED WISD }\end{gathered}$ two or three beans; the seeds are large, yelsor. lowish, of a flat, circular form, an inch broad, but vary in size according to soil, culture, and season. A quart contains from two hundred and fifty to two hundred and seventyfive seeds.

This familiar sort is much esteemed and extensively cultivated. It is considered the earliest of the late Garden varieties, and excellent as a sumner bean, on account of its remaining longer fit for use than any other, with the exception of the Green Windsor. It is a sure bearer; and, as the pods are produced in succession, pluckings may be made from day to day for many weeks.

The seeds are the heaviest of all the English Beans, nine well-grown specimens weighing an ounce.

\section{JAPAN PEA Hov. Mag.}

Cajanus bicolor.

The Japan Pea is a native of the East Indies, and also of Japan, as implied by the name. The plant makes a strong, erect growth, with numerous spreading branches; the leaves are large, light green, and downy beneath; the flowers are small, yellow at the centre, - the upper petal purple; the seed-pods are small and downy, and are produced in profuse abundance, - growing in clusters over the entire plant ; the seeds are small, roundish, or pea-form, and of a cream-yellow color when ripe. 
Propagation and Culture. - It is raised from seed, which, as the plant requires the entire season for development, should be sown as soon as the ground is warm and settled. Make the drills about twenty inches apart, and drop the seeds ten or twelve inches apart in the drills, covering half or three fourths of an inch deep. The plants will blossom the last of July or beginning of August, and the seeds will be suitable for use in their green state from the 20 th of August until destroyed by frost, the crop being seldom fully perfected in the Northern States.

Use. - The seeds are the only parts of the plant eaten, and these, while young, are tender and delicate. The ripe seeds, if soaked for an hour in moderately hot water, take the form and appearance of the Common White Bean, become quite soft and tender, and have a pleasant, nutty, and oily flavor. The whole plant, with the seeds, is also used for feeding stock.

A variety occurs with green seeds, which is not only considered superior to the Common Yellow-seeded just described, but is two weeks earlier.

\section{LEN T I L . Law.}

\section{Ervum lens.}

A hardy, annual plant, with an erect, angular, branching stem a foot and a half high. The leaves are winged, with about six pairs of narrow leaflets, and terminate in a divided tendril, or clasper; the flowers are small, numerous, and generally produced in pairs; the pods are somewhat quadrangular, flattened, usually in pairs, and enclose one or two round, lens-like seeds, the size and color varying in the different varieties. About four hundred and fifty are contained in an ounce, and their germinative properties are retained three years. 
Cultivation. - The Lentil succeeds best in dry, warm, and light soil.

When cultivated as green food for stock, it should be sown broadcast; but, if grown for ripe seeds, it should be sown in drills, - the last of April or beginning of May being the most suitable season for sowing.

Use. - "The Lentil is a legume of the greatest antiquity, and was much esteemed in the days of the patriarchs. In Erypt and Syria, the seeds are parched, and sold in shops, and are considered by the natives as excellent food for those making long journeys. In France, Germany, Holland, and other countries of Europe, it is grown to a considerable extent, both for its seeds. and haum. The former are used in various ways, but principally, when ripe, in soups, as split peas. When given as green food to stock, it should be cut when the first pods are nearly full grown."

\section{Varieties. -}

This variety is considered superior to the Common Large Lentil, though the seeds are much smaller. Lentil. Law. In the markets of Paris, it is the most esteemed of all the cultivated sorts. Its season is the same with that of the last named.

The Green Lentil somewhat resembles the Green Lentil. Small Lentil, particularly in its habit of growth, though its stem is taller and more slender, and its foliage deeper colored. The principal distinction is in the color of the seeds, which are green, spotted and marbled with black.

Flowers small, white, generally two, but Large Lentil. sometimes three, on each peduncle; the pods are three fourths of an inch long, half an inch broad, flattened, and generally contain a single seed, which is white 
or cream-colored, lens-shaped, three eighths of an inch in diameter, and an eighth of an inch in thickness. The plant is about fifteen inches high.

It is one of the most productive of all the varieties, though inferior in quality to the Common Lentil. One-flowered The stem of this quite distinct species is from
Lentil.

ERvum monas- twelve to fifteen inches high; the flowers are THOS.

yellow, stained or spotted with black, and produced one on a foot-stalk; the pods are oval, smooth, and contain three or four globular, wrinkled, grayish-brown seeds, nearly a fourth of an inch in diameter.

About five hundred and fifty seeds are contained in an ounce.

The One-flowered Lentil is inferior to most of the other sorts, but is cultivated to some extent, in France and elsewhere, both for its seeds and herbage.

Red Lentil. Seeds of the size and form of those of the Law.

Common Lentil, but of a reddish-brown color ; flowers light red. Its season of maturity is the same with that of the last named.

Small Lentil. Seeds about an eighth of an inch in diame-
Law. ter ; flowers reddish; and pods often containing two seeds.

This is the "Lentille petite" of the French, and is the variety mostly sown for green food in France, although its ripe seeds are also used. It is rather late, and grows taller than any of the other sorts, except the Green Lentil. When sown in drills, they should be from ten to fifteen inches apart, and the plants about four or five inches distant in the rows.

The Lentils are of a close, branching habit of growth, and a single plant will produce a hundred and fifty, and often a much greater number of pods. 


\section{U P INE.}

\section{Lupinus.}

The Lupines are distinguished among Leguminous Plants by their strong, erect, branching habit of growth. Of the numerous species and varieties, some are cultivated for oruament, others for forage, and some for ploughing under for the purpose of enriching the soil. The only species grown for their farinaceous seeds, or which are considered of much value to the gardener, are the two following:-

An annual species, with a sturdy, erect stem White Lutwo feet high; the leaves are oblong, covered Lunisus absus. with a silvery down, and produced, seven or eight together, at the end of a common stem; the flowers are white, in loose, terminal spikes; the pods are straight, hairy, about three inches long, and contain five or six large, white, flattened seeds, - these are slightly bitter when eaten, and are reputed to possess important medical properties.

"The White Lupine was extensively cultivated by the Romans for its ripened seeds, which were used for food; and also for its green herbage, which was employed for the support of their domestic animals."

It is of little value as an esculent, and, compared with many other Leguminous Plants, not worthy of cultivation.

The seeds should be sown where the plants are to remain, as they do not succeed well when transplanted. Sow early in May, in drills sixteen to eighteen inches apart ; cover an inch and a half deep, and thin to five or six inches in the rows.

The Yellow Lupine is a native of Sicily. It Yellow Luis a hardy annual, and resembles the foregoing pine. Laws. species in its general character. The flowers 
are yellow; the pods are about two inches long, hairy, flattened, and enclose four or five large, roundish, speckled seeds. It blossoms and ripens at the same time with the White, and is planted and cultirated in the same manner.

The species is grown in Italy for the same purposes as the White, but more extensively. It is also grown in some parts of the south of France, on poor, dry grounds, for cutting in a green state, and ploughing under as a fertilizer.

\section{THE PEA.}

Pisum sativum.

The native country of the Pea, like that of many of our garden vegetables, is unknown. It is a hardy, annual plant ; and its cultivation and use as an esculent are almost universal.

To give in detail the various methods of preparing the soil, sowing, culture, gathering, and use, would occupy a volume.

The following directions are condensed from an elaborate treatise on the culture of this vegetable, by Charles McIntosh, in his excellent work entitled "The Book of the Garden :" -

Soil and its Preparation. - The Pea comes earliest to maturity in light, rich soil, abounding in humus: hence the practice of adding decomposed leaves or vegetable mould has a very beneficial effect.' For general crops, a rich, hazel loam, or deep, rich, alluvial soil, is next best; but for the most abundant of all, a strong loam, inclining to clay. For early crops, mild manure, such as leaf-mould, should be used. If the soil is very poor, stronger manure should be employed. For general crops, a good dressing may be applied; and for the dwarf kinds, such as Tom Thumb, 
Bishop's New Long Pod, and the like, the soil can hardly be too rich.

Seed and Sowing. - A quart of ripe peas is equal to about two pounds' weight, and contains, of the largest sized varieties, about thirteen hundred, and of the smaller descriptions about two thousand, seeds. A pint of the small-seeded sorts, such as the Daniel O'Rourke, Early Frame, and Early Charlton, will sow a row about sixty feet in length; and the same quantity of larger growing sorts will sow a row of nearly a lundred feet, on account of being sown so much thinner. A fair average depth for covering the seed is two and a half or three inches; though some practice planting four or five inches deep, which is said to be a preventive against the premature decay of the vines near the roots.

As to distance between the rows, when peas are sown in the usual manner (that is, row after row throughout the whole field), they should be as far asunder as the length of the stem of the variety cultivated: thus a pea that attains a height or length of two feet should have two feet from row to row, and so on to those taller or lower growing.

They are sometimes sown two rows together, about a foot apart, and ten, twenty, or even fifty feet between the double rows; by which every portion of the crop is well exposed to the sun and air, and the produce gathered with great facility. There is no loss of ground by this method; for other crops can be planted within a foot or two of the rows, and this amount of space is necessary for the purpose of gathering.

A common practice in ordinary garden culture is to sow in double rows twelve or fourteen inches apart, slightly raising the soil for the purpose. When so planted, all of the sorts not over two feet in height may be successfully grown without sticking. When varieties of much taller growth are sown, a greater yield will be secured by bushing the plants, which is more economically, as well as more 
strongly, done if the planting is made in double rows. The staking, or bushing, should be furnished when the plants are three or four inches high, or immediately after the second hoeing; they should be of equal height, and all straggling side twigs should be removed for appearance' sake.

Early Crops. - The earliest crops produced in the open garden without artificial aid are obtained by judicious selection of the most approved early varieties, choosing a warm, favorable soil and situation, and sowing the seed either in November, just as the ground is closing, or in February or March, at the first opening of the soil; the latter season, however, being preferable, as the seed then vegetates with much greater certainty, and the crop is nearly or quite as early. Great benefit will be derived from reflected heat, when planted at the foot of a wall, building, or tight fence, running east and west. It is necessary, however, when warm sunshine follows cold, frosty nights, to shade the peas from its influence an hour or two in the morning, or to sprinkle them with cold water if they have been at all frozen.

They are sometimes covered with narrow glass frames of a triangular form, and glazed on both sides, or on one only, according as they may be used on rows running from north to south, or from-east to west. In the latter case, such frames may have glass in the south side only.

Subsequent Cultivation. - When the crop has attained the height of about five inches, a little earth should be drawn around the stems, but not so closely as to press upon them; it should form a sort of ridge, with a slight channel in the middle. The intention here is not, as in many other cases, to encourage the roots to diverge in a horizontal direction (for they have no disposition to do so), but rather to give a slight support to the plants until they take hold of the stakes that are to support them. Those crops which are not to be 
staked require this support the most; and they should have the earth drawn up upon one side only, that the vines may be thrown to one side; which will both facilitate the operation of gathering, and keep the ground between them clear at the same time, while it supports the necks of the plants better than if the earth was drawn up on both sides.

Mildew. - One of the most successful cultivators (T. A. Knight) says, "The secondary and immediate cause of this disease is a want of a sufficient supply of moisture from the soil, with excess of humidity in the air, particularly if the plants be exposed to a temperature below that to which they have been accustomed. If damp and cloudy weather succeed that which has been warm and bright, without the intervention of sufficient rain to moisten the ground to some depth, the crop is generally much injured by mildew."

While engaged in the production of those excellent peas which bear his name, he proved this theory by warding off mildew by copious waterings of the roots. The fashionable remedy, at present, is the application of sulphur. This, no doubt, subdues the disease, but does not remove the cause.

Gathering. - The crop should be gathered as it becomes fit for use. If even a few of the pods begin to ripen, young pods will not only cease to form, but those partly advanced will cease to enlarge.

Use. - In a sanitary point of view, peas cannot be eaten too young, nor too soon after they are gathered; and hence people who depend on the public markets for their supply seldom have this very popular vegetable in perfection, and too often only when it is almost unfit for use. This is a formidable objection to the use of peas brought from long distances. It is, of course, for the interest of the producer to keep back his peas till they are fully grown, because they measure better, and, we believe, by many are purchased 
quicker, as they get greater bulk for their money. This may be so far excusable on the part of such; but it is inexcusable that a gentleman, having a garden of his own, should be served with peas otherwise than in the very highest state of perfection, which they are not, if allowed to become too old, or even too large.

"Peas, in a green state, are with difficulty sent to a distance, as, when packed chosely together, heat and fermentation speedily take place. This is one of the causes why peas from the South, or those brought by long distances to market, are discolored, devoid of flavor, and, worst of all, very unwholesome to eat. Peas intended for long transportation should be packed in open baskets (not in boxes or tight barrels), and laid in layers not more than two inches thick; and between such layers a thick stratum of clean straw or other dry material should be placed."

Varieties. - These are very numerous, and, like those of the Broccoli and Lettuce, not only greatly confused, but often based on trifling and unimportant distinctions.

From experiments made a few years since in the gardens of the London Horticultural Society, under the direction of Mr. Thompson, who planted no less than two hundred and thirty-five reputed sorts (all of which were then enumerated in seedmen's catalogues), only twenty-seven of the number were selected as being really useful. About the same time, upwards of a hundred sorts were grown by Mr. McIntosh, from which twelve were selected as being truly distinct and valuable.

"New sorts are yearly introduced; and it would be injudicious not to give them a fair trial; for as we progress in pea-culture, as in every other branch of horticulture, we may reasonably expect that really improved and meritorious sorts will arise, and be substituted for others that may be inferior." 
Height about three feet; pods single or in Advancer. pairs, long and well filled, yielding seven or eight large peas.

The ripe seeds are green, but vary in depth of color, wrinkled, and somewhat resemble those of the Champion of England.

Sown May 1, the plants blossomed June 14, and pods were gathered for use June 28.

The variety is of recent introduction, and is the dwarfest and earliest of the wrinkled marrow peas. English writers describe it as being but a few days later than the Dan O'Rourke. It is very prolifie, podding well up the stem, and nearly as tender and sugary as the Champion of England.

It is one of the best sorts for the garden, and its earliness and great productiveness make it worthy the attention of market-gardeners.

The plant is of moderately strong habit of Auvergne. growth, producing a single stem from four to $\begin{gathered}\text { Cot. Garl. } \\ \text { WHTR SARE. }\end{gathered}$ five feet high, aceording to the soil in which it is grown, and bears from twelve to fifteen pods. These are generally single, but sometimes in pairs; when fully grown, four inches and a half long, and over half an inch broad ; tapering to the point, and very much curved. They contain from eight to ten peas, which are closely compressed, and of the size of the Early Frames. Even the small pods contain as many as six or seven peas in each. The ripe seed is white.

Plants from seed sown May 1 were in blossom June 26 ; and the pods were sufficiently grown for plueking, July 12.

The Auvergne Pea was introduced from France into England some years ago by the London Horticultural Society. Although it very far surpasses most of the varieties of the White Pea, it has never beeome much disseminated, and is very little known or cultivated. It is, however, a most 
characteristic variety, and always easily distinguishable by its long, curved pods. It is one of the most productive of all the garden peas.

Batt's Wonder. Trans.

Plant three feet in height, of robust growth ; foliage dark-green; pods narrow, nearly straight, but exceedingly well filled, containing seven or eight peas of medium size, which, when ripe, are small, smooth, and of a bluish-green color.

Planted May 1, the variety will flower about July 1, and the pods will be fit for use the middle of the month.

The variety withstands drought well, and the pods hang long before the peas become too hard for use. It is an excellent pea for a second crop.

Beck's Prizetaker. Trans.

PRIZE-TAKER.

Rising Sun.

Plant four and a half to five feet in height; pods roundish, curved or hooked near the end, well filled, containing seven to eight middlesized peas of a fine green color when young, and mixed olive and white when ripe.

Sown May 1, the variety will blossom June 25, and the pods will be suitable for plucking about the 12 th of July.

It is one of the best varieties for the main crop. Similar to, if not identical with, Bellamy's Early Green Marrow.

Bedman's Imperial. Cot.

The plant generally produces a single stem, which is from three to four feet high; the pods are usually in pairs, but sometimes single, three inches and a quarter long, five eighths of an inch broad, somewhat curved, and terminate abruptly at the points. Each pod contains six to seven peas, which are of an ovate form, and about a third of an inch in their greatest diameter. The ripe seed is pale blue.

Planted May 1, the variety blossomed the last of June, 
and furnished peas for use about the 18th of July. For many years this variety stood foremost among the Imperials, but is now giving place to other and greatly superior sorts.

Plant of strong and robust habit of growth, Bellamy's sometimes with a single and often with a branch- Early Green ing stem, four and a half or five feet high, and Cot. Gard. producing from twelve to eighteen pods; these are in pairs, rarely single, three inches and a half long, seven tenths of an inch broad, slightly curved, thick backed, and terminate abruptly at the point. The surface is smooth, and of a very dark green color. They contain, on an average, from six to seven large bluish-green peas. The ripe seed has a mixed appearance; some being dull yellowish-white, and others light olive-green, in about equal proportions.

Plants from seed sown the first week in May were in blossom the last week in June, and pods were plucked for use about the middle of July.

The variety is highly recommended, both as a good bearer and a pea of excellent quality, whether for private use or for marketing; for the latter purpose it is peculiarly adapted, as the pod is of a fine deep color, handsomely and regularly shaped, and always plumply filled.

Pods single or in pairs, about two inches long, Bishop's bent back at both ends, and increasing in size Early Dwarf. towards the middle; pea about a fourth of an inch in diameter, and irregularly shaped, cream-colored, with blotches of white, particularly about the eye. The plant grows little more than a foot high, and is fairly productive. Early sowings will give a supply for the table in about ten weeks.

This once popular Early-Dwarf sort is now rapidly giving place to Bishop's New Long-podded - a more prolific and much superior variety. 

Bishop's New Stem about two feet high; pods nearly
Long-podded.

straight, almost cylindrical, containing six or seven white peas. It is an early variety; an abundant bearer, of excellent quality, and in all respects much superior to the Common Bishop's Early Dwarf. Planted the 1st of May, it will blossom June 14, and yield peas for the table the 10 th of July.

McIntosh describes it as " a most abundant bearer, producing a succession of pods during most of the pea-season. Like all peas of its class, it requires a rich soil, and from four to six inches between the seed in the line. It is one of the most valuable sorts for small gardens and for domestic use. It originated in England with Mr. David Bishop, and is a hybrid between Bishop's Early Dwarf and one of the Marrowfats, carrying with it the characters of both its parents."

Black-eyed

Plant about five feet high, strong and vigMarrow. orous ; pods generally single, sometimes in pairs, three inches and a quarter in length, three fourths of an inch in breadth, becoming rough or wrinkled on the surface as they approach maturity, and containing about six large, round, cream-white or brownish-white black-eyed seeds, about three eighths of an iuch in diameter.

Its season is nearly the same with the Dwarf and Missouri Marrow. If sown the 1 st of May, the plants will blossom the 28th or 30 th of June, and yield peas for the table about July 15 ; the crop will ripen the last of the same month.

This is a very prolific as well as excellent variety. It is little cultivated in gardens at the North, though sometimes grown as a field-pea in the Canadas. In the Middle States, and at the South, it is a popular market-sort, and its cultivation is much more extensive. 
The dark color of the eye of the ripened seed distinguishes the variety from all others.

Plant about three feet high; pods generally Blue Cinıin pais, Thomp. in pairs, well filled, long, roundish, gradually SABRE. DWARF curved from the stem to the point, or eimeter- SABRE. shaped; seeds of good quality, larger than those ECLIPSE. of the Prussian Blue, from which the variety doubtless originated, and to which, when grown in poor soil, it has a tendency to return.

If planted the 1st of May, it will blossom about the 28th of June, and the pods will be suitable for plucking about the middle of July.

It bears abundantly, but not in succession, and for this reason is much prized by market-gardeners. The most of the pods being fit to pluck at the same time, the erop is harvested at once, and the land immediately occupied with other vegetables.

Plant strong and vigorous, four feet in height, Blue Impewith large, healthy foliage; pods single and in Dwarr Bure IMpairs, three inches and a quarter in length, three fourths of an inch in breadth, containing six or seven large peas.

The ripe seed is somewhat indented and irregularly eompressed, three eighths of an inch in diameter, and of a greenish-blue color.

With respect to season, the variety is intermediate. Sown the 1st of May, the plants were in blossom the 26th of June, and pods were plucked for use the 12 th of July. It is very hardy; yields abundantly; thrives well in almost any deseription of soil or situation; and, though not so sweet and tender as some of the mare recent sorts, is of good quality. It vegetates with much greater certainty, and its crops are 
more reliable, than the higher-flavored varieties; and these qualities will still secure its cultivation by those who prefer a certain and plentiful supply, of fair quality, to a precarious and limited yield of extraordinary sweetness and excellence. It has long been grown in this country, and is considered a standard variety.

Blue Prus-

sian. Cot.

Dwarf Bluf Gard.

Prussian. Prussian BLuk.

Plant of a vigorous, but not robust, habit of growth, with a single stem about three feet high, which is sometimes branching. The pods are generally produced in pairs, but are also sometimes single, and vary from twelve to sixteen on each plant. They are from two and three fourths of an inch to three inches long, three fourths of an inch wide, somewhat curved, and rather broader towards the point, where they terminate abruptly. They contain about seven peas, which are four tenths of an inch long, seven twentieths of an inch wide, about the same in thickness, and compressed on the sides, from being so close together. The ripe seed is blue.

Sown the 1st of May, the plants blossomed June 28, and yielded peas for use the middle of July.

It produces abundantly, and is a valuable sort for late summer use. "It is unquestionably the parent of the Blue Imperial and all like varieties."

Blue Spanish Plant from a foot and a half to three feet Dwarf. Cot. Gard.

Groom's SUPERr. high. The pods are single and in pairs, in BLUE FAN. about equal proportion, two inches and a half long, containing from six to seven peas each. The ripe seed is pale blue.

Plants from sowings made the first of May blossomed the last of June, and yielded peas for use the middle of July.

It is a good variety for small gardens, as it is a low grower and a fair bearer; but it is now much surpassed by Bishop's 
Long-podded and Burbridge's Eclipse, both of which are censidered more prolific and better flavored.

The plant is of a showy and robust habit of growth, from six to seven feet high, sometimes with a single stem, but generally branching within nine inches or a foot of the ground, and British
Queen. Cot.
Gard.

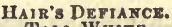
TALL WHITE МАMмоTH. ERIN'S QUEEN. frequently furnished with two and even three laterals, which are of the same height as the whole plant. The pods begin to be produced at the first joint above the first lateral shoot, and are in number from thirteen to eighteen on each plant. They are generally single, but frequently in pairs, from three inches and a quarter to three inches and three quarters long, rather flattened and broad when first fit to gather, but becoming round and plump when more advanced. They are quite smooth, of a bright green color, slightly curved, wavy on the upper edge, and contain from five to seven exceedingly large peas, which are not so close together as to compress each other. The ripe seed is white, large, and wrinkled.

Sown May 1st, the plants blossomed the 30th of June, pods were plucked for use the 15th of July, and the crop ripened off the 1st of August.

This is one of the best late peas in cultivation, and belongs to the class known as Wrinkled, or Knight's Marrows, but is much superior in every respect to all the old varieties usually called Knight's Marrows, being much more prolific and richly flavored. As an intermediate variety, it deserves a place in every garden.

Plant a robust grower, always with a simple Burbridge's stem, attaining the height of a foot and a half to about two feet; pods in pairs, rarely single,

Eclipse.

Cot. Gard. STUBB' DWARF. and from three inches to three inches and a quarter long, seven tenths of an inch broad, perfectly straight, and of 
equal width throughout, with a slight waving on the upper edge, - they contain from five to seven peas, which are ovate, nearly half an inch long, a third of an inch broad, and the same in thickness.

Seed was planted May 1, the plants blossomed June 26, and pods were plucked for use July 14 .

This may be classed among the valuable contributions which have been made to the list of peas during the last few years. Unlike many of the dwarf varieties, it is a most productive sort; and thus its dwarf character is not its chief recommendation. For private gardens, or for cultivation for market, few peas surpass this and Bishop's Long-podded.

Carter's Vic- Plant six to seven feet high; pods large, toria. Trans.

Carter's

ECLipse.

slightly curved, containing seven or eight large peas, which are sweet and of excellent quality. The ripe seeds are white, and much shrivelled or wrinkled.

Plants from seeds sown May 1 blossomed July 1 , and the pods were fit for plucking the 18th of the month.

The variety continues long in bearing, and the peas exceed in size those of Knight's 'Tall White Marrow. It is one of the best late tall peas.

Charlton. Cot. The original character of this variety may be Gard. Law. Thomp.

Earlt

ChanLton. described as follows : -

Plant about five feet high, and of vigorous growth; leaves large, with short petioles; tendrils small; pods broad, containing six or seven peas of excellent quality. They are rather larger than those of the Early Frame, with which this is often confounded. The Early Charlton may, however, be distinguished by its stronger habit of growth, flat pods, larger seeds, and by being fit for use about a fortnight later than the Early Frame; so that, when sown at the same time, it forms a succession. 
According to the Messrs. Lawson, this is the oldest, and for a long period was the best known and most extensively cultivated, of all the varieties of white garden-peas. Its history can be traced as far back as 1670 ; and from that time till about 1770 , or nearly a century, it continued to stand first in eatalognes as the earliest pea, until it was supplanted by the Early Frame, about 1770. It is further said by some to be the source from which the most esteemed early garden varieties have arisen, and that they are nothing else than the Early Charlton Pea, considerably modified in character from the effects of cultivation and selection. Although this idea may seem far-fetched, it is not improbable, especially when we take into consideration the susceptibility of change, from cultivation and other causes, which the Pea is ascertained to possess. Thus if the Early Charlton, or any other variety, be sown for several years, and only the very earliest and very latest flowering-plants be selected for seed each season, the difference in the time of ripening between the two will ultimately become so great as to give them the appearance of two distinct varieties; and by sowing the earlier portion on light, early soils, and the later on strong, black, coarse, or low soils, the difference will become materially increased. It is therefore probable that the Early Frame, with its numerous sub-varieties (including the Dan O'Rourke, Prince Albert, Early Kent, and a multitude of others), may have originated in the Charlton, though some of them differ essentially in their habit of growth.

The various names by which it has been known are Reading Hotspur, Master's or Flander's Hotspur, Golden Hotspur, Brompton Hotspur, Essex Hotspur, Early Nicol's Hotspur, Charlton IIotspur, and finally Early Charlton, the last name becoming general about 1750 .

An English writer remarks, "that the variety now exists only in name. That which is sold for the Early Charlton is 
often a degenerated stock of Early Frames, or any stock of Frames which cannot be warranted or depended upon, but which are, nevertheless, of such a character as to admit of their being grown as garden varieties. The Early Charlton, if grown at all by seed-growers as a distinct variety, is certainly cultivated to a very limited extent."

Of the popular American improved early sorts, the Hill's Early, Horey's Extra Early, Landreth's Extra Early, are hardy, as well as very prolific, and are not only well adapted for private gardens, but may be recommended as the most profitable kinds for cultivating for early marketing. In an experimental trial of these kinds with the Early Daniel O'Rourke, and some of the most approved of the earliest foreign varieties, they proved to be nearly or quite as early, fully as prolific, continued longer in bearing, and were much more stocky and vigorous in habit.

Champion of Paris, or Paradise Marrow. Cot. Gard.

EXCELSIOR. STUART S PARA-
DISE. three inches and a quarter to three inches and three quarters long, and five eighths of an inch wide. They are curved almost as much as those of the Cimeter; and, when near maturity, become quite fleshy, wrinkled, and thick-backed. They contain from six to seven large peas, which are close together without being compressed. The ripe seed is white, medium-sized, somewhat flattened and pitted. Sown May 1, the plants blossomed June 28, and pods were ready for plucking July 16.

This is a very excellent pea, an abundant cropper, and considerably earlier than the Auvergne and Shillings Grotto, to both of which it is also greatly superior. 
Plant six feet high, branching, and of strong, Champion of vigorous habit. Pods single and in pairs, large Scotland. and well filled.

Sown May 1, the variety blossomed July 1, and pods were gathered for use the 20th of the month.

In its general character, the Champion of Scotland somewhat resembles the Competitor, often remaining fresh and green till the middle of September. From the time of the first plucking, the plants continued to grow, blossom, and pod for nearly five weeks.

It is of excellent quality, and, as a late sort, one of the best for cultivation.

Stalk remarkably strong and vigorous, attain- Competitor. ing a height of six feet and upwards; pods single, sometimes in pairs, of large size, and well filled, - generally yielding from six to eight large peas.

The seeds, when ripe, are cream-yellow, above medium size, and much shrivelled and indented.

Sown May 1st, the plants blossomed the last of June, and pods were plucked for use the 20th of July.

The Competitor Pea is of recent origin, and is described as the latest of all the sorts now in cultivation. Aside from its large size and excellence, it is one of the most valuable of all varieties for the length of time the plants continue in bearing. In an experimental growth of this pea, the pods were first plucked, as stated above, about the 20th of July, and from this time the plants continued to yield abundantly until the last of August, or for a period of nearly six weeks.

Plant six to seven feet high, branching; pods Dantzic. Law. in pairs, two and a lialf inches long, half an inch broad, compact, and slightly bent. When ripe, the seed is the smallest of all the light peas, quite round or spherical, of a 
bright yellow color, beautifully transparent, with whitish eyes.

If sown the 1st of May, the plants will blossom the 8th of July, afford peas for the table about the 25th of the same month, and ripen from the 10th to the middle of $\mathrm{Au}$ gust.

It is not a productive variety, and is seldom cultivated in England or in this country, but is grown extensively on the shores of the Baltic, and exported for splitting or boiling whole.

Dickson's Plant five feet high, stocky, vigorous, and

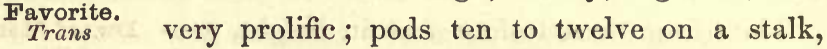
Dicrsox's EarLy
FAVOrITE.
long, round when full grown, curved, hooked at the extremity, but not so much so as in the Auvergne, to which, in many respects, it bears a strong resemblance. The pods are remarkably well filled, containing from eight to ten peas of medium size, round, and very white.

Planted the 1st of May, the variety blossomed June 25, and pods were gathered for use the 12th of July.

This pea is highly deserving of cultivation as a second early variety.

Dillistone's Early. Cot. Gard.
The plant is of slender habit of growth, produces a single stem two feet high, and bears, on an average, from seven to nine pods: these are smaller than those of the Dan O'Rourke, generally single, but occasionally in pairs, almost straight, and contain seven peas each. The seed, when ripe, is white.

Sown at the time of the Dan O'Rourke, the plants were a mass of bloom three days before the last named had commenced blossoming, and the crop was ready for gathering seven days before the Dan O'Rourke.

This is undoubtedly the earliest pea known, and is quite 
seven or eight days earlier than the Dan O'Rourke, which has hitherto been regarded as the earliest variety. A striking feature of Dillistone's Early is, that its changes take place at once. It blooms in a mass, its pods all appear together, and the whole crop is ready to be gathered at the same time.

In the Chiswick Garden, England, where a hundred and sixteen varieties were experimentally cultivated, during the season of 1860 , under the supervision of Robert Hogg, LL. D., this variety was beginning to die off when the Dan O'Rourke was yet green and growing.

Plant from three to four feet in height, gen- Dwarf Marerally with a single stem, but sometimes branch- DWARF WHITE ing; pods somewhat flattened, generally single, DWARF MARROWing; pods somewhat flattened, generally single, DWAT. EARLY but sometimes produced in pairs, three inches พAT.

to three inches and a half long, three fourths of an inch broad at the middle, tapering with a slight but regular curve to both ends, and containing about six closely-set peas : these are cream-colored and white; the white prevailing about the eye, and at the union of the two sections of the pea; not perfectly round, but more or less compressed, slightly wrinkled, and measuring nearly three eighths of an inch in diameter.

Planted the 1st of May, the variety blossomed the last of June, and afforded peas for the table the 15th of July.

The Dwarf Marrow is hardy and productive. Though not so sweet or well flavored as some of the more recent sorts, its yield is abundant and long continued; and for these qualities it is extensively cultivated. The variety, however, is rarely found in an unmixed state; much of the seed sown under this name produeing plants of stronger habit of growth than those of the true Dwarf Marrow, and more resembling the Tall White variety. 
Early Dan

O'Rourke.

DUNNETT'S FiRST

EARLY. WAITE'S

Dan O'Rourke.

CARTER'S EARLi-

NUMBER ONE.

Cot. Gard.

Plant from three and a half to four feet high, long, containing five or six peas.

When fully ripe, the pea is round, cream-colored, white at the eye and at the junction of the cotyledons, and nearly a fourth of an inch in diameter.

Plants from seeds sown May 1 were in bloom June 7, and pods were gathered for use from the 25th of the month.

The Dan O'Rourke is remarkable for its precocity, and, with the exception of Dillistone's Early and one or two American varieties, is the earliest of all the sorts now in cultivation. It is hardy, prolific, seldom fails to produce a good crop, appears to be well adapted to our soil and climate, is excellent for small private gardens, and one of the best for extensive culture for market.

Its character as an early pea can be sustained only by careful culture, and judicious selection of seeds for propagation. If grown in cold soil, from late-ripened seeds, the variety will rapidly degenerate ; and, if from the past any thing can be judged of the future, the Dan O'Rourke, under the ordinary forms of propagation and culture, will shortly followits numerous and once equally popular predecessors to quiet retirement as a synonyme of the Early Frame or Charlton.

Early Frame. Plant three to four feet in height ; pods in Thomp.

Early Dwary

Frame. Early

DOUBLE-BLOS-

SOMED FRAME.

Law. Essex
CHAMpion. Six- about two and a half inches long by from three GLE-BLOSSOMFD FrAME. pairs, slightly bent backwards, well filled, terminating rather abruptly at both ends, and about two and a half inches long by from three eighths to half an inch in breadth. The peas, when fully ripe, are round and plump, cream-colored, white towards the eye and at the union of the cotyledons, and measure nearly a fourth of an inch in diameter. 
Sown the 1st of May, the variety blossomed June 20, and the pods were ready for plucking the 6th of July.

This well-known pea, for a long period, was the most popular of all the early varieties. At present it is less extensively cultivated, having been superseded by much earlier and equally hardy and prolific sorts. "The flowers sometimes come single, and sometimes double; the stalk from the same axil dividing into two branches, each terminating in a flower : hence the name of 'Single-blossomed' and 'Doubleblossomed' hare both been occasionally applied to this variety."

Similar to the Early Frame. Mr. Thompson Early Hotrepresents it as identical. The Messrs. Lawson describe it as follows: " Pods generally in pairs, three inches long, half an inch broad, spur.

EARLY GOLDEN HotsPUR. GOLD EN Hotspur. SUPERFINE EARILY. nearly straight, and well filled; pea similar to the Doubleblossomed Early Frame, but rather larger."

Once at the head of early peas; now considered by the most experienced cultivators to be Early Warwick. identical with the Early Frame.

RACE-HOESE.

A sub-variety of the Early Frame, differing Early Washslightly, if at all, either in the size or form of CrDo xUцL. the pod, color and size of the seed, or in productiveness.

Once popular, and almost universally cultivated; now rarely found on seedsmen's catalogues.

Plant about three feet in height, with pale- Eugenie. green foliage; pods single or in pairs, three . Alliance. inches long, containing five or six peas. When ripe, the peas are of medium size, cream-colored, and much shrivelled and indented. 
Plants from sowings made May 1 were in blossom June 14, green peas were plucked July 10 , and the pods ripened from the 18 th to the 25 th of the same month. English catalogues describe the variety as being "the earliest white, wrinkled marrow-pea in cultivation, podding from the bottom of the stalk to the top, with fine large porls."

In a trial growth, it proved hardy and very prolific; and the peas, while young, were nearly as sweet as those of the Champion of England. The pods were not remarkable for diameter, but, on the contrary, were apparently slender. The peas, however, were large; and, the pods being thin in texture, the peas, when shelled, seemed to be equal in diameter to the pods themselves. As a new variety, it certainly promises well, and appears to be worthy of general cultivation. It will come to the table immediately after the earliest sorts, and yield a supply till the Marrows are ready for plucking.

Fairbeard's Champion of England. Cot. Gar.. CHAMPION oF ENGLAND.

Plant of strong and luxuriant habit of growth, with a stem from five to six feet in height, which is often undivided, but also frequently branching. The laterals are produced within about eighteen inches of the ground, and sometimes assume a vigorous growth, and attain as great a height as the main stem. They produce pods at the first joint above the lateral, and are continued at every succeeding joint to the greatest extremity of the plant. The pods are generally single, but frequently in pairs, about three inches and a half long, slightly curved, and terminate abruptly at the point; the surface is quite smooth, and the color light green till maturity, when they become paler and shrivelled. They contain six or seven quite large peas, which are closely packed together and compressed. The ripe seed is wrinkled, and of a pale olive-green. 
Sown the 1st of May, the plants were in flower June 25, and pods were gathered for use the 12th of July.

This variety was originated in England, by Mr. William Fairbeard, in 1843, and, with the Early Surprise, came out of the same pod, - the produce of a plant found in a crop of the Dwarf White Knight's Marrows, to which class it properly belougs. It is, without doubt, one of the most valuable acquisitions which have been obtained for many years, being remarkably tender and sugary, and, in all respects, of first-rate excellence. The rapid progress of its popularity, and its universal cultivation, are, however, the best indications of its superiority.

The variety was introduced into this country soon after it was originated, and was first sold at five dollars per quart.

Stem branching, three and a half to four feet Fairbeard's high, with a habit of growth and vigor similar $\begin{gathered}\text { Nonpareil. } \\ \text { Cot. Gurd. }\end{gathered}$ to the Early Frames. The pods are full and plump, but do not become thick-backed and fleshy as they ripen, like those of the Frames. They contain from six to eight peas, which are close together, much compressed, and of that sweet flavor which is peculiar to the Knight's Marrows. The ripe seed is small and wrinkled, and of the same color as the other white, wrinkled peas.

The variety was originated by Mr. William Fairbeard, who also raised the Champion of England. It is earlier than the last-named sort, nearly as early as the Frames, and a most valuable acquisition.

The plant of this variety is of a free but not Fairbeard's robust habit of growth, and always with a simple stem, which is about four feet high. The Surprise. Cot. Gard. EARLY SURPRISE. pods are produced at every joint, beginning at about two 
feet and a half from the ground. They are generally single, but sometimes in pairs, three inches long, slightly curved, but not quite so much as those of the Champion of England. They contain from six to seven peas, which are of good size, but not so sweet as those of the last-named sort. The ripe seed is somewhat oval, and of a pale olive-green color.

The variety is a day or two earlier than the Champion of England. It originated from the Dwarf White Knight's Marrow, and was taken from the pod in which was found the Champion of England.

Flack's Imperial. Cot. Gard.

Fuack's VictoRY. FIACK'S VICTORIA. FLACK'S New LARGE VICTORIA.

The plant is of a robust habit of growth, with a stem which is always branching, and generally about three feet in height; the pods are numerous, varying from twelve to eighteen on a plant, generally produced in pairs, but often singly, three inches and a half long, three fourths of an inch broad, and considerably curved, - terminating abruptly at the point, where they are somewhat broader than at any other part. Each pod contains from six to eight very large peas, which are of an ovate shape, half an inch long, seven twentieths of an inch broad, and the same in thickness. The ripe seed is blue.

Plants from seed sown May 1 blossomed June 28, and pods were plucked for the table July 15 .

It is one of the most prolific peas in cultivation; grows to a convenient height; and, whether considered for private gardens or for market supplies, is one of the most valuable varieties which has been introduced for years.

General Wyndham.

Cot. Gard.
The plant is of a robust habit, six to seven feet high, and frequently branched; the foliage is dark-green and blotched; the pods are either single or in 
pairs, and number from ten to fourteen on each plant, they contain eight very large peas, which are of the deep, dull green color of the Early Green Marrow. The ripe seed is white and olive mixed.

This is a valuable acquisition, and was evidently procured from the Ne Plus Ultra; but it is a more robust grower, and produces much larger pods.

The plant continues growing, blooming, and podding till very late in the season; and, when this is in the full vigor of growth, the Ne Plus Ultra is ripening off. The peas, when cooked, are of a fine, bright green color, and unlike those of any other variety.

Plant strong and vigorous, from three to three Hair's Dwarf feet and a half high, branching, with short Mammoth.

joints; pods single or in pairs, broad, comparatively flat, containing about six very large peas, which are sugary, tender, and excellent. The ripe seeds are shrivelled, and vary in color; some being cream-white, and others bluishgreen.

Sown May 1, the plants blossomed July 1, and pods were ready for use the 15 th of the same month.

Very prolific, and deserving of cultivation.

Plant three feet high, of a bushy, robust habit Harrison's of growth; pods rather short, nearly straight, and flattish, containing five or six medium-sized peas, of good quality; when ripe, the seeds are light olive, mixed with white, and also slightly indented.

Planted May 1, the variety was in flower June 23, and the pods were fit for gathering about the 10 th of July.

It is a good variety; but, like Harrison's Perfection, the pods are frequently not well filled. 
Harrison's

Perfection.

Trans.

Plant three feet in height, of vigorous habit ; pods small, straight, containing five peas of good size and quality.

Sown the 1st of May, the variety was in flower June 23 , and the pods were ready for plucking about the 12 th of July.

The only defect in this variety is, that the pods are of:ca not well filled. When growing, it is scarcely distinguishable from Harrison's Glory; but, in the mature state, the seec's of the former are smooth and white, while those of the latter are indented, and of an olive color.

King of the Plant six feet in height, stocky, and of remarkably vigorous habit; pods single or in pairs, containing five or six large seeds, which, when ripe, are yellowish-green, and much shrivelled and indented, like those of the Champion of England.

Planted May 1, the variety blossomed the last of Junc, and pods for the table were plucked the 15th of July.

Though comparatively late, it is one of the best of the more recently introduced sorts, and well deserving of general cultivation. When the pods are gathered as fast as they become fit for use, the plants will continue to put forth new blossoms, and form new pods, for an extraordinary length of time; in favorable seasons, often supplying the table for five or six weeks.

It is very tender and sugary, and little, if at all, inferior to the Champion of England.

In common with most of the colored peas, the ripe seeds, when grown in this country, are much paler than those of foreign production; and, when long cultivated in the climate of the United States, the blue or green is frequently changed to pale blue or yellowish-green, and often ultimately becomes nearly cream-white. 
A dwarfish sub-variety of Knight's Marrows, with wrinkled, blue seeds.

Knight's Dwart Blue Marrow.

Plant about three feet high; pods in pairs, Knight's three inches long, three fourths of an inch wide, Dwarrow. flattish, and slightly bent. The ripe peas are KNIGHT's DWARF GREEN WRINof a light bluish-green color. It differs from KLED. the foregoing principally in the height of the plant, but also to some extent in the form of the pods.

Plant three feet high; pods in pairs, three inches long, three fourths of an inch wide, Knight's Dwarf White Marrow. straight, or nearly so, well filled, and termi- $\mathrm{K}_{\mathrm{NrOH}}$ 's DWARE nating abruptly at both ends; pea, on an KLED MARROW. average, about three eighths of an inch in diameter, flattened, and very much wrinkled; color white: and sometimes of a greenish tinge. It is a few days earlier than the Dwarf Green.

A sub-variety of Knight's Tall Marrows, Knight's with blue, wrinkled, and indented seeds. It Marrow. resembles the Tall White and Tall Green Marrows.

Plant from six to seven feet in height, of Knight's strong growth ; pods large, broad, and well Marrow. Law. filled; the seed, when ripe, is green, and much Thomp. wrinkled or indented.

Planted the first of May, the variety blossomed the last of June, and supplied the table the middle of July.

The peas are exceedingly tender and sugary; the skin also is very thin. "From their remarkably wrinkled appearance, together with the peculiar sweetness which they all possess, Knight's Marrows may be said to form a distinct class of garden pers; possessing qualities which, together 
with their general productiveness, render them a.valuable acquisition, both to cultivators and consumers."

If planted not less than six feet apart, these peas will bear most abundantly from the ground to the top ; they also yield their pods in succession, and are the best for late crops.

Knight's Tall White Marrow. KNIGHT'S TALL WHITE WRINKLED MARROW.

Height and general character of the plant similar to Knight's Tall Green Marrow. Pods in pairs. The ripe seed is white. Very productive and excellent.

Lord Raglan. Plant strong and healthy, three feet high, quite short jointed, and generally branched. The pods, which are produced singly or in pairs, are comparatively large and broad, somewhat flattened, and contain six or seven very large peas. When ripe, the seeds are shrivelled, and of a blue, or greenish-blue color, - the American grown, however, being usually much paler than those received from England.

Sown May 1, the plants were in flower July 1, and pods were plucked for use the 15 th of the month.

The variety is prolific, appears to be adapted to our soil and climate, grows to a convenient height, is of excellent quality, - nearly or quite equalling the Champion of England, - and is recommended for cultivation.

By some of the most reliable of English cultivators, it is described as differing slightly, if at all, from Hair's Dwarf Mammoth.

Matchless Marrow. Cot. Gard.
This is a good marrow-pea, but now surpassed by the improved varieties of the Early Green Marrow. It possesses no qualities superior to that variety, and is not so early. The plant grows from five to six feet in height, and the pods contain about seven large peas, which are closely compressed together. 
The plant is of a strong and robust habit of Milford Margrowth, always with a single stem, attaining the row. Card. height of four and a half or five feet, and producing from twelve to sixteen pods, which are almost always in pairs, three inches and three quarters long, and three quarters of an inch wide. They do not become broad-backed, thick, or fleshy, but rather shrivelled, and contain from six to seven very large peas, which are roundish and somewhat compressed, half an inch long, nearly the same broad, and nine twentieths thick.

Its season is near that of Bellamy's Early Green Marrow ; if planted May 1, blossoming June 28, and being fit for plucking about the middle of July.

Plant three feet and a half or four feet high, Missouri strong and vigorous, generally simple, but some- Missourl MA. times divided into branches; pods single and in pairs, three inches long, wrinkled on the surface as they ripen, nearly straight, and containing about six peas, rather closely set together. When ripe, the pea is similar to the Dwarf Marrow in form, but is larger, paler, more wrinkled, and much more regular in size.

Plants from seed sown May 1 were in blossom the 30th of June, and pods were gathered for use the 14th of July. It is a few days later than Fairbeard's Champion of England, and nearly of the season of the Dwarf Marrowfat, of which it is probably but an improved or sub-variety.

It is of American origin, very productive, of good quality, and well deserving of cultivation.

Plant three feet and a half high, of robust habit; pods single or in pairs, three inches Napoléon. Climax. long, containing five or six peas; when ripe, these are of medium size, pale blue or olive, sometimes yellowish, 
shaded with blue, and, like the Eugénie, much wrinkled and indented.

Sown the beginning of May, the variety blossomed about the 15 th of June, pods were plucked for use the 10th of July, and the crop ripened the 25 th of the same month.

English catalogues represent the Napoléon as being "the earliest blue pea in cultivation, podding from the bottom of the haum to the top, with fine large pods." In a trial growth, it proved early and productive; not only forming a great number of pods, but well filling the pods after being formed. In quality it is tender, very sweet and well flavored, resembling the Champion of England. Its season is nearly the same with that of the Eugénie, and the variety is well deserving of cultivation.

Mr. Harrison, the originator of the Eugénie and Napoléon, states that both of the peas were originally taken from one pod.

Ne Plus UItra. Cot. Gard. JAY's CoNQUEROR.

This is comparatively a recent variety. It belongs to the wrinkled class of peas; is as early as Bellamy's Green Marrow; and possesses, both in pod and pea, the same fine, deep, olive-green color.

The plant is of strong and robust habit of growth, six to seven feet high, with a branching stem. It begins to produce pods at two or two and a half feet from the ground; and the number, in all, is from twelve to eighteen. The pods are generally in pairs, three inches and a half long, three fourths of an inch wide, very plump and full, almost round, slightly curved, and terminate abruptly at the end. Their color is deep, bright green, and the surface smooth. They contain seven very large peas, each of which is half an inch long, nearly the same broad; and, although they are not so closely packed as to compress each other, they fill the pods well. 
Sown the first of May, the variety blossomed the last of June, and afforded peas for use the 15th of July.

It is one of the best tall Marrows in cultivation. The ripe seed is mixed white and olive.

A sub-variety of Bellamy's Early Green Mar- Noble's Earrow. It is a much more abundant bearer, Marrow. Cot. producing from eighteen to twenty pods on a plant, which are singularly regular in their size and form.

Plant from two and a half to three feet in Prince Alheight, usually without branches; pods gen- EARLY PrixcB $_{\text {B }}$ erally in pairs, two inches and a half in length, half an inch broad, tapering abruptly at both ends, slightly bent backwards, and well filled; pea, when fully ripe, round, cream-colored, approaching to white about the eye and at the line of the division of the lobes, and measuring about a fourth of an inch in diameter.

Sown May 1, the plants blossomed June 15, and pods were plucked for use July 6 .

The Prince Albert was, at one period, the most popular of all the early varieties, and was cultivated in almost every part of the United States. As now found in the garden, the variety is not distinguishable from some forms of the Early Frame; and it is everywhere giving place to the Early Dan O'Rourke, Dillistone's Early, and other more recent and superior sorts.

A very dwarfish variety, from six to nine Queen of the inches high. Stem thick and succulent; foliage $\begin{gathered}\text { Dwarfs. } \\ \text { Gard. }\end{gathered}$ dark bluish-green. Each plant produces from four to six pods, which are of a curious, elliptic form, and contain three or four large peas. Ripe seed white, of medium size, egg-shaped, unevenly compressed. 
The plants are tender; the pods do not fill freely; and the variety cannot be recommended for cultivation.

Ringwood Marrow.

Flanagan's EARLY. EARLT RiNGW
Gaid. BECK'S

Plant three and a half to four feet high, usually simple, but sometimes sending out shoots near the ground. The pods are single and in pairs, and, as they ripen, become thick and fleshy, with a rough, pitted, and shrivelled surface: they contain from six to seven large peas, which are nearly round, and about seven tenths of an inch in diameter in the green state. The ripe seed is white.

The variety is comparatively early. Planted May 1, it blossomed the 25 th of June, and the pods were ready to pluck about the 10th of July.

A very valuable sort, producing a large, well-filled pod, and is a most abundant bearer. It has, however, a peculiarity, which by many is considered an objection, - the pod is white, instead of green, and presents, when only full grown, the appearance of over-maturity. This objection is chiefly made by those who grow it for markets, and who find it difficult to convince their customers, that, notwithstanding the pod is white, it is still in its highest perfection. So far from being soon out of season, it retains its tender and marrowy character longer than many other varieties.

A new sort, called the "Lincoln Green," is said to possess all the excellences of the Ringwood Marrow, without the objectionable white pod.

Royal Dwarf Plant of medium growth, with an erect stem, or White Prussian. which is three feet high, generally simple, but
Cot. Gard. DWARF PROLIFic. occasionally branching. The pods are usually POOR MAN'S single, but sometimes in pairs, nearly three inches long, half an inch broad, almost straight, and somewhat tapering towards the point. The surface is quite smooth, 
and the color bright green. They are generally well filled, and contain from five to six peas, which are ovate, not compressed, four tenths of an inch long, a third of an inch broad, and the same in thickness. The ripe seed is white.

Plants from seed sown the 1st of May blossomed June 25, and supplied the table about the middle of July. The crop will ripen the 25 th of the same month.

This is an old and prolific variety, well adapted for field culture, and long a favorite in gardens, but now, to a great extent, superseded.

Plant of rather slender habit, three feet and Sebastopol. a half in height; pods usually single, two inches and three quarters in length, containing from five to seven peas, which, when ripe, are nearly round and smooth, cream-colored, and scarcely distinguishable, in their size, form, or color, from the Early Frame and kindred kinds.

Planted May 1, the rariety blossomed June 16, afforded pods of sufficient size for shelling July 7 , and ripened the 20th of the same month.

It is early, very productive, of superior quality, and an excellent sort for growing for market, or in small gardens for family use. In an experimental cultivation of the variety, it proved one of the most prolific of all the early sorts.

Plant with a simple stem, four feet and a half to five feet high ; the pods are generally single,

Shillings Grotto. but frequently in pairs, three inches and a half long, about half an inch wide, slightly curved, and, when fully matured, assuming a thick-backed and somewhat quadrangular form. Each pod contains, on an average, seven large peas. The ripe seed is white.

A great objection to this variety is the tardiness with which it fills, the pods being fully grown, and apparently filled, 
when the peas are quite small and only half grown. Though considered a standard sort, it is not superior to the Champion of England, and will probably soon give place to it, or some other of the more recent varieties.

Spanish Plant about a foot high, branching on each Dwarf. Cot. Gard.

FarLy SPANirh DWARF. DWABF

FaN. STRAW

side in the manner of a fan; and hence often called the "Dwarf Fan." The pods are sometimes single, but generally in pairs, two inches and a half long, half an inch broad, terminate rather abruptly at the point, and contain from five to six rather large peas. The ripe seed is cream-white.

Sown May 1, the plants were in blossom June 26, and pods were plucked for use July 14 .

The Spanish Dwarf is an old variety, and still maintains its position as an Early Dwarf for small gardens, though it can hardly be considered equal to Burbridge's Eclipse or Bishop's Long-podded.

There is a variety of this which is called the Improved Spanish Dwarf, and grows fully nine inches taller than the old variety; but it possesses no particular merit to recommend it.

Tall White Plant six to seren feet in height, seldom Marrow.

LARGE CAROLINA. branched; pods three to three inches and a TALL MARBOW-

FAT. half long, three fourths of an inch broad, more bluntly pointed than those of the Dwarf variety, and containing six or seven peas. When ripe, the pea is nearly of the color of the Dwarf Marrow, but is more perfectly spherical, less wrinkled, and, when compared in bulk, has a smoother, harder, and more glossy appearance.

Planted May 1, the variety blossomed the 1st of July, and supplied the table from the 15 th to the 20th of the same month. It is a few days later than the Dwarf. 
In this country, it has been longer cultivated than any other sort; and, in some of the forms of its very numerous sub-varieties, is now to be found in almost every garden. It is hardy, abundant and long-continued in its yield, and of excellent quality. In England, the variety is cultivated in single rows, three feet apart. In this country, where the growth of the pea is much less luxuriant, it may be grown in double rows, three feet and a half apart, and twelve inches between the single rows.

Similar in habit, production, and early maturity, to the Early Dan O'Rourke.

Taylor's Early.

Plant strong and robust, six to seven feet Thurston's high; pods generally single, but occasionally in Cot.Gard. pairs, and from three inches and a half to four inches and a quarter long. They are broad and flat, shaped like the pods of the Blue Cimeter, and contain seven or eight very large peas. Ripe seed white, large, and unevenly compressed.

This is a quite distinct and useful pea ; an abundant bearer; and the pods are of a fine deep-green color, which is a recommendation for it when grown for market. It comes in at the same time as the Auvergne and Shillings Grotto, but is of a more tender constitution.

Plant of remarkably low growth, seldom Tom Thumb. much exceeding nine inches in height, stout and

BusH PEA. branching; pods single, rarely in pairs, two inches and a half in length, half an inch broad, containing five or six peas, which are cream-yellow, and measure about a fourth of an inch in diameter.

Planted the 1st of May, the variety blossomed the 12th of June, and the pods were of suitable size for plucking July 4. 
In the color of its foliage, its height and general habit, the variety is very distinct, and readily distinguishable from all other kinds. It is early, of good quality, aud, the height of the plant considered, yields abundantly. It may be cultivated in rows ten inches apart.

Mr. Landreth, of Philadelphia, remarks as follows: "For sowing at this season (November, in the Middle States), we recommend trial of a new variety, which we have designated 'Tom Thumb,' in allusion to its extreme dwarfness. It seldom rises over twelve inches, is an abundant bearer, and is, withal, quite early. It seems to be admirably adapted to autumn sowings in the South, where, on apprehended frost, protection may be given : it is also equally well suited to early spring planting for the same reason. It is curious, as well as useful, and, if planted on ground well enriched, will yield as much to a given quantity of land as any pea known to us."

It is a desirable variety in the kitchen garden, as, from its exceeding dwarfish habit, it may be so sown as to form a neat edging for the walk, or border.

Veitch's Perfection. Trans.
Plant three feet and a half to four feet high, of strong, robust growth, somewhat branched; pods ten or twelve on a stalk or branch, large, flat, straight, containing six or eight large peas, which are very sugary and excellent. The ripe seeds are large, of a light olivegreen color, some being nearly white.

Planted the 1st of May, the variety will be in flower Juue 28 , and the pods will be fit for use about the middle or 20th of July. It is one of the best peas for main or late crops.

Plant from six to seren feet high ; pods remarkably large, nearly four inches in length, 
generally in pairs, straight, roundish, well filled, containing from six to eight peas of extraordinary size and of good quality. The ripe peas are olive-green.

The Victoria Marrow is not early. Planted May 1, it blossomed the last of June, and was fit for the table from the middle of July.

This variety bears some resemblance to Knight's Tall Marrow; but, like nearly all others, it. is less sugary. Those who have a fancy for large peas will find this, perhaps, the largest.

This variety grows somewhat taller, and is a few days earlier, than the Prince Albert: the pods and peas are also somewhat larger. It is an abundant bearer, and, on the whole, must be considered a good sub-variety of the Early Warner's Early Emperor. Thomp.

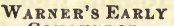
Cox OU R R OR.

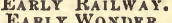

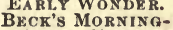

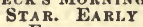
Frame.

Plant of strong and robust habit of growth, Woodford's like like a vigorous-growing Marrow ; rising with a $\begin{gathered}\text { Gard. } \\ \text { NosPariL. }\end{gathered}$ stem three feet and a half high, which is sometimes simple, but generally branching at about half its height from the ground. The pods begin to be produced at little more than half the height of the plant; and, from that point to the top, every joint produces single or double pods, amounting, in all, to ten or twelve on each. They are single or in pairs, in nearly equal proportions, about three inches and a half long, seven teuths of an inch broad, quite smooth, and of a dark green color. When ready to gather, they are rather flattened, but become round as they ripen. They contain, on an average, seven peas, which are of a dark olive-green color, rather thick in the skin, and closely packed, - so much so as to be quite flattened on the sides adjoining. 
Sown May 1, the variety blossomed June 28, and peas were gathered for the table July 17.

This is a very characteristic pea, and may at once be detected from all others, either by the ripe seed or growing plants, from the peculiar dark-green color, which, when true, it always exhibits. It is well adapted for a market-pea, its dark-green color favoring the popular prejudices.

\section{Eatable-Podded or Sugar Peas.}

String-peas. Skinless Peas. Pisum macrocarpum. Dec.

In this class are included such of the varieties as want the tough, inner film, or parchment lining, common to the other sorts. The pods are generally of large size, tender and succulent, and are used in the green state like string-beans; though the seeds may be used as other peas, either in the green state or when ripe. "When not ripe, the pods of some of the sorts have the appearance of being swollen or distended with air; but, on ripening, they become much shrivelled, and collapse closely on the seeds." The varieties are not numerous, when compared with the extensive catalogue of the kinds of the Common Pea offered for sale by seedsmen, and described by horticultural writers. The principal are the following : -

Common Stalk about two feet high, dividing into Dwarf Sugar. branches when cultivated in good soil; flower

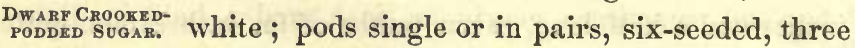
inches long by five eighths of an inch broad, crooked or jointed-like with the seeds, as in all of the Sugar Peas, very prominent, especially on becoming ripe and dry; pea fully a fourth of an inch in diameter, white, and slightly wrinkled.

The variety is quite late. Sown the beginning of May, 
the plants blossomed the last week in June, and pods were gathered for use July 17.

It is prolific, of good quality as a shelled-pea, and the young pods are tender and well flavored.

Plant about twenty inches high, branching; Farly Dwarf leaves of medium size, yellowish-green ; flowers white; pods two inches and three quarters in Dutch Sugar. Vil.

EarLy DWARF DE length, half an inch wide, somewhat sickle-shaped, swollen on the sides, flattened at the lower end, and containing five or six peas, which, when ripe, are roundish, often irregularly flattened or indented, wrinkled, and of a yellowish-white color.

The variety is the lowest-growing and earliest of all the Eatable-podded kinds. If sown at the time of the Common Dwarf Sugar, it will be fit for use twelve or fourteen days in advance of that variety. It requires a good soil; and the pods are succulent and tender, but are not considered superior to those of the Common Dwarf Sugar.

Stalk four to five feet high; leaves large, yellowish-green, stained with red at their union with the stalk of the plant; flower red-

Giant Eatable-podded. Vil.

Giant Sugar. dish; pods transparent yellowish-green, very thick and fleshy, distended on the surface by the seeds, which are widely distributed, curved, and much contorted, six inches long, and sometimes nearly an inch and a half in diameter, - exceeding in size that of any other variety. They contain but five or six seeds, which, when ripe, are irregular in form, and of a greenish-yellow color, spotted or speckled with brown.

It is about a week later than the Large Crooked Sugar. 
Lerge Crooked Sugar. Thomp. BROADSORD.
SIX-IXCII-POD SU- large, yellowish-green; flowers white; the pods
GAR. GAR.

Plant nearly six feet in height, and branching when grown in good soil; the leaves are are very large, - measuring from four to five inches in length and an inch in width, - broad, flat, and crooked. When young, they are tender, and easily snap or break in pieces, like the young pods of kidney-beans; and are then fit for use. The sides of the pods exhibit prominent marks where pushed out by the seeds, even at an early stage of growth. The ripe peas are somewhat indented or irregularly compressed, and of a yellowish-white color.

It is one of the best of the Eatable-podded sorts, and is hardy and productive. It is, however, quite late. Sown May 1, it blossomed the last of June, and produced pods for use in the green state the 20 th of July.

Purple-pod- Plant five feet high, generally without ded or Aus-
tralian. Law. branches; pods usually in pairs, flattened, with BLUE-PODED.
BOTANY-BA PEA. thick, fleshy skins, and commonly of a dark purple color; but this characteristic is not permanent, as they are sometimes found with green pods; in which case, they are, however, easily distinguished from those of other peas by their thick and fleshy nature. When ripe, the peas are of medium size, often much indented and irregularly compressed, and of a light, dunnish, or brown color. Season intermediate.

It is very productive, and seems possessed of properties which entitle it to cultivation.

Red-flowered Stem four or five feet in height, generally Sugar. Vil.

Cnocosatz. simple, but branching when grown in rich soil ; leaves long, yellowish-green, tinged with red where they connect with the stalk of the plant; flowers pale red; pods three inches long, seven tenths of an inch broad, more or 
less contorted, containing six to eight peas ; seed comparatively large, pale brown, marbled with reddish-brown.

Season nearly the same as that of the Common Dwarf Sugar. It is productive, remarkably hardy, and may be sown very early in spring, as it is little affected by cool and wet weather; but the green peas are not much esteemed, as they possess a strong and rather unpleasant flavor. The green pods are tender and good; and for these the variety may be worthy of cultivation.

Plant similar to the Common Dwarf Sugar, Tamarind but of more luxuriant habit, and with larger LATE DWARY SUfoliage ; flowers white ; pods single or in pairs, GAR. TAMARIND six to eight seeded, very large and broad, - often measuring four inches in length and an inch in breadth, - succulent, and generally contorted and irregular in form. A few days later than the Common Dwarf Sugar.

Hardy, prolific, and deserves more general cultivation.

Stem four to five feet high ; leaves yellowish- White-podgreen, and, like those of the Giant Eatable- ded Sil. podded, stained with red at their insertion with the stalk; flowers purple; the pods are nearly three inches loug, five eighths of an inch wide, sickle-shaped and contorted, of a yellowish-white color, and contain five or six peas. The ripe seeds are irregularly flattened and indented, of a greenish-yellow color, marbled or spotted with brown or black.

The variety is quite late. Sown May 1, the pods were not fit for use till July 24.

The pods are crisp and succulent, though inferior in flavor to most of the Eatable-podded varieties.

Stem three to four feet high; leaves large, Yellow-podyellowish-green; flowers white, tinted with yel- 
low; pods four inches long, tapering slightly at the ends, greenish-yellow, thick and fleshy, containing six or seven peas, widely separated. The ripe seeds are oblong, rather regular in form, and of a creamy-white color.

It is one of the earliest of the Eatable-podded sorts, coming to the table, if planted May 1, about the middle of July. It is of good quality, but not hardy or productive; and seems to have little to recommend it, aside from the singular color of its pods.

\section{PEA-N U T.}

Ground Bean. Earth Nut. Vil. Pindar Nut. Ground Nut. Arachys hypogea.

A native of Africa, and also of Central and Tropieal America. It is an annual plant; and the stem, when full grown, is about fifteen inches in height. The leaves are pinnate, with four leaflets, and a leafy, emarginate appendage at the base of the petioles; the flowers are yellow, and are produced singly, in the axils of the leaves; the fruit, or pod, is of an oblong form, from an inch to an inch and a half in length, rather more than three eighths of an inch in diameter, often contracted at the middle, but sometimes bottleformed, reticulated, and of a yellowish color; the kernels, of which the pods contain from one to three, are oblong, quite white, and enclosed in a thin, brown skin, or pellicle.

A remarkable peculiarity of this plant is, that the lower blossoms (which alone produce fruit), after the decay of the petals, insinuate their ovaries into the earth; beneath which, at the depth of several inches, the fruit is afterwards perfected.

The seed, or kernel, retains its germinative property but a 
single season; and, when designed for planting, should be preserved unbroken in the pod, or shell.

Soil and Cultivation. - The Pea-nut succeeds best in a warm, light, loamy soil. This should be deeply ploughed and well pulverized, and afterwards laid out in slightly raised ridges two feet apart. As the plants require the whole season for their perfection, the seed should be planted as early in spring as the weather becomes suitable. Drop nine inches apart in the drills, and cover an inch and a half or two inches deep. Weeding must be performed early in the season; as, after the blossoming of the plants, they are greatly injured if disturbed by the hoe, or if weeds are removed about the roots.

It is rather tropical in its character, and cannot be cultivated with success either in the Northern or Middle States.

"The seeds are sometimes dibbled in rows, so as to leave the plants a foot apart each way. As soon as the flowers appear, the vines are earthed up from time to time, so as to keep them chiefly within the ground. When cultivated alone, and there is sufficient moisture, the yield of nuts is from sixty to seventy-five bushels to the acre. If allowed to grow without earthing up, the vines will yield half a ton of hay to the acre. They are killed by the first frost, when the nuts will be mature, and ready for use."

\section{Varieties. -}

A comparatively small, smooth, and regularly formed sort. Shell thin, usually enclosing two African
Pea-nut. kernels.

Similar to the African. The pods, however, Wilmington are longer, and the shell is thicker and paler. Pea-nut. They rarely contain less than two, and often enclose three, 
kernels. Extensively cultirated in the Carolinas and Gulf States.

Tennessee Pea-nut.

Pods large, thick, and irregular in form; the reticulations very coarse and deep. The pods usually contain two kernels. Less esteemed than either of the preceding varieties.

\section{VETCH, OR TARE.}

Vicia sativa.

The Vetch, or Tare, in its properties and habits, somewhat resembles the Common Pea. There are numerous species as well as varieties, and the seeds of all may be used for food; but they are generally too small, or produced too sparingly, to repay the cost of cultivation.

The only variety of much importance to the garden is the following:-

White Tare, Annual; stem slender and climbing, about
or Vetch. Lavo.

LENTIL, of CANthree feet high, the leaves terminating in a ADA. NAPOLEON branching tendril, or clasper; flowers purplish ; pods brown, slender, containing from eight to twelve seeds, or grains, which are globular, sometimes slightly flattened, smooth, and of a yellowish-white color; they retain their germinative quality three years. An ounce contains about six hundred seeds.

In France and Canada, the seeds are used as a substitute for peas, both green and ripe, in soups and other dishes. They are also ground, and made into bread; but in this case their flour is generally mixed with that of corn, rye, or wheat.

The seeds may be sown in drills, in April or May, in the 
manner of garden peas, or broadcast with oats for agricultural purposes.

\section{Field Varieties. -}

An agricultural sort, grown at the north of

Summer England and in Scotland. It is sown broadcast, and cultivated as wheat or barley. Both the haum and seed are used.

Extensively grown in England and Scotland; usually sown in autumn, mixed with rye, for Winter Tare, or Vetch. early spring food for stock. The seeds are smaller than those of the summer variety.

Not sufficiently hardy to survive the winters of the Northern States.

\section{WINGED PEA.}

Red Birdsfoot Trefoil. Mill. Lotus tetragonolobus.

A hardy, creeping, or climbing, annual plant, fifteen or eighteen inches in height, or length ; leaves trifoliate ; flowers large, solitary, bright scarlet; pods three inches and a half long, with four longitudinal, leafy membranes, or wings; seeds globular, slightly compressed, yellowish-white.

Use. - The ripened seeds are sometimes used as a substitute for coffee ; and the pods, while young and tender, form an agreeable dish, not unlike string-beans. It is often cultivated as an ornamental plant, and for this purpose is generally sown in patehes, four or five seeds together on the border, where the plants are intended to remain.

When grown as an esculent, sow in double drills an inch and a half deep, and two feet apart, the single rows being made twelve inches from each other. 


\section{CHAPTER $\mathrm{X}$.}

\section{MEDICINAL PLANTS.}

Bene-plant. Chamomile. Coltsfoot. Elecampane. Hoarhound. Hyssop. Licorice. Mandrake, or May Apple. Pennyroyal. Poppy. Palmate-leaved or Turkey Rhubarb. Rue. Saffron. Southernwood. Wormwood.

\section{B EN E-P L A N T.}

Oily Grain. Sesamum sp.

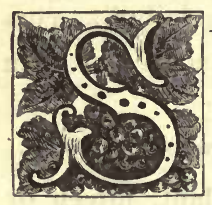

AID to have been introduced into this country from Africa by the negroes. It is cultivated in the south of Europe, and in Egypt is grown to a considerable extent for forage and culinary purposes.

It is a hardy annual, with an erect, four-sided stem from two to four feet high, and opposite, lobed, or entire leaves ; the flowers terminate the stalk in loose spikes, and are of a dingy-white color; the seeds are oval, flattened, and produced in an oblong, pointed capsule.

Propagation and Cultivation. - It is propagated from seeds, which should be sown in spring, as soon as the ground has become well settled. They may be sown where the plants are to remain; or in a nursery-bed, to be afterwards transplanted. The plants should be grown in rows eighteen inches or two feet apart, and about a foot apart in the rows. The after-culture consists simply in keeping the ground loose, and free from weeds. The plant is said to yield a much greater 
amount of herbage if the top is broken or cut off when it is about half grown.

Use._ "The seeds were at one time used for food; being first parched, then mixed with water, and afterwards stewed with other ingredients. A sort of pudding is made of the seeds, in the same manner as rice, and is by some persons much esteemed. From the seeds of the first-named sort an oil is extracted, which will keep many years without having any rancid smell or taste. In two years, the warm taste which the new oil possesses wears off, and it becomes quite mild and pleasant, and may be used as a salad-oil, or for all the purposes of olive-oil. Two quarts of oil have been extracted from nine pounds of the seeds."

The properties of the plant are cooling and healing, with some degree of astringency. A few of the leaves, immersed a short time in a tumbler of water, give it a jelly-like consistence, without imparting color or flavor ; and in this form it is generally used.

There are three varieties :-

Plant larger than that of the Oval-leaved; Biformedthe lower leaves ared. Mill. the lower leaves are three-parted, while those of the upper part of the stalk are oval or entire.

Stem about two feet high, with a few short Oral-leaved. branches; the leaves are oblong, and entire on the borders.

Taller and more vigorous than either of the Trifid-leaved. preceding. The upper as well as the lower Mill. leaves are trifid, or three-parted. 


\section{CHAMOMILE.}

Anthemis nobilis.

This is a half-hardy, herbaceous, perennial plant, growing wild in various parts of England, by roadsides and in gravelly pastures. Its stems rest upon the surface of the ground, and send out roots, by which the plants spread and are rapidly increased.

Soil and Culture. - Chamomile flourishes best in light, poor soil, and is generally propagated by dividing the roots, and setting them in rows a foot apart, and eight or ten inches from each other in the rows. They will soon entirely occupy the ground.

Gathering. - The flowers should be gathered in a dry day, and when they are fully expanded. They are generally spread in an airy, shady situation for a few days, and afterwards removed to a heated apartment to perfect the drying.

Common Chamomile.

The flowers of this variety are single. Though considered more efficacious for medicinal purposes, it is not so generally cultivated as the Double-flowering. The leaves are finely cut, or divided; and, when bruised, emit a peculiar, pungent odor. It may be grown from seeds, or slips, and from divisions of the plants, or roots.

Double-flowering Chamomile.

A variety of the foregoing, with large, white, double flowers. The leaves are of the same form, but milder in their odor and taste. It is equally hardy with the Single-flowering, and much more ornamental. Though generally considered less efficacious than the last named, it is generally cultivated for use and the market on account of the greater bulk and weight of its flowers. 
It is propagated by slips, with a few of the small roots attached. Both of the sorts are classed as hardy perennials; but, in the Northern and Eastern States, the plants are frequently destroyed in severe winters.

Use._ "The flowers, which are the parts principally used, have long been in high repute, both in the popular and scientific Materia Medica, and give out their properties by infusion in either water or alcohol. The flowers are also sometimes used in the manufacture of bitter beer, and, along with Wormwood, made, to a certain extent, a substitute for hops. In many parts of England, the peasants have what they call a 'Chamomile seat' at the end of their gardens, which is constructed by cutting out a bench in a bank of earth, and planting it thickly with the Double-flowering variety; on which they delight to sit, and fancy it conducive to health." - McInt.

It is considered a safe bitter, and tonic; though strong infusions, when taken warm, sometimes act as an emetic.

\section{COMMON COLTSFOOT.}

Tussilago farfara.

A hardy, herbaceous, perennial plant. The leaves are all radical, roundish-heart-shaped, and from five to seven inches in diameter; the flower-stem (scape) is six or seven inches high, imbricated, and produces a solitary yellow flower, which is about an inch in diameter. The plants blossom in February and March, before the appearance of the leaves, and often while the ground is still frozen, and even covered with snow.

Propagation and Culture. - Coltsfoot thrives best in rich, moist soil. It may be propagated from seeds, but is generally increased by dividing its long, creeping roots. The 
plants require little attention, and will soon occupy all the space allotted.

Gathering and Use. - The leaves are the parts of the plant used, and are generally cut in July and September. They should not be exposed to the sun for drying, but spread singly in an airy, shaded situation. They are esteemed beneficial in colds and pulmonary disorders.

\section{E LE CA M A NE.}

Inula helenium.

A hardy, herbaceous, perenuial plant, introduced from Europe, but growing spontaneously in moist places, by roadsides, and in the vicinity of gardens where it has been cultivated. Stem from three to five feet high, thick and strong, branching towards the top; the leaves are from nine inches to a foot in length, ovate, toothed on the margin, downy beneath; the flowers are yellow, spreading, and resemble a small sunflower; the seeds are narrow, four-sided, and crowned with down.

The plants blossom in July and August, and there is but one variety cultivated.

Propagation and Culture. - It is generally propagated by dividing the roots, but may be grown from seeds, which are sown just after ripening. The plants should be set in rows two feet asunder, and a foot from each other in the rows.

Use. - Elecampane is cultivated for its roots, which are carminative, sudorific, tonic, and alleviating in pulmonary diseases. They are in their greatest perfection when of two years' growth. 


\section{HOARHOUND.}

Marrubium vulgare.

Hoarhound is a hardy, herbaceous, perennial plant, introduced from Europe, and naturalized to a considerable extent in localities where it has been once cultivated. Stem hoary, about two feet high; leaves round-ovate; flowers white; seeds small, of an angular-ovoid form and grayish-brown color.

Propagation and Cultivation. - The plant prefers a rich, warm soil, and is generally propagated by dividing its long, creeping roots, but may also be raised from seeds. When once established, it will grow almost spontaneously, and yield abundantly.

Gathering and Use. - The plants are cut for use as they come into flower, and, if required, the foliage may be cut twice in the season.

The leaves possess a strong and somewhat unpleasant odor, and their taste is "bitter, penetrating, and durable." The plant has long been esteemed for its efficacy in colds and pulmonary consumption.

\section{HYSSOP.}

Hyssopus officinalis.

Hyssop is a hardy, evergreen, dwarfish, aromatic shrub, from the south of Europe.

Three kinds are cultivated, as follow :-

More generally found in gardens than either Common, or of the following varieties. The stems are $\begin{gathered}\text { Blue-flow } \\ \text { ering. }\end{gathered}$ square and tender at first, but afterwards become round and woody; the leaves are opposite, small, narrow, with six or 
eight bract-like leaves at the same joint; the flowers are blue, in terminal spikes; seeds small, black, oblong.

Red-flower- Quite distinct from the Common, or Blueing Hyssop. flowering. The stem is shorter, the plants are more branching in their habit, and the spikes more dense or compact; flowers fine red. It is not so hardy as the White or the Blue Flowering, and is often injured by severe winters.

White-flowering Hyssop.

This is a sub-variety of the Common Blueflowering, the principal if not the only mark of distinction being its white flowers. Its properties, and modes of culture, are the same.

Soil and Cultivation. - The plants require a light, warm, mellow soil, and are propagated from seeds, cuttings, or by dividing the roots. The seeds are sown in April; and, when the seedlings are two or three inches high, they are transplanted to rows eighteen inches apart, and a foot from each other in the rows. The roots may be divided or the slips set in spring or autumn.

Use. - The plant is highly aromatic. The leaves and young shoots are the parts used, and are cut, dried, and preserved as other pot-herbs.

"Hyssop has the general virtues ascribed to aromatic plants, and is recommended in asthmas, coughs, and other pulmonary disorders." - Rog.

\section{LICORICE.}

Glycyrrhiza glabra.

Licorice is a hardy, perennial plant. The roots are fleshy, creeping, and, when undisturbed, attain a great length, and penetrate far into the earth; the stem is herbaceous, dull 
green, and about four feet high ; leaves pinnate, composed of four or five pairs of oval leaflets ; flowers pale blue, in terminal spikes. The fruit consists of short, flattened pods, each containing two or three kiduey-shaped seeds.

Soil, Propagation, and Culture. - "Licorice succeeds best in deep, rich, rather sandy, or in alluvial soil. The ground should be well enriched the year previous to planting; and it should either be trenched three feet deep in autumn, laid in ridges, and allowed to remain in that state till spring; or it may be trenched immediately before planting. The former method is the preferable one.

"Licorice is propagated by portions of the creeping stem (commonly termed 'the creeping root'), from four to six inches in length, each having two or three buds. These are planted in March or April, or as soon as the ground can be well worked, in rows three feet apart, and eighteen inches from each other in the rows; covering with earth to the depth of two or three inches. Every year, late in autumn, when the sap has gone down and the leaves have turned yellow, the old stems should be cut down with a pruning-knife to a level with the ground. At this time, also, the creeping stems are forked up, cut off close to the main stems, and preserved in sand, or in heaps covered with straw and earth, for future plantations. The roots will be ready for taking up three years after planting. This should be done towards winter, after the descent of the sap. A trench three feet deep must then be thrown out, and the roots extracted; after which they may be stored in sand for use." - Thomp.

Use. - The roots are the parts of the plant used, and these are extensively employed by porter brewers. "The sweet, mucilaginous juice extracted from the roots by boiling is much esteemed as an emollient in colds." 


\section{MANDRAKE, OR MAY-A PPLE.}

Lime Plant. Podophyllum peltatum.

A hardy, herbaceous, perennial plant, growing in rich, moist localities, and more or less abundant in most of the Northern States. The root is creeping, nearly half an inch in diameter, brown without and yellow within. The stem is twelve or fifteen inches high, round and smooth, and terminates in two large, peltate, palmate leaves. In the fork of the stem is put forth a large, solitary, nodding, white flower, many of which, under cultivation, are found abortive. The fruit is of an oval form, an inch and a half or two inches in diameter, yellow, with brownish spots, at maturity, slightly acid, with somewhat of the flavor of the strawberry, pleasant to some palates, but disagreeable to others. The plants blossom in May, and the fruit ripens in June.

Soil, Propagation, and Culture. - The Mandrake requires a rich, moist soil, and thrives best when not too much exposed to the action of the sun. It propagates readily, and is of easy culture, but is seldom raised from seeds. It is usually increased by dividing the creeping, branching roots, which may be done either in spring or autumn, taking care to leave a bud or two on each division, and covering them about two inches deep. They quickly become established, rapidly multiply, and soon entirely cover the ground. They need no protection during winter, require little cultivation, and often extend into swarded ground, making their appearance year after year, healthy and vigorous.

Use. - Though the root and foliage are described by moderu botanists as being poisonous, it is considered one of the most important of all medicinal plants. As an alterative, cathartic, vermifuge, and especially for diseases of the liver, it is said to be one of the most efficient of remedial agents. 
It should, however, be employed with cantion, and is prudently administered only when prescribed and prepared by a physician.

\section{PENNYROYAL.}

Hedeoma pulegioides.

The American Pennyroyal is a small, branching, annual plant, common to gravelly localities, and abounding, towards autumn, among stubble in dry fields from whence crops of wheat or rye have been recently harvested. The stem is erect, branching, and from six to twelve inches high; the leaves are opposite, oval, slightly toothed ; flowers bluish, in axillary clusters; seeds very small, deep blackish-brown.

Sowing and Cultivation. - In its natural state, the seeds ripen towards autumn, lie dormant in the earth during winter, and vegetate the following spring or summer. When cultivated, the seeds should be sown soon after ripening, as they vegetate best when exposed to the action of frost during winter. They are sown broadcast, or in drills ten or twelve inches asunder. When the plants are in full flower, they are cut off, or taken up by the roots, and dried in an airy, shaded situation.

Use. - Pennyroyal possesses a warm, pungent, somewhat aromatic taste, and is employed exclusively for medical purposes. An infusion of the leares is stimulating, sudorific, tonic, and beneficial in colds and chills.

This plant must not be confounded with the Pennyroyal (Mentha pulegium) of English writers, which is a species of Mint, and quite distinct from the plant generally known as Pennyroyal in this country. 


\section{POPPY, OR MAW.}

Papaver somniferum, var. nigrum.

A hardy annual, growing naturally in different parts of Europe, and cultivated to a considerable extent in Germany for its seeds, which, under the name of "Maw-seed," are an article of some commercial importance. Stem five or six feet high, branching ; leaves smooth, glaucous, clasping, and much cut or gashed on the borders; flowers large, terminal, purple and white; the bud pendent, or drooping, until the time of flowering, when it becomes erect. The petals soon fall to the ground, remaining on the plant but a few hours after their expansion; and are succeeded by large, roundish heads, or capsules, two inches and upwards in diameter, filled with the small, darkish-blue seeds for which the plant is principally cultivated.

Soil, Sowing, and Culture. - "The soils best suited to the growth of the Poppy are such as are of medium texture and in the highest state of fertilization. As the seeds are small, and consequently easily buried, the land should be well pulverized by harrowing and rolling. The seeds are sown in April, in drills about half an inch in depth, and twenty inches or two feet distant from each other. The young plants are afterwards thinned out to from six to ten inches' distance in the rows, and the whole crop kept free from weeds by frequent hoeing.

"The period of reaping is about the month of August, when the earliest, and generally the largest, capsules begin to open. The plants are then cut or pulled, and tied in small bundles, taking care not to allow the heads to recline until they are carried to the place allotted for the reception of the seed, which is then shaken out, and the sheaves again set upon their ends for the ripening of the remaining capsules. 
"In Germany and Flanders, a mode of obtaining the îrst crop is to spread sheets by the side of the row, into which the seeds are shaken by bending over the tops of the plants: these are then pulled, tied in bundles, and removed; when the sheets are drawn forward to the next row, and so on, until the harvesting is completed." - Law.

Use. - Maw-seed is imported to some extent from different parts of Europe, and is principally used in this country for feeding birds.

Stem three feet high, smooth and branching; Oil-Poppy. flowers dull red, or grayish; capsules very GRAYPoprr. large, oblong; seeds of a brownish color, and PrerUM OLIFR. produced in great abundance.

It is chiefly cultivated in Italy, the south of France, Germany, and Flanders.

Use. - "The oil of the seeds of the Poppy is of an agreeable flavor, and in Europe is chiefly applied to domestic purposes, for which it is esteemed nearly equal to that of the olive. Its consumption in this country is comparatively trifling, being principally used for the finer kinds of oil-painting and by druggists."

Plant strong and vigorous, - the stem, in favorable situations, reaching a height of five or six feet; flowers large, white, and of short duration; seed-pods globular, of large size, often

Opium, or py. Low. P. SOMNIFERUM, ALBUM VEL CAN DIDUM. measuring upwards of two inches in diameter; seeds small, white, ripening in August and September.

Sowing and Cultivation. - "Being an annual plant, the Poppy, when sown in spring, matures its seed the last of summer or early in autumn. It is of easy culture, and can be successfully grown in any section of the Northern or Mid- 
dle States. It may be sown at any time during the month of April, or the first week in May. The best method of cultivating the plant is in rows two feet and a half apart; and, on the poppies attaining a few inches in height, they are hoed out to a distance from one another of six or eight inches.

"Opium is obtained from the capsules or heads of seed, and is extracted after they are fully formed, but while yet green. The process is simple, and may be taught to children in an hour.

"Two or more vertical incisions are made in the capsule with a sharp knife or other instrument, about an inch in length, and not so deep as to penetrate through the capsule. As soon as the incisions are made, a milky juice will flow out, which, being glutinous, will adhere to the capsule. This may be collected by a small hair-brush such as is used by painters, and squeezed into a small vessel carried by the person who collects the juice. The incisions are repeated at intervals of a few days all round the capsule, and the same process of collecting the exuded juice is also repeated.

"The juice thus collected is Opium. In a day or two, it is of the consistence to be worked up into a mass. The narcotic matter of the plant may also be collected by boiling; but it is only the exuded juice that forms pure Opium.

"In the opium countries of the East, the incisions are made at sunset by several-pointed knives or lancets. On the following day the juice is collected, scraped off with a small iron scoop, and deposited in earthen pots, when it is worked by the hand until it becomes consistent. It is then formed in globular cakes, and laid in small earthen basins to be further dried. After the opium is extracted from the capsule, the plant is allowed to stand, and ripen its seeds.

"The seeds of the Poppy have nothing of the narcotic principle, and are eaten by the people of the East as a 
nourishing and grateful food; and they yield, by expression, an oil which is regarded as inferior only to that of the olive." - Low.

The expense of labor forms the principal objection to the cultivation of the Poppy in the United States for its opium. As, however, the plants succeed well, and can be easily and extensively grown in any section of the country, and as the process of extraction, though minute, is yet simple, the employment of females or children might render its production remunerative.

\section{PALMATE-LEAVED RHUBARB. Law.}

Turkey Rhubarb. Rheum palmatum.

This species is readily distinguished by its deeply divided or palmate leaves, and is generally considered as that from which the dried roots chiefly used in medicine are obtained. Like the Pie Rhubarb, it requires a deep, rich soil, which should be thoroughly stirred, and put in as fine a state of cultivation as possible, before setting the plants. These should be placed about three feet apart in each direction, and kept free from weeds during the summer. They will not be ready for taking up until five or six years old.

The roots are thick and succulent, with a brownish skin and bright yellow flesh, streaked or variegated with red. After being dug, they are washed clean, cut in rather large pieces, and dried, either by the sun or in kilns formed for the purpose, when they are ready for use.

Rhubarb from Turkey and the neighboring countries is generally preferred; but it is said its superiority, to a great degree, is attributable to the manner in which it is dried and prepared for market. It is propagated by seed, or by a division of the roots. 
R UE.

Ruta graveolens.

Rue is a hardy, shrubby, nearly evergreen plant, and thrives best in poor but dry and warm soil. It is propagated by seeds, or slips, and by dividing the roots. The seeds are sown in April, and the roots may be separated in spring or autumn. The plants should be set about eighteen inches apart in each direction. When extensively cultivated, they are set in rows eighteen inches apart, and a foot asunder in the rows.

Use. - " Rue has a strong, unpleasant odor, and a bitter, pungent, penetrating taste. The leaves are so acrid as to irritate and inflame the skin, if much handled. Its efficacy as a vermifuge is unquestioned; but it should be used with caution. It was formerly employed in soups; and the leaves, after being boiled, were eaten pickled in vinegar." The plant is rarely used in this country, either as an esculent or for medical purposes.

The kinds cultivated are the following:-

Broadleaved Rue.

Stem shrubby, four or five feet high; leaves compound, of a grayish-green color and strong odor; flowers yellow, in terminal, spreading clusters; the fruit is a roundish capsule, and contains four rough, black seeds.

At one period, this was the sort principally cultivated, and is that referred to in most treatises on medicine. More recently, however, it has given place to the Narrow-leaved, which is much hardier and equally efficacious.

Narrow- Stem three or four feet high; foliage narleaved Rue. rower than that of the preceding, but of the same grayish color, and strong, peculiar odor; the flowers 
are produced in longer and looser clusters than those of the Broad-leaved, and the seed-vessels are smaller. Now generally cultivated because of its greater hardiness.

\section{SAFFRON. Law.}

Safflower. Carthamus tinctorius.

A hardy, annual plant, with a smooth, woody stem, two and a half or three feet high; leaves ovate, spiny ; flowers large, compound, bright orange, or vermilion; seeds ovate, whitish, or very light brown, a fifth of an inch long, and a tenth of an inch thick.

Soil and Cultivation. - It grows best on soils rather light, and not wet, and the seed should be sown the last of April, or early in May, in drills about two feet apart and an inch deep. When the plants are two inches high, they should be thinned to six inches apart in the rows, and afterwards occasionally hoed during the summer, to keep the earth loose, and free the plants from weeds.

Use. _ "It is cultivated exclusively for its flowers, from which the coloring-matter of Saffron, or Safflower, is obtained. These are collected when fully expauded, and dried on a kiln, under pressure, to form them into cakes, in which state they are sold in the market. It is extensively cultivated in the Levant and several countries of Europe, particularly France, Spain, and Germany, in the latter of which the first gathering of flowers is obtained in the beginning of September; and others, for six or eight weeks following, as the flowers expand. It flowers somewhat earlier in this country, and seems well adapted to our climate.

"Though the color of the petals is of a deep orange, they are used for dyeing various shades of red, the yellow matter being easily separated from the other. The flowers of Saffron 
are employed in Spain and other countries for coloring dishes and confectioneries, and from the seed a fixed oil is obtained, somewhat similar to that of the Sunflower; for which purpose alone, it does not, however, seem deserving of cultivation."

It was formerly much used in medicine in cases of humors and diseased blood.

\section{SOUTHERN W OOD.}

Artemesia abrotanum.

A hardy, shrubby plant, about three feet high. The leaves are pale green, and cut, or divided, into narrow, thread-like segments; the flowers are numerous, small, yellow, drooping; the seeds resemble those of the Common Wormwood, and retain their germinative properties two years.

The plant is generally propagated by dividing the roots in the manner of other hardy shrubs.

Use. - The leaves have a strong, resinous, somewhat aromatic and rather pleasant odor, and are quite bitter to the taste. The root is seldom used, but the leaves and young branches are employed in the same manner and for the same purposes as those of the Common Wormwood.

\section{WORM WOOD.}

Artemesia.

The cultivated species are as follow :-

Common Wormwood. ARTEMESIA ABSYNTHIUM. 
pale green above, and hoary beneath; the flowers are small, numerous, pale yellow; the seeds are quite small, and retain their powers of germination two years.

The leaves, when bruised, have a strong, somewhat pungent, yet aromatic odor, and are proverbial for their intense bitterness.

This species somewhat resembles the fore- Roman going; but the roots are smaller, less woody, ARTraksia Poxand more fibrous, and the stalks are shorter and more slender ; the leaves are smaller, more finely cut, or divided, pale green above, and hoary on the under surface, like those of the Common Wormwood; the flowers, which are produced on the upper branches, are small, and of a pale yellow color ; the seeds are similar to those of the above species, and retain their vitality two years.

It is generally preferred to the Common Wormwood for medicinal purposes, as the taste is more agreeable, and its odor less pungent.

Indigenous to Great Britain, and common to Sea Wormthe seaco wood. the sea-coast of Holland and the low countries ABTEMESAA MABIof Europe. Roots creeping, tough, and fibrous ; stalks two or three feet high, and, like the roots, tough and woody; leaves numerous, long, narrow, and hoary; flowers yellow, produced on the small branches towards the top of the plant; seeds similar to those of the Common Wormwood.

The leaves are somewhat bitter to the taste, and, when bruised, emit a strong, pleasant, aromatic odor.

Soil and Cultivation. - All of the species are hardy, aromatic perennials ; and, though they will thrive in almost any soil, their properties are best developed in that which is warm, dry, and light. They are generally propagated, as other 
hardy shrubs, by dividing the plants, but may be raised from seeds or slips. The seeds are sown in April, in shallow drills, and the seedlings afterwards transplanted to rows two feet apart, and a foot from each other in the rows.

Use. "An infusion of the leaves and tops of the Common Wormwood is used as a vermifuge, tonic, and stomachic, and the leaves are found to be beneficial to poultry." - Thomp.

Most of the other species possess the same properties in a greater or less degree, and are used for the same purposes. 


\section{CHAPTER XI.}

\section{MUSHROOMS, OR ESCULENT FUNGI.}

Agaricus. Boletus. Clavaria. Morchella, or Morel. Tuber, or Truffle.

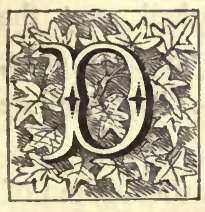

IFFICULT as is the artificial management of Mushrooms, there can be no doubt that all of the edible kinds would finally submit to, and probably be improved by, cultivation, though as yet but a single species has been generally introduced to the garden. Many of them are natives of this country, abounding in our woods and pastures, and may be gathered wild, and freely enjoyed by those who have not the means of raising them artificially. In Poland and Russia, there are about thirty sorts of edible Fungi in common use among the peasantry. They are gathered in all the different stages of their growth, and used in various ways, - raw, boiled, stewed, roasted, - and being hung up, and dried in stoves or chimneys, form a part of their winter's stock of provisions.

\section{COMMON MUSHROOM. McInt. Rog.}

Champignon. Agaricus campestris.

This Mushroom, when it first appears, is of a rounded or button-like form, of a white color, and apparently rests on 
the surface of the ground. When fully developed, "the stem is solid, two or three inches high, and about half an

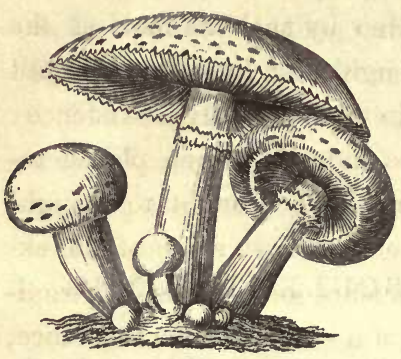

Common Mushroom. inch in diameter; its cap measures from an inch to three, and sometimes even upwards of four inches in diameter, is of a white color, changing to brown when old, and becoming scurfy, fleshy, and regularly convex, but, with age, flat, and liquefying in decay ; the gills are loose, of a pinkish-red, changing to liver color, in contact with, but not united to, the stem, very thick-set, some forked next the stem, some next the edge of the cap, some at both ends, and generally, in that case, excluding the intermediate smaller gills."

Loudon says that it is most readily distinguished, when of middle size, by its fine pink or flesh-colored gills and pleasant smell. In a more advanced stage, the gills become of a chocolate color; and it is then more liable to be confounded with other kinds of dubious quality: but the species which most nearly resembles it is slimy to the touch, and destitute of the fine odor, having rather a disagreeable smell. Further, the noxious kind grows in woods, or on the margin of woods; while the true Mushroom springs up chiefly in open pastures, and should be gathered only in such places.

Cultivation. - "This is the only species that has as yet been subjected to successful cultivation; though there can be little doubt that all or most of the terrestrial-growing sorts would submit to the same process, if their natural habitats were sufficiently studied, and their spawn collected and propagated. In this way the Common Mushroom was first brought under the control of man.

"1." The seeds of the Common Mushroom, in falling from the 
gills when ripe, are, no doubt, wafted by the wind, and become attached to the stems and leaves of grasses and other herbage ; and notwithstanding they are eaten by such animals as the horse, deer, and sheep, pass through their intestines without undergoing any material change in their vegetative existence : and hence, in the dung of these animals, when placed together, and kept moderately dry, and brought to a slight state of fermentation, we discover the first stage of the existence of the future brood of mushrooms. This is practically called 'spawn,' and consists of a white, fibrous substance, running like broken threads through the mass of dung, which appears to be its only and proper nidus." - McInt. It is prepared for use as follows: -

"In June and July, take any quantity of fresh horse-droppings, - the more dry and high-fed the better, - mixed with short litter, one third of cow's dung, and a good portion of mould of a loamy nature; cement them well together, and mash the whole into a thin compost, and spread it on the floor of an open shed, to remain until it becomes firm enough to be formed into flat, square bricks; which done, set them on an edge, and frequently turn them till half dry; then, with a dibble, make two or three holes in each brick, and insert in each hole a piece of good old spawn about the size of a common walnut. The bricks should then be left till they are dry. This being completed, level the surface of a piece of ground, under cover, three feet wide, and of sufficient length to receive the bricks, on which lay a bottom of dry horse-dung six inches thick; then form a pile by placing the bricks in rows one upon another, with the spawn side uppermost, till the pile is three feet high; next cover it with a small portion of warm horse-dung, sufficient in quantity to diffuse a gentle glow of heat through the whole. When the spawn has spread itself through every part of the bricks, the process is ended, and the bricks may then be laid up in 
a dry place for use. Mushroom-spawn thus made will preserve its vegetative power many years, if well dried before it is laid up ; but, if moist, it will grow, and exhaust itself." - Trans.

The next step to be taken is the formation of the bed, in the preparation of which no dung answers so well as that of the horse, when taken fresh from the stable: the more droppings in it the better. The process recommended by Rogers is as follows :-

"About July or August is the general season for making mushroom-beds, though this may be done all the year round. A quantity of the dung mentioned should be collected and thrown together in a heap, to ferment and acquire heat; and, as this heat generally proves too violent at first, it should, previously to making the bed, be reduced to a proper temperature by frequently turning it in the course of the fortnight or three weeks; which time it will most likely require for all the parts to get into an even state of fermentation. During the above time, should it be showery weather, the bed will require some sort of temporary protection, by covering it with litter or such like, as too much wet would soon deaden its fermenting quality. The like caution should be attended to in making the bed, and after finishing it. As soon as it is observed that the fiery heat and rank steam of the dung have passed off, a dry and sheltered spot of ground should be chosen on which to make the bed. This should be marked out five feet broad; and the length, running north and south, should be according to the quantity of mushrooms likely to be required. If for a moderate family, a bed twelve or fourteen feet long will be found, if it takes well, to produce a good supply of mushrooms for some months, provided proper attention be paid to the covering.

"On the space marked for making the bed, a trench should be thrown out about six inches deep. The mould may be 
laid regularly at the side, and, if good, it will do for earthing the bed hereafter : otherwise, if brought from a distance, that of a more loamy than a sandy nature will be best.

"Whether in the trench, or upon the surface, there should be laid about four inches of good litter, not too short, for forming the bottom of the bed; then lay on the prepared dung a few inches thick, regularly over the surface, beating it as regularly down with the fork ; continue thus, gradually drawing in the sides to the height of five feet, until it is narrow at the top, like the ridge of a house. In that state it may remain for ten days or a fortnight, during which time the heat should be examined towards the middle of the bed by thrusting some small sharp sticks down in three or four places, and, when found of a gentle heat (not hot), the bed may be spawned; for which purpose, the spawn-bricks should be broken regularly into pieces about an inch and a half or two inches square, beginning within six inehes of the bottom of the bed, and in lines about eight inches apart. The same distance will also do for the pieces of spawn, which are best put in by one hand, raising the manure up a few inches, whilst with the other the spawn can be laid in and covered at the same time.

"After spawning the bed, if it is found to be in that regular state of heat before mentioned, it may be earthed. After the surface is levelled with the back of the spade, there should be laid on two inches of mould, - that out of the trench, if dry and good, will do ; otherwise make choice of a rich loam, as before directed. After having been laid on, it is to be beaten closely together ; and, when the whole is finished, the bed must be covered about a foot thick with good oat or wheat straw; over which should be laid mats, for the double purpose of keeping the bed dry, and of securing the covering from being blown off. In the course of two or three days, the bed should be examined, and, if it is coil- 
sidered that the heat is likely to increase, the covering must be diminished for a few days, which is better than taking it entirely off.

"In about a month or five weeks, - but frequently within the former time, if the bed is in a high state of cultivation, mushrooms will most likely make their appearance, and, in the course of eight and forty hours afterwards, they will have grown to a sufficient size for use. In gathering, instead of cutting them off close to the ground, they should be drawn out with a gentle twist, filling up the cavity with a little fine mould, gently pressed in level with the bed. This method of gathering is much better than cutting, as the part left generally rots, and breeds insects, which are very destructive, both in frames and on mushroom-beds.

"Where a mushroom-bed is to remain permanently, a covered shed will be found convenient.

"Sometimes it happens that a bed suddenly ceases to produce any mushrooms. This arises from various causes, but principally from the cold state of the bed in winter, or from a too dry state in summer. In the former case, a slight covering of mulchy hay laid over the bed, and on that six or eight inches of well-worked, hot dung, and the whole covered lightly with the straw that was taken off, will most likely bring it about again. In the latter instance, moisture, if required, should be given moderately, two or three mornings; when, after lying about an hour, the whole may be covered up, and be found of much service. In summer, most mushroom-beds in a bearing state require more or less slight waterings. Soft water should be used for the purpose : spring water is of too hard and too cold a nature, and, when at any time applied, checks vegetation. In summer time, a gentle shower of rain, on open beds that are in bearing and seem dry, will add considerably to their productiveness. 
"A mushroom-bed seldom furnishes any abundance after two or three months : it has often done its best in six or seven weeks. Heavy rains are most destructive to mushrooms : therefore care should be taken to remove the wet straw, or litter, aud directly replace it with dry. Hence the utility of a covered shed, or mushroom-house."

In addition to the foregoing, the following native species may be eaten with perfect safety, if gathered young and used while fresh :-

"An excellent species, much employed for making catchup, but should be used in a young Agaricus Comatus. state. It is found growing abundantly on stumps of trees, appearing both in spring and autumn."

Found in September and October, growing under fir and pine trees. It is of medium size, yellowish, zoned, with deep orange on the top, Agaricus Deliciosus. McInt. SWEET MusiBOOM.

somewhat resembling $A$. torminosus (a deleterious species), but readily distinguished from it, as its juice is, when fresh cut, quite red, afterwards turning green, while that of the latter is white and unchangeable.

Sir James Edward Smith says it well deserves its name, and is really the most delicious mushroom known; and Mr. Sowerby is equally high in its praise, pronouncing it very luscious eating, full of rich gravy, with a little of the flavor of mussels.

This species often attains a weight of five or six pounds. It is generally considered less delicate than the common cultivated mushroom (A. campestris), but in Hungary it is regarded Agaricus Exquisitus. Budham.

ST. GKORGE's MUSHROOM. MeInt AGARI. cUS Grokg1I. as a special gift from the saint whose name it bears. Persoon describes it as superior to A. campestris in smell, taste, 
and digestibility; on which account, he says, it is generally preferred in France.

It is found abundantly in many places, generally growing in rings, and reappearing for many successive years on the same spot, and, though sometimes met with in old pastures, is generally found in thickets, under trees.

Agaricus Personatus. BLEWITs. BLuE
HATs. Cooke.

pileus, with a solid, somewhat bulbous stem, tinted with lilac. The gills are dirty-white, and rounded towards the stem.

The Agaricus personatus constitutes one of the very few mushrooms which have a market value in England. It is quite essential that it should be collected in dry weather, as it absorbs moisture readily, and is thereby injured in flavor, and rendered more liable to decay.

Agaricus Prunulus. Vitt. IICInt.

This is found only in spring, growing in rings on the borders of wood-lands, at which time abundance of its spawn may be procured, and may be continued in the same way that the spawn of the common cultivated mushroom is; namely, by transplanting it into bricks of loam and horse-dung, in which it will keep for months.

This mushroom is used both in its green and dried state. In the latter it constitutes what is called "Funghi di Genoa," and is preserved by being simply cut into four pieces, and dried in the air for a few days, when it is strung up, and kept for use.

There is little difficulty in distinguishing this mushroom, which is found growing in rings. The pileus is of a brownish-ochre color 
at first, becomes paler as it grows older, until it fades into a rich cream-yellow.

Dr. Badham says, "Independent of the excellent flavor of this little mushroom, two circumstances make it valuable in a domestic point of view - the facility with which it is dried, and its extensive dissemination." It may be kept for years without losing any of its aroma or goodness.

BOLETUS. Fries.

Of this, two species are considered eatable - the $B$. edulis and the $B$. scaber; the former resembling the Common Mushroom in taste, and the latter of good quality while in a young, fresh state, but of little value when dried, as it loses much of its odor, and becomes insipid, and unfit for use:

\section{A V A R I A.}

All the species are edible, and many of them indigenous to our woods, being usually found in damp, shady places.

\section{THE MOREL. McInt.}

\section{Morchella esculenta.}

In its natural state, the Morel is found growing in orchards, damp woods, and in moist pastures. Its height is about four inches. It is distinguished by its white, cylindrical, hollow, or solid, smooth stem; its cap is of a pale brown or gray color, nearly spherical, hollow, adheres to the stem by its base, and is deeply pitted over its entire surface. It is in 
perfection early in the season, but should not be gathered soon after rain, or while wet with dew. If gathered when dry, it may be preserved for several months.

Use. - The Morels are used, like the Truffle, as an ingredient to heighten the flavor of ragouts, gravies, and other

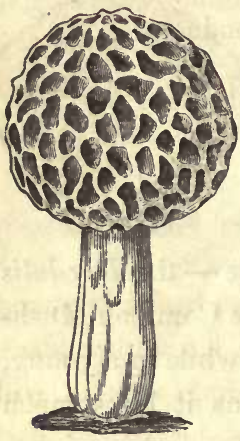

The Morel. rich dishes. They are used either fresh or in a dried state.

Cultivation. - Its cultivation, if ever attempted, has been carried on to a very limited extent. Of its capability of submitting to culture there can be little doubt. If the spawn were collected from its natural habitats in June, and planted in beds differently formed, but approximating as nearly as possible to its natural conditions, a proper mode of cultivation would assuredly be in time arrived at. Persoon remarks that "it prefers a chalky or argillaceous soil to one of a sandy nature, and that it not unfrequently springs up where charcoal has been burned, or where cinders have been thrown."

"The great value of the Morel - which is one of the most expensive luxuries furnished by the Italian warehouses, and which is by no means met with in the same abundance as some others of the Fungi - deserves to be better known than it is at present." The genus comprises a very few species; and they are all edible.

\section{COMMON TRUFFLE.}

Tuber cibarium.

On the authority of our most distinguished mycologists, the Common Truffle has not yet been discovered within the 
limits of the United States. It is said to be found abundantly in some parts of Great Britain, particularly in Wiltshire, Kent, and Hampshire. It is collected in large quantities in some portions of France, and is indigenous to other countries of Europe.

The following description by Mascall, in conuection with the engraving, will give an accurate idea of its size, form, color, and general character: "The size rarely much exceeds that of a large walnut. Its form is rounded, sometimes kidney-shaped, and rough

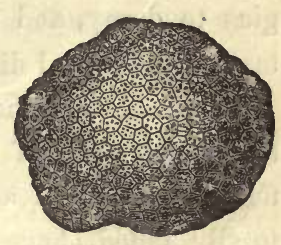

The Truffle. with protuberances. The surface, when the truffle is young, is whitish, but in those that are full grown it is either blackish or a deep black. The color of the inside is whitish, with dark blue and white, gray, reddish, light brown, or dark brown veins, of the thickness of a horsehair, which are usually variously entangled, and which form a kind of network, or mat. Between the veins are numerous cavities, filled with mucilage, and small, solid grains. These scarcely visible glands were formerly said to be the seeds, or germs, of the young truffles. The less the inside of the truffle is colored with dark veins, the more tender and delicious is its flesh.

"The blackish, external rind is hard, and very rough, by means of fine fissures, grains, and protuberances, and forms, with its small facets (which are almost hexagonal), an appearance by which it somewhat resembles the fir-apples of the larch. Whilst the truffle is young, its smell resembles that of putrid plants, or of moist vegetable earth. When it has nearly attained its full growth, it diffuses an agreeable smell, which is peculiar to it, resembling that of musk, which lasts only a few days : it then becomes stronger, and the nearer the fungus is to its dissolution, which speedily ensues, 
so much the more unpleasant is its odor, till at last it is quite disagreeable and putrid. Whilst young, the flesh is watery, and the taste insipid: when fully formed, its firm flesh, which is like the kernel of the almond, has an extremely aromatic and delicious taste; but as soon as the fungus begins to decay, and worms and putrescence to attack it, its taste is bitter and disagreeable."

Many attempts have been made in Great Britain, as well as in other parts of Europe, to propagate the Truffle by artificial means; but all experiments thus far, if they have not totally failed, have been attended by very unsatisfactory results.

Use. - Like the Common Mushroom, it is used principally in stuffings, gravies, and sauces, and in other very highly seasoned culinary preparations. It has long been held in high esteem by epicures and the opulent, but, from its extreme rarity, has always commanded a price which has effectually prohibited its general use. It has been truthfully remarked, "that few know how to raise it, and fewer still possess the proper knowledge to prepare it for the table."

Piedmontese Truffle.

Thomp. TUBER MAGNATUM.

This species is the most celebrated of all the truffles, and always comnands an enormous price. It occurs abundantly in the mountains of Piedmont, and probably nowhere else.

Tuber Mela- This is the Truffle of the Paris markets. It nosporum.

Thomp. is richly scented, and also greatly superior in flavor to the common sorts.

Other genera and species of Fungi are considered harmless, and are occasionally used for food. Some of the edible 
kinds, however, in size, form, eolor, and organization, so closely approach certain poisonous or deleterious species, as to confuse even the most experienced student. None of the family (not excepting even the common cultivated Mushroom) should therefore be gathered for use, except by those who may possess a thorough knowledge of the various species and their properties. 


\section{CHAPTER XII.}

\section{MISCELLANEOUS VEGETABLES.}

Alkekengi, or Ground Cherry. Corn. Egg-plant. Martynia. Oil Radish. Okra, or Gumbo. Pepper. Rhubarb, or Pie-plant. Sunflower. Tobacco. Tomato.

\section{A L K E K ENGI.}

Strawberry Tomato. Winter Cherry. Ground Cherry. Barbadoes Gooseberry. Physalis edulis.

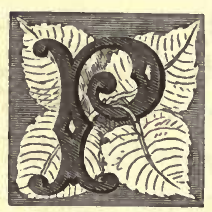

ROBABLY from Central or Tropical America. It is a hardy, annual plant, with an angular, branching, but not erect stem, - in good soil attaining a height or length of more than three feet. Leaves large, triangular; the flowers are solitary, yellow, spotted or marked with purple, and about half an inch in diameter; the fruit is roundish or obtuse-heart-shaped, half an inch in diameter, yellow, semi-transparent at maturity, and enclosed in a peculiar thin, membranous, inflated, angular calyx, or covering, which is of a pale green color while the fruit is forming, but at maturity changes to a dusky white or reddish-drab. The pedicel, or fruit-stem, is weak and slender, and most of the berries fall spontaneously to the ground at the time of ripening.

The seeds are small, yellow, lens-shaped, and retain their germinative properties three years.

The plants are exceedingly prolific, and will thrive in almost any description of soil. Sow at the same time, and 
thin or transplant to the same distance, as practised in the cultivation of the Tomato. On land where it has been grown, it springs up spontaneously in great abundance, and often becomes troublesome in the garden.

Use. - The fruit has a juicy pulp, and, when first tasted, a pleasant, strawberry-like flavor, with a certain degree of sweetness and acidity intermixed. The after-taste is, however, much less agreeable, and is similar to that of the Common Tomato.

By many the fruit is much esteemed, and is served in its natural state at the table as a dessert. With the addition of lemon juice, it is sometimes preserved in the manner of the plum, as well as stewed and served like cranberries.

If kept from the action of frost, the fruit retains its natural freshness till March or April.

This species grows naturally and abundantly in some of the Western States. The fruit is roundish, somewhat depressed, about an inch in diameter, of a deep purple color, and en-

Purple Alkekengi.

Perpi.e Ground CHERRY. PURPLE STRAWBERRY TOMATO. PURPLE

Winter Citerry. PHYSalis SP. closed in the membranous covering peculiar to the genus.

Compared with the preceding species, the fruit is more acid, less perfumed, and not so palatable in its crude state, but by many considered superior for preserving. The plant is less pubescent, but has much the same habit, and is cultivated in the same manner.

A perennial species, much less stocky in habit, and with smoother foliage than the ComScarlet Alkekengi. mon Yellow Alkekengi. The fruit, as well as the calyx in which the fruit is enclosed, is of a brilliaut scarlet color at maturity, and the plant is then highly ornamental. It makes a beautiful garnish. 
Tall Alkekengi.

TALl Ground CHERRY. Tale STRAWRERRY'TOMaTO. PHYSALIS PUBESCENS.

Stem about four feet high, erect and branching; leaves oval, somewhat triangular, soft and velvety; flowers yellow, spotted with deep purple; fruit yellow, of the size of the Common Yellow Alkekengi, enclosed in an angular, inflated calyx, and scarcely distinguishable from the last named.

It is grown from seeds, which are sown like those of the Tomato. It is later, and much less prolific, than the species first described.

\section{CORN.}

\section{Zea mays.}

Garden and Table Varieties. -

Adams's
Early White. distinct and well-marked table variety.
Ears seven to eight inches in length, two inches in diameter, twelve or fourteen rowed, and rather abruptly contracted at the tips; kernel white, rounded, somewhat deeper than broad, and indented at the exterior end, which is whiter and less transparent than the interior or opposite extremity. The depth and solidity of the kernel give great comparative weight to the ear, and, as the cob is of small size, the proportion of product is unusually large.

In its general appearance, the ear is not unlike some descriptions of Southern or Western field corn, from which, aside from its smaller dimensions, it would hardly be distinguishable. In quality it cannot be considered equal to some of the shrivelled-kernelled, sweet descriptions, but will prove acceptable to those to whom the peculiar sugary character of these may be objectionable. Though later than the Jefferson or Darling's, it is comparatively early, and may be classed as a good garden variety.

Much grown for early use and the market in the Middle 
States, but less generally known or cultivated in New England.

Plant, in height and general habit, similar to Black Sweet, Darling's Early; ears six to eight inches in or Mexican. length, uniformly eight-rowed; kernels roundish, flattened, deep slate color, much shrivelled at maturity. Early.

The variety is sweet, tender, and well flavored, remains a long period in condition for use, and, aside from its peculiar color (which by some is considered objectionable), is well worthy of cultivation.

An improved variety of the 'Twelve-rowed Burr's ImSweet. The ears are from twelve to sixteen $\begin{gathered}\text { proved. } \\ \text { Burn's SwEx. }\end{gathered}$ rowed, rarely eighteen, and, in good soils and seasons, often measure eight or ten inches in length, nearly three inches in diameter, and weigh, when in condition for the table, from eighteen to twentytwo ounces; cob white; kernel rounded, flattened, pure white at first, or while suitable for use, - becoming wrinkled, and changing to dull, yellowish, semitransparent white, when ripe.

The variety is hardy and productive, and, though not early, usually perfects its crop. For use in its green state, plantings may be made to the 20 th of June.

The kernel is tender, remarkably sugary, hardeus slowly, is thin skinned, and generally considered much superior to the Common 'Twelve-rowed.

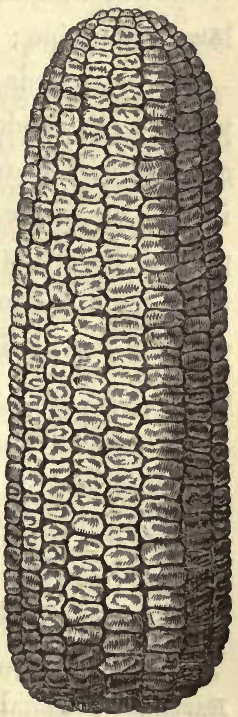

Burr's Improved Corn.

It is always dried or ripened for seed with much difficulty, 
often moulding or decaying before the glazing or hardening of the kernel takes place. If the crop is sufficiently advanced as not to be injured by freezing, it will ripen and dry off best upon the stalks in the open ground; but if in the milk, or still soft and tender at the approach of freezing weather, it should be gathered and suspended, after being husked, in a dry and airy room or building, taking care to keep the ears entirely separate from each other.

\section{Darling's}

Early.

DARLING'S EARLY SWEET.
Stalk about five feet in height, and comparatively slender; the ears are from six to eight inches in length, an inch and a half in diameter, and, when the variety is unmixed, uniformly eightrowed; the kernels are roundish, flattened, pure white when suitable for boiling, - much shrivelled or wrinkled, and of a dull, semi-transparent yellow, when ripe; the cob is white.

The variety is early, very tender and sugary, yields well, produces little fodder, ears near the ground, and is one of the best sorts for planting for early use, as it seldom, if ever, fails to perfect its crop. In the Middle States, and in the milder sections of New England, it may be planted for boiling until near the beginning of July.

The hills are made three feet apart in one direction by two feet and a half in the opposite; or the seeds may be planted in drills three feet apart, dropping them in groups of three together every eighteen inches.

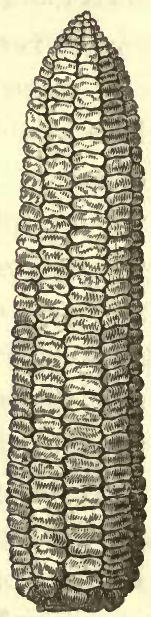

Darling's Early Corn.

Early Dwarf Plant three or four feet high, and very slenSugar.

EXTRA EARLY der; the ears, of which from one to three are DWARF. produced on a stalk, are put forth near the 
ground, and are uniformly eight-rowed. They are about six inches long, and comparatively slender, - in their general form resembling Darling's Early, though of smaller size; the kernels are white before maturity, dull yellowish-white and much shrivelled when ripe.

Like Darling's Early, it is a valuable sort for early use, and also for planting for a succession. The kernel is sweet and tender, and, with others of the class known as "Sugar" varieties, is slow in ripening, and thus for a long season continues in good condition for table use.

Stalk five to six feet high, producing one or two ears, which are of small size, eight-rowed, Early
Jefferson. and measure six or eight inches in length, and about an inch and a half in diameter at the largest part; cob white; kernel white, roundish, flattened, - the surface of u portion of the ear, especially near its tip, often tinged with a delicate shade of rose red. The kernel retains its color, and never shrivels or wrinkles, in ripening.

The variety is hardy and productive, but is principally cultivated on account of its early maturity, though, in this respect, it is little, if at all, in advance of Darling's. The quality is tender and good, but much less sugary than the common shrivelled varieties, on which account, however, it is preferred by some palates. It remains but a short time tender and in good condition for boiling, soon becoming hard, glazed, and unfit for use.

Stalk and general habit similar to Darling's Golden Sweet. Early; ears six to eight inches long, an inch GOLDEN Svosa. and a half or an inch and three fourths in diameter, regularly eight-rowed; the kernel, when ripe, is semi-transparent yellow.

The variety is apparently a hybrid between the Common 
Ycllow or Canada Corn and Darling's Early. In flavor, as well as appearance, both of these rarieties are recognized. It does not run excessively to stalk and foliage, yields well, is hardy, and seldom fails to ripen perfectly in all sections of New England. For boiling in its green state, plantings may be made until the last week of June or first of July.

In respect to quality, it is quite tender, sweet, and well flavored, but less sugary than most of the other sugar or sweet varieties.

Narraganset. The plants of this variety are of slender habit, With. Figrire. and produce but little forage. The ears, which are put forth low on the stalk, are eight or ten rowed, and quite small, seldom measuring more than five inches in length; the kernel is comparatively large, and, like other sugar varieties, shrivelled or wrinkled at maturity; the cob is red.

It is tender, and of excellent quality, and, as a first early, is recommended for cultivation. It is also a good sort for a succession, for which a planting should be made at intervals of two weeks until the last of June. In warm and comparatively light soil it not only thrives better, but is much earlier, than when grown in soil naturally strong or very highly enriched. The hills should be two feet and a half apart.

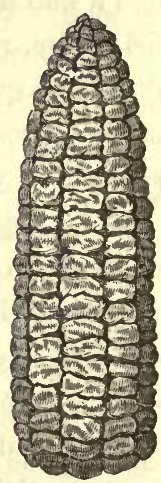

Narraganset Corn.

Old Colony.
Hov. Mag.

This variety was originated by the late Rev. A. R. Pope, of Somerville, Mass. At the time of its production, he was a resident of Kingston, Plymouth County, Mass., and, in consequence of the locality of its origin, it received the name above given. In a communication at the close of the sixteenth volume of the "Magazine of Horticulture," Mr. Pope describes it as follows:- 
"It is a hybrid, as any one can readily perceive by inspection, between the Southern White and the Common Sweet Corn of New England, and exhibits certain characteristics of the two varieties, combining the size of the ear and kernel and productiveness of the Southern with the sweetness and tenderness of the Northern-parent."

The stalks are from ten to twelve feet in height, and of corresponding circumference. The ears are from five to seven inches in length, and the number of rows varies from twelve to twenty; the kernels are very long, or deep; and the cob, which is always white, is quite small compared with the size of the ear. When ripe, the kernels are of a dull, semi-transparent, yellowish-white, and much shrivelled. The ears are produced on the stalk, four or five feet from the ground. Very productive, but late.

For cultivation in the Southern States and tropical climates, it has been found to be peculiarly adapted, as it not only possesses there the sweetness and excellence that distinguish the Sweet Corn of the temperate and cooler sections, but does not deteriorate by long cultivation, as other sweet varieties almost invariably are found to do.

Stalk six feet high, usually producing two ears, which are from six to eight inches long, quite slender, and uniformly eight-rowed; cob Parching Corn (White Kernel). POP-CORN. white; kernel roundish, flattened, glossy, flinty, or rice-like, and of a dull, semi-transparent, white color. When parched, it is of pure snowy whiteness, very brittle, tender, and well flavored, and generally considered the best of all the sorts used for this purpose.

In many parts of New England the variety is somewhat extensively cultivated for commercial purposes. Its peculiar properties seem to be most perfectly developed in dry, gravelly, or silicious soils, and under the influence of short and 
warm seasons. In field culture, it is either planted on hills three feet apart, or in drills three feet apart, and eighteen inches apart in the drills. The product per acre is usually about the same number of bushels of ears that the same land would yield of shelled corn of the ordinary field varieties.

Increase of size is a sure indication of deterioration. The cultivator should aim to keep the variety as pure as possible by selecting slender and small-sized, but well-filled, ears for seed, and in no case to plant such as may have yellow or any foreign sort intermixed. The value of a crop will be diminished nearly in a relative proportion to the increase of the size of the ears.

Parching Corn (Yellow).

A yellow variety of the preceding. It retains its color to some extent after being parched; and this is considered an objection. It is tender, but not so mild flavored as the white, and is little cultivated. The size and form of the ears are the same, and it is equally productive.

Red-cob Sweet.

Ears about eight inches in length by a diameter of two inches, - usually twelve, but sometimes fourteen, rowed; kernels roundish, flattened, white when suitable for boiling; shrivelled, and of a dull, semitransparent white when ripe ; the cob is red, which may be called its distinguishing characteristic. Quality good, the kernel being tender and sweet. It remains long in good condition for the table, and is recommended for general cultivation. Season intermediate.

Rhode Island So named from its origin on the grounds of Asylum. Am. Agr. With Figure. this institution. The plant is of medium size, producing one or two ears; foliage abundant. The ears are rather large, and eight or ten rowed; kernel yellowish-white at maturity, shrivelled and indented. 


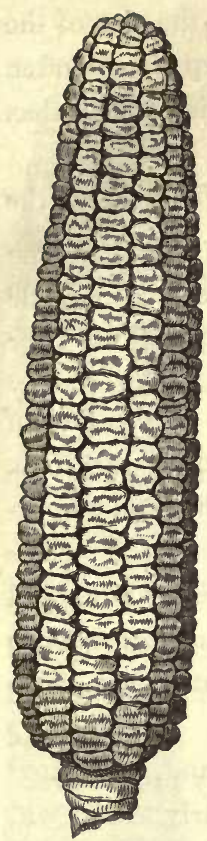

Rhode Island Asylum Corn.

The variety is not early, but is recommended for productiveness, and for the tender, sugary character of the kernel.

Like most of the later and larger descriptions of sugar-corn, the plants attain a greater size, the ears are more fully developed, and the sweet, succulent character of the kernel is greatly increased when grown in soil under a high state of cultivation.

A sub-variety occurs with eight rows, the form and size of the ear and kernel resembling Darling's Early.

This is a variety of the White Rice, with deep purplish-red or Rice (Red Kernel). blood-red kernels. The ears are of the same size and form. Its quality, though inferior to the white, is much superior to the yellow. Productiveness, and season of maturity, the same.

Stalk six feet or more in height; ears five or Rice (White six inches long, an inch and a half in diameter, Kernel). somewhat conical, broadest at the base, and tapering to the top, which is often more or less sharply pointed; the cob is white; the kernels are long and slender, angular, sharply pointed at the outward extremity, as well as to some extent at the opposite, and extremely hard and flinty. They are not formed at right angles on the cob, as in most varieties of corn, but point upward, and rest, in an imbricated manner, one over the other.

The variety is hardy and prolific; and, though not late, should have the benefit of the whole season. For parching it is inferior to the common Parching Corn before described, 
though it yields as much bulk in proportion to the size of the kernel, and is equally as white; but the sharp points often remain sound; and it is, consequently, less crisp and tender.

Rice (Yellow Another sub-variety of the White Rice, the Kernel).

ear and kernel being of the same form and size. It is equally productive, and matures as early; but, when parched, is inferior to the white both in crispness and flavor.

Stowell's Ev- $\quad$ Stalk from six to seven feet in height, and of ergreen.

STOWELL'S EVER- average diameter; ears of a conical form, six or seven inches long, and two inches and a quarter in diameter at the base; kernels long or deep, pure white when suitable for boiling; of a dull, yellowish-white, and much shrivelled when ripe; cob white, and, in consequence of the depth of the kernels, small in comparison to the diameter of the ear.

The variety is intermediate in its season; and, if planted at the same time with Darling's or equally early kinds, will keep the table supplied till October. It is hardy and productive, very tender and sugary, and, as implied by the name, remains a long period in a fresh condition and suitable for boiling.

Tuscarora. Plant five to six feet in height, moderately TUREEY Whest. strong and vigorous; ears eight-rowed, and of remarkable size, - exceeding, in this respect, almost every sort used for the table in the green state. In good soil they are often a foot and upwards in length, and from two inches and three fourths to three inches in diameter at the base. The kernel, which is much larger than that of any other table variety, is pure white, rounded, flattened, and, when divided in the direction of its width, apparently filled with fine flour of snowy whiteness; the cob is red, and of medium size. 
In point of maturity, the Tuscarora is an intermediate variety. In its green state, it is of fair quality, and considered a valuable sort by those to whom the sweetness of the sugar varieties is objectionable. In their ripened state, the kernels, to a great extent, retain their fresh and full appearance, not shrivelling in the manner of the sugar sort, though almost invariably indented at the ends, like some of the Southern Horse-toothed field varieties.

When ground, in the ripe state, it is muclu less farinaceous and valuable for cooking or feeding stock than the fine, white, floury appearance of the kernel, when cut or brokes, would seem to indicate.

A large, comparatively late Twelvevariety. Stalk seven feet high; rowed Sweet. the ears are from ten to fourteen rowed, seven to nine inches long, often two inches and a half in diameter in the green state, and taper slightly towards the top, which is bluntly rounded; cob white; the kernels are large, round, or circular, sometimes tooth-shaped, pure white when suitable for the table, dull white and shrivelled when ripe.

The variety is hardy, yields a certain crop, and is sweet, tender, and of good quality. It is the parent of one or two varieties of superior size and excellence, to which it is now gradually giving place.

\section{Field Varieties. -}

Ear small, about seven inches in length, symmetrical, broadest at the base, and tapering to 
the tip, uniformly eight-rowed, in four double rows; kernel roundish, smooth, and of a rich, glossy, orange-yellow color; cob small, white; stalk four to five feet high, slender; the leaves are not abundant, and the ears, of which the plant very rarely produces more than two, near the ground.

On account of the small size of the ear, the yield per acre is much less than that of almost any other field variety; twenty-five or thirty bushels being an average crop. The dwarfish character of the plants, however, admits of close culture, - three feet in one direction by two or two and a half in the opposite affording ample space for their full development; four plants being allowed to a hill.

Its chief merit is its early maturity. In ordinary seasons the crop will be fully ripened in August. If cultivated for a series of years in the Eastern or Middle States, or in a latitude much warmer than that of the Canadas, the plant increases in size, the ears and kernels grow larger, and it is slower in coming to maturity.

Dutton. EARLY DUTTON.

Ears nine or ten inches long, broadest at the base, tapering slightly towards the tip, ten or twelve rowed, and rarely found with the broad clefts or longitudinal spaces which often mark the divisions into double rows in the eight-rowed varieties, - the outline being almost invariably smooth and regular; kernel as broad as deep, smooth, and of a rich, clear, glossy, yellow color ; cob

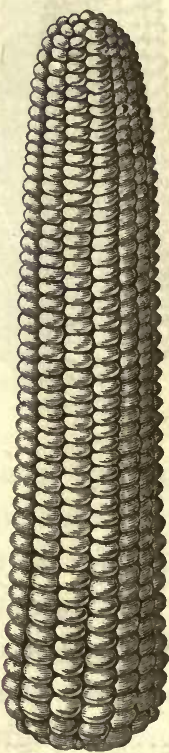

Dutton Corn. comparatively large, white; stalk of medium height and strength, producing one or two ears.

It is one of the handsomest of the field rarieties, nearly as 
early as the King Philip, and remarkable for the uniformly perfect manner in which, in good seasons, the ears are tipped, or filled out. In point of productiveness, it compares favorably with the common New England Eight-rowed; the yield per acre varying from fifty to seventy bushels, according to soil, culture, and season.

It is also much prized for mealing, both on account of its quality and its peculiar, bright, rich color. In cultivation, the hills are made three feet and a half apart in each direction, and five or six plants allowed to a hill.

A sub-variety, known as the Early Dutton,

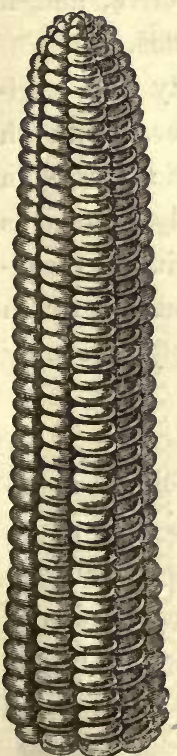

Ilill Corn. is common to many localities. The ears are ten or twelve rowed, well filled at the tips, and the kernel has the bright color of the common Dutton. The plant, however, is less stocky, the ears are smaller, and the yield, particlarly in strong soil, generally less. On light land it succeeds better than the old variety, compared with which it is also about two wecks earlier.

Stalk six feet or more in height, Hill. moderately strong at the ground, WmTMAN. Wmirmoderately strong at the ground, Max's Mmpover.

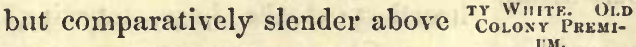
the ear; foliage not abundant; the ears are produced low on the stalk, often in pairs, are uniformly eight-rowed, well filled at the tips, and, when fully grown, ten or eleven inches in length; cob white, and comparatively small ; kernel dusky, transparent-white, large and broad, but not deep.

The Hill Corn is nearly of the season of the common New England Eight-rowed, and is, unquestionably, the most productive of all field varieties. In Plymouth County, $50 *$ 
Mass., numerous crops have been raised of a hundred and fifteen bushels and upwards to the acre; and, in two instances, the product exceeded a hundred and forty.

This extraordinary yield is in a degree attributable to the small size of the plant, and the relative large size of the ear. The largest crops were obtained by planting three kernels together, in rows three feet asunder, and from fifteen to eighteen inches apart in the rows.

No variety is better adapted for cultivation for farm consumption; but for market, whether in the kernel or in the form of meal, its dull white color is unattractive, and it commands a less price than the yellow descriptions.

From the most reliable authority, the variety was originated by Mr. Leonard Hill, of East Bridgewater, Plymouth County, Mass., and was introduced to public notice in 1825-6. Though at present almost universally known as the "Whitman," it appears to have been originally recognized as the "Hill;" and, of the numerous names by which it has since been called, this is, unquestionably, the only legitimate one.

IIlinois

Yellow.

WESTERS

YeLLOW.

Stalk ten feet or more high; foliage abundant; ears high on the stalk, single or in pairs, twelve to sixteen rowed, eleven to thirteen inches long, broadest at the base, and tapering gradually towards the tip, which is bluntly rounded; kernel bright yellow, long and narrow, or tooth-formed, paler at the outer end, but not indented; cob white.

The variety ripens perfectly in the Middle States, but is not suited to the climate of New England.

Similar in its general character to the Illinois Yellow. Kernel rice-white ; cob generally white, but sometimes red. 
Ears ten to twelve inches in length, uniformly King Philip, eight-rowed when the variety is pure or un- Improven KIse mixed ; kernel copper-red, rather large, somePHILIP. what broader than deep, smooth and glossy; cob comparatively small, pinkiśh-white; stalk six feet in height, producing one or two ears, about two feet and a half from the ground.

In warm seasons, it is sometimes fully ripened in ninety days from the time of planting, and may be considered as a week or ten days earlier than the Common New England Eight-rowed, of which it is apparently an improved variety.

Very productive, and recommended as one of the best field sorts now in cultivation. In good soil and favorable seasons, the yield per acre is from seventy-five to ninety bushels, although crops are recorded of a hundred and ten, and even of a hundred and twenty bushels.

As grown in different localities, and even in the product of the same field, there is often a marked variation in the depth of color, arising either from the selection of paler seed, or from the natural tendency of the variety towards the clear yellow of the New England Eight-rowed. A change of color from yel-

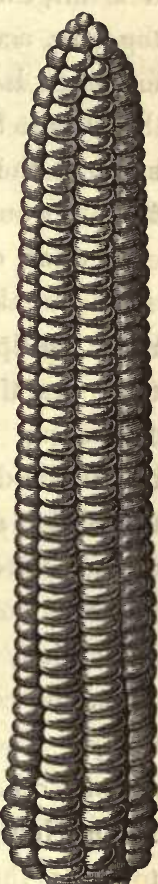

King Philip Corn. lowish red to paler red or yellow should be regarded as indicative of degeneracy.

Said to have originated on one of the islands in Lake Winnipiseogee, $\mathbf{N}$. H.

Stalk six or seven feet high, producing one or two ears, which are from ten to eleven inches

New Fngland Eightrowed. 
long, and uniformly eight-rowed; kernel broader than deep, bright yellow, smooth and glossy; cob comparatively small, white.

The variety is generally grown in hills three feet and a half apart in each direction, and five or six plants allowed to a hill, the yield varying from fifty to seventy bushels to the acre, according to season, soil, and cultivation. It is a few days later than the King Philip, but ripens perfectly in the Middle States and throughout New England, except, perhaps, at the extreme northern boundary, where the Canada Yellow would probably succeed better.

It often occurs with a profuse intermixture of red, sometimes streaked and spotted, sometimes copper-red, like the King Philip, and occasionally of a rich, bright, clear bloodred. As the presence of this color impairs its value for marketing, and particularly for mealing, more care should be exercised in the selection of cars for seed; and this, continued for a few seasons, will restore it to the clear yellow of the Dutton, or Early Canada.

Many local sub-varieties occur, the result of selection and cultivation, differing in the size and form of the ear, size, form, and color of the kernel, and also in the season of maturity. The Dutton, Early Canada, King Philip, and numerous other less important sorts, are but improved forms of the New England Eight-rowed.

Parker.

A variety remarkable for the extraordinary size of the ears, which, if well grown, often measure thirteen or fourteen inches in length; they are comparatively slender, and uniformly eight-rowed. Cob white and slim; kernels bright yellow, rounded, broader than deep.

Productive, but some days later than the Common New England Eight-rowed. 
Stalk twelve feet or more in height, with large, luxuriant foliage; ears single, often in pairs, short and very thick, sixteen to twenty-

White

Horse-tooth.

SOITHERN

two rowed; kernel remarkably large, milk-white, wedgeformed, indented at/the outer end; cob red.

Plant similar to that of the White Horse- Yellow tooth ; kernel very large, bright yellow, indent- Horse-tooth. ed; cob red.

Extensively cultivated throughout the Southern States, but not adapted to the climate of the Middle or Northern.

\section{EGG-PLANT.}

Solanum melongena.

The Egrg-plant is a native of Africa, and is also indigenous to Tropical America. It is a tender annual, with an erect, branching stem, and oblong, bluish-green, powdered leaves. The flowers are one-petaled, purple, and produced on short stems in the axils of the branches; the fruit is often somewhat oblong, but exceedingly variable in form, size, and color; the seeds are small, yellowish, reniform, flattened, and retain their germinative properties seven years.

Soil. - The Egg-plant will thrive well in any good garden soil, but should have the benefit of a sheltered situation.

Sowing and Culture. - The seed should be sown in a hotbed in March, at the time and in the manner of sowing tomato seed. The young plants are, however, more tender, and should not be allowed to get chilled, as they recover from its effects very slowly. The plant being decidedly tropical in character, the seedlings should not be transplanted 
into the open ground until the commencement of summer weather, when they may be set out in rows two feet apart, and two feet asunder in the rows. Keep the ground free from weeds, earth up the plants a little in the process of cultivation, and by the last of August, or beginning of September, abundance of fruit will be produced for the table.

If no hot-bed is at hand, sufficient seedling plants for a small garden may be easily raised by sowing a few seeds in March in common flower-pots, and placing them in the sunny window of the sitting-room or kitchen.

In favorable seasons, a crop may be obtained by sowing the seeds in May in the open ground, and transplanting the seedlings, when two or three inches high, in a warm and sheltered situation.

Use. - "It is used both boiled and stewed in sauces, like the Tomato. A favorite method among the French is to scoop out the seeds, fill up the cavity with sweet herbs, and fry the fruit whole." - McInt.

A common method of cooking and serving is as follows: Cut the fruit in slices half an ineh thick; press out as much of the juice as possible, and parboil ; after which, fry the slices in batter, or in fresh butter in which grated bread has been mixed; season with pepper, salt, and sweet herbs, to suit; or, if preferred, the slices may be broiled as steaks or chops.

\section{Varieties. -}

American Large Purple.

Fruit remarkably large, - often measuring eight inches in depth, seven inches in diameter, and weighing four or five pounds; skin deep purple, with occasional stripes of green about the stem; plant hardy and stocky.

The American Large Purple is more generally cultivated 
in this country than any other variety. The plants produce two (and rarely three) fruits, but the first formed are invariably the best developed.

It is similar to, if not identical with, the Round Purple of English and French authors.

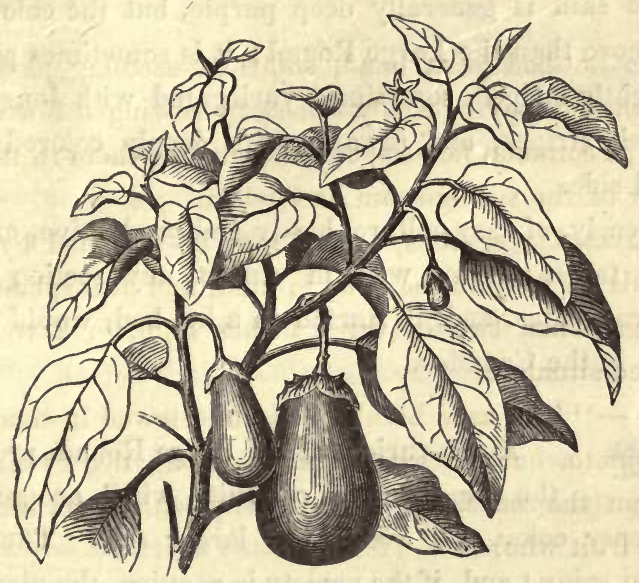

American Large Purple Egg-plant.

Quite distinct from the Common White or the Purple. Plant of low growth, with comChinese
Long White. paratively pale foliage; fruit white, eight or nine inches long, two inches and a half in diameter, and often more or less curved, particularly when the end is in contact with the ground.

It is later than the White or Purple rarieties, and nearly of the season of the Scarlet-fruited. To obtain the fruit in full perfection, the plants must be started in a hot-bed.

Fruit nearly ovoid, smaller than the Round or Long Purple; skin white, streaked and vaGuadaloupe riegated with red. 
Long Purple. The plants of this variety are of the height of the Round Purple, but are subject to some variation in the color of the branches and in the production of spines; flowers large, purple, with a spiny calyx; the fruit is oblong, somewhat club-shaped, six or eight inches in length, sometimes straight, but often slightly bent; at maturity, the skin is generally deep purple, but the color varies much more than the Large Round; it is sometimes pale purple, slightly striped, sometimes variegated with longitudinal yellowish stripes, and always more deeply colored on the exposed side.

It is early, of easy culture, hardy and productive, excellent for the table, thrives well in almost any section of the Northern States, and, if started in a hot-bed, would perfect its fruit in the Canadas.

New York Improved.
A sub-variety of the Large Round, producing the same number of fruits, which are generally of a deeper color, and average of larger size. The leaves are often spiny ; and, if the variety is genuine, the plants will be readily distinguished from those of the last named by their more dense or compact habit of growth.

It is, however, comparatively late, and better suited to the climate of the Middle States than to that of New England, though it is successfully cultivated in the vicinity of Boston, Mass., by starting the plants in a hot-bed, and setting them in a warm and sheltered situation.
Round Purple. Trans.

LARGE ROUND PURPLE.

Plant from two to three feet high, branching, generally tinged with purple, producing two and sometimes three fruits; the leaves are large, downy, oblong, lobed on the borders, with scattered spines on the midribs ; flowers large, pale purple, - the flower-stem and calyx invested with purple spines; the fruit 
is obovate, four or five inches in diameter, six or seven inches deep, slightly indented at the apex, and of a fine deep purple when well matured, - specimens sometimes occur slightly striped or rayed with yellowish-green.

The American Large Purple, if not the same, is but an improved form of this variety.

A highly ornamental variety, introduced saarlet-fruitfrom Portugal. The plant attains the height ed Hov. Mlag. of three feet, with leaves about six inches long. In general appearance, it resembles the Common Egg-plant; but the fruit, which is about the size of a hen's egg, is of a beautiful scarlet.

It is rarely if ever used for food, but is principally cultivated for its peculiar, richly colored, and ornamental fruit, which makes a fine garnish.

The rariety is late, and comparatively tender. The seeds should be started early in a hot-bed, and the plants grown in a warm and sheltered situation. Fruit milk-white, egg-shaped, varying from White Eggthree to five inches in length, and from two inches and a half to three inches and a half in diameter.

It is the earliest, hardiest, and most productive of all varieties. The plants frequently produce five or six fruits each; but the first formed are generally the largest.

If sown in the open ground early in May, the plants will often perfect a portion of their fruit ; but they are most productive when started in a hot-bed.

The fiuit is sometimes eaten cooked in the manner of the Purple varieties, but is less esteemed. 


\section{MARTYNIA.}

Unicorn Plant. Gray. Martynia proboscidea.

A hardy, annual plant, with a strong, branching stem two feet and a half or three feet high. The leaves are large, heart-shaped, entire or undulated, downy, viscous, and of a peculiar musk-like odor when bruised or roughly handled; the flowers are large, bell-shaped, somewhat two-lipped, dull white, tinged or spotted with yellow and purple, and produced in long, leafless racemes, or clusters; the seed-pods

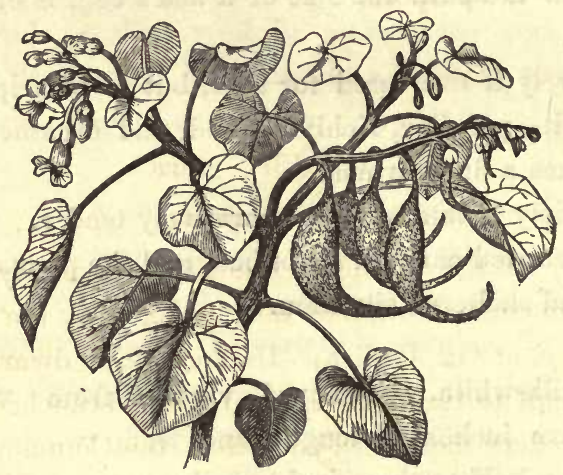

The Martynia.

are green, very downy or hairy, fleshy, oval, an inch and a half in their greatest diameter, and taper to a long, comparatively slender, incurved horn, or beak. The fleshy, succulent character of the pods is of short duration; they soon become fibrous, the elongated beak splits at the point, the two parts diverge, the outer green covering falls off, and the pod becomes black, shrivelled, hard, and woody. The seeds are large, black, wrinkled, irregular in form, and retain their germinative properties three years.

Sowing and Cultivation. - The Martynia is of easy culti- 
vation. As the plants are large and spreading, they should be two feet and a half or three feet apart in each direction. The seeds may be sown in April or May, in the open ground where the plants are to remain, or a few seeds may be sown in a hot-bed, and the seedlings afterwards transplanted.

Gathering and Use. - The young pods are the parts of the plant used. These are produced in great abundance, and should be gathered when about half grown, or while tender and succulent; after the hardening of the flesh they are worthless. They are used for pickling, and by many are considered superior to the Cucumber, or any other vegetable employed for the purpose.

\section{OIL RADISH. Law.}

Raphanus sativus.

A variety of the Common Radish, particularly adapted for the production of oil, and distinguished by the name $R$. sativus olifer, or Oil Radish. Its stems are dwarf, from a foot and a half to two feet in height, much branched, spreading, and produce more seed-pods than the Common Radish. It is grown rather extensively in China for its oil, from whence it has been introduced into and cultivated in some parts of Europe; but it does not appear with any particular success, though much has been said and written in its favor.

It seems best suited for southern latitudes, where it may be sown in September, and harvested the following May or June; but, in the northern portions of the United States, it will be found too tender to withstand the winter, and the seed will therefore require to be sown in spring.

The oil is obtained from the seed, and is considered superior to rape-seed oil, but is extracted with greater difficulty. 


\section{OKRA, OR GUMBO.}

Ocra. Hibiscus esculentus.

Okra is a half-hardy annual, from Central America. Stem simple, sometimes branched at the top, and from two to six feet in height, according to the variety; the leaves are large, palmate, deep green; the flowers are large, fivepetaled, yellowish on the border, purple at the centre; the seed-pods are angular, or grooved, more or less sharply pointed, an inch or an inch and a half in diameter at the base, and from four to eight inches in length; the seeds are large, round-kidney-shaped, of a greenish-drab color, black or dark brown at the eye, and retain their power of germination five years.

Soil, Sowing, and Cultivation. - Okra may be raised in any common garden soil, and is propagated by seeds sown in April or May. The Dwarf varieties may be grown in rows two feet apart, and a foot from each other in the rows; but the taller sorts require a space of at least three feet between the rows, and nearly two feet from plant to plant in the rows. Keep the soil about the plants loose and open, and, in the process of cultivation, earth up the stems slightly, in the manner of earthing peas. The pods will be fit for use in August and September.

It requires a long, warm season, and is most productive when started in a hot-bed, and grown in a warm, sheltered situation.

Use. - The green pods are used while quite young, sliced in soups and similar dishes, to which they impart a thick, viscous, or gummy consistency. Thus served, they are esteemed not only healthful, but very nutritious.

The ripe seeds, roasted and ground, furnish a palatable substitute for coffee. 
Varieties. -

A variety recently introduced by $\mathrm{Mr}$. Robert Buist, of Philadelphia. Height two feet, beBuist's
Dwarf Okra. ing about half that of the old variety. Its superiority consists in its greater productiveness, and the little space required for its development, while the fruit is of larger size and superior quality. It is said to produce pods at every joint.

Stem two feet and a half high, sometimes Dwarf Okra. branched at the top, but generally undivided; leaves large, and, as in all varieties, five-lobed; flowers yellow, purple at the centre; pods erect, obtusely pointed, nearly as large in diameter as those of the Giant, but generally about five inches in length.

It is the earliest of the Okras, and the best variety for cultivation in the Northern and Eastern States.

Between this and the Tall, or Giant, there are numerous sub-varieties, the result both of cultivation and climate.

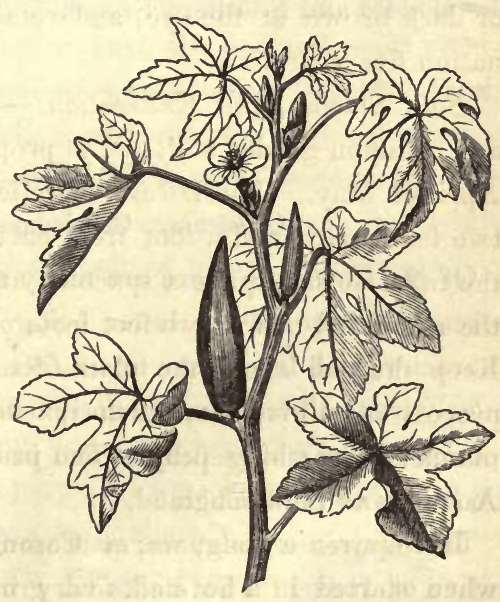

Dwarf Okra.

The Tall sorts become dwarfish and earlier if long cultivated at the North, and the Dwarfs, on the contrary, increase in height, and grow later, if long grown in tropical climates.

The seeds of all the sorts are similar in size, form, and color.

The plants of this variety differ slightly, if at all, from those of the Common, or Dwarf Okra. podded. 
It is principally, if not solely, distinguished by the pendulous or drooping character of its pods, those of all other sorts being erect.

Tall, or Giant Stem five to six feet in height; pods erect, WHITE-PODDED. sharply tapering to a point, eight to ten inches in length, and about an inch and a half in diameter near the stem, or at the broadest part.

With the exception of its larger size, it is similar to the Dwarf, and, if long cultivated under the influence of short and cool seasons, would probably prove identical.

It yields abundantly, but is best adapted to the climate of the Middle and Southern States.

\section{PEPPER.}

Capsicum. Capsicum annuum.

Of the Capsicum there are many species, both annual and perennial, some of the latter being of a shrubby or woody character, and from four to six feet in height. As they are mostly tropical, and consequently tender, none but the annual species can be successfully grown in open culture in the Middle States or New England.

The Capsicum annuum, or Common Garden-pepper, is a native of India. The stalks vary in height from a foot to nearly three feet; the flowers are generally white or purple; the pods differ in a remarkable degree in size, form, color, and acridness ; the seeds are yellow, nearly circular, flattened, and, like the flesh or rind of the fruit, remarkable for their intense piquancy. Nearly forty-five hundred are contained in an ounce, and their vitality is retained five years.

Propagation and Cultivation. - The plants are always propagated from seeds. Early in April sow in a hot-bed, in 
shallow drills six inches apart, and transplant to the open ground when summer weather has commenced. The plants should be set in warm, mellow soil, in rows sixteen inches apart, and about the same distance apart in the rows; or, in ordinary seasons, the following simple method may be adopted for a small garden, and will afford an abundant supply of peppers for family use: When all danger from frost is past, and the soil is warm and settled, sow the seeds in the open ground, in drills three fourths of an inch deep, and fourteen inches apart; and, while young, thin out the plants to ten inches apart in the rows. Cultivate in the usual manner, and the crop will be fit for use early in September.

Use. - "The pod, or fruit, is much used in pickles, seasonings, and made dishes, as both the pod and seeds yield a warm, acrid oil, the heat of which, being imparted to the stomach, promotes digestion, and corrects the flatulency of vegetable aliments. The larger and more common sorts are raised in great quantities, by market-gardeners in the vicinity of populous towns, for the supply of pickle warehouses."

\section{Species and Varieties. -}

Plant two feet and upwards in height, stocky Bell-Pepper. and branching, the stem and branches often LARGL-BELL. stained or clouded with purple; leaves large, on long stems, smaller, smoother, and less sharply pointed, than those of the Squash-pepper ; flowers white, sometimes measuring nearly an inch and a half in diameter.

The pods, which are remarkably large, and often measure nearly four inches deep and three inches in diameter, are pendent, broadest at the stem, slightly tapering, and generally terminate in four

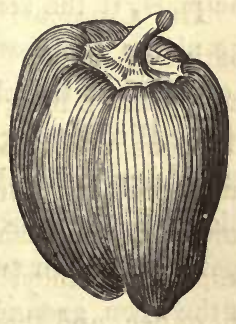

Bell-pepper. obtuse, cone-like points. At maturity, the fruit changes to brilliant, glossy, coral red. 
The Bell-pepper is early, sweet and pleasant to the taste, and much less acrid or pungent than most of the other sorts. In many places, it is preferred to the Squash-pepper for pickling, not only because of its mildness, but for its thick, fleshy, and tender rind.

In open culture, sow in May, in drills sixteen inches apart, and thin the plants to twelve inches in the drills.

In England, they are pickled as follows: The pods are plucked while green, slit down on one side, and, after the seeds are taken out, immersed in salt and water for twentyfour hours, changing the water at the end of the first twelve. After soaking the full time, they are laid to drain an hour or two, put into bottles or jars, and boiled vinegar, after being allowed to cool, poured over them till they are entirely covered. The jars are then closely stopped for a few weeks, when the pods will be fit for use. In this form, they have been pronounced the best and most wholesome of all pickles.

Bird-Pepper Stem fifteen to eighteen inches high; leaves very small; flowers white, about two thirds of an inch in diameter ; pods erect, sharply conical, an inch and three quarters long, about half an inch in diameter, and of a brilliant coral-red when ripe.

The variety is late. If sown in the open grouna, some of the pods, if the season be favorable, will be fit for use before the plants are destroyed by frost; but few will be fully perfected uuless the plants are started under glass.

The Bird-pepper is one of the most piquant of all varieties, and is less valuable as a green pickle than many milder and thicker-fleshed sorts. It is cultivated in rows fourteen inches apart, and ten or twelve inches asunder in the rows. If sown in the open ground, make the rows the same distance apart, and thin the young plants to the same space in the rows.

The "Cayenne Pepper-pot" of commerce is prepared from 
Bird-pepper in the following manner: "Dry ripe peppers well in the sun, pack them in earthen or stone pots, mixing common flour between every layer of pods, and put all into an oven after the baking of bread, that they may be thoroughly dried; after/which, they must be well cleansed from the flour, and reduced to a fine powder. To every ounce of this add a pound of wheat flour, and as much leaven as is sufficient for the quantity intended. After this has been properly mixed and wrought, it should be made into small cakes, and baked in the same manner as common cakes of the same size; then cut them into small parts, and bake them again, that they may be as dry and hard as biscuit, which, being powdered and sifted, is to be kept for use."

The pods of this variety are quite small, cone-shaped, coral-red when ripe, intensely acrid,

Cayenno Pepper. C. FruTESCENs. and furnish the Cayenne Pepper of commerce. Like the other species of the family, it is of tropical origin, and being a perennial, and of a shrubby character, will not succeed in open culture at the North.

Both the green and ripe pods are used as pickles, and also for making Chili vinegar, or pepper-sauce, which is done by simply putting a handful of the pods in a bottle, afterwards filled with the best vinegar, and stopping it closely. In a few weeks it will be fit for use.

The process of preparing Cayenne Pepper is as follows: The pods are gathered when fully ripe. "In India, they are dried in the sun; but in cooler climates they should be dried on a slow hot-plate, or in a moderately heated oven: they are then pulverized, and sifted through a fine sieve, mixed with salt, and, when dried, put into close, corked bottles, for the purpose of excluding the air. This article is subject to great adulteration, flour being often mixed with it, and, still worse, red lead, which is much of the same color, and greatly increases the weight. 
"A better method is to dry the pods in a slow oven, split them open, extract the seeds, and then pulverize them (the pods) to a fine powder, sifting the powder through a thin muslin sieve, and pulverizing the parts that do not pass through, and sifting again, until the whole is reduced to the finest possible state. Place the powder in air-tight glass bottles, but add no salt or other ingredient whatever." McInt.

The pods of either of the long-fruited sorts, or those of the Cherry-pepper, prepared as above, will furnish a quality of "Cayenne" Pepper greatly superior to that ordinarily sold by grocers, or even by apothecaries and druggists.

The larger and milder kinds, powdered in the same manner, make a wholesome and pleasant grade of pepper of sufficient pungency for a majority of palates.

Cherry-Pepper.

Capsicum cerasiFORME.

Stem twelve to fifteen inches high, strong and brauching; leaves comparatively small, long, narrow, and sharply pointed ; flowers white, three fourths of an inch in diameter; pod, or fruit, erect, nearly globular or cherry-form, and, at maturity, of a

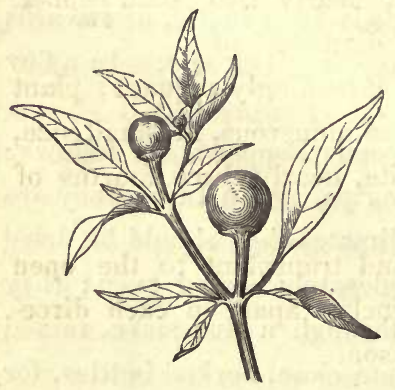

Cherry-pepper. deep, rich, glossy scarlet color. It is remarkable for its intense piquancy, exceeding in this respect nearly all the annual varieties.

It is not so early as some of the larger sorts, but in favorable seasons will perfect a sufficient portion of its crop in the open ground, both for seed and pickling. For the latter purpose, the peppers should be plucked while still green, put into a common jar or wide-mouthed bottle, and vinegar 
added to fill the vessel. In a few weeks they will be fit for use.

When in perfection, the plants are very ornamental, the glossy, coral-red of the numerous pods presenting a fine contrast with the deep-green foliage surrounding them.

A variety occurs with larger, more conical and pendent pods. The plant is also much larger, and quite distinct in its general character.

This is a variety of the Red Cherry. The Cherry-Pepplants have the same general habit, require the Per. same treatinent, and perfect their fruit at the FRUITED.

same season. There is little real difference between the sorts, with the exception of the color of the fruit, - this being clear yellow.

To preserve either of these varieties for use in the dry state, all that is necessary is to cut off the plants close to the roots when the fruit is ripe, and hang them, with the fruit attached, in any warm and dry situation. They will retain their piquancy for years.

Pods pendent, sharply conical, nearly two Chili Pepper. inches in length, half an inch in diameter, of a brilliant scarlet when ripe, and exceedingly piquant; plant about eighteen inches high ; leares numerous, of small size, and sharply pointed; flowers white, nearly three fourths of an inch in diameter.

Sow in a hot-bed in April, and transplant to the open ground in May, about fourteen inches apart in each direction. Requires a long, warm season.

Fruit brilliant coral-red, generally pendulous, sometimes erect, conical, often curved towards Long Red
Pepper. the end, nearly four inches in length, and from an inch to an 


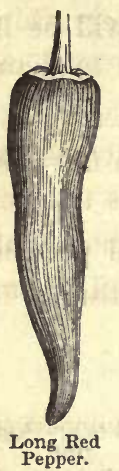

Long Yellow. Vil.

inch and a half in diameter; skin, or flesh, quite thin, and exceedingly piquant.

Stalk about two feet ligh ; foliage of medium size, blistered and wrinkled; flowers an inch in diameter, white.

The variety yields abundantly, but attains its greatest perfection when started in a hot-bed. The ripe pods, dried and pulverized as directed for Cayenne Pepper, make an excellent substitute for that article.

The plants, with ripe fruit, are very ornamental.

est diameter. At maturity they assume a lively, rich, glossy yellow, and the plants are then showy and ornamental.

Stem two feet and upwards in height, slightly colored with purple at the intersection of the branches and insertion of the leaf-stems; leaves of medium size, smaller and paler than those of the Long Red; flowers white, nearly an inch in diameter. Like the last named, it is very piquant. It is also late, and, to obtain the variety in perfection, the seed should be started in a hot-bed in April.

Purple or Fruit erect, on long stems, bluntly coneBlue Podded.

BLACK PODDED. shaped, two inches and a half in length, and a half or three fourths of an inch in diameter at the broadest part. Before maturity the skin is green, or reddish-green, clouded or stained with black or purplish-brown; but, when ripe, changes to rich, deep, indigo-blue.

Plant two feet or upwards in height, more erect and less branched than other varieties, and much stained with purple at the intersection of the branches and at the insertion of the leaf-stems; leaves of medium size, or small, long, and 
sharply pointed ; leaf-stems long, deep green ; flowers white, tipped with purple, about three fourths of an inch in diameter; flower-stems long, purple.

A rare, richly-colored, and beautiful pepper, but not cultivated, nor of much value as an esculent. For its full perfection, a long, warm season is requisite. The plants should be started in a hot-bed in March or April, and transplanted in May to the open ground, fifteen inches apart.

This variety is similar to the Sweet Spanish ; Quince-Pepbut the fruit is rather longer, and its season of Pusexr. perponmaturity is somewhat later. Its flavor is comFORME. Vil. paratively mild and pleasant; but, like the Sweet Spanish, it is not generally thick fleshed. At maturity, the fruit is a brilliant coral-red.

This is but a sub-variety of the common Red Round or Cherry-pepper, differing only in its larger size. $\begin{gathered}\text { Large Red } \\ \text { Cherry-Pep- }\end{gathered}$ It is quite late, and should be started in a hot-bed.

Fruit compressed, more or less ribbed, about Squashtwo inches and three quarters in diameter, and Pepper. two inches in depth; skin smooth and glossy, - when ripe, of a brilliant coral-red; flesh thick, mild, and pleasant to the taste, though possessing more piquancy than the Large Bell or Sweet Spanish.

Plant about two feet high, stout, and branching; leaves broad and large; flowers white, an inch and a quarter in diameter; fruit drooping; fruit-stem short and thick.

The Squash-pepper is extensively grown for the market, and is most in use in the pickle warehouses of the Eastern and Middle States. In field-culture the plants are started in hot-beds in April, and, after the beginning of summer weather, transplanted to the open ground, fourteen to eighteen inches 
apart, according to the quality of the soil. The fruit is generally sold by weight; and an acre of land, in a fair state of cultivation, will yield about three tons, - a bushel of the thick-fleshed sort weighing nearly thirty-two pounds. An excellent pickle may be made by preparing the peppers in the manner directed for the Bell variety.

As grown by different market-men and gardeners, there are several sub-varieties of the Squash-pepper, differing both in form and in the thickness of the flesh; the latter quality, however, being considered of the greater importance, as the thick-fleshed sorts not only yield a greater weight to the acre, but are more esteemed for the table.

The Squash-pepper succeeds well when sown in the open ground in May, in drills fourteen inches apart. The plants should be ten or twelve inches apart in the rows; when grown too closely, they are liable to draw up, making a weakly, slender growth, and yield much less than when allowed sufficient space for their full development. Low-growing, stocky, and branching plants are the most productive.

Sweet Mountain Pepper.

This variety resembles the Large Bell, if it is not identical. The Sweet Mountain may be somewhat larger; but, aside from this, there is no perceptible' difference in the varieties.

SweetSpan- Fruit obtusely conical, often four inches in ish.

length, and nearly three inches in diameter, brilliant glossy scarlet at maturity; stem strong and sturdy, two feet or more in hẹight; leaves large, but narrower than those of the Large Bell; flowers white, and of large size,usually an inch and a half in diameter ; fruit sometimes erect, but generally drooping.

Though one of the largest varieties, the Sweet Spanish is also one of the earliest. The flesh is sweet, mild, and pleas- 
ant, and the variety is much esteemed by those to whom the more pungent kinds are objectionable. When prepared in the same form, it makes a pickle equally as fine as the Large Bell.

The Sweet Spanish Pepper succeeds well if sown in the open ground in May. Make the rows sixteen inches apart, and thin the plants to a foot apart in the rows.

Fruit similar in form to the Squash-pepper, Yellow but of smaller size, erect or pendulous; orange- Pepper. Vil. yellow at maturity.

Yellow TomatoFORMED.

The variety is later than the last named, much less productive, and, for pickling, is comparatively not worthy of cultivation.

\section{R H U B A R B.}

Pie-plant. Rheum sp. et var.

This is a hardy, perennial plant, cultivated almost exclusively for its leaf-stalks. Its general character may be described as follows : Root-leaves large, round-heart-shaped, deep green, and more or less prominently blistered; leafstems large, succulent, furrowed, pale green, often stained or finely spotted with red, varying from two to three inches in diameter at the broadest part, and from a foot to three feet in length. The flower-stalk is put forth in June, and is from five to seven feet in height, according to the variety; the flowers are red, or reddish-white, in erect, loose, terminal spikes; the seeds are brown, triangular, membranous at the corners, and retain their germinative properties three years. Soil and Cultivation. - Rhubarb succeeds best in deep, somewhat retentive, soil: the richer its condition, and the deeper it is stirred, the better, as it is scarcely possible to cultivate too deeply, or to manure too highly.

It may be propagated by seeds, or by a division of the 
roots, - the latter being the usual method. When grown from seeds, the plants not only differ greatly in size and quality, but are much longer in attaining a growth suitable for cutting.

"Whether grown from seed, or increased by a division of the roots, a deep, rich soil, trenched to the depth of two or even three feet, is required to insure the full development of the leaf stalks; for upon their size, rapidity of growth, and consequent tenderness of fibre, much of their merit depends. The seed should be sown in April, in drills a foot asunder, - thinning the plants, when a few inches high, to nine inches apart. In the autumn or spring following, they will be fit for transplanting in rows three feet asunder, and the plants set three feet apart. If propagated by dividing the roots, it may be done either in autumn or spring, the same distance being given to the sets that is allowed for seedling plants. As, however, some of the varieties grow to a much larger size than others, a corresponding distance should be accorded them, extending to five feet between the rows, and three feet from plant to plant.

"The plants should be set out singly, and not in threes, as is so often done. For the first year, the ground between the rows may be cropped with lettuce, turnips, beans, or similar low-growing crops; but, after the second year, the leaves will cover the whole space, and require it also for their full development." - McInt.

After-culture. - This consists in keeping the soil well enriched, open, and clear of weeds, and in breaking over the flower-stalks, that they may not weaken the roots, and consequently reduce the size and impair the quality of the leafstalks.

Gathering the Crop. - "This is usually done in spring, commencing as soon as the stalks have attained a serviceable size. No leaves, however, should be plucked the first year, 
and only a few of the largest and first formed during the second; and this plucking should not be made too early in the season, because, in that case, the plants would be weakened. From the third year, as long as the roots or plantations last, it may be gathered with freedom. A plantation in good soil, and not overmuch deprived of its foliage, will last from ten to fifteen years.

"When the leaves are about half expanded, they may be plucked for use ; but, when the largest returns are expected (as in the case of market-gardens), they should be allowed to attain their full size. In removing them, they should be pulled off close to the base, and not cut, to prevent an unnecessary escape of sap, which, in all succulent plants, flows more copiously from a clean cut than from one slightly lacerated or torn. The foot-stalks should then be separated from the leaves, and tied up in bundles of suitable size for market." - McInt.

Rhubarb is sometimes blanched. This may be effected without removing the plants, by mean's of sea-kale pots, or by empty casks open at the top, put over the crowns in March. It can, however, be more perfectly done by taking up the roots, and setting them in some dark place, with a temperature of $55^{\circ}$ or $60^{\circ}$, where they should be slightly covered with soil to prevent them from drying. When so treated, they are much more tender, crisp, and delicate than when grown exposed to the sun and air; but the quality is greatly impaired, the pulp, though somewhat acid, being generally comparatively flavorless.

Use. - As before remarked, it is cultivated for its leafstalks, which are used early in the season, as a substitute for fruit, in pies, tarts, and similar culinary preparations. When fully grown, the expressed juice forms a tolerably palatable wine, though, with reference to health, of doubtful properties. "As an article of commercial importance in the vege- 
table markets, it is of very recent date. In 1810, Mr. Joseph Myatts, of Deptford, England, long known for his successful culture of this plant, sent his two sons to the borough-market with five bunches of Rhubarb stalks, of which they could sell but three." It is now disposed of by the ton, and many acres in the vicinity of nearly all large towns and cities are devoted exclusively to its cultivation.

Varieties. - These are very numerous, as they are readily produced from the seed; but the number really deserving of cultivation is comparatively limited. Old kinds are constantly giving place to new, either on account of superior earliness, size, productiveness, or quality. The following are the prominent sorts cultivated :

Cahoon.

Leaves remarkably large, often broader than long, and more rounded than those of most varieties; stalk short and thick, - if well grown, measuring from twelve to sixteen inches in length, and three inches or more in diameter; skin thick, uniformly green.

Its remarkable size is its principal recommendation. The texture is coarse, the flavor is harsh and strong, and it is rarely employed for culinary purposes.

In some localities, it is cultivated to a limited extent for the manufacture of wine, the juice being expressed from the stalks, and sugar added in the ratio of three pounds and a half to a gallon. This wine, though quite palatable, has little of the fine aroma of that made from the grape, and, if not actually deleterious, is much less safe and healthful. Any of the other varieties may be used for the same purpose, the principal superiority of the Cahoon consisting in its larger stalks, and consequently its greater product of juice.

Downing's A large variety, nearly of the size of Myatt's
Colossal.

Victoria. It is described as being less acid than the last named, and of a fine, rich, aromatic flavor. 

Stalks of medium size; recommended by D. Early Prince T. Curtis, Esq., Chairman of the Vegetable

Committee of the Massachusetts Horticultural Society, as in all respects the best flavored of any variety ever tested, and commended for general cultivation, as particularly adapted to the wants of the family, if not to the wishes of the gardener, to whom size and productiveness are more than flavor. It invariably turns red in cooking, which makes it preferable for the table as a sauce. When cooked, it is of the color of currant-jelly, and remarkably fine flavored.

In 1862 , it received the first prize of the Massachusetts Horticultural Society, as the best for family use.

An early sort, well adapted for forcing. The Flford. stalks are rather slender, covered with a thin Bucz's RHUBARB. skin of a bright scarlet color, and their substance throughout is of a fine red, which they retain when cooked, if not peeled - a process which, owing to the thinness of the skin, is not considered necessary. Even when grown in the dark, the stalks still preserve the crimson tiuge. It was raised from the seed of Rheum undulatum.

A new variety, said to equal the Prince Albert in earliness, and also to be of a deeper and Hawke's Champagne. finer color, and much more productive. It forces remarkably well, is hardy in open culture, and commands the highest market prices, both from its great size, and fine, rich color.

Stalks large, red, and of excellent flavor. Early and prolific.

Mitchell's Royal Albert. Thomp.

A medium-sized or comparatively small variety, recently introduced. "Besides being the Myatt's Lin. næus. earliest of all, and remarkably productive as

LINN $\operatorname{LuS.}$ 
well as high flavored, and possessing little acidity, it has a skin so thin, that removing it is hardly necessary; and its pulp, when stewed, has the uniform consistence of baked Rhode Island Greenings, and it continues equally crisp and tender throughout the summer and early autumn." One of the best sorts for a small garden or for family use.

Myatt's Vic- Leaves large, broader than long, deep green, victoris. blistered on the surface, and much waved or undulated on the borders. Leaf-stalks very large, varying from two inches and a half to three inches in their broadest diameter, and frequeutly measuring upwards of two feet and a half in length; the weight of a well-developed stalk, divested of the leaf, is about two pounds. They are stained with red at their base, and are often reddish, or finely spotted with red, to the nerves of the leaf.

It has rather a thick skin, is more acid than many other varieties, and not particularly high flavored; but no kind is more productive; and this, in connection with its extraordinary size, makes it not only the most salable, but one of the most profitable, kinds for growing for the market.

It requires a deep, highly-manured soil; and the roots should be divided and reset once in four or five years. It is about a fortnight later than the Linnæus.

Nepal. RHEUM AUstraLE. Thoinp.

The leaf-stalks attain an immense size, but are unfit for use on account of their strongly purgative properties; but the leaves, which are frequently a yard in diameter, are useful in covering baskets containing vegetables or fruit, and for these the plant is sometimes cultivated. 
It is perceptibly less acid than most varieties, and remarkable for fineness of texture and delicacy of flavor.

\section{SUNFL OWER.}

Tall Sunflower. Annual Sunflower. Helianthus annuus.

Stem from five to eight feet or more in height; leaves heart-shaped, rough, three-nerved ; flowers very large, terminal, nodding; the seeds are large, ovoid, angular, or compressed, nearly black, sometimes striped with white, and retain their germinative properties five years.

The plant is a native of South America.

This species, which was introduced from Egypt, differs from the last principally in its Dwarf Sunflower. Lavo. more dwarfish habit of growth, but also in beH. Invicus. ing less branched. The flowers are much smaller, and generally of a lighter color.

Soil and Cultivation. - The Sunflower will thrive in almost any soil or situation, but succeeds best on land adapted to the growth of Indian Corn. It is always grown from seed, which should be sown in April, or the beginning of May, in drills three feet apart. When the plants are well up, they should be thinned to a foot asunder, and afterwards cultivated in the usual manner, stirring the ground occasionally, and keeping the plants free from weeds. The flowers appear in July, and the seeds ripen in August and September. The central flower is first developed, attains a larger size than any that succeed it, and ripens its seeds in advance of those on the side branches. The heads of seeds should be cut as they successively mature, and spread in a dry, airy situation for three or four weeks, when the seeds will become. dry and hard, and can be easily rubbed or threshed out. 
Use. - "The seeds of both species yield an oil little inferior to that of the Olive for domestic purposes, and which is also well adapted for burning. In Portugal, the seeds are made into bread, and also into a kind of meal. They are also sometimes roasted, and used as a substitute for coffee; but the purpose for which they seem best adapted is the feeding of domestic fowls, pheasants, and other game. The greatest objection to its culture is, that it is a most impoverishing crop, particularly the Large, or Common Tall species." $-M c I n t$.

\section{T O B A CCO.}

Nicotiana, sp.

All the species and varieties of Tobacco in common cultivation are annuals; and most, if not all, are natives of this continent. "Like other annual plants, it may be grown in almost every country and climate, because every country has a summer; and that is the season of life for all annual plants. In hot, dry, and short summers, like the northern summers of Europe or America, Tobacco-plants will not attain a large size, but the Tobacco produced will be of delicate quality and good flavor. In long, moist, and not very warm summers, the plants will attain a large size, - perhaps as much so as in Virginia; but the Tobacco produced will not have that superior flavor, which can only be given by abundance of clear sunshine, and free, dry air. By a skilful manufacture, and probably by mixing the Tobacco of cold countries with that of hot countries, by using different species, and perhaps by selecting particular varieties of the different species, the defects in flavor arising from climate may, it is likely, be greatly remedied."

The species and varieties are as follow :- 
Leaves oblong, regularly tapering, stemless and clasping, eighteen inches to two feet long, and from nine to twelve inches in diameter. Connecticut Seed-leaf.

Peacit-lear.

VIROINIA TOBACco. Nicotiana When fully developed, the stem of the plant is erect and strong, five feet high, and separates near the top

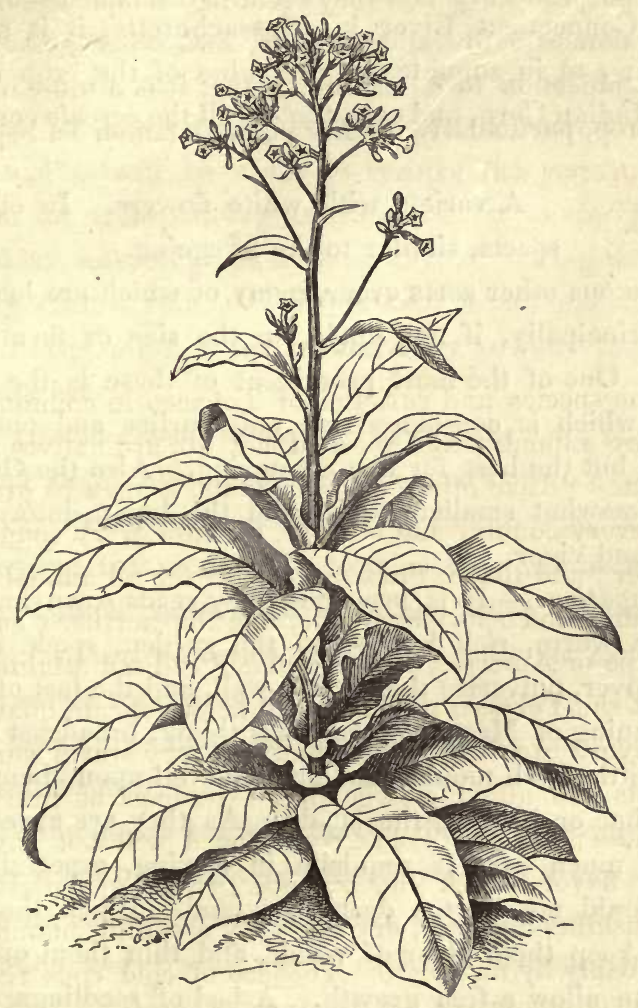

Connecticut Seed-leaf Tobacco.

into numerous, somewhat open, spreading branches; the flowers are large, tubular, rose-colored, and quite showy and ornamental; the capsules are ovoid, or somewhat conical, and, if well grown, nearly half an inch in their greatest 
diameter; the seeds, which are produced in great abundance, are quite small, of a brownish color, and retain their germinative properties four years.

This species is extensively cultivated throughout the Middle and Southern States, and also in the milder portions of New England. In the State of Connecticut, and on the banks of the Connecticut River in Massachusetts, it is a staple product; and in some towns the value of the crop exceeds that of Indian Corn, and even that of all the cereals combined.

Guatemala Tobacco.

A variety with white flowers. In other respects, similar to the foregoing.

Numerous other sorts occur, many of which are local, and differ principally, if not solely, in the size or form of the leaves. One of the most prominent of these is the Broadleaved, which is considered not only earlier and more productive, but the best for manufacturing. Also the Oronoco, with somewhat smaller leaves, and the Japan, intermediate in size and vigor.

Propagation. - It is propagated by seeds sown annually. Select a warm, rich locality in the garden, spade it thoroughly over, pulverize the surface well, and the last of April, or beginning of May, sow the seeds thinly, broadcast; cover with a little fresh mould, and press it well upon them either by the hoe or back of the spade. As they are exceedingly minute, much care is requisite in sowing, especially that they should not be too deeply covered. When the plants appear, keep them clear of weeds, and thin them out sufficiently to allow a free growth. A bed of seedlings nine or ten feet square will be sufficient for an acre of land. If preferred, the plants may be raised in drills eight inches apart, slightly covering the seeds, and pressing the earth firmly over them as above directed. When the seedlings are four or five inches high, they are ready for transplanting. 
Size and Cultivation. - Tobacco requires a warm, rich soil, not too dry or wet; and, though it will succeed well on recently turned sward or clover-turf, it gives a greater yield on land that has been cultivated the year previous, as it is less liable to be infested by worms, which sometimes destroy the plants in the early stages of their growth. The land should be twice ploughed in the spring; first as soon as the frost will permit, and again just previous to setting. Pulverize the surface thoroughly by repeated harrowing and rolling, and it will be ready to receive the young plants. The time for transplanting is from the 1st to the 20th of June, taking advantage of a damp day, or setting them immediately after a rain. If the ground is not moist at the time of transplanting, it will be necessary to water the plants as they are set.

"The ground should be marked in straight rows three feet apart, and slight hills made on these marks two feet and a half apart; then set the plants, taking care to press the earth firmly around the roots. As soon as they are well established, and have commenced growing, run a cultivator or horse-hoe between the rows, and follow with the hand-hoe; resetting where the plants are missing. The crop should be hoed at least three times, at proper intervals, taking care to stir the soil all over.

"When the plants begin to flower, the flower-stem should be broken or cut off, removing also the suckers, if any appear, leaving from twelve to sixteen leaves to be matured."

Harvesting and Curing. - In ordinary seasons, the crop will be ready for harvesting about the beginning of September, and should all be secured by the 20th of the month, or before the occurrence of frost. The stalks must be cut at the surface of the ground, and exposed long enough to the sun to wilt them sufficiently to prevent breaking in handling. They should then be suspended in a dry, airy shed or build- 
ing, on poles, in such a manner as to keep each plant entirely separate from the others, to prevent mouldiness, and to facilitate the drying by permitting a free circulation of the air. Thirty or forty plants may be allowed to each twelve feet of pole. The poles may be laid across the beams, about sixteen inches apart.

"When erected for the purpose, the sheds are built of sufficient height to hang three or four tiers, the beams being about four feet apart, up and down. In this way, a building forty feet by twenty-two will cure an acre and a half of Tobacco. The drying-shed should be provided with several doors on either side, for the free admission of air."

When the stalk is well dried (which is about the last of November or beginning of December), select a damp day, remove the plants from the poles, strip off the leaves from the stalk, and form them into small bunches, or hanks, by tying the leaves of two or three plants together, winding a leaf about them near the ends of the stems; then pack down while still damp, lapping the tips of the hanks, or bunches, on each other, about a third of their length, forming a stack with the buts, or ends, of the leaf-stems outward; cover the top of the stack, but leave the ends or outside of the mass exposed to the air. In cold weather, or by midwinter, it will be ready for market; for which it is generally packed in damp weather, in boxes containing from two to four hundred pounds.

A fair average yield per acre is from fourteen to eighteen hundred pounds.

To save Seed. - "Allow a few of the best plants to stand without removing the flowering-shoots. In July and August, they will have a fine appearance, and, if the season be favorable, each plant will produce as much seed as will sow a quarter of an acre by the drill system, or stock half a dozen acres by transplanting." A single capsule, or seed-pod, contains about a thousand seeds. 
Leaves oval, from seven to ten inches long, and six or seven inches broad, produced on long petioles. Compared with the preceding RUSTICA. species, they are much smaller, deeper colored, more glossy, thicker, and more/succulent. When fully grown, the plant is of a pyramidal form, and about three feet in height. The flowers are numerous, greenish-yellow, tubular, and nearly entire on the borders; the seed-vessels are ovoid, more depressed at the top than those of the Connecticut Seed-leaf, and much more prolific; seeds small, brownish.

The Green Tobacco is early, and remarkably hardy, but not generally considered worthy of cultivation in localities where the Connecticut Seed-leaf can be successfully grown. It is well adapted to the northern parts of New England and the Canadas, where it will almost in-

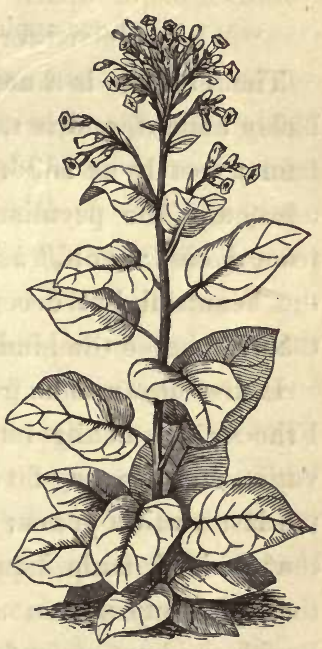

Green Tobacco. variably yield an abundance of foliage, and perfect its seeds.

"It is very generally cultivated, almost to the exclusion of the other species, in the north of Germany, Russia, and Sweden, where almost every cottager grows his own Tobacco for smoking. It also seems to be the principal sort grown in Ireland."

There are several varieties, all of which have the hardiness and productiveness common to the species, but are not considered remarkably well flavored.

The plants should be started in spring, and transplanted as directed for the Connecticut Seed-leaf; but, on account of its 
smaller size and habit, two feet, or even twenty inches, between the plants, will be all the space required.

\section{TOMATO.}

Love-apple. Solanum lycopersicum.

The Tomato is a native of South America. It is a halfhardy annual, and is said to have been introduced into England as early as 1596. For a long period it was very little used, and the peculiar, specific term, lycopersicum, derived from lykos, "wolf," and persicon, "a peach" (referring to the beautiful but deceptive appearance of the fruit), more than intimates the kind of estimation in which it was held.

It first began to be generally used in Italy, subsequently in France, and finally in England. In this country, its cultivation and use may be said to have increased fourfold within the last twenty years; and it is now so universally relished, that it is furnished to the table, in one form or another, through every season of the year. To a majority of tastes, its flavor is not at first particularly agreeable ; but, by those accustomed to its use, it is esteemed one of the best, as it is also reputed to be one of the most healthful, of all garden vegetables.

When fully grown, the Tomato-plant is from four to seven feet and upwards in height or length, with a branching, irregular, recumbent stem, and dense foliage. The flowers are yellow, in branching groups, or clusters; the fruit is red, white, or yellow, and exceedingly variable in size and form ; the seeds are lens-shaped, yellowish-white, or pale gray. Twenty-one thousand are contained in an ounce, and they retain their vitality five years.

Propagation. - The Tomato is raised from seeds, which should be sown in a hot-bed in March, or in the open ground 
as soon as the frost will permit. As the plants, even in the most favorable seasons, seldom perfectly mature their full crop, they should be started as early and forwarded as rapidly as possible, whether by hot-bed or open-air culture. If the seeds are sown in a hot-bed, the drills should be made five inches apart, and half an inch deep. When the plants are two inches high, they should be removed to another part of the bed, and pricked out four or five inches apart, or removed into small pots, allowing a single plant to a pot. They are sometimes twice transplanted, allowing more space or a larger pot at each removal, by which process the plants are rendered more sturdy and branching than they become by being but once transplanted.

As early in May as the weather is suitable, the plants may be set in the open ground where they are to remain, and should be three feet apart in each direction; or, if against a wall or trellis, three feet from plant to plant. Water freely at the time of transplanting, shelter from the sun for a few days or until they are well established, and cultivate in the usual form during summer.

If sown in the open ground, select a sheltered situation, pulverize the soil finely, and sow a few seeds in drills, as directed for the hot-bed. This may be done in November (just before the closing-up of the ground), or the last of March, or first of April. In May, when the plants are three or four inches high, transplant to where they are to remain, as before directed.

In gardens where Tomatoes have been cultivated, young plants often spring up abundantly from the seeds of the decayed fruit of the preceding season. These, if transplanted, will succeed as well, and frequently produce fruit as early, as plants from the hot-bed or nursery-bed.

Sufficient plants for the garden of a small family may be started with little trouble by sowing a few seeds in a garden- 
pan or large flower-pot, and placing it in a sunny window of the sitting-room or kitchen. If the seed is sown in this manner about the middle or 20th of March, the plants will be of good size for setting by the time the weather will be suitable for their removal.

Forcing the Crop. - "The ripening of the fruit may be hastened by setting the plants against a south wall or close fence. As the plants increase in size, they must be nailed or otherwise attached to the wall or fence, and, if the weather be dry, liberally watered. When the two first trusses of bloom have expanded over each shoot, the shoot should be

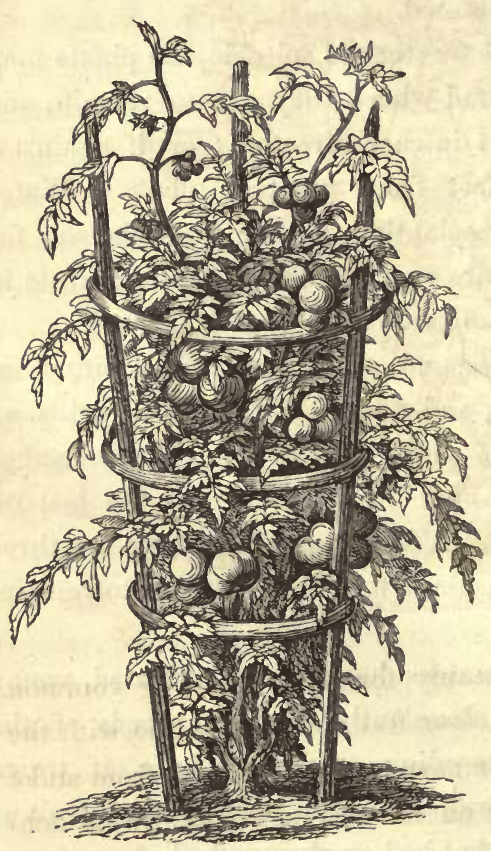

Hoop-training of the Tomato. stopped by pinching off the portion which is beyond the leaf above the second truss, and no more lateral shoots should be suffered to grow; but the leaves must be carefully preserved, especially those near the trusses of bloom. The number of shoots on each plant will vary according to the strength and vigor of the particular plant ; but three or four will be quite enough, leaving about half a dozen trusses of fruit."

Culture and Training. - A convenient, simple, and economical support for the plants may be made from three narrow hoops, 
- one twelve, another fifteen, and the third eighteen or twenty inches in diameter, - and attaching them a foot from each other to three stakes about four feet in length, placing the lower hoop so that it may be about ten inches from the surface of the ground after the stakes are driven. The figure on the preceding page illustrates this method of training. It secures abundance of light, free access of air, and, in skilful hands, may be made quite ornamental.

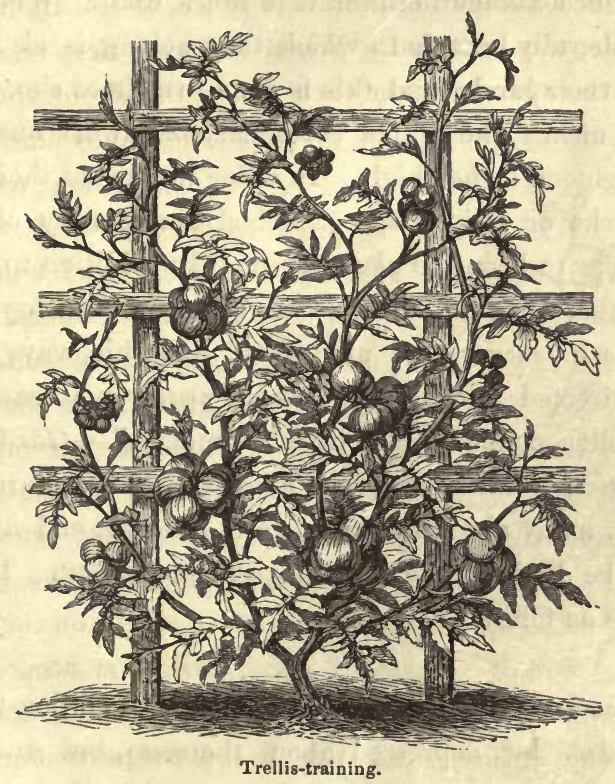

Or a trellis may be cheaply formed by setting common stakes, four feet in length, four feet apart, on a line with the plants, and nailing laths, or narrow strips of deal, from stake to stake, nine inches apart on the stakes, afterwards attaching the plants by means of bass, or other soft, fibrous material, to the trellis, in the manner of grape-vines or other climbing plants. By either of these methods, the plants not 
only present a neater appearance, but the ripening of the fruit is facilitated, and the crop much more conveniently gathered when required for use.

The French mode of raising tomatoes is as follows: "As soon as a cluster of flowers is visible, they top the stem down to the cluster, so that the flowers terminate the stem. The effect is, that the sap is immediately impelled into the two buds next below the cluster, which soon push strongly, and produce another cluster of flowers each. When these are visible, the branch to which they belong is also topped down to their level; and this is done five times successively. By this means, the plants become stout, dwarf bushes, not above eighteen inches high. In order to prevent their falling over, sticks or strings are stretched horizontally along the rows, so as to keep the plants erect. In addition to this, all laterals that have no flowers, and, after the fifth topping, all laterals whatsoever, are nipped off. In this way, the ripe sap is directed into the fruit, which acquires a beauty, size, and excellence unattainable by other means."-Gard. Chron.

Varieties. - These are quite numerous. Some are merely nominal, many are variable or quite obscure, and a few appear to be distinct, and, in a degree, permanent. The principal are as follow :Apple-Toma- Fruit somewhat flattened, inclining to globu-
to. APPLE-SHAPED. lar, depressed about the stem, but smooth and regular in its general outline. The size

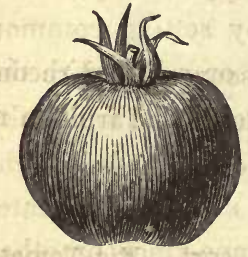

Apple-tomato. is quite variable; but, if well grown, the average diameter is about two inches and a half, and the depth two inches. Skin deep, rich crimson; flesh bright pink, or rose-color, - the rind being thick and hard, and not readily reduced to a pulp when cooked. 
The Apple-tomato is early, hardy, productive, keeps well, and, for salad and certain forms of cookery, is much esteemed ; but it is more liable to be hollow-hearted than any other of the large varieties.

In form, as well as in the thick, tough character of its rind, it resembles the Bermuda.

This is a red or rose-colored, apple-formed Bermuda. sort, extensively imported from Bermuda into the Middle and Northern States in May and the early summer months.

Like the preceding variety, it varies considerably in size, - some specimens measuring little more than an inch in diameter, while others from the same plant, matured at nearly the same season, frequently exceed a diameter of two inches and a half.

It possesses a thick, rather tough rind, which rarely becomes pulpy in the process of cooking, and, besides, is quite light and hollow-hearted. In size and form, it somewhat resembles the Apple-tomato. When cultivated in New England or the Middle States, it has little merit, either for its productiveness or early maturity.

Fruit quite large, red, often blushed or tinged Fejee. with pinkish-crimson, flattened, sometimes ribbed, often smooth, well filled to the centre; flesh pink, or pale red, firm, and well flavored; plant hardy, healthy, and a strong grower.

Seeds received from different reliable sources, and recommended as being strictly true, produced plants and fruit in no respects distinguishable from the Perfected.

A small, red, pyriform or pear-shaped sort, Fig-Tomato. measuring from an inch and a quarter to an $\begin{gathered}\text { RED PARA- } \\ \text { SHAED TOMATO. }\end{gathered}$ 
inch and a half in length, and nearly an inch in its broadest diameter. Flesh pale red, or pink, very solid and compact,

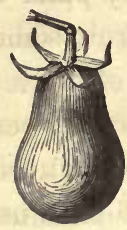

Fig-tomato. and generally completely filling the centre of the fruit.

Like the Plum-tomato, it is remarkably uniform in size, and also in shape; but it is little used except for preserving, - other larger varieties being considered more economical for stewing, making catchup, and like purposes.

The variety is usually employed for making tomato-figs, which are thus prepared :-

"Pour boiling water over the tomatoes, in order to remove the skin; after which, weigh, and place in a stone jar, with as much sugar as tomatoes, and let them stand two days; then pour off the sirup, and boil and skim it till no scum rises; pour it over the tomatoes, and let them stand two days as before; then boil, and skim again. After the third time, they are fit to dry, if the weather is good; if not, let them stand in the sirup until drying weather. Then place them on large earthen plates, or dishes, and put them in the sun to dry, which will take about a week; after which, pack them down in small wooden boxes, with fine, white sugar between every layer. Tomatoes prepared in this manner will keep for years." - Mrs. Eliza Marsh, in Hov. Mag.

Giant Tomato. Hov. Mag. МАммотн.
An improved variety of the Common Large Red, attaining a much larger size. Fruit comparatively solid, bright red, sometimes smooth, but generally ribbed, and often exceedingly irregular; some of the larger specimens seemingly composed of two or more united together. The fruit is frequently produced in masses or large clusters, which clasp about the stem, and rest so closely in the axils of the branches as to admit of being detached only by the rending asunder of the fruit itself; flesh pale pink, and well flavored. 
Like most of the other varieties, the amount of product is in a great degree dependent on soil, culture, and season. Under favorable conditions, twenty-five pounds to a plant is not an unusual yield. Single specimens of the fruit sometimes weigh four, and even five or six pounds.

The Giant Tomato is not early, and, for the garden, perhaps not superior to many other kinds; but for field-culture, for market, for making catchup in quantities, or for the use of pickle-warehouses, it is recommended as one of the best of all the sorts now cultivated.

This variety, or more properly species, differs essentially in the character of its foliage, and manner of fructification, from the Garden

Grape or Cluster Tomato.

SolaNuM SP. Tomato. The leaves are much smoother, thinner in texture, and have little of the musky odor peculiar to the Common Tomato-plant. The fruit is nearly globular, quite small, about half an inch in diameter, of a bright scarlet color, and produced in leafless, simple, or compound clusters, six or eight inches in length, containing from twenty to sixty berries, or tomatoes; the whole having an appearance not unlike a large cluster of currants.

The plants usually grow about three feet in height or length, and, in cultivation, should be treated in all respects like those of other varieties. The flowers are yellow, and comparatively small. Early.

Though quite ornamental, it is of little value in domestic economy, on account of its diminutive size.

In size and form this variety differs little from the common Apple Tomato. Its superiImproved Apple ority consists in its much greater solidity, in the absence of the tough rind common to the old variety, and in the less seedy and much more pulpy character of its flesh. 
The color also is somewhat deeper, and it ripens nearly two weeks earlier.

The Improved Apple-tomato is remarkable for its uniform size and smoothness, and must be classed as being decidedly one of the best. Recommended for general cultivation.

Large Red Tomato.

Fruit sometimes smooth, often irregular, flattened, more or less ribbed; size large, but varied much by soil and cultivation, - well-grown specimens are from three to four inches in diameter, two inches and a

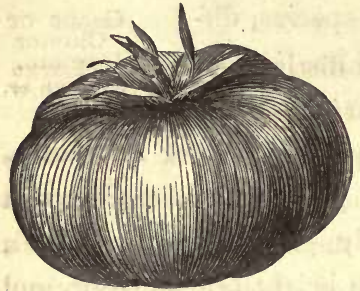

Large Red Tomato. half in depth, and weigh from eight to twelve ounces; skin smooth, glossy, and, when ripe, of a fine red color; flesh pale red, or rose color, - the interior of the fruit being comparatively well filled; flavor good.

Not early, but one of the most productive of all the varieties; the plants, when properly treated, producing from twelve to fifteen pounds each.

From the time of the introduction of the Tomato to its general use in this country, the Large Red was almost the only kind cultivated, or even commonly known. The numerous excellent sorts now almost everywhere disseminated, including the Large Red Oval, Fejee, Seedless, Giant, and Lester's Perfected, are but improved sub-varieties, obtained from the Common Large Red by cultivation and selection.

Large Red Oval-fruited

Tomato.

well-grown specimens measure about four inches in one direction, three inches in the opposite, and two inches in depth; 
skin fine, deep-red, smooth, and shining; flesh paler, the interior of the fruit well filled with pulp, and, when cooked, yielding a large product in proportion to the bulk. Prolific and well flavored, but not early, - ripening at the time of the Large Red.

The variety is exceedingly liable to degenerate, constantly tending towards the Large Red, and can only be maintained in its purity by exclusive cultivation, and a continued use of seeds selected from the fairest, smoothest, best ripened tomatoes, having the peculiar oval form by which the variety is distinguished.

Plant, in its general character, not distinguishable from the Large Red. The fruit, also, is Large quite similar in form and size, the principal mark of distinction being its color, which is a fine, clear, semi-transparent yellow. Flesh yellow, well filling the centre, and perhaps a little sweeter or milder than the Red, though generally not distinguishable when stewed or otherwise prepared for the table.

The variety is hardy, yields abundantly, and comes to perfection with the Large Red. It is, however, not generally cultivated, the Red descriptions being more commonly used, and consequently better adapted for cultivation for the market.

Fruit large, comparatively smooth, frequently Mexican. of an oval form, bright red, often tinted with rose or bright pink; flesh pink, solid, filling the fruit to the centre.

It is similar to, if not identical with, the Perfected.

A recently introduced and comparatively distinct variety. Plant remarkably healthy and vigorous, often attaining a height or length of 
six or eight feet, and, in strong soil, of more than ten feet; fruit pinkish-red, or rose-red, of large size, comparatively smooth and regular, flattened, remarkably solid, and well filled to the centre, and, when cooked, yielding a large return in proportion to its bulk; flesh firm, well flavored, with comparatively few seeds intermixed. In this last respect, not unlike the Seedless.

When started at the same time, it ripens two weeks after the early varieties, and continues to yield in great abundance until the plants are destroyed by frost. It is considered one of the best sorts for cultivation for the market, and by many is preferred to all others for the garden.

On the authority of a recent writer, the variety has already, to some extent, degenerated. Impure seed, or the influence of some peculiar locality, may have furnished grounds for the statement; but if the variety is genuine, or unmixed, it will, in almost any soil or exposure, commend itself by its hardiness, solidity, and great productiveness.

Red Cherry- A small, red Tomato, nearly spherical, and
Tomato. about half an inch in diameter. The fruit is produced in great profusion, in large bunches, or clusters, but is comparatively of little value, on account of its small size. It is sometimes used as a preserve, and by some esteemed for pickling.

Red PlumTomato.

Fruit bright-red or scarlet, oval, solid, an inch and a quarter or an inch and a half in depth, and about an inch in diameter ; flesh pink, or rose-red, mild, and well flavored; seeds comparatively few.

The variety is remarkable for its symmetry and for its uniform size. When ripe, the fruit is not easily distinguished from some varieties of scarlet plums. It is hardy, early, and yields abundantly; but the fruit is employed principally for 
pickling and preserving, - its small size rendering it of little value for stewing or for catchup.

Mixed with the Yellow, they make a fine garnish, and are excellent for salad.

A small, round, red variety, about an inch in Round Red. diameter. It is one of the earliest of all the cultivated sorts, but of little value except for pickling or preserving.

Of the size and form of the foregoing, differing only in color.

Round Yellow.

Very similar to, if not identical with, the PerSeedless. fected. Fruit almost rose-red, solid, and with comparatively few seeds.

This recently introduced variety originated in Burlington County, New Jersey. The plant is The Cook's Favorite. strong and vigorous, with fine, broad, light green foliage. The fruit is of medium size, roundish, or oval, smooth, of a rich, deep color and remarkable solidity, - rarely with a cavity or hard, unripe parts at the centre. It is a few days earlier than the Perfected. The variety is popular in the Middle States, where it is said to yield abundantly, and is extensively grown in the vicinity of New York and Philadelphia for marketing. It is also raised to some extent in New England, but has proved somewhat less productive than the Perfected and other larger-fruited sorts.

A new variety, raised from seed by Grenier, Tree Tomato. gardener to M. de Fleurieux, at a place in France called Chateau de Laye (whence the name), and introduced by M. Vilmorin of Paris. 
It is distinct from all others, rising quite erect to the height of two feet or upwards, with a stem of remarkable size and strength. The branches are not numerous, and comparatively short, usually eight or ten inches in length, - thus requiring no heading-in; leaves not abundant, rather curled, much wrinkled, very firm, closely placed on the sturdy branches, and of a remarkably deep, shining-green color ; fruit bright red, of large size, comparatively smooth, and well filled to the centre, - in many respects resembling the Perfected, though more regular in form.

From the peculiar, tree-like character of the plants, the variety is remarkably well adapted for cultivation in pots; but its late maturity greatly impairs its value as a variety for forcing. It is a slow grower, tardy in forming and perfecting its fruit, and, for ordinary garden culture, cannot be recommended as being preferable to the Perfected and other earlier and much more prolific varieties. It has been described as strictly self-supporting; but, though the fruit is produced in a remarkably close and almost clasping manner about the sturdy stem and branches, its weight often brings the plants to the ground; and consequently, in exposed situations, it will be necessary to provide stakes, or some similar means of support; though the plants never exhibit the rambling, recumbent character of the Common Tomato.

White

Tomato.

Plant similar in habit to the Large Red; fruit large, generally ribbed, often irregular, but sometimes comparatively smooth. Its distinguishing characteristic is its color, which, if the fruit be screened by foliage, or if grown in the shade, is almost clear white; if much exposed to the sun, it assumes a yellowish tinge, - much paler, however, than the Large Yellow. Flesh yellowish, more watery than that of the Large Red, and of a somewhat peculiar flavor, much esteemed by some, and unpalatable to others. 
The variety is hardy, remarkably productive, as early as the Large Red, and equally large and solid; but its color, before and after being cooked, is unattractive; and it is rarely seen in the markets, and seldom cultivated for family use.

A medium-sized Red variety, generally round, but frequently of an oval form, flattened, sometimes ribbed, but comparatively smooth, and, White's Extra Farly. EARLY RED. EXtra EARLY. when fully matured, of a deeper color than the later Red sorts. Average specimens measure about two inches and a half in diameter, and an inch and a half in depth. The plants are moderately vigorous, and readily distinguished by their peculiar curled and apparently withering foliage.

Flesh pale red, quite firm, mild, not very seedy, and well filling the fruit, which is considerably heavier than the Appleshaped. When cooked, it yields a much greater product, in proportion to its size, than the last-named and similar hollowhearted varieties. Productive, and of good quality.

Planted at the same time with the Common Red varieties, it will ripen about two weeks earlier. An excellent sort for the garden, and recommended for general cultivation.

In order to retain this or any other early variety in its purity, seed for planting should be saved from the smoothest, best-formed, and earliest-ripened fruit. Few of the numerous kinds now cultivated possess much permanency of cliaracter, and rapidly degenerate if raised from seed taken from the scattered, irregular, and comparatively immature tomatoes remaining upon the plants at the close of the season. A yellow variety of the Red Cherry-tomato, Yellow Cher- differing only in color.

Quite showy, but of little value for culinary purposes. 
Yellow

Pear-shaped

Tomato.

YeLLOW Fig-Tomato.

A sub-variety of the Red Pear-shaped, with a clear, semi-transparent, yellow skin, and yellow flesh. Like the preceding, it is little used except for preserving and pickling.

Yellow PlumTomato.

A variety of the Red Plum, of the same size and form, and equally symmetrical, - distinguished only by the color of its skin, which is a fine, clear, transparent yellow. It is used principally for preserving, its small size rendering it comparatively valueless for use in any other form.

When the two varieties are intermixed, the colors present a fine contrast, and a basket of the fruit is quite a beautiful object. 


\section{N D E X.}

\begin{tabular}{|c|c|c|c|c|}
\hline & & & & \\
\hline STRIS, . & ... & - 567 & JM GRAVEOLENS, . . & . \\
\hline comatus,... & . . & - 573 & petroselinum, ... & • \\
\hline deliclosus, .. & ... & - 573 & ARRACH, . & .. \\
\hline exquisitus, . & ... & - 573 & ARACHYS HYPOGEA, & . \\
\hline Georgii, ... & $\cdots \cdot$ & - 573 & Aromatic Nig & . 4 \\
\hline eg. & $\ldots$ & - 574 & ARTEMESIA ABRotANUM, & .. 564 \\
\hline tus, . & $\cdots$ & - $5 \pi 4$ & aium, . & \\
\hline prunulus, .. & . . & - 574 & dracunculus, . & . 385 \\
\hline LECOST, ....... & $\cdots$ & - 401 & maritimum, . & ... 565 \\
\hline EXANDERS, . . . & $\cdots \cdot$ & - 305 & pontica, ... & . . 565 \\
\hline Perfoliate, .... & $\cdots$ & - 306 & ARTICHоке, . & •. 130 \\
\hline ISANDERS $\ldots$. & $\cdots$ & - 305 & Common, ..... & - \\
\hline KEKENGI, .... & $\cdots \cdot$ & - 580 & ed-spined, . . & .. 142 \\
\hline Purple, ..... & $\cdots \cdot$ & - 581 & Purple, .... & . 142 \\
\hline Searlet, ..... & $\cdots \cdot$ & - 581 & $\cdots \cdot$ & ... \\
\hline Tall, .... & ... & - 582 & $\ldots .$. & - \\
\hline Liaceous Plants, . . & $\ldots$ & . 11 & $\ldots \ldots$ & ... 142 \\
\hline IUM AMPE & $\cdots$ & - 11 & be, .... & - $140-142$ \\
\hline licum, . . & $\cdots$ & - 13 & nce, .... & . 142 \\
\hline$\cdots \cdot$ & $\cdots$ & - 120 & ... & .. 143 \\
\hline fistulosum, ... & $\cdots$ & - 137 & tany, . & . 143 \\
\hline porrum, $\cdots$ : & & - 116 & leaded, & - \\
\hline sativum, .... & & - 115 & Pur & - 1 \\
\hline prasum, . & ... & - 11 & Globe, .... & - \\
\hline scorodoprasum, & ... & - 134 & $d, \ldots$. & 14: \\
\hline LLSPICE, $\ldots \ldots$ & $\cdots \cdot$ & - 414 & us Plants, & .. 139 \\
\hline MARANTHUS, .... & $\cdots$ & - 279 & , ... & • \\
\hline Chinese, ...... & ... & - 279 & $a, \ldots . .$. & .. 149 \\
\hline$\therefore \ldots$. & & - 28 & ... & . \\
\hline Hantsi Shanghai, ... & & - 28 & $\bullet \bullet \bullet ・ \bullet$ & - \\
\hline IERICAN BROOK-LIME, & $\ldots$ & - 306 & $\ldots \cdots \cdots$ & . \\
\hline RICAN GARDEN-BEAN & $\mathrm{N}, \ldots$ & - 434 & rple-top, ... & - \\
\hline RICAN WINTER-CRES & $\mathrm{ss}, \ldots$ & - 388 & nd, ... & . 14 \\
\hline ETHUN GRA & $\cdots$ & - 403 & s Giant, & - 149 \\
\hline GELICA, & & . 3 & Gre & . 150 \\
\hline 66 & & & & \\
\hline E, & & & - & \\
\hline AL $P$ & & 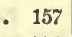 & $\ldots \ldots \ldots$ & \\
\hline HEMIS XOBILIS, . & & & RAGUS OFFICINALIS, & \\
\hline
\end{tabular}

(643) 
Astragalus hamoses, . . 390 Atriplex hoRTENSIS, .... 288 Avilès CABbage, ...... 265

BALM, . . . . . . . 394

BALSAMITA vUlgaris, . ... 401

BARbadoes GoOseberry, . . 580

Barbarea Praciox, ..... 388

" $\quad$ vulgaris, . . . . . 388

" cordifolia,...... 284

" rubra, ....... 284

BAsIL, ......... 395

Bush, ........ 396

Common, ....... 395

Green Bush, . . . . . . 396

Large Sweet, . . . . . 305

Lettuce-leaved, . . . . 396

Purple, ......... 396

Purple Busl, ...... 396

BeAn, American Garden, . . . 434

Dwarf varieties, . . . . 434

Bagnolet, ........ 435

Black-eyed Chlna, ..... 436

Blue Pod, ........ 437

Canada Yellow, ..... 4.38

Canadian, ........ 447

Chilian, ......... 439

China, ......... 445

Crescent-eyed,....... 439

Drab Tampico,...... 440

Dun-colored,...... 440

Dwarf Case-knife, ..... 443

Dwarf Cimeter, ...... 443

Dwarf Cranberry, ..... 441

Dwarf Horticultural, . . . 442

Dwarf Sabre, ...... 443

Dwarf Soissons, . . . . 444

Dwarf White Cranberry, . . 464

Dwarf Yellow, ..... 458

Early China,....... 445

Early Molıawk, ...... 449

Early Rachel, . . . . . . 446

Early Valentine, . . . . 446

Excelsior, ........447

Fejee, ......... 462

Golden Cranberry, . . . . 447

Kidney, ......... 464

Large White Kidney, . . . 464

Long Yellow Six-weeks, ... 448

Mohawk, ....... 449

Negro Long-pod, ..... 450

Newington Wonder, . . . 451
BEAN, Am. Garden (Continued).

Nonpareil, . . . . . 452

Pea, ........... 452

Pottawottomie, ...... 454

Red-eyed China,...... 445

Red Flageolet, . . . . . . 454

Red-speckled, ......455

Refugee,........ 456

Rice, ........ 457

Rob-Roy, . . . . . . 457

Round American Kidney, 438, 447

Round Yellow, ..... 458

Round Yellow Six-weeks, . . 458

Royal Dwarf, ...... 46t

Scarlet Flageolet, . . . 45t

Scarlet Swiss, . . . . . 460

Six-weeks, ..... 448

Solitaire, ...... 459

Swiss Crimson, . . . . 460

Tampico, ....... 461

Thousand to One,.....456

Turtle-soup, ...... 461

Valentine, ....... 446

Variegated Dwarf Prague, . . 442

Victoria,........ 461

White's Early, . . . . 462

White Egg, . . . . . . 404

White Flageolet, . . . . 463

White Kidney, . . . . . 464

White Marrow, . . . . 464

White Marrowfat,. . . . . 464

Yellow-eyed China, .... 466

Yellow Flageolet, .... 448

Yellow Six-weeks, . . . . 448

Beans, Running or Pole, . . . 466

Algerian, ....... 471

Asparagus, ...... 481

Butter, ........ 471

California,....... 467

Carolina, ....... 488

Carolina Sewee, . . . . 488

Case-knife, ....... 468

Cimeter,........ 478

Concord,........ 469

Corn, ......... 469

D'Alger, ....... 471

Green Lima, . . . . . . . 485

Horticultural, . . . . . 470

Indian Chief, ......471

Lima, .......... 482

London Horticultural, . . . 4 470

Long-podded Dolichos, . . . 481

Marbled Prague, ..... 470 
Br.sxs, Run. or Pole (Continued).

Mottled Case-knife, .... 472

Mottled Cranberry, .... 472

Mottled Lima,....... 485

Mottled Prolific,...... 473

Mottled Sieva,...... 48!

Painted Lady-runner, . . . 487

Prédhomme,....... 4it

Princess, ........4 474

Red Cranberry, ...... 475

Red Orleans, . . . . . . 4t 4 i

Rhode Island Butter, . . . 4 477

Saba, ......... 488

Sabre, ........ 478

Scarlet Orleans, ...... 476

Scarlet-runner, ..... 485

Sieva, ......... 488

Small Lima, . . . . . . 488

Soissons, ....... 478

Stringless, ....... 472

Wax, ......... 471

West Indian, ...... 488

White Cranberry, ..... 479

White-runner, ...... 487

Wild-goose,.......480

Yellow Cranberry, . . . . 480

BEan, English, .......4491

Bog,......... 493

Cluster, ......... 493

Dark-red, ....... 497

Iutch Long Pod, . . . . 493

Dwarf Fan, . . . . . 493

Early Dwarf, . . . . . . 493

Farly Dwarf Crimson-seeded, $49 t$

Early Long Pod, . . . . 496

Early Malta, ...... 494

Early Mazagan, . . . . 4 494

Evergreen Long Pod, . . . 494

Green China, ...... 495

Green Genoa, ...... 494

Green Julienne, . . . . . 495

Green Long Pod, . . . . . 49t

Green Nonpareil, ..... 494

Green Windsor, ...... 495

Hang-down Long Pod, . . 493

Horse-bean, ........ 495

Johnson's Wonderful, . . . 496

Kentish Windsor, ..... 499

Large Toker, . . . . . 498

Lisbon, ......... . 496

Long-podded, . . . . . . 496

Marshall's Early Dwarf Pro-

lific,........ 490
Bes,, English, (Continued.)

Muniford,....... 499

Purple, . . . . . . . . 498

Red-blossomed, . . . . 497

Red Windsor, ... . . 497

Royal Dwarf Cluster, . . . . 497

Sandwich,........ 496

Scarlet-blossomed, .... 497

Scarlet Windsor, .... 497

Scotch, ........ 495

Sword Long I'od, ..... 496

'Taylor's Large Windsor, . . 499

Toker,....... 495-498

Turkey Long Pod, . . . . . 496

Vilmorin's Dwarf Red-sceded, 494

Violet, ........ 498

White-blossomed Long Pod, 498

White Broad Windsor, . . 499

Windsor, ........ 499

Wrench's Improved Windsor, 499

BEan, French, ....... 434

BEAN, Kidney, ........ 434

BEET, .......... 1

Bark skinned, ....... 5

Barrott's New Crimson,... 5

Bassano,......... 6

Betterave Blanche, .... 16

Betterave Globe Rouge, . . . 15

Betterave Jaune Globe, ... 18

Cattell's Dwarf Blood,. . . . 6

Common Long Blood,.... 11

Cow-horn Mangel Wurzel, • 7

Cow-horn Scarcity, .... 7

Disette Blanche à Collet Verte, 13

Disette d'Allemagne, .... 9

Disette Hative, . . . . . 7

Dwarf Blood, ....... 10

Early Blood Turnip-rooted, . 8

Early Flat Bassano, ..... 6

Early Half Long Blood, . . . 10

Early Mangel Wurzel,.... 7

Early Scareity, ..... 7

Early Turnip, ...... 8

Extra Early, ....... 6

Fine Dwarf Red, ..... 10

German Red Mangel Wurzel, 9

German Yellow Mangel Wur-

zel, .......... 9

Green Mangel Wurzel, ... 9

Green-top White Sugar, . . 13

Half Long Blood,...... 10

Improved Long Blood, . . . 10

Jaune d'Allemagne, . . . . 9 9 
BEET (Continued).

Jaune Grosse, ......

Long Blood,.......

I.ong Red Mangel Wurzel, .

Long Smooth Blood, ....

Long White Green-top Man-

gel Wurzel,......

Long White Mangel Wurzel,

Long Yellow Mangel Wurzel,

Marbled Field, .......

Oak Bark-skinned, . . . . .

Olive-shaped Mangel Wurzel,

Red,.........

Olive-shaped Mangel Wurzel,

Yellow, ........

Orange Globe Mangel Wurzel,

Pine-apple Short-top, ....

Red Castelnaudary, .....

Red Globe Mangel Wurzel, .

Red Mangel Wurzel, ... .

Red Oval Mangel Wurzel, . .

Rouge de Whyte, .....

Rouge Nain,.......

Rouge Plate de Bassano, . .

Serpent-like,.......

Sutton's Large Globe Mangel

Wurzel, .......

Turnip-rooted Bassano, ...

White Globe Mangel Wurzel,

White Silesian, ......

White Sugar, ...... 10

White Turnip-rooted, .... 17

Whyte's Dark Crimson, . . . 17

Wyatt's Dark Crimson, ... 17

Yellow Castelnaudary, . . . 17

Yellow Globe Mangel Wurzel, 18

Yellow Oval Mangel Wurzel, 14

Yellow Turnip-rooted,.... 19

BEET, LEAF, . . . . . . 281

BEET, SEA, . . . . . . 293

Belle-Isle Cress, . . . . . 388

BENE-PLANT, . . . . . . 548

Biformed-leaved, .... 549

Oval-leaved, ....... 549

Trifid-leaved, ..... 549

BFTA CICLA, ........ 281

" maritima,........ 293

" vulgaris, ....... 1

BLACK Cumin, ........ 414

Black Nightshade,..... 280

Black Oyster Plant, .... 88

Black Salsify, ...... 88

Blituri Bonus Henricus, . . 303
Boletus EDULIS, . . . . 575

13 "6 scaber, ...... 575

BORAGE, ......... 397

Blue-flowering, ..... 397

Red-flowering, . . . . 397

Variegated, ....... 397

White-flowering, .... 397

Borago OFFICLNALIS, . . . 397

BorkCole, or Kale, . . . . 222

Asparagus, ....... 224

Buda, ......... 224

Cabbaging, ....... 224

Canada Dwarf Curled, . . . 225

Caulet de Flanders, . . . 226

Cesarean, ........ 224

Cesarean Cabbage,. . . . 224

Cockscomb, ....... 22t

Cow-cabbage, ....... 224

Curled Brown, . . . . . . 228

Curled Proliferous, .... 22t

Dalmeny Sprouts, ..... 225

Daubenton's Creeping, ... 225

Dwarf Feather, ...... 224

Dwarf Curled,....... 225

Dwarf Curlies, ..... 225

Dwarf Green Curled, . . . 225

Field Cabbage, . . . . . 226

Field Kale, . . . . . . 220

Flanders, ........ 226

Green Marrow-stem, . . . 226

Green Scotch, . . . . . 225

Imperial Hearting, .... 224

Lannilis, . . . . . . 226

Lannilis Tree-cabbage, . . . 226

Manchester, ....... 224

Neapolitan, ....... 227

Neapolitan Curled, . . . 227

Oak-leaved, ........ 224

Palm, . . . . . . . 227

Purple, ......... 228

Red,........... 228

Red Marrow-stem, . . . 228

Red-stalked, ....... . 228

Russian, ........ 224

Tall Green, . . . . . . 228

Tall German Greens, . . . 228

Tall Green Curled, . . . . . 228

Tall Purple, . . . . . . 228

Tall Scoteh, . . . . . 228

Thousand-headed, . . . . 228

Tree-cabbage, ...... 224

Variegated, ....... 229

Variegated Canadian, . . . 229 
Borecole, or Kale (Continued).

Variegated Cockscomb, . . 229

Woburn Perennial, . . . 229

BotTle Gound, ....... 169

Brassica Canpestris, . . . . 380

" campestris Ruta-baga, 78

" caulo-rapa, ..... 265

" chinensis, ..... 269

" eruca, ....... 380

" napa,....... 379

". oleracea, ... 230, 240,258

" oleracea bullata, ... 270

" oleracea capitata, . . 242

" oleracea sabellica, . . 222

" præcox, ...... 379

" rapa, ......97, 378

Rrassicaceous Plants,.... 222

\$RocColi,.......... 230

Adam's Early White, . . . 238

Ambler's Early White, . . . 233

Asparagus, ....... 234

Autumnal Cape,..... 236

Autumu White, ...... 234

Bath White, ....... 235

Blue Cape,....... 237

Brimstone, ....... 239

Cauliflower, ....... 238

Chappell's Large Cream, . . 233

Chappell's New Cream, ... 233

Covent Garden Market, . . . 239

Cream-colored, ...... 237

Danish, ......... 233

Devonshire White, . . . . 234

Dilliston's Late White, . . . 230

Dwarf Brown Close-headed, . 233

Dwarf Danish, ..... 237

Dwarf Roman, ..... 236

Dwarf Swedish,..... 237

Early Branching, ..... 234

Early Gem, ....... 236

Early Purple,....... 234

Early Purple Cape, .... 23z

Early Purple Sprouting,. . . 234

Early Sprouting, ..... 234

Early White, .... 234, 238

Early White Cornish, . . . 237

Edinburgh Sulphur,..... $\approx 39$

Elletson's Gigantio Late

White,...... 234

Elletson's Mammoth, . . . 234

Fine Early White, . . . . 234

Fine Late Sulphur, . . . . 239

Frogmore Protecting, .... 235
Broccoli (Continued).

Gem, ......... 236

Gillespie's, ....... 235

Gill's Yarmouth White, . . . 238

Grange's Cauliflower, . . . 239

Grange's Early Cape, ... . 237

Grange's Early Cauliflower,. 235

Grange's Early White, . . 235

Green Cape, ........ 235

Green Close-headed Winter, . 236

Hammond's White Cape, . 236

Hampton Court, . . . . . 236

Hopwood's Early White, . . 235

Howden's Superb Purple, . . 237

Imperial Early White, ... 238

Invisible, ....... 235

Invisible Late White, ... 236

Italian Purple, . . . . 237

Italian Sprouting, . . . . . 234

Kent's Late White, .... 236

Kidderminster, ..... 236

Knight's Protecting, . . . 236

Lake's Gem, . . . . . . 236

Late Brimstone, . . . . . 239

Late Danish, . . . . . 233

Late Dwarf Purple, . . . . 237

Late Green, . . . . 233, 236

Late Willcove, . . . . . . 239

Maher's Hardy Cape, . . . 236

Maher's New Dwarf, . . . 237

Marshall's Early White, . . 235

Miller's Dwarf, . . . . . 237

Miller's Late White, . . . . 237

Mitchell's Ne Plus Ultra, . . 237

Mitchinson's Early White, • 237

Mitchinson's Penzance, . . . 237

Naples White,. . . . . 238

Neapolitan White,.... 238

North's Early Purple,. . . . 234

Portsmouth,. . . . . 237

Purple Cape, ...... 237

Purple Silesian, . . . . . 237

Reading Giant, ..... 238

Siberian, ....... 233, 236

Snow's Spring White, ... 238

Snow's Superb White Winter, 238

Southampton, ...... 237

Sulphur,......... 239

Walcheren, ...... 239

Ward's Superb, . . . . 239

Waterloo Late White, . . . 236

White Cape, . . . . . 239

Willcove, ....... 239 
BROOK-LINE,

American, ....... 306

Brussels Sprouts, ..... 210

Dwarf, ........ 241

Giant,........ 241

Tall,.......... 241

Buckshory Plantain, ... 307

BURnet, . . . . . . . 308

Hairy-leaved, . . . . . 309

Large-seeded, . . . . . . 309

Smooth-leaved, ...... 309

Cabbage, ........ 242

American Drumhead, . . 2 249

American Green Glazed, . . . 249

Atkins's Matchless, . . . 243

Barnes's Early, . . . . . 24t

Barnes's Early Dwarf, . . 244

Bergen Drumhead, .... 244

Champion of America, . . . 244

Dwarf Battersea, ..... 245

Early Battersea,...... 215

Early Cornish, . . . . . 245

Early Urumhead, . . . . 240

Early Dutch Drumhead,. . . 243

Early Dutch Twist, .... 243

Early Dwarf Battersea, . . 245

Early Hope, . . . . . . 240

Early Low Dutch, . . . . 246

Early Nonparcil, ..... 247

Early Sugar-loaf, . . . 2 247

Early Wakefield, ..... 2t8

Early York, . . . . . 248

East Ham, . . . . . . 248

Great American, . . . . 24t

Green Glazed, . . . . . 249

Large Bergen, . . . . . . 244

Large Flat Dutch, . . . . 252

Large French Ox-heart, . . . 250

Large German Drumhead, . . 244

Large Late Drumhead, . . 249

Large Ox-heart, . . . . : 250

Large York, . . . . . 250

Little Pixic, . . . . . . . 250

Marblehead Mammoth Drumhead,

251

Mason, ........ 251

Paignton, ........ 245

Penton, ........ 245

Pentonville, ....... 245

Pointed-head, ....... 25i

Pomeranian, . . . . . . 252

Premium Flat Dutch, ... 252
CABBAGE (Continued).

Quintal,.......244

Shilling's Queen, ..... 253

Small Ox-heart, ..... 253

St. Denis, ....... 253

Stone-mason, ...... 254

Sutton's Dwarf Comb, . . 25t

Tom 'Thumb, ...... 250

Vannack, ....... 255

Vaugirard,....... 255

Waite's New Dwarf, . . . . 255

Winnigstadt, ...... 256

CABbage, Red Varjeties, ... 256

Early Blood-red, . . . . . . 256

Early Dwarf Red, . . . . 256

Large Red Dutch, . . . . . 257

Small Red, ....... 250

Superfine Black, . . . . . 257

Utreeht Red, . . . . . 257

CAJANUS Bicolor, ..... 499

Calabash, or Common Gourd, . 169

Bottle Gourd, ....... 169

Courge Poire à Poudre, . . . 170

Courge Siphon, . . . . 170

Hercules Club, . . . . . 170

Powder-horn, ...... 170

Siphon, ........ 170

Calendula officinalis, . . 410

Canpanula rapunculus, ... 77

Capsicum annuear, .... 606

“ frutescens, ..... 609

“ cerasiforme, .... 610

Capucine, ....... 3/4

Dwarf, ........ 376

Caramay, ....... 398

Cardahine pratensis, ... 332

Cardoon, ......... 150

Artichoke-leaved, ..... 15t

Blood-ribbed, ...... 15t

Common, ....... 153

Lance-leaved, . . . . 15t

Large Purple, . . . . 154

Large Smooth, . . . . 153

Large Spanish, . . . . 153

Large Tours Solid, . . . . 154

Puvis, ......... 15t

Red,......... 15t

Red-stemmed, ........15t

Smooth Large Solid, . . . 153

Tours, ......... 15t

Carolina Potato,..... 91

Carrot, ............ 19

Altrincham,....... 21 
Carrot (Continued).

Altringham,....... 21

Blanclie des Vosges, .... 27

Blood Red, ....... 27

Common White,..... 20

Dutch Horn, . . . . . . 23

Earliest Short Foreing Horn, 22

Early Forcing Horn, ... 22

Early Frame, ...... 22

Early Half-long Scarlet,. . . 23

Early Horn, . . . . . . 23

Early Scarlet Horn, . . . 23

Early Short Dutch, . . . 2?

Early Short Scarlet, . . . . 22

Flander's Large Pale Scarlet, 24

Flander's Pale Red, ..... 24

Green-top White, ..... 28

Half-long Red, ...... 23

James's Scarlet, ...... 26

Long Lemon, . . . . . 25

Long Orange, ....... 24

Long Red,. . . . . . . 26

Long lied Altringham, . . . 21

Long Red Belgrian, ..... 25

Long Red Brunswick, . . . . 27

Long Surrey, ....... 25

Long White, . . . . . 20

Long Yellow, ....... 25

New Intermediate, .... 26

Purple, ........ 27

Short White, ...... 27

Studley,........ 27

Transparent White, .... 28

Violette, ........ 27

White Belgian, ...... 28

White Belgran Horn, . . . 28

Yellow Belgian, . . . . . 25

Yellow Green-top Belgian, . 25

Cartilane's tinctorius, . . . 503

Carum carti, ....... 393

Caterpillar, ....... 300

Common, ....... 310

Furrowed,....... 3:0

Hairy, ........ 3:0

Prickly, ........ 3:0

Small, ........ 3:0

Villous, ......... 310

Cauliflower, ....... 258

Early Leyden, . . . . . . 202

Early London, . . . . . 260

Early Parls, .. . . . 260

Erfurt's Early, ...... 260

Erfurt's Extra Early, . . 260
Cauliflower (Continued).

Fiteh's Early London, . . . 260

Frogmore Early Forcing, . . 260

Large Asiatic, . . . . . 260

Legge's Walcheren Broccoli, 202

Le Normand, . . . . . 201

London Particular, .... 200

Mitchell's Hardy Early, . . 261

New Erfurt, . . . . . . 261

Dwarf Mammoth, . . . . 201

Stadtholder, . . . . . 201

Waite's Alma, . . . . . . 201

Walcheren, ....... 2 .

Wellington, ....... 202

Celeriac, ........ 319

Curled-leaved,..... 321

Early Erfurt, ...... 321

Celery, ......... 311

Boston Market, ....... 315

Cole's Superb Red, .... 315

Cole's Superb White, . . . 316

Dwarf Curled White, ... 316

Early Dwarf Solid White, . . 316

Fine White Solid, ..... 310

Giant Patagonian, ..... 316

Gi:ınt Wlite, ...... 318

Italian, ......... 316

Laing's Improved Mammoth

Red,........ 317

Large Upright, . . . . . 316

Lion's Paw, ........ 319

Manchester Red, . . . . . 317

Manchester Red Giant, . . 317

New Large Purple, . . . . 317

New Large Red, . . . . . 317

Nutt's Champion White, . . 317

Prussian, ....... 318

Red Solid, ......... 317

Seymour's Superb White

Solid, ....... 317

Scymour's White Champion, 318

Shepherd's Giant lied, . . . 318

Shepherd's Red,...... 318

Small Dutch, ...... 318

Sutton's White Solil, . . . 318

Tours Purple, ...... 317

Turkey,........ 318

Turkish Giant Solid, . . . 318

Wall's White, ...... 319

White Lion's Paw, . . . 319

White Solid,. . . . . . 319

CIIAROPHYLlUa BUl.Bostrar, . . 29

" cerefolium, .. 321 
Chamomile,

550 [ Collards, ........ 202

Common,

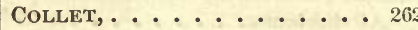

Double Flowering, .....

Champignon, ........

Chardon, .........

Chardoon, ........

Chenopodiun quinoA,....

Chervil, .........

Common, ........

Curled, ......... 321

Double-curled,...... 322

French, ........ 322

Frizzled-leaved, ...... 322

Parsnip, . . . . . . 29

Plain-leaved, ...... 321

Sweet-scented,....... 384

Turnip-rooted,...... 29

CHICCORY, ......... 322

Brunswick Large-rooted, . . 325

Coffee, . . . . . . . 324

Improved, . . . . . . . 324

Improved Variegated, . . . 324

Large-rooted, . . . . . . 3 324

Magdebourg Large-rooted, . 325

Spotted, ........ 324

Turnip-rooted, ..... 324

Variegated, ........ 324

Chickling Vetcir, . . . . . 490

White-flowered,..... 491

CHICK-PEA, . . . . . 489

Red,......... 490

White,........4490

Yellow, ........ 490

Chinese Amarantius, . . . 279

" Cabbage, ...... 269

" Potato, ...... 30

“ Spinach,...... 279

Chrve, .......... 114

Chufa, .......... 32

Ciboule, .......... 137

Cickr a rietinum, ..... 489

Cichorium Exdivia, .... 335

" intybus,..... 322

Crve, ........... 114

Claky, .......... 399

Sage, ......... 399

Clavaria, ........ 575

Climbing Nightshade, ... 283

Cochlearia armoracia, ... 343

" officinalis,.... 382

Cole-seed, . . . . . . . 379

Colewort, ......... 262

Rosctte,....... 263

Colza, .......... 380

Convolvulús batatus, .... 91

Corchorus, ...... 326

" olitorius, ... 326

Coriander, . . . . . . 400

Coriandeum sativua, . . . 400

Cons, Garden Varieties, . . . . 582

Adam's Early White, . . . 582

Black Sweet, . . . . . . 583

Burr's Improved, ..... 583

Burr's Sweet, . . . . . 5 583

Darling's Early, . . . . 584

Darling's Eariy Sweet, . . . 584

Early Dwarf Sugar,. . . . 584

Early Jefferson, . . . . 585

Extra Early Dwarf, . . . 584

Golden Sweet, . . . . 585

Golden Sugar,...... 585

Mexican, ...... 583

Narraganset, ..... 586

Old-Colony, ...... 586

Parching, white kernel, .. 587

Parching, yellow, .... 588

Pop, ......... 587

Red-cob Sweet, . . . . 588

Rhode Island Asylum, . . . . 588

Rice, Red Kernel, . . . . . 589

“ White Kernel,..... 589

“Yellow Kernel, .... 590

Slate Sweet, . . . . . 583

Stowell's Evergreen, . . . 590

Stowell's Evergreen Sweet, . 590

Turkey Wheat, ..... 590

Tuscarora, ...... 590

Twelve-rowed Sweet, ... 591

Cons, Field Varieties, . . . . 591

Brown, ....... 595

Canada Yellow, ..... 591

Dutton, ....... 592

Farly Canada, ...... 591

Early Dutton, . . . . 592

Hill, ......... 593

Illinois White, . . . . . 594

Illinois Yellow, . . . . . 594

Improved King Philip, . . 595

King Philip, . . . . . 595

New England Eight-rowed, . 595

Old-Colony Premium, . . . 593

Parker, ........ 596

Smutty White, ..... 593 
Cors, Field Varieties (Continued).

Southern White, ..... 597

Southern Yellow, ..... 597

Webster, ........ 593

Western White, ...... 594

Western Yellow, ..... 594

White Horse-tooth, .... 597

Whitman,....... 593

Whitman Improved, . . . 5 593

Yellow Horse-tooth, . . . . 597

CoRN SALAD,....... 327

Common, ....... 328

Italian, . . . . . . . 329

Large Round-leaved, . . . 328

Large Seeded Round, . . . 328

Costmaliy, ........ 401

Hloary-leaved, ...... 402

Couve TronchudA, ..... 263

Dwarf, ........ 264

Fringed,........ 205

Large-ribbed, . . . . . 263

White-ribbed, ...... 265

Crambe Maritma, ...... 276

Cress, or Peppergrass, .... 329

Broad-leaved, ...... 330

Common, ........ 330

Curled, ........ 330

Garnishing, ...... 330

Golden, ........ 331

Normandy Curled,...... 331

Plain-leaved, ...... 330

Crithitum MaRITIMUM, ... 381

Cruminock, .......... 90

CUCKOO Flower, ...... 332

Double Purple Flowering, . . 332

Double White Flowering, . . 332

Purple, ........ 332

White, ........ 332

Cucumber, ......... 158

Carter's Champion, .... 162

Coleshill, ......... 162

Conqueror of the West, . . 162

Cuthill's Black Spine, .... 162

Doctor, ........ 162

Early Cluster,...... 160

Early Frame, ....... 161

Early Green Cluster, . . . 160

Early Long Green Prickly, . 165

Early Russian, ....... 161

Early Short Green Prickly, . 166

Early White-spined,..... 167

Eggleston's Conqueror, . . . 162

Egyptian, ........ 168
Cucumbre (Continued).

Extra Long Green Turkey, • 165

Flanigan's Prize, ..... 163

Giant of Arnstadt, . . . . 163

Globe, ......... 168

Hairy, . . . . . . . 168

Henderson's Number One

Black-spined, ..... 163

Hunter's Prolific, ...... 163

Improved Sion House, . . . . 163

Irishman, . . . . . . 163

Jamaica, . . . . . . 189

London Long Green, . . . 162

Long Green Prickly, . . . 165

Long Green Turkey, . . . 165

Long Prickly, ....... 165

Lord Kenyon's Favorite, . . 163

Manchester Prize, . . . . 163, 164

Napoleon III., . . . . . . 164

Nepal,.......... 164

New York Market, ..... 167

Norman's Stitehworth-park

Hero, ........ 164

Old Sion House, . . . . . 164

Prize-fighter, ...... 164

Rifleman, ........ 164

Ringleader, ........ 164

Roman Emperor, . . . . 164

Round-leaved Egyptian,. . . 168

Serpent, . . . . . . 196

Short Green, . . . . . . 161

Short Green Prickly, .... 166

Short Prickly, . . . . . 166

Snake,......... 196

Southgate,....... 165

Sponge, ......... 188

Star of the West, ..... 165

Stockwood, ....... 165

Sugden's Aldershott, .... 165

Underwood's Short Prickly,. 166

Vietory of Bath, ..... 165

West-Indian, ...... 189

White Spanish, ..... 167

White-spined, ...... 167

Cucumis acutangulus, ... 188

“ anguria, ....... 189

" chate,........ 168

" flexuosus, ...... 196

" melo, ........ 173

“ prophetarum, ..... 168

“ sativus, ...... 158

Cucurbita aurantiaca, ... 202

" citrullus,..... 182 
Cucurbita lagenaria, ... 169 " maxima,..... 211 "6 ovifera, .....200 "6 piliformis, .... 214 " pepo,....... 190 " verrucosa, ..... 198 Cucurbitaceous Plants, ... 159 Cultivated Latiy ius, . . . 490 Cunin, ........... 402 Cuminum cyminum, .... 402 Cynara Cardunculus, ... 150 Cynarus scolynus, ..... 139 Cyperus esculentus, ..... 32

Dandelion, ........ 333

Daucus carota,...... 19

DePPE's OXALIS, ....... 38

DILL, ........... 403

Dioscorea batatas,..... 30

DoLICHOS SESQUIPEDALIS, . . 481

Earti Almond, ...... 32

EARTH Nut, ........ 5H4

Eatable ponded Peas, . . . 5 540 Eatable-rooted Pea, ... . 95 EDIble CYPERUS, ...... 32 EgG-PLANT, ....... 597 American Large Purple, . . 5 598 Chinese Long White, . . . 599 Guadaloupe Striped, . . . 599 Large Round Purple, . . . 600 Long l'urple, ...... 600 New York Improved, ... 600 Round Purple,...... 600 Scarlet-fruited, ...... 601 White, ......... 601 Egyptian Cucumber, . . . . 168 Egyptian Pea, . . . . . 480 Elecatipane, ...... 552 Endive, ........ 335 Exdives, Batavian, . . . . 337 Broad-leaved, ...... 337 Common Yellow, ..... 337 Curled,........ 338

Large, . . . . . . . . 338

Lettuce-leaved, . . . . 338 Small,......... 339 White,........ 338

Endives, Curled, ...... 339

Dutch Green Curled,. . . . 339

Early Fine Curled Rouen, . . 341

Ever-blanched, ..... 342

Green Curled, ....... 339
Endives (Continued).

Green Curled Summer, . . 340

Italian Green Curled, . . . 340

Large Green Curled . . . . 341

Long Italian Green, . . . . 341

Picpus Fine Curled, . . . . 341

Ruffee Curled, ....... 311

Small Green Curled, . . . . 339

Staghorn, ........ 341

Triple-curled Moss, .... 342

White Curled, ....... 342

Winter Moss, ....... 342

ENGlish BeAN,....... 491

ExGlish TURxip, ..... 97

ERVuM LENS, ...... 500

"6 monanthos,..... 502

Esculent Fungi, . . . . 567

ESCULENT Roots, ...... 1

Evening Prinirose, . . . . 33

Faba vulgaris arvensis, . 495

FEDia CORXUCOPIE, ..... 386

Fennel, ........ 404

Bitter,........ 405

Common, ....... 40.5

Dark Green-leaved, . . . . 405

Florence, ....... 405

Italian, ........ 405

Malta, ......... 406

Sweet,........ 406

Sweet Azorian, ..... 405

Fetticus,........ 327

Finochlo,........ 405

Feniculum duice, ..... 405

" officinale, .... 406

" vulgare,..... 405

Four SPICES,....... 414

FKENCH BEAN, ...... 434

French Spinach, ..... 288

French Tulunit,...... 78

Friar's BeARd, ...... 324

Garden Bean, American, .. 434

Garden Beas, English, ... 491

Garden Patience, .... 291

Garden Picridium, .... 376

G.ARden Rocket, .... 380

GARGET, ....... 15t

Garlic, .......... 115

Common, ....... 115

Early Pink, ....... 116

Early Rose, . . . . . . 116

Great-headed, ...... 116 
Geritan Rampion, ..... 33

GHerkin,......... 189

Globe Clcunber, ...... 168

GLYCYRRHIZA GLABRA, . . . 554

Goldex SAMPHIRE, . . . . 382

Good liryg Henry, . . . . 303

Goosefuut, . . . . . 202,303

Gourd, ........... 169

Green Mint, . . . . . 4 428

Ground BEAx, ....... 544

Ground Cheriry, ..... 580

Purple, ........ 5s1

Scarlet, ........ 581

Tall, ......... 582

Grounn Nut, ....... 544

Gunibo, ........... 604

Hairy Cucuniber, . . . . . 168

HARICOT, .......... 434

HEDEOMA PULEgIOIDES, ... . 557

Helianthus axveus, .... 621

" Indicus, .... 621

“ tuberosus, .... 34

Herb Patience,...... 291

Hibiscus esculentes, . . . . $60 t$

HOARHOUND, ....... 553

Hoosung, . . . . . . 156

HOP, ................ 154

IIORSE-BEAN, . . . . . . 491

Holise-RADISH, . . . . . . 343

Hunelus lupulus, . . . . 154

Hyssop, ......... 553

Blue-flowering, ..... 553

Common, ....... 553

Red-flowering,...... 55t

White-flowering, .... $55 t$

IIYSSOPUS OFFICINALIS, ... 553

Indian Cress, ....... 374

INULA CRITIMIFOLIA, .... 382

" helenium, ...... 552

IPOMEA BATATAS, ...... 91

Jamaica Cucumber, . . . . 189

JAPAN PEA, . . . . . . . 499

JAPANESE YAM, ....... 30

J FRUSALEM ARTICIIOKE, . . . . 34

Common White,...... 35

Purple-skinned,...... 35

Red-skinned, ....... 35

Yellow-skinned,...... 36

KALE (see "Borecole"), . . . 222
KIDNET-BEAN, . . . . . 434

KOHL RABI, ....... 265

Artichoke-leaved, ..... 268

Cut-leaved, ....... 207

Early Dwarf White,. . . . 267

Early Purple Vienna, . . . 267

Early White Vienna, . . . 268

Green,....... 266,268

Purple, ........ 268

White, ........ 268

LACTUCA INTYBACEA, .... 368

" perennis,...... 368

“ quercina,...... 369

" sativa, ...... 344

LAMB's LetTuce, . . . . . 327

LARGE-RIBBED BORECOLE, . . . 263

LARge Stinging NetTle, . . . 285

LATHYRUS SATIVUS, ..... 490

“ tuberosus,..... 95

Lavender, ......... 407

Blue-flowering, ..... $40 \mathrm{~s}$

Broad-leaved, ...... 408

Common, ........ 408

Narrow-leaved Blue-flowering, 408

Narrow-leaved White-flower-

ing, ........ 408

Spike, ........ 408

LaVENDULA SPICA, ..... 407

LEAF-BEET, or Swiss Chard, . . 281

Common, ....... 282

Curled, ........ 283

Great White, . . . . . 283

Green, ......... 282

Large-ribbed Curled, . . . 283

Large-ribbed Scarlet Brazil-

ian, ........ 283

Large-ribbed Silver, . . . . 283

Large-ribbed Yellow Brazilian, 283

Red-stalked,....... 283

Sea-kale, ........ 283

Silver-leaf, . . . . . 283

Swiss Chard, . . . . . 283

Yellow-stalked, ...... 283

LEEK, ........... 116

Broad Flag, . . . . . 119

Common Flag, ..... 118

Edinburglı Improved,. . . 119

English Flag, ....... 119

Large Flag, . . . . . 119

Large Rouen, . . . . . . 118

Little Montagne, . . . . . 119

London Flag, . . . . . . 119 
LEEK (Continued).

Long Flag, . . . . . 118

Musselburgh, ...... 119

Proliferous, ....... 119

Scotch Flag, . . . . . 119

Small Early Netherland, . . 120

Small Summer Brabant, . . . 120

Yellow Poitou, ...... 120

LEEK-LEAVED SALSIFY, . . 85

Leguminous Plants, .... 434

LENTIL, . . . . . . 500

Canada, ........ 5 546

Common, ........ 501

Green,........ 501

Large, ........ 501

Of Spain, . ..... 490

One-flowered, ..... 502

Red,......... 502

Small,........ 502

Yellow, ........ 501

LEONTODON TARAXACUM, ... 333

LEPIDIUM SATIVUM, ..... 329

LetTUCE, . . . . . . . 344

Lettuces, Cabbage, . . . . 348

American Brown Dutcl, . . 362

Black-seeded Gotte, .... 350

Blond Versailles, ..... 359

Boston Curled, ...... 351

Brown, ........ 350

Brown Batavian, . . . . . 348

Brown Dutch Black-seeded, . 348

Brown Silesian, ..... 348

Brown Winter, ..... 349

Button, ....... 359

Capuchin, ....... 359

Curled, ........ 351

Drumhead, . . . . 355,361

Early Cape, ....... 349

Early Dwarf Dutch,.... 352

Early Frame, ...... 352

Early Simpson, ..... 350

Early White Spring, ... 350

Endive-leaved,...... 351

English Endive-llke Curled-

leaved,....... 351

Green Ball, . . . . . . 359

Green Curled, ...... 351

Green Dutch, . . . . 352

Green Winter,...... 352

Hammersmith Hardy, . . 352

Hardy Green Hammersmith, 352

Hardy Hammersmith, . . . 359

Hardy Winter, ...... 352
LetTuCES (Continued).

Ice, ....... 353,355

Ice $\mathrm{Cos}, \ldots \ldots \ldots . . .355$

Imperial Head, ...... 353

India, ......... 354

Large Brown, . . . . . 354

Large Brown Winter, . . . 349

Large Drumhead, . . . . 361

Large Golden Summer, . . 361

Large Gray, . . . . . . 354

Large India,. . . . . . 354

Large Red, . . . . . 355

Large White, . . . . . 358

Large Winter, . . . . . 355

Madeira,....... 355

Malta, ........ 355

Mammoth, ...... 354

Marseilles, ....... 348

Mogul, ........ 354

Naples, ....... 356

Neapolitan, ...... 356

Palatine,....... 356

Red-bordered, ..... 360

Royal,........ 358

Royal Cape, ....... 343

Spanish,........ 361

Spotted, Black-seeded, . . . 357

Spotted, White-seeded, . . 357

Stone Tennis-ball, . . . . 357

Sugar,....... 358, 359

Summer, ....... 358

Summer Blond, ...... 358

Summer Cape,...... 349

Swedish, ....... 359

Tennis-ball, ....... 358

Turkey, ...... 353, 359

Union,........ 353

Versailles, . . . . . 359

Victoria,....... 360

White,....... 355

White Batavian, . . . . 361

White Dutch, ....... 362

White Gotte, Black-seeded, - 360

White Gotte, White-seeded, . 360

White Silesian, ...... 361

White Stone, ...... 361

White Tennis-ball, ... 360

Yellow-sceded Brown Duteh, 362

LetTuces, Cos, . . . . . . 362

Ady's Fine Largre, . . . . 365

Aleppo,........ 366

Alphange, Black-seeded, . . 362

Alphange, White-seeded, . . 363 
Lettuces, Cos (Continued).

Artichoke-leaved, ..... 363

Bath, ......... 364

Bath Green, . . . . . 364

Bearfield, ....... 36t

Bloody, ....... 366

Brown, ........ 364

Endive-leaved,. . . . . . 368

Florence, Black-seeded, . . . 362

Florence, White-seeded, . . . 363

Gray Paris, ....... 364

Green Paris, . . . . . 305

Green Winter, . . . . 365

Kensington, ...... 365

London White, ..... 368

Magnum Bonum, ..... 363

Monstrous Brown, .... 365

Oak-leaved, .... 366, 369

Perennial, ....... 368

Red-spotted, . . . . . 366

Red Winter,....... 366

Spinach Lettuce, . . . . . 369

Spotted, Black-seeded, ... 366

Spotted, White-seeded, ... 366

Sutton's Berkshire Brown, - 364

Sutton's Superb Green, . . 365

Sutton's Superb White, . . 368

Two-headed,....... 365

Waite's White, ..... 367

Wellington, ....... 365

White Brunoy, Black-seeded, 367

White Brunoy, White-seeded, 367

White Paris, ...... 368

White-seeded Brown, ... 364

Wood's improved Bath, . . . 364

LiCorice, . . . . . . . 554

LIGUSTICUM LEVISTICUM, . . 409

LIMA Bean, . . . . . . 482

Green,........ 485

LIME-PLANT, ........ 556

LONG-PODDED Dolichos, . . 481

LOTUS TETRAGONOLOBUS, . . 547

LOVAGE, .......... 409

LOVE-APPLE, . . . . . . 628

LUPINE, . . . . . . . . 503

White,........ 503

Yellow, ........ 503

LUPINUS ALBUS, ..... 503

" luteus, ....... 503

Madras Radish, . . . . . 369

Malabar Nightshade, ... 283

Large-leaved Chinese, . . . 284
Malabar Nightshade (Con.).

Red,.......... 284

White,.........283

MALABAR SPINACH, ..... 283

MaLlow, Curled-leaved, .... 370

MALVA CRISPA, ....... 370

MANDRAKE, ....... 556

MARIGOLD, ........ 410

Childing, ....... 411

Common Orange-flowered, - 411

Double Lemon-flowering, . . 411

Double Orange-flowering, . . 411

Lemon-flowered, . . . . 411

Pot, ......... 410

Proliferous, ....... 411

MARJoRAM, ........ 412

Common, ........ 412

Knotted,........4 412

Pot, .......... 413

Sweet,......... 412

Winter Sweet,. . . . . 414

MaRsh SPEedWell, .... 306

Martynia, ........ 602

" proboscidea, .... 602

MARRUBIUM vULGARE, . . . . 553

Maw, .......... 558

MAY-APPLE, ....... 556

MEdicago oRbICULARIS, . . . 383

Medicinal Plants, . . . . 548

MELISSA OFFICLNALIS, . . . . 394

MELON, ........... 17

MeLoN, Musk, ........ 173

Beechwood, ........ 173

Black-rock Cantaloupe, . . 173

Christiana, ....... 174

Citron, .......... 174

Common Musk, ...... 175

Early Cantaloupe, . . . . 175

Green Citron, ....... 174

Green-fleshed Citron, . . . 174

Hardy Ridge, . . . . . . 175

Large-ribbed Netted Musk, • 175

Munroe's Green Flesh, . . . 176

Nutmeg, . . . . . . 176

Orange Cantaloupe, .... 176

Pine-apple, ........ 176

Prescott's Cantaloupe, . . . 177

Skillman's Fine-netted, . . . 177

Vietory of Bath, ....... 177

White Japan, ....... 178

Melon, Persian Varietles, . . 178

Dampsha,........ 178

Daree, .......... 179 
Melon, Persian Var., (Continued).

Geree,........ 179

Germek,....... 179

Green Hoosainee, . . . . 179

Green Valencia, ..... 180

Ispahan, . . . . . . . 180

Large Germek, ...... 179

Melon of Keiseng, . . . . 180

Melon of Seen, ...... 181

Small Germek, . . . . . 181

Striped Hoosainee, .... 181

Sweet Ispahan, . . . . . 180

Melon, Water, ........ 182

Apple-seeded, ...... 182

Black Spanish,. . . . . . 182

Bradford, ........ 183

California Pie,....... 18i

Carolina, ....... 183

Citron, ....... 184

Clarendon,........ 184

Dark-speckled,. . . . . 184

Ice-cream, . . . . . . 185

Imperial, ....... 185

Mountain Sprout, .... 185

Mountain Sweet, .... 186

Odell's Large White, . . . 186

Orange, ........ 187

Pie, ........ 18z

Ravenscroft,....... 188

Spanish,......... 182

Souter, ......... 188

mentha piperita, ..... 419

" viridis, ....... 428

Mrscellayeous Vegetables, . 580

Morchella esculenta, . . . 575

MTOREL, .......... $5 \% 5$

MORELTL, ........ . 280

Mountain Spinach,..... 288

MUrciana, ........ 264

Mushroon, ........ 567

Blewits, ........ 574

Blue Hats, . . . . . . 5 5/4

Common, ....... 567

Fairy-ring, ....... 574

St. George's, . . . . . . 573

Sweet,......... 573

MuskMelon, ....... 173

Mustard, ............ 370

Black, ........ 370

Brown, ........ 370

Cabbage-leaved, ...... 372

Chinese, ......... 372

Curled, ......... 372
Mustard (Continued).

Cut-leaved, ....... 373

Pekin, .......... $37^{2}$

Red,.......... 370

White,......... 373

Napoleon PeA, or Veteh, .. 546

Nasturtium, ....... 374

Dark-flowering, ..... 375

Small, ........ 376

Tall, ......... 375

Variegated, ....... 375

Nasturtium ARMIORACia, ... 343

" officinale, .... 386

Nettle, . . . . . . 285

New Zealand Spinacil, . . 286

Nicotiana, ........ 622

" tabacum, .... 623

" rustica,...... 627

Nigella sativa, ..... 414

Nut Rush, ......... 32

$\mathrm{OCA}, \ldots \ldots \ldots . \ldots 36$

Blanca, ........ 36

Colorado, ....... 37

OCRA, ............. 604

OCYMUM Basilicum, ..... 395

" minimum,..... 396

ENothera bieñis, . . . 33

Orl Radish, ....... 603

Olly Grain, ....... 5 . .

OKRA, ........... 604

Buist's Dwar,. . . . . 605

Dwarf, ........ 605

Giant, ........ 606

Pendent-podded,. . . . . 605

Tall, ......... 606

White-podded,......606

Oleraceous Playts, .... 391

Onron, ........... 120

Blood-red, . . . . . . 122

Brown Deptford, . . . . . 124

Brown Portugal, ..... 122

Brown Spanish, . . . . . 122

Brunswick Deep Blood-red, . 127

Cambrai,......... 122

Cambridge, ....... 133

Cow-horn, ....... 125

Danvers, ........ 123

Danvers Yellow, . . . . 123

Deptford, ......... 124

Dutch, ......... 130

Dutch Blood-red, . . . . 122 
Oxion (Continued).

Early I.isbon, . . . . . . 132

Early Red Wethersfield, . . . 12t

Early Silver Nocera, . . . . 124

Early Silver-skin, . . . . 125

Early Small Silver Nocera, . $12 t$

Egyptian, ........ 130

Essex,......... 130

Flanders, ........ 130

Flat Madeira, . . . . . . 131

French Blood.red, . . . . 122

Fusiform, ........ 125

Intermediate Red Wethersfield,........ 125

James's Keeping, . . . . . 125

James's Long-keeping, . . . 125

Large Globe Tripoli, . . . . 126

Large Red, ....... 126

Lisbon, . . . . . . . 132

Madeira, ......... 126

New Deep Blood-red, . . . . 127

Oporto, ......... 122

Pale-red,........ 127

Paris Straw-colored, . . . . 127

Pear-shaped, ....... 127

Potato, ......... 128

Romain, ......... 126

Silver-skin, ....... 129

Silver-skin of New England, . 133

Spanish, ....... 132

Strasburg, ....... 130

St. Thomas, ....... 122

Top, .......... 130

Tree, .......... 130

Tripoli, ......... 131

Two-bladed, ....... 131

Underground, . . . . . 128

Wetherstield Large Red,. . . 126

White Florence, . . . . . 132

White Globe, ....... 132

White Lisbon, . . . . . . 132

White Nocera,........ 124

White Portugnl, . . . . 129, 132

White Reading, . . . . . 133

White Spanish, ...... 1333

Yellow, ......... 133

Yellow Globe, . . . . . . 132

Yellow Strasburg, . . . . 130

Oosung, ........... 156

Orach, ........... 288

Dark Green, . . . . . . 289

Dark Purple, . . . . . . 289

Dark Red, ........ 290
OrAcII (Continued).

Deep Green, . . . . . . 289

Green, ......... 289

Lurid, . . . . . . . 289

Pale Green, . . . . . 290

Pale Red, ........ 289

Purple, ......... 289

Purple-bordered Green, ... 290

Red,.......... 290

Red-stalked Green, .... 290

Red-stalked White, .... 230

White,.........2 290

White French Spinach, . . 290

Yellow, ........ 290

ORIGANUM HERACLEOTICUM, . . 414

"6 marjorana, .... 412

" onites, ...... 413

“ vulgare,...... 412

OsMorkHIzA ODORATA,.... 384

Oxalis,.......... 36

" acetocella, ..... 389

. crenata, ....... 36

" Deppei, ....... 33

" Deppe's ........ 38

" Red Tuberous-rooted, . 37

" Tuberous-rooted, ... 36

"White-rooted, ..... 36

OYSTER Plant, ...... 85

PАk-Chöı, . ....... 269

Palmate-leaved lihebarb, - 561

Papanjay, ........ 188

Papayler sominiferua, . . . 558

Parsley, ......... 415

Celery, ........ 419

Celery-leaved, ...... 419

Common, ........4 417

Curled, ........ 417

Dwarf Curled, ....... 417

Hamburg, ....... 418

Large-rooted, . . . . . 418

Mitchell's Matchless Win.

ter, .........4 417

Myatt's Extra Flne Curled. . 417

Myatt's Garnishiug, . . . . 417

Myatt's Triple-curled,. . . 417

Naples, ......... 419

Neapolitan, .......4 419

Plain, .......... 417

Rendle's Treble Garnishlng, . 418

Sutton's Dwarf Curled, ...417

Turnip-rooted, ...... 418

Usher's Dwarf Curled, . . . 417 
Parsley (Continued).

Windsor Curled,. . . . 417

Parsley-PeRt, . . . . . 381

PARSNIP, ......... 39

Common, ....... 42

Dutch, ........ 42

Early Short Horn, . . . . 42

Guernsey, ....... 42

Hollow-crowned, ..... 43

IIollow-crowned Guernsey, . 43

Hollow-headed,...... 43

Long Jersey, ....... 43

Long Smooth,....... 42

Long Smooth Dutch, . . . 42

Panais Long, ....... 42

Panais Rond, ....... 44

Siam, ......... 43

The Student, ...... 43

Swelling, ........ 42

Sutton's Student, ..... 43

Turnip-rooted,....... 44

Yellow, ........ 43

Parsmip Chervil,...... 29

Pastivaca sativa, ..... 39

Patience, ......... 291

PATIENCE DOCK, ....... 291

PEA, ........... 504

Advancer, ........ 509

Alliance, ....... 523

Auvergne,........ 509

Batt's Wonder, ...... 510

Beck's Felipse, ...... 513

Beck's Gem,. . . . . 5. 534, 537

Beck's Morning-star, . . . 539

Beck's Prize-taker, ..... 510

Bedmau's Imperial, . . . . 510

Bellamy's Early Green Mar

row, .........

Blshop's Early Dwarf, . . . 511

Bishop's New Long-podded, . 512

Black-eyed Marrow, . . . . 512

Blue Cimeter, ....... 513

Blue Fan, ........ 514

Blue Imperial, . . . . . 513

Blue Prussian,...... 514

Blue Sabre, ....... 513

Blue Spanish Dwar,. . . . . 514

British Queen,...... 515

Brompton Hotspur, . . . . 517

Burbridge's Eclipse, . . . . 515

Bush, .......... 537

Carter's Earliest, ..... 522
Pea (Continued).

Carter's Eelipse, . . . . . . 516

Carter's Victoria, ..... 516

Cedo Nulli, . . . . . . 523

Champion of England, . . 5 524

Champion of Paris, .... 518

Champion of Scotland, . . 519

Charlton, ....... 516

Charlton Hotspur, . . . . 517

Climax, ........ 531

Competitor, ....... 519

Dantzic, ........ 519

Dickson's Early Favorite, . . 520

Dickson's Favorite, .... 520

Dillistone's Early, . . . . . 520

Dunnett's First Early, . . . 5 522

Dwarf Bluc Imperial, . . . 513

Dwarf Blue Prussian, . . . 514

Dwarf Fan, ...... 536

Dwarf Marrow, ...... 521

Dwarf Marrowfat, .... 521

Dwarf Prolific, ...... 534

Dwarf Sabre, ...... 5:3

Dwarf White Marrow, . . 521

Early Charlton, ...... 510

Early Dan O'Rourke, . . . . 522

Farly D'ble-blossomed Frame, 522

Early Dwarf Frame, . . . 522

Early Dwarf Marrowfat, . . 521

Early Emperor, . . . . 539

Early Frame, . . . . . . 522

Early Golden Hotspur, . . . 523

Early Hotspur, ...... 5 3

Early Kent, . . . . . . 533

Early May, ....... 533

Early Nicol's Hotspur, .. 5iz

Early Prince Albert, ... 533

Early Railway, . . . . 539

Early Ringwood, ..... 53t

Early Spanish Dwarf, .... 536

Early Surprise, ...... 525

Early Warwick, ...... 523

Early Washington, .... 523

Early Wonder, ..... 539

Erin's Queen, ....... 515

Essex Champion, ..... 522

Essex Hotspur, . . . . . 517

Eugénie,........ 523

Excelsior,........ 518

Fairbeard's Champion of Eng-

land,......... 524

Fairbeard's Nonpareil,. . . . 525 
PeA (Continued).

Fairbeard's Surprise, . . . 525

Flack's Imperlal, . . . . . 52i

Flack's New Large Victoria, 526

Flack's Victoria,. . . . . 520

Flack's Victory, . . . . . 526

Flander's Hotspur, . . . . 517

Flanagan's Farly, . . . . 534

General Wyndham, ....5 520

Golden Hotspur, . . . 517, 523

Green Prússian, . . . . . . 514

Groom's Superb, ..... 514

Hair's Defiance, ...... 515

Hair's Dwarf Mammoth, .. 527

Harrison's Glory, . . . . 527

Harrison's Perfection,. . . 5 528

Hill's Early, . . . . . . 518

Hovey's Extra Farly, . . . 518

Jay's Conqueror, ..... 532

King of the Marrows, . . . 528

Knight's Dwarf Blue Marrow, 529

Knight's Dw'f Green Marrow， 529

Knight's Dwarf Green Wrin-

kled Marrow, ......

Knight's Dwarf White Marrow, .........

Knight's Dwarf White Wrinkled Marrow, . . . . . 529

Knight's Tall Blue Marrow, . 529

Knight's Tall Green Marrow, 529

Knight's Tall White Marrow, 530

Knight's Tall White Wrinkled

Marrow, . . . . . 530

Landreth's Extra Early, . . 518

Large Carolina, ...... 536

Lincoln Green, . . . . . 5. 534

Lord Raglan, . . . . . 530

Matchless Marrow, . . . 530

Master's Hotspur,. . . . 517

Milford Marrow, ..... 531

Missouri Marrow, ..... 531

Missouri Marrowfat, ... 531

Napoléon, ........ 531

Ne Plus Ultra, ....... 532

New Sabre, ....... 513

Noble's Early Green Marrow, 5.33

Nonpareil,. ....... 539

Paradise Marrow, . . . . 518

Poor Man's Profit, ..... 534

Prince Albert, . . . . . 533

Prize-taker, ....... 510

Prussian Blue, ...... 514
Pea (Continued).

Queen of the Dwarfs, . . . 533

Race-horse, . . . . . . 523

Reading Hotspur, .... 517, 523

Ringwood Marrow, . . . . 534

Rising-sun, ....... 510

Royal Dwarf, . . . . . 534

Sabre, ......... 513

Sangster's Number One, . . . 522

Sebastopol, ...... 535

Shillings Grotto, ..... 535

Single-blossomed Frame, .. 522

Spanish Dwarf, ...... 536

Strawberry, ....... 530

Stuart's Paradise, . . . . 518

Stubb/s Dwarf, . . . . 515

Superfine Early,. . . . . 523

Surprise, ....... 525

Tall Marrowfat, ...... 536

Tall White Mammoth, . . 515

Tall White Marrow, . . . . 536

Taylor's Early, . . . . . 537

Thurston's Relianee, ... 537

Tom Thumb, ...... 5 537

Veitch's Perfection, .... 538

Victoria Marrow, . . . . 538

Waite's Dan O'Rourke, ... 522

Warner's Early Conqueror, . 539

Warner's Early Emperor,. . 539

White Cimeter, ...... 509

White Prussian,...... 534

White Sabre, ...... 509

Woodford's Marrow, ... 539

PEAs, Eatable-podded or String, 540

Australian, ....... $5+2$

Blue-podded, ....... 542

Botany Bay, . . . . . . . 542

Broadsword, ....... 542

Chocolate,........ $5+2$

Common Dwarf, . . . . . 540

Dwarf Crooked-podded, . . . 540

Early Dwarf de Grace, . . $5 \$ 1$

Early Dwarf Dutch,..... $5+1$

Giant, ........... 541

Large Crooked, ...... 542

Late Dwarf, . . . . . . . 543

Purple-podded, ...... 542

Red-flowered, ....... 542

Six-inch Pod,....... 542

Tamarind, ........ 543

White-podded, ...... 543

Yellow-podded, ..... 543 
PEA, Tuberous-rooted,

PEA-NUT,

African,

Carolina,

Tennessee,........

Wilmington, ...... 5

PenNyROYal, ........ 557

PePper, ........ 606

Bell,.......... 607

Bird, ......... 608

Black-podded, ....... 612

Blue-podded, ...... 612

Bull-nose, ....... 607

Cayenne, ........ 609

Cherry,........6 610

Cherry Yellow-fruited, . . 611

Chili, ......... 611

Large Bell, . . . . . . 607

Large Red Cherry, ... . 613

Long Red, . . . . . . 611

Long Yellow, ...... 612

Purple-podded, ..... 612

Quince, ........ 613

Round, ........ 613

Squash, ....... 613

Sweet Mountain, ..... 614

Sweet Spanish, ..... 614

Tomato-shaped,...... 613

Yellow Squash, ..... 615

Yellow Tomato-formed, . . 615

Peppergrass, ...... 329

Peppermint, ....... 419

Perenyial Phytolacca, . . 156

Perenial Spin.ch, .... 303

Persian Melons, ..... 178

Pe-Tsai, ......... 269

Physalis EDUlis, ..... . 580

“ pubescens, .... 582

Phaseolus lunatus, .... 482

" multiflorus, ... 485

" vulgaris, ..... 434

Phytolacca DeCANDRA, . . 156

" esculenta,.... 157

Picridium, ......... 376

" vulgare, ..... 376

Pie-plant, ......... 615

Pigeon Berry, ...... 156

Pimpinella anisum, . . . . 392

Pindar NuT, ........ 544

Pisum sativum, ...... 504

c6 macrocarpum, ..... 540

Plantago coronopus, . . 307
Podophylium Peltatum, . . 556

POKE, ......... 156

POPPY,........ 558

Gray, ........ 559

Oil,.......... 559

Opium, ........ 559

White, ....... 559

Portugal Borecole, .... 263

Portugal Cabrage, .... 263

Portulaca, ....... 377

" oleracea, .... . 377

" oleracea, var. aurea, $\mathbf{3 7 7}$

"sativa,..... 378

Potato,......... 45

Abington Blue, ..... 66

Ash-leaved Early, ..... 50

Ash-leaved Kidney, . . . 50

Atkinson's Early, ..... 51

Biscuit, ....... 51

Black Chenango, ..... 51

Black Mercer, ...... 51

Buckeye,....... 51

Calico,......... 52

California Red, ..... 52

Carter,........ 52

Chenango,....... 60

Churchill, ....... 52

Cow-horn,........ 62

Cristy, ........ 53

Cups, .......... 53

Danvers Red, ....... 53

Dunvers Seedlling, ..... 53

Davis's Seedling, .... 53

Dover,......... 67

Dykeman, ........ 54

Early Blue, ....... 55

Early Cockney, ..... 55

Early Dykeman,...... 54

Early Manly, ...... 55

Flour-ball,........ 55

Fluke Kidney,...... 56

Forty-fold, ...... 56-65

Garnet Chlli, ...... 56

Gilly flower, ....... 57

Green-top,........ 57

Hill's Early, ....... 57

Irish Cups, ....... 58

Jackson White, .... . 58

Jenny Lind, . . . . . . 59

Lady's Finger, ..... . 59

Laplander,......... 64

Lapstone Kídney, . ... 60 
Potato (Continued).

Long Red,........ 60

Mercer, ........ 60

Meshannock, ...... 60

Mexican, ....... 61

Nichol's Early, ...... 60

Nova-Scotia Blue, ..... 61

Old Kidney, . . . . . . . . 62

Peach blow ....... 62

Pink-eyed, ....... 62

Poggy, ........ 62

Porgee, ......... 62

Quarry, ........ 63

Rhode Island Seedling, . . 59

Riley, ......... 67

Rohan, ........ 63

Ruffort Kidney, ...... 59

Shaw's Early, ....... 64

State of Maine, ...... 64

St. Helena, ........ 64

Taylor's Forty-fold,..... 65

Tolon,......... 65

Vermont White,...... 65

Veto, ......... 66

Western Red,...... 60

White Chenango, ..... 60

White $\mathrm{Cups}, \ldots \ldots \ldots \ldots 6$

White Mountain, ..... 66

Worcester Seedling, .... 67

Poterium SANguisorba ... 308

Pot Marigold, ....... 410

Prickly-fruited Ghekkin, . 189

Punpkin, . . . . . . . 190

Canada, ......... 191

Cheese, .......... 191

Common Yellow Field, ... 192

Connecticut Field,...... 193

Hard-shell, ....... 194

Long Yellow Ficld, ..... 193

Nantucket, . . . . . 194

Nigger-head, ....... 194

Small Sugar, ...... 195

Striped Field, ....... 194

Sugar, ......... 195

Vermont, ......... 191

Purple Goat's Beard, ... 85

Purslain, ............ 377

Common, ........ 377

Golden, ........ 377

Green, .......... 378

Large-leaved Golden, . . . 378

QuinoA,......... 292
QUINOA (Continued).

Black-seeded, ....... 292

Red-seeded, . . . . . 293

White, ........ 292

White-seeded, . . . . . . 292

Radish,......... 67

RADISHES, Spring or Summer, • 69

Crimson Turnip-rooted, . . 73

Early Biack,....... 70

Early Frame, ....... 71

Early Long Purple, . . . . 70

Early Purple Turnip-rooted, . 70

Early Scarlet Short-top, . . . 71

Early Scarlet Turnip-rooted, . $\quad \mathbf{7 0}$

Early White Turnip-rooted, . 70

Gray Olive-shaped, .... 70

Gray Summer,...... 71

Gray 'Turnip-rooted,.... 71

Long Purple, ....... 71

Long Salmon, ....... 71

Long Scarlet, ....... 71

Long Scarlet Salmon, .... 71

Long White, . . . . . . 72

Long White Purple-top, . . 72

Naples, ........ 72

New London Particular,. . . 72

Noir IIatif, ....... 70

Oblong Brown, ...... 73

Oblong Rose-colored, .... 73

Olive-shaped Scarlet, ... 73

Purple Turnip-rooted, . . . 73

Rave Violette Hative, ... 70

Rond Blane Hatif, . . . . 70

Rond Rose Hatif, ..... 70

Round Brown, ...... 71

Scarlet Turnip-rooted, . . . 73

Small Early Yellow Turniprooted, ....... 74

Tortillée du Mans, . . . . . 74

White Crooked,...... 74

White Italian, ....... 72

White Transparent, .... 72

White Turnip-rooted, .... 74

Wood's Frame, ....... 72

Yellow Summer, . . . . . 74

Yellow Turnip rooted, . . . . 74

Radishes, Autumn and Winter, 74

Autumn White, . . . . 76

Black Spanish, ....... 75

Blane d'Augsbourg, ..... 76

Large Purple Winter, . . . 75

Long Black Wiuter, . . . . 76 
RADIshes (Continued).

Long-leaved White Chinese, . 76

Purple Chinese, ...... 76

Purple Spanish, ...... 75

Rose-colored Chinese, . . . 76

Scarlet Chinese Winter, . . . 76

Winter White Spanish, ... 76

RAMPION, ........ 77

RAPE, ............ 378

Annual, ......... 379

Annual Rough-leavedSummer, 378

Cole-seed, ........ 379

Colza, ......... 380

Common, ........ 379

Early, . . . . . . . 379

German, . . . . . . . 379

Smooth-leaved Summer,. . $37^{9}$

Summer,........ 380

Turnip, ........ 378

Wild Navew, ...... 380

Winter, ........ 379

RAPHANus, ........ 369

" sativus, ....67,603

RED BEET, .......... 1

RED BIRDSFOoT TrEFoIL, ... 547

RHEUM, . . . . . . 615

Australe, ....... 620

Emodi, ........ 620

Palmatum, ....... 561

RHUBARB, ....... 615

Buck's.......... 619

Cahoon,.........618

Downing's Colossal, . . . . 618

Early Prince Imperial, . . 619

Early Red Tobolsk, . . . . 620

Elford, ......... 610

Hawkes's Champagne, . . 619

Linnæus, . . . . . 6 610

Mitchell's Royal Albert, . . . 619

Myatt's Linnæus, . . . . 619

Myatt's Vletoria, .....620

Nepal,......... 620

Tobolsk,........620

Victorin,........ 620

RoCAMBOLE, ........... 134

Rocket, ......... 380

Garden,......... 380

Roquette, ........ 380

ROSMARINUS OFFICINALIS, ... 421

RosemaRY, ........ 421

Common, ....... 422

Green-leaved, .......4 422

Gold-striped, ......4 422
Rosemary (Continued).

Narrow-leaved, ..... 422

Silver-striped, ...... 422

Ruv, ........... 562

Broad-leaved, ....... 562

Narrow-leaved, . . . . 562

RUMEX, ......... 295

" acetosa, ...... 296

" montanus, ...... 298

" nivalis,....... 296

" patientia,...... 291

" scutatus, ...... 298

Russian Turnip, ...... 78

RUtA-BAGA TURNiP, ..... 78

Ruta GRaveolens, . . . . 562

SAFFLOWER, ...... 533

SAFFRON, ........ 563

SAGE, ............ 423

Balsamic, ........ 424

Broad-leaved Green,.... 424

Common, ....... $42 t$

Green-leaved, ...... 425

Green-top, ….... 425

Narrow-leaved Green, . . . 4:5

Purple-top, ....... 42t

Red-leaved, ....... 424

Red-top, ........442t

Sage of Virtue, . . . . 4 425

Variegated Green-leaved, . $4: 6$

Variegated Red-leaved, . . 426

SAlad Plants, ...... 305

SALSIFY, ........ 85

SALVIA OFFICINALIS, ..... 424

" sclarea, ...... 399

SAMPHIRE, ........ 381

SATURJEA CAPITATA,.....426

" hortensis, ..... 427

" montana, ..... 428

“ viminea, ..... 427

SAvory, ......... 426

Headed, ........ 426

Shrubby, ....... 4 427

Summer, ....... 427

Winter, ........ 428

SAvoY, ......... 270

SayoY CABBAGE, ..... 270

Blocmendaal, ...... 272

Cape, ......... 272

Drumhead, ....... 272

Dwarf Green Curled, . . . 276

Earllest Ulm, . . . . . 273

Early Dwarf, ...... 272 
Sayoy Cabbage (Continued).

Early Flat Green Curled, . . 2;3

Early Green, ...... 272

Early Long Yellow, . . . . 273

Early Ulm, . . . . . 273

Early Yellow, ....... 274

Feathered-stem, ..... 273

Golden, ........ 2r4

Green Curled, . . . . . 274

Green Globe, ....... 274

Large Green, ....... 274

Large Late Yellow, . . . 276

Long-headed, ....... 275

Marcelin, ....... 275

New Ulm, . . . . . . 273

Tours, ........276

White,........ 276

Yellow Curled, ..... 276

Scandix odorata, ..... 384

Scarlet-runNer Bean, . . 485

“ Painted-lady, .... 487

“ White-runner, ... 487

Scolyuus, ........ 87

Scolyuius Hispaxicus, ... 87

SconpluRus, ........ 309

" muricata,.... 310

" subvillosa, ... 310

" sulcata, .... 310

"s vermiculata, ... 310

ScorzonerA, ........ 88

" Hispanica, .... 88

SCOTCH BeAN, ....... 495

SCURVY-GRASS, . . . . 382, 388

SEA-BEET, . . . . . 293

English,........ 294

Irish, ......... 294

SEA-FENNEL, ....... 381

SEA-KALE, ........ 276

Serpent Cucumber,..... 196

SESAMUM, . . . . . . 548

Shallot, ......... 135

Common, ........ 136

Jersey, ........ 136

Large, ......... 137

Large Alençon, ...... 136

Long-keeping, . . . . . 137

Small, .......... 130

Sherherd's Purse, ..... 294

SIClliAN BEET, . . . . . . 281

SINAPIS ALIBA, ....... 373

" nigra, ...... 370

" Pekinensis,...... 372

SistabriUn NASTURTIUM, . . . 386
StuM SISARUM, ........ 90

Skinless Peas, . . . . . 540

SKIRRET, ......... 90

SMallage, ........ 311

Syall Water-Cress, . . . 332

SMYRIIUM OLUSATRUM, . . . 305

" perfoliatum,.... 306

SNaIls, ......... 383

SNaIl Trefoll, ...... 383

Snake Cucumber, ...... 196

SOLANUM LYCOPERSICUM, . . . 628

" melongena,..... 597

“ nigrum, ...... 280

" tuberosum, ..... 45

SORREL,......... 295

Alpine, ........ 296

Belleville, ........ 297

Blistered-leaf, . . . . . 297

Blistered-leaf Mountain, . . . 299

Broad-leaved, ...... 297

Common, ........ 296

Common Garden, . . . . 298

Feryent's New Large, . . . . 297

French, ........ 298

Green, .......... 298

Green Mountain, . . . . 299

Mountain, ....... 298

Roman, ........ 298

Round-leaved, . . . . . 298

Sarcelle Blond, . . . . . 298

SouTHERNWOOD, ...... 564

Spanish Potato,...... 91

SPANISH OYSTER-PLANT, .... 87

SPANISH SCOLYMUS, ..... 87

SPEARMINT, ........ 428

Curled-leaved,...... 429

SPINACEA OLERACEA, . . . 299

Spinaceous Plants, . . . . 279

SPINACH, ......... 299

Common Prickly, ..... 303

Flanders, ........ 301

Gaudry, ......... 302

Large Prickly-seeded, . . . 302

Large Winter, . . . . . . 302

Lettuce-leaved, . . . . 302

Round Dutch, . . . . 302

Round-leaved,...... 302

Sorrel-leaved, ...... 302

Summer, . . . . . . 302

White Sorrel-leaved, . . . 303

Winter, ........ 303

Yellow Sorrel-leaved, ... 303

SPonge Cucumber, ..... 188 
Squash, ............ SQUASH, Autumn and Winter Varieties,........202

Acorn,..........

Autumnal Marrow, ....

Bostou Marrow, ......

Bush Vegetable Marrow, .

Canada Crookneck, ....

Cashew, .........

Cocoa,.........

Cocoa-nut, .......

Commodore Porter, .....

Courge de l'Ohio, ......

Cuckaw,........

Cushaw Pumpkin, .....

Custard, .........

Dwarf Vegetable Marrow, .

Egg-shaped,.......

Honolulu, ........ 208

Hubbard, ....... 209

Improved Turban, . . . . 215

Italian Vegetable Marrow, . . 210

Large Yellow Gourd, ... . 211

Mammoth,........ 211

Mammoth Pumpkin, .... 211

Neapolitan, ....... 211

Patagonian, ...... 212

Porter's Valparaiso, . . . 215

Puritan, ........ 212

Reeve's, ........ 208

Stetson's Hybrid, ..... 218

Succade Gourd, . . . . 217

Sweet Potato, ...... 213

Turban, ........ 214

Turk's Cap, ....... 214

Valparaiso, ....... 215

Vegetable Marrow, . . . 217

Wilder, ........ 218

Winter Crookneck, .... 219

Winter Striped Crookneck, . 219

Yokohama, .......221

SQUASH, Summer Varieties, . . 198

Apple, . . . . . . . . 198

Bush Summer Warted Crookneck,...... 198

Cymbling, ........ 199

Early Apple, ....... 198

Early Summer Crookneck, . . 198

Early White Bush Scalloped, 199

Early Yellow Bush Scalloped, 199

Egg,......... 200

Green Bush Scalloped,. . . 201
SqUAsh, Summer Varieties (Con.),

Green Striped Bergen, . . . 201

Large Summer Warted Crookneck, . . . . . 202

Orange, ........ 202

Pattypan, ........ 199

Variegated Bush Scalloped, . 202

White Pattypan, . . . . . 199

White Summer Scalloped,. . 199

Yellow Pattypan, ..... 199

Yeilow Summer Scalloped, . 199

Yellow Summer Warted

Crookneck, ...... 198

STAR OF TIE E.ARTH, .... 307

STRAWBERRY TOMATO, . . . 580

Purple, ........ 581

Scarlet, ........ 581

Tall, ......... 582

St. PETER's Heri, . . . . 381

STRING-PEAS, ...... 540

SUCCORY, ......... 322

SUgAR-PEAS, ....... 540

SUNFLOWER, ........ 621

Annual, ........ 621

Dwarf, ........ 621

Tall,.......... 621

SWEde or RUTA-BAGA TURNip, 78

Asheroft, ........ 79

Common Purple-top Yellow, 80

Drummond's Extra Improved, 80

Early Stubble,...... 80

Green-top White, ..... 81

Green-top Yellow, . . . . 81

Laing's Improved Purple-top, 81

Long White French, . . . 84

New Hardy White, ..... 82

Purple-top White,..... 82

River's, ......... 82

Skirving's Improved Purpletop, ........ 83

Skirving's Liverpool, . . . . 83

Skirving's Purple-top, . . . 83

Southold, ....... 83

Sutton's Champion, ..... 83

Sweet German,...... 84

White French, . . . . . 84

SweEt Cickly, . . . . . 384

Sweft Potato, ....... 91

American Red, ...... 94

Kentucky Early Red, . . . 93

Large White, . . . . . 93

Nansemond,....... 93 
Sweet Potato (Continued).

New Orleans Purple, . . . 93

Patate Ilanche, ..... 93

Patate Violette, . . . . . 93

Purple-skinned, ...... 93

Red Nansemond, ...... 93

Red-skinned, . . .... 94

Rose-colored, ....... 94

Yellow Carolina, ..... 94

Yellow Nansemond, ..... 93

Yellow-skinned,...... 94

Sweet-SCENTEd Chenvil, . . . 384

Swiss Chard, ....... 281

TANACETUM vUlgare, . ...430

TANSY, ........ 430

Curled-leaved, ...... 430

Double, ........ 430

Large-leaved, . . . . 4 431

Variegated, ....... 431

TARE, ......... 546

Summer, ...... 547

White,........ 546

Winter, ....... 547

TARHAGON, ....... 385

Tetragonia expansa, ... 286

Thlaspi Blrsa Pastoris, . 294

Thousand-headed Cabbage, . 240

THYME, ......... 431

Broad-leaved, ...... 432

Common, ........4 431

Evergreen, ....... 431

Lemon, ........ 433

Narrow-leaved, ..... 432

Variegated, ....... 432

Thymus Citriodorus, .... 433

" vulgaris,...... 431

TobaCCO,......... 622

Broad-leaved, ...... 624

Connecticut Seed-leaf, . . . 223

Green,......... 627

Guatemala, ....... 624

Japan, ......... 624

Oronoco, ........ 624

Peach-leaf,....... 623

Turkish,........ 627

Virginian, .......6 623

Tomato, ......... 628

Apple,......... 632

Apple-shaped,...... 632

Bermuda, ....... 633

Cluster,.........6 635
Tomato (Continued).

Early Red,......... 641

Extra Early, ...... 641

Fejee, ........ 633

Fig, .......... 633

Giant,........ 634

Grape,........ 635

Improved Apple, ..... 635

Large Red, . . . . . . 636

Large Red Oval, . . . . . 636

Large Yellow, . . . . . 637

Lester's Perfected, . . . . 637

Mammoth, ...... 634

Mexican, ........ 637

New Upright, . . . . . 6339

Perfected,........ 637

Pomo d'Oro Lesteriano, . . . 637

Red Cherry, . . . . . 638

Red Pear-shaped, ..... 633

Red Plum,........ 638

Round Red, . . . . . 639

Round Yellow, ...... 639

Seedless,........ 639

The Cook's Favorite, . . . 639

Tomate de Laye, . . . . . . 639

Tree, ......... 639

White,........ 640

White's Extra Early, ...641

Yellow Cherry, ...... 641

Yellow Fig, . . . . . . 642

Yellow Pear-shaped, . . . . 642

Yellow Plum, ...... 642

TOTA BONA, ........ 303

Tragopogon PORRIFolius, .. 85

Trauxuda Kale, ..... 263

Tree Primrose, ....... 33

Tropelulu, ........ 374

“ majus, ..... 375

"6 minus, ..... 376

“ tuberosum, ....96

TRUFFLE, ........ 576

Common, ....... 576

Piedmontese, ...... 578

TUber Cibariem, ..... 576

“ magnatum, ..... 578

“ melanosporum, .... 578

Tuberous-rooted Chickling

VЕTCH, ....... 95

Pea, .......... 95

Tropæolum,....... 96

Wood-sorrel, ...... 36

Turkey Rhubarb, ..... 561 
TURNIP, ......... 97

Altrincham, ...... 98

Altringham, ....... 98

Autumn Stubble, ..... 107

Border Imperial, . . . . . 9 98

Border Imperial Purple-top Yellow, ....... 98

Chiva's Orange Jelly, . . . 98

Common Field Globe, . . . 109

Cow-horn, ....... 99

Dale's Hybrid, . . . . . . 99

Decanter, ........ 102

Early Dwarf, . . . . . 107

Early Flat Dutch, . . . . 99

Early Stone, . . . . . 110

Early White Dutch, . . . 99

Early Yellow Dutch, . . 100

Finland, ........ 100

Freneuse, ...... 100

Golden Ball, . . . . . . 101

Golden Maltese, . . . . . . 112

Green Globe, . . . . . . 101

Green Norfolk, . . . . . 102

Green Round, . . . . . . 102

Green Tankard, . . . . . 102

Green-top Flat, . . . . . 102

Green-top Norfolk, .... 102

Green-top White Globe, . . . 101

Green-top Yellow Aberdeen, . 103

Green-top Yellow Bullock, . 103

Hungarian Green-top Globe, 101

Lincolnshire Red Globe, . . . 103

Liverpool Yellow,...... 104

Long Black, . . . . . . 103

Long Early White Vertus, . 99

Long White Clairfontaine, . . 103

Long White Maltese, . . . 103

Maltese, ......... 112

Mouse-tail, ........ 111

Navet Boule de Neige, . . . . 108

Navet Gros d'Alsace, .... 111

Petrosowoodsk, ...... 103

Pomeranian Globe, . . . . 104

Preston, . . . . . . . 104

Purple-top Aberdeen, . . . 105

Purple top Flat,...... 104

Purple-top Strap-leaved, . . . 105

Purple-top Yellow Aberdeen, 105

Purple-top Yellow Bullock, . 105

Red Globe, ........ 106

Red Norfolk, ....... 106

Red Round, ........ 106
Turvip (Continued).

Red Tankard, ...... 106

Red-top Flat, . . . . . 104

Red Mouse-tail, ...... 111

Red-top Norfolk, . . . . 106

Robertson's Golden Stone, • 106

Round Black, ....... 107

Six-weeks, . . . . . 107

Small Berlin, . . . . . . 108

Small Long Yellow, . . . . 107

Snow-ball, . . . . . . 108

Stone Globe, . . . . . . 108

Tankard, ....... 102

Teltau, ........ 108

Teltow, ......... 108

Waite's IIybrid Eclipse, . . . 109

White Dutch, ...... 99

White Garden Stone, . . 110

White Globe, . . . . 109

White Norfolk, ...... 110

White Round, . . . . . 110

White Stone, ...... 110

White Tankard, ...... 111

White-top Flat, . . . . . 111

White-top Strap-leaved, . . . 111

Yellow Altrincham, . . . . 98

Yellow Dutch, . . . . 100

Yellow Finland, . . . . . 100

Yellow Globe,....... 101

Yellow Malta, . . . . . . 112

Yellow Scarlsbrick, .... 112

Yellow Stone, . . . . . 112

Yellow Tankard,...... 112

TuRnip CaBbage, ..... 265

Turnip-rooted Celery, . . . 319

TURNIP-ROOTED Chervil, . . . 29

TUSSILAgo FARFARA, .... 551

Unicorn Plant,...... 602

URTICA DIOICA,...... 285

VAleriana, . . . . 3 327, 386

" cornucopix, ... 386

“ locusta, ..... 327

VAlerianella eriocarpa, . 329

Vegeta ble OYSTER. . . . 85

Veronica BeccabUNGa, . . 306

VETCH, or 'Tare, . . . . . 546

Napoléon Pea,...... 546

Summer, ....... 547

White,........ 546

Winter, ........ 547 


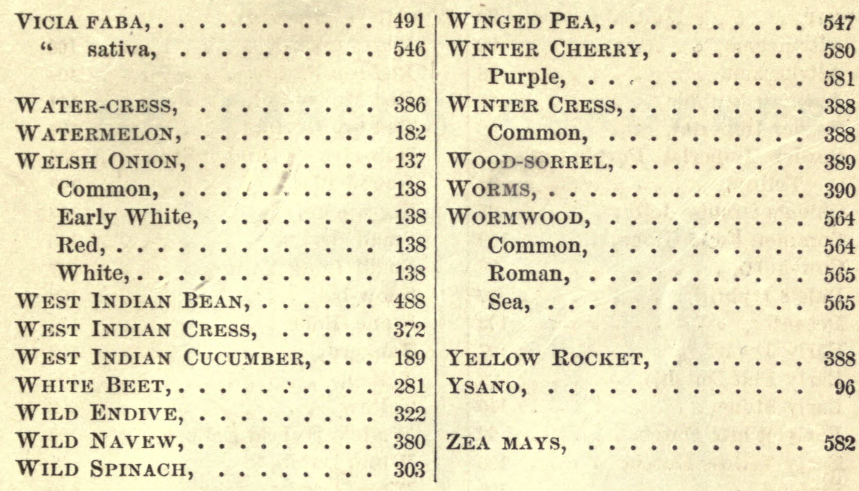




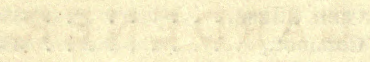

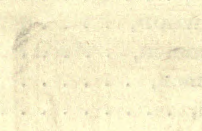




\section{THE PARLOR GARDENER.}

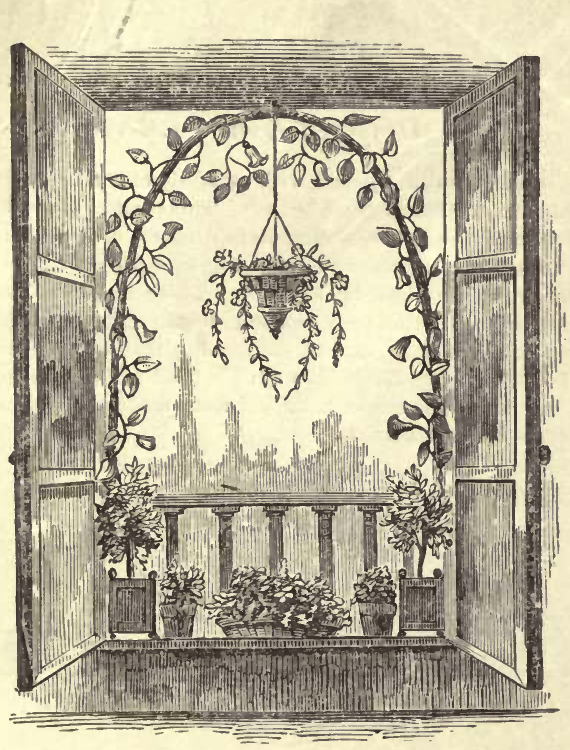

A Treatise on the House Culture of Ornamental Plants. Translated from the French, and adapted to American use. By CorneliA J. RANDOLPH, of Virginia. With eleven illustrative cuts.

A bijou of a book. Every lady who cultivates flowers will want a copy. It will teach them how to bring a bit of nature into all their homes, and give them in their parlors some of the pleasures of out-door life. It contains minute directions for " the mantle-piece garden," the " étagère garden," " the flower-stand garden," "the portable green-house," "the house aquarium," the garden upon the balcony, the terrace, and the double window, besides describing many curious and interesting experiments in grafting. The book is neatly printed, beautifully illustrated, and is just the size for a pocket companion.

$$
\text { Price . . . . }: \$ 1.00
$$




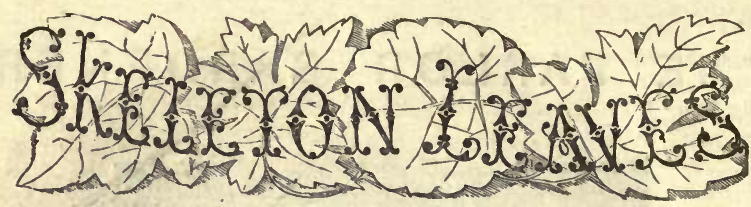

AND PHANTOM FLOWERS.

"It is printed on elegant paper, with carefully executed engravings, and typographical execution of great beauty. This treatise gires full and careful instruction in the art of skeletonizing leaves, commencing with the proper selection of varieties, and following up with the various processes of preparation to the phantom bouquet. There is an endless source of amusement and instruction provided here, which must be fascinating to all who pursue it. Tlis book, and its companion Wax-flowers, 1ssued in the same style by the same publishers, give a fund of information, which, if followed, will largely increase botanical knowledge. We commend it to our readers." - Horticulturist.

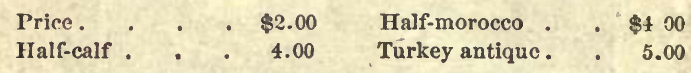

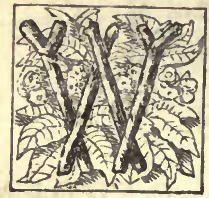

\section{AX FLOWERS, AND HOW TO} MAKE THEM.

Most person who teach this art know but very little about it, with the modern improvements, \&c. With this book, any person of taste may learn how to make flowers, fruit, and all articles in wax; also how to make sheet wax and wax materials.

The best and most popular teachers have had no other instruction. Much valuable information is here that teachers not owning the book do not possess.

A lady in this city has, during the past year, realized sixteen hundred dollars from the sale of wax flowers. This fascinating art is becoming nearly as popular here as in England, where ladies of all classes practise it in common with painting, drawing, embroidery, \&c.

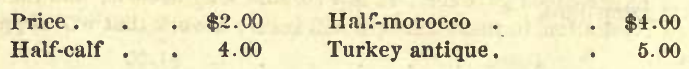




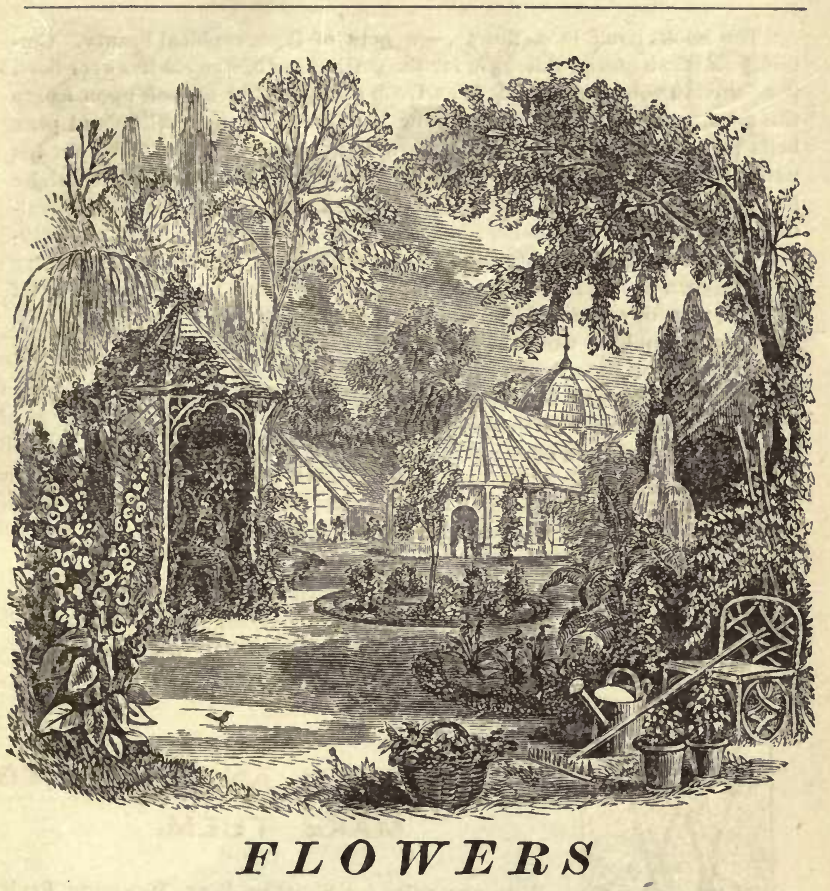

\section{FOR THE PARLOR AND GARDEN.}

BY EDWARD SPRAGUE RAND, JR.

A splendid illustrated volume on the culture of Greenhouse, Conservitory, Stove, Parlor, and Garden Flowers, Ferns, Bulbs, etc. Instructions and plans on the building, stocking, and kecping Conservatories, Greenhouses, etc.; Waltonian Cases, Ferneries, etc.; Soil for the Flower Garden; list of best Plants and Seeds; how to propagate; time of planting and flowering. In short, every information needed by the amateur or the most experienced gardner. It is a volume long needed; and the author's high reputation in these matters will insure a work that wiil supply every want. 


\section{J. E. TILTON \& CO.'s PUBLICATIONS.}

"The book itself is a flower, - a gem of typographical beauty. Certainly no handsomer guide-book for the cultivation of flowers has ever been published in this country. It is as fresh and pleasant to look upon as are the arbutus blossoms which are now putting forth their white and pink bells in token of spring. Mr. Edward Rand, jun., could not have put his name upon a more memorable page than upon the title leaf of lns exquisite book upon the culture of flowers. No space is occupied with useless poctical quotations and rhapsodies; but every thing is plain, practical, and valuble. It is just what it professes to be, - a guide-book for the garden. Every lady can own it, and feel assured that she is, for one, favoring nothing of politics, war, or sensation-literature. She has that which can make every one liappicr, and the world brighter. Of course, those ladies who are too exquisite to cultivate flowers will not care for its instructions; but every true woman who would make home pleasanter, more genicl and clieerful, and herself more refined in the lighest sense of the world, will welcome any help in the culture of her flowers." - The Round Table.

\begin{tabular}{|c|c|c|c|c|}
\hline Extra muslin & . & • & 。 & 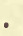 \\
\hline Half-calf . & . & & & \\
\hline Half-morocco, & gilt top & & & \\
\hline Turkey antique & . & $\bullet$ & $\theta^{\circ}$ & \\
\hline
\end{tabular}

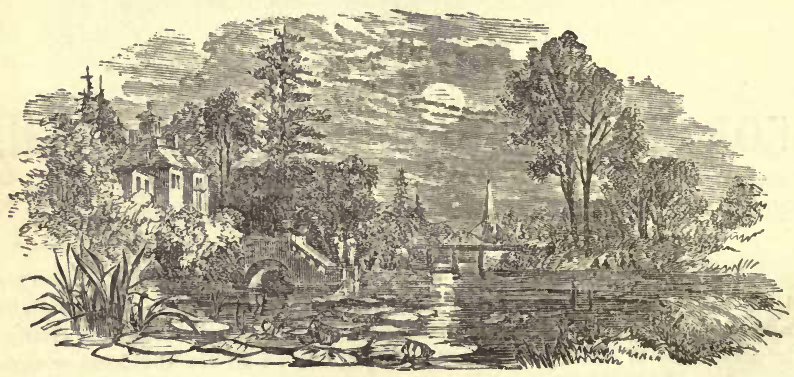







\section{HOME USE CIRCULATION DEPARTMENT MAIN LIBRARY}

This book is due on the last date stamped below.

1-month loans may be renewed by calling 642-3405. 6-month loans may be recharged by bringing books to Circulation Desk.

Renewals and recharges may be made 4 days prior to due date.

ALL BOOKS ARE SUBJECT TO RECALL 7 DAYS AFTER DATE CHECKED OUT.

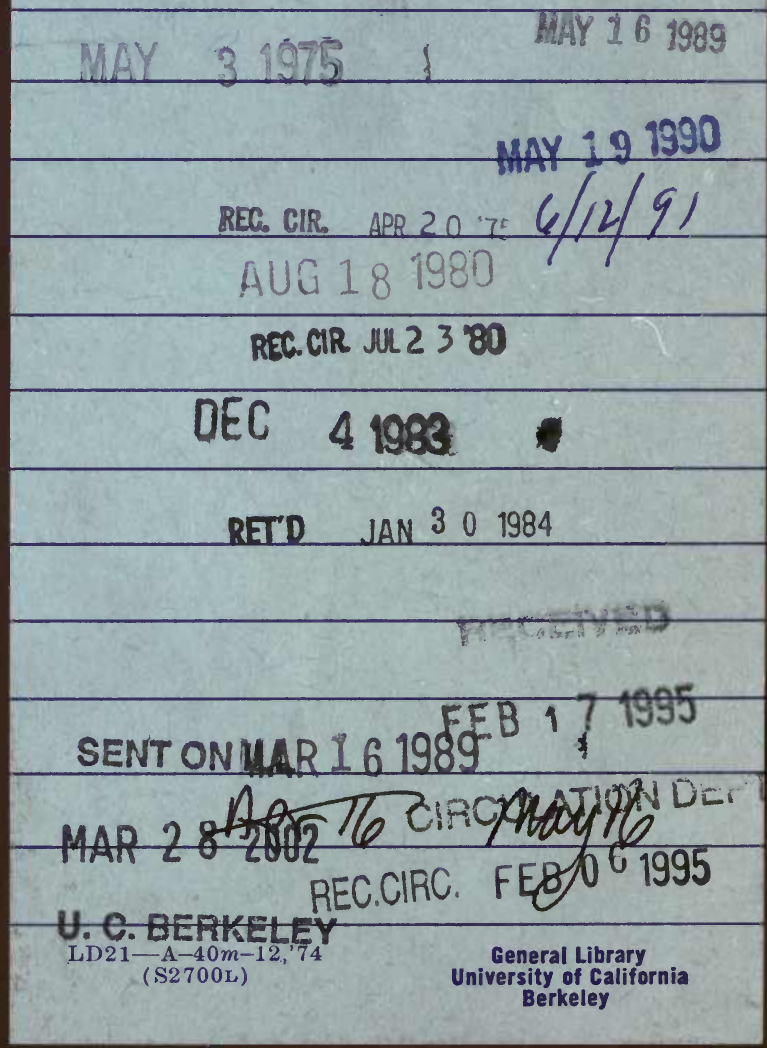


U.C. BERKELEY LIBRAF

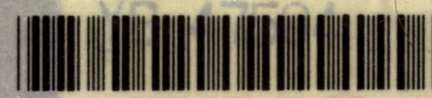

C005265650

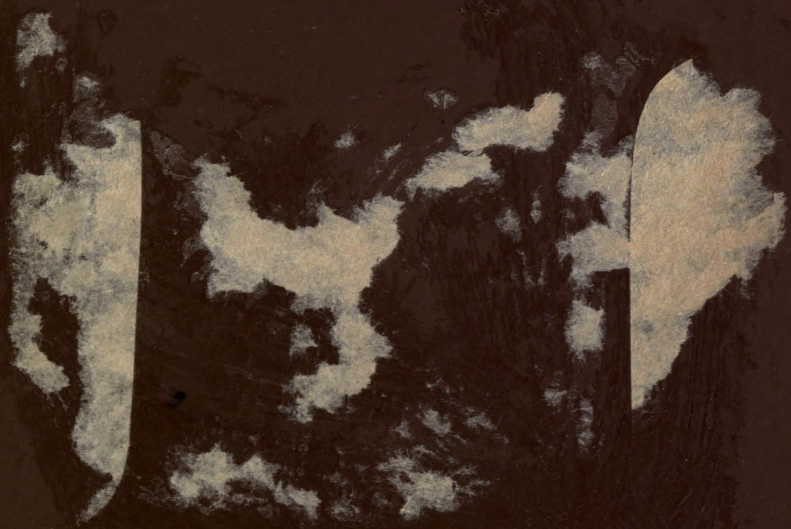


